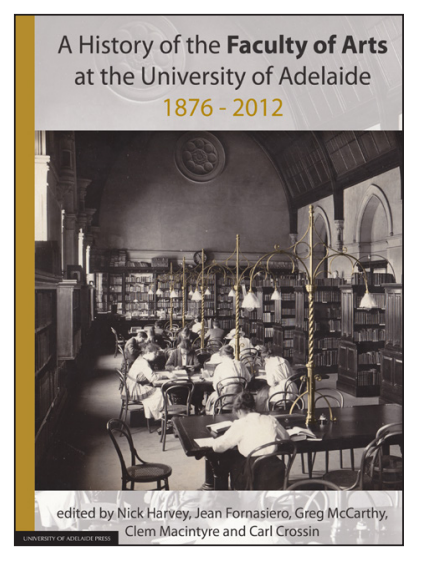

Welcome to the electronic edition of $A$ History of the Faculty of Arts at the University of Adelaide 1876-2012.

The book opens with the bookmark panel and you will see the contents page. Click on this anytime to return to the contents. You can also add your own bookmarks.

Each chapter heading in the contents table is clickable and will take you direct to the chapter. Return using the contents link in the bookmarks.

The whole document is fully searchable.

Enjoy. 


\section{A History of the Faculty of Arts at the University of Adelaide}

$$
1876-2012
$$

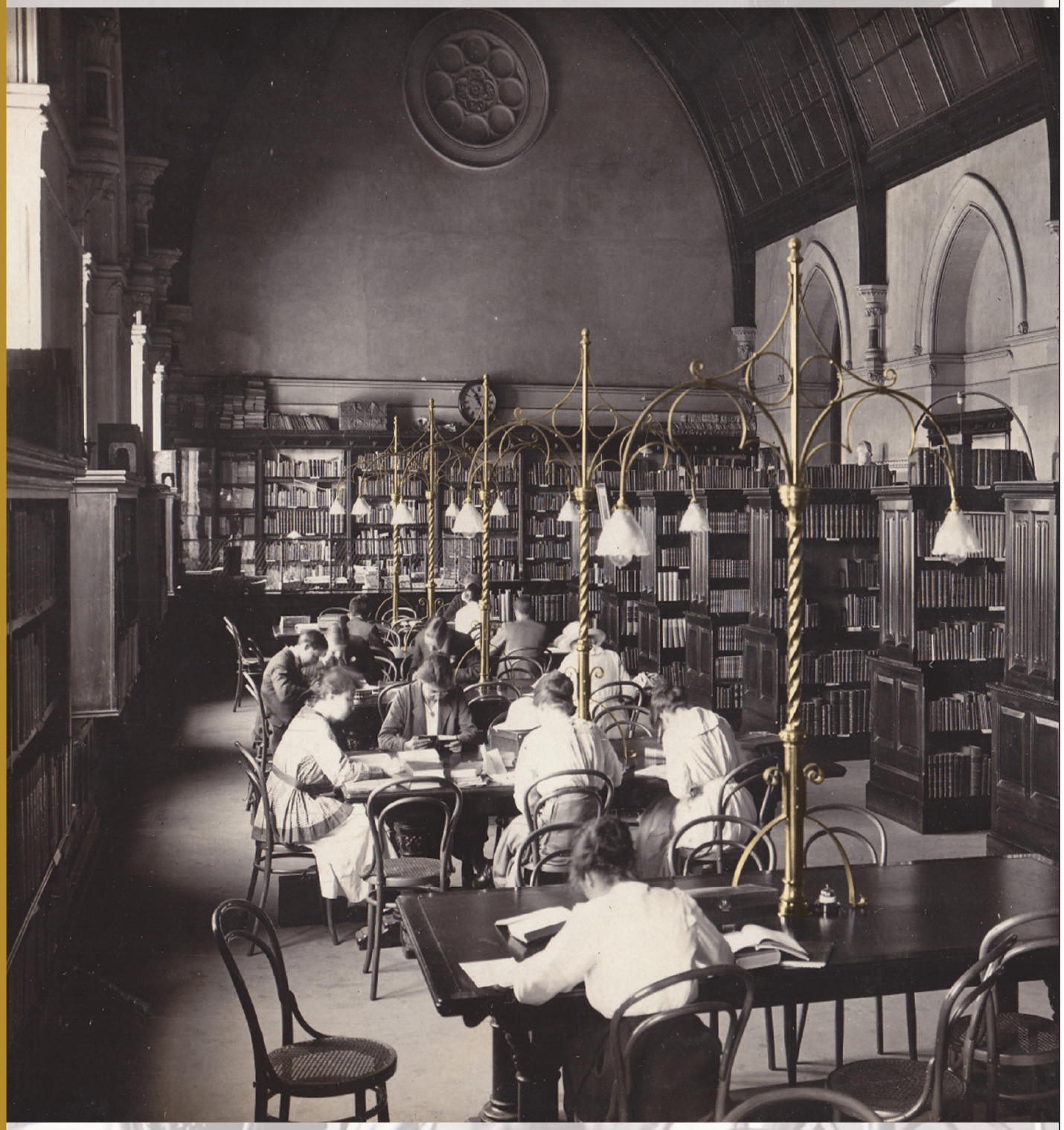

edited by Nick Harvey, Jean Fornasiero, Greg McCarthy, 


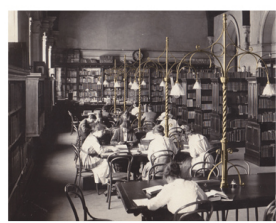

\section{A History of the Faculty of Arts at the University of Adelaide 1876 - 2012}

\section{Edited by Nick Harvey, Jean Fornasiero, Greg McCarthy, Clem Macintyre and Carl Crossin}

The Bachelor of Arts (BA) was the first recognised degree at the University of Adelaide. Although informal classes for some subjects were held at the University between 1873 and 1875, the first official University lecture was a Latin lecture at 10am on Monday 28 March 1876.

This was followed by lectures in Greek, English and Mental Philosophy. By 1878 , the first BA student, Thomas Ainslie Caterer, completed his studies for the BA degree and in 1879 became the first graduate of the University of Adelaide.

Even though the BA was the first degree it was not until eight years later in 1887 that the Faculty of Arts was inaugurated (after the Faculty of Law in 1884, a Board of Studies in Music in 1885 and the Faculty of Medicine in 1885). Following the creation of a separate science degree in 1882 many scientific subjects were removed from the BA.

For the next five years the subjects were Latin, Greek, Mathematics, Natural Philosophy, Logic, English, History, and Comparative Philology. Later other subjects such as French, German and Political Economy were added toward the end of the nineteenth century. In 1897 the Elder Conservatorium of Music was created as the first music school of its type in Australia, although at that time it was not part of the Faculty of Arts.

In the first 50 years of the University's existence, less than ten BA students graduated each year. At the start of the twenty-first century this figure had climbed to over $300 \mathrm{BA}$ graduates per year but what is interesting is that by 2010 the number of BA graduates was equalled by the number of graduates from separate named degrees within the Faculty plus 70 Music graduates.

In addition, during the first decade of the twenty-first century, there were over 60 coursework postgraduates plus more than 40 research postgraduates graduating each year. 


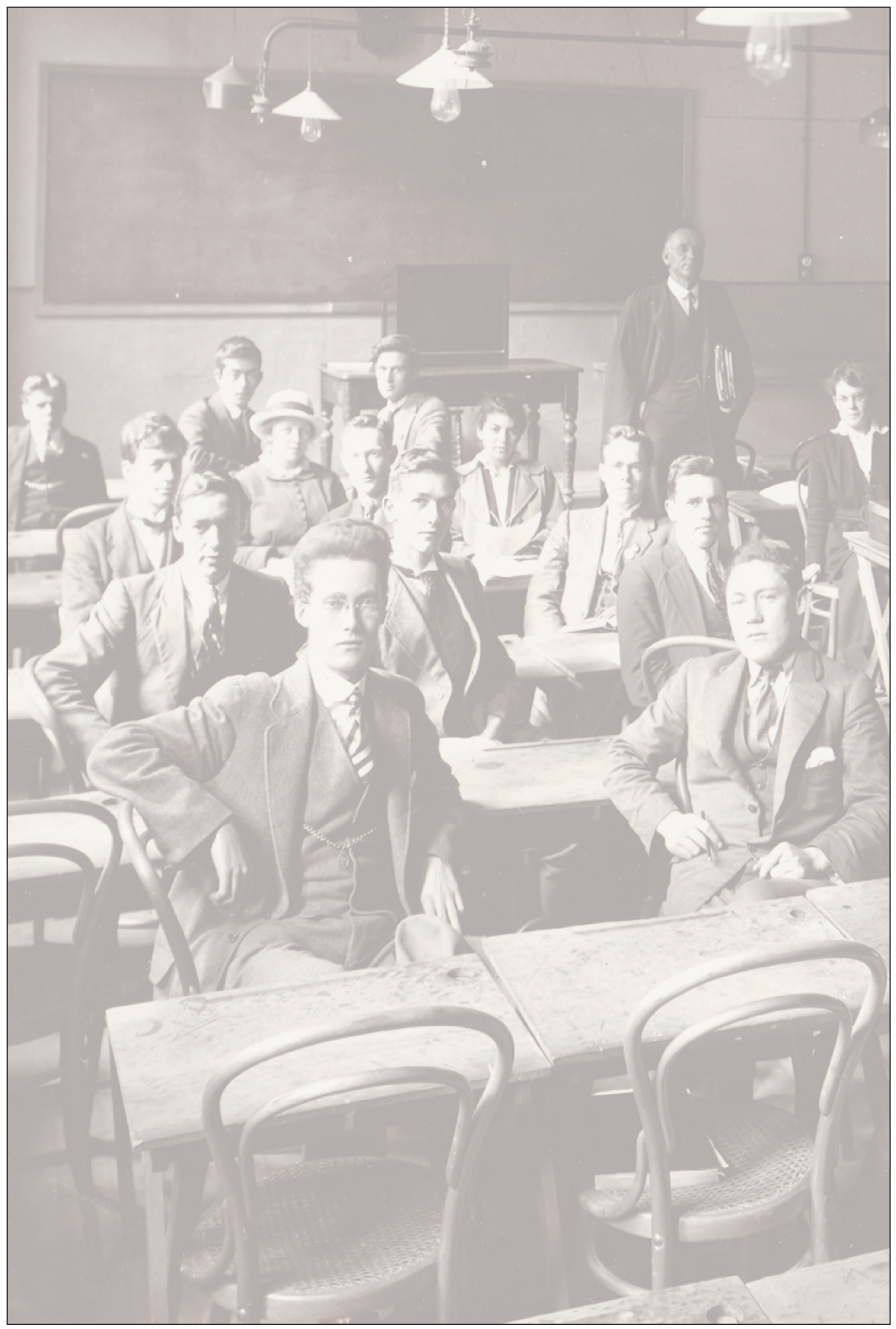




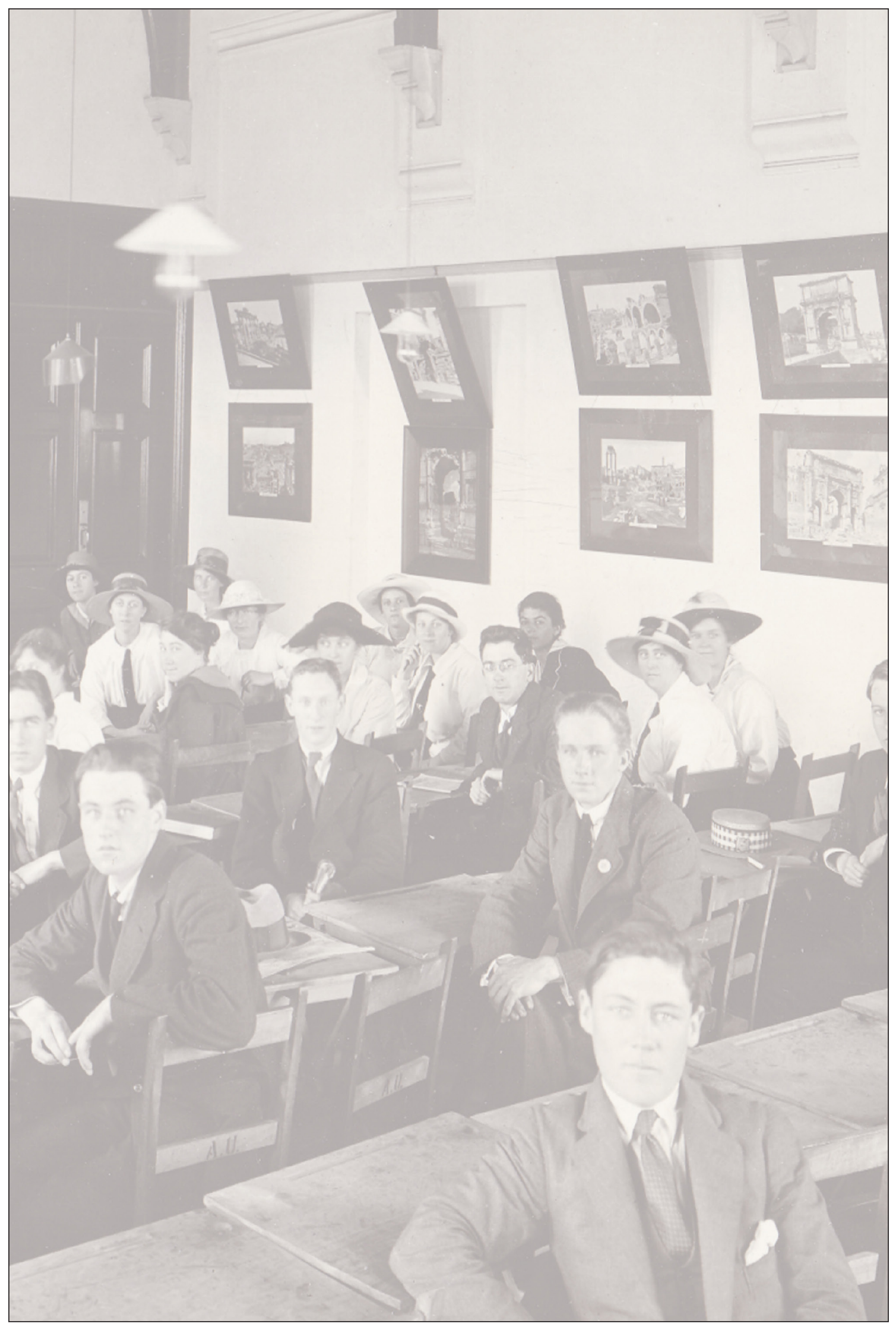




\section{A History of the Faculty of Arts at the University of Adelaide 1876-2012}

ofADELAIDE 



\title{
A History of the Faculty of Arts at the University of Adelaide 1876-2012
}

Celebrating 125 years of the Faculty of Arts

\author{
edited by
}

Nick Harvey

Jean Fornasiero

Greg McCarthy

Clem Macintyre

Carl Crossin

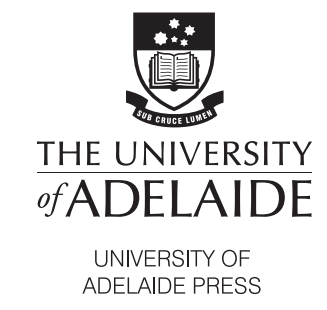


Published in Adelaide by

University of Adelaide Press

The University of Adelaide

Level 1, 230 North Terrace

South Australia

5005

press@adelaide.edu.au

www.adelaide.edu.au/press

The University of Adelaide Press publishes externally refereed scholarly books by staff of the University of Adelaide. It aims to maximise the accessibility to its best research by publishing works through the Internet as free downloads and as high quality printed volumes on demand.

Electronic Index: this book is available from the website as a down-loadable PDF with fully searchable text. Please use the electronic version to serve as the index.

\section{(C) 2012 The Authors}

This book is copyright. Apart from any fair dealing for the purposes of private study, research, criticism or review as permitted under the Copyright Act 1968 (Cth), no part may be reproduced, stored in a retrieval system, or transmitted, in any form or by any means, electronic, mechanical, photocopying, recording or otherwise without prior written permission. Address all inquiries to the Director at the above address.

For the full Cataloguing-in-Publication data please contact the National Library of Australia: cip@nla.gov.au

A history of the Faculty of Arts at the University of Adelaide, 1876-2012 : celebrating 125 years of the Faculty of Arts / edited by Nick Harvey ... [et al.]

University of Adelaide - Faculty of Arts - History

Harvey, Nick

ISBN (paperback) 978-1-922064-37-0

ISBN (ebook) 978-1-922064-36-3

Project Editor: John Emerson

Project Coordinator: Julia Keller

Cover design: Emma Spoehr

Book design: Zoë Stokes

Paperback printed by Griffin Press, South Australia 


\section{Contents}

List of Contributors viii

1 The Faculty of Humanities and Social Sciences and 1 the BA Degree at the University of Adelaide since 1876 Nick Harvey

2 Webs of Significance: an Ethnographer's Account of Anthropology at the University of Adelaide from 1973 to 2011

John Gray

3 The History of the Centre for Asian Studies at the University of Adelaide

Gerry Groot

4 Classics at the University of Adelaide (1874-2012) 81 Ron Newbold

5 English and Creative Writing: 'the abode of ... 109 literature; the home of poetry and fiction' Philip Butterss 
6 A Tale of Resilience: the History of Modern European 133 Languages at the University of Adelaide

Jean Fornasiero and Fohn West-Sooby

7 Geography, Environment and Population at the University of Adelaide, 1904-2012

Nick Harvey

8 Gender Studies and Social Analysis

Margaret Allen and Susan Magarey

9 History

235

Wilfrid Prest

10 The History of Aboriginal Languages and Linguistics at the University of Adelaide

Rob Amery

11 The Digital, Participatory and International Turn: Media at the University of Adelaide Mary Griffiths

12 Musical fusions Jenny Rosevear 
14 Politics at the University of Adelaide

Peter Mayer

Appendices

I Deans of the Faculty of Arts at the University of Adelaide 1887-2012

II The University of Adelaide Fulbright Scholars 1950-2012

III Australia Day and Queen's Birthday Honours, Faculty 393 of Arts staff and alumni 2003-2012

IV The University of Adelaide Rhodes Scholars 1904-2011 399 


\section{List of Contributors}

Professor Margaret Allen is Professor Emerita in Gender Studies at the University of Adelaide. She has researched gendered histories for four decades, publishing on women writers and Australian cultural history, South Australian women's history and nineteenth century British Quakers. Currently she researches transnational, postcolonial and gendered histories and on whiteness, in particular, on links between India and Australia from c1880-1940. Publications include as co-author, Fresh Evidence, New Witnesses: Finding Women's History (1989) and Limited Access: Women's Disadvantage in Higher Education Employment (1995).

Dr Rob Amery is Head of Discipline of Linguistics at the University of Adelaide and Convener of Kaurna Warra Pintyandi (KWP). Rob completed a $\mathrm{PhD}$ in 1998 at the University of Adelaide (published in August 2000) on Kaurna language reclamation. He serves as consultant linguist to Kaurna programs in schools and various community projects and naming activity. From October 2010 until February 2011 he was guest professor of Australian Studies (Aboriginal languages) at the University of Cologne, Germany and Lansdowne Scholar at the University of Victoria, British Columbia, Canada in 2004. Teaching and research interests include Australian Indigenous languages, Kaurna linguistics, endangered languages, language revival, languages in contact and lexical semantics.

Dr Phil Butterss is a Senior Lecturer in the Discipline of English and Creative Writing at the University of Adelaide. Phil has taught Australian literature and film in the Discipline since 1991. He has recently completed a biography of G.J. Dennis and is currently working on a history of literary Adelaide.

Professor Garrett Cullity is Professor of Philosophy at the University of Adelaide. His widely-acclaimed book The Moral Demands of Affluence (Clarendon 
Press) won him the Eureka Prize for Ethics in 2008. Widely published, his research interests include practical reasons and rationality; 'moral reasons' and their content; beneficence and aid; moral theory and anti-theory; moral virtues and 'virtue ethics'; moral epistemology; and cooperation and public goods.

Professor Jean Fornasiero is Professor of French Studies and Head of the School of Humanities at the University of Adelaide. She has published widely on nineteenth-century French history and literature - on individual authors such as Balzac, Maupassant, Nerval, Verne, Zola, and on the history of utopian thought. As part of an ARC funded project to rehabilitate the reputation of French explorer, Nicolas Baudin, she has published studies on the artwork, the personnel and the scientific results of his voyage. Her work includes an award-winning book, with John West-Sooby and Peter Monteath, entitled Encountering Terra Australis: The Australian Voyages of Nicolas Baudin and Matthew Flinders, 1800-1803 (Wakefield Press, 2004; revised edition 2010; Frank Broeze Maritime History Prize, 2005). She was awarded the title of Chevalier dans l'Ordre des Palmes académiques by the French Government in 2003.

Professor John Gray is Professor of Anthropology in the Discipline of Anthropology and Development Studies at the University of Adelaide. His research interests are anthroplogical theory, anthropology of experience, historical anthropology, space, place and movement, ritual, kinship, caste and forms of social asymmetry, gender relations, local economy, human-animal relations, European Union policy (Common Agricultural Policy), rural communities in contemporary society, aesthetics, Local poetry, national identity; architecture - the construction and meaning of built forms; cultural geography - experience of place and space in social life. John is sole author of three books, joint editor of another book, and has written 10 book chapters and 18 articles in professional journals.

Associate Professor Mary Griffiths is Associate Professor of Media at the University of Adelaide and served as Head of the Discipline from 2006-2011. Previously at Monash University, she took a leadership role in internationalising the Arts faculty's blended delivery, offshore communications programs. Later, she 
held a senior position in Screen and Media at the University of Waikato, NZ. Visiting professorships include Napier University and the University of Leeds, UK. Her research and teaching focuses on the social and political impact of new technologies, participatory media and narrative forms. She has held editorial roles on four international academic journals, including Communication, Politics and Culture; and annually chairs the e-participation track at the European Conference of E-Government. A media commentator on new technologies and their impact, she has served on the boards of Radio Adelaide and 44 Adelaide.

Dr Gerry Groot joined the Centre for Asian Studies in 1999 and is currently Senior Lecturer in Chinese Studies and Head of Discipline at the University of Adelaide. Gerry graduated from the Centre for Asian Studies with an Honours degree in 1989. In 1997 he completed a PhD in the Centre under the supervision of Sylvia Chan.

Professor Nick Harvey is Executive Dean, Faculty of Humanities and Social Sciences and Professor of Geography and Environmental Studies, the University of Adelaide. He is also Director of the Centre of Coastal Research (CCR) at the University. Nick has expertise in areas including coastal processes, global coastal change; the greenhouse effect; coastal management and environmental impact assessment. He has authored nine books and monographs, 18 chapters and nearly 40 refereed articles as well as a number of shorter refereed contributions. In 2007 Nick was jointly awarded the Nobel Peace Prize to the Intergovernmental Panel on Climate Change (IPCG), of which he was one of the Lead Authors.

Professor Emerita Susan Magarey, founding Director of the Research Centre for Women's Studies at the University of Adelaide (1983-2000) and founding Editor of the journal Australian Feminist Studies (1985-2005), was made a Member of the General Division of the Order of Australia for pioneering Women's Studies as an academic field and elected to the Academy of the Social Sciences in Australia in 2006. Her publications include thirteen books, one a prize-winner, and over seventy articles and book chapters. She is also the founder of the Magarey Medal for Biography. 
Associate Professor Peter Mayer is a Visiting Research Fellow in the Discipline of Politics at the University of Adelaide. He received his doctorate from the University of Wisconsin at Madison. He has written on many aspects of Indian politics and economics and is a frequent media commentator on South Asian issues. He was appointed to the Politics Department in 1970.

Emeritus Professor Chris Mortensen is a Research Fellow in the Discipline of Philosophy at the University of Adelaide. He was appointed Lecturer in Philosophy at Adelaide in 1982 and was Hughes Professor of Philosophy between 1998-2005. He was awarded a DSc in mathematics (2005). Chris was elected as a Fellow of the Australian Academy of Humanities (FAHA, 1997). His research interests are logic, metaphysics, philosophy of mathematics, philosophy of science, cognitive science, and Buddhism. Chris's publications include the books Inconsistent Mathematics (Kluwer, 1995) and Inconsistent Geometry (Kings College London, 2010).

Emeritus Professor Graham Nerlich is a Research Fellow in the Discipline of Philosophy at the University of Adelaide. Graham's expertise is in the areas of general philosophy; philosophy; existence of God; meaning of life; mind and body; what ethics is; and philosophy of science (scientific reasoning). Graham has written two book chapters, seven journal articles and seven book reviews.

Dr Ron Newbold joined the Classics Department at the University of Adelaide in 1969 and retired as Senior Lecturer in 2008. Primarily a historian, he taught almost everything but specialised in late antiquity and a desperately obscure Greek poet called Nonnus, who may not have been a household name even in his own household. Only once ever forgot he had a class to teach.

Professor Gerard O'Brien is Professor of Philosophy at the University of Adelaide. He was Head of the School of Humanities at the University from 2004 to 2011. Widely published, his research interests include theoretical foundations of cognitive science, neurocomputational models of cognition, consciousness, mental representation, and naturalised theories of ethics and values. 
Professor Emeritus Wilfrid Prest is a Visiting Research Fellow in History and Law at the University of Adelaide. He joined Adelaide's Department of History as a lecturer in 1966 and taught history there until 2002. Prest has published extensively in early modern English and Australian social, legal and cultural history. He is currently preparing a variorum edition of William Blackstone's Commentaries on the Lawes of England, is co-author of the 1689-1760 volume in the Oxford History of the Lawes of England, and co-editor of a forthcoming history of History at the University of Adelaide.

Dr Jennifer Rosevear is the Head of Music Education at the Elder Conservatorium of Music at the University of Adelaide. Since 2002, she has been head of the 4-year Bachelor of Music Education program. Her research interests are the role of improvisation and playing by ear in developing musicianship, and the relationship between musical involvement, academic achievement and the development of self-concept in adolescents. Jennifer has written a number of journal articles, conference papers and book chapters and has been editor on several publications.

Associate Professor John West-Sooby is Head of French studies at the University of Adelaide. John has a long-standing interest in the nineteenth-century French novel, with a particular focus on the Napoleonic period and the works of Stendhal. He has also worked on various aspects of the literary and historical connections between France and Australia, and most notably on the history of French scientific voyaging in the Pacific during the age of sail. He was a member of 'The Baudin Legacy' project team, which was funded by the ARC, and is the co-author, with Jean Fornasiero and Peter Monteith, of Encountering Terra Australis: The Australian Voyages of Nicolas Baudin and Matthew Flinders (2004, republished in 2010; awarded the Frank Broeze Memorial Maritime History Book Prize in 2005). 


\section{The Faculty of Humanities and Social Sciences and the BA Degree at the University of Adelaide since $1876^{1}$}

Nick Harvey

\section{INTRODUCTION}

The Bachelor of Arts (BA) was the first recognised degree at the University of Adelaide. Although informal classes for some subjects were held at the University between 1873 and 1875, official lectures began in 1876 with a curriculum comprising Humanities subjects that remain an integral part of the Arts degree in traditional universities, namely Philosophy, English and the classical languages. The Humanities provided the University's founding subjects because the BA was the only degree offered in the first eight years of the University's existence. The BA began to adopt a wider brief of basic scientific knowledge through additional courses in Physics, Chemistry and Biology but this changed in 1882, when the

\footnotetext{
${ }^{1}$ The author acknowledges detailed comments from Jean Fornasiero on an earlier draft, which has helped to improve the chapter. The author also thanks Felicity Prance for undertaking background research for the chapter and to Greg de Cure, Linda Christensen, Susan Magarey and Robert Ewers for contributing various data.
} 
Bachelor of Science (BSc) was added to the curriculum and the natural sciences were transferred from the BA to the BSc. In response the BA imposed a new and compulsory curriculum, comprising Latin, Greek, Mathematics, Natural Philosophy, Logic, English, History, and Comparative Philology.

Even though the first graduate of the University was awarded a BA degree in 1879, it was not until eight years later, in 1887, that the Faculty of Arts was inaugurated. At the same time, modern languages, such as French and German, were formally added to the range of subjects. In 1897, the Elder Conservatorium of Music was created as the first music school of its type in Australia, although at that time it was not part of the Faculty of Arts. Within the first two decades, many of the major components of what would eventually become the Faculty of Humanities and Social Sciences were already in place.

This chapter describes the evolution of the Faculty of Humanities and Social Sciences as it exists today, by reflecting on the past 136 years of teaching in the BA and key events in its history. The chapter examines the major changes that shaped the Faculty, focusing on aspects of its administration, various degree programs and courses, and its achievements in teaching, learning and research. This analysis draws upon research conducted in the University archives, in Special Collections within the Barr Smith Library and in Faculty records. More detailed analysis of individual disciplines is contained in other chapters of this book. There is insufficient space here to discuss disciplines such as Economics, Psychology and Education, which were once an important part of the Faculty and its offerings, but which are now located in other parts of the University. The Faculty itself has adapted to such changes that mark its history, while pursuing its essential mission to provide a comprehensive education in the liberal arts; indeed the capacity to adapt to rapid and continuous change is one of the defining characteristics of the Faculty.

\section{Evolution OF THE FAGUlty}

\section{The BA and the Faculty of Arts in the late nineteenth century}

The University's first teaching programs began with the appointment of two foundation professors in the Humanities in 1874 funded by an endowment 

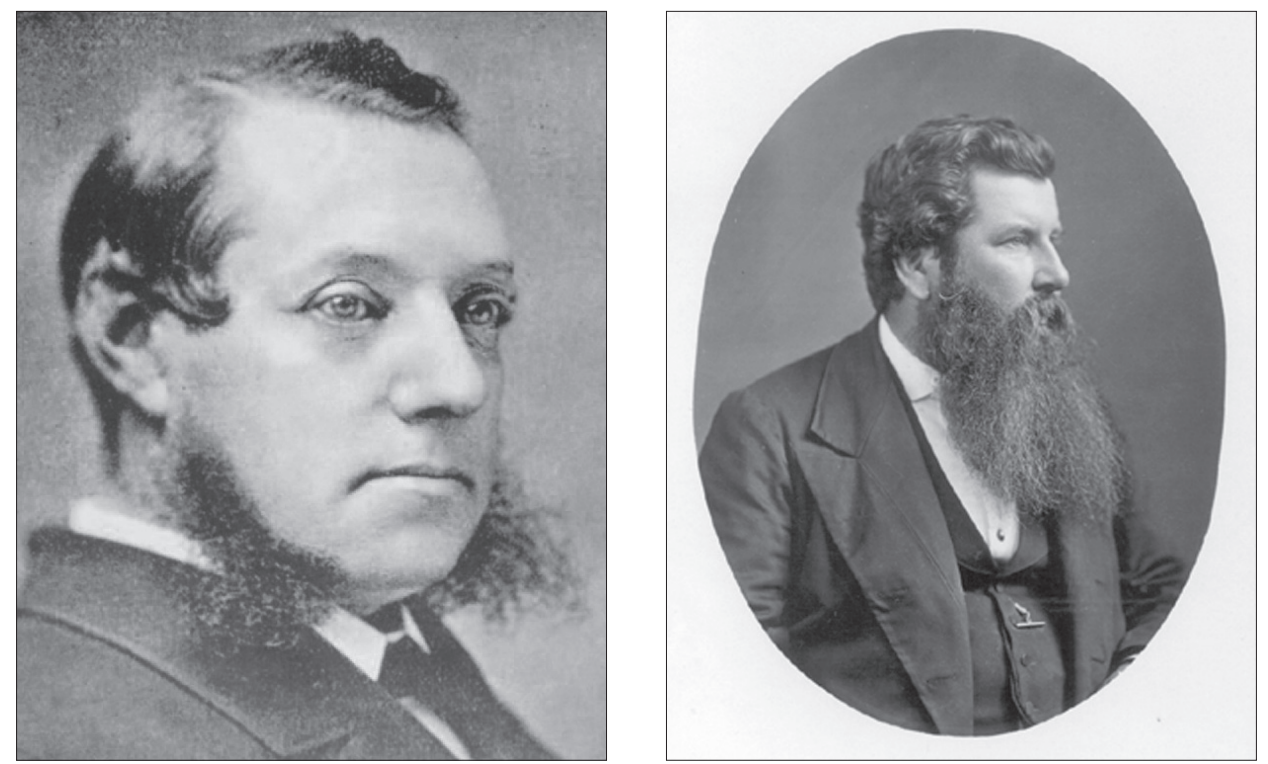

Reverend Henry Read (left, photograph courtesy of Mitcham Parish) and Reverend John Davidson (right)

from Walter Watson Hughes, who specified that they should be in Classical and Comparative Philology and Literature and in English Language and Mental and Moral Philosophy. ${ }^{2}$

Classics was the first discipline to be officially taught at the University, by the Reverend Henry Read who was appointed as the Hughes Professor of Classical and Comparative Philology and Literature in 1874 and also assisted in setting up the BA degree. Academic work began in 1876 with 60 students. The first University lecture was a Latin lecture at 10am on Monday 28 March 1876 followed by Greek at 1 lam. The Reverend John Davidson, who was appointed as the Hughes Professor in English Language and Literature and Moral and Mental Philosophy, gave the first Philosophy and English lectures on Tuesday 29 March 1876. The first University graduate, Thomas Caterer, passed his final exam in 1878 and was admitted to his degree of Bachelor of Arts on 2 April 1879.

During the first eight teaching years the University offered tuition in Classics,

\footnotetext{
${ }^{2}$ S. Woodburn, The Founding of a University: the First Decade of the University of Adelaide (Adelaide, Susan Woodburn, 1983).
} 


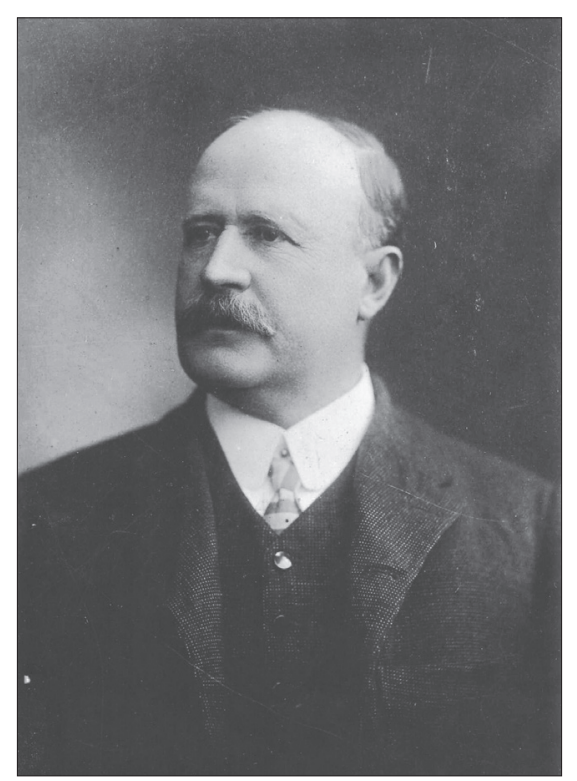

\section{Thomas Caterer}

English language and literature, the mental and moral sciences and philosophies, mathematics and a limited range of the natural sciences. Notwithstanding the fact that the University's founding Act provided for it to confer degrees in arts, science, law medicine and music the only degree that was approved to be conferred by examination was the Bachelor of Arts because the Colonial Office in London objected to the University conferring degrees in science. ${ }^{3}$ In the face of this objection, the University could not effectively expand its offerings until it had been granted the Royal Charter, an act designed to ensure that the University and its degrees were recognised throughout the British Empire. However, once the Charter was granted in 1881 the University made separate regulations for the degrees of the BA and BSc early in 1882. This was the first of a number of major changes that took place throughout the 1880s.

Following the inauguration of the Faculties of Law and Medicine in 1884 and 1885, and of the Board of Studies in Music in 1885, came the creation, in 1886, of separate faculties of Arts and Science. This decision came into effect in

\footnotetext{
${ }^{3}$ V. A. Edgeloe, Annals of the University of Adelaide (Adelaide, The University of Adelaide, 2003).
} 


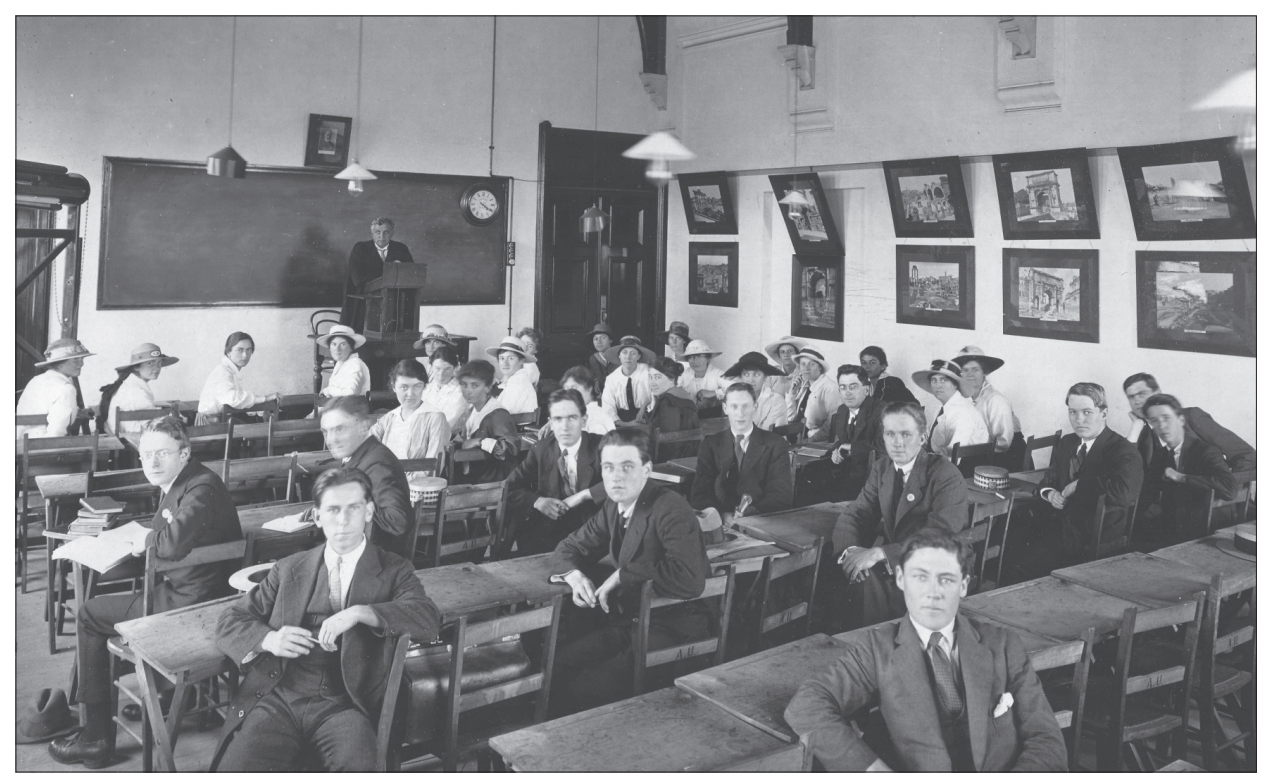

\section{An early Classics class}

1887, when the Faculty of Arts commenced operations with a substantially revised curriculum based on regulations that had been allowed on 18 December 1886. With the new set of courses came the possibility of taking most of them with 'honours'. This was an accolade, or a recognition that subjects had been passed with merit or at a higher level; it was based on the completion of additional work in individual subjects, and was not a forerunner to the Honours degree that was introduced in the early twentieth century.

Duncan and Leonard assert that, with Music, Adelaide scored a 'double first', being the first University in Australia to establish a Chair of Music (1884) and a Conservatorium of Music (1897). ${ }^{5}$ Both of these initiatives were funded through generous bequests from the Scottish-Australian pastoralist, Sir Thomas Elder. The first incumbent of the Chair was Professor Joshua Ives, who was appointed in 1884 and began teaching the first year of the music degree in 1885. Sir Thomas Elder also made a bequest in 1887 to establish Australia's first university-based

\footnotetext{
${ }^{4}$ Ibid.

${ }^{5}$ W. G. K. Duncan \& R. A. Leonard, The University of Adelaide, 1874-1974 (Adelaide, Rigby, 1973).
} 


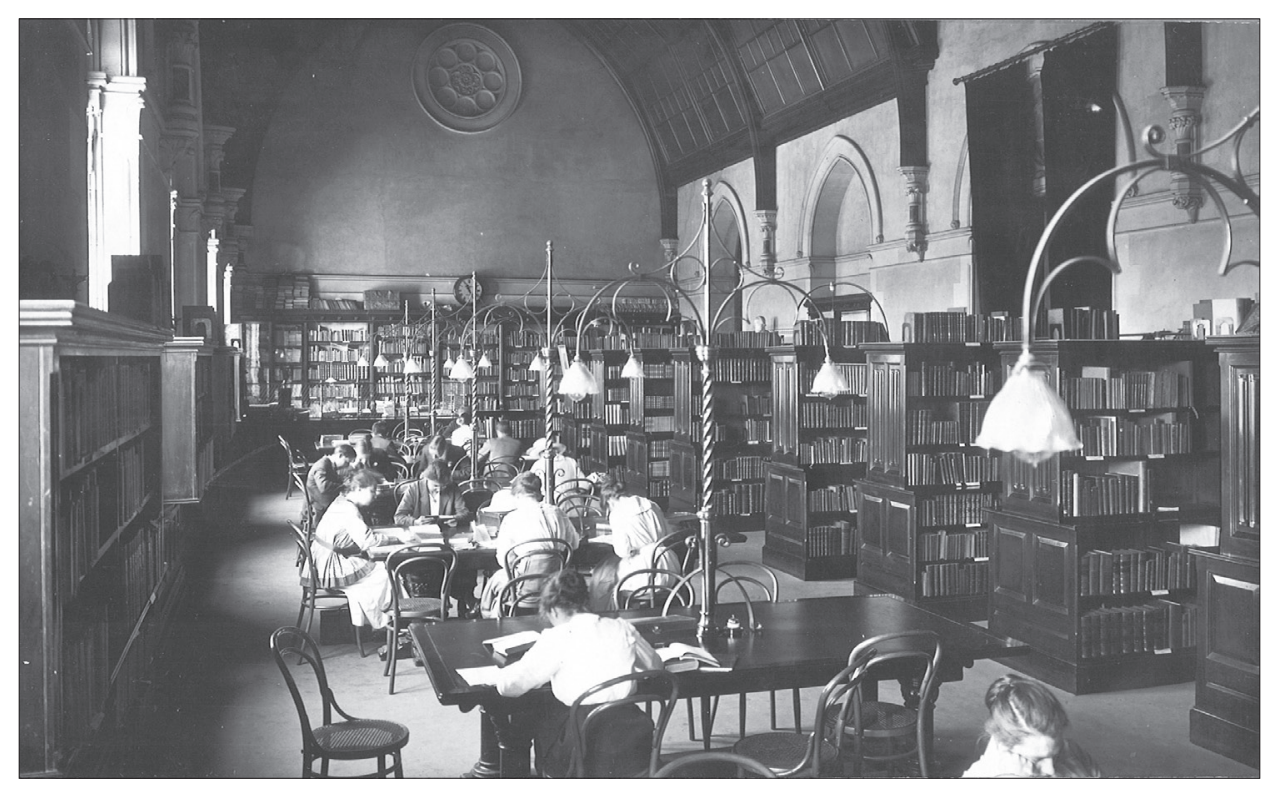

The Library in 1918

school of music, The Elder Conservatorium of Music, of which Joshua Ives also became the Director in 1898.

Other disciplines such as French and German were part of the early curriculum but professors in these disciplines were not appointed until much later. French lectures were first given in 1884 by Professor Edward Vaughan Boulger, who at the time was the Hughes Professor of English and Philosophy. In 1886, a series of lectures in French and German was given by Monsieur Aucher and Herr Kirchner respectively but it was not until 1887 that these languages were included as part of the BA degree. In contrast, students in the sciences had been able to include the study of French and German in the first year of the BSc since 1882. The first dedicated appointment in modern languages was in 1899 when the Reverend Eitel was appointed as a part-time lecturer in German.

\section{First half of the twentieth century: growth and consolidation}

In the early decades of the twentieth century, the place of two fundamental disciplines within the Faculty was consolidated and expanded. Modern History 
was first introduced to the BA curriculum in 1900 with the appointment of Robert Langton Douglas to a new Chair in Modern History and English Language. This was a significant innovation, given that previous chairs in English had been linked to Philosophy, in accordance with the original terms of the Hughes bequest. The professor of English and Philosophy at the time, William Mitchell, was known more for his philosophy expertise rather than English and gave up his responsibilities for literature when Douglas was appointed. Professor George Cockburn Henderson, whose primary discipline was History, replaced Douglas in 1902 and held the Chair for almost twenty years. It was only then that the English and History disciplines acquired their autonomy through the creation of a new Chair of English. Thanks to a bequest made by Mrs G A Jury in 1921, the Jury Chair of English Language and Literature came into being and Professor Archibald Strong became its first incumbent in 1922, while Henderson continued to fulfil his role as Professor of History. In the following year, 1923, John McKellar Stewart was appointed Professor of Mental and Moral Philosophy, thus separating it from former linkages with English.

Another discipline introduced at the start of the twentieth century was Geography, which was introduced and taught by the first University Librarian John Clucas in 1904. It then continued to be taught largely via evening lectures by part-time staff up until 1950 when it finally gained support as an independent discipline.

German and French were similarly allocated a marginal role in the Faculty, even though these subjects had been officially part of the syllabus since 1887 . German had a part-time teacher, the Reverend Eitel, but after his death in 1908, neither language had a dedicated lecturer. This was to change in 1918 when John Crampton was appointed as the first Lecturer in the French Language and Teacher of French in the Elder Conservatorium. This job description revealed the cooperation between teaching areas in the early days of the University, when disciplinary boundaries were less rigid than today. This link between German and Music existed well into the twenty-first century through their shared interest in opera. This also demonstrates the fact that, by the 1920s, the modern languages had cemented their place in the curriculum. However, the real status change for languages occurred in 1944, with the appointment of the first Professor of French, 
James Gladstone Cornwell. In the meantime, German teaching was maintained on a part-time basis by Adolf Schulz, the Principal of the Teachers Training College from 1920, but it would take some time until a chair was appointed.

Politics was another discipline taught for some time before a separate department was created. The appointment of Professor Jerry Portus as Professor of Political Science and History in 1934 (cf History and English at the start of the twentieth century and a separate History chair from 1922-1933) and the introduction of third-year and Honours established Politics as a discipline, but without a dedicated professor.

\section{Second half of the twentieth century: expansion and realignment}

The second half of the twentieth century saw the introduction of a number of new disciplines along with the loss of two established disciplines to other faculties. The first of these to move out of the Faculty was Economics, which split off to create its own Faculty of Economics in 1951. This would have reduced the size of the Faculty by over 100 students. In the same year Geography became a Department with its first full-time appointment in 1951, a Reader-in-Charge, growing to six full-time staff by the late 1950s. German also secured the appointment of a Reader-in-Charge, Derek Van Abbe, in 1952.

A number of disciplines that had been taught for some time did not have their first chairs appointed until the 1950s or 1960s. In 1951 a separate chair in Politics, Professor Walter George Keith Duncan, was created whereas it had previously been linked with History. Similarly, a separate chair in Modern History, Professor Hugh Stretton, was created in 1954, breaking its link with Political Science. In 1959, Graham Lawton was promoted to be the first chair in Geography, and in 1962 Brian Coghlan was promoted to be the first professor of German.

Although the Faculty of Arts had discussed the establishment of an Anthropology discipline since the 1950s, there was some debate over whether it should be in physical or social anthropology. In fact, the matter was not reactivated until the 1970s, when the political situation created opportunities for expansion in the higher education sector. Finally, it was decided to focus on the social aspects of the discipline and in 1973 a Department of Anthropology was created with the appointment of its first chair, Professor Bruce Kapferer. 
Two years later, in 1975, the Centre for Asian Studies was created as a cross-faculty Centre and a multi-disciplinary committee mostly from Arts and Economics. A limited-term appointment of a Chair in Asian Studies was given to Professor Michael Yahuda in 1982, who was replaced by a tenured appointment given to a Japanese specialist, Professor Gavan McCormack, in 1987. However, it wasn't until 1992 that Asian Studies was given independent departmental status with Professor Andrew Watson (a China specialist) as its Head. Subsequently, Professor Purnendra Jain was appointed in 1994 as a Professor of Japanese within Asian Studies.

In the same year (1975) that Asian Studies began as a cross-faculty venture, Environmental Studies began outside the University's faculty structure but eventually became incorporated into the Faculty of Arts in 1984 and gained departmental status and a Chair in Environmental Studies, Professor Martin Williams, in 1993. It subsequently merged with the Department of Geography in 1998.

In the 1990s, political circumstances impacted upon the size and shape of the Faculty. The major change that affected the tertiary education sector as a whole, was the decision made by the Federal Government to merge the traditional University sector with the Institutes of Technology and the Colleges of Advanced Education resulting in the merger of the former South Australian College of Advanced Education (CAE) with the University in 1991. For the Faculty of Arts, this decision resulted in the creation of a Department of Women's Studies in 1992. The department was later amalgamated with former CAE Labour Studies staff to form a new Department of Social Inquiry to which the first Chair in Women's Studies, Professor Chilla Bulbeck, was appointed in 1998.

In 1993 the Foundation Professor in Linguistics, Professor Peter Mülhaüsler, was appointed even though much earlier in 1970 a Professor of Australian Linguistics, Professor Ted Strehlow, had been appointed. Strehlow's main interest was in anthropology and literature and he did not develop the teaching of a Linguistics program. However, the current Linguistics discipline has some links with Strehlow's legacy through its teaching of Aboriginal languages and linguistics.

In the late 1990s there was an important addition to the Discipline of English with the creation of the first Australian Chair in Creative Writing, Professor Tom 
Shapcott in 1997. Subsequently, the appointment of other distinguished writers as professors, including the Nobel Laureate Professor John Coetzee, have gained national recognition for this program.

In 1997 the Department of Psychology moved to the Faculty of Health Sciences, in part related to funding issues but also to develop synergies with other disciplines and research within Health Sciences. This created a loss of over 350 students to the Faculty of Humanities and Social Sciences.

Humanities and Social Sciences became a Division of the University in 1996, which included the Faculty of Arts but by 1999 the name 'Division' was abandoned so that the Division of Humanities and Social Sciences became the Faculty of Humanities and Social Sciences. There was some debate over the name and the move away from the former Faculty title of 'Arts'.

\section{The twenty-first century: Faculty restructuring}

The twenty-first century saw the introduction of two new disciplines, Media and Spanish, plus some major structural changes to the Faculty. Media began from cross-disciplinary teaching, first in Education and then Anthropology, in the latter part of the twentieth century. It then became formalised as a sub-disciplinary part of English before it became a separate discipline as part of the School of Humanities in 2006. There is currently no Chair in Media. Spanish for University of Adelaide students was originally taught on the Adelaide campus by Flinders University staff but with increasing enrolments from Adelaide it was decided to appoint separate lecturing staff at the University of Adelaide and create a discipline of Spanish in 2007. There is currently no Chair in Spanish.

One of the major events to affect the Faculty occurred in 2001 when the University reorganised the entrenched university governance system of organisational units, linked to departments of varying size and aligned to individual disciplines. Perhaps the greatest impact was on the two faculties of Science and Humanities and Social Sciences, which each had to be restructured into four separate schools. At the same time, there was a decision to move the Department of Education out of the Faculty of Humanities and Social Sciences resulting in a loss of around 160 students, and another decision to move the Elder Conservatorium of Music into the Faculty, resulting in a gain of nearly 270 
students. This essentially meant that that the Faculty had one self-contained school (Music) but had to reorganise its remaining nine disciplinary-based departments into three schools. This was not without some debate over the rationale for the restructuring exercise. There was also significant discussion over different scenarios for the structure and membership of the new schools.

Eventually by mid-2002 it was agreed to have four schools within the Faculty:

- The Elder Conservatorium of Music

- The School of History and Politics

- The School of Humanities

- The School of Social Sciences.

A Head of School was appointed for each school: Professor Charles Bodman-Rae (Director, Elder Conservatorium of Music), Associate Professor Robert Dare (History and Politics), Professor Chris Mortensen (Humanities) and Professor John Gray (Social Sciences).

Music was already organised into separate areas of study but the other three schools contained between two and eight separate disciplines, some of which were amalgamations of former departments rather than traditional academic disciplines. Currently, the School of History and Politics has just the two disciplines of History and Politics but the School of Social Sciences has four separate disciplines: 1) Anthropology and Development Studies, 2) Asian Studies, 3) Gender Studies and Social Analysis, and 4) Geography, Environment and Population. The School of Humanities, however, currently has eight separate disciplines: 1) Classics, 2) English, 3) French, 4) German, 5) Linguistics, 6) Media, 7) Philosophy, and 8) Spanish. This change required some adjustment because the former departments, which had traditionally been responsible for their own staffing and funding, now had to justify their budgets to a Head of School and also had to compete for school resources against other disciplines within the same school.

\section{FAGULTY ADMINISTRATION}

While the organisational units have been subject to radical change over the Faculty's lifetime, the major leadership role within its administration has changed relatively little. There have been 50 academics in total appointed to the position of 

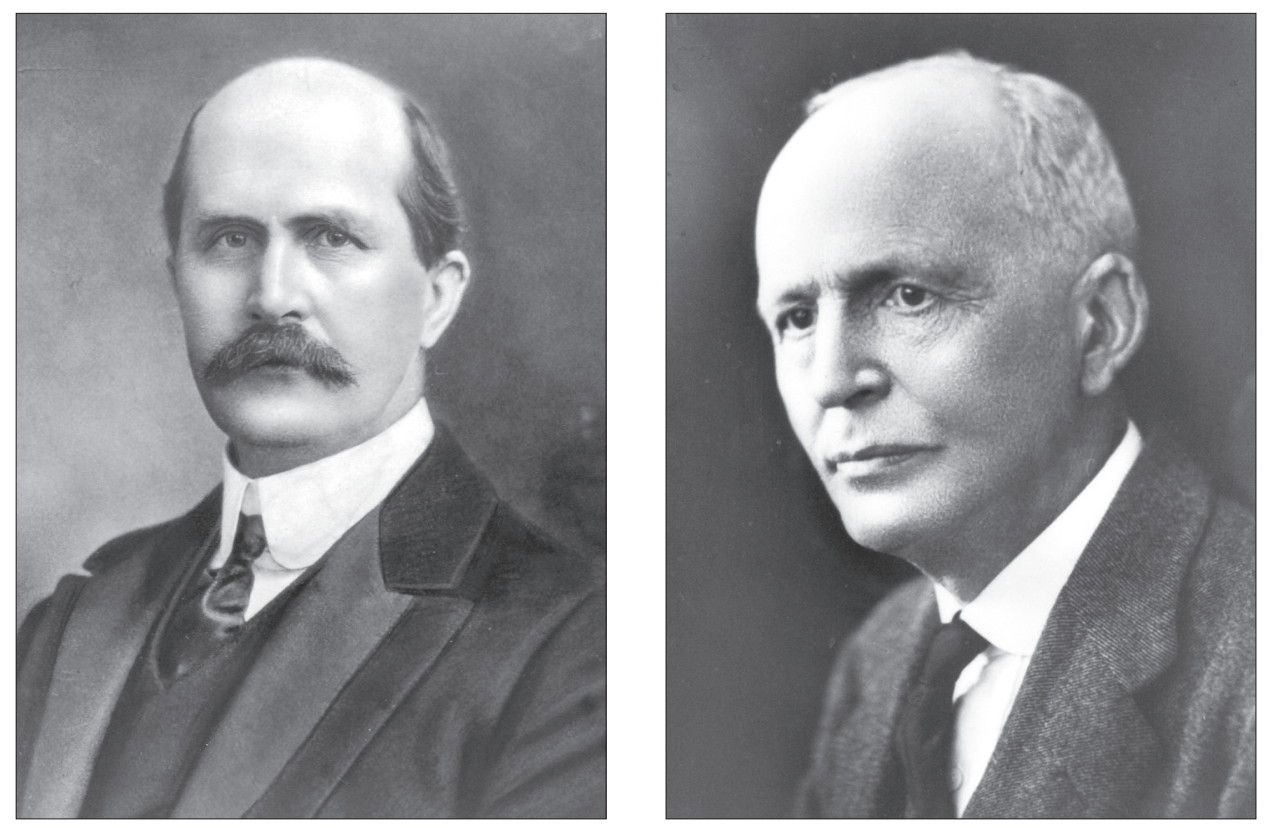

William Henry Bragg (left) and William Mitchell (right)

Dean (now called Executive Dean) since the inauguration of the Faculty in 1887 and a number of these held the position more than once (see Appendix I). The first Dean of Arts was William Henry Bragg, who was appointed to the Elder Chair in Mathematics and Physics in 1885 and 23 years later returned to England where he subsequently won a Nobel Prize in Physics. William Bragg was appointed as Dean of Arts in 1887 and initially held the position for two years (1887 and 1888) but was also appointed in 1891, 1895 and 1899, a total of five years. ${ }^{6}$ Two of the early deans William Mitchell and John McKellar Stewart, went on to become ViceChancellor from 1916 to 1942 and 1945 to 1948 respectively. William Mitchell also became the Chancellor of the University from 1942 to 1948.

In the late nineteenth century most dean appointments were for one year only with two deans holding the position for consecutive years. This changed in the twentieth century when 40 of the dean appointments made were for a period

\footnotetext{
${ }^{6}$ V. A. Edgeloe, Humanities and Associated Studies at the University of Adelaide, 1876-1976: An Administrator's Monograph on their Growth and Changing Nature and Structure During the University's First Hundred Teaching Years (Adelaide, The University of Adelaide,1986).
} 
of two years with only two deans holding the position for three consecutive years. More recently in the twenty-first century a five-year dean's appointment has become the norm.

Of the total 50 academics appointed as deans between 1887 and 2012, many had repeat appointments with 12 appointed for one year or less; 24 for two years; three for three years; three for four years; four for five years; three for six years and one for seven years. The eight deans who held the position for five years or more were:

(5 yrs) 1887-8, 1891, 1895, 1899

(7 yrs) 1896, 1900, 1905, 1907-8, 1913-14

William Henry Bragg

(5 yrs) 1906, 1911-12, 1917-18

William Mitchell

(6 yrs) 1909-10, 1915-16, 1919-20

George Cockburn Henderson

(6 yrs) 1921-2, 1929-30, 1941-2

Henry Darnley Naylor

(5 yrs) 1931-2, 1947-9

John Raymond Wilton

(5 yrs) 2002-2007

(6 yrs) 1999*, 2001-2002**, 2007-2012

John Aloysius Fitzherbert

(terms of $* 3$ and $* * 7$ months respectively)

John Michael Innes

Nick Harvey

These deans have been supported in the administration of the Faculty by non-academic professional staff in the Faculty and school offices and former departments. Up until the early 1980s Faculty administration was conducted under the auspices of the University Registrar. From the early 1980s Faculty 'Assistant Registrars' were appointed to work for the University Registrar, Frank O'Neil, through Judy Philip who was the Senior Assistant Registrar, Faculties. The Faculty's Assistant Registrars were Mr A. J. Flack (1982), Mr R. Hannay (1983), Mr J. C. Mitchell (1984-85), Ms D. Shaw (1986-87), Mr D. Longo (1988-92) and Mr D. Hallam (acting-1993).

By 1993 the Faculty had its own independent Registrar, Gary Martin, who could formally write letters and do business under his own name or the name of the Dean. Robert Ewers took over this position on an acting basis in 1999 until he was officially made Registrar in 2002. However, the increasing importance and complexity of budgeting and financial matters has necessitated changes over the last decade so that the traditional Registrar position has been discontinued. The Faculty now has two senior managers: a Business Manager, Gavin Smith, and a 
Faculty Manager of Strategy and Administrative Services, Robert Ewers. Each of the four schools has a Head of School: Professor Greg McCarthy (Social Sciences), Associate Professor Carl Crossin (Director, Elder Conservatorium of Music), Professor Clem Macintyre (History and Politics) and Professor Jean Fornasiero (Humanities) who reports to the Executive Dean. In turn, each school has a School Manager who reports to the Head of School.

\section{Programs, gourses, teaching AND Learning}

\section{The changing nature of undergraduate degree programs and student enrolments}

Seven out of the Faculty's current nine undergraduate degree programs are relatively new arrivals, and only two date back to the late nineteenth century. Of these, the BA is the only current undergraduate degree program that has been in existence since the start of the University in 1876. There was also a BA (Jurisprudence) introduced in 1876, which was on the books for a long time but was eventually discontinued due to lack of interest. Ten years later the B Music was introduced. In 1991 the merger of the University with part of the Adelaide CAE saw some degree and sub-degree programs incorporated into the Faculty's offerings so that existing students from the former CAE could complete their studies. These programs, the Associate Diplomas in Labour Studies and Liberal Studies and bachelors degrees in Dance, Liberal Studies, Labour Studies, Interpretation and Translation, were later discontinued.

In 1996 two separate named undergraduate degrees were introduced, the B Labour Studies and the B Social Sciences, but Labour Studies was discontinued after six years due to declining student numbers. Similarly, in 1997 a B Environmental Studies degree was introduced but was discontinued after 10 years due to low student numbers. There was also an attempt to identify specialisms within the BA degree by creating focused BA degrees in Asian Studies, Australian Studies, Cultural Studies, European Studies and International Studies, but these were discontinued in 2008 because of low enrolments. In their place four new specific named degrees were created in the first decade of the twentyfirst century as separate degrees from the BA whilst drawing on it for various 
component courses. These were the B International Studies \& Hons (2002); the B Media \& Hons (2002); the B Development Studies \& Hons (2006); and the B Environmental Policy and Planning \& Hons (2008). These four degrees, along with the B Soc Sci (1996), now collectively produce as many graduates each year as the traditional BA degree.

Duncan and Leonard provide a breakdown of student enrolments by $10-$ year intervals for approximately the first 100 years of the University. ${ }^{7}$ Their data reveal that the Faculty of Arts after beginning with $100 \%$ of the students, then dropped to less than $20 \%$ once other degrees such as science, medicine and law were introduced in the late nineteenth century. This changed in the early part of the twentieth century with the Faculty having around $50 \%$ of students up until the 1940 s. This then dropped to around $30 \%$ up to the 1970s. It then stayed between 25 and $30 \%$ for some time but more recently has dropped to around $20 \%$.

For the last six years the Faculty has had the second highest number of students in the University out of the five faculties but there has been only been a modest growth in student numbers, from 3,890 in 2006 to 4,443 in 2011 (total student headcount). In terms of equivalent full-time student load (EFTSL) this has increased over the same period from 3,019 to 3,619 EFSTL. The Faculty has consistently had the highest first-year domestic student load (by EFTSL) for the University with a $46 \%$ increase of this cohort over the last five years but international student enrolments have remained the lowest in the University. The total student load per full-time equivalent academic staff increased from 25.2 in 2009 to 28.3 in 2010 indicating an increasing staff workload.

In the early years when the BA was the only degree available at the time there were less than ten BA students graduating from the University each year. During the first 50 years (1879-1929) there was a total of 461 graduates from the University, which equates to an average of 9.22 graduates per annum. This increased up to the mid-twentieth century so that in the 25 years from 1924-1949, there was a total of 898 graduates giving an average of 35.9 graduates per annum, or about four times greater than for the first 50 years.

A recent snapshot from the Faculty of Humanities and Social Sciences for the five years from 2006 to 2010 reveals an average of over 300 BA graduates per

\footnotetext{
${ }^{7}$ W. G. K. Duncan \& R. A. Leonard, The University of Adelaide.
} 
annum, or over eight times the total University output of graduates for the midtwentieth century. However, the specialist named degrees now collectively account for another 300 graduates per annum, thus equalling the output of the traditional BA degree.

\section{Postgraduate coursework degree programs and enrolments}

In 1930 regulations were introduced to permit students to take an MA by coursework, an option which was taken by some French students in the 1940s. However, specialised postgraduate coursework programs were not introduced until the mid 1970s. Many of these have nested Professional Certificates, Graduate Certificates and Graduate Diplomas, which provide exit points for students who complete only part of the Masters degree program. The first specialised postgraduate degree program was the Master of Environmental Studies, which was originally created outside the faculty structure in 1975 but eventually became one of the largest postgraduate coursework programs in the University with around 180 students. It was finally disbanded in 2007 because of low enrolments related to the government's introduction of upfront postgraduate coursework fees. In the 1990s Masters degrees in Population Studies, International Studies, Environmental Management, and Spatial Information Science were introduced but all of these, apart from International Studies, were discontinued because of declining enrolments, in part related to changes in government funding and the introduction of fees.

In 2002 Masters degrees in Gastronomy and Art History were introduced. The Gastronomy program was jointly badged with Le Cordon Bleu but has since been replaced in 2012 by a separate Masters program in Food Studies and an allied Graduate Certificate in Food Writing. The Art History program is taught jointly with the Art Gallery of South Australia, the University's next-door neighbour, and is still going strong. It is also linked to a Masters program in Museum and Curatorial Studies introduced in 2007.

In Music there are two Masters coursework degrees, one in Performance Studies and the other in Performance \& Pedagogy, although numbers of enrolments in these programs have been persistently low. A Masters program in Creative Writing was introduced in 1997 but enrolments in that program have declined 
as greater interest has been shown in the PhD program in Creative Writing. Linguistics offers two Masters programs which have attracted international student enrolments, the M Applied Linguistics and the M Advanced Applied Linguistics. In the discipline of Geography, Environment and Population (GEP) the Master in Environmental Policy and Planning was introduced in 2008 to replace the former Master of Environmental Studies. Since 2011, the same discipline has also been administering the Masters program in Planning and Planning (Urban Design), a joint program with the School of Architecture. In 2012, in a response to international student demand for language skills an MA in Translation and Transcultural Communication was introduced.

Between 2006-2010, there was a total of over 60 coursework postgraduates graduating from Faculty programs per annum.

\section{Quality of Teaching and Learning}

University-based student feedback (SELT) demonstrates that the Faculty has some of the best teachers, with consistent achievement of the highest SELT broad agreement scores for the University over the last five years (85\% in 2010). This achievement is mirrored by the fact that a number of the Faculty staff have won national 2011 ALTC (former Australian Learning and Teaching Council) outstanding teaching awards and the University of Adelaide's own prizes for teaching excellence in 2011.

The Faculty achieves good results in the nationally benchmarked Course Evaluation Questionnaire (CEQ). For example the GEQ percentage agreement for overall satisfaction for domestic students from 2009 to 2010 increased from $65 \%$ to $85 \%$ for undergraduate $(\mathrm{UG})$ and from $66 \%$ to $84 \%$ for postgraduate $(\mathrm{PG})$ and international (UG) increased from $47 \%$ to $90 \%$. These figures are all above the University average. The CEQ results for good teaching in 2010 increased significantly between 2009 to 2010 from $56 \%$ to $71 \%$ (UG) and from $62 \%$ to $77 \%$ $(\mathrm{PG})$ and international (UG) increased from $49 \%$ to $78 \%$. These percentages are also above the University average.

Many Faculty staff are members of the national academies of both the Humanities and the Social Sciences. A fifth (22 out of 110) of the Leverhulme scholarships awarded to University staff and students come from the Faculty. 
There have also been over 80 Australia Day and Queen's Birthday honours awarded to Faculty staff and former students (alumni) during the last 10 years including $1 \mathrm{AC}, 11 \mathrm{AOs}, 30 \mathrm{AMs}$ and 42 OAMs (see Appendix III). This indicates the level of standing and expertise of these staff, which has also been recognised through community service.

Students have also excelled in winning numerous awards and scholarships. Perhaps the most prestigious of these is the Rhodes Scholarships where 37 (36\%) out of the University's total 104 Rhodes scholars have come from the Faculty, at times combined with a second degree from another faculty (see Appendix IV). The most recent of these was Rebecca Richards, Australia's first Indigenous Rhodes Scholar (see Chapter 2).

\section{THE INGREASING IMPORTANCE OF RESEARGH AND HIGHER DEGREES}

Academics with a strong research record have been attracted to the Faculty from its early days and such academics have been important in building the research reputation of the Faculty. This has resulted in some outstanding researchers and research teams in individual disciplines. In the latter part of the twentieth century, there was a need for a coordinated approach to improving the Faculty's research performance, particularly when the Australian government introduced the Research Quantum in the 1990s. This exercise provided an allocation of funds based on a composite index of research inputs (grants) and research outputs (publications and research degree completions).

In 1995 the Deputy Vice-Chancellor Research conducted a research benchmarking exercise across a number of Australian universities, which indicated that five of University of Adelaide's departments at the time were above standard on all criteria. Only one of these was in the Faculty of Arts, the Department of Geography.

In an attempt to improve research performance in the Faculty, an Adelaide Research Centre for Humanities \& Social Sciences (ARCHSS) was created in 1997 and led by Associate-Professor Susan Magarey. ARCHSS's aim was to foster interdisciplinary and collaborative research in the Faculty's priority areas of Aboriginal and Australian Studies, Asian Studies, Cultural and Media Studies, 
Environmentalism, Gender Studies, Globalisation, and Social Justice. Susan Magarey secured over $\$ 0.25 \mathrm{M}$ in funding, which supported two Postdoctoral positions and eight Teaching Release fellowships for existing Faculty staff, thus enabling them to improve their publication rate. ARCHSS was wound up in 2000 due to a lack of funding support.

At the start of the twenty-first century the Faculty was winning around 12\% of the total number of nationally competitive ARC Discovery and ARC Linkage grants coming to the University of Adelaide. The Faculty's publication output was good but relied too heavily on a relatively small number of outstanding researchers who lifted the Faculty's average. In 2009, the Faculty initiated an independent research review resulting in research initiatives such as the appointment of a Research Development Manager and the creation of new and highly focused research centres. For the last three years total research income for the Faculty has been around $\$ 6$ million $\$ 5.6 \mathrm{M}$ in 2009 , $\$ 6.3 \mathrm{M}$ in 2010 and $\$ 5.9 \mathrm{M}$ in 2011 ) across funding categories 1-3 with a significant increase in the most prestigious Category 1 funding. The Faculty now has seven university-endorsed research centres, focused on key research strengths:

- Australian Centre for Workplace Innovation and Social Research

- Australian Population and Migration Research Centre

- Centre for Coastal Research

- Centre for Housing, Urban and Regional Planning

- Fay Gale Centre for Gender Research

- Indo-Pacific Governance Research Centre

- J. M. Coetzee Centre for Creative Practice.

In addition, the School of History and Politics is hosting a major node of the ARC Centre of Excellence for the History of Emotions. The federal funding of this Centre is a major coup for the Humanities in Australia.

The most recent national research benchmarking exercise, Excellence in Research Australia (ERA) conducted in 2010 resulted in a strong performance for the Faculty with 11 out of its 15 coded field of research rankings at or above world standard. One of the University's highest rankings, a '5' was achieved in Performing Arts and Creative Writing; plus three '4' rankings in Anthropology, 
Applied Ethics and Philosophy; and seven '3' rankings in Demography, Political Science, Sociology, Other Studies in Human Society, Literary Studies, Historical Studies and Linguistics.

Higher degree research students are an important component of the Faculty's research output. For almost 100 years between 1879-1975, according to Edgeloe, there were 294 Master of Arts graduates, seven Masters of Arts (Honours), 10 Doctors of Letters, and 12 Masters of Education. ${ }^{8}$ Less data are available for $\mathrm{PhD}$ graduates, which was 'a degree of the university' rather than being administered by faculties. The records for the period 1994-2010 reveal an average of just over six MA students and $27 \mathrm{PhD}$ students graduating from the Faculty each year. However, within these figures is an upward trend so that in recent years (2006-2010) the average has increased to nine MA students and 35 $\mathrm{PhD}$ graduates per year, with a peak of $54 \mathrm{PhD}$ completions in 2010.

These figures demonstrate a noticeable increase in $\mathrm{PhD}$ enrolments since the Research Training Scheme (RTS) was introduced in 2001. This scheme provides Commonwealth-funded higher degree by research (HDR) students with an 'entitlement' to exemption from tuition fees for the duration of an accredited HDR course, up to a maximum period of four years full-time equivalent study for a Doctorate by research and two years full-time equivalent study for a Masters by research. The RTS scheme funding has placed an emphasis on completions rather than student load. Notwithstanding the pressure for completions, there has been an improvement in the nationally benchmarked Postgraduate Research Experience Questionnaire whereby the percentage agreement for overall satisfaction increased from $76 \%$ in 2009 to $83 \%$ in 2010 and the percentage agreement for supervision increased from $71 \%$ in 2009 to $82 \%$ in 2010. In postgraduate, as in undergraduate teaching, the Faculty is clearly performing its role with distinction.

\section{SUMMARY}

The Faculty and the BA had their origins in the late nineteenth century when Classics (Greek and Latin), Philosophy, and English all became established with professorial appointments. The first University graduate was awarded a BA in 1879. French and German were part of the curriculum for the BA degree but

\footnotetext{
${ }^{8}$ V. A. Edgeloe, Humanities and Associated Studies at the University of Adelaide.
} 
were at an early stage of development. In addition, Music was established with a professorial appointment and the creation of the Elder Conservatorium of Music, both Australian firsts. In the first half of the twentieth century three disciplinespecific chairs were created, in History, a specialist chair in English and a chair in French, even though French had been taught for some time. In the second half of the twentieth century Economics moved out of the Faculty and 10 new discipline-specific chairs were created. The first two chairs in Geography and German were for disciplines that had been taught for over 50 years. Apart from a chair in Anthropology, most other new chairs were created in the 1990s for largely cross-disciplinary programs such as Asian Studies (Chinese and Japanese), Environmental Studies, Linguistics, and Social Inquiry (Women's Studies), which became independent departments. It was also in the 1990s that Psychology moved out of the Faculty. The twenty-first century has seen the introduction of two new disciplines plus the loss of Education and the inclusion of the Elder Conservatorium of Music into the Faculty but the most significant impact has been the restructuring of the Faculty into four schools.

The current Faculty of Humanities and Social Sciences has about one fifth of the University's students compared to $100 \%$ when the University began and the BA was the only degree. The Faculty's graduates have excelled in many areas, for example over one third of all the University's Rhodes Scholars come from the Faculty. The Faculty has increased the number of disciplines and created named degrees, which sit alongside the BA in response to the changing educational priorities and the marketplace. It has also increased in the number of postgraduate coursework programs. Student feedback rates Faculty staff as some of the best teachers in the University and many staff have won national teaching excellence awards.

There has been an increasing focus on quality research through greater numbers of postgraduate research students, particularly over the last decade. Competitive grant funding has increased particularly for the prestigious Category 1 grants. The Faculty has focused its research strengths into university-recognised research centres to maximize quality outputs. Finally, there has been a recognition of the world standard for the majority of the Faculty's research outputs through the recent national ERA research benchmarking exercise. 
Most importantly, the Faculty remains committed to providing a tertiary liberal arts education through developing student skills and attributes such as critical thinking, effective communication and engagement with current social and political issues. The Faculty aims to equip its graduates with an understanding of the world around them and provide them with an adaptability to engage with the diverse range of career opportunities they will encounter in the twenty-first century.

\section{REFERENCES}

Duncan, W. G. K. \& Leonard, R. A., The University of Adelaide, 1874-1974 (Adelaide, Rigby, 1973).

Edgeloe, V. A., Annals of the University of Adelaide (Adelaide, The University of Adelaide, 2003).

Edgeloe, V. A., Humanities and Associated Studies at the University of Adelaide, 18761976: An Administrator's Monograph on their Growth and Changing Nature and Structure During the University's First Hundred Teaching Years (Adelaide, The University of Adelaide, 1986).

Edgeloe, V. A., Classics at the University of Adelaide, 1876-1975 (Adelaide, the University of Adelaide, 1989).

MacDonagh, O., The University of Adelaide: Review of the Department of History (Adelaide, The University of Adelaide, 1980).

Newbold, R. F., Classics at the University of Adelaide, Part Two: 1976-2008 (Adelaide, The University of Adelaide, 2008).

The University of Adelaide, The University of Adelaide (Adelaide, Griffin Press, 1955).

Wesley-Smith, H. E., Arts Graduates at the University of Adelaide, 1924-1949: a Survey (Melbourne, The University of Melbourne, 1952).

Woodburn, S., The Founding of a University: the First Decade of the University of Adelaide (Adelaide, Susan Woodburn, 1983). 


\section{2}

\section{Webs of Significance: an Ethnographer's Account of Anthropology at the University of Adelaide from 1973 to $2011^{1}$}

John Gray

In this chapter, I spin 'webs of significance' - to use Geertz's² well-known rendition of Max Weber's phrase - about a past of which I was and still am an active participant. I came to the Department of Anthropology in 1975 as a Tutor and will retire as Professor at the end of 2012. The account of the past I present is interpretive in a number of ways. First, it is constructed. Ireceived several suggestions about how to periodise flow of events that took place from the establishment of

\footnotetext{
${ }^{1}$ It is important to distinguish between an ethnographic account and an ethnographer's account of the past. This is not an ethnographic account. While I lived in and was participant in the events, I also recognise that to be ethnographic the account should be based upon the act of studying living in society that is distinct from sheerly living in society. Still, I consider myself to be an ethnographer not an historian; accordingly, my interest in social/historical events is to go beyond merely reporting them to understanding them 'from the native's point of view'. C. Geertz, 'From the Native's Point of View: On the Nature of Anthropological Understanding', Bulletin of the American Academy of Arts and Sciences, 2.1 (1974), pp. 26-45.

${ }^{2}$ G. Geertz, 'Thick Description: Towards an Interpretive Theory of Culture', in ibid., The Interpretation of Culture (New York, Basic Books, 1973), p. 5.
} 
the Department in 1973 to the present. Many proposed I do so around the three occupants of the Chair of Anthropology - Bruce Kapferer (1973-1985), James Weiner (1994-1999) and myself (2003-present) - on the presumption that it is the leadership of an individual that is most important in understanding the events and evolution of historical processes. My rejection of this approach was guided by Foucault's scepticism of the modern era's presupposition of the 'sovereign subject' whose actions provide the principal dynamic of history. ${ }^{3}$ Still, I include some of Kapferer's vision because it provided the starting point for the Department and consequently for my account of it. In reflecting back on the nearly forty years since the Department was established, I analyse and name one of the periods that I identify, well known within the University community, around Turner's conception of 'social drama', which he described as 'a way of understanding a sequence of social events which, seen retrospectively by an observer, can be shown to have a [processual] structure'. ${ }^{4}$ For Turner the processual structure of a social drama entailed four phases: breach of regular norm-governed social relations, crisis that creates a dominant cleavage in the social group, redressive action in the form of personal advice, informal mediation and/or arbitration and reintegration of the social group. ${ }^{5}$ Accordingly, in the following I have structured my account in terms of: a period of foundation and growth during the years following the establishment of the Department and the appointment of Kapferer to the Chair; a period of 'social drama' of conflict and division within the Department that led to redressive action being taken by the University and reintegration of the Department at the end of the 1990s; and the most recent period characterised by the arrival of new staff and a concomitant expansion of and new directions for Anthropology's teaching and research. A processual perspective, however, should not always assume a progressive movement in which the present is always better than the past, though in the case of the Discipline of Anthropology, its present situation does look better than at some points in its past.

Second, as this periodised structure implies, my account is present-oriented though not teleological since, again drawing on Foucault's contrarian view of

\footnotetext{
${ }_{3}^{3}$ M. Foucault, The Archaeology of Knowledge (London, Tavistock, 1972), p. 55.

${ }^{4}$ V. Turner, Dramas, Fields and Metaphors: Symbolic Action in Human Society (Ithaca, Cornell University Press, 1974), p. 35.

${ }^{5}$ Ibid., pp. 38-41.
} 
history, ${ }^{6}$ what the Discipline of Anthropology is today was not inevitable. Social relations and organisations have the quality of equifinality - the present state of social relations or a social organisation is not determined by its initial conditions so that the same initial conditions can lead to quite different future states. ${ }^{7}$ This is a point made in Bourdieu's theory of practice with its emphasis on strategic improvisation of individuals and groups pursuing their interests as the dynamic of change. ${ }^{8}$ The current state of Anthropology is one of success in both teaching and research: 2011 total enrolments in our undergraduate courses are among the highest in the Faculty; our research performance was assessed in the 2010 Excellence in Research Australia exercise as high as any other Anthropology Department in Australia; and members of the Discipline have been awarded ARC Grants and a Future Fellowship for 2012-2015. The path to this successful state was not a straightforward predetermined outcome of the vision of Kapferer nor of other initial conditions in which the Department was established. Again drawing upon Bourdieu's theory of practice, I used his metaphor of a conductorless orchestra to understand this outcome as 'collectively orchestrated without being the product of the organising action of a conductor'.

Third, in taking this analytic stance and through my research in the University archives for this account, I have tried to turn myself more into an observer than a participant (a conundrum that characterises all ethnographic fieldwork). Yet, all observers are positioned and, consequently, so is my account.

\section{Pre-History}

While a Chair and a Department of Anthropology was established in the Faculty of Arts in 1973, anthropology had been practiced at the University from the early twentieth century. Research in the physical anthropology of Indigenous Australians had been carried out by members of the Medical Faculty, largely under the aegis of the Board of Anthropological Research. ${ }^{10}$ A Chair in anthropology was first

\footnotetext{
${ }^{6}$ See M. Foucault, The Archaeology of Knowledge.

${ }^{7}$ P. Watzlawick, J. H. Beavin \& D. D. Jackson, Pragmatics of Communication: A Study of Interactional Patterns, Pathologies and Paradoxes (New York, W. W. Norton \& Company Ltd, 1967), pp. 127-8.

${ }^{8}$ P. Bourdieu, Outline of a Theory of Practice (Cambridge, Cambridge University Press, 1977).

${ }^{9}$ P. Bourdieu, The Logic of Practice (Stanford, Stanford University Press, 1990), p. 53.

${ }^{10}$ For an extended account of the expeditions sponsored by the Board of Anthropological Studies,
} 
proposed in 1922 by Frederic Wood-Jones, the Elder Professor of Anatomy at the University of Adelaide from 1920-1926. In 1926, Wood-Jones together with Thomas Draper Campbell were instrumental in establishing the Board of Anthropological Research. Campbell was one of the founders of the University's course in dentistry and he was one of its first graduates. ${ }^{11}$ His interest in dental anthropology became one of the hallmarks of research in physical anthropology at the University; it was a focus that was carried on by his student, Murray Barrett, who led important expeditions to Yuendumu in the 1950s. ${ }^{12}$

The aim of the Board was 'to provide guidance and co-ordination of expeditions and studies in the anthropology of the Australian Aborigines'. ${ }^{13}$ The Board sponsored a number of expeditions into central Australia between 1926 and $1939^{14}$ and to Yuendumu in the 1950s. ${ }^{15}$ Draper led eight of the expeditions; also prominent were the expeditions led by Sir John Burton Cleland, who was Professor of Pathology at the University from 1920 to 1948. Like other members of the Board, Cleland's research focused on physical characteristics of individuals and groups and their relation to the environment. ${ }^{16}$ In addition, Cleland was Deputy Chairman of the Aboriginal Protection Board; in that capacity he visited a number of missions in relation to the welfare of Aboriginal Australians. ${ }^{17}$ By combining his research on physical anthropology with an institutionalised concern for the welfare of Indigenous Australians, Cleland's practice of anthropology was

see T. Brown, G. C. Townsend, S. K. Pinkerton \& J. R. Rogers, Nuendumu: legacy of a longitudinal growth study in Central Australia (Adelaide, University of Adelaide Press, 2011).

${ }^{11}$ <http://health.adelaide.edu.au/dentistry/cfbrg/TDCSymp/tb01.htm>, accessed 3 May 2012.

${ }^{12}$ T. Brown et al., Yuendumu, p. $47 \mathrm{ff}$.

${ }^{13}$ <http://health.adelaide.edu.au/alumni/medicine125/history/>, accessed 13 February 2012.

${ }^{14}$ T. Brown et al., Yuendumu, list sixteen, see p. 15. Many of these are also listed in the papers of Sir John Burton Cleland held by the University of Adelaide Library: The Mt Liebig expedition 1932; 7th BAR expedition to the North-West of South Australia [Musgrave Ranges] 1933; the 10th-12th Board expeditions [Granites 1936, Flinders Ranges 1937, Ooldea 1937; and the Joint Research of the University of Adelaide and the Division of Anthropology of Harvard University, <http://www. adelaide.edu.au/library/special/mss/cleland/>, accessed 13 Febraury 2012. For a listing of the Expeditions sponsored by the Board see Brown, et al. Figure 1.7, p. 16. Board expedition members also included Professor of Pathology, Sir John Cleland, who had a particular interest in the physical anthropology of the Indigenous people of Australia and their environment, dental educator T. D. Campbell and physiologist Sir Cedric Stanton Hicks.

${ }^{15}$ T. Brown et al., Yuendumu, pp. 15 and 53.

${ }^{16}$ <http://www.adelaide.edu.au/library/special/mss/cleland/>, accessed 13 February 2012.

${ }^{17}$ Ibid. 
potentially an extension of Australian 'governmentality', a term employed by Foucault to highlight the use of knowledge as a form of power whose aim was to transform people, in this case Indigenous Australians, into citizens who conformed to the government's view of a well-ordered society. ${ }^{18}$ In the context of the colonial expansion of Europe's power in the twentieth century, the practice of anthropology - 'of recording and analysing the ways of life of subject populations' 19 - by members of the Board of Anthropological Research was not unique. However, it was a legacy that, due to a reflexive turn in Anthropology in the 1960s against such a positioning of the discipline, the newly established Department would eschew.

Notable among the participants in the 1930s and 1950s expeditions of the Board of Anthropological Research were Norman Tindale of the South Australian Museum and Charles Mountford. ${ }^{20}$ Diversifying beyond the physical anthropological expertise of most of the other expedition participants, both were ethnologists who studied - and were pioneers in documenting with sound and film - the social customs, kinship structures, mythology and material culture of Indigenous Australians. Mountford's legacy continues in the current Discipline's activities through his bequest supporting anthropological research among Indigenous Australians. It has supported the PhD fieldwork of Yvonne Ellinghaus, whose thesis entitled Making connections: Aboriginal ways and everyday worlds in regional South Australia was completed in 2008, and also the candidature of Dennis O'Brien, who in 2012 was awarded the first Mountford Bequest PhD Scholarship for his research on the ethnography of Gladys Elphick.

The Faculty of Arts began to push for the establishment of a Department of Anthropology in 1956. The Faculty made a submission to the University's Education Committee that a Chair of Anthropology be appointed during the 1967-1969 triennium. In their submissions to the Education Committee, both The Board of Anthropological Research ${ }^{21}$ and the Faculty of Arts $^{22}$ supported

\footnotetext{
${ }^{18}$ M. Foucault, 'Governmentality', in G. Burchell, C. Gordon \& P. Miller (eds), The Foucault Effect: Studies in Governmentality (Hemel Hempstead, Harvester Wheatsheaf, 1991), pp. 87-104.

${ }^{19}$ T. Asad, 'Afterword: From the History of Colonial Anthropology to the Anthropology of Western Hegemony', in G. Stocking (ed.), Colonial Situations: Essays on the Contextualisation of Ethnographic Knowledge (Madison, University of Wisconsin Press, 1991), p. 315.

${ }^{20}$ T. Brown et al., Yuendumu, pp. 15 and 53.

${ }^{21}$ Extract of the Minutes of the Board for Anthropological Research held on 21 September 1964.

${ }^{22}$ Faculty of Arts Meeting, 14 October 1964.
} 
the establishment of a Chair of Anthropology and reaffirmed the proposal made in 1958 that there should be no limitation on the field of interest of the appointed professor. In doing so, the Board and Faculty were adopting the US model of anthropology as a four-fold discipline including physical or biological anthropology, social/cultural anthropology, linguistics and archaeology. However, in its 11 November 1964 meeting, the Faculty of Arts amended its recommendation by withdrawing its support of Physical Anthropology and recommended instead the establishment of a Chair and Department of Social Anthropology in the tradition of British Anthropology. ${ }^{23}$ Due to financial constraints in the late 1960s, the appointment of the Chair was delayed. It was only with the disestablishment of the Chair of Slavonic Studies in 1970 that funding became available for the appointment of a Chair in Anthropology and the establishment of a Department of Anthropology could be planned for the 1973/75 triennium.

\section{Foundation AND GROWTH}

The Foundation Chair in Anthropology was offered to Bruce Kapferer, then a Senior Lecturer in Anthropology at the University of Manchester. Kapferer had completed his PhD in 1969 under the supervision of Professor Max Gluckman based on his fieldwork in Zambia in association with the Rhodes-Livingstone Institute, ironically part of the British colonial establishment its researcher criticised..$^{24}$ From his experience in the Manchester Department, Kapferer brought what he considered to be a radical and critical anthropology to Adelaide. There were several dimensions to this. First, he distanced the practice of Anthropology from its historical links to colonialism at home and abroad. Reflecting on his appointment to the Chair, Kapferer in August 2011 told me that he resisted the University's idea of anthropology, largely based on the long-term activities of the Board of Anthropological Research, as principally Aboriginal Studies:

Aborigines at that time were beginning their campaign for recognition and land rights ... They just got the vote and were recognised in the census. My

\footnotetext{
${ }^{23}$ Extract from the minutes of the Meeting of the Faculty of Arts held 11 November 1964. Agenda Item II. Matters from Minutes; Item III. A.U.C. Submission for 1967/69; 2. Chair in Anthropology (D.2718/64).

${ }^{24}$ See J. Ferguson, Expectations of Modernity: Myths and Meanings of Urban Life on the Zambian Copperbelt (Berkeley, University of California Press, 1999), p. 32.
} 
view was, having worked in [colonial] Africa ... that it was the responsibility of Aborigines to fight for their own interests and not for anthropologists, usually white, to continually subject them to observation on behalf of those that were governing.

In this he was echoing the increasing reflexive critique of anthropology's past difficulty of accepting responsibility for the political implications of their practice that had been occurring since the mid-1960s. ${ }^{25}$

Second, Kapferer emphasised long-term intensive fieldwork as the foundation of the discipline and the basis upon which anthropology was able to make a coherent and distinctive contribution to understanding humanity. Accordingly, a Special Research Leave program was negotiated with the University that allowed six months of leave at half pay which could only be used for ethnographic research; such 'special research leave' could be added to a six month period of Study Leave to enable a full year of ethnographic fieldwork. ${ }^{26}$ This centrality of fieldwork continues to be one of the principal features of current teaching and research in the Discipline.

Third, Kapferer wanted to build a Department with an international reputation. One strategy to achieve this was to bring to Adelaide renowned scholars from overseas, many for several weeks, under the Faculty's Distinguished Visiting Scholar Program. A second strategy was the establishment of a peer-reviewed and internationally respected journal, Social Analysis, whose editorial policy of publishing articles longer than those allowed in other journals reflected Adelaide Anthropology's commitment to intensive fieldwork and the use of rich and complex ethnographic data in the analysis of human society. The first issue of Social Analysis was published in 1979. It was a special issue entitled The Power of Ritual. It was edited by Kapferer and included articles by both Department members (Tom Ernst, John Gray, Peter Laird and Bruce Kapferer) and international scholars (Don Handelman, The Hebrew University of Jerusalem, and Patricia Pessay, Duke University). Before being taken into the stable of Berghahn Book's international

\footnotetext{
${ }^{25}$ See D. Hymes, Reinventing Anthropology (New York, Pantheon Books, 1969); D. Lewis, 'Anthropology and Colonialism', Current Anthropology, 14.5 (1973), pp. 581-602; T. Asad, 'Afterword: From the History of Colonial Anthropology to the Anthropology of Western Hegemony'.

26 See <http://www.adelaide.edu.au/hr/policies/polbrowse/dev_training/anthrospec.html>, accessed 23 February 2012.
} 
journals, first Michael Roberts and then Kingsley Garbett served as the journal's editors. Both displayed great dedication in making it the internationally prestigious journal that it is today. ${ }^{27}$

Fourth, Kapferer wanted to replicate the collaborative and regionally focused research strategy of Manchester. His research policy was to develop a strong research concentration in South and Southeast Asia and in Australia, including 'white Australian and Aboriginal Australian communities (especially urban Aboriginals)'. ${ }^{28}$ This had two consequences in the early years of the Department. First, staff appointments were guided by this research policy. ${ }^{29}$ Second was the successful 1978 application to the Australian Research Grant Committee for a project entitled Urbanisation Processes in a Regional Context. The grant involved four member of the staff working on different aspects of Urbanisation Processes in Sri Lanka: Kingsley Garbett was to examine the significance of caste and class among urban workers; Bruce Kapferer was to explore the relationship between religious ideology and urban stratification; Michael Roberts was to build upon his earlier historical study of elite formation and upward mobility; and Lee Sackett was to study employment patterns and tourism in a peri-urban region of Colombo. Another outcome of this research policy was the recruitment of postgraduates to conduct ethnographic fieldwork among urban Aboriginals. The Department's first postgraduate student, Jeff Collman, conducted his $\mathrm{PhD}$ research in an urban fringe community near Alice Springs. He qualified for the award of the Department's first $\mathrm{PhD}$ in 1979 with his thesis, Burning Mt. Kelly: Aborigines and the administration of social welfare in Central Australia. The regional focus on Australia and South/ Southeast Asia has been another continuity of the Department/Discipline with over $60 \%$ of the fifty-two postgraduate theses completed between 1979 and 2010 (see Appendix A) based upon ethnographic fieldwork among white Australian and Indigenous Australian communities and in South and Southeast Asia (see Figure 1). ${ }^{30}$

\footnotetext{
${ }^{27}$ It was rank 'A' in the 2010 Journal List for Excellence in Research Australia.

${ }^{28}$ Bruce Kapferer. Department of Anthropology, Application for Staff Development, 5/8/75.

${ }^{29}$ Ibid., pp. 3-4; Bruce Kapferer. Department of Anthropology, Application for Staff Development $1975,13 / 9 / 74$.

${ }^{30}$ In saying this I am not implying that Kapferer's vision for was the conducting factor, to continue Bourdieu's metaphor. Rather, the concentration in Australia and South/Southeast Asia as well as the research done in Europe and other areas of the world also reflects student research preferences
} 


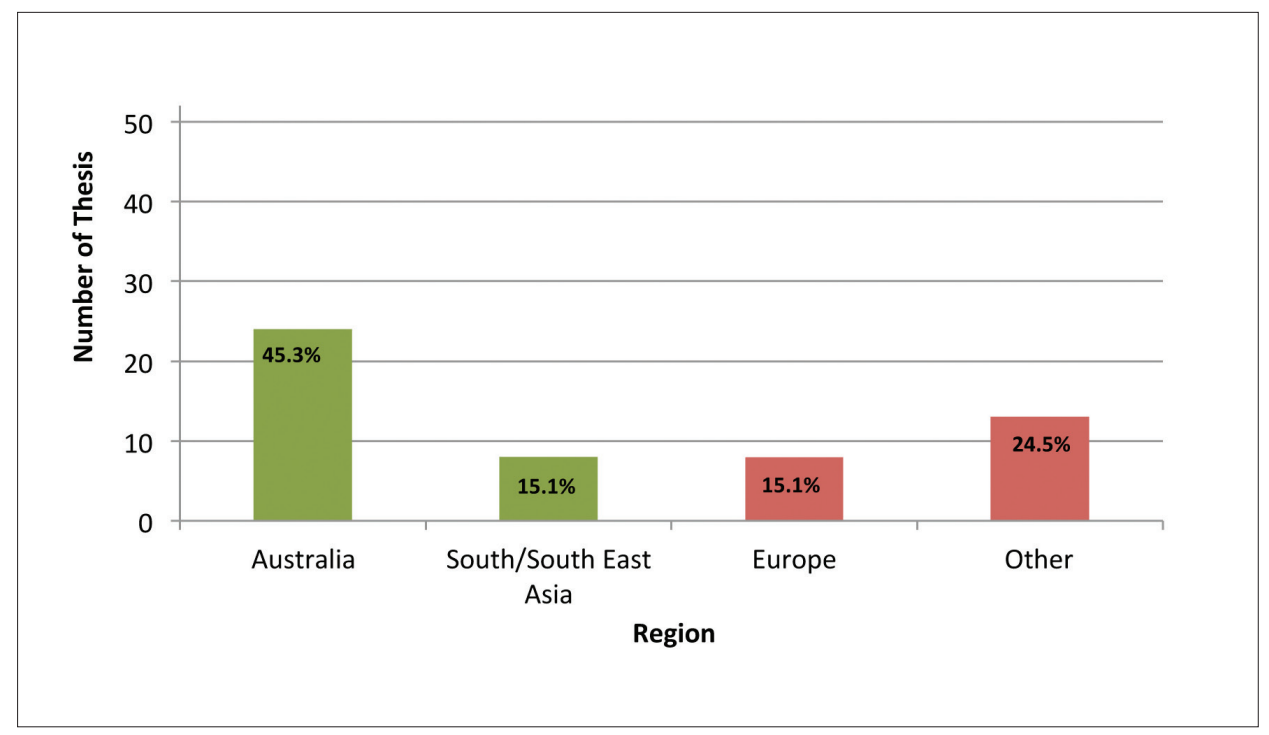

Figure 1: Department of Anthropology Theses by Region, 1979-2010

The early years of the newly established Department were characterised by rapid growth ${ }^{31}$ and a collegial sense of creating something new and important. Part of this was the enthusiastic response of students to the new program which began in 1974 with the offering of the introductory course, Anthropology I, convened by Kapferer who gave the opening lectures. Rather than the 150 to 200 students expected by the University, 435 enrolled in the course. In addition, four Masters of Arts students had enrolled as well as six Honours students. In 1975 there were again over 450 students enrolled in the Level 1 Introductory course. There was also a very high follow-on rate from the Introductory course in 1974 with over 400 enrolments in the newly offered Anthropology II courses, Economic and Political Anthropology (116), Anthropological Studies in Ritual

that are shaped by regional location of Australia, family and financial considerations in addition to the research specialisations of staff.

${ }^{31}$ By 1979 there were nine full-time tenured staff: Bruce Kapferer (appointed Professor in 1973), Tom Ernst (appointed Lecturer in 1974), Roy Fitzhenry (appointed Lecturer in 1974), Adrian Peace (appointed Lecturer in 1974), Lee Sackett (appointed Lecturer in 1975), John Gray (appointed Tutor in 1975), Kingsley Garbett (appointed Reader in 1976), Michael Roberts (appointed Senior Lecturer in 1977) and Susan Barham (appointed Lecturer in 1979). In addition there were 4 full-time tutors (see Appendix B). 
and Religion (81), Systems of Inequality and the Distribution of Power (112), and Communication and Culture (110). In 1976 the first Anthropology III courses were offered: Melanesian and Australian Anthropology, Social Organisation and Culture, Anthropological Problems in South and South-East Asia and Peasant and Proletarians: Anthropological Studies in the Third World. After the new Department introduced courses at all undergraduate levels, the 1977 student-staff ratio was 19.6:1, a figure that was higher than other large departments (Geography 13.5:1, History 13.9:1, Politics 12.4:1 and Psychology 14.5:1). ${ }^{32}$

Another factor in the collegial excitement was the exploration of new analytic paradigms for anthropology that was stimulated by a dynamic Departmental seminar series and very active visiting scholar program. Seminars were rigorous and often intense working sessions in which members of the Department collaboratively and critically assessed the theoretical perspectives and modes of analysis that presenters were developing. This was enhanced by the visitors brought to Adelaide under the Faculty's Distinguished Visitor Program. Between 1974 and 1985, some of anthropology's most internationally eminent scholars visited the Department. They included Marshall Sahlins (University of Chicago), Nancy Munn (University of Chicago), Dan Handelman (The Hebrew University of Jerusalem), Mervin Meggitt (City University of New York), Luc de Heusch (Universite Libre de Bruxelles), Clifford Geertz (Princeton University), Sir Edmund Leach (Cambridge), Clyde Mitchell (Manchester University), John Barnes (ANU), F. G. Baily (University of California), Robert Paine (Memorial University Newfoundland), Kageaki Kajiwara (Osaka University), Andre Beteille (University of Delhi), and Roy Rappaport (University of Michigan). Each of these scholars participated in the Departmental Seminar as well as presenting public lectures. Of particular note is the visit of Marshall Sahlins in 1980 during which he completed and presented in a public seminar series one of his most influential books, Historical Metaphors and Mythical Realities: Structure and Early History of the Sandwich Island Kingdom (University of Michigan Press, 1981).

\footnotetext{
${ }^{32}$ Roy Fitzhenry, letter to Professor Miller, Chairman, Staffing Development Committee, 26 May 1977. In his case for staff development, Fitzhenry mentioned that the student-staff ratio was lower (18.2:1) only if an unappointed lecturing position was included in the staffing figures.
} 


\section{Social Drama}

After the effervescence and excitement of the early years of the Department, a period of conflict followed in the early 1980s that was characterised by problems of governance and division among staff that was not intellectual but based on personal values. These problems were counterbalanced throughout the 1990s by collaboration in curriculum development and teaching. ${ }^{33}$ While staff continued their research activities, the Department rebuilt its reputation and credentials as an organisational unit within the University through its teaching activities, some of which were recognised with awards of excellence.

A significant cleavage developed between staff concerning the conduct of relations among themselves and with students which was not effectively dealt with by the departmental governance processes. In response to what Turner would describe as a 'crisis' ${ }^{34}$ of continuing division and conflict, in early 1988 the ViceChancellor, Professor Kevin Majoribanks, took redressive action ${ }^{35}$ to limit the effects of the cleavage among staff by establishing a Committee of Enquiry, chaired by Professor Fay Gale. The terms of reference were to: enquire into the governance of the Department; enquire into the Department's assessment procedures; consider issues relating to Equal Opportunity; enquire into Special Research Leave for members of the Department; provide advice regarding the Chair in Anthropology to which an appointment was impending; and examine whether Anthropology should be taught in the present Departmental arrangement or whether it might be more appropriate to have anthropology as part of a different organisational structure, and examine the suitability of the Department's present location.

In April 1988, upon the Committee's recommendation, the ViceChancellor disestablished the Department by suspending its Departmental governance organisation, withdrew the pending offer of a Chair appointment to Dr Jonathan Friedman of Lund University, reassigned and physically relocated

\footnotetext{
33 The conflicts and division events were exacerbated by disruptions caused by comparatively frequent re-locations of the Department's office and research accommodation around the University (see Appendix G).

${ }^{34}$ V. Turner, Dramas, Fields and Metaphors: Symbolic Action in Human Society (Ithaca, Cornell University Press, 1974), p. 38.

${ }^{35}$ Ibid., p. 39.
} 
staff to other Departments in the Faculty, and proposed the Department to be reestablished after five years. However, because of the strong teaching performance of the staff, the explicit support of students - some of it organised through the Anthropological Society ${ }^{36}$ - and continuing high enrolments throughout the turbulent period - from 1983-1986 the Department had a student-staff ratio above 17.0, the highest for any Anthropology Department in Australia ${ }^{37}$ - the Vice-Chancellor decided that anthropology was to be maintained and continue to be taught at undergraduate, honours and postgraduate level through a Committee of Anthropology. All Anthropology staff were members of the Committee that was Chaired by Mr Paul Nursey-Bray of the Politics Department. There followed a period of staff turnover in late 1980s with the resignations of Roy Fitzhenry, Tom Ernst and Susan Barham and the appointments of Deane Fergie and Michael Nihill.

The Department was re-established in 1994 with the appointment of James Weiner to the Chair. Weiner received his $\mathrm{PhD}$ from the Australian National University in 1984 based upon his fieldwork among the Foi of Papua New Guinea. His research on myth and social structure in Papua New Guinea complemented existing research on PNG of Deane Fergie and Rod Lucas; his analytics, inspired by the philosophy of Martin Heidegger, more broadly strengthened the existing strong theoretical focus on interpretive and phenomenological approaches in Anthropology that continues in the research and teaching of several members of the Department. Weiner left the Department in 1999 to pursue a career as a consultant anthropologist conducting contract research and publishing on Indigenous land rights, resource extraction and native title. In following this career, he, like Lee Sackett who left the Department in 1995, joined an emerging trend toward applied research in Adelaide Anthropology and Australian Anthropology more generally. This trend took place in the wider Australian context of the Mabo decision on native title and the consequent need for anthropological expertise

\footnotetext{
${ }^{36}$ A petition asking that the Department not be disestablished and bearing 696 signatures was tabled in Council Meeting of 13 May 1988 by Mrs S. Chamberlain, a postgraduate student in anthropology. Council Meeting 4/88, item 27.

${ }^{37}$ Submission of the Department of Anthropology, Faculty of Arts, to the Compact Working Party, 1987, prepared by Dr Adrian Peace, Chairman of Department.
} 
about Indigenous Australians for native title claims and land clearances for mining operations.

Throughout the 1990s, the University was involved in a process of changing the course structure from one-year to semester courses. This provided an impetus to the beginnings of the reintegration of the Department. Until 1988, all courses offered by the Department were full-year and the curriculum was progressive with distinctive first, second and third 'year' or level courses, and an Honours or 'fourth' year. By the end of the 1990s, the Anthropology Curriculum was a more complex semesterised program in which there were a greater number of course offerings each semester, except for the Level I introductory course, which remained a full-year offering. One of the features of the curriculum, common throughout the Faculty, was the combining of most Level II and Level III courses such that Level II and Level III students attended the same lectures but had differentiated required readings and essay assignments.

This significant reorganisation and redesigning of the Anthropology curriculum took place over most of the 1990s. There were full Departmental reviews of the undergraduate teaching program in 1992, 1994 and 1998, of the Honours program in 1997 and of the postgraduate program in 1993 and 1999. These reviews and consequent development of the curriculum entailed necessary and recurring collaboration among staff to meet the University aims of semesterisation and to continue to attract students in a climate of what was called 'EFTSU Wars' - the competition among Departments in the Faculty to attract relatively higher enrolments that was becoming the explicit basis of a Department's staffing and funding. This internal collaboration and external competition created ties among the staff that cross-cut the remnants of the cleavages that had caused the turbulence of the 1980s.

There are several other developments of note in the evolution of the curriculum. First, in 1993 Anthropology assumed responsibility for teaching the media courses that had formerly be offered by the Education Department. One of the Department's postgraduates, Charmaine McEachern, who had done a pioneering ethnography on media and politics in Thatcherite Britain, ${ }^{38}$ was central

\footnotetext{
${ }^{38}$ C. McEachern, Down on the Farm: Soap opera, rural politics and Thatcherism, Thesis submitted in fulfilment of $\mathrm{PhD}$ (The University of Adelaide, 1991).
} 
to this new direction in the curriculum and was appointed Lecturer in 1993. She offered the two media-focused courses. The popularity of these offerings was built upon by the Faculty in establishing a B Media degree in 2001, first 'housed' within the Department of Anthropology. ${ }^{39}$ Second was the incorporation of major theoretical developments in the discipline into the Level II/III courses: Foucault was central to the course Discourse and Power and Bourdieu was the main theorist covered in the course Theories of Practice; and theories of experience, particularly the phenomenology of Heidegger, Schutz and Merleau-Ponty, were introduced in Culture and Society: Contemporary Debates. Third, most courses were thematic rather than regional, focusing on particular dimensions of anthropological debate - ethnicity, sexuality and, in later years, medical anthropology. In addition, from 1993 to 1996, the introductory course was fully collaborative with several members of staff (Deane Fergie, Kingsley Garbett, Lee Sackett, Charmaine McEachern, Adrian Peace) involved in presenting lecture modules tied together by bridging lectures given by the course convenor (John Gray).

These curriculum initiatives established the department as popular and accomplished in learning and teaching. Throughout the 1990s enrolments in the undergraduate program remained high (representing between $8 \%$ to $9 \%$ of total Faculty load); $\mathrm{PhD}$ completions remained strong (see Figure 2); two staff were awarded The Stephen Cole the Elder Prize for Excellence in Teaching (Deane Fergie in 1997 and John Gray in 1999); under the leadership of the Head, the Department developed a learning and teaching plan that was the winner in 1998 of the Inaugural Departmental Learning and Teaching Prize established by Professor Penny Boumelha, Deputy Vice-Chancellor (Academic); and in 2002, Phyllis Turner completed her BA (Honours) in Anthropology at the age of 90. In addition, members of staff published major monographs with international publishers: Adrian Peace (Institute of Social and Economic Research), Michael Roberts (Cambridge University Press), James Weiner (University of Wisconsin Press) and John Gray (Oxford University Press).

\footnotetext{
${ }^{39}$ In 2002/3, the media degree was convened by the English Department in the School of Humanities; in 2004 a separate Department of Media was established. Still, the Department continued to offer media-focused courses that emphasised an anthropological and ethnographic analytic perspective.
} 


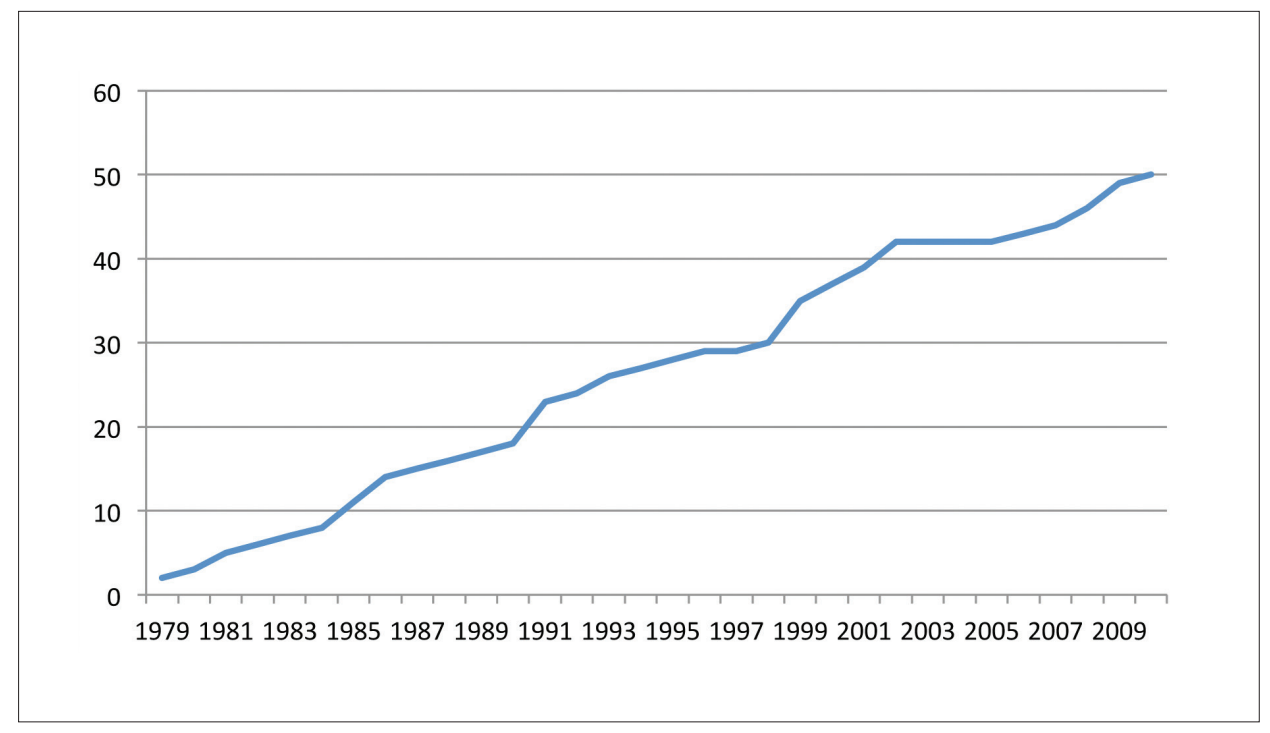

Figure 2: Cumulative Number of Research Theses

\section{EXPANDING DiREGTIONS}

Without imputing any causality, the new century was accompanied by new institutional structures in the Faculty and new directions in Anthropology. In 2003, the Faculty was reorganised into three Schools. John Gray, recently appointed to the Chair of Anthropology, became the inaugural Head of the newly established School of Social Sciences, incorporating Disciplines that included the former Departments of Anthropology, Asian Studies, Geography and Gender, Work, and Social Inquiry.

In the early 2000s the Australian Research Council, at the behest of the Howard Government, developed an plan to introduce National Research Priorities in the consideration of application for research support. ${ }^{40}$ This was another contextual feature - in addition to the earlier emergence of applied anthropology in relation to native title claims - within which the Department's direction began

\footnotetext{
${ }^{40}$ The first National Research Priorities announced by Prime Minister John Howard in December 2002 were: 'an environmentally sustainable Australia; promoting and maintaining good health; frontier technologies for building and transforming Australian industries; and safeguarding Australia' (ARC 2003: 2).
} 
to expand to include applied anthropology, particularly in relation to development programs in the Asia-Pacific region and Indigenous Australia. This was a reminiscent of a proposal for the introduction of a course in Applied Anthropology that had been put forward by Kapferer and Garbett in association with Peter Sutton in 1983. That proposal was debated in the Department and ultimately not supported by a majority of its members. ${ }^{41}$ Recognising the importance of applied anthropological research that had been emerging in Australian Anthropology, an initiative to include applied anthropology in the teaching and research agenda was adopted by Departmental members and the first appointment of an anthropologist with professional experience in applied anthropology, James Taylor, was made in 2001. Taylor had done applied work in rural development, community forestry and native title and had links with AusAid. His appointment was followed by the arrival in 2002 of Andrew Skuse who had done his PhD fieldwork in Afghanistan and worked in the UK Department for International Development, particularly in the field of communication and information technology for development, and Alison Dundon in 2008 whose research focused on HIV/AIDS, natural resource management and community development in Papua New Guinea. In addition, from the mid-1990s, Deane Fergie and Rod Lucas began contract research among Indigenous Australians in the contexts of the 1992 Australian High Court Mabo case recognising native title in Australia and the burgeoning mining industry's need for site clearances. The increasing demand for such contract research led Fergie and Lucas to form an applied social research company, LocuSAR (Locus for Social Analysis and Research), that combined a commitment to anthropological theory with an applied anthropology perspective. The Department curriculum reflected this expansion of expertise into applied anthropology and the anthropology of development with the offering of new courses: Poverty and Development: Conditions and Experience; Conflict and Crisis in Contemporary Society; Anthropology of Development; Communication Technologies for Development; and Gender and Development.

These changes in staffing and research that added applied anthropology and development to a continuing focus on basic anthropological research culminated

\footnotetext{
${ }^{41}$ Proposal for the Establishment of a Qualification in Applied Anthropology at the University of Adelaide. Letter from G. K. Garbett, Chairman, to Professor D. R. Stranks, Vice Chancellor, 6 June 1983.
} 


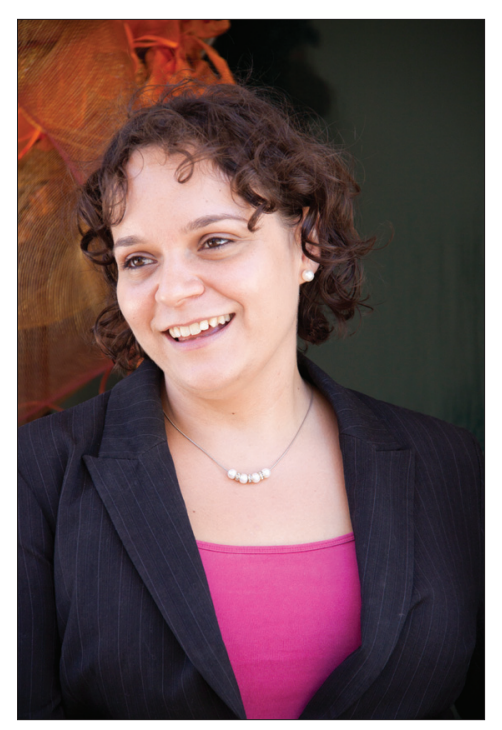

\section{Rebecca Richards}

in the introduction of Development Studies as a major sequence in the Bachelor of Arts degree and the first intake into the new Bachelor of Development Studies degree in 2007. Andrew Rosser, who had extensive professional experience in the policy and practice of development studies, particularly in Southeast Asia, during his tenure at the Institute for Development Studies (University of Sussex, UK), joined the Discipline of Anthropology in 2007 to be convenor of the new degree program. The initial intake was about 60 students. To cater for the continuing enrolments in the Bachelor of Development Studies as well as the increasing enrolments in anthropology courses, Susan Hemer, whose PhD from the University of Melbourne was based upon ethnographic research in Papua New Guinea on the social impact of mining and development projects as well as on HIV and women's health, was appointed to a joint position in Anthropology and Development Studies in 2009.

In 2011, the name of the Discipline was officially changed to 'Anthropology and Development Studies' in recognition of the complementary relation between the two that has significantly enhanced the research performance of the Discipline. Since 2000, Discipline staff have published nearly 200 referred research outputs, 
including thirteen books, and were recipient of several Category 1 research grants (ARC, AusAid, etc.) and an ARC Future Fellowship. In 2010, this research performance was rated by the Excellence in Research Australia as 4 ('The Unit of Evaluation profile is characterised by evidence of performance above world standard presented by the suite of indicators used for evaluation'), ${ }^{42}$ as high as any Anthropology Department in Australia. ${ }^{43}$ In the same year, Rebecca Richards, an Honours Graduate in Anthropology 'made history by becoming Australia's first indigenous Rhodes Scholar in 108 years'. ${ }^{44}$

\section{CONGLUSION: Is THERE AN 'AdELAIDE ANTHROPOLOGY'?}

I bring this account to a conclusion by asking if the outcome of the conductor-less orchestra (to use Bourdieu's metaphor again) that was and is the Department/ Discipline of Anthropology at the University of Adelaide produced a distinctive anthropology. My answer is yes with two caveats. First, the features of Adelaide Anthropology that I identify are not individually distinctive to it. Many other Departments engage the same practices and orientations, making it difficult to claim a separate distinctiveness for Adelaide Anthropology except through the way these features have been realised in the biography of the Department/Discipline. Second, I am focusing here on how anthropology as a scholarly discipline is practiced at Adelaide as distinct from the practice that now characterises the fruitful combination of anthropology and development studies as an organisational Discipline within the Faculty.

What has most characterised anthropological practice at the University of Adelaide from its establishment to the present is the commitment to intensive and extensive ethnographic fieldwork - with all its entailments. It is the central theme of our teaching and the basis of our research and the particular contribution it can make to the understanding of the human world. Anthropology is not just a stock of knowledge about the distinctive lifeworlds of people around the world.

\footnotetext{
${ }^{42}$ Australian Research Council, Excellence in Research For Australia 2010: National Report (Commonwealth of Australia, 2011), p. 5.

${ }^{43}$ Due to the Australian Bureau of Statistics categorisation of fields of research used by the ERA, research outputs in Physical/Biological Anthropology are combined with Social/Cultural Anthropology in the assessment procedure.

${ }^{44}$ See <http://www.adelaide.edu.au/news/news42681.html>, accessed 2 June 2012.
} 
It is more fundamentally a mode of knowing and ethnographic fieldwork is at the heart of Adelaide Anthropology's epistemological approach. Because the nature of the knowledge produced through ethnography emphasises the meaningfulness of these lifeworlds, the theoretical approach adopted is broadly interpretive. Because ethnography necessarily entails the ethnographer engaging in social relations with and participating in the lifeworld of people constituted as 'other', a critical and reflexive human relation - one that dissolves the apparent commonsense truth of a scientistic subject-object relation into the self-other relation that for George Herbert Mead is the foundation of the emergence of the self ${ }^{45}$ - is also central to the epistemology. The critical aim of this ethnographic relation is to uncover the tacit dimension of others' meaningful lifeworlds and in doing so the ethnographer must perforce reflect back upon and disclose the tacit and taken-for-granted dimension of his/her lifeworld, even if only implicitly, in the analysis of the lifeworlds of others. ${ }^{46}$ Because of this critical and reflexive ethnographic relation, anthropology is intrinsically comparative. From the early days of the Department, many of Adelaide's anthropologists have practiced this comparative framework explicitly by choosing to do ethnography formally in more than one social group. ${ }^{47}$ This has provided a breadth of ethnographic and theoretical expertise - enabling more choice for students for their $\mathrm{PhD}$ research - that is perhaps greater than may be available in some Departments of similar size where staff have tended to conduct research among one social group. More recently, with the expansion of the Discipline's teaching and research to include applied and development anthropology, there has been a concomitant adoption of a diversity of fieldwork practices by both staff and postgraduate students. Some examples of this diversity are: the use of ethnographic teams (by Fergie and Lucas) in contract research among Indigenous Australian groups; the implementation of

\footnotetext{
${ }^{45}$ G. H. Mead, Mind, Self and Society: From the Standpoint of a Social Behaviorist (Chicago, Chicago University Press, 1967).

${ }^{46}$ This aim of disclosing the tacit dimension that enlivens the meaningfulness of people's lifeworld is examined of some of our most popular undergraduate courses: Anthropology of Everyday Life [ANTH 1 105], Emotion Mind and Person [ANTH 2037], Consuming Passions [ANTH 2042], and realised in some of the major research publications by staff (Gray 2000, 2006; Peace 2001).

${ }^{47}$ Kapferer (Africa and Sri Lanka), Garbett (Africa and Sri Lanka), Gray (Nepal and Scotland), Peace (Africa and Ireland), Fergie (Papua New Guinea and Indigenous Australia), Lucas (Australia and Indigenous Australia), Dennis (Australia and Christmas Island), Skuse (Afganistan and Africa), Taylor (Vietnam and Thailand).
} 
multi-sited fieldwork ${ }^{48}$ in research on anorexia, ${ }^{49}$ folk festivals by Rachel Massey (current postgraduate student) and the Greek diaspora in Australia by Val Liddle (current postgraduate student); the incorporation of ethnographic methods in the construction of case studies for development studies research in South Africa by Andrew Skuse and Bangladesh by Yan Yan (current postgraduate student); and the use of ethnographic-derived methods of rapid appraisal and participatory research in development studies projects and consultancies engaged in by staff in Africa by Andrew Skuse and the Asia-Pacific region by Jim Taylor.

My ending to this account - a kind of valedictory - is that the contribution that Adelaide anthropologists can make to understanding the human condition continues to be based upon their ethnographic relation with people and their lifeworld: that is, we continue to engage in long-term, intensive, and usually affective multi-dimensional social relations with people and their lifeworld as a epistemological mode of collaboratively producing the rich and intimate knowledge of the continuing, intensive and affective social relations that constitute their lifeworld. Or as Paul Rabinow more elegantly and incisively put it: 'Anthropology is an interpretive science. Its object of study, humanity encountered as Other, is on the same epistemological level as it is. Both the anthropologists and [the people whose lifeworld is being studied] live in a culturally mediated world, caught up in "webs of significance" they themselves have spun, ${ }^{50}$ Ethnography mediates our analytic relation to the human world; it is the web of significance that we have and continue to spin for ourselves, our colleagues and our students.

\section{REFERENCES}

Asad, T., 'Afterword: From the History of Colonial Anthropology to the Anthropology of Western Hegemony', in G. Stocking (ed.), Colonial Situations: Essays on the Contextualisation of Ethnographic Knowledge (Madison,

\footnotetext{
${ }^{48}$ G. Marcus, 'Ethnography in/of the World System: The Emergence of Multi-sited Fieldwork', Annual Review of Anthropology, 24 (1995), pp. 95-117.

${ }^{49}$ M. Warin, Abject Relations: Everyday Worlds of Anorexia (New Brunswick [New Jersey], Rutgers University Press, 2010).

${ }^{50}$ P. Rabinow, Reflections on Fieldwork in Morocco (Berkeley, University of California Press, 1977), p. 151.
} 
University of Wisconsin Press, 1991).

Australian Research Council, Implementation Plan for National Research Priorities

(Commonwealth of Australia, 2003), <http://www.arc.gov.au/pdf/

Implementation_Plan-final.pdf $>$, accessed 13 June 2012.

Australian Research Council, Excellence in Research For Australia 2010: National

Report (Commonwealth of Australia, 2011).

Bourdieu, P., Outline of a Theory of Practice (Cambridge, Cambridge University Press, 1977).

Bourdieu, P., The Logic of Practice (Stanford, Stanford University Press, 1990). Brown, T., Townsend, G. G., Pinkerton, S. K. \& Rogers, J. R., Yuendumu: legacy of a longitudinal growth study in Central Australia (Adelaide, University of Adelaide Press, 2011).

Ferguson, J., Expectations of Modernity: Myths and Meanings of Urban Life on the

Zambian Copperbelt (Berkeley, University of California Press, 1999).

Foucault, M., The Archaeology of Knowledge (London, Tavistock, 1972).

Foucault, M., 'Governmentality', in G. Burchell, G. Gordon \& P. Miller (eds),

The Foucault Effect: Studies in Governmentality (Hemel Hempstead, Harvester

Wheatsheaf, 1991), pp. 87-104.

Geertz, C., 'Thick Description: Towards an Interpretive Theory of Culture', in ibid., The Interpretation of Culture (New York, Basic Books, 1973).

Geertz, C., 'From the Native's Point of View: On the Nature of Anthropological Understanding', Bulletin of the American Academy of Arts and Sciences, 2.1 (1974), pp. 26-45.

Gray, J., At Home in the Hills: Sense of Place in the Scottish Borders (London, Berghahn Books, 2000).

Gray, J., Domestic Mandala: Architecture of Lifeworlds in Nepal (Aldershot, Ashgate, 2006).

Hymes, D., Reinventing Anthropology (New York, Pantheon Books, 1969).

Lewis, D., 'Anthropology and Colonialism', Current Anthropology, 14.5 (1973), pp. 581-602.

Marcus, G., 'Ethnography in/of the World System: The Emergence of Multisited Fieldwork', Annual Review of Anthropology, 24 (1995), pp. 95-117.

McEachern, C., Down on the Farm: Soap opera, rural politics and Thatcherism, Thesis 
submitted in fulfilment of $\mathrm{PhD}$, (The University of Adelaide, 1991).

Mead, G. H., Mind, Self and Society: From the Standpoint of a Social Behaviorist

(Chicago, Chicago University Press, 1967).

Peace, A., A World of Fine Difference: The Social Architecture of a Modern Irish Village (Dublin, University of Dublin Press, 2001).

Rabinow, P., Reflections on Fieldwork in Morocco (Berkeley, University of California Press, 1977).

Turner, V., Dramas, Fields and Metaphors: Symbolic Action in Human Society (Ithaca, Cornell University Press, 1974).

Warin, M., Abject Relations: Everyday Worlds of Anorexia (New Brunswick, New Jersey, Rutgers University Press, 2010).

Watzlawick, P., Beavin, J. H. \& Jackson, D. D., Pragmatics of Communication: A Study of Interactional Patterns, Pathologies and Paradoxes (New York, W. W. Norton \& Company Ltd, 1967).

\section{Appendix A: Postgraduate Research Thesis 1979-2011}

Collmann, Jeffrey R. 1979. Burning Mt. Kelly: Aborigines and the administration of social welfare in Central Australia.

Dey, Josephine. 1979. An anthropological study of revivalist religion in Adelaide (MA).

Grimes, Sandra. 1980. An anthropological perspective on gender in the workplace: A case study of women working in hotel bars.

Hall, Meredith.1981. Music as a Social Activity (MA).

Muetzelfeldt, Michael. 1981. Nuclear Culture Social Reaction: Opposition to Uranium Mining in Australia.

Mearns, David. 1982. Religious practice and social identity : the social and ritual organisation of South Indians in Melaka.

Souchou, Yao. 1983. Class Culture and Structural Domination in a colonial Situation: changing community leadership on Cheung Chau Island, Hong Kong.

Loomis, Terence. 1984. The counterfeit savage: A Study of Cook Islands Migrants, Class and Racialisation in New Zealand. 
Clark, Jeffrey L. 1985. From Cults to Christianity: continuity and change in Takuru.

Fergie, Deane. 1985. Being and becoming: ritual and reproduction in an Island Melanesian Society.

Lattas, Andrew. 1985. The new panopticon: newespaper discourse and the rationalisation of society and culture in New South Wales 1803-1830.

Cheng Yeen, Chooi. 1986. Blooding a lion in Little Bourke Street : the creation, negotiation and maintenance of Chinese ethnic identity in Melbourne (MA).

Mares, Margaret. 1986. Doing English: An Ethnography.

Nihill, Michael. 1986. Roads of Presence: social Relatedness and Exchange in Anganen Social Structure.

Barrett, Robert J. 1987. Psychiatric practice and the definition of mental illness: the case of schizophrenia.

Edward, Marlene. 1988. The social organisation of a second-hand clothing store: informal strategies and social interaction amongst volunteer workers.

Wigman, Albertus. 1989. Childhood and Compulsory Education in South Australia: A Cultural Political.

Zubrinich,Kerry. 1990. A study of femaleness and maleness in the construction of schizophrenia: an Australian case (MA).

Fordham, Graham S. 1991. Protestant Christianity and the transformation of Northern Thai Culture.

McEachern, Charmaine. 1991. Down on the Farm: Soap opera, rural politics and Thatcherism.

Pannell, Sandra.1991. Narrative Boundaries National Horizons: the Politics of Identity in Amaya Maluku Tenggara Indonesia.

Warrell, Lindy. 1991. Cosmic Horizons and Social Voices.

Williams, Gary.1991. Supervised Autonomy: medical specialities and structured conflict in an Australian general hospital.

Merrett, Leanne. 1992. New women: discursive and non-discursive processes in the construction of Anganen womanhood.

Kaneff, Deema. 1993. Social constructions of the past and their significance in the Bulgarian socialist state.

Olsson, Margareta. 1993. Patterns of Protest: Sweedish Farmers in Times of Cereal Surplus Crisis. 
Lovell, Christine. 1994. Legal Discourse on Rape.

Hutchings, Suzi. 1995. Social contexts personal shame: an analysis of Aboriginal engagement with juvenile justice in Port Augusta.

Palmer, Catherine. 1996. A Life of its own - the social construction of the Tour de France.

Lucas, Rodney. 1998. Uncommon lives: an ethnography of schizophrenia as extraordinary experience.

Connon, Aileen.1999. Living on the city margins: homelessness, violence and stratagems of survival in an Australian metropolis (MA).

Sansom, Jane. 1999. Contested Authenticity identity and the performance of the Anastenaria. Telfer, Jon. 1999. Per Alienus Per Intimus: Agency and the dialectics of Identity in Adoption.

Sherkin, Samantha. 1999. Forever United: Identity-Construction across the Rural-Urban Divide.

Bloustein, Gerry. 1999. Striking Poses: an investigation into the constitution of gendered Identity as process in the worlds of Australian Teenage Girls.

Raftery, David. 2000. Competition, conflict and cooperation: an ethnographic analysis of an Australian forest industry dispute (MA).

Weir, Michael. 2000. In the Shadowes of Consciousness: Uncanny composures in the City of Adelaide.

Cohen, Erez. 2001. Rethinking the 'Migrant Community' A study of Latin American migrants and refugees in Adelaide.

Forte, Maximillian. 2001. Re-Engineering Indigeneity: Cultural Brokerage, the Political Economy of Tradition, and the Santa Rosa Carib community of Arima, Trinidad and Tobago.

Dennis, Simone. 2002. Sensual Extensions: Foy, Pain and Music-Making in a Police Band.

Saniotis, Arthur. 2002. Sacred Worlds. An analysis of mystical mastery of North Indian Faqirs.

Warin, Megan. 2002. Becoming and Unbecoming: Abject Relations in Anorexia.

Amanatidis, Agapi. 2006. 'Coming Into Being': Metaphors of self and becoming in Carnival on the Aegean Island of Skyros.

Thompson, Kirrilly. 2007. Performing human-animal relations in Spain : an anthropological study of bullfighting from horseback in Andalusia. 
Corfield, Sophia. 2008. Negotiating existence: asylum seekers in East Anglia, UK.

Butle, Nadia. 2008. Coca communications: tales from the Bolivian coca field.

Lam, Lia Ming. 2009. Park, hill migration and changes in household livelihood systems of Rana Tharus in Far-western Nepal.

Lejukole, James Wani-Kana Lino. 2009. "We will do it our own ways": a perspective of Southern Sudanese refugees resettlement experiences in Australian society.

Ellinghaus, Yvonne. 2009. Making connections: Aboriginal ways and everyday worlds in regional South Australia.

Zivkovic, Tanya. 2010. Tibetan Buddhist embodiment: The religious bodies of a deceased lama. 
APPENDix B: STAFF MEMBERS (WITH TENURABLE APPOINTMENTS): 19742011

\begin{tabular}{|c|c|c|c|c|c|c|c|c|c|c|c|c|c|c|c|c|c|c|c|c|c|c|c|c|c|c|c|c|}
\hline & 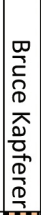 & 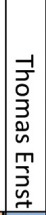 & 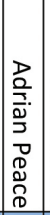 & 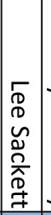 & 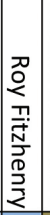 & 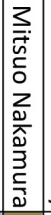 & 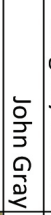 & 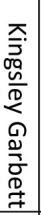 & 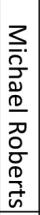 & 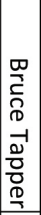 & 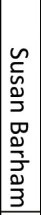 & 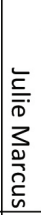 & $\begin{array}{l}n \\
3 \\
a \\
n \\
\frac{1}{2} \\
\frac{1}{3} \\
\frac{1}{0} \\
\frac{0}{3} \\
\frac{0}{3}\end{array}$ & 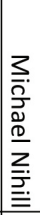 & 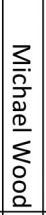 & 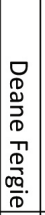 & 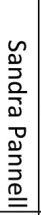 & 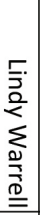 & 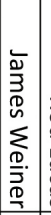 & 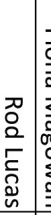 & 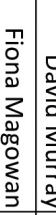 & 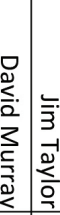 & 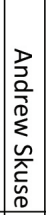 & 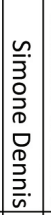 & 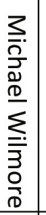 & 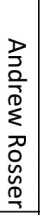 & 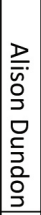 & 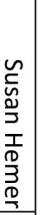 \\
\hline 1974 & N) & & & & & & & & & & & & & & & & & & & & & & & & & & & \\
\hline 1975 & & & & & & & & & & & & & & & & & & & & & & & & & & & & \\
\hline 1976 & & & & & & & & & & & & & & & & & & & & & & & & & & & & \\
\hline 1977 & & & & & & & & & & & & & & & & & & & & & & & & & & & & \\
\hline 1978 & & & & & & & & & & & & & & & & & & & & & & & & & & & & \\
\hline 1979 & & & & & & & & & & & & & & & & & & & & & & & & & & & & \\
\hline 1980 & & & & & & & & & & & & & & & & & & & & & & & & & & & & \\
\hline 1981 & & & & & & & & & & & & & & & & & & & & & & & & & & & & \\
\hline 1982 & & & & & & & & & & & & & & & & & & & & & & & & & & & & \\
\hline 1983 & & & & & & & & & & & & & & & & & & & & & & & & & & & & \\
\hline 1984 & & & & & & & & & & & & & & & & & & & & & & & & & & & & \\
\hline 1985 & & & & & & & & & & & & & & & & & & & & & & & & & & & & \\
\hline 1986 & & & & & & & & & & & & & & & & & & & & & & & & & & & & \\
\hline 1987 & & & & & & & & & & & & & & & & & & & & & & & & & & & & \\
\hline 1988 & & & & & & & & & & & & & & & & & & & & & & & & & & & & \\
\hline 1989 & & & & & & & & & & & & & & & & & & & & & & & & & & & & \\
\hline 1990 & & & & & & & & & & & & & & & & & & & & & & & & & & & & \\
\hline 1991 & & & & & & & & & & & & & & & & & & & & & & & & & & & & \\
\hline 1992 & & & & & & & & & & & & & & & & & & & & & & & & & & & & \\
\hline 1993 & & & & & & & & & & & & & & & & & & & & & & & & & & & & \\
\hline 1994 & & & & & & & & & & & & & & & & & & & & & & & & & & & & \\
\hline 1995 & & & & & & & & & & & & & & & & & & & & & & & & & & & & \\
\hline 1996 & & & & & & & & & & & & & & & & & & & & & & & & & & & & \\
\hline 1997 & & & & & & & & & & & & & & & & & & & & & & & & & & & & \\
\hline 1998 & & & & & & & & & & & & & & & & & & & & & & & & & & & & \\
\hline 1999 & & & & & & & & & & & & & & & & & & & & & & & & & & & & \\
\hline 2000 & & & & & & & & & & & & & & & & & & & & & & & & & & & & \\
\hline 2001 & & & & & & & & & & & & & & & & & & & & & & & & & & & & \\
\hline 2002 & & & & & & & & & & & & & & & & & & & & & & & & & & & & \\
\hline 2003 & & & & & & & & & & & & & & & & & & & & & & & & & & & & \\
\hline 2004 & & & & & & & & & & & & & & & & & & & & & & & & & & & & \\
\hline 2005 & & & & & & & & & & & & & & & & N) & & & & & & & & & & & & \\
\hline 2006 & & & & & & & & & & & & & & & & & & & & & & & & & & & & \\
\hline 2007 & & & & & & & & & & & & & & & & & & & & & & & & & & & & \\
\hline 2008 & & & & & & & & & & & & & & & & & & & & & & & & & & & & \\
\hline 2009 & & & & & & & & & & & & & & & & & & & & & & & & & & & & \\
\hline 2010 & & & & & & & & & & & & & & & & & & & & & & & & & & & & \\
\hline 2011 & & & & & & & & & & & & & & & & & & & & & & & & & & & & \\
\hline
\end{tabular}


Appendix G: LoGations of the Department/Disciplne of ANTHROPOLOGY

\begin{tabular}{|c|c|c|c|c|c|c|c|c|c|}
\hline 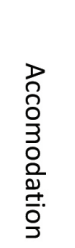 & 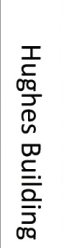 & 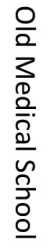 & 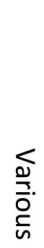 & $\begin{array}{l}\bar{D} \\
\stackrel{D}{D} \\
\frac{D}{D} \\
z \\
\frac{D}{0} \\
\frac{0}{D}\end{array}$ & 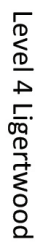 & 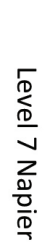 & 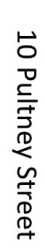 & 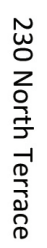 & 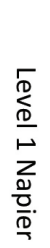 \\
\hline \multicolumn{10}{|l|}{1974} \\
\hline \multicolumn{10}{|l|}{1975} \\
\hline \multicolumn{10}{|c|}{1976} \\
\hline \multicolumn{10}{|l|}{1977} \\
\hline \multicolumn{10}{|c|}{1978} \\
\hline \multicolumn{10}{|l|}{1979} \\
\hline \multicolumn{10}{|l|}{1980} \\
\hline \multicolumn{10}{|l|}{1981} \\
\hline \multicolumn{10}{|l|}{1982} \\
\hline \multicolumn{10}{|c|}{1983} \\
\hline \multicolumn{10}{|l|}{1984} \\
\hline \multicolumn{10}{|l|}{1985} \\
\hline \multicolumn{10}{|l|}{1986} \\
\hline \multicolumn{10}{|c|}{1987} \\
\hline \multicolumn{10}{|l|}{1988} \\
\hline \multicolumn{10}{|l|}{1989} \\
\hline \multicolumn{10}{|l|}{1990} \\
\hline \multicolumn{10}{|l|}{1991} \\
\hline \multicolumn{10}{|c|}{1992} \\
\hline \multicolumn{10}{|l|}{1993} \\
\hline \multicolumn{10}{|l|}{1994} \\
\hline \multicolumn{10}{|l|}{1995} \\
\hline \multicolumn{10}{|l|}{1996} \\
\hline \multicolumn{10}{|l|}{1997} \\
\hline \multicolumn{10}{|l|}{1998} \\
\hline 1999 & & & & & & & & & \\
\hline 2000 & & & & & & & & & \\
\hline 2001 & & & & & & & & & \\
\hline 2002 & & & & & & & & & \\
\hline 2003 & & & & & & & & & \\
\hline 2004 & & & & & & & & & \\
\hline 2005 & & & & & & & & & \\
\hline 2006 & & & & & & & & & \\
\hline 2007 & & & & & & & & & \\
\hline 2008 & & & & & & & & & \\
\hline 2009 & & & & & & & & & \\
\hline 2010 & & & & & & & & & \\
\hline 2011 & & & & & & & & & \\
\hline
\end{tabular}





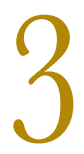

\title{
The History of the Centre for Asian Studies at the University of Adelaide ${ }^{1}$
}

\author{
Gerry Groot
}

\section{INTRODUGTION}

In September 2011, Prime Minister Julia Gillard announced a White Paper, Australia in the Asian Century, declaring that 'the shift of economic and strategic weight to Asia has never been more rapid or profound for Australia's interests than it is now. ${ }^{2} \mathrm{~A}$ key aim of the enquiry is to seek ways of 'deepening engagement' with Asia. At the beginning of 2012, first semester enrolments at the Centre for Asian Studies ('CAS' or 'Centre') totalled almost 1500 students across twenty courses, coordinated and taught by twelve full-time academics assisted by thirteen casual and contract staff. In addition, there were five honours students and fourteen postgraduates. ${ }^{3}$ The Centre should be well placed to help achieve the

\footnotetext{
${ }^{1}$ The author would like to express his thanks to those who have contributed to this paper, including Sandra Horne, Peter L. Burns, Andrew Watson, Peter Mayer, Purnendra Jain and others.

2 Press Office, Prime Minister of Australia, 'Australia in the Asian Century' (Press Release), <http:// www.pm.gov.au/press-office/australia-asian-century>, accessed 23 April 2012.

${ }^{3}$ These include four students on Chinese government scholarships, one Chinese on an Adelaide
} 
goals enunciated in the White Paper. Total enrolments for each semester of 2011 had exceeded 1200. These figures also represent by far the largest generator of international fee-paying student revenue in the Faculty of Humanities and Social Sciences ('HUMSS' or 'Faculty') though only a minority of the fee-paying students are enrolled in HUMSS degrees. This is a very different situation from 1975, the year the Centre's combined language and social science courses saw four fulltime staff teach 104 students. It is unlikely that there was even one international student in 1975 and there were only a few from outside the Faculty. These statistics reflect dramatic shifts not only within the Centre, but in Australia's university sector generally, particularly in the attitudes of students and institutions towards the study of Asia and its languages.

The history of the Centre can be seen as a microcosm of the changes in tertiary education. The Centre has evolved from a small, totally governmentdependent, elitist institution to a system with a significant user-pays mass-education emphasis dependent, to a significant extent, on fee-paying foreign students. The Centre also provides a window on the shifts in attitudes towards Asia and Asian Studies since the 1970s. For CAS, the dramatic increase in student numbers does not necessarily mean unmitigated success. Student interest in Asian languages and institutional support for Asian Studies generally has not kept pace with the vast overall increases in tertiary enrolments since 1975. In relative terms and in some ways even in absolute ones, it has gone backwards.

This brief overview traces the evolution of the Centre from its origins in the early 1970s up to 2012. The Centre originated in a confidence about the future of Asian Studies and this optimism fortuitously coincided with a time of rapid and dramatic expansion of the Australian university system and an increasing openness towards Asia and what the study of it might offer students. The Centre was a beneficiary of a number of related influences, including the Colombo plan, the impending centenary of the establishment of the University, openness and collegiality within and between universities, and political currents in which Asia had a significant place.

The second phase was the gradual institutional evolution of the Centre into more than a locus of language teaching culminating in a coordinator of

University Scholarship and two Chinese students undertaking the new MA program. 
interdisciplinary teaching being granted the status of a formal bureaucratic unit in 1992. This success both raised the Centre's administrative status and exacerbated pre-existing broader tendencies of disciplines to maximise student numbers in their own areas. The consequence was increasing self-reliance and the decline of the Centre's cooperative approach.

The subsuming of the Centre within the School of Social Sciences in 2002 marked a pronounced loss of autonomy and status. Decided more on administrative reasons than pedagogic ones, there were few synergies between the Schools' various elements, especially Asian ones. ${ }^{4}$ Nevertheless, despite some problems, the Centre for Asian Studies has been able to take advantage of the changes reshaping Australian higher education, particularly the growing internationalisation of the student cohort, and has revised its courses to suit. These changes have helped bring about a dramatic rise in student numbers and have been reflected in the Centre winning major teaching awards. The postgraduate program has also developed to reflect these trends. Still, this success masks the extent of the relative ambivalence towards Asian studies and languages by both Australian students and the rest of the University. The success of the Centre in ways not originally intended, the present relative isolation of Asian Studies courses and the general withering of Asian expertise in other disciplines across the University and nationwide, say much about student, disciplinary and institutional engagement with Asia when Australia's degree of economic integration, cultural interaction and reliance on Asia today would have been unimaginable in 1975 .

\section{The Background to the Establishment of the Centre for Asian STUDIES}

The rise of academic interest in Asia within Australia is inextricably linked with the post-World War Two collapse of European colonialism, the advent of the Cold War soon after, Indian independence in 1947, the Malayan insurgency (1948-1960), the Korean War (1950-1953), unrest in Indonesia (1963-1966), and the Indo-China wars of the 1950s, 1960s and 1970s (particularly Australia and the United States' involvement in the Vietnam War, which ended in 1975). For

\footnotetext{
${ }^{4}$ The School of Social Sciences consists of the disciplines of Anthropology, the Centre for Asian Studies, Gender, Work and Social Enquiry, and Geography, Environment \& Population.
} 
conservatives and liberals, the rise of communism and its success in Asia, notably China, was a major fear, encapsulated in the idea of the 'domino effect' - which held that one country would fall after another. For many on the left of politics, a number of the same issues were seen through the prism of resistance and overthrow of imperialism, capitalism, European/white supremacy and profound progressive experimentation. While Asia held both fear and promise in abundance, for both sides these factors necessitated understanding it better. At the same time, Australia's need to learn how to deal with Asian leaders leading Asian countries not European viceroys leading colonial outposts became pressing in the wake of the dramatic shifts in regional power. By 1970, the Federal Government was therefore mulling over how to promote the study of Asian languages and cultures and commissioned James Auchmuty to indicate the state of Asian expertise and what might be done. ${ }^{5}$

In 2012 it is surprising to see just how much Asian expertise there was in Adelaide in the early 1970s, bearing in mind that the 'White Australia Policy' has so long been a key part of understanding Australia's attitude to Asia. The University of Adelaide had a remarkably rich supply of staff either teaching, researching or interested in relevant countries or issues. The History Department had, amongst its members, the China historian, Yen Ching-Hwang, who was to come to regional prominence as a leading authority on Overseas Chinese, a South East Asianist (Peter Burns), a Japan specialist (Steven Large), an Indonesianist (Roger Knight) and a South Asianist (Petrus (Piet) Van den Dungen). The Politics Department contained Neale Hunter, who taught on China and had personal experience of the Cultural Revolution, ${ }^{6}$ the India expert Peter Mayer and the Marxist Dr Bruce McFarlane. McFarlane wrote on China, while Greg O'Leary was then undertaking his $\mathrm{PhD}$ on China-related issues. Economics also had a number of people with a keen interest in Asia, including Barry Worrall and Derek Healy.

There were also other local sources of expertise at Flinders University, which was established in 1966. Asian specialists, notably China expert Bill Brugger and experts on South East Asia - especially Indonesia - were appointed early

\footnotetext{
${ }^{5} \mathrm{~J}$. Auchmuty, The Teaching of Asian Languages and Cultures: Report of the Commonwealth Advisory Committee (Canberra, Commonwealth Government Printing Office, 1970).

${ }^{6}$ Neale Hunter and his wife Deirdre spent time in China in the 1960s and wrote a number of books, notably Shanghai Fournal: An eyewitness account of the Cultural Revolution (New York, Praeger, 1969).
} 
on. On North Terrace, the Art Gallery of South Australia had Dick Richards, an activist on behalf of both South East Asian art and knowledge of Asia.

These lists are not exhaustive but they do demonstrate that by 1974, there was widespread Asia expertise within the University of Adelaide and in South Australia generally. The reason behind this florescence was the dramatic postwar expansion of the university system which occurred after the Commonwealth Government began to exert more control over universities, providing scholarships and consequent expansion of enrolments as Human Capital Theory came to dominate thinking about higher education. ${ }^{7}$

It is unclear whether the relatively poor showing of South Australia in the Auchmuty report or whether the fact that Flinders was establishing an Asian Studies unit had any influence on the academics on North Terrace, but even without these factors Adelaide's Asianists were sufficient in numbers, enthusiastic and were committed to promoting a better understanding of Asia. The first practical outcome of this coalescence of interest was their creation of a committee to promote Asian Studies. In 1973, this body was formalised as the Centre for Asian Studies Committee, an interdisciplinary committee covering those in the Faculties of Arts and Economics wishing to establish interdisciplinary subjects on Asia. The first such subject offered by the Centre was Asian Economic Development, notable for its juxtaposition of ideologies, with Bruce McFarlane teaching a Marxist and Derek Healy a mainstream economist view. This initiative was followed by a course on Asian Civilisation and Culture, taught using available expertise across the disciplines. The missing element was any capacity to teach Asian languages, however, an opportunity began to appear with the impending centenary of the University in $1974 .^{8}$

As early as 1972, the University's Centenary Celebrations Committee led by Dr Harry Medlin had made an extensive tour of South East Asia, meeting with hundreds of Adelaide graduates, most of whom had studied under the Colombo Plan. ${ }^{9}$ All graduates were invited to Adelaide for the Centenary, of which the

\footnotetext{
${ }^{7}$ A. R. Stokes \& S. J. Wright, Higher Education Policy in Australia since World War II (Mt Lewis, Greenacre Educational Publications, 2011), pp. 5-6.

${ }^{8}$ Personal interviews with Peter L. Burns and Peter Mayer.

${ }^{9}$ D. Oakman, Facing Asia: A History of the Colombo Plan (Canberra, ANU E-press, 2010). An important if largely unrecognised factor helping breakdown the White Australia Policy, the Colombo plan
} 
Asia Seminar would be a highlight. Interested parties were asked to contribute to raising $\$ 100,000$ to set the proposed Centre for Asian Studies on a firm and formal footing.

The Asia Seminar itself was duly held over two days, 5-6 March 1974. It was opened by South Australian premier Don Dunstan and addressed by Prime Minister Gough Whitlam, while the Asia Lecture itself, 'Higher Education in Asia - Dilemmas and Prospects', was given by Professor R. L. Huang, the ViceChancellor of the University of Hong Kong. In his address, Whitlam praised Adelaide for its interest in Asian education and culture as 'striking proof of a progressive interest in our neighbours'. ${ }^{10}$ The new Centre for Asian Studies was to build on existing strengths and in the words of the Vice-Chancellor, G. M. Badger, 'Social scientific aspects of Asian Studies will be emphasized, with an interdisciplinary approach'. ${ }^{11}$ A related move by the Whitlam government with crucial material consequences to the entire tertiary sector and indirectly therefore to the Centre, was the abolition of student fees and the beginning of a wave of expansion in student numbers.

The successful fundraising for the Centenary Fund provided the basis for the formal establishment of the Centre for Asian Studies, which began operating out of the Oliphant Wing in 1975. In preparation for the launch, the first fulltime staff were recruited from overseas and appointed in 1974, notably Andrew J. Watson and Sylvia Shiu-Wah Chan (Chinese) and Hiroko C. Quackenbush and Hisako Nakamura (Japanese). ${ }^{12}$

The teaching of Chinese was apparently not a foregone conclusion as there had been an initial desire for the Centre to teach Indonesian and Japanese as these languages were the most commonly taught at high school. ${ }^{13}$ University Council

allowed thousands of Asian students to come to Australia to study after 1949-50. Hundreds came to South Australia to a generally warm reception and their success helped break down local anti-Asian attitudes. See G. Groot \& G. Stafford, 'China and South Australia', in J. Spoehr \& P. Jain (eds), The Engaging State: South Australia's Engagement with the Asia-Pacific Region (Adelaide, Wakefield Press, 2012).

${ }^{10}$ G. Whitlam, 'Australia and Asia: The challenge of education', The University of Adelaide Asian Seminar Proceedings, March 1974, p. 11.

${ }^{11}$ G. M. Badger, 'Asian Students and the University of Adelaide', The University of Adelaide Asian Seminar Proceedings, March 1974, p. 30.

${ }^{12}$ Calendar of the University of Adelaide 1975, p. 96. There were some casual staff, such as Mr John Wanchu Shih and Junko Kumamoto, formally appointed as tutors in 1977.

${ }^{13}$ The Auchmuty report has details on Asian language offerings at South Australian high schools. 
was successfully lobbied by History's Yen Ching-Hwang with support from the local Chinese Community and a key state politician. Chinese was then only taught at Freemont Elizabeth and some believed that Indonesian would be easier for students to master. ${ }^{14}$ Subsequent negotiations with Flinders University resolved that Indonesian would be taught by Flinders and available to Adelaide students via an outreach program while CAS staff would travel to Flinders to teach Chinese and Japanese. This need to travel across town to teach later became increasingly difficult as workloads at Adelaide rose at the same time as funding model changes resulted in declining numbers of available staff.

In 1974, when student enrolment at Adelaide totalled 7,361 of whom 2,359 were in Arts, ${ }^{15} 17$ students enrolled in the Centre's Asian Development II, which was tutored by Vivian Hope with lectures by McFarlane and Healy. In 1975, with new staff in place, 46 students enrolled in Chinese, 17 in Japanese I and 15 in Japanese IA (reflecting the flow on from high school). Numbers in Asian Development enrolments grew to $26 .{ }^{16}$

From its formal establishment until it was redesignated as an independent formal department in its own right in 1992, the Centre was governed by a multi-disciplinary committee with members drawn from across the faculties, primarily Arts and Economics. Each new Centre appointment became a member automatically. In 1981, for example, the committee had 27 members from amongst politics, economic geology, music, history, economics, anthropology, the Barr Smith Library, mechanical engineering, geography, and the Faculty's language laboratory. ${ }^{17}$ Their aims for the Centre were:

a. To foster the coordinated development of studies relating to Asia in the University at both undergraduate and post-graduate levels

b. To develop interdisciplinary courses of study on Asia

c. To assume responsibility for courses offered by members of staff appointed to the Centre and

\footnotetext{
${ }^{14}$ Y. Ching-Hwang, 'East Meets West: Memoirs of an Ethnic Chinese Scholar and Social Activist in Australia and Asia' (Unpublished draft manuscript, 1999), Ch. 7.

${ }^{15}$ W. G. K. Duncan \& R. A. Leonard, The University of Adelaide 1874-1974 (Adelaide, Rigby, 1973), p. 190. These were estimates but nevertheless indicative.

${ }^{16}$ CAS Minutes, April 181980 in University of Adelaide Archives, Series 1320 Box 1.

${ }^{17}$ Centre for Asian Studies Handbook, 1981, frontispiece.
} 
d. To maintain communications with tertiary institutions in South Australia on questions connected with Asian Studies in this state, and to promote co-operation between them in these matters. ${ }^{18}$

The philosophy behind the teaching of social science and languages was also important and reflected Vice-Chancellor Badger's ideal. A 1994 Review submission declared this was 'so that the study of Asian society could be grounded in a proper knowledge of language and culture and language could be studied in relation to the social sciences' ${ }^{19}$ Ideally, academically able and committed students would combine languages and social sciences to prepare them to both better understand Asia as well as research it. The best students were to be encouraged to go on to honours and postgraduate study.

The Centre's guiding philosophy was apparent in the preference for appointing staff who had 'two strings to their bow': staff who were able to both teach language and social science, such as Andrew Watson (Chinese and political economy) and Sylvia Chan (Chinese and literature). While the staffing on the Chinese side stayed relatively stable into the late 1990s, the Japanese side was subject to constant change almost from the outset as many appointees soon moved elsewhere. In the 1970s and 1980s, the demand for tertiary level lecturers in Japanese social sciences and language was very high. It was, after all, the time of the rising Japanese economic might, famously summed up in Ezra Vogel's Japan as Number One. ${ }^{20}$ Around Australia and internationally, demand for teachers outstripped supply and the turnover of Japanese staff in the Centre reflected this high demand for Japanese expertise. Likewise, trying to find academics with the expertise to teach both language and social science was even more difficult. Disciplinary specialists who rarely taught language as a first preference usually sought to move out of language teaching as soon as possible.

In the early 1980s, as Centre arrangements settled down, there were moves to establish a professorial chair in Asian Studies. There were major difficulties and setbacks in bringing this about and in subsequent professorial appointments but the nature of the first resulted in what became jokingly referred to as the 'folding

\footnotetext{
${ }^{18}$ From Centre for Asian Studies Review: Background, Volume 1, 1994, p. 5

${ }^{19}$ Ibid.

${ }^{20}$ E. Vogel, Japan as Number One: lessons for America (Cambridge [Mass], Harvard University Press, 1979).
} 
chair'. It was so-called because the first appointment to the new chair of East Asian Studies, that of international relations expert Michael B. Yahuda, was limited to three years (1982-1984) after which it 'folded'. It then took four more years before Japan specialist Gavan McCormack was appointed as the first tenured professor in 1987. McCormack became a prominent figure in debates about the multifunction polis proposed for South Australia around the time he arrived. ${ }^{21}$ Three years later, after he moved to Canberra, the position was readvertised calling for a social scientist willing and able to also lead and manage language teaching. The successful candidate was Andrew Watson, the Centre's earliest appointment.

The problems with funding high level positions had not been fully solved, however. Having effectively covered Chinese studies with Watson's appointment, there were moves to appoint a professor of Japanese studies. When this chair was finalised in 1994 and Professor Purnendra Jain was appointed, it was because the Centre had secured significant funding from the Japan Foundation to cover the costs of his appointment for the first three years. The Faculty would fund the position after the seeding fund agreement finished.

This need to find external funding was repeated when Andrew Watson's own chair fell vacant after 1999. This time the financial situation of the Faculty was such that the chair remained unfilled until 2008 when Mobo (Changfen) Gao was appointed Professor of Chinese Studies. Gao's position was half paid for by China's National Office for Teaching Chinese as a Foreign Language for five years, in return for Gao devoting half his time as director of the newly established Confucius Institute at the University of Adelaide. The Centre's Ning Zhang subsequently joined him as Deputy Director, but like Gao, this regularly took her away from core Centre business.

The Centre's first two decades saw both a steady increase in students, course offerings and staff, trends strongly shaped by federal government policies such as the Hawke government's 1980s Asia Literacy Program. Undergraduate enrolments in the languages flourished. By 1991 there were a record 40 students in Chinese III, a remarkable retention rate from the 95 enrolled in 1989.

\footnotetext{
${ }^{21}$ See G. McCormack, 'And shall the Multi-Function Polis yet be built?', in P. James (ed.), Technocratic Dreaming: Very Fast Trains, and Japanese Designer Cities (Melbourne, Left Book Club Co-operative Ltd, 1990).
} 
Also in 1989, the Chinese Communist Party ruthlessly suppressed the student and workers movement in Beijing, notably in Tian'anmen Square on 4 June. While many of the students enrolled that year went on to complete two more years, 1990 saw a 30 per cent decline in first-year numbers. China's lustre had begun to dim. Until 1994, the gradual decline in those taking up Chinese was partially offset by continuing high retention rates but the 1988-1989 high point for local students taking up Chinese has not been revisited.

One important consequence that flowed from the first offerings of Chinese in 1975 was that many CAS graduates soon began teaching in South Australian schools. Some have since also gone on to senior positions in schools, roles in academia or have branched out in related areas. Many remain in contact with the Centre, often through the Confucius Institute and its active outreach and training programs for teachers of Chinese - which in turn often involve CAS staff and so allow regular renewal of acquaintances and catch ups.

The growth in numbers of students learning Japanese was even more dramatic. Enrolments in first-year leapt from 11 to 77 in 1987, doubling to 177 in 1988, peaking at 189 in 1990 and then tapering off. Flinders enrolments in Japanese I (which began in 1992) started with 40, bringing total Adelaide/Flinders first-year enrolments in 1992 to 204. While many graduates of Japanese also went on to become teachers, the lack of any sort of equivalent to the Confucius Institute has meant that CAS lacks significant knowledge and contact with them.

The year 1991 was also notable for the addition of Vietnamese to the Centre's program as a result of the University's amalgamation with parts of the former South Australian College of Advanced Education (following the implementation of the Dawkins reforms). Unfortunately, this offering was destined to be short-lived. Although 107 enrolments carried over from the SCAE in 1991, numbers began declining soon after with enrolments overwhelmingly dependent on background speakers and cross-institutional enrolments - particularly from the University of South Australia.

Funding the Vietnamese program was also an issue due to dependence on the Department of Education Employment and Training (DEET) and the South Australian Institute of Languages to try to defray costs increasing over time. Despite the intense efforts of the Vietnamese Coordinator, Sister Marie Nien, to 
recruit students and win institutional support, enrolments dwindled to the point that the Vietnamese program was eventually wound up by the Executive Dean in 2001. The Vietnamese program also lacked supporting subjects in the social sciences and failed to attract many non-background speakers; very few took up the program and perhaps as few as two ever completed a full three-year major.

Another initiative that subsequently became crucial to the Centre was the establishment of the first 'native speaker' subjects for Chinese in 1992. Mainland (People's Republic of China) Mandarin speaking students were still uncommon, particularly as undergraduates, but there was a growing interest among the increasing numbers of students of Chinese backgrounds from Hong Kong and South East Asia, whose first language was often Cantonese, in learning Mandarin and improving their reading and writing skills. These courses tapped into what has become a crucial part of the Centre's work. For many years, however, they struggled to win acceptance in the eyes of many in other departments and faculties which saw such courses as, at best, soft options. Such criticisms eventually became a driver of changes which eventually resulted in a comprehensive set of courses whose underlying pedagogy is to extend the students by stressing the learning of social science approaches.

As noted, the Centre's non-language courses began with a small number of cross-disciplinary social science offerings which were subsequently supplemented with new courses from within the Centre as things settled down and more staff were appointed. Eventually, CAS offerings dominated and interdisciplinary offerings declined.

Over time, CAS offerings have included Japanese Literature (1981-1988) Japanese Political Economy (1986) and Japanese Modern History (1991). In 1989, the Centre began teaching Chinese Politics II \& III following History of Traditional China, first offered in 1983.

There were other initiatives aimed at increasing the attractiveness of CAS courses in this period. In 1991, the Centre launched a Graduate Certificate of Japanese or Chinese and Graduate Diplomas in Chinese; these initiatives, however, were short-lived with few takers. Despite the growing obviousness of Asian economic success in the 1980s, there was remarkably little flow on to active interest in Asia-specific learning in the 1990s. Yet the limits on Asia's attractiveness 
were not yet obvious and the late 1980s can now be seen as a high point for Asian Studies in Australia.

Postgraduate work also started to develop in the 1980s, initially in cooperation with established departments. The first thesis in the Centre's collection, K. M. Bills' 1979 work on a 'new international order', was supervised by McFarlane (Politics) and Healy (Economics), the latter also being Chairman of the Centre's Committee. The second honours graduate, Philip Wilson, completed a thesis on the Great Leap Forward jointly supervised by History's Dr Yen, graduating in 1981. ${ }^{22}$ In 1988 students began completing their honours in-house. University of Adelaide students with Chinese or Japanese subjects could now combine this with their disciplinary speciality to undertake research training using original language sources. By 1992, 26 students had graduated with honours. A significant number went on to do postgraduate study though only a few did so at Adelaide. ${ }^{23}$ The first $\mathrm{PhD}$ to graduate from the Centre was Susan Young in 1992 while the second, Tamara Jacka in 1994, was supervised by Andrew Watson and Susan Magarey in History. $^{24}$

The Tian'anmen demonstrations in China in 1989 were also a major event in the Centre. Almost immediately after the protestors in Tian'anmen Square were ruthlessly suppressed by the Chinese military beginning on 4 June, Centre staff wrote to the South Australian Premier, John Bannon, condemning the violence and organising a memorial service in Elder Hall on June 9. Along with thousands of others, many also joined a candle-lit demonstration down King William Street. Ten years later in September 1999, the event was reprised when hundreds packed

\footnotetext{
${ }^{22}$ Philip Wilson went on to become an influential teacher of Chinese in the South Australian high school system. He is now Assistant Principal at Adelaide High School and with responsibility for Global Education, Special Language Programs and International Programs.

${ }^{23}$ This author is one of those who returned to Adelaide in 1992 to undertake a PhD on Chinese Communist Party United Front work. Other honours graduates who have gone on to become academics after postgraduate study elsewhere include Professor Rikki Kersten, a specialist on Japanese studies, now with the Australian National University's School of International, Political \& Strategic Studies, Assistant Professor Elaine Jeffreys, an Australian Research Council Future Fellow at University of Technology Sydney, and Dr Mark Harrison, Head of Chinese in the School of Asian Languages and Studies at the University of Tasmania. Likewise, Michael Keane has since become a Professor at the Queensland University of Technology.

${ }^{24}$ Now a prominent researcher on Chinese women's issues, Jacka is Senior Fellow in the Department of Social and Political Change at the Australian National University. Her Adelaide thesis was subsequently published as Women's Work in Rural China: Change and Continuity in an Era of Reform, Cambridge Modern China Series (Cambridge, Cambridge University Press, 1997).
} 
the auditorium in the Napier Building to hear the famous democracy activist, Wei Jingsheng, discuss 'Human Rights and Democratisation in China', an event jointly organised by CAS and Politics. ${ }^{25}$

The Centre's interdisciplinary teaching for undergraduates experienced many changes in this period. The original Asian Development II ran until 1978 when it was replaced by Asian Civilisations II (1979-1983). The CAS-History firstyear subject, Old Societies and New States, continued into the mid-1990s drawing largely from staff who had supported the creation of the Centre from the outset. There were other short-lived courses and a brief revival of Asian Development in 1980 and 1983 but with the eventual demise of 'Old Socs', as it was affectionately known, a key part of interdisciplinary cooperation died out, leaving cross-listing of courses as the main way for students to gain a broad understanding of Asia if the growing offerings in CAS were not practical or attractive. ${ }^{26}$ In broad terms the pattern that emerged was that of declining cooperation with other disciplines and reduction of Asia-related subjects as CAS increased its own offerings.

From the early 1990s onwards another factor was also at work: the change in the tertiary system as a whole as funding from Canberra declined and faculty and departmental budgets tightened. There was a concomitant increasing emphasis on disciplinary interests with their immediate benefits at the expense of cooperation, collegiality and a broader view of academic mission. It should not be a surprise that as the Centre's staffing profile grew and its offerings increased, the financial incentives to 'struggle' for students and EFTSUs (Equivalent Fulltime Student Units) intensified. This narrowing of vision and cooperation contradicted the Centre's basic philosophy of broadening knowledge of Asia. At other times, appeals to disciplinary purity and personality clashes were also factors.

Nevertheless, after the initial consolidation of teaching, the scope for research began to grow. Andrew Watson quickly developed fruitful relations with Economics, particularly Christopher Findlay, which culminated in 1989 in the formation of the Chinese Economic Research Unit (CERU). Like the Centre itself, as CERU's profile and output grew, it started taking on honours students

\footnotetext{
${ }^{25}$ See <http://www.adelaide.edu.au/news/news84.html>.

${ }^{26}$ The 1994 Review lists nine subjects across History (4), Architecture (1), Politics (1) and Music (3), p. 11.
} 
and postgraduates. Watson's interest in Chinese political economy meshed well with those in Economics keen to understand the nature and implications of the profound reforms reshaping China. Many if not most of CERU's graduates have gone to very successful careers. ${ }^{27}$ Unfortunately, the Unit did not survive the loss of both Findlay (to ANU) and Watson in 1999 and was absorbed into what became the Centre for International Economic Studies.

Another benefit of Andrew Watson's work in China was his development of strong links with many government officials at various levels and in diverse areas. In the mid-1980s, when ties with China were improving rapidly, Watson played a significant role in the establishment of official relations between the South Australian Government and Shandong Province and between the University of Adelaide and Shandong University. Formal agreements for the sister state and university relationship were signed in $1986 .{ }^{28}$

\section{Centre of Asian Studies as a Department 1992-2002}

In August 1992, University Council recognised the Centre as a full department and it was moved to the top floors of the Ligertwood Building. For the next decade until the advent of the school system the Centre continued to grow, though slowly, while experiencing the effects of changes to the tertiary system and the limits of its structure. However, when the Centre was comprehensively reviewed in 1994 those problems were still ahead. Overall, the reviewers were clearly impressed by the Centre and its Head Andrew Watson and commended its growth, high standards and the work of its key researcher. ${ }^{29}$ Their findings and recommendations, however, remain germane.

In light of the Centre's origins and mission, the Review reflected keen interest in the problems associated with interdisciplinary cooperation. When the Centre

\footnotetext{
${ }^{27}$ These include Cheng Enjiang (Victoria University) Wu Yanrui (now a professor at University of Western Australia), Chen Chunlai (Crawford School, Australian National University) Harry Wu (Hitotsubashi University) Yang Hong (Swiss Federal Institute for Aquatic Science and Technology) and James Xiaohe Zhang (Newcastle School of Business).

${ }^{28}$ For details on the establishment of the South Australian Shandong relationship see Groot and Stafford 'China and South Australia', in Spoehr and Jain 2012.

${ }^{29}$ The reviewers were Assistant Professor Paul Nursey-Bray, Assistant Professor Tessa Morris Suzuki, and Professor Colin Mackerras, assisted by Maria Russo.
} 
became a department, one immediate consequence was the restructuring of its governance so that the CAS Committee became a staff committee while the once crucial interdisciplinary representatives were relegated to an Advisory Committee that met ad hoc. For the Review, this new arrangement was a step backwards when more such cooperation was needed. The Review's hopeful suggestion was that the Faculty (then also being reviewed) adopt a structure that explicitly promoted such cooperation. Other recommendations included supporting joint appointments to facilitate teaching between departments. ${ }^{30}$ Sadly, perhaps, neither such a faculty structure nor joint appointments eventuated, but, anticipating this likelihood, the reviewers added a proposal to create a university-wide committee to bring those with Asia-related interests together. This recommendation also lapsed.

The reasons for this and subsequent attempts to increase linkages deserve more attention. It is worth comparing the reasons for the success of initial cooperation between disciplines such as the establishment of the Centre itself and the CERU. In the former, there were many factors coming together to make it a success: timing, a critical number of interested parties and highly motivated individuals willing to work together, as well as funding at a time when the government wished to see results. Similarly, CERU emerged when keenly interested parties, particularly Watson and Findlay, could use their synergies to drive the search for funding, undertake research and build a strong research base of postgraduates and others.

When John Makeham met Stanislaus Fung in Architecture after arriving in Adelaide in 1992, another example of fruitful interdisciplinary cooperation developed as they researched Chinese gardens, secured funding, organised workshops and published their research. Some years later, after negotiations with Purnendra Jain, the head of Asian Studies, the CAS historian Carney Fisher, invested considerable effort and passion in a course on Asian Art - also taught in Architecture - until he retired in 2003. Most subsequent attempts at interdisciplinary cooperation have failed for want of any one of these necessary pre-conditions in the absence of clear and explicit institutional support to combat a narrowing of Commonwealth funding that encourages student capture in particular disciplines.

\footnotetext{
${ }^{30}$ Review of the Centre for Asian Studies, November 1994, p. 12.
} 
Another reason the Review wanted to increase interdisciplinary cooperation was to address complaints by some of the Centre's 'two string' academics about their 'ghettoization' from their disciplinary colleagues in the Faculty. ${ }^{31}$ Yet this was not a simple problem. Cooperation with CAS from other disciplines and departments was also influenced by issues of disciplinary identity on their part. For some of Adelaide's Asia specialists in other disciplines, identification with their discipline has often seemed more important than the promotion of Asian Studies in general. ${ }^{32}$

The Review also advocated separating such staff from language teaching altogether ${ }^{33}$ Not only did this recommendation undermine an inherent pillar of Centre philosophy, it left unaddressed the tension between researcher academics and the specialist language teachers, although recommendations calling for mechanisms to improve communications between staff to overcome 'structural problems' alluded to these. ${ }^{34}$ Not surprisingly, the Centre's official response gave only very qualified support to such suggestions. ${ }^{35}$

The Review's other major recommendation was the introduction of a BA Asian Studies. Among other things, it was believed that this would allow a better range of courses and an expansion of research interest as well as result in more honours and hence postgraduate students. ${ }^{36}$ The take-up rate from the 1990s for both, however, was low.

In some key ways, the Review had reported favourably on a decade that would in some ways prove to be a high point in terms of staffing, flexibility and autonomy, features that had already begun to erode and that would fade even further when the Centre became a part of a school system. In staffing terms, Asian Studies had grown to some nineteen full-time teaching staff in 1993/1994, albeit five were on limited-term contracts supported by the Japan Foundation. Staff included nine teachers of Japanese, one in Vietnamese, four in Chinese, a

\footnotetext{
31 'Ghettoization' was the word used in the 1994 Review.

${ }^{32}$ Very few from outside Asian Studies, for example, attended the CAS hosted 2008 ARC AsiaPacific Futures Research Network Signature Event, Globalising Religions and Cultures Conference or the 2010 18th Biennial Asian Studies Association of Australia Conference.

${ }_{33}$ Review of the Centre for Asian Studies, November 1994, Recommendation 3, p. 14.

${ }^{34}$ Ibid., p. 15.

${ }^{35}$ See the official CAS response in the Review of the Centre for Asian Studies, November 1994.

${ }^{36}$ Review of the Centre for Asian Studies, November 1994, p. 19.
} 
Japan and a China historian, a philosopher and a sociologist. Almost all had been appointed at the height of the Asia literacy boom between 1989 and 1992. ${ }^{37}$ One advantage for the Faculty's staff profile was that thirteen of the staff were female. Total student numbers for 1994 reached 705 or just over 250 EFSU per semester; a staff ratio of 1:18, which was high by the standards of the time.

Importantly, though, as a department the Centre had a very wide discretion to allocate teaching hours and it had direct control over teaching spaces and its own timetabling. Languages therefore tended to be scheduled at the same time each day throughout the week and even from year to year. The Centre's other courses could be scheduled on the assumption that language students would take them and so timetable clashes were avoided. With workloads based on teaching rather than student numbers, teaching hours per staff averaged between eight and ten hours per week. In 1993 there were 26 courses. Within this framework new courses for even very small cohorts were viable. In 1989, for example, two Korean history subjects were offered for 12 students. In practice, the 'two sides' of the Centre - Chinese- and Japanese-oriented staff — also settled teaching and other matters among themselves.

As noted, another key Centre decision, supported by the Faculty after initial seed funding was secured from the Japan Foundation, was the appointment of Purnendra Jain as the University's first Professor of Japanese Studies in 1994. This appointment and the earlier one of John Makeham in 1992 would prove to be very important to the Centre's research output, especially after Watson took up his post in Beijing. By 2005, Makeham had developed his research to the extent that he won the preeminent English language award for a book on China, the Levenson Prize, for his work Transmitters and Creators: Chinese Commentators and Commentaries on the Analects, a major work of Confucian studies. ${ }^{38} \mathrm{He}$ had also won a University Stephen Cole the Elder teaching prize in 2001.

Professor Jain would go on to become one of the Faculty's outstanding researchers and of international renown, while at the same time going to some

\footnotetext{
${ }^{37}$ Ibid., p. 36.

${ }^{38}$ J. Makeham, Transmitters and Creators Chinese Commentators and Commentaries on the Analects, Harvard East Asian Monographs (Cambridge [Mass] \& London, Harvard University Press, 2004). In 2007 former CAS academic, Michael Dutton, also won the Levenson for his work Policing Chinese Politics (Durham [North Carolina],Duke University Press, 2005).
} 
lengths to try to build and secure links with academics throughout the University, notably in Politics. In 1996, for example, Jain secured Japan Foundation funds for an international symposium on 'Economic Change, Political Pluralism and Democratic Reform in the Asian Region', which, in addition to guests from China, India and Indonesia, also had substantial contributions from staff in Politics and from Flinders. ${ }^{39} \mathrm{~A}$ similar widely inclusive initiative followed in 2001 as a response to the 1996 Asian Financial Crisis proceedings, which were published in 2002, ${ }^{40}$ while there was yet another in 2005. ${ }^{41}$ The fact that Purnendra Jain became the first president of the Japan Studies Association of Australia in 2003-2005 and more recently of the Asian Studies Association of Australia (2011-2012) undoubtedly helped.

The other key attempt to work closely with other departments was Purnendra Jain's negotiations with those in Politics and History who wished to create a new program of International Studies. Jain had suggested such a program in 1997. The program, which eventually began taking students in 2001, was intended to be a whole-of-faculty program and one in which Asian Studies should have been of major importance. Ideally, language, too, could have been central to it. While International Studies allows the possibility of students undertaking almost all of the Centre's courses as electives, these were never made integral. After persistent negotiations, CAS was allowed to develop a first-year survey course for the program, Asia \& the World, which began in 2003, but rather than being overseen by a Faculty-wide committee, much as the Centre was in its early days, control over the program came to be vested in one department and later one school.

While the late 1980s and early 1990s had seen strong growth in Centre enrolments, the Centre had also benefitted greatly from outside sources of funding for its Japanese program, not only from the Japan Foundation but also from Japan's Shoyu Club. The latter had at various times subsidised or paid outright for Centre

\footnotetext{
${ }^{39}$ Centre for Asian Studies, Symposium Proceedings, Economic Change, Political Pluralism and Democratic Reform in the Asian Region, 20-21 April 1996.

${ }^{40}$ P. Jain, G. O'Leary \& F. Patrikeeff (eds), Crisis and Conflict in Asia: Local, Regional and International Responses (New York, Nova Science Publishers, 2002).

${ }^{41}$ See P. Jain, F. Patrikeeff \& G. Groot (eds), Asia Pacific and a New International Order: Responses and Options (New York, Nova Science Publishers, 2006).
} 
language teachers, social scientists and the Barr Smith Library's Asia librarian. ${ }^{42}$ However, the context changed as Commonwealth funding tightened and courses were capped in response. From the mid 1990s, unless such additional funding could be secured, when staff left they were often not replaced and workloads began to rise.

Some CAS initiatives, like a Graduate Diploma in Chinese Studies, were short-lived, but the greatest disappointment was the failure of the named degree, the BA Asian Studies, to appeal to students, particularly to keen language students studying social sciences who could be encouraged to go on to honours. This problem was in keeping with the paradox that even as Australia's engagement with Asia grew, governments in general and students in particular lost interest in Asian studies and languages. Reflecting this decline, the Centre prize for the best language students in Asian Studies established by Sylvia Chan at her retirement in 1999 could not always be awarded because in some years no BA Asian Studies student qualified. Behind this problem was an important shift: the best language students were increasingly from areas such as Law, Engineering, and the Health Sciences and not in the Faculty of Humanities and Social Sciences.

Teaching loads in languages rose gradually but the trend of interest in Japanese growing faster than that in Chinese continued. By 1989 there were almost twice as many students doing Japanese as Chinese, 305: 168, and this dominance has persisted to the present, although some important drivers behind it have changed.

When Watson left to become Representative of the Ford Foundation in China in 1999 it was at a time when the University, Faculty and Centre were under increasing pressure as a result of Canberra's ever-changing funding arrangements. It also followed major budget reviews within the Faculty. Together these factors resulted in a major restructure which amalgamated sometimes disparate departments into schools in the hope of achieving significant administrative efficiencies.

\footnotetext{
${ }^{42}$ The Shoyu Club is a non-profit organisation established in 1928 by former members of the House of Peers. After World War II it also supported Japan studies around the world. Some information on it was sent to the Centre in the form of a booklet, Introducing Shoyu Club: Incorporated Association for Promotion of Public Interest [sic], which outlined its extensive contributions to the encouragement of the study of Japan and Japanese. Jain's personal files contain letters about the funding of such studies at Adelaide from 1994-1998.
} 
The Executive Dean at the time, Malcolm Gilles, had strong functionalist views on the place of teaching languages at university that were starkly at odds with Centre philosophy of combining training in language and social sciences something that could only happen at university. Relevant to Gilles' position was the tension underlying the employment of specialist language teachers lacking research-based postgraduate degrees. Dating from the founding of the Centre, this issue was a major one for language teachers who usually found it almost impossible to forge a career path. No matter how good they were as teachers, they were often unable to produce the research that universities normally demand. When they published in Asian languages these works were ineligible, and translations, so crucial to dissemination of Asian knowledge, usually went unrecognised. Worse, there were no effective teaching-only paths as alternatives. At the same time, workload models based on teaching hours could mean relatively light loads because these also assumed research as well as teaching and administration. One result was the occasional outburst of resentment between the research active and research inactive. For the Centre as a whole, the low research output from language teachers resulted in recurring pressures from the Faculty administration about 'underperformance'.

In this atmosphere, discussions about restructuring included the possibility of creating a School of Languages - disbanding the other staff between Politics and History, or perhaps merging with Politics. These suggestions caused considerable disquiet but Faculty administration eventually decided not on what was perhaps an obvious solution of making Asian Studies integral to the new International Studies program in a new School of History and Politics but on making it part of a School of Social Sciences where the possible synergies were far less obvious. The unity of the Centre was preserved but its relative isolation from those in the Napier Building increased.

\section{2-2012: The Gentre as Part of the School of Social Saiences}

After a mere decade as an independent unit, there was perhaps less of a shock at being part of a school than might be expected. The changes were unlikely to be noticed by students but important internal changes took place. There was an initial settling down period under the headship of Anthropology's Professor John 
Gray (2002-2007), during which the Confucius Institute was founded and courses were rationalised, a brief and unsettled one under the sociologist Professor Anne Brooks (2007-2008) and a third period under Professor Greg McCarthy from 2009 to the time of writing. Under the latter, especially, much progress has been made in developing and strengthening the Centre.

With the appointment of a school head, the position of Head of Centre lost much of its authority and autonomy, particularly over allocating resources. Influence over administrative staff also declined dramatically as these staff were now responsible to the Head of School. Worse, there were fewer of them and appointments were less stable, all factors contributing in small ways to a loss of internal cohesion. Still, the complexity of the school and the settling-in required meant that the great bulk of the Centre's internal matters were still resolved internally through collegial negotiation, though external constraints were coming increasingly into play. For example, relatively small but important centrally imposed changes included the loss of experienced office staff, the loss of control over classroom allocations which in turn meant that far fewer students ever needed to visit the Centre office and weakened student identification with Asian Studies. Even software changes such as the introduction of PeopleSoft influenced control over many issues with many changes to practices demanded to meet the limits and requirements of the new programs. The loss of classroom allocation powers increased efficiency but often at the cost of commonsense timing of classes. Online enrolment rather than face-to-face consultative enrolment has often cost students in terms of poor choices, or cost the Centre when the software ruled out enrolments due to ostensible real or other clashes.

More importantly for the Centre staff, their numbers were slowly declining while enrolments continued to grow. By 2000, Centre staff had declined to 15 and by 2008 there were only 12.5 staff members. The resultant increasing workloads were compounded at times when funds for supportive casual teaching were in short supply. No new courses could be created without eliminating old ones in order to rationalise offerings and costs. In a key shift, new guidelines were instituted to try to achieve minimum numbers of around 70 students for social science courses and 50 for languages to ensure viability. One casualty of staff reductions was the unsuccessful BA Asian Studies, which was finally abolished in 
2009. Another was the Outreach Program with Flinders. While it remained on the books until 2006, in practice it became increasingly difficult to send staff to Flinders when there were fewer available. This lack of resources, combined with administrative problems, meant that it was officially maintained in the hope of it being revived when money became available. In 2005, however, the Outreach agreement was abrogated by the then acting Executive Dean of HUMSS, and the program, which had seen CAS staff teaching at Flinders since 1992, ended. Fortunately, the Flinders agreement to teach Indonesian survived and Indonesian continues to be taught at Adelaide by Flinders staff.

Over the course of several years the social science courses were reorganised, first by the 2003 establishment of a major level one course, Asia in the World, to support courses in International Studies as well as Asian Studies. The advanced level courses (which had replaced level II and III courses in 2009) for both China and Japan were reorganised and renamed to be more complementary and coherent. CAS courses could now be regarded as social science ones because by 2007 the Centre had lost both its historians and its philosopher. Along with several Japanese staff, the retirement of Sylvia Chan in 2000 and the last Chinese teaching stalwart C. C. Hsu in 2009, the last link to the Centre's earliest days were gone. In the rare circumstances that the Faculty permitted it, attempts to recruit senior level staff to teach Japanese and replace those who had left had proved fruitless. One person offered a position subsequently failed to arrive while on another occasion the few candidates who applied were judged unsuitable. The situation on the Chinese side was a bit better as a result of the establishment of the Confucius Institute.

In 2007, the Centre became central to the Pro Vice-Chancellor International Professor John Taplin's wish to establish a Confucius Institute. ${ }^{43}$ With the Centre's Gerry Groot as Interim Director, assisted by CAS postgraduate Glen Stafford, the University's Confucius Institute (CI) Committee put in place the necessary structures and began organising events that supported the Institute's aims of promoting the study of Chinese language and culture. These arrangements were formalised in 2008 and were accompanied by the appointment of Mobo Gao as

${ }^{43}$ The Confucius Institutes are an initiative by the Chinese Office Chinese National Office for Teaching Chinese as a Foreign Language (often known as Hanban for its Chinese abbreviation) to promote the learning of Chinese language and culture around the world. Unlike the French or German equivalents, the Institutes are usually joint ventures with foreign universities and schools. 
the first director (50\%) and as Professor of Chinese Studies in the Centre (50\%), filling the vacancy left by Watson's departure in 1999. As already discussed, key to this appointment was securing funding from the Chinese side to help defray the costs. In reality, though, the Institute demands considerably more from the Director than the half-time appointment would indicate.

The CI also came to support the Centre by providing teachers from China to help teach and ease the burden on the four Chinese teaching staff who by 2008 were teaching 248 students in 9 courses each semester. Although Mr Hsu's position was replaced (by Delia Lin), no other appointments had been approved despite the overall increases in student numbers.

While numbers in classes for local students were suffering, there was considerable unmet demand among the University's many Chinese students for relevant electives. By 1998 the Centre was offering both level II and III courses but from 2009 onwards it began offering a growing number of courses increasingly aimed at enhancing the ability of students to understand and undertake social science courses in Chinese with the aim of building their research and analytical skills rather than merely developing their language proficiency in isolation. ${ }^{44}$ Another consequence of this growing cohort of Chinese students was a rapid increase in numbers of students taking up Japanese. By 2008 more than 60 per cent of students in Japanese I (86 out of 134) were international students. One early effort to reconcile the conflicting demands on reducing staff workloads and student expectations about credit points for time spent - reducing contact hours to three per week - was short-lived. Instead, as a result of intense efforts in curriculum development, preparation and coordination, the Japanese courses have, since 2009, become an increasingly valuable asset to the Centre and the Faculty.

When the Centre was subjected to an internal review in 2009 the conclusions were very positive. Overall, the Review judged that CAS compared favourably with other Asian Studies centres around Australia - comparable to the top three or four - and was continuing to grow. ${ }^{45}$ The extremely positive nature of student

\footnotetext{
${ }^{44}$ These courses now include Chinese Literature and Media, Issues in Chinese Culture, and Research Project for Chinese Speakers as well as more standard ones such as Classical Chinese.

${ }^{45}$ Internal Review into the Centre for Asian Studies, 2009 (external Reviewer Michael Dutton, Internal Reviewers Professor Purnendra Jain, Professor Mobo Gao and Assistant Professor Greg McCarthy),
} 
evaluations was also commended since many staff were achieving or were close to the maximum Student Evaluation Score of Teaching of seven. ${ }^{46}$ This success was despite the growth of class sizes to around 50 for languages, a state of affairs the reviewers deplored. The problem of research output was also discussed but this time the obviousness of the workload imposts on many language teaching staff was highlighted as a major problem, as was the way that publications in Chinese or Japanese went unrecognised under the prevailing rules. Overall, though, the contradictions between research and teaching were judged to be similar at any of the Group of Eight Asian Studies units. ${ }^{47}$ One way to build on the Centre's strengths and build the research culture was to develop new programs such as a Masters in Translation and Trans-communication. In light of the growing imbalance in teacher to student ratios, the Review strongly recommended that several more staff be appointed and that such appointments be able to teach both language and about society or cultural aspects, ${ }^{48}$ a return to the two strings model.

\section{The Centre for Asian Studies Today}

Many of the 2009 Review recommendations reflected moves already underway but the appointment of Greg McCarthy, someone with a real interest in Asian Studies, as head earlier that year helped to bring about a much more positive atmosphere which was then reflected in subsequent successes in teaching and research. The Japanese staff continued to achieve remarkable results in the student evaluations. ${ }^{49}$ By 2011, as a result of the outstanding efforts by the Japanese language staff, Kayoko Enomoto, Akiko Tomita and Naomi Aoki, this success extended across the entire language program at all levels as well as within the social sciences taught by Yoneyama and Sejin Pak. Crucially, the Dean's recognition also included all the highly motivated and experienced casual tutors - now a crucial part of the language program. The Executive Dean, Nicholas Harvey, recognised this success with a special award in 2010 while Enomoto was also awarded an Australian

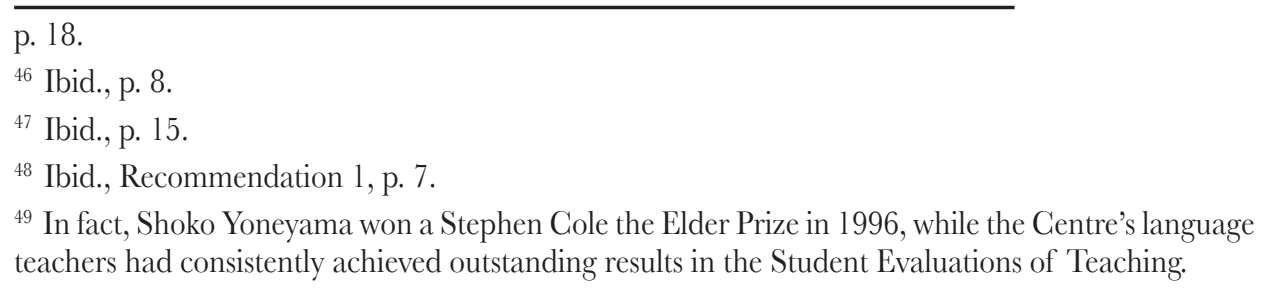


Learning and Teaching Council Award for Australian University Teaching for Outstanding Contributions to Student Learning in 2011.

While these international students were a boon for the languages, it was not necessarily so for the social sciences. The Centre's 2012 withdrawal from the long-running East Asian Economies course taught with Economics was to a significant extent also related to the increases in international students. Student evaluations showed a steadily increasing unhappiness among economics students, particularly international ones, about coping with a political economy framework and essay format examinations. The disciplinary disjunction was compounded for those for whom essay writing in English was a major problem. This loss has left Professor Jain's teaching of a Masters course for International Studies as the only real remaining interdisciplinary interaction between CAS and the rest of the University.

Another problem for CAS social science offerings is that the limits on offerings and the reduction of such courses - because staff have not been replaced as well as the recurrent need to rest courses as staff go on leave - means students can have difficulty completing a major within the Centre. There are also declining numbers of complementary courses in Politics, History and Media, with some only available as intensive summer or winter courses. Founding members of the Centre, Burns, Yen, Mayer and Knight have already or will soon retire. This will leave one lecturer on Chinese politics in the School of History and Politics but no Asia historians. There are several others with Asia interests in the Faculty or in Architecture and Economics but none teaching Asia-specific courses or actively working with the Centre. This attrition means that there will soon be less Asia-expertise within the Faculty (language teachers aside) than when the Centre was founded! ${ }^{10}$ Even within the Centre, the longstanding requests for more staff, including those in the 2009 Review, have not been able to be fulfilled because the Faculty is facing severe restrictions on recruitment.

Another recurrent problem for the Centre has been a pattern of academically able students who, while interested in Asian Studies issues and graduates of CAS

\footnotetext{
${ }^{50}$ A similar scene is unfolding at Flinders, while the CAS Chinese outreach program with Flinders was unceremoniously dumped in 2005 by the then Dean of HUMSS. Although in practice CAS was hard-pressed to supply teachers, the hope was for more staff would eventually be appointed and the Outreach programs reinvigorated.
} 
courses, nevertheless strongly prefer to undertake honours or postgraduate work in what they see as bigger, more relevant or more useful units, such as History and Politics - the home of the International Studies program. This does not necessarily prevent them from continuing to seek Centre advice, though. The phenomenon of the best language students usually being from outside the Faculty has further cruelled the ideal of training students in both language and social science. So few such students now apply that CAS was forced to drop the requirement for having both strings. And despite the large enrolments in the International Studies program, the Centre's social science courses sometimes struggle to attract students who are often unaware of CAS' existence, or vague about what they can choose for electives. When CAS social sciences courses attract international students the Faculty benefits but unfortunately, even if such students are very successful, very few go on to further study. ${ }^{51}$ The biggest problem for the Centre, though, is that the number of local students taking up languages has declined in real terms. In 2012, only 70 commenced studying Chinese, of whom fully half were international students (Korean, European, etc.). A similar pattern applies in Japanese where many of the students studying it are Chinese nationals. That most of the local students are also in other faculties means severe problems for retention and little to no flow on to postgraduate study. The ideal of training students in both languages and social sciences so as to further understanding and promote research seems further away than ever. The bright spot in this picture, though, is the success of the Diploma of Languages which was originally launched in 1998 but which became more practical and attractive to students the curriculum reforms of 2008 that introduced a three-year degree of four courses per semester with a standard course weighting of three points. This has made completing a language major much more attractive to many students, especially those in other faculties with more inherent restrictions on electives.

Yet the Centre has been very successful in many ways. It has survived and grown its student numbers when others around the nation have struggled. ${ }^{52}$ It has

\footnotetext{
${ }^{51}$ A 2011 attempt to put two Chinese students through Honours highlighted the problems when such students did make such an attempt. Both struggled to cope.

${ }^{52}$ See Asian Studies Association of Australia, Maximising Australia's Asia Knowledge: Repositioning and Renewal of a National Asset (Asian Studies Association of Australia, 2002).
} 
hosted the discipline's major conferences and numerous international workshops. ${ }^{53}$ Both past and present staff have had and continue to have international impacts with their research, while Jain and Gao have significant and growing international profiles. More than one hundred have completed Honours, Masters or PhDs. The Centre's graduates are using their knowledge and skills around the world and many are building Asia knowledge in schools or using it in their work. From the office of Prime Minister and Cabinet to the school room and in numerous businesses, Centre graduates are doing their bit to shape the world.

The Centre's language teachers, long seen by some as a 'problem', have not only delivered crucial enrolments and become the largest generator of international fees for the Faculty, many have adopted the research of teaching approach and become more active as researchers. Dr Xianlin Song and Dr Kate Cadman have edited the resultant papers for publication. The book, Bridging Transcultural Divides: Asian Languages and Cultures in Global Higher Education ${ }^{54}$ is also notable for its discussion of transcultural communication, the theory underlying a substantial part of the new program for Chinese speakers developed by the Chinese teaching staff. The recent moves within the University to allow teaching-only positions also has important implications for the career paths of some of these staff, who have clearly proven that they can work wonders despite the limitations on them.

The current biggest strength of the Centre, the teaching of language knowledge and skills to international students, the majority of the students among the more than 600 doing Chinese and the almost 500 doing Japanese courses, as well as a significant portion of the more than 300 students in CAS social science courses, are generating unprecedented income for a Faculty facing a declining recruitment pool as South Australia's population ages. The cost to an international

\footnotetext{
53 The Chinese Studies Association of Australia 1997, the Japan Studies Association of Australia in 2005, the ARC Asia Pacific Research Network Signature Event in 2008, the Asian Studies Association of Australia in 2010. In addition, Jain has organised numerous high-level international workshops related to publishing and research projects, such as a 2010 workshop on Japan drawing scholars from Australia, Japan, Korea, Singapore, the United States and Europe. This became an edited volume, P. Jain \& B. Williams (eds), Fapan in Decline: Fact or Fiction? (Kent, Global Oriental, 2011). Another example is the book that emerged from the 18th ASAA conference held at Adelaide in 2010: J. Spoehr \& P. Jain (eds), The Engaging State: South Australia's Engagement with the Asia-Pacific Region (Adelaide, Wakefield Press, 2012).

${ }^{54}$ X. Song \& K. Cadman (eds), Bridging Transcultural Divides: Asian Languages and Cultures in Global Higher Education (Adelaide, University of Adelaide Press, 2012).
} 
student of a native course like Translation for Chinese Speakers: English-Chinese is $\$ 3,342$. Thus, there can be no talk of closing the language programs when they are now more than covering their costs and have never done so much with so few staff for such a positive response from their students. Although the Centre is clearly a major 'service' centre for other faculties and departments, the increasing emphasis on developing the social science focus of the native speakers course in particular, is almost certainly developing student understandings of critical thinking and research in ways that would not have happened had the students stayed within the narrower confines of their original study programs. If these students and the Chinese postgraduate students now studying and using social sciences apply their new knowledge and skills when they return home, we should all benefit. The pity is that the Centre is now the University of Adelaide's locus of Asian Studies expertise rather than one of several and the study of Asia has not become an ordinary part of the student experience. While Auchmuty might have been aware of the shortcomings of Asia expertise in Australia at the end of the 1960s, he would not have envisaged this outcome although he might nevertheless be satisfied.

\section{REFERENGES}

Asian Studies Association of Australia, Maximising Australia's Asia Knowledge:

Repositioning and Renewal of a National Asset (Asian Studies Association of Australia, 2002).

Auchmuty, J., The Teaching of Asian Languages and Cultures: Report of the Commonwealth Advisory Committee (Canberra, Commonwealth Government Printing Office, 1970).

Badger, G. M., 'Asian Students and the University of Adelaide', The University of Adelaide Asian Seminar Proceedings, March 1974, p. 30.

CAS Minutes, 18 April 1980 in University of Adelaide Archives, Series 1320 Box 1.

Calendar of the University of Adelaide 1975, p. 96. 
Ching-Hwang, Y., 'East Meets West: Memoirs of an Ethnic Chinese Scholar and Social Activist in Australia and Asia' (unpublished draft manuscript, 1999), Ch. 7.

Centre for Asian Studies Handbook, 1981, frontispiece.

Centre for Asian Studies Review: Background, Volume 1, 1994, p. 5.

Centre for Asian Studies, Symposium Proceedings, Economic Change, Political

Pluralism and Democratic Reform in the Asian Region, 20-21 April 1996.

Duncan, W. G. K. \& Leonard, R. A., The University of Adelaide 1874-1974

(Adelaide, Rigby, 1973), p. 190.

Dutton, M., Policing Chinese Politics (Dunham [North Carolina], Duke University Press, 2005).

Internal Review into the Centre for Asian Studies, 2009 (External Reviewer Michael

Dutton, Internal Reviewers Professor Purnendra Jain, Professor Mobo

Gao and Assistant Professor Greg McCarthy), p. 18.

Groot, G. \& Stafford, G., 'China and South Australia', in J. Spoehr \& P. Jain (eds), The Engaging State: South Australia's Engagement with the Asia-Pacific Region (Adelaide, Wakefield Press, 2012).

Jain, P., O'Leary, G., \& Patrikeeff, F. (eds), Crisis and Conflict in Asia: Local, Regional and International Responses (New York, Nova Science Publishers, 2002).

Jain, P., Patrikeeff, F. \& Groot, G. (eds), Asia Pacific and a New International Order: Responses and Options (New York, Nova Science Publishers, 2006). Jain, P. \& Williams, B. (eds), Fapan in Decline: Fact or Fiction? (Kent, Global Oriental, 2011).

Makeham, J., Transmitters and Creators Chinese Commentators and Commentaries on the Analects, Harvard East Asian Monographs (Cambridge [Mass] \& London, Harvard University Press, 2004).

McCormack, G., 'And shall the Multi-Function Polis yet be built?', in P. James (ed.), Technocratic Dreaming: Very Fast Trains, and Fapanese Designer Cities (Melbourne, Left Book Club Cooperative Ltd., 1990).

Oakman, D., Facing Asia: A History of the Colombo Plan (Canberra, ANU E-press, 2010).

Press Office, Prime Minister of Australia, 'Australia in the Asian Century' (Press Release), <http://www.pm.gov.au/press-office/australia-asian-century>, 
accessed 23 April 2012.

Song, X., Cadman, K. (eds), Bridging Transcultural Divides: Asian Languages and Cultures in Global Higher Education (Adelaide, University of Adelaide Press, 2012).

Spoehr, J. \& Jain, P. (eds), The Engaging State: South Australia's Engagement with the Asia-Pacific Region (Adelaide, Wakefield Press, 2012).

Stokes, A. R. \& Wright, S. J., Higher Education Policy in Australia since World War II (Mt Lewis, Greenacre Educational Publications, 2011), pp. 5-6.

Vogel, E., Japan as Number One: lessons for America (Cambridge [Mass], Harvard University Press, 1979).

Whitlam, G., 'Australia and Asia: The challenge of education', The University of Adelaide Asian Seminar Proceedings, March 1974, p. 11. 


\section{4}

\section{Classics at the University of Adelaide (1874-2012) ${ }^{1}$}

Ron Newbold (with contributions by Margaret O'Hea and Han

Baltussen)

\section{HistoRY OF THE CLASSICS DISCIPLINE}

\section{The Early Years, 1874-1927}

Although the University of Adelaide was founded in 1874, teaching did not start until 1876. The Hughes Professor of Classical and Comparative Philology and Literature, Reverend Henry Read, a product of St John's College, Cambridge, however, arrived from England in 1874 to take up one of the foundation chairs and to assist in designing the Bachelor of Arts degree which admitted its first students in 1876. The degree, which required the taking of all five subjects offered

\footnotetext{
${ }^{1}$ This history depends on five sources: (1) The 22 page history of the Classics Department, from 1874 to 1975, produced by Victor Edgeloe (1907-2003); (2) personal observations and recollections for the period 1969 to 2008 of Dr Ron Newbold, which included two brief encounters with Professor Emeritus Fitzherbert before he died in 1970, supplemented by colleagues' recollections of events, pre-and post-1969, who had been associated with the department since 1932, 1950, 1958, 1958, 1959 and 1964; (3) the University calendars and (4) (from 1990) Classics departmental handbooks have been invaluable in checking facts, especially dates; (5) current staff. [RFN, Dec. 2011].
} 
in first-year, at least three out of five in second-year, and at least two out of five in third-year (students typically did more), offered Classics at all levels. Classics students studied Greek and Latin language, literature and history. Numbers were small and Reverend Read did all the teaching. In 1878, Read was involved in a scandal, the exact nature of which is unverifiable, and was forced to resign and leave the state. Clearly a versatile man, he qualified as a doctor, practised medicine, and died at 57 in 1888.

Read was succeeded in 1879 by David Kelly, an Irishman and product of Trinity College, Dublin, and Trinity College, Cambridge, 'a strong defender of the educational value ... of the Latin and Greek languages and literature', and a deplorer of the growing trend towards 'utilitarian' subjects, and hence of the push to remove Greek from the secondary school curriculum. A notable University development that year was the introduction of a coursework-only MA in five fields, including Classics. From 1887, students could undertake an Honours degree, not by completing a fourth year (as now applies) but by doing extra work in the third year.

Kelly was plagued by ill health and died in March 1894, aged 46. Whereas Read had authored one minor publication, Kelly appears to have not managed that, nor inaugurated any significant changes within the department. For the rest of the year the Classics chair was occupied by Edward Boulger, then also occupying the Philosophy chair. An extremely well credentialed Irishman, he came as a Doctor of Letters from Dublin, with experience as a lecturer in English in Dublin and as a professor of Classics at Cork. His tenure, however, was brief: 'By late 1894 he had become so dependent on alcohol and/or other drugs that after a clear instance near the end of the year of inability to carry out his duties properly his resignation from the chair was accepted and he disappeared from the records of the University and of the State' ${ }^{3}$

His successor was Edward Bensley, a graduate of Trinity, Cambridge, in 1885 and later a student at Leipzig and Tübingen. Without giving notice he resigned from his 11-year tenure in 1905, to take up the chair of Latin at the

\footnotetext{
${ }^{2}$ V. A. Edgeloe, Classics in the University of Adelaide, 1876-1975 (Adelaide, University of Adelaide, 1989), pp. 6-7.

${ }^{3}$ Ibid., p. 8.
} 

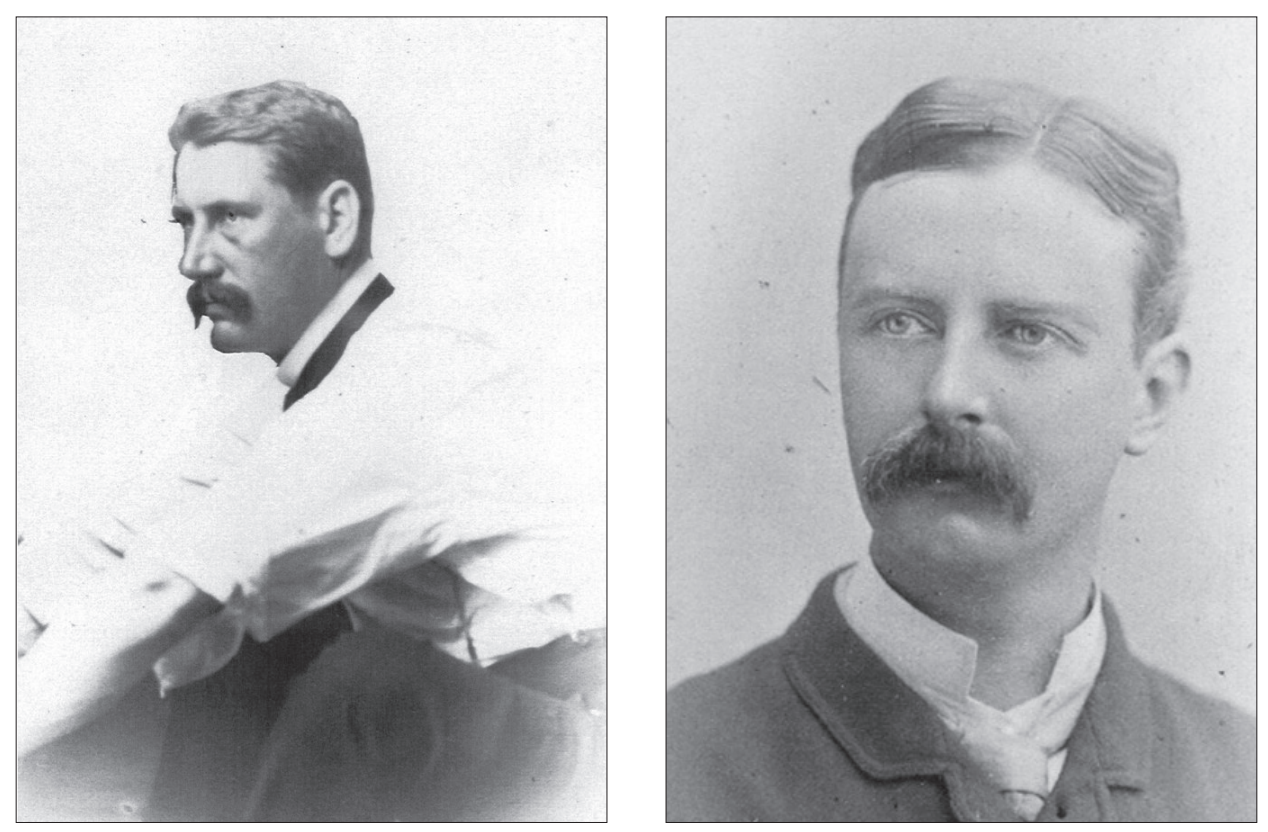

\section{David Kelly (left) and Edward Boulger (right)}

Aberystwyth College of the University of Wales, where he seems to have been a more active publisher than when at Adelaide. He gave, as his reason for resigning, a heavy teaching load (typically for the time he had little or no assistance) and that may help explain his lack of publications while there, for a restructure of the Bachelor's and Master's degrees in 1901 meant more students and more contact hours. Although Latin and Greek were compulsory at matriculation level, they were not so at University (the requirement was only that of the six subjects taken over the three years at least one had to be Latin, Greek, French or German); in practice, the vast majority of students took Latin or Greek, and in many cases, both. Honours at Bachelor level now required a discrete fourth year. The two-year Masters degree could now lead to an Honours Masters which required a further two years of study. Classics remained one of the four possible fields of study. In addition, trainee teachers could now attend classes for two years without fee, and many of these teachers took Latin and/or Greek, thus adding to Boulger's work. 
It is not clear how and by whom classics was taught in 1906 because the next Classics Professor, Darnley Naylor, did not take up his position until 1907. Another product of Trinity College, Cambridge, he came to Adelaide after 11 years at Melbourne University. Of the nine Hughes Professors of Classics, three stand out as internationally recognised scholars. Naylor is clearly one (the others are Robert Ussher and Han Baltussen). ${ }^{4}$ Besides articles, Naylor published five books on Latin literature and language and in 1911 he was elected vice-president of the British Classical Association. An energetic and able man, he founded the South Australian Classical Association, helped promote the activity of the Elder Conservatorium and the University Sports Association, and in various ways showed his commitment to education and the craft of teaching. Edgeloe calls him a 'lecturer of distinction' and, as a one-time member of his Latin class, recalls 'with pleasure and mature appreciation the clarity with which he dealt with Latin texts, whether prose or verse, and the scholarship and skill he displayed in expounding the linguistic and literary qualities of some of the passages under consideration' ${ }^{5}$

Naylor also succeeded where Bensley had failed, in getting teaching assistance. David Hollidge, the University's first Classics MA in 1889, was appointed part-time assistant lecturer in 1909. The 1920 restructure of the Arts degree, occurring when Naylor was Faculty Dean, resulted in Latin and Greek each being able to constitute $25 \%$ of what was required for a degree - up from $16.6 \%$ under the former regulations - and Comparative Philology now achieved a separate second- or third-year status as a separate 'unit' (this term now replaced 'subjects'). These gains for Classics, however, were tempered by making either Latin or Greek compulsory at matriculation level, but not both, as previously. And at university, whereas previously taking Classics meant doing both Latin and Greek, now it was possible to choose just one. The result was that enrolments in Latin increased, while Greek numbers dropped sharply.

Moved by the cataclysm that was World War I, Naylor invested great hopes in the League of Nations to prevent a repeat in Europe. This led him to retire

\footnotetext{
${ }^{4}$ It is worth mentioning that Alf French, Reader in Classics from 1964 until his retirement in 1981, was also an impressive scholar, author of eight monographs in two distinct areas of studies (Ancient History and Czech literature) and a Fellow of the Academy of the Humanities; see further below.

${ }^{5}$ V. A. Edgeloe, Classics in the University of Adelaide, 1876-1975 (Adelaide, University of Adelaide, 1989), p. 12.
} 

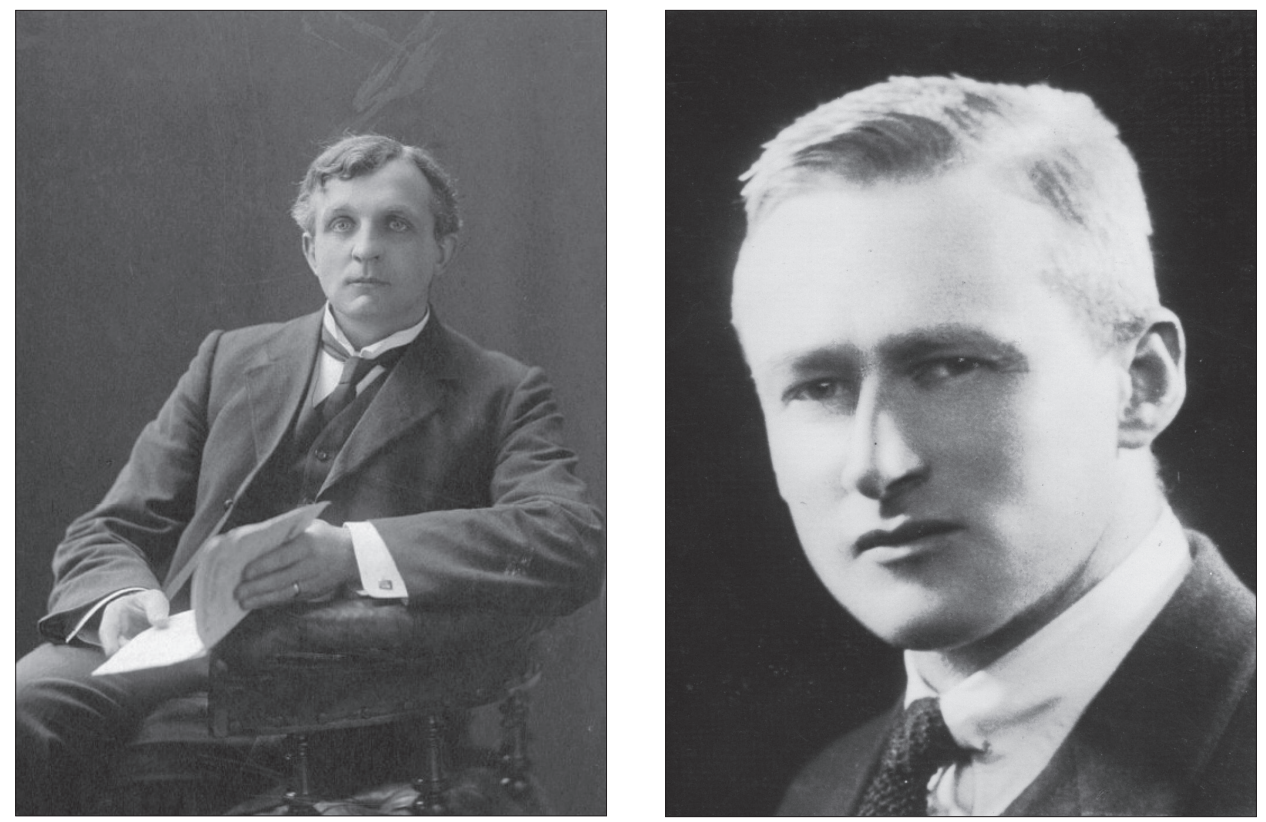

Darnley Naylor (left) and John Fitzherbert (right)

after a 21 -year tenure in 1927, aged 55, to campaign for peace and the League in Britain until 1939. He died in 1945.

\section{The Middle Years, 1928-1983}

The middle years were presided over by the two long tenures of John Fitzherbert (1928-1957) and John Trevaskis (1958-1983). They were both men with scholarly minds who published little or nothing. But whereas Fitzherbert was socially challenged and trapped in the past, Trevaskis was socially competent and conscious of the need for change. In short, tenures of stagnation and innovation. Fitzherbert was a product of Sydney University and Trinity College, Cambridge. He was lecturer in Greek at Edinburgh University at the time of his appointment, aged 35. Then engaged on a project on Pindar, he never brought it to fruition, and did not publish anything significant. He was for many years on the editorial committee of the prestigious Classical Quarterly. 'As a lecturer he was poles apart from Naylor; his voice was rather expressionless and he rarely raised his eyes from 
his lecture notes; consequently the lectures were dull and uninspiring for the great majority of students, though the substance was almost certainly first-rate ${ }^{9}{ }^{6}$ His lack of charisma combined with the diminishing status of Classics meant that only nine students completed Classics Honours during his tenure but three of them, Eric Gray, Theodor Dorsch and Margaret Hubbard (d. 2011), went on to distinguished academic careers, and Hubbard, for one, acknowledged the quality of his instruction. In 1938, a change in the BA regulations diminished the privileged position of Classics: French I or German I could replace Latin I or Greek I as the compulsory language unit.

Four men assisted Fitzherbert with his teaching duties. The University Librarian, Bill Cowan, from 1933 provided part-time assistance as lecturer and tutor for 20 years. Hollidge, who became a full-time lecturer in 1927, continued until retirement in 1937. Of him Edgeloe writes: 'a rather dull lecturer, but in personal relations with students he was kindly, considerate and helpful'. ${ }^{7}$ His position was filled in 1938 by Ron Corney, who had graduated with Honours in 1936 and who was always referred to by Fitzherbert as 'the boy'. In 1950, Selwyn College, Cambridge, graduate and part-time lecturer at Sydney University, Alf French, was appointed Senior Lecturer. French was to prove an outstanding scholar and teacher. His appointment may well have been the best thing to happen to Classics under Fitzherbert.

From 1948, there had been an increase in the University's funding and hence the number of academic positions. While other departments expanded significantly, Classics' share in the expansion had been very modest (Alf French was the only appointment). This was to change when John Trevaskis, graduate and Fellow of Queen's College, Cambridge, assumed the chair in 1958, and was able to appoint David Hester of Jesus College, Cambridge, to a lectureship. However, in that year, a change at matriculation level meant that Latin was no longer compulsory and thus, both at secondary and tertiary level, pressures to study Latin were greatly diminished. (It was still required for Law.) Fortunately, however, 1958 was also the year of the Murray Commission, which recommended to the federal government a substantial increase in university funding, which, for Classics, led to

\footnotetext{
${ }^{6}$ Ibid., p. 13.

${ }^{7}$ Ibid.
} 
the appointment of Ron Garson as lecturer (Sydney and Cambridge) in 1959 and Kath Hassell (a Naylor graduate) as senior tutor in 1960. That year also saw the introduction of a one-year level II Greek and Roman history course, which was open to all BA students, since there was no ancient language requirement, and a level I elementary Greek course that provided entry to Greek I. These innovations boosted student numbers at both undergraduate and Honours level. Furthermore, Trevaskis was able to appoint Carmel Young (Auckland and Oxford) as lecturer in 1964, to convert Kath Hassell's position into a lectureship when she retired and to appoint Ron Newbold (London and Leeds) to that position in 1969. Newbold completed his doctoral thesis in 1970, on public disorders in the city of Rome in the early empire.

However, with removal of Latin (for at least one year) as a requirement for a Law degree, enrolments in Latin were now declining fast and something had to be done for the department to justify its staff numbers. Ancient History was only attracting 20-30 students. The introduction in 1971 of in-translation Classical Studies courses, mainly literature based but including art and architecture, saved the jobs of most of the staff. The courses were introduced at levels 1-3 from 1971 to 1973 and attracted excellent student numbers, so that an eighth staff member, Frank Sear, was appointed in 1975. Sear was an art and archaeology specialist (his doctoral thesis was on Roman wall mosaics) who could provide the expertise to run the non-text-based courses. Still riding the Whitlam-generated expansionary wave, the University appointed numerous tutors (i.e., current lecturer level As) and Classics got two of them, Joe Ahern and Michael Apthorp, for a three-year term in 1976. In addition, Anne Askew (later Geddes), who was doing a PhD with John Trevaskis, did some part-time tutoring from 1974 to 1978. When the tutors' terms expired, they were replaced by Anne Geddes and Hugh Lindsay (University of WA) from 1979-81, and then by Judith Sinclair (later Maitland), from UWA, until 1988, as well as Janet DeLaine, an Adelaide undergraduate and Honours and Doctoral graduate, until 1985. Janet subsequently went on to greater things by becoming a lecturer at the Institute of Archaeology in Oxford and gaining a reputation for her work on Roman baths and the Roman building industry.

These years were a high-water mark for the Classics Department as far as staff numbers went. However, despite continued good enrolment figures, Ron 
Corney's position was not filled when he took early retirement in 1978, aged 63. Ron had had a major health scare and, having taught Latin and Greek since his appointment in 1938, he never really came to terms with the demands of in-translation teaching and was not enjoying his work any more. Geniality personified, Ron was a much-loved figure, both by his colleagues and students. In a department where several bad handwriters constantly tested the deciphering skills of colleagues and students, Ron's, which could be mistaken for cuneiform, was easily the most impenetrable. Ron never published anything and his contribution to the department was as a teacher, as an occasional acting Head of Department, and, above all, as a kind mentor and friend. He died in 1984 and, needless to say, generations of former students were present to pay their respects at his funeral.

Alf French retired in 1981, aged 65. Retirement at 65 was compulsory in those days, otherwise there is little doubt that he would have continued to teach and regale listeners on the campus with his impish humour and observations. Like Ron, French was a survivor of the Fitzherbert years, about which he had a fund of funny stories - as he did about many other things, including his war experiences (e.g., nearly being blown up by a mine). It's not that what he related was always that funny, it was just that as he got into his tale he would be laughing so much that the audience would succumb to the infectiousness of his laughter and add to the uproarious hilarity. Alf was both an excellent and popular teacher (students dug his humour). He enjoyed an international reputation for his publications - books as well as articles - on Greek history and was a Reader from 1964. But that was not all. He had gone to Prague in 1938 after graduating from Cambridge and was there teaching English to Czechs when the Nazis grabbed slices of Czechoslovakia in that year of the Munich crisis. He acquired a Czech wife and proficiency in the Czech language, and as a Classicist he moonlighted as a Czech scholar, publishing in English and Czech on Czech history and literature. An authority twice over (and a Fellow of the Humanities Academy), therefore, he kept researching long after his retirement and helped to keep his colleagues amused by his frequent presence in the department as a Visiting Research Fellow. This continued until 1997, when he died shortly after his 81st birthday. After the death of his wife, Alf married (and was survived by) Aleeta Garson, who was formerly the wife of Ron Garson.

Alf's position was filled in 1982 by Jenny Webb, a graduate of Melbourne 
University. She was appointed specifically to take over Alf's Greek History course. She was primarily an archaeologist - an expert in the Cypriote Bronze Age. She resigned after four years to return to Melbourne and to start a family. Her position was filled in 1986 by Anne Geddes. Anne's immediate task was to take over the Greek history courses, but she also took over the Roman Republican history course from David Hester. David had taught this course for many years but was a rather reluctant historian, not to say Romanist, convinced as he was, and still is, of the manifest superiority of things Greek.

John Trevaskis could have equalled or surpassed the tenure of Fitzherbert, but chose to retire, aged 60, in 1983. He assumed the Chair in Classics with a publication record of one article and two brief 'notes', adding very little while Professor. His particular interest was philosophy. He had sufficient standing to be invited to do reviews of books, and he made significant progress on an edition and commentary of Plato's The Sophist but it never came to fruition. He was a very capable administrator, serving spells as Arts Faculty Dean and Deputy ViceChancellor, but by the mid-1970s he was weary of administration and gladly embraced the University reform whereby the head of a department no longer had to be a professor. Or, to put it another way, professors who enjoyed research and teaching were no longer ground down by decades of departmental administration. From now on heads were elected for a limited term, typically three years, and Alf became head in 1974. John was a good teacher, clear and well organised, but by the 1980s he had lost enthusiasm for that too. He particularly hated marking student essays and gave this as one of his reasons for early retirement: 'The next five years could be the best years of my life and I don't intend to spend it marking essays'. It was rather sad that his last class as a teacher was so anti-climactic. Neither of the two students turned up. John deserves credit for the way he refounded both the Classical Association and the Classics Department, realising sufficiently early that it was doomed as a mainly-language facility. He was very interested in the art and architecture of the classical world, and taught some new art and architecture courses even before the arrival of Frank Sear. There was a small departmental collection of coins and other artefacts when he arrived that he added to significantly, every year using some of the departmental funds to make new purchases (yes, there was money for such things in those days). The current 
Classics museum collection would be much less imposing without his efforts. He and Carmel Young married in 1984, both having divorced their first spouses. John died in 2002.

\section{Recent history, 1984-2011}

Robert Ussher became the eighth Hughes Classics Professor in 1984. He had lost his job when the Classics Department at the New Ulster University closed. He was 54 and needed a job to see him through to retirement age. Robert came with a distinguished publication record, mainly on Greek drama and Theophrastus, and added a number of works to his academic record while in Adelaide. He was enthusiastic about the reception of Classics and he soon introduced and did most of the teaching in a Byzantine Studies course, which went up to 1453 and which he saw as a way of helping to bridge the gap between the ancient and modern worlds.

Every few years the University and/or the Arts Faculty experiences a financial crisis. The year 1987 was one of those times and the Classics department sort of came out in sympathy with not one but two resignations, and early retirements by disgruntled members, Ron Garson and Carmel Young, with the upshot that only one of those posts was filled and not until 1989. Ron could be very kind but had a rather formidable classroom presence, which was not to everybody's liking. Those who could perceive and appreciate an excellent linguist learnt much Greek and/ or Latin from him. For a number of years he ran a Latin reading competition for Year 12 school students. His publications included quite a few Latin prose and verse compositions. He died in 2000.

The upheavals of 1987 may have contributed to the crisis of 1988. That year there was a dastardly proposal to terminate Classics as a separate discipline and distribute the existing staff members to other departments. Fortunately, that move was defeated and things improved the next year when local product Jane Olsson and Jacqueline Clarke from Newcastle (Australia) became tutors. Jacque's threeyear contract was renewed in 1992, but Jane's was not. Jacque assumed primary responsibility for elementary language teaching, and became the coordinator for all the language courses, taking over from Judith Maitland who had got a job at 
UWA. In 1994, at the expiry of her second three-year contract, she was made a tenured Level A lecturer. She had begun a doctoral thesis, Imagery of colour and shining in Catullus, Propertius and Horace, supervised at first by Robert Ussher and then, when he retired, by Peter Toohey (then University of New England). It was completed in 1998 and published as a book in 2003. In 1991, Frank Sear, who had been building his reputation as an expert on Roman architecture (especially Roman theatres), left for higher academic things, in this case the Chair of Classics at the University of Melbourne. This left a vacancy for an art and archaeology expert, which was filled that year by Margaret O'Hea from Sydney, whose doctoral thesis had been on the villas of late Roman Gaul. From 1994-1996, she co-directed jointly with Dr Pamela Watson (University of Sydney) the Pella Hinterland Project, a three-year field survey, funded by a small ARC grant, which examined in detail the evidence for utilisation of the land and water systems of the hinterland of the city of Pella (in Jordan). This has led to teaching an archaeological field school in Jordan as part of her co-direction of the excavation of the ancient Nabataean town of Zoara in the Ghor es-Safi. Apart from being a dirt (and sometimes dirty) archaeologist, she has become an expert in the analysis of glass in the ancient Near East - how it was used and in what proportions to the use of other media of utensils (pottery, metal), and how those uses changed over time and across regions.

Ussher retired in 1992. A gregarious and sociable man, he stayed at St Mark's Residential College when in Adelaide, commuting back in the longer holidays to Northern Ireland where his wife remained. Letter writing is essentially an affiliative characteristic and ancient epistolography was fittingly one of his chief interests while at Adelaide. Letter writing was also an activity he engaged in when he retired, keeping in touch with Adelaide friends, often former students, from Castlerock in Northern Ireland, whither he returned permanently in retirement (that is when he was not tourist-travelling or going to Classics conferences). An Irishman and language lover, it was natural for him to teach himself Gaelic to keep his brain in shape when in retirement. Inevitably, as an Irishman he heard plenty of Irish jokes, all of which he bore with fortitude and good humour. Robert was clearly one of the most academically distinguished incumbents of the Hughes Chair. He died in 2006, aged 79. From 1992 to 2011, the Classics Department had no professor. 
In 1993, as a result of the University's amalgamation with a nearby College of Advanced Education, the department acquired the services of Paul Tuffin, thus bringing the tenured staff complement to 6 (with Clarke, Geddes, Hester, Newbold and O'Hea). Paul had trained in ancient as well as modern Greek while at Birmingham University and soon proved a great asset as he brought imagination, humour and commitment to the teaching of ancient Greek, and expanded the teaching of Byzantine studies with the introduction of The World of Early Byzantium and The World of Late Byzantium semester courses in 1994. Modern Greek never became part of the department's offerings, but Paul's numerous contacts with the Adelaide Greek community led to initiatives like the foundation of the annual Galatis lectures, named for a local benefactor and dedicated initially to illuminating aspects of the Byzantine world.

In 2002 the University was in the middle of another financial crisis and, hence, staff-cutting mode. Classics had to reduce from 6 to 5 positions. Actually, it had already done that, because David Hester and Anne Geddes had both gone half-time from 2002. However, Paul Tuffin decided to take advantage of a generous superannuation scheme that he was on and retire just short of 55 . He is fondly remembered for his warmth and generosity.

Paul's resignation made possible the new appointment of Han Baltussen, who earned both his bachelor and doctoral degrees at the University of Utrecht and who had to overcome University attempts to cancel his contract before arriving in late 2002. The title of his doctoral thesis was Theophrastus on Theories of Perception: Argument and Purpose in the De Sensibus. Appointed at Level A, he was seriously overqualified for such a position, but remedied the anomaly by being promoted to Level B in 2005 and Level G in 2007. Han was trained as a Classicist, but his primary research interest was in ancient philosophy as well as in many aspects of the ancient world, including its reception. He took over the important role of co-ordinator of the level one in-translation courses, took over and revamped the Ancient Philosophy course, and was happy to contribute to the Papyrus to Print, Classical Mythology, and Afterlife and Underworld in Antiquity courses. He established his own upper-level course, Ancient Science, Technology and Medicine, in 2005, which after a few years was given a more medical focus and renamed 'From Hippocrates to Harvey: Ancient Medicine and Its Legacy' 
(2009). He gained an ARC grant for a project entitled 'Psychotherapy and the Consolation of Philosophy in Antiquity' for the years 2007-2009, a topic on which he started work in 2004. A further grant application in 2010 was successful, this time in collaboration with Associate Professor Emeritus Peter J. Davis, who had joined Adelaide Classics as Visiting Research Fellow in 2009, to work on a project entitled 'The Dynamics of Censorship in Antiquity'.

In 2003, David Hester retired, full of years and honour, 46 of them as a servant of the Classics Department (the last two at 0.5). He thereby outlasted as many Arts Faculty deans as Fidel Castro did US presidents. In past times he would have had to retire in 1999, but David loves teaching and even though nominally retired he kept teaching several undergraduate classes a week - for free, on top of his courses for the University of the Third Age, where he provided courses on such Greek luminaries as Homer, Plato and Herodotus until 2009. David was originally appointed to teach the Comparative Philology course that the department used to offer until the early 1970s, and his first publications were in this area. He then became very enthusiastic about Geek tragedy and most of his circa 40 published articles were in this area. He did more than his fair share of the third sphere that academics are supposed to engage in - administration and administrative chores. However, David's first love was teaching and he brought an enthusiasm and gusto to the task that students responded well to. He was fittingly awarded the prestigious Stephen Cole prize for Excellence in Teaching in 1994, the only Classicist ever to earn this accolade. In the largeness of their hearts, students forgave him for his truly terrible jokes, appalling puns and, shocking as it is to relate, his occasional bursting into song.

In 2006, Anne Geddes retired, having been 0.5 for the preceeding four years and having had an association with the department going back to 1974. Anne had a ten-year spell as head of the Classics Discipline (officially the favoured term for a Department) and throughout her time as a staff member was always willing to acquire new areas of expertise, which made her such a versatile and valuable member of the department. Eoghan Moloney from Dublin was appointed to take over her Greek history courses and arrived after a month of the second semester in 2006 to carry on the lectures that Anne had begun in her last year. Eoghan's doctoral thesis was on Greek theatre in Macedon. 
In 2011, several different unrelated events raised concerns about the status of Classics at Adelaide. Eoghan decided to return to Ireland for family reasons, at a time that the Faculty was again looking at a gloomy future in terms of finance. The appointment of Han Baltussen, who had been promoted to Associate Professor in January 2010, to the Hughes Chair of Classics in September of the same year lifted the spirits of the Classics community somewhat, but could not remedy the concerns over staffing and tight budgets.

\section{The Gurriculum: Classics courses Within the struGture of the BA}

When the Classical Studies courses were introduced during 1971-73, the guiding principle was that first-year students concentrated on Greek literature (epic and drama, basically), which were the subject of weekly tutorials and one of the lectures, with a second lecture on the socio-political-economic-cultural background. This course was popular with students from the outset, regularly attracting over 150 starters and serving as a recruiter for both the upper level in-translation courses, and to a lesser extent, the languages. Second-year students followed a similar pattern over the three terms in Roman literature (no options were available at first-year), and in third-year, emphasis was on comparative courses, such as Greek and Roman historiography, comparative literature (a course that involved English, French and German too, with each discipline covering 2 or 3 texts), and the late Roman Empire. Assessment in these days was mainly by examination. Classics was slower than most other disciplines to adopt continuous assessment and moved cautiously, so that Classical Studies I initially awarded just 7\% for a medium length essay, keeping 93\% for exams. This was soon increased, but in courses that had exams Classics usually limited non-exam assessment to 60\%. However, in 1973 the new Late Roman Empire course had no exam assessment and included a diagram in its assessment.

An important innovation at this time was the introduction of Latin IA, that is, elementary Latin for those who had done no Latin at school. Greek IA had long been a departmental offering, in recognition of the lack of Greek teaching at school, but with Latin numbers in schools in decline (by 2007 the decline was virtually terminal, with only one student doing Year 12 Latin), it was time to offer the same facility to prospective Latin students. At that time, two years of Latin 
and Greek were considered essential for any student considering Honours, even in-translation Classical Studies Honours. Since a student had to be invited to do Honours, and was invited on the basis of good performance in first-year, Latin or Greek IA had to serve also as a second-year course. It was common for Greek and Latin elementary language courses to be quite popular, attracting 20-30 starters. However, the dropout rate was quite high as students discovered how much time and effort needed to be invested. Of those that lasted the distance in first-year, only a handful went on to further language study.

The second-year Classical Studies course, seeking to do for Rome what the first-year course did for Greece and in much the same way, was not, after two or three years, felt to be working that well. In the 1970s, the Adelaide BA moved towards offering greater choice and flexibility, the so-called smorgasbord degree, where students could freely mix and match across disciplines. This meant that a year-long course (except in the case of language courses) gave way to separate, term-length options, and students built up the units needed for their degree by moving freely in and out of departments. Disciplinary prerequisites became less important. Students could choose to do an option at either second-year or thirdyear level. Third-years attended the same lectures and tutorials as the secondyears, but did extra written work. Classical Studies I was kept as a year-long course without options. At levels two and three, students could enrol for Classical Studies and then choose options every term, such as Roman Poetry and Ancient Philosophy. The one lecture per week on the cultural background was accordingly abandoned and Roman and Greek courses alternated.

The same thing happened with the year long Classical Art and Archaeology course that Frank Sear introduced, Roman in one year and Greek the following (e.g. on special subjects such as Pompeii, the Athenian agora, Late Bronze Age Cyprus, South Italian pottery, Roman mosaics, Roman baths, and Roman Libya). Upper level Classical Studies students now had three Classics options to choose from each term, i.e., a historical, literary, or art and archaeology option. Further options were provided for students when the ancient history and art and archaeology courses were spread over two years, so that, for example, a student could do one or more Greek history options in one year and then one or more Roman ones in the next. In order to provide more choice for literature-minded students, Pastoral, Satire 
and the Novel, and Narrative and Didactic Poetry were introduced. This, then, was the arrangement that persisted until the advent of semesters in 1989. Staff unavailability because of study or long service leave meant that these courses were sometimes not available. Courses in Latin and Greek I, II and III were provided, sometimes to very small numbers at level 3 . Because of an ever-declining number of students with an understanding of grammar and syntax, a trend not unrelated to the diminishing number of students of Latin in school, Introduction to Greek and Latin (ILAG) was introduced in 2004, to give students a better grounding in language and extend beginners Greek/Latin from 2 to 3 semesters. The course proved popular, attracting 40-60 students and providing some increased flow-on to Greek and/or Latin in subsequent semesters.

A kind of de facto semesterisation existed prior to 1989 where disciplines, including Classics, offered half-subjects (designated $\mathrm{H}$ ) that began and ended midway through the second term. It was an opportunity to rethink, rationalise, consolidate and expand (from 8- or 9-week to 13-week) courses. Classics maintained the two-year rotating cycle for level 2 and 3 in-translation subjects and in 1989 and 1990, for example, and to provide a snapshot of how things worked, offerings were as follows:

First semester 1989: Classical Mythology, Greek Art and Archaeology (Bronze Age to 500 BC), Roman Republican History (133 BC-AD 14).

Second semester 1989: Roman Literature, Greek Art and Archaeology (5th Century to Hellenistic period), Roman Imperial History (AD 14-192).

First semester 1990: Ancient Philosophy, Roman Art and Archaeology (origins to Hadrian), Greek History Archaic and Classical (c. 750-404 BC).

Second semester 1990: Late Roman and Byzantine Studies, Roman Art and Archaeology (Hadrian to Constantine), Greek History to Alexander the Great (404-322 BC).

An important innovation in 1998 was the revamping of the level 1 Classical Studies course. Initial enrolments had been slowly declining over the years from $180+$ to around 130 (with fewer than 100 completing the course). Something had to be done. The first semester course now covered ancient Egypt, Mesopotamia, Israel, Hittites, Persia and Archaic Greece, including Homer. The second semester 
included Classical Greece and Rome up to late Antiquity. This reform proved popular, with enrolments several times exceeding 200, before starting to decline to pre-1998 levels. (This caused another revamp for 2009 and again in 2010.)

Classics had, since 1974, offered no less than four Honours courses. The in-translation Classical Studies course was the most popular, though the language requirement kept numbers down. Provided their results were good enough, students who did Latin and/or Greek III could do Latin, Greek, or both Latin and Greek Honours. Few did. Apart from some set texts, Classical Studies students had to write a quite long essay every week in the first part of the year (the Oxbridge model is evident in this, and the tutorial discussion it entailed), which was pretty tough, and a thesis in the last part. The language requirement was gradually relaxed, firstly for those particularly interested in art and archaeology, and then for almost everyone unless they planned to do a thesis involving close examination of texts.

The advent of semesterisation provided an opportunity to rethink the structure and content of Honours degrees and, together with new faculty requirements for greater uniformity in Honours degrees across disciplines, led to a larger component for the thesis, which was to comprise $50 \%$ of the assessment and be 15-20,000 words long. If the thesis occupied mainly the second semester, the first semester was occupied by two major components (worth 25\% each): two special subjects, each lasting 6 weeks, and the so-called Common Course - weekly seminars for which every student wrote and presented on two topics and participated in the discussion with staff. Much depends on the numbers and abilities of students for the success of such a programme but in recent years, with occasional exceptions, numbers at least (averaging 5-6) have been sufficient and better than other small departments. Language Honours students write a shorter thesis (12-15,000 words, 40\% of assessment) and do the most of the Common Course but not the special subjects. Instead they do set texts, including an essay, and unseen prose composition exam papers. It had always been possible to do a joint Honours degree, where a student in effect did an individualised course splitting course work and theses work between two disciplines, or a thesis that embraced two disciplines and split coursework requirements. Markers are sought outside the department. 
Clearly a major challenge faced by any small and shrinking department is being able to offer a sufficient range of expertise to supervise Honours and postgraduate students. Having some postgraduate students is particularly important for a Classics Department, as qualification to do postgraduate research is one of the important justifications for continuing to teach Latin and Greek in fairly small advanced level classes. There also has been a huge change in the supervision of postgraduates at this University, attempting to adopt international best practice to ensure the dropout rate was cut and completion rates expedited. Gone are the laissez-faire days of the pre-1980s when a student and a single supervisor could meet rarely or irregularly and research skills were often acquired, if at all, by a process of osmosis rather than by formal instruction. Nowadays at least two supervisors per student are required, postgraduate co-ordinators exist to assess and assist progress, and together with annual progress reports, training for supervisors, induction courses and an exercise known as the Research Proposal basically a draft introduction to be submitted to a faculty postgraduate panel are seen as ways of countering the aimlessness and supervisory neglect that used to 'characterise' so much postgraduate research (in)activity in the Arts Faculty in the past. Students clearly benefit from having more than one expert to guide them but, as indicated above, finding sufficient expertise within a small department is a challenge.

Developments in 2008 have left the Discipline seriously wounded and its future will be different, even more a struggle for survival than before. The year 2008 proved to be very much a watershed year, marking the end of an era, and going far beyond a planned name change (more in line with practice elsewhere in Australia, and clarifying just what and how much it does) to Classics, Ancient History and Archaeology. Changes imposed this year upon the Faculty have some effect on all disciplines but Classics is the hardest hit. As a result of the University of Adelaide governance becoming increasingly infused by managerialism (marked by 'key performance indicators', 'change management', 'benchmark indices' etc.) and the concentration of power in the hands of the Vice-Chancellor and assistant executives, such as the Deputy VCs, much collegiality and consultation (and, it 
has to be conceded, time spent by many academics at meetings) has been replaced by an 'executive' hierarchy (i.e. edicts from above). Thus the faculty was told by administrative fiat to adopt a scheme of four courses at each level in the BA, but envisaged new courses, including capstone courses designed to round off study in a discipline in the last semester level three, were aborted by another edict in which the number of courses that any discipline could offer was to be drastically cut, and the capstone idea jettisoned. Classics was now limited to just eight semester courses. Considering that in 2008 Classics provided 17 (11 languages courses, 6 non-language ones), this impacted on the offering of majors in Latin and Greek: any student doing a level I or II language course in 2008 and hoping to continue it beyond that year would have to abandon the idea (or enrol for distance learning). 'Generously', the choice of what to axe was left to the discipline, but since Classics was also told that it must boost its staff/student ratio from 1 to 25 to 1 to 30 (in the halcyon 1980s, 1 to 10 was thought appropriate for a prestigious university like the University of Adelaide), the choice was to limit language courses to just two and try to boost enrolments in the few non-language courses that could be offered from the existing 13-item menu. Any other course of action would be suicidal. Ron Newbold, retiring at the end of that year, was not immediately replaced, and may never be, even with an increase in student enrolments, if the threat to make the faculty teaching-only materialises, and the pursuit of ever higher staff/student ratios continues. Long-established courses on subjects such as Greek archaeology and Roman history have thus come under threat, as have Honours courses in the languages. While most disciplines felt some pain at these imposed, somewhat arbitrary, restrictions, Classics is the worst affected. The heart of its activity (languages, other core subjects) have been 'shelved' or removed and the task of attracting and training postgraduate and Honours students made more difficult. Being able to offer summer schools as extra subjects is hardly an attractive option for staff, who want to pursue research or have a domestic life. This Discipline entered uncharted waters in 2009 with just four full-time staff and in an administrative environment not very sympathetic to its endeavours. Pressures have increased with the departure of one of the four staff (for personal reasons) in 2011 and in 2012 the discipline still awaits a replacement for his post (ancient history). 


\section{OTHER DEVELOPMENTS AND AGTIVITIES}

\section{The changing environment}

The Discipline of Classics has had to cope with many kinds of change (as is clear from the above), which are partly the product of wider, societal changes, and partly the University seeking to satisfy federal government policies and to demonstrate accountability and international best practice as it strives to improve its international tertiary institution ranking. The number of students taking Latin, Ancient History (AH) and Classical Studies (CS) at school has declined steeply from the heyday of the 1970s when Ancient History could attract about 500 students for the Year 12 matriculation exam and CS about 1500. Less than half that number enroll today. The schools offering AH shrunk to a handful and about 15 years ago the AH and CS syllabuses were amalgamated into a single subject. Latin is almost dead in South Australian schools and, together with a general decline in primary and secondary schools of the teaching of grammar and syntax, this has made the teaching of university elementary Greek and Latin more difficult. School students have a range of new subjects to choose from these days, such as Legal Studies and Computer Studies, and, as at university, they gravitate to 'practical' subjects they think will ensure them a job. At this University, the introduction of generic degrees within the BA, such as Cultural Studies, Media Studies, International Studies, exemplify this trend and reduce the pool from which to attract students to Classics. Subjects like Classics also lose in the competition to attract research funding and foreign, fee-paying students. Australian university students are among the most heavily charged in the world, with federal governments imposing increased financial burdens on students. Mature-age students, who often return to university to satisfy long-deferred desires to learn more about the ancient world, are consequently less common in Classics courses than they once were. On the other hand, interest in the community at large in the ancient world remains high and $\mathrm{ABC}$, SBS and commercial television broadcast many programmes on the ancient world. Technological advances such as computer-generated imagery have meant that films can now once again be made about the ancient world without incurring extravagant costs. Gladiator, released in 2000, was the first Hollywood film for 36 years to be set in classical antiquity, and it has been followed by several 
others set in the same period. In addition, the Internet and online learning can make the ancient world in its many aspects more accessible to billions, although this is true of all subjects.

\section{Accommodation and restructuring}

In 1967 Classics moved from the Old Classics wing of the Mitchell building to share the third floor of the Ligertwood building (where Law was housed) with Philosophy. The plan was always to add a fourth floor, which meant that the roof was only a temporary one, and that meant it didn't offer much protection from the summer sun. It also meant that the Philosophy professor stripped to his underpants on occasion. Although the law library was air-conditioned, the upper floors had only fans to assuage the furnace-like temperatures prevalent during heat waves. Bar heaters warmed rooms in winter. Otherwise, the standard of accommodation wasn't too bad: adequately sized academic offices, a secretarial room, a tearoom, tutorial rooms and, at the end of the corridor, a large seminar room/Honours room/departmental library.

In 1988, Classics moved to the upper floor of the Mitchell building. The Ligertwood then gained its fourth floor and a thorough refurbishment that included air-conditioning on every floor! The Classics section of the Mitchell building had a pleasant ambience. It was conveniently close to the Classics museum and to two teaching rooms, the Edgeloe room and the attic, which had once been the site of many classes delivered by Fitzherbert, among others. Academic offices varied considerably in size and were mostly unheated and uncooled, except by fan and bar heater - until Classics moved out and the space was taken over by administration and air-conditioning was installed. Quel surprise.

That move came in 1997 when Classics moved to the seventh floor of the Hughes building, air-conditioned and with a conveniently central location on the campus. This move was part of a Faculty restructuring into Schools. Classics (6 staff) now formed part of the School of European Studies and General Linguistics (ESGL), with French (5), German (5), European Studies (1) and Linguistics (2, later 4). The last 4 disciplines occupied the eighth floor, while Classics shared the seventh with Philosophy and secretarial offices, including those of the administration. David Hester was elected first head of this new academic unit and served from 1997-99. 
Linguistics had a professor, but French has remained a professor-free zone since 1988, Classics and German since 1992. Disciplines lost their own secretaries to a central pool of 3.5, later reduced to 2 and then just 1 (but none at all if that 1 is away, as is sometimes the case for extended periods), secretarial assistance having largely migrated to the Napier. The size of academic offices varied, with most being rather cramped. The school initially shared access to five teaching rooms ( 3 were later lost to postgraduate rooms when the students were transferred from the Napier), and Classics kept its slide room in the Mitchell. It was then time for that periodic exercise so beloved of the administration - restructuring (again!). The Faculty was divided into 4 Schools, each with an appointed head. The old CESGL as an administrative and academic unit (spellcheckers would correct CESGL to 'cesspool', but it really wasn't like that) was slowly dissolved (the final death knell came in 2006), and its constituents were lumped with Philosophy, Media and English to form the School of Humanities headed by Gerard O'Brien. Longstanding plans to co-accommodate all constituent disciplines in the Napier building were not realised until mid-2011.

\section{Teaching and Assessment}

In the 1970s, most boards in teaching rooms were black and required chalk. White boards and 'textas' were beginning their advance. Some staff still wore academic gowns to classes (useful for keeping chalk dust off clothing). Some departments had decided to abolish formal written examinations as the sole or substantial means of assessing student performance, moving wholly or partly to continuous assessment, that is, counting the marks given to exercises written during the term/semester.

Classics was initially slower than many Arts departments to move in this direction and even today the assessment Latin is overwhelmingly exam-based. Most of the Classics non-language (and non-summer school) courses have had a mixture of continuous and exam assessment, although some courses have introduced new forms of assessment, allowing students to choose between the exam and an academic journal or participation in an online discussion programme. Slide tests have long been part of the assessment of art and archaeology courses. Student Evaluation of Learning and Teaching (SELTs) became frequent and mandatory exercises in seeking student (increasingly regarded as 'clients') feedback on courses. 
Without good SELTs, applications for tenure or promotion were likely to fail. Such applications, like applications for study leave, have become much more rigorous and time-consuming.

Probably to the great surprise of some critics in the 1970s, the lecture continues to have an important place in teaching at the University of Adelaide. However, a number of technical innovations have greatly changed the way teaching is delivered, in Classics as elsewhere. The two great boons of the 1980s were the photocopier, which made the production of teaching material so much easier and cleaner, and the overhead projector. In the 1990s, new technologies (CDs, DVDs, the computer and the Internet) offered both opportunities and challenges (e.g., curbing plagiarism) that Classics too has had to embrace. Combined with the facilities offered by BlackBoard/MyUni, new ways of assessing, presenting or preserving information (recording of lectures, using PowerPoint instead of slides or transparencies), and relating to students (e.g., by email) mean that today's Classics lecturer or tutor is less dependent on secretarial help but more dependent on technical, computer-savvy help.

\section{The Classical Association of South Australia}

This association was founded in 1908, most probably on the initiative of Professor Darnley Naylor, who joined the University the previous year. It was founded in the days when the number of people well versed in Latin and Greek was comparatively large and the topics at meetings were often very scholarly. A mark of the centrality of Classics in society at the time is shown by the generous coverage of meetings (e.g., several hundred-word summaries of talks) by the local newspapers, The Advertiser and The Register, until the 1930s. Although membership numbers and attendance at meetings was never large (10-20 at a meeting was normal), holding a position in this evidently prestigious body was clearly valued, with Vice-Chancellor Mitchell and other professors taking the vice-presidencies (numbering five in 1924), and the South Australian Chief Justice/University Chancellor, Sir Samuel Way, as patron. Later patrons included Chief Justices and University Chancellors Sir George Murray and John Bray, and (currently) former Justice Doreen Bulbeck.

The president in early decades was usually the Hughes professor. However, although Trevaskis became Hughes professor in 1957, his predecessor, Fitzherbert, 
continued as president until 1967, when Trevaskis took over. Ken Peake-Jones served as president from 1972 to 1975, Ron Corney from 1976 to 1978 and then Les Wilhelm until 1996, when he was succeeded by Ron Newbold, who was president until 2008, followed by Han Baltussen in 2010.

The six meetings a year at $8 \mathrm{pm}$ were on Friday evenings and continued through WWI. Meetings were suspended during WWII, and in the 1970s, to avoid competition with newly available late night shopping in the city, meetings were changed to Mondays. The number of meetings per year was reduced to five in 1980 and to four from 1995.

The association has had its up and downs, mainly because the organisational duties became a further item on the ever-growing list of staff activities. It came close to collapse in 1966 after a prolonged series of meetings at which only four or five people were present, but survived on the condition that meetings were opened to non-members and topics were less scholarly, directed more at an intelligent lay public. Soon meetings attended by 100 or more were common and in the 1970s and 1980s they could attract close to 200 (on one occasion in 1990, circa 250) - when a topic dealt with material in the matriculation CS or AH syllabi, and teachers brought their classes along to the Ligertwood (sometimes Napier) lecture theatres. By the 1990s, however, schoolteachers were less willing to do this and attendances dwindled to the point that 15-20 became a good turnout. Accordingly, a committee meeting in December 1995 devoted considerable time to discussing ideas for boosting membership and attendance. Part of the problem was the venue for meetings - the Mitchell building's Edgeloe room, which had no lift access.

One of the factors that boosted attendances in the 1980s and early 1990s was joint meetings with The Friends of the Classics Museum when the topic was an archaeological one. But a proposal to amalgamate the two organisations was not adopted. Amelioration came in 1997 when Classics moved to the Hughes building (using Hughes 723 and then the nearby council room). Attendances improved to an average of 30-40. The year 2008 was marked by the designation of all four lectures as centenary lectures and the presentation of a brief potted history of the association. However, the first lecture, held on 31 March, 100 years and 11 days after the inaugural meeting in 1908, was the Centenary lecture, given 
by Associate Professor Chris Mackie (University of Melbourne): 'Gallipoli 1915: Encounters with Antiquity'.

The association has had a longstanding association with schools in the form of prizes offered to the Year 12 student achieving the best results in matriculation C.S and AH, and presented, usually, at a meeting. Ron Garson, a long-time vicepresident and servant of the association, ran a Latin reading competition for Latin school students from the 1960s to the early 1980s, for which the association provided the prize. When AH ceased to exist as a separate subject, a prize was offered to Latin matriculants instead. Unfortunately, a candidate of sufficient merit never manifested and from 2007 only the Classical Studies prize has been offered.

\section{The Museum of Classical Archaeology and Friends of the Classics Museum}

The University's museum was formally opened in August 1983 after five years of negotiations and derives from material bought and donated since the department began. John Trevaskis did much to improve the collection but it was Frank Sear who became the museum's first curator and who established the museum in the Basten room of the Mitchell building, securing funds for a custodian to be paid and hence for it to be open to the public (free) 3 hours per weekday. Margaret O'Hea assumed the curatorship on Frank's departure. Funds are no longer available to pay a custodian and tours must now to be booked in advance, and paid for. The museum is now housed in the basement of the Mitchell building. It is opened to the public as one of the campus attractions on University open days.

The museum contains a fine collection of Egyptian, Etruscan, Greek and Roman artefacts, some of them on loan from the SA Museum and Art Gallery. There are particularly good examples of Cypriot, Etruscan bucchero and South Italian pottery as well as Roman glass, pottery and lamps. Also on display is a large model of Athens as it would have appeared in the 2nd Century AD, and seventy casts of Classical Greek and Hellenistic sculptures. The Friends of the Classics Museum, established when the museum was opened, help provide funds for purchases of new artefacts and have an annual programme of talks given by (mostly visiting) archaeologists. 


\section{Galatis/Moraïtis Events}

A major benefactor of the Classics Department, Nick Galatis, has through his generosity made it possible for the department to triple the number of prizes it offers, but he has also borne the expense of a series of well-attended public lectures on aspects of Byzantium and, from 2007, ancient Greece broadly conceived. At these occasions the department's (non-language) prizes were awarded. Paul Tuffin organised these events from 1997-2002, and Han Baltussen since 2003. ${ }^{8}$

\section{APPENDIX A: Hughes Professors of Glassics in Adelaide Official title Foundation Chair}

Hughes Professor of Classical and Comparative Philology and Literature

(1) 1874-1878 Reverend Henry Read (St John's College, Cambridge)

(2) 1879-d. 1894 David Kelly (Trinity College, Dublin, and Trinity College, Cambridge)

(3) 1894 Edward Boulger, (Dublin) (also Hughes Chair of Philosophy)

(4) $1895-1905$ Edward Bensley, (Trinity, Cambridge in 1885; and student at Leipzig and Tübingen)

(5) $1907-1927$ Henry Darnley Naylor (Trinity College, Cambridge)

(6) 1928-1957 John Fitzherbert (Sydney University; Trinity College, Cambridge)

(7) 1958-1983 John Trevaskis (Queen's College, Cambridge)

(8) 1984-1992 Robert Ussher (Dublin)

(9) $2011-\ldots$ Han Baltussen (Utrecht University, The Netherlands)

\footnotetext{
${ }^{8}$ Galatis Lecturers: 1997 Professor William Adler (U. North Carolina); 1998 Professor Sam Lieu (Macquarie U.); 1999 Dr Anne Moffat (ANU); 2000 Professor Michael Jeffrey (U Sydney); 2001 D. Hester, A. Geddes, R. Newbold, P. Tuffin (U. Adelaide); 2002 Professor John Haldon(U. Birmingham); 2003 Professor Eunice Maguire (Brown U.); 2004 Professor Margaret Mullet (Queen's U. of Belfast); 2005 Professor E. Chrysos (U. Athens); 2007 Dr Han Baltussen (U. Adelaide); 2009 Professor Dick Green (U. of Sydney); 2012 Professor Emeritus John Davidson (Wellington, NZ). Reports by students on Constantinos Moraitis travel scholarships to Greece: 2006 Simon Bucsai; 2008 Jennifer Turner.
} 


\section{APPENDIX B: HEADS OF DEPARTMENT}

Since departmental/discipline heads became elected positions (elected by the academic staff), the following have held this position. The list does not include those who acted as head when the permanent head was absent.

$\begin{array}{ll}\text { 1974-76 } & \text { Alf French } \\ \text { 1977-79 } & \text { David Hester } \\ 1980 & \text { Ron Newbold } \\ \text { 1981-83 } & \text { John Trevaskis } \\ \text { 1984-88 } & \text { Robert Ussher } \\ \text { 1989-91 } & \text { Frank Sear } \\ \text { 1992-2001 } & \text { Anne Geddes } \\ 2002-2009 & \text { Margaret O’Hea } \\ 2009-\ldots & \text { Han Baltussen }\end{array}$





\title{
English and Creative Writing: 'the abode of ... literature; the home of poetry and fiction'
}

\author{
Philip Butterss
}

At the University's formal opening ceremony on 25 April 1876, the Adelaide Town Hall reverberated with the words of Shakespeare, Milton, Coleridge, and Wordsworth, as dignitaries set forth their visions for the institution's future. ${ }^{1}$ English literature was an important symbol of the British civilisation they wished to implant in a dry and dusty city in the antipodes and, as well as quoting from revered authors, the speeches stressed the value of a literary education. ${ }^{2}$ Walter Watson Hughes was not present, but for him, too, the discipline of English represented the best and most respectable traditions of culture and learning, and he had specified that one of the two chairs to be founded with his gift of $£ 20,000$ should be in 'English Language and Literature and Mental and Moral Philosophy'. Hughes

\footnotetext{
${ }^{1}$ I would particularly like to thank Leigh Dale, who very generously gave me access to the manuscript of her book on the history of English at Australian universities, Enchantment of English, forthcoming from Sydney University Press. I would also like to acknowledge gratefully the assistance of past and present staff and students far too many to name. And I would like to make special mention of the helpfulness of Tony Slade, Barbara Wall and Tom Burton.

${ }^{2}$ The Advertiser, 26 April 1876, pp. 5-6.
} 
had first established himself in the rough and tumble world of whaling and opium trading but, in South Australia, had been able to take up more reputable pursuits; the chair's lofty title in part signified how far he had come.

For the University of Adelaide's first decades, professors of English were from Scotland and Ireland, reflecting the fact that, internationally, the discipline was strong in the Universities of Edinburgh, Glasgow, and Dublin; there was no chair of English at Oxford until 1904 or Cambridge until 1911. Hughes stipulated that the English and Philosophy chair should be filled by the Reverend John Davidson, a Scottish Presbyterian minister who was lecturing on these topics at Union College, a multi-denominational theological institution founded in Adelaide in 1872. ${ }^{3}$ Support for the appointment was not unanimous. In debating the bill to establish the University in 1874, one member of the South Australian Parliament bluntly expressed his opinion that the first professor of English 'was not a University man, that he was not a man of any great culture, and that he was not even a third-rate man'. ${ }^{4}$ While it was true that Davidson had - like many students of his era - not taken a degree, he had for some years attended the Universities of St Andrews (1851-55) and Edinburgh (1855-56). The other judgments were also very unfair. His work at the University demonstrated his erudition, as did his sermons. Both his congregation and his students regarded him highly. ${ }^{5}$

At 4 pm on Tuesday 28 March 1876, Davidson gave the first lecture in English literature in the new institution. As well as two literature lectures per week (repeated in the evening), students were offered a lecture on the 'Structure of English Language'. Classes were held in the Training School of the Council of Education in Grote Street, and then in rented premises in Morialta Chambers, Victoria Square, until the new University building was opened in 1882. ${ }^{6}$ As well as teaching undergraduates, Davidson regularly gave well-attended public lectures

\footnotetext{
${ }^{3}$ R. Linn, The Spirit of Knoweledge: A Social History of the University of Adelaide (Adelaide, University of Adelaide Press, 2011), p. 7.

${ }^{4}$ Parliamentary Debates South Australia, 1874, p. 2063a.

${ }^{5}$ M. Allen, 'The author's daughter, the professor's wife: Harriet Miller Davidson', Fournal of the Historical Society of South Australia, 27 (1999), pp. 103-24; R. B. Walker, 'Davidson, John (18341881)', Australian Dictionary of Biography, <http://adb.anu.edu.au/biography/davidson-john-3372/ text5097>.

${ }^{6}$ S. Woodburn, The Founding of a University: the First Decade of the University of Adelaide (Adelaide, Susan Woodburn, 1983), pp. 9, 13.
} 
on, for example, Chaucer and Shakespeare. The status of poetry at this stage of the discipline's international history can be seen in the books ordered for the fledgling library by the professor in 1877: editions by Byron, Southey, Wordsworth, Tennyson, and Keats; a copy of The Legendary Ballads of England and Scotland; Johnson's Lives of the Poets; Lockhart's The Life of Sir Walter Scott; and Tomlinson's The Sonnet: Its Origin, Structure and Place in Poetry.?

English language and literature was a compulsory component of the BA, though it was initially only available at first-year level. To address, slightly, the lack of upper level classes, the first of the discipline's scholarships was established - in memory of John Howard Clark, a newspaper proprietor active in the forerunner of the State Library. Awarded for the first time in 1882, it allowed a gifted student to continue studying English for two further years under the guidance of the professor. ${ }^{8}$ Davidson had died in the middle of 1881, and had been replaced by William Roby Fletcher, a Congregational minister, who acted in the chair for almost two years until he took up the post of Vice-Chancellor.

Edward Vaughan Boulger, a graduate of Trinity College, Dublin, arrived in September 1883 to be professor of English Language and Literature and Mental and Moral Philosophy. Though classics was his greatest area of expertise, and though he had been professor of Greek at Queen's College, Cork since 1875, he had previously been a lecturer in English at the Queen's Institute, Dublin. By now, enrolments were increasing and, in 1884, a class of more than twenty students attended English literature lectures; most of their first term was devoted to the study of Hamlet. ${ }^{9}$ Boulger's lively public lectures on literary topics were also popular, and he was foundation Vice-President and an active member of the University's Shakespeare Society. He also wrote poetry, for example publishing 'A Doubter's Dole' in the October 1889 edition of Sydney's Centennial Magazine. ${ }^{10}$

In late nineteenth-century Adelaide, literature was important to the city's cultural life, and Boulger's argument - in a public lecture - that Shakespeare

\footnotetext{
${ }^{7}$ Books recommended by John Davidson, 24 August 1877, Registrar's Department Correspondence (1872-1923), University of Adelaide Archives, item 70.

${ }^{8}$ The Advertiser, 29 June 1880, p. 7; M. R. Casson, George Cockburn Henderson: A Memoir (Adelaide, Libraries Board of South Australia, 1964), p. 21.

${ }^{9}$ The Register, 28 June 1884, p. 6.

${ }^{10}$ The Register, 21 October1889, p. 5.
} 
was not intentionally instructing his readers in morals was regarded as 'a startling theory' in press reports. ${ }^{11} \mathrm{He}$ expressed his views forcefully, and soon letter-writers were angry about another lecture in which he described a passage in King fohn as 'patriotic claptrap'. ${ }^{12}$ After a series of other rows with members of the public and with his employer, at the end of 1894, Boulger was forced to resign when, according the Vice-Chancellor, he had been incapacitated, 'due to the effects of either narcotics or alcohol', at a meeting of the Board of Examiners for the Junior and Senior Public Examinations. ${ }^{13}$

Like his predecessors, the next professor was not a specialist in English literature. William Mitchell held an MA in Philosophy from Edinburgh, where he lectured in moral philosophy. Nevertheless, he had been an examiner in English at that institution, and, in giving the address at a commemoration ceremony soon after his arrival in Adelaide in 1895, was eloquent on the importance of a literary education. ${ }^{14}$ One of his contributions to this end was the publication in 1898 of What is Poetry, a 24-page pamphlet deriving from a lecture he had given to the South Australian Teachers' Union. Mitchell's credentials in English language were much weaker, and the literary scholar, W. P. Ker, is said to have given him an Anglo-Saxon primer to read on the voyage to the colonies, assuring him that this would equip him perfectly adequately. ${ }^{15}$

Students of English must have found the conditions difficult. They sat on hard benches and tried to copy down the lectures, which, in the absence of textbooks, were essentially dictated at slow pace for this purpose. The small library in what is now the Mitchell building was cold in winter. In spite of its motto, sub cruce lumen, the University chose not to adopt electric lighting in 1899, and students had to read and take notes using inadequate gas illumination. ${ }^{16}$

In 1900, English was combined with the discipline of History, when Mitchell added Economics to his duties in Philosophy and relinquished his responsibilities

\footnotetext{
${ }^{11}$ The Advertiser, 11 November 1886, pp. 5-6.

${ }^{12}$ The Register, 28 December 1886, p. 7.

${ }^{13}$ Council Minutes, 30 November 1894, University of Adelaide Archives.

${ }^{14}$ The Advertiser, 19 December 1895, p. 7.

${ }^{15}$ J. I. M. Stewart, Myself and Michael Innes: A Memoir (London, Gollancz, 1987), p. 96.

${ }^{16}$ W. G. K. Duncan \& R. A. Leonard, The University of Adelaide 1874-1974 (Adelaide, Rigby, 1973), pp. $22,56,60$.
} 
in literature. It was at this point that the discipline of English at the University of Adelaide began its long tradition of finding professors who had been trained at Oxford: Robert Langton Douglas, the first appointee to the new chair of Modern History and English Language and Literature had taken his MA at Oxford, and almost every professor of English appointed since has been a graduate. The tradition, though, had an unpromising beginning. The London Times of 6 June 1901 included a detailed report about Douglas's desertion of his wife and three children to take up the post at the University of Adelaide and he was forced to resign abruptly. ${ }^{17}$

Douglas's successor to the new chair, George Cockburn Henderson, was the first of the professors of English to have been born in Australia - near Newcastle, New South Wales. After studying history and philosophy at Balliol College, Oxford, he arrived in Adelaide in June 1902 to a salary of $£ 600$ per annum. ${ }^{18}$ The syllabus for Henderson's work in the discipline of English included the then standard textbook, T. R. Lounsbury's History of the English Language, and J. W. Hales's edition of Longer English Poems. For each of the nineteen years of his English teaching at the University of Adelaide, his students studied Hamlet; other Shakespearean plays changed from year to year. Every week, he delivered four lectures in English and the same number in history. ${ }^{19}$ Henderson was primarily an historian, but he was an evangelist for literature, too, and his public presentations were very successful. After one extension lecture on Hamlet to a packed Adelaide Town Hall, a reporter for The Register named him 'the people's lecturer' for his ability to inspire a love of literary study. ${ }^{20}$

In 1913, Ellen Milne Bundey made provision for the award of a poetry prize in honour of her parents, the late Sir Henry - a Justice of the Supreme Court - and Lady Bundey. A sufficiently worthy recipient was not found until 1917, when Leon Gellert, whose studies had been interrupted by the war, entered his Songs of a Campaign, which drew on his experiences at Gallipoli. ${ }^{21}$ Since then,

\footnotetext{
${ }^{17}$ The Times, 6 June 1901, p. 14.

${ }^{18}$ Charles Hodge to G. C. Henderson, 1 May 1902, Henderson Papers, SLSA PRG 6/1/1.

${ }^{19}$ M. R. Casson, George Cockburn Henderson: A Memoir (Adelaide, Libraries Board of South Australia, 1964), p. 20.

${ }^{20}$ The Register, 26 June 1907, p. 5.

${ }^{21}$ The Advertiser, 19 May 1917, p. 13.
} 
the Bundey prize has given encouragement to many young poets, including Rex Ingamells, Paul Pfeiffer, Max Harris, Christopher Pollnitz, Kate Llewellyn, and Anna Gibbs.

As tertiary institutions grew, specialist chairs in English were established at the Universities of Melbourne in 1911, Western Australia in 1912, and Sydney in 1920. ${ }^{22}$ The following year, Mrs Elizabeth Jury gave $£ 12,000$ to the University of Adelaide to fund the Jury chair of English Language and Literature, in honour of her husband, a wealthy merchant. The donation was made in the expectation that her son, Charles Rischbieth Jury — who had recently graduated from Magdalen College, Oxford, with a degree in English - would take up the post. However, he already had an independent income and, when it was duly offered to him, he declined, preferring to devote his attention to the writing of poetry, which he saw as his life-long vocation. ${ }^{23}$ Twenty-five years later, he would finally take up the chair that had his name on it.

With the arrival of Archibald Strong as Jury professor in 1922, there was at last a specialist whose full attention could be devoted to teaching and research in English; the discipline had come of age at the University of Adelaide. Strong had been educated largely in Britain, having completed a degree in classics at Liverpool and then graduating in literae humaniores from Magdalen College, Oxford, in 1900. Back in Melbourne, the city of his birth, he developed his credentials in literature by, among other things, editing the literary journal, the Trident, from 1908-1909 and acting as literary critic for the Herald for fifteen years. From 1912-1921, he taught at the University of Melbourne, including a three-year period as acting professor of English. Prior to his appointment to the Jury chair, Strong had published books of his own poetry, volumes of literary criticism, and an edition of King Lear, as well as a number of articles on literary topics. His Short History of English Literature, published in 1921 with some small input from Robert Wallace, ran to more than 400 pages. Among his publications while at Adelaide were editions of Beowulf and of George Herbert's The Church Porch. He had been a founding member of the Melbourne Repertory Theatre and soon after arriving in his new home was

\footnotetext{
${ }^{22}$ L. Dale, Enchantment of English: Professing Literature in Australian Universities (Sydney, Sydney University Press, forthcoming 2012).

${ }^{23}$ C. R. Jury, 'Life and Letters in Adelaide', Jury Papers, SLSA PRG 20/20; Barbara Wall, 'Charles Rischbieth Jury: Poet of Adelaide', South Australiana 5 (1966), p. 94.
} 


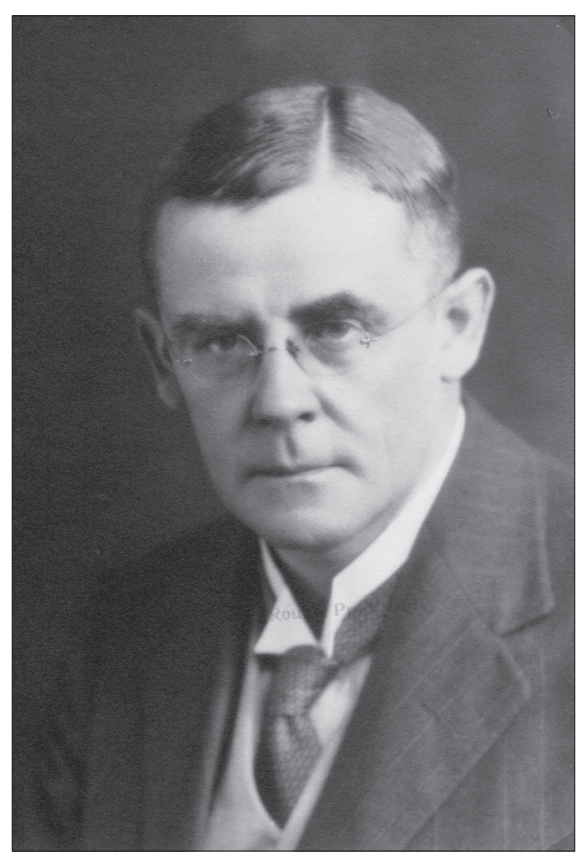

\section{Archibald Strong}

elected president of the Adelaide Repertory Theatre. Strong had a long-standing interest in Australian writing and it was he who wrote the entry on 'Literature' for Angus \& Robertson's Australian Encyclopedia in 1925. In that year he received a knighthood for service to literature and drama. ${ }^{24}$

In 1921, in preparation for the new professor, the Faculty of Arts had finally made English a three-year course; Strong immediately added an Honours course. Unlike some of his predecessors, he had proper expertise in English Language and it was he who introduced the serious study of Old and Middle English to the University of Adelaide. Students remembered him as 'dour and forbidding', and one observer recalled that 'late-comers to his lecture-room quailed before his indignant glare as he stopped in the middle of a sentence and waited in silence for them to reach their seats'. ${ }^{25}$ Those who knew him better saw a twinkle in his

\footnotetext{
${ }^{24}$ V. A. Edgeloe, Archibald Thomas Strong (Adelaide, The University of Adelaide, 1995).

${ }^{25}$ G. Semmler, Pictures on the Margin: Memoirs (St Lucia, University of Queensland Press, 1991), pp. 43-4; R. C. Bald, 'Memoir', in A. Strong, Four Studies (Adelaide, Preece, 1932), p. 11.
} 
eye, and a colleague described him as 'the kindest and most generous of men'. ${ }^{26}$ During his tenure, Strong made his personal library of some 500 books freely available to promising students; after his sudden death in 1930, it was transferred to the Barr Smith Library. In 1948, a prize was donated in his memory. ${ }^{27}$

As the discipline grew under Strong, the first non-professorial appointments were made: Robert Bald to an assistant lectureship in 1923 and, the following year, Albert Kirwood to a lectureship, and Marjorie Walker to a tutorship, which she held from 1924-26. When Strong died, the Depression was beginning to bite and the chair remained unfilled for a period, with Bald and Kirwood running the department. Bald's lectures were, according to one student, 'monotones, delivered at such a fast clip that note-taking was impossible', but his tutorials - in groups of four or five - were inspirational. ${ }^{28} \mathrm{He}$ went on to establish a reputation as a Donne scholar, and, after leaving the University of Adelaide in 1934, was appointed to professorships in Stellenbosch, Cornell, and Chicago. ${ }^{29}$ His colleague, Kirwood, was notable for drawing on the most recent literary criticism, and he introduced students in the early 1930s to I. A. Richards's Practical Criticism and William Empson's Seven Types of Ambiguity. ${ }^{30}$ Elsie Morriss was appointed as a tutor between 1933 and 1935 and, when Bald was on leave, she and Charles Jury carried out his tutoring and lecturing work. At the end of the 1933, Jury was informally offered the chair again, and again he declined. ${ }^{31}$

William Mitchell had become Vice-Chancellor in 1916 and, although his long tenure of that post has been criticised for expanding the sciences at the expense of the humanities, he at least involved himself closely in professorial appointments in the discipline of English. ${ }^{32}$ His replacement for Strong was a bold choice. While in London, Mitchell interviewed and appointed a twenty-eight-year-old lecturer from the University of Leeds, who had an MA from Oxford. At that point,

\footnotetext{
${ }^{26}$ Ibid.

${ }^{27}$ V. A. Edgeloe, Archibald Thomas Strong, pp. 26-7.

${ }^{28}$ C. Semmler, Pictures on the Margin, p. 44.

${ }^{29}$ V. A. Edgeloe, Archibald Thomas Strong, p. 44.

${ }^{30}$ C. Semmler, Pictures on the Margin, p. 44.

${ }^{31}$ R. C. Bald to Vice-Chancellor, 18 July 1932, University of Adelaide Archives, 121/1932; B. Wall, ibid., p. 98.

${ }^{32}$ L. Dale, ibid.
} 
J. I. M. Stewart had published just two items in Review of English Studies: a one-anda-half page note on Montaigne and an annotated transcription of six Coleridge letters running to six pages. Mitchell rightly saw that he had the potential to make an impact, though the Vice-Chancellor could not have predicted exactly how.

Stewart quickly established an international reputation as a creative writer, publishing twelve crime-fiction novels during his ten years in Adelaide under the pseudonym of Michael Innes, and writing something like sixty works of fiction over his lifetime. During his tenure of the Jury chair, he also managed to produce some literary criticism, including reviews of Australian poets and some pieces in Review of English Studies and Modern Language Review. ${ }^{33}$ Students, particularly those at upper levels, admired his flamboyance, and some went so far as to imitate his rakish dress and his pipe. ${ }^{34}$ In spite of his background in the careful scholarship of Oxford, Stewart was eclectic in his approach to literary analysis, drawing on the work of those associated with Cambridge, such as I. A. Richards and F. R. Leavis, and applying Freudian theory to the examination of Shakespearean characters. ${ }^{35}$ Where Strong's syllabus had essentially finished at the end of the nineteenth century, his successor was interested in more contemporary literature, and taught the moderns, including Joyce, Eliot, Auden, and Spender. When Ulysses was rebanned in Australia in 1941, upper level students took it in turns to borrow their professor's copy. ${ }^{36}$

Today in Australia, Stewart is notorious for views he aired at the commencement of a series of Commonwealth Literary Fund lectures in Adelaide in 1940. Adopting the striking, almost-falsetto voice that he used for public performances, he began: 'I am most grateful to the C.L.F. for providing the funds to give these lectures in Australian literature, but unfortunately they have neglected to provide any literature - I will lecture therefore on D. H. Lawrence's Kangaroo' ${ }^{37}$

\footnotetext{
${ }^{33}$ Ibid.

${ }^{34}$ J. Miles, Lost Angry Penguins: D. B. Kerr, P.G. Pfeiffer, and the Real Founding of the Angry Penguins (Hindmarsh [SA], Crawford House, 2000), p. 15.

${ }^{35}$ V. A. Edgeloe, 'A Century of English Studies at Adelaide', AUGU Monthly Newesletter and Gazette, June 1975, n.p.; F. H. [Tim] Mares, 'Southern Review: The Oldest Inhabitant Reminisces', Southern Review, 26 (1993), p. 146.

${ }^{36}$ C. Semmler, ibid., p. 46.

${ }^{37}$ G. Dutton, Snow on the Saltbush (Ringwood, Viking, 1984), p. 18.
} 
Colin Horne later claimed that this was 'just his teasing manner, ${ }^{38}$ and further research shows that these introductory words were, to an extent, tongue-in-cheek. In fact, Stewart saw the encouragement of Australian literature as 'laudable', and it was he who had organised the C.L.F. series, which were, according to the press, the first lectures on Australian literature at the University of Adelaide. Stewart, himself, gave the initial five lectures on novels, and these were followed by five on the development of Australian poetry, delivered by Brian Elliott, whom Stewart had appointed as a tutor that year. The C.L.F. lectures were open to the public, but they also formed part of the regular first-year English course, and, for over a decade, students received a lecture on Australian literature in each of the ten weeks of third term. ${ }^{39}$ In addition, Stewart went on to appoint Elliott to a position designated 'Lecturer in Australian Literature' in 1943, the first of its kind anywhere. He was, therefore, instrumental in establishing the study of Australian literature at universities. Whether he thought much of it as literature, though, is another question. His memoir indicates that he looked down on most of what he came across in this country - architecture, climate, theatre, people, and Australianborn academics, whom he believed had 'a certain dimness' about them. ${ }^{40}$

Stewart did, though, think highly of some of his undergraduates, and encouraged them both in their study of English literature and in their own writing. One of his students was Max Harris, who, while editing the modernist journal, Angry Penguins, soon after finishing his degree, was involved in the Ern Malley affair. At its fag end, when Harris was being tried for obscenity, Stewart put his verbal condescension to good use in dealing with the prosecutor's questions, though his disdain was directed as much at the literary value of the journal as it was at the absurdity of the trial. ${ }^{41}$ At the start of 1946, he left Australia, with what one friend called feelings of 'relief and liberation' for an appointment at Queen's College, Belfast. ${ }^{42}$ A couple of years later, he accepted a fellowship at Christ Church,

\footnotetext{
${ }_{38}$ The Australian, 30 November 1994, p. 16.

${ }^{39}$ The Advertiser, 22 July 1940, p. 15; N. Jeffares, 'Australian Literature and the Universities', Meanjin 13.3 (1954), p. 432. Jeffares points out that by 1954, Australian literature had been moved to the third-year course.

${ }^{40}$ J. I. M. Stewart, ibid., p. 104.

${ }^{41}$ J. I. M. Stewart, ibid., p. 108.

${ }^{42}$ J. I. M. Semmler, ibid., p. 54.
} 
Oxford, where his extensive critical output included books on Shakespeare, Hardy, Conrad, and Joyce.

Finally in 1946, Charles Jury agreed to take up the chair originally intended for him. His decision, as always, was a generous and principled one: he would occupy the post while Herbert Piper, who had been awarded a lectureship at the University and a Rhodes scholarship that year, went off to complete a degree at Magdalen College, Oxford. English students would be looked after until Piper returned to take up the position that Jury felt he deserved.

Many have seen Adelaide as the Athens of the South but Charles Jury experienced it intensely as such, finding strong physical and cultural connections between the two cities. Reflecting on his vocation as a poet, he wrote that he had wanted to link Adelaide 'imaginatively with classical Greece'. ${ }^{43}$ By the time of his appointment, he had published some poems and two verse dramas, as well as some annotations on Eliot's The Wasteland, derived from a lecture to the Adelaide branch of the English Association. Although his poetry used classical diction and drew on classical themes and subject matter, he was an enthusiastic supporter of contemporary Adelaide's literary and artistic life, encouraging young writers such as Max Harris, Douglas Muecke, Barbara Wall, Margaret Finniss, John Bray, Alison Gent, Michael Taylor and Brian Medlin, and providing financial assistance to Angry Penguins. In fact, it was on his suggestion that those two words from a Max Harris poem were chosen as the journal's title. Jury's knowledge of current critical theory was slight, but his understanding of, and love for, literature were profound. Among his particular interests were Shakespeare, Milton, Keats, Shelley, and Jane Austen; one of his students records that being taught by him was 'a moving experience'. ${ }^{44}$

By the time he vacated the chair in 1949, it was clear that the new ViceChancellor, A. P. Rowe, was not going to appoint Piper — who had done poorly in his exams at Oxford on account of illness - to the chair of English. Jury was angry that what he had understood as a firm agreement with a previous ViceChancellor was not going to be honoured. However, he gained a certain revenge by writing two verse plays, The Administrator and The Sun in Servitude, both of which

\footnotetext{
${ }^{43}$ C. R. Jury, 'Life and Letters in Adelaide', SLSA PRG 20/20.

${ }^{44}$ B. Wall, ibid., pp. 104-5.
} 
were intended to be read as highly critical of university administrations. Piper returned to Adelaide as a lecturer and later accepted a professorship in English at the University of New England, Armidale. ${ }^{45}$

During 1950, while the University sought what it saw as a more suitable candidate than Piper, the Jury chair was filled by an interim appointment, the eighteenth century scholar, David Nichol Smith. Today, he remains the only Jury professor not to have held an Oxford degree; he had, however, only recently retired from seventeen years as Merton Professor of English Literature at Oxford. Barbara Wall was an acting lecturer for 1950, the first woman to hold a post formally designated as a lectureship.

As a Vice-Chancellor, Rowe saw the University through a scientist's eyes, aiming to transform it into a centre of scientific excellence and believing that books would soon be replaced by microfilm. ${ }^{46}$ Nevertheless, like Mitchell, he involved himself in appointments to the discipline whose chief concern was books. Norman 'Derry' Jeffares took up the Jury chair in 1951, arriving at the age of thirty-one as a Yeats expert with a PhD from Trinity College, Dublin, a D Phil from Oxford, and lots of energy and ideas. Some of his proposals for the University were ahead of their time, such as establishing an institute of Australian studies and a radio station - the latter would eventuate, but not for almost twenty years. In 1954, he was more successful in founding, with Brian Elliott, the Australian Humanities Research Council, which was to become the Australian Academy of the Humanities. These two men were firm friends and each encouraged the other's poetry writing. Among the lecturers Jeffares appointed who would have an important impact on the discipline were Bryn Davies, described by an observer as 'one of the most scholarly and picturesque staff-members of the University', ${ }^{47}$ Geoffrey Dutton, and Tim Mares.

Jeffares's five years at Adelaide were pivotal for his own career, too. Leigh Dale has commented on the apparently inconsistent views he expressed in an article published in Meanjin in 1954, where he stressed his own institution's long involvement in teaching Australian literature, argued against separate 'courses' in

\footnotetext{
${ }^{45}$ L. Dale, ibid.

${ }^{46}$ A. P. Rowe, If the Gown Fits (Melbourne, Melbourne University Press, 1960), p. 93.

${ }^{47}$ V. A. Edgeloe, 'A Century of English'.
} 
Australian literature, and concluded that Australian studies were 'bound to become an integral part of English studies in this country in the future' ${ }^{48}$ Evidently, though, his participation in such discussions - and his time in Australia, more generally helped him to develop an interest in writing usually regarded as peripheral to the English canon. After he left for a chair at the University of Leeds in 1956, Jeffares was instrumental in establishing the study of Commonwealth literature, later more commonly known as new literatures in English or post-colonial literature.

Colin Horne's appointment as the Jury professor in 1957 coincided with the release of the Murray Report into Australian universities, the results of which had a huge impact on his period of tenure, allowing him to build up a large department. Horne had an MA from Melbourne and an MA and an M Litt from Oxford; he had published a number of pieces in Notes and Queries and Review of English Studies in his chief area of expertise: Swift and the eighteenth century. When he reached Adelaide, his department had four lecturers and one tutor. As funding for universities became a federal rather than state responsibility and as the Menzies government poured resources into the sector, the expansion began. In 1958, four more lecturers were appointed and, within a few years, the full-time members of the discipline had risen to twenty-two. Student numbers also began to rise substantially, though for a long time the staff student ratios were excellent, with six students per tutorial, and, in Honours, two or three. ${ }^{49}$ Some in the University mourned the loss of intimacy and community that had characterised the 1930s and 1940s, when it was possible to know all the full-time academic and administrative employees, and when staff and students ate together in the Helen Mayo refectory. ${ }^{50}$ For others, though, the funding that followed the Murray report began a golden age.

The influx of new, young, staff members was able to take advantage of the study leave scheme established by Rowe, and there was a lively atmosphere and a great deal of talent in the discipline. Appointments during Horne's first five years included Peter Dixon, who later became professor of English at Queen Mary and Westfield College, University of London; Alan Rudrum, who went on

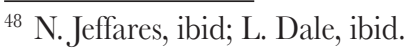

49 T. Mares, 'Colin James Horne (1912-1999)', F. H. Mares and Robin Eaden Papers, Special Collections, Barr Smith Library, MSS 0079, Series 20/1.

${ }^{50}$ W. G. K. Duncan \& R. A. Leonard, ibid.; A. P. Rowe, ibid., p. 62.
} 
to become professor of English at Simon Fraser University, British Columbia; Ralph Elliott, soon to be foundation professor of English at Flinders University and then professor at ANU; Tony Gibbs, later professor of English at Macquarie; and Peter Meredith, who would become professor of Medieval Drama at Leeds. Bryn Davies, employed five years before the Murray report, resigned in 1967 to take up a chair at the University of Ghana.

Others felt the many attractions of Adelaide, both within and outside the University, and chose to continue their careers as teachers and researchers here. A letter from Phil Waldron to the head of English at the University of Canterbury in New Zealand, in the middle of 1971, read: 'Dear Professor Copland. Thank you for your letter of 20 July suggesting that I apply for a position in your department. However, as I have now heard that Gary Sobers is definitely to represent South Australia in the Sheffield Shield competition this season, I have decided to remain in this department. Yours faithfully, ${ }^{51}$ Members of staff were active in the English Association, the Theatre Guild, and the Friends of the State Library. Waldron had a lengthy term as Chief Examiner in English for the state Education Department. The discipline's long-standing involvement in producing and fostering creative writing continued, too: Randolph Stow was a part-time tutor in the 1950s; Geoffrey Dutton wrote novels and books of poetry; Tim Mares and Rob Johnson ran a thriving creative writing group that included staff and students through the 1960s; Geoff Thurley gave poetry readings; later Andrew Taylor and Ian Reid would found the Friendly Street poets. Horne and Dutton were significant forces in establishing Writers' Week at the Festival of Arts.

In 1962, Kevin Magarey assembled a small group of people, including Rudrum and Gibbs, and founded the journal that was to be one of the major contributions from the University of Adelaide to the discipline worldwide. Its initial working title, 'Aspect', derived from the idea of interdisciplinarity that was central to its aims: as the constitution explained, 'the literary "aspect"' needed to be explored in relation to life's 'other aspects'. ${ }^{52}$ This open-mindedness extended to the canon, and the journal declared an interest in regional literatures. By the time of its first issue in the latter part of 1963 it had become Southern Review.

\footnotetext{
${ }^{51}$ Tony Slade Papers, held privately.

${ }^{52}$ Colin Horne Papers, Special Collections, Barr Smith Library, MS 92 H8125p Series 59.
} 
During this period of expansion, the discipline was continuing its early involvement in the teaching and research of Australian literature. Brian Elliott's pioneering biography, Marcus Clarke, was published by Clarendon in 1958. With Max Harris, Geoffrey Dutton published the journal, Australian Letters, from 1957, and he co-founded the first version of Australian Book Review in 1961. His influential collection of essays by a number of prominent scholars, The Literature of Australia, was published in 1964, a year after he had left the University.

During the 1970s, five members of the department were fellows of the Australian Academy of the Humanities, more than any other English department in the country. ${ }^{53}$ For students, the breadth of coverage of English language and literature was at its widest, and many still remember the inspirational instruction they received. Old and Middle English were taught by George Turner, Vida Russell and the recently arrived Tom Burton. Alan Brissenden and Tim Mares were among those who taught Shakespeare. Colin Horne was expert in the eighteenth century. Rob Johnson, Rosemary Sweetapple (later Moore) and David Smith were among the staff members with strengths in the nineteenth century; Smith also taught drama, as did John Edge. Michael Tolley was an expert on Blake and the eighteenth century. Tony Slade's interests included Chaucer, Dickens, Hardy, Lawrence, and the rise of modernism. Phil Waldron introduced students to romanticism and the detailed study of Joyce and Eliot. Geoff Thurley gave what have recently been described as 'spellbinding performances' in his lectures on the nineteenth and twentieth centuries. ${ }^{54}$ Rob Sellick joined Brian Elliott and others in teaching Australian literature, while Kevin Magarey, the kind-hearted Haydn Williams, and Ian Reid (later foundation professor of Literary Studies at Deakin) were among those lecturing on new literatures in English. Barry Westburg and Andrew Taylor taught American literature; the latter subsequently went to the foundation chair in English literature at Edith Cowan. Linguistics was also taught by Turner, who had an international reputation for his work on Australian and New Zealand English, and by Mares and Williams. The department produced books on, among other things, Lawrence, Dickens, socialism in the twentieth-century

\footnotetext{
${ }^{53}$ T. Mares, 'Submission to Review of English Department', F. H. Mares and Robin Eaden Papers, Special Collections, Barr Smith Library, MSS 0079, Series 3.

${ }^{54}$ B. White, 'My Literary Adelaide', paper delivered to the Literary Adelaide conference, University of Adelaide, February 2012.
} 
novel, and editions of Shakespeare, Middleton, and Jonson. During this period, the discipline managed to avoid the bitter fights over Leavisism that so troubled the English departments at the Universities of Melbourne and Sydney, and its range of teaching and research was accompanied by a breadth of approaches, with different staff members drawing on traditions of careful scholarship, on the work of Leavis, on the new critics, and on historicism.

As women began to move into previously male-dominated areas of the Australian workforce, the discipline of English - like the wider University - was slow to respond. Sheila Smith was the first woman to hold a tenured lectureship in English - from 1961 to 1966, when she returned to England. Rosemary Sweetapple was appointed to a lectureship in 1965 and Vida Russell in 1970, but a decade later they remained the only women in substantive posts. By contrast, the English department at the University of Sydney in 1975 had one female professor and eleven other women in continuing positions, including the Adelaide graduate, Margaret Clunies-Ross, who would later hold the McCaughey chair of English Language and Early English Literature. ${ }^{55}$ At Adelaide, women did much of the tutoring work, but needed to go elsewhere to find lectureships. Among those who did this were Dorothy Jones, Susan Higgins (later Sheridan), Jacqui Cook, Virginia Kenny, Diana Brydon, and Kerryn Goldsworthy; some, such as Alison Gent, Margaret Finnis, and Dorothy Colmer, remained in Adelaide, holding tutorships for a period and, in the latter's case, at one point a temporary lectureship.

In other areas, too, women played a significant role in supporting the academic work of the department. Shirley Bowbridge had been forced to resign as a secretary in the early 1960s, when she married, but after the University's practices became less discriminatory, she returned to lead the team of office staff and to manage the complex operations of a large and active department. When she retired in the late 1990s her work was ably continued by Shirley Ball. At times, the office provided administrative support to Southern Review while Robin Eaden, the department's research officer, worked on the journal and assisted in a number of research projects.

\footnotetext{
${ }^{55}$ University of Sydney, Calendar, 1975, pp. 43-4, <http://calendararchive.usyd.edu.au/Calendar /1975_voll/1975.pdf>.
} 
By 1964, the discipline had become large enough to warrant a second professor, and John Colmer - who had arrived three years earlier as a senior lecturer with an MA from Oxford and a $\mathrm{PhD}$ from London - was appointed to the new post. His influence on departmental life was so profound that some still call the following two decades 'the Colmer years'. He had an international reputation as a Coleridge scholar and could be an excellent teacher; he could also, at times, be a good head of department. On the other hand, he was a forceful character, with strong opinions and a considerable sense of his own importance: at home his living room contained a bust of himself in an imperious pose. As his correspondence indicates, he was quick to take offence and had a sharp tongue. Many remember him as a bully. He was also, among other things, an amateur oil painter, sometimes using female postgraduate students as live models. For his part, Colmer believed that 'the spirit of envy, malice and spite' prevailed among his colleagues, as he wrote in an accusatory letter to one of them. ${ }^{56}$

In 1971, the University was still in the process of introducing a more collegial system of departmental governance under which heads of department would no longer be appointed by the Vice-Chancellor from among the professoriate; instead, staff members would elect one of their fellows to chair departmental meetings and administer the department. However, by August of that year, the relationship between Colmer and his colleagues was so bad that the Vice-Chancellor, Geoffrey Badger, was forced to intervene. He privately polled each member of staff and then appointed Tim Mares as head of department. The following January, when the new system had been introduced, a formal election was held confirming him as chair of the departmental committee. Efforts to restore harmony were successful, though the peace was not always enduring. Colmer's antagonism towards Horne, for instance, could break out at any moment. One observer remembered 'an attack on the work of a student at a graduate seminar that was really an attack on the supervisor (... Colin Horne) but it caused considerable distress and damaged the student's confidence, so that the completion of the thesis was considerably delayed' ${ }^{57}$ After Horne retired in 1977, Colmer was appointed to the Jury professorship, despite the reservations of many in the department.

\footnotetext{
${ }^{56}$ John Colmer to Tony Slade, n.d. [early 1970s], Tony Slade Papers, held privately.

${ }^{57}$ T. Mares, Submission to Review.
} 
Although a degree from Oxford had seemed to be a prerequisite for holding the Jury post, the discipline had never been sectarian, as the diversity of approaches to literature demonstrates. The appointment in 1980 of Ken Ruthven to the other chair was another instance of this openness, for his interests were manifestly in contemporary theory; perhaps the department did not realise how set in its ways it was. Soon there began a version of the theory wars that raged, during this period, in English departments throughout the world, most notoriously at Cambridge. In his teaching and publishing, by bringing visitors, and with his questions at staff and graduate seminars, Ruthven helped to introduce theories of deconstruction, post-structuralism, contemporary French Marxism, and feminism to the intellectual life of the fifth and sixth floors of the Napier building. He also quickly became involved in Southern Review and, in 1981, its rubric was broadened to encourage 'contributions from exponents of newer and more radical styles of critical discourse ${ }^{, 58}$ The journal began to publish theoretical material from critics such as Simon During, Anne Freadman, John Frow, Sneja Gunew, Ian Hunter, Meaghan Morris, Terry Eagleton, Tony Bennett, Catherine Belsey, Christopher Norris, and Stuart Hall. Eventually - in the mid-1990s after the University of Adelaide withdrew its in-kind support - the editorship of Southern Review was transferred to Monash.

Many of Ruthven's new colleagues found the turn to theory challenging, and some were openly hostile. Colmer, though he had earlier been interested in the structuralism of Levi-Strauss and the Marxist criticism of Lucien Goldmann, was opposed to these new directions. He was joined by some of those who had been most at odds with him a decade earlier. Again, graduate seminars could be faction fights and, again, students could be caught in the crossfire. ${ }^{59}$ After Ruthven left for a chair at Melbourne in 1985 and Colmer retired in 1986, theory gradually became a less contentious aspect of teaching and research.

The discipline was without a professor, and some of those members of staff who remained were jaded and had poor publication records. In response, Tony Slade, who was now in his second term as head of department, initiated an external review. Among the findings - released in 1988 — were that some staff needed

\footnotetext{
${ }^{58}$ T. Mares, 'The Oldest Inhabitant', p. 143.

${ }^{59}$ T. Mares, Submission to Review.
} 
either 'to become recommitted to their discipline and the exciting changes taking place in it or be prepared to accept early retirement to allow room for more willing appointees'. At the same time, the review acknowledged the revitalisation that was already taking place through the energy of young, capable academics who had recently been appointed. Though it did not name them, this was a reference to Russell McDougall and Deirdre Coleman. It noted of Southern Review that 'many would judge it the best journal of its kind in Australasia'. It concluded that a 'lively and forward-thinking professor' should be found quickly. ${ }^{60}$

In 1991, Andrew Milner could write that 'Australian university English departments have remained one of the last important British garrisons east of Suez ${ }^{61}$ In fact, this was no longer true in regard either to Adelaide's personnel or to its offerings. Jeffares had begun the process of appointing British-born lecturers, and their numbers had swelled during Horne's tenure of the chair, although there were also representatives from, for example, New Zealand and South Africa. However, a series of Australian-born appointments had begun to shift the balance. So had the recent arrival of three new staff members as part of the University's merger with the city campus of the South Australian College of Advanced Education. Nor was the Adelaide department single-mindedly focused on British culture, as its lengthy interest in Australian literature and new literatures in English indicates. In addition, American literature was well catered for and Slade had long been teaching European literature in translation, as had Smith in his drama course. More radically, by the start of the 1990s, the first-year course, Major English Texts I, had been transformed - particularly through the efforts of McDougall - into a post-colonial course where canonical British texts and postcolonial texts were explored for the interrelationships between them.

In 1990, four years after Colmer's retirement, the Jury chair was finally filled by Penny Boumelha, and a series of female appointments meant that by the end of the decade, women were in a substantial majority. Boumelha's highly regarded work on Thomas Hardy and Charlotte Brontë combined a subtle reading of literary texts with an awareness of contemporary critical theory. As the University's only female professor, she was immediately in demand for committee

60 'Review of the Department of English' (Adelaide, University of Adelaide, 1988), p. 24.

${ }^{61}$ A. Milner, Contemporary Cultural Theory: An Introduction (North Sydney, Allen \& Unwin, 1991), p. 32. 
work, and soon moved into the upper levels of administration, as Dean of the Faculty and later as Deputy Vice-Chancellor. The Jury chair has not been filled since she left in 2009 for a DVC post at Victoria University in Wellington, New Zealand.

By the 1990s, a new set of critical vocabularies could be encountered among the various offerings in English language and literature. Forty years earlier, students were instructed to learn a page of terms, including 'anacoluthon, apposition, anacrucis, and anagnorosis'; they needed to know the difference between, for instance, an Horatian and a Pindaric ode. ${ }^{62}$ Now, during first-year, students learnt about subjectivity, intertextuality, subversion, and the death of the author. Literary theory as a separate course was reserved for the Honours year, but many undergraduate offerings drew on feminism and other contemporary theoretical approaches. While the department continued to teach canonical and other literatures, it also began to offer courses in newer interdisciplinary and multidisciplinary areas such as cultural studies, Australian studies, gender studies, media studies, and film studies. During this decade and into the next, staff members won six Stephen Cole the Elder Awards for outstanding teaching - a number unequalled by any other department in the University - as well as several other University and national awards.

Financial pressures resulting from the serious decline in the University's federal funding from the late 1980s began to impact significantly on the operations of the discipline. A team of staff members established a course called 'English for Professional Purposes', both for native speakers and in an ESL version, thus contributing usefully to the wider institution while attracting large numbers of students - including international students - to the Faculty. On the other hand, the long emphasis on the scholarly study of the English language and of Old and Middle English literature was in decline. Where, for instance, in the late 1960s, students in the Honours strand had received three years of instruction in AngloSaxon, few were now interested, and courses with small enrolments were regarded as unviable. Only one expert remained on the staff. In recognition of this reality, it was agreed to adopt the shortened name, 'Department of English', a phrase that, internationally, now denoted the range of offerings and approaches seen

${ }_{62}$ Colin Horne Papers, Special Collections, Barr Smith Library, MS 92 H8125p, Series 10. 
at Adelaide. Soon, the University would abolish departments and locate English as a discipline within the School of Humanities. As economic rationalism made further inroads into the tertiary sector, some elements of an earlier academic life remained: Rosemary Moore's Pekinese continued quietly to snore its way through meetings, research seminars, and tutorials, until a 'pet policy' banned it from the Napier building.

Certainly the most significant development in the last twenty years has been the introduction of creative writing as an official part of the discipline's work. After an approach from ArtsSA's Penelope Curtin, offering financial assistance, the University established the first chair in creative writing in Australia. The poet and novelist Tom Shapcott was appointed in 1997, and he began what was immediately a thriving MA program. By 2000, the first students were enrolling in a $\mathrm{PhD}$ consisting of a major creative work plus a 20,000 word critical essay. After Shapcott's retirement in 2005, other distinguished writers have held the chair - Nicholas Jose from 2005 and then Brian Castro from 2008. The program has become probably the most successful of its kind in Australia, responsible for an extraordinary array of novels and collections of short stories and poems from staff and students - that have been published around the globe, winning numerous awards. The discipline also hosts the national magazine of writing, Wet Ink. Since his relocation to Adelaide in 2002, John Coetzee has been involved in the creative writing program, as a mentor and research fellow, and now professor. He was awarded the Nobel Prize for literature in 2003, and has recently lent his name to the J.M. Coetzee Centre for Creative Practice, a joint initiative with the Elder Conservatorium of Music.

As staff numbers available for non-creative writing courses have diminished, there has been a decrease in the focus on interdisciplinarity and a shift back towards what were, for a long time, core areas of the discipline - for instance, new, team-taught courses in modernism and the nineteenth century fill gaps that had emerged through retirements. Throughout Australia there has been a slow decline in traditional research PhDs in English but, at the University of Adelaide, the drop has been more than matched by the substantial enrolments in creative writing PhDs. In 2012, for the first time, the Faculty offered a major in creative writing as part of the Bachelor of Arts. To reflect the fact that staff and students 
in this area now make up a significant proportion of the discipline, its name has recently been revised to Discipline of English and Creative Writing.

Today, those working at the University of Adelaide face the same difficulties as humanities departments through the whole tertiary sector. Academic workloads are so high as to be hardly sustainable, and collegial decision-making processes have been replaced by managerialism. Over-large class sizes are a serious problem with, for example, almost three times as many students in a first-year tutorial as there were in the mid-1970s. But in spite of these constraints, members of staff continue to teach and research effectively across a broad range of areas: Tom Burton (Medieval literature, William Barnes); Phil Butterss (Australian literature and film); Brian Castro (creative writing, melancholia); Dorothy Driver (South African literature, modernism, postmodernism); Phillip Edmonds (creative writing, short story, literary magazines); Sue Hosking (Aboriginal writing, creative writing); Jill Jones (creative writing, poetry); Nicholas Jose (creative writing, Australian literature); Heather Kerr (early modern literature, history of emotions); Joy McEntee (film, American literature); Amanda Nettelbeck (life-writing, Australian literature, frontier history); Lucy Potter (early modern literature, professional and academic English); Ros Prosser (creative writing, memoir, fictocritical writing); Di Schwerdt (African literature, English for professional purposes); and Mandy Treagus (Victorian literature, Pacific writing and culture, embodiment).

For almost 140 years, then, English has been an important discipline in the University of Adelaide. It has been peopled by some interesting characters - sometimes difficult, sometimes saintly, but always with a love for their subject and a deep commitment to teaching, research, and writing. Academics here have remained connected to changing emphases in the broader discipline, and have made their own significant contributions, nationally and internationally, through individual research projects, through helping to establish Australian literature as an academic subject, through Southern Review, and, most recently, through the creative writing program. As the only English department in South Australia for almost ninety years and, after that, as part of the state's only sandstone university, the discipline has had a profound impact on the life of the city of Adelaide. It has attracted many of the state's most able students, and has often fostered in them a life-long interest in reading, a desire to write creatively, and a set of analytic, 
critical, and argumentative skills crucial in their lives outside the University's walls.

At the very first commemoration ceremony in 1877, in a speech peppered with frequent applause, the Chancellor celebrated the University's participation in 'the great republic of letters', which he defined as 'the abode of science, art and literature; the home of poetry and fiction' ${ }^{6}{ }^{3}$ Ever since, the University has been a strong home for English and Creative Writing.

\section{REFERENCES}

Allen, M., 'The author's daughter, the professor's wife: Harriet Miller Davidson', Fournal of the Historical Society of South Australia, 27 (1999), pp. 103-24. Australian Dictionary of Biography online, <http://adb.anu.edu.au>. Bald, R. C., 'Memoir' in A. Strong, Four Studies (Adelaide, Preece, 1932), pp. $3-14$.

Brissenden, A., 'Introduction', in A. Brissenden (ed.), Aspects of Australian Fiction: Essays presented to Fohn Colmer (Nedlands [WA], University of Western Australia Press, 1990), pp. ix-xii.

Casson, M. R., George Cockburn Henderson: A Memoir (Adelaide, Libraries Board of South Australia, 1964).

Dale, L., Enchantment of English: Professing Literature in Australian Universities (Sydney, Sydney University Press, forthcoming 2012).

Duncan, W. G. K. \& Leonard, R. A., The University of Adelaide 1874-1974 (Adelaide, Rigby, 1973).

Dutton, G., Snow on the Saltbush, (Ringwood, Viking, 1984).

Edgeloe, V. A., 'A Century of English Studies at Adelaide', AUGU Monthly

Newsletter and Gazette, June 1975, n.p.

Edgeloe, V. A., Archibald Thomas Strong (Adelaide, University of Adelaide, 1995). Jeffares, N., 'Australian Literature and the Universities', Meanjin 13.3 (1954), p. 432.

Linn, R., The Spirit of Knowledge: A Social History of the University of Adelaide

${ }^{63}$ The Advertiser, 3 May 1877, p. 5. 
(Adelaide, University of Adelaide Press, 2011).

Mares, F. H. [Tim], 'Southern Review: The Oldest Inhabitant Reminisces', Southern Review 26 (1993), pp. 144-50.

Miles, J., Lost Angry Penguins: D.B. Kerr, P.G. Pfeiffer, and the Real Founding of the Angry Penguins (Hindmarsh [SA], Crawford House, 2000).

Milner, A., Contemporary Cultural Theory: An Introduction (North Sydney, Allen \& Unwin, 1991).

Parliamentary Debates South Australia, 1874.

Rowe, A. P., If the Gown Fits (Melbourne, Melbourne University Press, 1960).

Ruthven, K. K., 'Remembering Southern Review 1980-1985', Southern Review 26 (1993), pp. 151-6.

Semmler, C., Pictures on the Margin: Memoirs (St Lucia [Qld], University of Queensland Press, 1991).

Stewart, J. I. M., Myself and Michael Innes: A Memoir (London, Gollancz, 1987).

Wall, B., 'Charles Rischbieth Jury: Poet of Adelaide', South Australiana 5 (1966), pp. 79-114.

White, B., 'My Literary Adelaide', paper delivered to the Literary Adelaide conference, University of Adelaide, February 2012.

Woodburn, S., The Founding of a University: the First Decade of the University of Adelaide (Adelaide, Susan Woodburn, 1983). 


\title{
6
}

\section{A Tale of Resilience: the History of Modern European Languages at the University of Adelaide $^{1}$}

\author{
Jean Fornasiero and John West-Sooby
}

The history of modern European languages at the University of Adelaide is almost as old as the University itself. When teaching for the Bachelor of Arts began in 1876, two years after the establishment of the University, there was naturally a limited number of classes available to students, and these covered what were at that time the traditional subject areas for an Arts degree in the British system: Latin and Greek, Philosophy, Mathematics, English Language and Literature, and the Natural Sciences. Right from the outset, however, French and German were formally recognised as areas of study at the level of the matriculation examination.

\footnotetext{
${ }^{1}$ Much of the information presented in this paper has been derived from the University of Adelaide Calendars, as well as from Education Committee minutes and the minutes of Council meetings. Additional information on German was provided by Lee Kersten, to whom we express our thanks. We would also like to thank Helen Bruce, Reference Archivist at the University of Adelaide, and the staff in Special Collections at the Barr Smith Library for their gracious assistance with our background research.
} 
Italian would soon be added (in 1882) to the range of matriculation subjects for which the University had oversight. While it would be several more years before modern language study could be counted towards the Bachelor of Arts (1887), and despite the fact that the first dedicated teaching appointment would not be made until another decade after that (in German), it is nevertheless the case that languages in general, and modern European languages in particular, formed part of the landscape of the University from its beginnings.

Expertise in foreign languages was indeed readily available among the academic and administrative staff of the University from itsinception - a reminder that training in languages, both classical and modern, was an integral component of the well-rounded scholar's education at the end of the nineteenth century. This expertise was regularly called upon during the first decades of the institution, with Education Committee setting the curriculum at matriculation level, for example, in French, German and Italian, and the University often providing examiners from its own staff to mark the final papers in those subjects. Some teaching (of French) was also conducted by senior members of staff in the Faculty of Arts as early as 1884, though instruction in foreign languages and literatures would prove sporadic until dedicated appointments were made. The role played by modern languages in those early years was no doubt modest, and it would take some time for them to emerge from the shadows of the more traditional teaching areas; nevertheless, the part they played in the educational project of the fledgling campus and in its intellectual life was undeniable and helped pave the way for the landmark decisions that would establish them as enduring disciplines of study within the Faculty of Arts. In order to gain a better understanding of the long-term history of modern languages at the University of Adelaide, it is therefore important to begin not with their formal emergence as stand-alone academic disciplines or departments, but with their 'pre-history', as it were.

\section{FIRST STEPS}

There is nothing particularly unusual in the fact that modern languages were not at the forefront of preoccupations when the University of Adelaide was established in 1874. An easy familiarity with the art and literature of Europe, along with the ability to slip into conversation the odd French or German expression, may 
well have been de rigueur for the well-educated citizen at that time, as perhaps is still the case today, but there was some ambivalence about the status of modern language study as an academic pursuit - a double standard from which languages have suffered at various times over the past century and a half in the Australian community generally, and in our tertiary institutions in particular. Drawing on the example of Dr Anselme Ricard, who had the honour of being the first person to teach French and German at an Australian university, but whose salary of $£ 150$ per annum contrasted rather poorly with the $£ 800$ paid at that time (1854) to the Professor of Classics at the University of Sydney, John Woolley, Ivan Barko and Angus Martin make the following observation in their 'Short History of the Teaching of French in Australian Universities':

From the outset the concept that modern languages can be taught on the cheap was embraced by the powers that be. Underlying this idea there was the covert feeling that the teaching of modern languages was not an academic discipline. ${ }^{2}$

The initial absence of French and German from the undergraduate curriculum at Adelaide was therefore not especially surprising: it was no more, and no less, than a reflection of the kind of hesitation that had surrounded their introduction at Adelaide's two older 'sisters', the University of Sydney and the University of Melbourne. ${ }^{3}$

In terms of the overall educational project of the University of Adelaide, however, there is ample evidence to suggest that languages were part of the institutional ethos from the very beginning. As already noted, it was only in 1887 that undergraduate students were allowed to count the study of French and German towards the requirements of the Bachelor of Arts; but given that European languages featured in a number of the examinations conducted by the institution, and given the involvement of various members of staff in the setting and marking of these examinations, the part languages played in the early intellectual and administrative life of the University was far from negligible. At the

\footnotetext{
${ }^{2}$ I. Barko \& A. Martin, 'A Short History of the Teaching of French in Australian Universities', in P. Lane \& J. West-Sooby (eds), Traditions and Mutations in French Studies: The Australian Scene (Mount Nebo, Boombana Publications, 1997), p. 23.

${ }^{3}$ As documented by Barko \& Martin in their 'Short History of the Teaching of French in Australian Universities', pp. 25-30.
} 
very least, their role appears to have been much more significant than is suggested by Victor Edgeloe in his (admittedly brief) account of French and German during the first hundred years of teaching at the University of Adelaide. ${ }^{4}$ Edgeloe's history of these two languages essentially begins in December 1886, with the changes that were made to the regulations for the Bachelor of Arts allowing students for the first time the option of counting the study of English, French and German languages and literatures, along with the national histories of their countries, towards the requirements for the degree. This was undoubtedly a significant moment for modern languages, but it was also the result of a certain momentum that had been gathering thanks to various developments that had taken place during the 1880s, at the matriculation level and more generally within the University. It is important to remind ourselves of this context, and to acknowledge the contribution made to modern languages in those early years by a number of key figures at the University of Adelaide.

Already in 1876, the very first matriculation examination had identified French and German as 'special subjects', together with Latin and (Ancient) Greek. They remained optional subjects in the 1877 version of the matriculation examination, in which candidates were required to undertake Latin, Mathematics, English Language, English History and Geography, but could also present for examination in any or all of a number of other subjects: Natural Philosophy, Chemistry, Natural History and one of Greek, French or German. When the University Primary Examination was established in 1878, following the model of the Oxford and Cambridge Local Examinations, French and German comprised one of the five Divisions in which students needed to demonstrate their level of general education. ${ }^{5}$ The same languages also featured in the various other examinations that were introduced during the 1880s: the Junior and Senior Public Examinations, the Higher Public Examination and the University Scholarships Examination, to name the main ones.

\footnotetext{
${ }^{4} \mathrm{~V}$. A. Edgeloe, French and German in the University of Adelaide during the University's first hundred years of teaching, 1876-1975: a brief account (Adelaide, University of Adelaide, 1990), pp. 1-2.

${ }^{5}$ The five divisions were as follows: Division A - The History of England and English Literature; Division B - Latin and Greek; Division C - French and German; Division D - Mathematics (Arithmetic, Algebra, Geometry); Division E - the various science disciplines.
} 
Languages were in addition a recognised area of study in the various undergraduate degrees that came into effect during the 1880s, either as a prerequisite for entry to the degree (or for taking it out), or as an optional subject within it. When the Bachelor of Science degree was introduced in 1882, for example, room was allowed in the first-year curriculum for the study of French and German ${ }^{6}$ - a point worth noting, since modern languages would not be allowed to count towards the Bachelor of Arts until five years later. A pass in 'one other language' at the Senior Public Examination was also required for students to take out the Bachelor of Music degree, which was introduced in 1887. And in order to gain entry to the Bachelor of Medicine, which commenced in 1886, a pass in Greek, French, German, Italian or 'any other Modern Language' at the Preliminary Examination of Medical Students was sufficient to fulfil one of the five requirements. ${ }^{7}$ Clearly, the study of modern languages was both valued and encouraged by the University in its early years of operation.

The numbers of students presenting for the various examinations in French and German were small but nevertheless significant in the context of the times. In 1881, for example, the year in which women were admitted for the first time as undergraduate students at the University, 4 boys and 1 girl presented for the French matriculation examination (March and December sessions combined), with 25 boys and no girls presenting for the German examination. This means that just over half of the 58 matriculation candidates took French or German as one of their optional subjects. For the University Primary Examination in that same year, 9 girls and no boys presented for French, with 1 boy and 3 girls presenting for German. In 1882, all examinations combined, there were 17 candidates for French ( 6 boys and 11 girls) and 33 for German (all boys). The following year, the figures were 26 candidates for French ( 4 boys and 22 girls) and 14 for German (10 boys

\footnotetext{
${ }^{6}$ In their first year of study, students in the Bachelor of Science had to pass in two of Latin, Greek, French or German. The records show, however, that most science students, in those early years, chose to present for examination in Latin and Greek. It is only in the 1886 Calendar that we find French and German examination papers for the BSc, which suggests that there were no candidates prior to that.

${ }^{7}$ As indicated in the 1887 University Calendar, the Preliminary Examination of Medical Students required students to sit for papers in English, Latin, Elements of Mathematics, Elementary Mechanics of Solids and Fluids, and one of a number of optional subjects, as follows: Greek, French, German, Italian, any other Modern Language, Logic, Botany, Zoology and Elementary Chemistry.
} 
and 4 girls). To contextualise these numbers, the Annual Report for 1881, which is reproduced in the University Calendar for the 1882 'Academical Year', records that 38 students matriculated (in the March and December 1881 examinations combined); in 1882, there were 48 candidates for matriculation, whereas in the BA 4 students commenced, 3 completed first-year, 1 finished second-year, and 2 passed their third year. It is interesting to note the strong numbers of candidates for German in this first decade of the University - in all likelihood a reflection of South Australia's unique heritage. The candidate numbers for that period also reflect a distinct gender bias, with boys gravitating towards German and girls towards French - a trend that can be detected at various stages throughout the longer history of the two languages at the University of Adelaide. Be that as it may, it is clear that there was a significant amount of study taking place in French and German during the early years of the institution, albeit at the non-matriculant level.

As noted above, the records also indicate that there was a good deal of expertise in French and German available among staff on campus, and that this served to provide what we might call today the 'quality control' for the study of language and literature in those subjects in the days before dedicated appointments were made and regular teaching commenced. Some of the leading figures in the institution's early history are listed as having had responsibility for the various examinations in French and German. ${ }^{8}$ None other than the Elder Professor of Mathematics, Horace Lamb, was the examiner for German from 1882 until October 1885, when he left the University to take up the Chair of Pure Mathematics in Owen's College, Manchester. In the ten years following his departure, it was the Hughes Professor of English Language and Literature, and of Mental and Moral Philosophy, Edward Vaughan Boulger, who served as examiner for both German and French. Boulger, who was one of the prime movers in establishing some teaching in modern languages, as we shall see below, was also responsible for the two language examinations at the BA level, once French and German were permitted as third-year subjects for the degree (from 1887). Others responsible for the German examinations in the 1880s and 1890s were Adolph von Treuer,

8 That is to say, for the pre-undergraduate level examinations already mentioned above: the matriculation examination, the University Primary Examination, the University Scholarship Examination and the Junior and Senior Public Examinations. 
who, like Lamb, was a member of Council (first elected 5 December 1877), and who also examined in Geography, John Anderson Hartley, likewise a member of Council (first appointed 11 November 1874) and Inspector General of Schools, not to mention future Vice-Chancellor (1893-1896), and William Mitchell, who had succeeded Boulger as Hughes Professor of English and who, would go on to become Vice-Chancellor (1916-1942) and then Chancellor of the University (1942-1948). It is worth noting that, in his first public address (1895), Mitchell, who also examined for French, had emphasised the contribution that the study of foreign languages could make to the appreciation and mastery of English - an enlightened view that remains as valid today as it was in 1895. Mitchell's personal involvement as examiner in modern languages was an eloquent illustration of his commitment to that philosophy. Other notable figures to examine for French were Frederick Augustus D'Arenberg, MA, who was a member of the Senate, and the University Registrar himself, J. (John) Walter Tyas. These distinguished scholars and officers of the University had clearly received the kind of rounded education that made such 'multi-tasking' possible.

It is interesting to note, however, that the University of Adelaide did not hesitate to seek more specialised help, when it was available, from the Universities of Melbourne and Sydney. Among those who served as examiners for French and German was Edward Ellis Morris, who was Professor of Modern Languages and Literatures at the University of Melbourne from 1882 until his death in 1902. A. F. Morrison, who assisted Morris in the teaching of modern languages at Melbourne in the 1890s, also served as examiner at Adelaide, as did the man who succeeded Morris as teacher of French at the University of Melbourne, Ferdinand Isidore Maurice-Carton. Emil J. Trechmann, an Oxford graduate with a $\mathrm{PhD}$ from Heidelberg who taught French and German at the University of Sydney from 1889 to 1903, was similarly called upon to serve as examiner at Adelaide from 1890 to 1902. He might perhaps have made a more enduring contribution in this capacity had he not left the University of Sydney under a cloud following an enquiry into his teaching. ${ }^{9}$ Be that as it may, this use of external examiners which also included members of the Adelaide community - provides an early

\footnotetext{
${ }^{9}$ On Trechmann, see Barko and Martin, 'A Short History of the Teaching of French in Australian Universities', p. 30.
} 
example of inter-institutional cooperation and of what we know today as 'benchmarking'. ${ }^{10}$

The curriculum that these specialists and 'non-specialists' alike had to examine was a sign of the level of scholarship they possessed in French and German. While the focus was firmly on the written language, the depth of knowledge that students had to acquire was impressive by anyone's standards. The list of texts set for study each year included works of literature along with grammar books; as the curriculum developed, during the 1880s and 1890s, works on philology, literary history and the national histories of France and Germany were added to the mix. The examination papers were, as a result, quite demanding: in addition to questions on grammar and aspects of philology, students were required to translate several quite lengthy extracts from their literary texts as well as other unseen passages into English, and also to translate sentences or longer passages from English into French or German. Some of this involved 'sight' translation, which is no easy task. There was little by way of actual literary analysis in that early period, though in the BA Examination for French to be found in the 1893 Calendar, students were asked a set of questions on Beaumarchais's play Le Barbier de Séville that for the first time required them to exercise some critical judgment:

Describe the plot of the 'Barber of Seville'. What merits, if any, does it possess as a literary work. Refer to any passage in it which you consider witty. When did Beaumarchais live, and how far did the circumstances of the time affect his work?

The German examination in that same year likewise involved the analysis of 'the character of any prominent personage' of Schiller's 1798 play, Wallensteins Lager. It was not until 1900, however, following the appointment of the first Lecturer in German, that more sophisticated and systematic literary analysis was

\footnotetext{
${ }^{10}$ One interesting figure to serve as examiner for French (as well as Geography) was LieutenantColonel George Le Mesurier Gretton, Esq., who would later write a book entitled The Campaigns and history of the Royal Irish regiment. 'Additional examiners' who were employed for French in the period from 1901-1917 (that is, prior to the appointment of the first Lecturer in French, John Crampton) included a number of women: Mrs E. von Bloomberg Bensley (1902-1903) (Edward von Bloomberg Bensley was Hughes Professor of Classics), Miss Violet de Mole (1907-1911), Miss E. A. Allen (1912-1913), along with the aforementioned Maurice-Carton of the University of Melbourne (1904-1906 and 1914-1916) and John Crampton himself in the year before his appointment (1917). On the German side, it was A. J. Schulz, a Lecturer in Education, who served as additional examiner in the period 1909-1920 (that is to say, until he took on the duties of lecturing also in German).
} 
formally specified in the curriculum for German, with French soon following suit.

Despite the early focus on grammar and translation, students preparing for the BA Examination would nevertheless have developed a strong knowledge of the rich literary traditions of France and Germany through the study of literary history and of the canonical works in those two languages: writers such as Molière, Racine, Corneille, Boileau, Voltaire, Beaumarchais, de Maistre, Hugo and Sand featured regularly in the French curriculum, both at the matriculation level and for the BA and BSc; and Lessing, Goethe, Hauff, Schiller and Heine were prominent in the German curriculum. ${ }^{11}$ Students presenting for the third-year examination of the BA, at both Pass and Honours levels, were also required to demonstrate their knowledge and understanding of the national history of the country whose language they had studied. The focus in the French curriculum was on the reign of Louis XIV and on the French Revolution, whereas for German it was the Middle Ages and the Thirty Years War. Anyone who passed those examinations would certainly have earned their stripes.

How the students managed to develop their knowledge and skills in French and German in that early period of the University is another matter altogether. Because there were no dedicated appointments until 1899 for German and 1918 for French, there were no formal lectures in those subjects for students to attend on a regular and ongoing basis, though it is known that some tuition in European languages did take place within the Elder Conservatorium, most notably for voice students (for obvious reasons). As mentioned above, however, there were some early attempts to establish classes in French and German, thanks largely to the efforts of two men: J. A. Hartley, a member of Council and future Vice-Chancellor, and E. V. Boulger, Hughes Professor of English and the second member of the teaching staff at Adelaide to be elected to the University Council.

The versatile Boulger had been trained in the Classics at Trinity College, Dublin, where he had also read for history, political science and English literature. He had then studied at universities in Canada and Germany before going on to serve as Professor of Greek at Queen's College, Cork, where he also acted

\footnotetext{
${ }^{11}$ Silvio Pellico's Le mie Prigioni was regularly set for Italian, but the fact that no Italian examination papers are reproduced in the University Calendar for this period suggests that no candidates presented themselves for Italian.
} 
as Professor of Modern Languages for a year. ${ }^{12}$ Given this background, it is not surprising to find that Boulger quickly became an advocate for the teaching of languages at Adelaide following his appointment in July 1883. From the records, we can surmise that he wasted no time in beating the drum for this cause, and that he soon managed to persuade Hartley to take up the cudgels. The Education Committee Minutes for 13 June 1884 note that there was discussion of a motion by Hartley, referred to them by Council, ${ }^{13}$ regarding the feasibility of making arrangements for classes in modern languages:

Mr Hartley said that Professor Boulger had expressed to him his willingness to give instruction in French and German in the first instance in order to try the experiment of founding such classes and that without raising any question of payment. Mr Hartley suggested that the fees paid by students should be paid to the lecturer or teacher as an honorarium. After some discussion it was resolved to recommend that the idea of forming a German class should be postponed for the present but that a class for French shd be established under Professor Boulger - the success (or otherwise) of which would be a guide as to the future establishment of a German class.

Boulger was, in fact, of the view that it would be preferable for the University to hire a teacher who was not engaged in other work to teach languages, as soon as it could afford the necessary funds. But in order to get language teaching off the ground, he indicated that he was willing to take on the task of offering French classes, in addition to his other duties, starting in third term 1884. The proposal was accepted and the Registrar was duly instructed to insert advertisements for these new French classes in the two daily newspapers. If these classes were a success, Boulger hoped that an instructor might then be engaged, and suggested that the appointee should be a Frenchman. ${ }^{14}$

And thus the Professor of English had the distinction of being the first person at the University of Adelaide to teach French. Boulger conducted two

\footnotetext{
${ }^{12}$ For more information on Boulger, see the entry on him in the Australian Dictionary of Biography, available on-line at: <http://adb.anu.edu.au/biography/boulger-edward-vaughan-3030/ text4445>.

${ }^{13}$ The Minutes of the Special Council Meeting held on 9 May 1884 record a notice of motion from Hartley: 'That it is desirable for the University to give instruction in French and German and that the Education Committee be requested to report whether it is possible to make arrangements for classes in these subjects.'

${ }^{14}$ These views are recorded in the Education Committee Minutes for 16 June 1884.
} 
series of classes, in his room, during that third term of 1884: a day class devoted purely to French literature (a course of 10 lectures, held on Fridays at 4.30 pm, commencing 20 June); and two evening sessions on matters grammatical (a course of 20 lectures held on Tuesdays and Thursdays at $8.00 \mathrm{pm}$, commencing 24 June). In the event, the evening classes were much less successful than the day sessions. Whether this reflected a particular preference for literature or a certain reluctance on the part of students to attend lectures at 8 o'clock in the evening remains a matter for speculation, but the result of this experiment was that, while the afternoon classes continued in 1885, the language classes were dropped. Nevertheless, languages were now on the agenda, and on 19 August 1885, the Education Committee met to discuss the question: 'Whether it were practicable to give instruction in Modern Languages - and whether it were desirable to make two modern languages optional instead of Greek in the Arts course.' In the timehonoured manner, the question was deferred until further information could be gathered, and the Registrar was requested to prepare a report on the subjects required by the Universities of Melbourne, Sydney, New Zealand and Adelaide for matriculation examinations and for the BA and BSc degrees.

Unsurprisingly, the push for languages suffered a loss of momentum at this point, though some changes would eventually be made (making modern languages a possible replacement for Greek, for example, or including them as subjects in the BA as from 1887). Teaching nevertheless continued, with evening classes offered in most years during the late 1880s and into the 1890s, in both French and German. These classes were open to students as well as to the general public, on a fee-paying basis, and were delivered either by staff of the University or by appropriately qualified members of the wider Adelaide community. In 1886, for example, Council appointed Monsieur A. G. Aucher of North Adelaide to give a series of 25 lectures for French, and Herr Kirchner to give the same number of lectures for German. ${ }^{15}$ In 1890, Boulger returned to the fray, delivering 13 evening lectures on French; in 1894, 30 lectures were presented on French by a Monsieur Calais and 30 on German by Herr Rechner. Numbers were not always sufficient

\footnotetext{
${ }^{15}$ It is interesting to note that Hartley opposed Aucher's reappointment the following year, for reasons that are not explained. The Council Minutes for 11 March 1887 simply record that 'Mr Hartley desired that his vote might be recorded against the appointment of M. Aucher.' The appointment nevertheless went ahead.
} 
to ensure that these evening classes were held, in French or German, but in some years enrolments outstripped those in a number of the more prominent curriculum areas. In 1886, for example, 12 people (not studying for degrees) attended the evening lectures presented by Monsieur Aucher - an enrolment figure better than those for English Literature, Mineralogy and Senior Mathematics, though second to the numbers in Junior Mathematics (16). In 1890, 10 non-graduating students attended Boulger's French lectures compared to 4 for English Language and Literature, 2 for Latin and 1 for Mental and Moral Science. Classes in these other subject areas were, of course, available to students during the day-time as well, in contrast to French and German. Apart from these rare opportunities to attend evening lectures, then, undergraduate students were left largely to their own devices when it came to preparing the curriculum in French and German for the BA or the BSc. ${ }^{16}$ Long before this kind of learning was articulated as a 'graduate attribute', language students had no choice but to develop autonomous study skills!

\section{FOUNDING THE DisciPLINES}

At the end of the nineteenth century and at the beginning of the twentieth, building on this early momentum, a number of landmark decisions would lay the foundations for the establishment of French and German as mainstream disciplines of study within the Faculty of Arts. The first of these developments related to the curriculum. As has already been noted, the regulations for the BA were modified in December 1886 so that, from 1887 onwards, students could count modern languages towards their degree. The new regulations required BA students in their first year to study Latin, (Ancient) Greek, Elementary Pure Mathematics, Elementary Physics, and English Language and Literature. In second-year, the curriculum comprised Latin, Greek, Elementary Applied Mathematics and Logic. Some choice was available in third-year, however, with students simply required to complete three of four possible subjects (two, if one of them was in Honours): Classics and Ancient History, Mathematics, Mental and Moral Science, and

\footnotetext{
${ }^{16}$ Classes were, of course, available to students at the non-matriculant level. The timetable published in the University Calendar for 1890, for example, shows that there was a class for students undertaking the Senior Public Examination in French (Thursdays from 2 to 5) and in German (Fridays from 2 to 5$)$.
} 
Modern Languages, Literature and History. As two of the three languages on the syllabus (English, French and German) were needed to constitute the subject of Modern Languages, this effectively meant that each, individually, could represent no more than one-sixth of the third-year curriculum. It also meant that students had to complete two languages at Honours level if they wanted to achieve Honours overall in Modern Languages. Despite these constraints, however, and notwithstanding the fact that numbers were at first relatively low, ${ }^{17}$ the inclusion of French and German in the third-year curriculum of the BA represented an important milestone for modern languages at the University.

In view of this curriculum development, and taking into account the longstanding interest in French and German on the part of students at the matriculation and pre-matriculation levels, it might be considered that the University was then somewhat tardy in appointing dedicated teaching staff to those languages, notwithstanding the various experiments and initiatives outlined above. Be that as it may, when such appointments were eventually made - 12 years after the introduction of modern languages to the BA curriculum in the case of German, and 31 years in the case of French - some genuine impetus was finally given to language study at the University.

The first such appointment was made in 1898, in the context of the expansion of the University's teaching program that resulted from Sir Thomas Elder's 1897 bequest. Serendipitously, a German scholar of some note arrived in Adelaide in that year of 1897 to take up duties as Pastor of St Stephen's Lutheran Church in Pirie Street. Ernst Johann Eitel (1838-1908), or Ernest John Eitel as he was also known, had arrived not from Germany but from Hong Kong, where he had been head of the education department and had also served for two years as private secretary to the Governor, Sir John Pope Hennessey. His interest in education had stemmed from his service as a missionary in China and Hong Kong. A native

\footnotetext{
${ }^{17}$ As noted by Victor Edgeloe (French and German in the University of Adelaide, pp. 1-2), the record of enrolment in the 1890s was as follows:

1890: two students took two of the three language subjects (Pass level), though it is not known what combination(s) they studied;

1891: one student achieved Honours (Class I) in French and German - Agnes Marie Johanna Heyne; 1892: one student took English and German (Pass level);

1894: one student achieved Honours (Class I) in French and German;

1895-1899: there were no candidates for Modern Languages at either Pass or Honours level.
} 
of Württemberg, he had studied as a young man at the Theological Seminary at Schönthal before entering the University of Tübingen, from which he graduated in 1860 with the degrees of Master of Arts and Doctor of Philosophy. He then went on to become vicar of the State Church of Württemberg, but left after twelve months, with the blessing of his church, to undertake work as a missionary at the Basel Mission in China. In April 1865, he transferred to the London Missionary Society at Guangzhou to take responsibility for the Boluo Mission and the Hakka villages outside Guangzhou. All in all, Eitel spent some 16 years in China, where he occupied the position of superintendent of the various mission schools. In 1878, he took up an appointment as head of the education department in Hong Kong, a position he held until 1897, the year of his departure for Adelaide. Over the course of this extended period of service in the Orient, Eitel became deeply interested in Chinese language and culture, and published a number of books, including A Chinese Dictionary in the Cantonese Dialect (1877), drawing on previous work undertaken by James Legge and Samuel Wells Williams, ${ }^{18}$ and studies on topics as diverse as Buddhism (1873), Feng-shui (1878) and the history of Hong Kong (1895). ${ }^{19}$

Having retired from Imperial service in 1897, Eitel came to Adelaide where his work at St Stephen's Lutheran Church brought him into close contact with the German-Australian community. Under his stewardship, the Lutheran parish soon prospered to the point where St Stephen's was no longer considered adequate to cater for the growing needs of the parishioners, and in 1899 the foundation stone for a new church in Wakefield Street was laid. That church still stands today. Eitel's work attracted the attention of some of the leading figures of the town, and of the University. At that stone laying ceremony, as reported in the obituary for Eitel published in The Advertiser on 11 November 1908, the day after his death, 'Sir Samuel Way made eulogutic [sic] references to Dr Eitel's great life-work, and said

\footnotetext{
${ }^{18}$ Legge had previously compiled a Kangxi Dictionary. Williams expanded on this work with his Cantonese glossary dictionary: Tonic Dictionary of the Chinese Language in the Canton Dialect (written in 1856).

${ }^{19}$ The details of Eitel's main publications are as follows: Three Lectures on Buddhism (London \& Hong Kong, Trübner \& Co \& Charles A. Saint, 1871), revised and published under the title Buddhism: Its Historical, Theoretical and Popular Aspects in 1873 (a 3rd edition was published in 1884); A Chinese Dictionary in the Cantonese Dialect (Hong Kong, Lane, Crawford \& Co, 1877, 2 volumes); Feng Shui: or, The Rudiments of Natural Science in China (Hong Kong, Lane, Crawford \& Co, 1878); Europe in China: The History of Hong Kong From the Beginning to the Year 1882 (Hong Kong, Lane, Crawford \& Co, 1895).
} 
that under his pastorate it was small wonder that the Pirie-street church should have become too small.' Given his distinguished background, his prominent role in the church and his links with the German-speaking community, not to mention the support of people such as Samuel Way, William Barlow and William Mitchell, it is not surprising that the Reverend Eitel was chosen to fill a position as part-time lecturer in German at the University of Adelaide. ${ }^{20}$

Eitel's appointment, which was made in 1898, was to take effect in 1899. However, as there were no undergraduate students in German in that first year, his teaching was limited to a series of evening lectures - a situation that did not last long. Under Eitel, the curriculum for German at the BA level did not change radically, but he was responsible for bringing a degree of sophistication to the study of literature. The list of texts set for the 1901 German Examination, for example, published in the 1900 Calendar (p. 63), is preceded by the heading: 'Books specially set for criticism'. Following the list, in parentheses, is a definition of what this means: 'By criticism is meant (1) critical history of the work, (2) critical analysis of its contents, (3) critical estimate of its value'. This is an important innovation that can only be the result of Eitel's appointment (no such indication is included in the French syllabus during the period of his tenure). Following Eitel's appointment, the Calendar entry for the German BA syllabus also specifies for the first time that classes will be held (presumably during the day-time): 'The course of lectures is begun every year, and is completed in two years.' The fee is also indicated: $f^{4} 4.4$ s. (or 14 s. per term). ${ }^{21}$ German now had a formal and more central presence within the institution.

As the Calendar entry just quoted indicates, the place of German and French within the curriculum of the BA had evolved during the period when Eitel was teaching. Where they had previously been 'half subjects' for the third-year examination, French and German became full-scale individual subjects from 1907

\footnotetext{
${ }^{20}$ His letter of acceptance suggests otherwise, but it was clearly not a full-time position. On 23 October 1899, he wrote to the Registrar: 'In reply to your letter No. 1057 of 20th inst. Asking, by direction of the Council, of the Adelaide University, if I would accept an appointment as Lecturer on German for the ensuing year at an honorarium of $£ 100$ with the understanding that, failing any students in German, I give a course of Extension Lectures, I have the honour to inform you that I am writing to accept the position on the terms mentioned.' (Letters to the Registrar, No. 854 1899).

${ }^{21}$ In contrast, the entry for French, where there is still no dedicated teaching appointment, notes: 'No course of lectures is at present provided, but an annual examination is held.'
} 
onwards, to be completed over two years, with a pass in the first year required before students proceeded to the second year of study. Interestingly, from 1909 onwards, the syllabus also specified that students in second-year, in both French and German, were required to answer all questions in the target language, with the obvious exception of translations into English. One of the distinctive and enduring features of modern European languages at the University of Adelaide has been the use of the target language in class and in student work; the fact that lectures would be delivered in French, for example, is specifically mentioned in the syllabus entries for that subject area right throughout the ensuing decades, and this remains the practice in the discipline today. The examination requirement introduced in 1909 is therefore an early sign of what would become a long-standing tradition.

Sadly, following the death of Eitel in 1908, at the age of 70, no one was appointed to replace him, and there was still no one to lecture in French. That situation would be remedied at the end of the World War I, with appointments first in French and then in German. It was with these teaching appointments that the two disciplines of study finally received due and proper recognition, and were set firmly on the path to establishing a more stable and enduring presence within the University.

\section{Consolidation}

In 1918, John Crampton commenced duties, having been appointed in 1917 as 'Lecturer in French language in the University and Teacher of French in the Elder Conservatorium'. ${ }^{22}$ Two years later, Adolf John Schulz, who was Principal of the Teachers' Training College and who had been part-time Lecturer in Education at the University since 1910, was given the extra duties of teaching the two-year course in German. Although at that stage neither appointment was properly full-time - Schulz's other commitments kept his involvement in German to a relatively modest level, and Crampton's duties would only become a full-time occupation following the addition of a third-year course in French in 1924 and the introduction of evening classes in the subject in 1927 — both languages would nevertheless consolidate their presence in the curriculum of the BA under the stewardship of these two men.

\footnotetext{
${ }^{22}$ As recorded in the Annual Report for 1917, published in the 1918 University Calendar.
} 
Of the two, it was John Crampton who would have the more significant impact, as, unlike Schulz, he was able to devote all of his attention to the teaching of language and literature. A native of the north of England, he had completed a Bachelor of Arts at the University of London before immigrating to Australia. Crampton's training, as Edgeloe surmises, was almost certainly in the Classics, given his involvement with the Classical Association of South Australia during the 1920s, as a member and committee man. It is also known, however, that he had earlier spent some time in Paris studying at postgraduate level. While he did not go on to qualify for an award, his time in France was clearly instrumental in developing his knowledge and appreciation of French language and culture to the level required to teach them. Exactly when he arrived in South Australia is not known, but Edgeloe notes that 'by 1892 he had acquired a fruit block at Renmark'. ${ }^{23}$ At some point he obviously made the move to Adelaide and was identified as the right man for the job when the University finally decided to make its first dedicated appointment in French.

During his long tenure in that position, Crampton introduced a number of significant curriculum changes, and student numbers grew to healthy levels. This allowed him in 1924 to relinquish his teaching duties at the Elder Conservatorium and to devote all his efforts to the development of the BA curriculum for French. Classes were now offered on a more regular basis, both during the day-time and in the evening. In each year of the two-year French course, students were required to attend lectures in language and composition twice per week. In the second year, they had to attend in addition lectures on the history of French literature. The Calendar entries also specify that the lectures 'will be in French' and that, as had been the practice since 1909, students in second-year would be required to answer all questions (except for translations into English) in the target language. Most of the elements of the previous curriculum were retained (translation both ways, the study of literary texts) but there was a new emphasis on spoken French. Phonetics was added to the curriculum in the first year of the course, and a conversation test was added to the traditional reading test at the end of the first- and second-years. Students in both years also had to memorise selections from Spiers' Senior French Reader. Philology featured prominently in both years as well, through a focus on

\footnotetext{
${ }^{23}$ V. A. Edgeloe, French and German in the University of Adelaide, p. 11.
} 
historical grammar. Literary texts were set not just as a source of language work, but as objects of study in their own right, with a strand on the history of French literature now a central part of the second-year curriculum. A third-year course was introduced in 1924, devoted exclusively, at first, to the literature and history of a particular century (the seventeenth century in 1924, the eighteenth in 1925, the nineteenth in 1926). A language component would be added to third-year French in 1927, with students required to do composition with the second-year students. It was also in 1927 that students in first-year French ${ }^{24}$ were required for the first time to attend group tutorials 'for exercises in oral French, including conversation, reading, and dictation. ${ }^{25}$

This focus on spoken French would receive a further boost in 1930 with the appointment of John Crampton's only daughter, Hope, as Assistant Lecturer and Tutor for French Language. Mary Hope St Clair Crampton was born in Renmark on 18 May 1901 and, having received some early schooling from her father, completed her secondary education at Girton Girls' School. She then went on to study Arts at the University of Adelaide, where she completed her BA in 1923 with Class II Honours in Classics and credits in English III, French III and Philosophy. She subsequently enrolled in an MA, which she was awarded in 1927. Her thesis was a comparative study of Shelley and the French Parnassian poet Leconte de Lisle. In that same year, she won a free passage to Europe from the British Passenger Lines, for the purpose of continuing her studies, and spent two years in Paris, where she earned a Diploma from the Institut de Phonétique in Paris.

Hope Crampton's main brief, when she was appointed, was to foster the development of speaking skills in French. One of her more important duties was to establish a 'French Language Club', where students could practise their oral skills, and this she promptly did in her first-year of teaching (1930). The Adelaide University French Club has been in operation ever since, but participation in it is now an optional, extra-curricular activity. Back in 1930, its meetings played a

\footnotetext{
${ }^{24}$ It was only in 1933 that the individual years of the three-year course were given the nomenclature French I, French II and French III. This change in nomenclature was of course adopted across the undergraduate curriculum. The two-year course in German likewise became German I and German II at that same time.
}

${ }^{25}$ As noted on p. 10 of the 1927 Calendar. 
central part in the curriculum, as the Calendar entry for that year makes clear: 'All students are expected to attend regularly once a week the French Language Club, in which all conversation is in French.' Matters of a general nature were discussed at these meetings, with students also encouraged to practise their French by playing games and acting out scenes from plays by Molière and the like. The annual French Club play, which has been an integral part of campus life for many decades now, has its origins here. Literature was also a regular subject of conversation, and from 1933 onwards, students were required to read a work of 'popular' fiction (namely, Maurice Leblanc's Arsène Lupin) for discussion at French Club. The timetable specifies that the meetings were to take place on Thursday evenings, 'at an hour to be arranged. Each session of the Club will be of two hours' duration. First-year students will be required to attend in addition an oral class of one hour's duration on alternate Saturday mornings, at an hour to be arranged'. Attendance at French Club, as it was renamed in 1952, would remain compulsory for undergraduate students from 1930 until 1958 - three years before the retirement of Hope Crampton, at the age of 60, in 1961. ${ }^{26}$

By all accounts, Hope Crampton was a colourful figure possessed of what is euphemistically referred to as a 'strong character'. A sketch of her made by Ruth Tuck, and which hangs in the Discipline of French today, shows that she had a piercing gaze, but with a mischievous twinkle. Departmental meetings between Hope and her father John, who had the reputation of being a quiet and selfeffacing man and something of a recluse, must have been interesting affairs. Hope nevertheless proved to be a good foil for her father. She generated a great deal of enthusiasm for all things French, and is remembered as a teacher who was lively and engaging, if at times somewhat unnerving. One of her former students, Margaret Denat (née Johnson), writes in her obituary of Hope, who died on 8 August 1996 at the ripe old age of 95:

As a teacher she was infectiously enthusiastic in her presentation of writers she liked, and devastatingly dismissive of those she did not. She had a passion for the well-turned phrase and a distaste for the pedantic. A badly-

\footnotetext{
${ }^{26}$ Because French I students had dedicated oral tutorials, they were exempted from attendance at the French Language Club meetings from 1933. It nevertheless remained compulsory for students in French II and French III until 1958.
} 
written essay would earn, 'You have indeed shown us what French prose can be', with a glare from her famous lorgnette. ${ }^{27}$

The year after Hope Crampton's retirement, the French Club provided $£ 100$ in order to establish a prize in her honour. It stands as an enduring reminder of her contribution to French at the University and of her role as founder of the club, for which she was the driving force for over thirty years.

The creation of the French Club was not the only pioneering feature of Hope Crampton's long association with the University of Adelaide. In terms of the curriculum in French, she took responsibility for the oral work her father had introduced in 1927, adding classes in phonetics at all three levels and extra conversation tutorials for French I students. ${ }^{28}$ The annual oral examination grew in importance under her tutelage, with a pass in both oral and written French required at any given level before students could count their course as a unit towards the degree. ${ }^{29}$ As a woman on the staff of the University, Hope was also something of a rarity back in those days. Other women had previously been involved with the teaching and examining of French - Violet de Mole and E. A. Allen had served as 'additional examiners' from 1908 to 1912 and from 1913 to 1914 respectively, and Maria Luisa Masullo taught French and Italian at the Elder Conservatorium from 1926 to 1945 — but Hope Crampton certainly has the distinction of being the first woman to be appointed to a position in modern languages at the University of Adelaide. ${ }^{30}$ She is also the first member of staff in

\footnotetext{
${ }^{27}$ Margaret Denat, 'Don't you dare write me a dull Obituary! Mary Hope St Clair Crampton 18 May 1901-8 August 1996', The Adelaidean, 23 September 1996, p. 7.

${ }^{28}$ The 1931 timetable indicates that first-year students had a class in phonetics on Tuesdays from 6 to $7 \mathrm{pm}$ followed by an oral tutorial from 7 to $8 \mathrm{pm}$. Students in second- and third-year were required to meet on Thursday evenings for oral work - this was presumably the meeting time of the French Language Club.
}

${ }^{29}$ As from 1934, students in French III, for example, had to complete a dictation test and discuss questions on the laws of pronunciation, as well as read and comment on a passage from one of the set authors and discuss questions of literary history. Questions on pronunciation were added to the oral examination in 1935.

${ }^{30}$ She was not, however, the first woman appointed to teach French at a university in Australia. In 1911, when teaching began at the University of Queensland, a lectureship in modern languages was created and the post was filled by a woman, Hermiene Ulrich. In 1921, Gladys Marks was appointed Lecturer in French at the University of Sydney, where she remained 'second in charge' to Professor G. G. Nicholson until 1943. And in 1928, Margaret Clarke was appointed to replace George Irving at the University of Western Australia, and remained in charge of French until her resignation in 1940. For further details on these three women, see Barko \& Martin, 'A Short History of the Teaching of French in Australia', pp. 36, $39 \&$ 45, respectively. 
the French discipline to record a publication, thanks to her 1935 book Gaudissart: A Guide to Better French Pronunciation and Brighter French Conversation (Melbourne: OUP). As this was a textbook, it would not pass muster today as a 'research' publication, but it was widely used in schools and for many years was a permanent fixture in the list of prescribed books for French I. Hope's promotion to Senior Lecturer in 1950 was another milestone achievement, and her 32 years of service as a teacher of French at the University would be equalled only by her father's successor, J. G. Cornell.

If the focus for this inter-war period is on French, it is because there were no significant developments in German during that time. German nevertheless maintained a steady presence in the BA curriculum throughout those years and into the 1950s, thanks to the dedicated efforts of A. J. Schulz. Following the death of Eitel in 1908, Schulz had served as examiner for German from 1910 up to his appointment as part-time tutor in the subject in 1920. He would continue to serve in that capacity, upgraded to part-time lecturer in 1946, right up to 1952, when a full-time appointment in German was finally made. The fact that he was able to keep German going almost single-handedly during all that time is testimony to his commitment and is all the more remarkable as teaching German was not his primary occupation. His main duties were as part-time lecturer in Education, a position he occupied from 1910 through to 1951. He was also Principal of the Teachers Training College (later renamed the Adelaide Teachers College) from 1909 right up to his retirement from that post in 1948. His record of service thus invites us to provide some insights into his training and the knowledge he brought to the teaching of German, as well as the character with which he went about the task.

Adolph John Schulz was born in Stepney, Adelaide, on 6 August 1883. His father was a hairdresser and tobacconist from Silesia who, on migrating to South Australia, became a member of the state's substantial Lutheran community. In 1902, Adolph Schulz began his studies at the University of Adelaide, where he completed a BA(1905) and an MA (1909). He won a scholarship that took him to the University of Zurich, where he studied for two years, completing his PhD in 1908. On his return home, he was appointed superintendent of students at the University Training College, at the relatively young age of 25. According to H. H. Penny, he 
was a brilliant scholar, who specialised in psychology, philosophy, education and languages (of which he could speak seven). ${ }^{31}$ A sign of that scholarship was his publication activity. His research was devoted to the philosophy of education and educational psychology, on which he published several books, including one in German - Sein und Bereusstsein: einige Hauptfragen der Philosophie. ${ }^{32}$ This makes him the first German teacher at the University to feature in the University's annual bibliography, albeit in a discipline other than German language and literature. Schulz was also something of an ascetic and a teetotaller, as he neither smoked, drank, danced, played sport or mixed socially with others - though 'many found him kind in their difficulties, ${ }^{33}$ If the range and longevity of his duties at the University of Adelaide are any guide, he might be said to have been imbued with the protestant work ethic.

Given his other commitments, it is not surprising to find that the German curriculum did not expand or develop significantly during Schulz's time at the helm. Where French introduced a third-year course in 1924 and Honours in 1939, not to mention an MA program in the 1940s, it was only in 1952 that German III was introduced, with Honours German established two years after that. For virtually the entire period of Schulz's involvement, the classes for German I and German II were combined, with students at both levels offered two hours of tuition per week (Wednesday afternoons at 4 or at 5 and Saturdays at 9 was the enduring pattern). The syllabus for both years was also the same, though it was a solid and rigorous course of study, and second-year students, like their French counterparts, had to answer questions in the final examination in the target language.

Schulz no doubt had many other calls on his time, so offering separate class times for German I and II would have been difficult; but this combined class was primarily the result of the small student numbers in German during that extended period. In 1923, for example, only 3 students passed in German I and the same number in German II, whereas 27 students passed French I and 10 passed French II. The following year the pass numbers were 34 for French I, 15 for French II and

${ }_{31}$ See H. H. Penny, 'Schulz, Adolf John (1883-1956)', Australian Dictionary of Biography, vol. 11 (Melbourne, Melbourne University Press, 1988), available online at: <http://adb.anu.edu.au/ biography/schulz-adolf-john-8361/text14671>.

${ }^{32}$ A. J. Schulz, Sein und Bereusstsein: einige Hauptfragen der Philosophie (Bonn, Kurt Schroeder, 1928).

${ }^{33}$ H. H. Penny, 'Schulz, Adolf John'. 
7 for French III (including Hope Crampton, as it happens), but only 1 for German I and 1 for German II. In 1927, the pass numbers were 30 for French I, 18 for French II and 9 for French III (and this was just for the BA - there were other French pass students in the BSc), but only 3 for German I and 3 for German II. To contextualise these numbers further, 52 students passed English I in 1927, 21 passed English II and 10 passed English III. At a time when English, French and German were grouped together under the banner of 'Modern Languages and Literatures', German was struggling to keep pace with its two 'sister' languages.

Whether the demand for German remained low because of the lack of a full-time lecturer and 'figurehead', or whether, conversely, the failure to appoint a dedicated lecturer to the subject was the result of low demand, is perhaps something of a moot point. Given the strength of the German community in South Australia, however, it is surprising to find that numbers in German remained modest for such a long period - several decades, in fact. ${ }^{34}$ The two wars would not have helped the cause, and would have made it more difficult for the German community to champion the teaching of their language and culture. Schulz, for his part, was deeply affected by the anti-German sentiment that emerged in Australia during and after World War I, though he continued to carry himself with dignity and to devote himself to the task of teaching German I and II with a steady hand. In view of his service to the University, it is only fitting that he should now have a building named after him, even if it is one of the more 'aesthetically challenged' features of the North Terrace campus. ${ }^{35}$ Schulz also ensured he would be remembered by bequeathing to the University $£ 4,500$ for the purpose of establishing prizes in his name and of promoting postgraduate research work in the theory of education and in the study of German language, literature and culture. The A.J. Schulz prize for German III was first awarded in 1962, to Marie-Louise Thiersch. The Honours prize in his name was shared that same year between Fred H. Dobberstein and

\footnotetext{
${ }^{34}$ One possible explanation might be that, precisely because of the strength of the German community in South Australia, a significant number of young men and women went to spend a year or so in Germany. This was certainly the case for trainee pastors from the South Australian Lutheran community, for example.

${ }^{35}$ The Schulz Building initially belonged to the South Australian College of Advanced Education, but fell under the aegis of the University of Adelaide following the realignments that resulted from the creation of the University of South Australia in 1991, in the wake of the Dawkins reforms to the tertiary education sector.
} 
Peter Paul. Schulz's death, on 5 February 1956, marked the end of an era. Like Hope Crampton, he remained unmarried - a result, perhaps, of the exclusive relationship that sometimes develops between staff members and their university.

\section{EXPANSION}

If the inter-war period saw the consolidation of the two languages at the University and in the BA curriculum - German on a steady but modest basis, French in a gradually developing mode - the 1940s and 1950s would see significant growth in both areas in terms of syllabus and staffing. French was the first to take off, with the appointment in 1938 of J. G. Cornell to the position of Lecturer in French Language. This position had become available following the resignation of John Crampton at the end of 1937 after 20 years of service, and at the impressive age of 75 (there were clearly no prescriptions at that time regarding retirement age!). Crampton had left French in a fairly strong position, with healthy student numbers and a rigorous and coherent curriculum. He was also a well respected member of the University community. Following his death in June 1946, the Chancellor, in his March 1947 Commemoration address, noted that he was 'a devoted student of languages, ancient and modern, a recluse who was our pride and an example to us all' ${ }^{36}$ It is therefore no surprise to find that, having been given notice of his retirement, the University sought immediately to replace him. The time was right for someone with vision and ambition to build on the solid foundation laid by John Crampton.

James Gladstone Cornell was just the man for the job. Born in Melbourne in 1904, he received an excellent education in the classics and in French, first at Scotch College and then, thanks to an Exhibition and Senior Government Scholarship, at the University of Melbourne, where he studied under Professor A. R. Chisholm, one of the major figures in the history of French studies in Australia. He graduated with First Class Honours in French in 1925 and was subsequently awarded the prestigious Aitchison Travelling Scholarship, which allowed him to pursue his studies at the Sorbonne, from 1927 to 1929. There, he earned the esteem of his professors for the quality of his French and his knowledge of French literature. In the final examination for the 'Licence ès Lettres', he was placed first,

\footnotetext{
${ }^{36}$ Commemoration address reproduced in the 1948 University Calendar.
} 
beating all of the French students - a feat which Gustave Cohen, the celebrated mediaeval scholar, still remembered with wonderment twenty years later. ${ }^{37}$ On his return to Australia, he was appointed Lecturer in French at the University of Melbourne, where he worked under his old mentor, Chisholm, from 1930 to 1937. The following year, the opportunity to take up a position as Lecturer-in-Charge of French at the University of Adelaide lured him to South Australia, with his wife Helen and their four daughters. A new era in French studies was about to begin.

Cornell's appointment could not have been better timed, as some significant changes to the regulations for the BA were decided in 1938, to come into effect in 1939. These provided him with the opportunity to build student numbers in French and to expand the curriculum - which he promptly did, increasing the number of courses available and establishing a solidly structured syllabus that would stand, more or less unchanged, for the following thirty years or so. It was a well-balanced syllabus, which pursued the twin aims of developing language proficiency and fostering an understanding and appreciation of French literature. In keeping with these aims, and consistent with previous practice under John Crampton, maximum exposure was given to the target language: lectures on literature continued to be delivered in French in second- and third-year, and students were required to answer all questions on literature in the final examination in French. A number of innovations, however, would give extra impetus to the discipline.

In terms of course development, Cornell's first move was to introduce an Honours degree in French Language and Literature, starting immediately, in 1939. He also redesigned the existing courses in second- and third-year to give the major a greater degree of consistency. The literature strand in French II was devoted to the seventeenth and eighteenth centuries, and the focus in French III was on the nineteenth and twentieth centuries. The introduction of an Honours program involved setting additional work for students in French II and French III, in the form of a reading course devoted to a particular period or theme (e.g. in 1939, 'Le théâtre comique depuis 1660 jusqu'à la Révolution'), and creating two new courses: Old and Middle French I (to be taken in second-year) and Old and

\footnotetext{
${ }^{37}$ According to Elliott Forsyth, whose unpublished reminiscences of J. G. Cornell are the source of some of the information provided here, Cohen was still shaking his head twenty years after the event, saying: 'Il a battu tous les Français!'
} 
Middle French II (to be completed in third-year). A fourth year was to be devoted entirely to Honours work in literature and philology.

This course pattern was in fact very much in keeping with those in operation at several other Australian universities during that period - the sequential treatment of literature, for example, on a century-by-century basis. ${ }^{38}$ The emphasis in the Honours program on mediaeval and Renaissance literature, and on historical grammar and philology, was likewise a reflection of a certain tradition in French studies at the time in Australia, though it also corresponded to Cornell's own particular interests and expertise. In any event, this new focus on the early development and evolution of the language perhaps explains why students in the Ordinary BA were now allowed to count Comparative Philology, a third-year course offered by the Classics Department, as an alternative to French III for their major in French. (In the absence of a German III course, there was no alternative to Comparative Philology for students wishing to complete a major in German.)

The requirement to complete two such major sequences, of three courses each, was one of the features of the Ordinary BA under these new regulations. Other changes that favoured the growth of numbers in languages included the requirement that one of the ten courses for the Ordinary BA should be a language other than English (in addition to at least one science subject). Candidates for BA Honours needed to pass Greek I, Latin I, French I or German I. At least one course in a modern European language was required for Honours in English Language and Literature; and, in the same vein, the ability to translate from French, German or Italian into English was a requirement for Honours in History and Politics.

The effects of these changes were immediate, in terms of both student numbers and the general standing of the discipline within the institution. There is no doubt that the introduction of an Honours program, followed shortly by the addition of a French Language and Literature syllabus for the MA, served to

\footnotetext{
${ }_{38}$ The French syllabus at the University of Tasmania, for example, had from the outset (the 1890s) been organised in this way, with the first year devoted to seventeenth-century literature, second-year to the eighteenth century and third-year to the nineteenth century, whereas sixteenth-century study was an additional requirement for 'Credit' students. The same pattern for the three-year sequence in French was established at the University of Western Australia when teaching began there in 1913, with historical grammar and Old French additional requirements for Honours students. The Adelaide model offered a slight variation from this pattern, in that a 'smorgasbord' approach was taken in French I (a mix of texts from the seventeenth century to the present time) and contemporary literature featured more prominently.
} 
enhance the status of French. ${ }^{39}$ The promotion of J. G. Cornell to Professor of French Language and Literature in 1944, was both a reward for his efforts and a further sign of the respect afforded to the discipline, which was now on a more equal footing with the other disciplines in the Faculty. This new found parity was also reflected in the Honours cohorts. For a considerable period, the numbers of students graduating with French Honours rivalled those in other subject areas. In 1943, for example, when the first two Honours degrees were awarded in French, there were only two other Honours graduates in the Faculty (both in Political Science and History). The two French graduates in question, Alison Hogben (combined Honours in French and English) and Therese Rice, were both awarded David Murray Scholarships. Alison Hogben (later Alison Gent), who had begun her Honours study in 1940 (as part of the first Honours cohort in French), would go on to serve as Tutor in the French and English departments. Therese Rice, whose Honours work (as a second-year French student) began in 1941, would likewise go on to tutor in French, after becoming the first to complete an MA (by thesis) in the subject, in 1947. She would later endow a postgraduate scholarship for Honours graduates in languages, in memory of her father. Also in that first Honours cohort were Neile Osman and a certain Jeffrie Pash. A champion sportsman (he had won the Magarey Medal in 1939), Jeff Pash would become a stalwart of the languages scene in South Australia, as a teacher of French and Latin, and then as an inspector (he is also, incidentally, the father of the current Professor of French Studies, Jean Fornasiero, who, as Jean Pash, would share the J. G. Cornell Prize for French Honours when it was introduced in 1969 - an eloquent illustration of the links formed by the accidents of history, and a sign of the distinctions that many Honours graduates in languages would go on to achieve).

Over the following years, student numbers grew in French, slowly at first, as the University's intake stagnated because of the war, and more rapidly from 1948 onwards. Numbers also grew in German, though on a more modest scale. In 1935, for example, there had been 32 passes in the French I written examination and 28 for the oral, 24 (written) and 22 (oral) in French II, and 5 (written) and 10 (oral) in French III. In German, the numbers were 1 for German I and 4 for

\footnotetext{
${ }^{39}$ Students could complete the MA in French either by undertaking course work or by writing a thesis. In 1947, Therese Rice became the first French student to be awarded an MA by thesis. E. E. Muetzelfeldt was the first to undertake course work in French for the MA, commencing in 1945.
} 
German II (there was no distinction made between oral and written examinations in German). In 1948, the figures were: 50 (written) and 66 (oral) in French I, 18 (written) and 20 (oral) in French II, and 11 (written) and 11 (oral) in French III. In that same year, there were 14 passes in German I and 7 in German II.

The staffing complement in French also began to expand. In 1945, Alison Hogben was appointed part-time tutor in French Language and Literature. She also tutored part-time in English, where she would subsequently become a fixture (from 1950 to 1974). After Hogben's departure at the end of 1946, Marcelle Ellis (with a Licence ès Lettres from Geneva) was appointed temporary tutor in French in her place. In 1950, Therese Rice was listed as a temporary part-time lecturer in French, along with Ellis. A fifth person was added to the department in 1951, thanks to the persuasive efforts of Cornell. When overseas Study Leave was introduced in 1949, he was quick to take advantage of the new scheme and consequently spent about ten months in Paris in 1951. While there, he managed to negotiate a special deal with the French authorities, as the Annual Report for 1951 records:

During his stay in Paris, Professor Cornell negotiated with the French Government the extension to Adelaide of an arrangement whereby officers of the French education system are made available as lecturers abroad for terms of three years while retaining their status, rights and privileges in that system. Taking advantage of this arrangement, we have appointed Mr. Maurice Valuet, Licencié es-lettres (Paris), as lecturer in French for the next three years. ${ }^{40}$

Valuet remained in the position for seven years, not three, and when he left at the end of 1957 he was replaced by Henri Souillac (1958-1962), who was followed by Andrée David (1962-1990), a graduate of the University of Paris who was married to an Australian. Another French native speaker to be appointed during these years was Nicole Garçon (1965-1989), a graduate of the University of Poitiers.

The scholarly dimension of the staffing profile was enhanced by the appointment of people who had graduated from Australian universities and gone on to earn doctorates in France. The first such appointment was that of Elliott

\footnotetext{
${ }^{40}$ The Annual Report for 1951 is reproduced in the 1952 University Calendar.
} 
Forsyth, who had completed his Honours degree in French at the University of Adelaide in 1947 and gone on to qualify as Docteur de l'Université at the Sorbonne. Appointed to a lectureship in 1954, and promoted to senior lecturer in 1959, Forsyth left at the end of 1965 to take up the foundation Chair of French at La Trobe University in Melbourne in 1966. The appointment of Forsyth established a pattern of hiring former graduates who had gone on to qualify for doctorates in France. Bruce Ellis, who was appointed in 1960 and would serve till 1971, had, like Forsyth, earned his doctorate from the University of Paris after graduating from Adelaide. Peter Hambly, who joined the staff in 1964 after a two-year stint as Lecturer in French at the University of Melbourne (1961-1962), was another. Hambly's appointment was a significant one, not just because of the length of service he gave to French and to the University (31 years, from 1964 to 1994, eclipsed only by the 32 years for Hope Crampton and J. G. Cornell), but also because of the distinguished publication record he would achieve during his career - a pioneering achievement for the French Department at Adelaide.

To a large degree, this expansion in the student and staff numbers in French was a product of the times. University enrolments grew substantially following World War II, and the Vice-Chancellor, A. P. Rowe, was consequently successful in negotiating a major increase in funding with the State Premier, Thomas Playford, in the early 1950s. Cornell's role in the development of French should, however, not be underestimated. After all, A. P. Rowe was hardly a supporter: he is on record as classifying French as one of what he calls the 'self-perpetuating subjects' whose usefulness he considered to be outdated. ${ }^{41}$ The high regard in which Cornell was held, both within the University and in the wider community, was surely, therefore, one of the reasons why French enjoyed such good standing during the 1940s and for several decades after that. His contribution to the University was undeniable. He was a long-standing member of the University Council (1949-1971) and a prominent figure in the life of the institution. Within the French Department,

${ }^{41}$ The following extract from his book If the Gown Fits (p. 162) is clear enough: 'A professor of French, for example, cannot be dismissed and left to starve, but a live university can note the date of his retirement and aim gradually to discard the teaching of French and, in consultation with other Australian universities, to replace it by a language which is no less a discipline, but is likely to be more useful in the world in which students have to live.' (Quoted in Elliott Forsyth, The Relevance of Rabelais: some thoughts on the place of French Studies in an Australian University, Inaugural Lecture (Bundoora [Melbourne], La Trobe University, 1970), p. 6. 
he was revered by students and colleagues for his knowledge of French and for his kind and courteous manner, although this did not prevent students from poking fun at his quirks, of which he had several. 'The Prof' or 'J. G.', as he was affectionately known, accepted with good grace the 'ragging' they gave him in the dramatic productions of the French Club, in which well-known plays were parodied. One such short piece, entitled Trois scènes de la vie cornélienne, took as its theme the master's legendary 'flexibility' with respect to time (his lectures may have had a starting time, but their duration was a much less precise affair). The fact that students felt confident to indulge in such acts of irreverence was a sign of the rapport that 'the Prof' developed with them.

Just as importantly from an institutional point of view, Cornell engaged in a great variety of what we would call today 'outreach' activities. He was President of the Alliance Française of South Australia from 1939 to 1960, and in that position provided great support to the local French community. During the war years, he gave a weekly broadcast in French on Radio Australia for the French communities of Asia and the Pacific, encouraging his listeners to rally behind the leaders of Free France. The French Government would subsequently award him the Légion d'honneur in recognition of this work. Cornell also provided leadership for language teaching in the schools, through his role as examiner for the public examinations and as foundation President of the Modern Language Teachers' Association. From 1945 to 1965, he served as Chairman of the Council of Girton School, where his daughters were educated (and where, coincidentally, his colleague in the French Department, Hope Crampton, had also studied). His interest in the arts led him to take on the role of Chairman of the University Theatre Guild, from 1952 to 1956 - a difficult time in which to promote the dramatic arts, as theatre did not feature prominently in the cultural life of the city back then. He was also known to tread the boards himself, during the early years of his career, taking on several 'leading man' roles in French theatre productions at the Alliance Française of Victoria, for example. And when the Musica Viva Society first presented concerts in Adelaide in 1948, Cornell became President of the local branch committee and continued in that role until 1983. All of these activities served to give French a status that not even A. P. Rowe could deny. 
Jim Cornell's enormous contribution is remembered in a number of ways. An Honours prize was established in his name in the year of his retirement (1969). The Cornell Chapter, which is the Creative and Performing Arts 'branch' of the University of Adelaide's Alumni Association, commemorates his work in that domain. And his books and papers have been preserved in the Barr Smith Library as the Cornell Collection. Finally, and less tangibly, his passion for all things French lives on as a source of inspiration for all of those who studied under him.

The dramatic expansion that began in French in 1939, under the leadership of J. G. Cornell, took a little longer in the case of German. But when it came, German would take the lead in many respects, particularly in terms of teaching innovations. During the 1940s and 1950s, when French was implementing its brave new curriculum, A. J. Schulz was still valiantly keeping the German fires burning, or perhaps smouldering. The numbers of students were still small, and he taught them in a combined German I/II class of two lectures per week right up until 1951. It was at this time that the fortunes of German took a turn for the better. Some years earlier, in 1946, Schulz had been upgraded from part-time tutor to part-time lecturer in German - a largely symbolic gesture but one which heralded a more significant development. ${ }^{42}$ This came in 1949, when a position of Senior Lecturer-in-Charge of German was created, as part of the A. P. Rowe expansion plan. The post remained unfilled for two years, but finally, during the course of 1951, Derek Van Abbe (or van Abbé) ${ }^{43}$ was appointed to a full-time position not as Senior Lecturer but as Reader in German, with duties to commence at the beginning of 1952. The wait would prove to have been worthwhile.

Van Abbe was born in London in 1916 and studied Modern and Mediaeval Languages at Cambridge, where he achieved First Class Honours in 1938. He then went to the University of Zurich to begin studying for his doctorate, but the war

\footnotetext{
${ }^{42}$ It is interesting to note that, in that same year (1946), a second name was included in the staff list for German. This was none other than Theodor (Ted) Strehlow, who had just been appointed Research Fellow in Australian Linguistics and Lecturer in English. It is not clear how many tutorials (if any) Strehlow actually conducted for German (the timetable still indicates only the two weekly lectures, that Schulz presumably continued to deliver); but Strehlow continued to be listed as (parttime) tutor in the subject until the end of 1949, when he left Adelaide (temporarily, as it would turn out) to take up a two-year postgraduate fellowship at the Australian National University in Canberra. ${ }^{43}$ Van Abbe's father, Salomon, had migrated from Amsterdam to England at the age of 5 and added the accent to his name when he became naturalised. The accent is not used in the University Calendars of the period, however, so we have followed that practice here.
} 
interrupted his plans and he spent the next six or seven years in the armed forces, first in the Infantry then in the Allied Intelligence Service. He came to Adelaide via the University of Tasmania, where he was assistant lecturer in modern languages in 1946 and 1947, and then the University of Melbourne, where he lectured in German from 1948 till 1951 and also studied Russian. Importantly for the fate of German at Adelaide, Van Abbe was a real scholar, with a special interest in the baroque period and several publications already to his name. In his first year at the University (1952), he published two substantial articles on the work of Niklaus Manuel of Berne, and in 1953, he gave a public lecture on the topic: 'Germany Bismarck or Beethoven?' In 1956, he was invited to edit a number of volumes for the new edition of the complete works of Goethe, to be published by the German Academy of Sciences. During his ten years at Adelaide, Van Abbe would prove to be a prolific publisher, establishing a research agenda ${ }^{44}$ for German at a time when this was not yet the norm in the Arts Faculty, and well before staff in the French Department began to publish on a regular basis. ${ }^{45}$ Interaction with distinguished colleagues was very much a part of that agenda. While Van Abbe was at the helm, various scholars from interstate and abroad were invited to Adelaide to help stimulate the intellectual life of the German Department. In 1957, taking advantage of the Fulbright scheme, it brought Dr E. (Edda) T. Hankamer of the University of Tennessee out to Adelaide. ${ }^{46}$ Two years earlier, Professor R. (Richard) H. Samuel of the University of Melbourne visited the German Department and took part in some teaching. These were the first of many such visitors.

\footnotetext{
${ }^{44}$ At that time, the University Calendars included information on research projects being undertaken within the institution, and there was always an entry for German during Van Abbe's tenure. In contrast, there was hardly ever any such entry for French, the exception being the mention, in the Annual Report for 1957, of research on 'the interaction of politics and literature as evidenced in the work of certain French writers of the late nineteenth and early twentieth centuries'.

${ }^{45} \mathrm{~J}$. G. Cornell, for example, was an outstanding scholar who read assiduously all the new books relating to French that came into the library, usually annotating them with corrections where he detected mistakes. He was not, however, a publisher. Apart from an edited collection of short stories, Cinq maitres du conte français (Sydney, Shakespeare Press, 1936), which regularly featured in the list of set texts for undergraduate students, he produced a report on the teaching of modern languages in the secondary school in 1939. That, however, is about the extent of his publication record. Of course, the annotations he made to books in the Barr Smith Library as they came in, as well as to the books in his own personal library, most of which are now kept in the Cornell Collection, would amount to a considerable research corpus!

${ }^{46}$ Interestingly, her visit to Australia was announced in the 'Social News and Gossip' column of The Sydney Morning Herald on 27 February 1957.
} 
Van Abbe was also busy on the curriculum front. At the time when he took over the reins from Schulz, the syllabus entries for French and German provided a stark contrast: the entry for French ran to six pages, and contained long lists of texts for study at the various levels; the entry for German comprised barely one page, and had hardly changed over the previous 30 years. That anomaly was about to be rectified. The 1952 Calendar, for example, noted that German III would henceforth be provided, and that arrangements were under way for 'the establishment within two or three years of a full Honours School in German'. The syllabus entry for German in 1953 is indeed much more substantial, thanks to the addition of German III and of a much more extensive list of set texts and books recommended for background reading. The syllabus in German had always been reasonably solid, despite being limited to just two courses, but Van Abbe gave it the extra substance and coherence that a full three-year sequence demanded. He introduced, for example, a survey course in German II on the history of German life and culture that would, in varying shapes and forms, and at different levels, remain an enduring feature of the German curriculum almost to the present day. The new German III syllabus was a rigorous one: it involved translation (both ways) and 'stylistic appreciation', as well as a course of lectures on the history of German literature from 1780 to 1830 (Lessing, Goethe, Schiller, Novalis, Chamisso) and another strand on the history of the German language.

The German Honours syllabus, which had been foreshadowed in the 1954 Calendar, finally appeared the following year. It was constructed along the lines of the French model: a major sequence, with additional Honours work in German II and German III, as well as a pass in Interim Honours German I and II, to be taken in the second and third years respectively (these would be re-named Older German Language and Literature I and II in 1960). A fourth year devoted entirely to Honours work in literature and philology was also required. The final examinations for Honours comprised translation (both ways), an essay (written in German), a paper on Middle High German and philology, a paper on German history, three papers on literature (to be answered partly in German), and an oral examination consisting of a test in conversation and the discussion of set texts and literary history. The first Honours graduate in German was Ian Keith McGill, who completed his examinations in 1955 and was awarded the degree the following 
year. He proceeded to the MA degree in 1958. With a syllabus to match that of French, German student numbers finally began to grow.

Van Abbe was, however, not content simply to 'catch up' with French, as it were, on the curriculum level; he also introduced a number of innovations that would set German apart. One such innovation was the establishment in 1954 of a course in 'Scientific German', available to University staff and senior science students who might need a reading knowledge of the language for their work. This was an early experiment in the provision of a service course, but it proved to be successful. A second course was offered in 1955 for people who had completed the first, and it remained on the books right up to the early 1990s (albeit with a name change in 1983 to 'German for Reading and Research'). It was also an early example of a beginners' language course. No doubt buoyed by its success, Van Abbe subsequently introduced a mainstream beginners' course in German at firstyear level (German IA). That was in 1959 - well before beginners' courses were the accepted norm in this country (French at Adelaide would not have a beginners' course until 1973). The German IA syllabus was a testing one. In addition to the four weekly language classes, students had to attend a lecture devoted to German background, geography, cultural history and social institutions in Term 1. In Terms 2 and 3, this class provided an introduction to the history and criticism (in English) of German literature. During the third term, students also began the study of the literary texts set for German I - which they continued to work on over the vacation in order to take an examination the following February, at the time of the supplementaries. This was to prepare them for entry into German II, if they chose to continue with the subject.

Another change, and one that was perhaps inspired by the French example, was the requirement, from 1955, that students attend the Deutscher Verein as well as the meetings of the Goethe Society in order to practise their speaking skills (this becomes simply a recommendation from 1964 onwards, and the Deutscher Verein transforms into the German Club as from 1969). The first prizes for German were also established under Van Abbe's watch. In 1956, Mrs Leonore Ohlstrom gave $£ 300$ to the University for the purpose of creating prizes in memory of her late husband, Patrick. To be known as the Weimar-Ohlstrom Prizes, these would be awarded to the best students in German I and German II. The first recipients were 
Dietrich Wilhelm Frido Behrens (German I) and Lee Irving Kersten (German II). Lee Kersten also won the M. Rees George prize for French in 1956 and would go on to become a long-serving member of the German Department.

Given the growth in student numbers and in the range of curriculum offerings, it was only natural that the staffing complement in German should also begin to expand. In 1953, a lectureship was created and duly filled with the appointment of Brian Coghlan, a graduate of the University of Birmingham. In 1955, a third position was created, this time a tutorship, which was filled by Hendricus Siliakus, likewise a graduate of Birmingham. He would take up duties in 1956, the year in which Coghlan was promoted to Senior Lecturer, and would soon find himself promoted to Lecturer, in 1958. The 'Birmingham Connection' would have a profound influence on German studies, and on European languages generally, over the following two decades, with Brian Coghlan going on to become the first Professor of German, in 1962, and Henk Siliakus (as he was known) taking on responsibility for the technological innovation that was the Language Laboratory (first as part-time director, in 1964, and then in a full-time capacity, from 1974 until his retirement in 1989). In 1959, a new tutor, Hans Christopher Sasse (with a BA from Adelaide), commenced work in the German Department. That same year, Brian Coghlan left to take up the Chair of German at the University of New England, and a lectureship in German was advertised to replace him. Rodney Simon Livingstone, a graduate of Cambridge, was appointed and took up duties in 1960. At this point, the French and German Departments both had four members of staff. That parity would be short-lived, however, with German outstripping French in terms of staff for almost the next three decades.

This period of prosperity for German began, however, under something of a cloud, with the departure of Van Abbe at the end of 1961 and the return of Brian Coghlan in 1962. These two staff movements were closely related. When, in 1960, Council decided to establish a Chair of German, Van Abbe quite reasonably would have anticipated that it might be offered to him. Instead, the young man he had previously appointed and whose career he had nurtured was invited to take up the position, and so Van Abbe left. Therein lies a tale, no doubt. In any event, the University lost in Van Abbe a top-rate and productive scholar who was 
well liked by students and who had worked hard to put German on the map. ${ }^{47}$ Like Eitel and Schulz before him, he had also established close and productive links with the German Australian community in South Australia. ${ }^{48}$ But in Brian Coghlan the University gained someone who, in the Jim Cornell mould, would create many connections with the wider community. Coghlan took an active role, for example, in the South Australian branch of the Goethe Society as well as in the University Music Society. He had a particular passion for Wagner and for German opera more generally, and gave many public talks on that subject. Like Cornell, he served as President of the University Theatre Guild for four years in the 1980s. As early as 1974, he had been awarded the Order of Merit by the Federal Republic of Germany, in recognition of his work in promoting German language and culture. When he retired, in 1991, his record of service was unrivalled, for a member of staff in modern languages: 37 years in total, 30 of them as Professor of German.

On returning to Adelaide in 1962 as foundation Professor of German, Brian Coghlan had plenty of forward momentum to work with. With student numbers on the rise, on the back of the introduction of the first-year beginners' course, the numbers of staff in German also increased. The introduction of a second-year beginners' course (German IIA) in 1968 would add further impetus to the discipline. In 1973, with Henk Siliakus just promoted to Reader, a second position at that senior level was filled. The appointee, Anthony Stephens, was an accomplished scholar who had read French and German as an undergraduate student at the University of Sydney. He had gone on to complete a $\mathrm{PhD}$ at the University of Sydney, where he was given a lectureship in 1967 after spending two years in Munich under a Commonwealth Postgraduate Scholarship. He was promoted to Senior Lecturer at Sydney in 1971, two years before his move to Adelaide. His recruitment would greatly enhance the profile of German at Adelaide: a prolific publisher, Stephens was elected to the Australian Academy of the Humanities in 1978 and also had the distinction of being a Humboldt Fellow.

\footnotetext{
${ }^{47}$ Van Abbe also involved himself in the wider community, speaking frequently on the radio (in the Notes on the News segment, for example).

${ }^{48}$ On tangible legacy of these connections are the papers left by Schulz and Van Abbe, which feature in the 'German Settlers in South Australia' collection in the Barr Smith Library Special Collections. A digital list of the contents of this collection, compiled by Cheryl Hoskin and Lee Kersten, is available online at: <http://www.adelaide.edu.au/library/special/mss/german_settlers/>.
} 
The arrival of Stephens boosted staff numbers in German to nine. In addition to the Chair and the two Readers, the department boasted a Senior Lecturer (Alois Otto Bönig), along with two Lecturers (Dushan Stankovich, who had been appointed in 1970, and Lee Kersten, who was the first woman appointed to a full-time position in German, in 1963), two Teaching Fellows (Ursula McGowan and Evelyn Urban, who had both begun as tutors in 1969), and one Tutor (Roger Hillman, who was appointed in 1971). When Tony Stephens, who was a prolific publisher, was promoted to a personal Chair in 1980, German enjoyed the relatively rare distinction for European languages in this country of having two Professors, right up till the retirement of Brian Coghlan at the end of 1991. ${ }^{49}$

At the same time (1973), French had a staffing complement of seven — still a respectable number, especially by today's standards. Following the retirement of Cornell at the end of 1969, the Chair remained vacant for a year, but, despite A. P. Rowe's foreboding, was filled in 1971 with the appointment of John Davies. Davies was another graduate of the University of Sydney, having obtained his Honours degree in French and Latin there in 1942. After a four-year hiatus due to war service, he spent two years as a teacher in the New South Wales system before securing a French Government Scholarship to undertake postgraduate study in France. He obtained his doctorate from the University of Paris in 1953, with a thesis on the works of André Gide. He then spent a number of years as a lecturer at Queen's University, Belfast, before taking on the position of Professor of French at the University of New England in 1959 - the year when Brian Coghlan also took up duties in Armidale, as Professor of German. Davies remained at New England until his appointment to the Chair at Adelaide in 1971. Under Davies' watch, the curriculum in French would evolve from the long-standing pattern

\footnotetext{
${ }_{49}$ There had been a number of precedents at other institutions during the 1970s, notably in French. Richard Coe, for example, was appointed to a personal Chair at the University of Melbourne in 1969 with Ron Jackson already Professor of French. This was to prove short-lived, however, as Coe left Melbourne in 1972 for the University of Warwick in England. In the early 1970s, there were likewise two established Chairs of French at Monash University, held by Ivan Barko and François Van Laere. The second Chair lapsed when Van Laere resigned in 1974. In that same year (1974), the University of Queensland appointed a second Professor of French, Michael Spencer (who had previously taught at Adelaide, as well as at Cambridge and Monash), to join the holder of the Foundation Chair of French, J.C. Mahoney. Again, the second Chair lapsed when Mahoney retired in 1977.
} 
established by Cornell. A first-year beginners' course was finally introduced in 1973, for example, and the Honours program gradually shifted away from the Cornell model, which had been based on philology and Old and Middle French literature. Times were changing, and so was the teaching of French and German.

\section{Diversification}

During the 1960s, and right through to the end of the 1980s, languages were in a relatively healthy position at Adelaide, as elsewhere in the country. There were some set-backs during that period, most notably the decision taken by universities towards the end of the 1960s to remove foreign languages as an entry requirement for matriculants. But this served to put the onus on staff to find ways of making language study more attractive, and led to a number of positive developments. The result was a greater diversity in terms of course content and an expansion in the range of languages available for study.

\section{Teaching methodology and curriculum development}

The first major change to language teaching at the University of Adelaide came about with the creation of the Language Laboratory, which became operational in 1965. This gave students the opportunity to listen to a wide range of authentic materials in the foreign language and to record their own voice. Exercises in phonetics were well suited to this new environment, but dictation work along with drill and practice exercises on points of grammar also featured prominently. As noted above, use of the language laboratory was pioneered by the German Department, thanks to the efforts of Henk Siliakus. He devoted much time and energy to the development of the laboratory, for which he served as part-time director from 1964 to 1973, before leaving the German Department in 1974 to take on full-time responsibility for its management. The use of the laboratory for teaching and learning became an area of research for Siliakus, and he published several articles on the subject. In 1967, exercises in the language laboratory became an integral component of the curriculum in German I and II, and would remain so for many years. The following year, this was extended to the beginners' stream, with students in German IA and in the newly created German IIA required to 
work in the laboratory. It was also in 1968 that 1-2 hours of work in the language laboratory became compulsory for students in French I. This was soon extended to the other levels.

Another pedagogical innovation, also introduced by the German Department, was the use of a teaching methodology known as 'suggestopedia'. Developed in the 1970s by the Bulgarian psychotherapist Georgi Lozanov, this technique involved creating a relaxed and comfortable atmosphere in the classroom, notably through the use of music, in order to enhance student learning. The method was adopted for beginners' German at Adelaide in the early 1980s, and a dedicated classroom was set up for this purpose. The experiment lasted about a decade. The cause of suggestopedia was championed by Dr Sigrid Gassner-Roberts, who gained international renown as a pioneer of the technique through numerous conference presentations and publications. It was one of the more original of the various innovations to language teaching that were introduced during the latter decades of the twentieth century.

The teaching of French and German culture also became more diversified during this period, with a broader range of topics becoming available from the mid-1970s onwards. In 1974, for example, the civilisation component in French I included some lectures on modern French cinema. This would quickly develop into a mainstream area of study. Films 'of contemporary interest' were introduced in German I in 1976, as a component in the civilisation strand (Introduction to Modern Germany). That same year, a course on screen adaptations of literary texts, 'Novel and Film', was among the options available to students in German II and III. As in the case of French, film study would become an important part of the syllabus in German from that point onwards. An experiment in comparative literature was introduced in 1975, with students in English III, French III and German III given the option of meeting for a term to discuss selected English works and French and German texts in English translation as a substitute for their 'home-based' literature and civilisation study. Applied Linguistics was then establishing itself as a field of scholarly enquiry in Australia, and students in French III could choose that as an alternative to literature in second term in 1975. The following year, in similar vein, students in German II and III were offered as one of their options a course on Language Learning and Teaching. 
The study of literature nevertheless remained a constant feature of the syllabus in both languages, but variety was the order of the day. Austrian literature, for example, made its first appearance in the German syllabus in 1976, with East German literature added to the mix in 1979. In 1977, French students could study literary criticism, while students in German could sign up for a course on music and literature. Thematic courses of study were gradually introduced German travel literature, for instance, or German music and literature. Various aspects of contemporary French and German society were now an object of study in their own right. French politics and the West German press figured among the options available to students in the respective languages in 1978. Optional courses of study on the media - press, radio, cinema and television - were subsequently introduced in French as well (1986). The year 1979 saw the first course on Francophone culture in the French Department, involving five weeks of fieldwork in New Caledonia in May/June. 'La Francophonie' went on to become a regular topic of study in French, in one form or another, and remains so today. Along similar lines, a survey course on German-speaking countries was introduced in 1990. Another innovation was the use of drama as a tool for learning French, which was trialled in 1981 with the introduction of the course 'Pratiques du texte dramatique'. A course on practical theatre would later feature on the German syllabus, in 1995. The fact that many of the curriculum initiatives introduced by one language department were then taken up by the other suggests that there may have been some healthy emulation between them during that period. Such courses of study were, however, also part of the Zeitgeist.

\section{Expansion of language offerings}

Demand for other languages emerged during this period, and universities were at that time in a position to respond. Chinese and Japanese were introduced at the University of Adelaide in 1975, but European languages were also set to benefit from this diversification. Italian had been taught at the Elder Conservatorium throughout the first half of the twentieth century, and service courses in a variety of languages were provided to students and the general public by the Language Laboratory, but French and German had been the only modern languages taught within the BA right up to the mid-1970s. Some attempts had been made in previous 
years to expand the range of languages available. The German Department had offered its Honours students an optional strand on Dutch language and literature in 1961, but this only lasted two years on the books. The University had also created a Chair in Slavonic languages around 1966, but had never managed to fill it, and when the Faculty of Arts finally tried to make an appointment, in 1969, the University's Education Committee decided to abolish the Chair on financial grounds. ${ }^{50}$ The real expansion in language offerings took place much later, towards the end of the 1980s. It was achieved not by the creation of new positions, but through the introduction of collaborative arrangements between the University of Adelaide and other universities, most notably Flinders.

The impetus for these changes came from students, rather than staff, though the Faculty Registrar at the time, Don Longo, was a fervent supporter and had the vision and savoir-faire required to smooth the administrative path for this development. The push began during the early 1980s, when students at the University of Adelaide organised a petition protesting against the absence of Italian from the language offerings available to them and requested that something be done to remedy the situation. Having been made aware of this need, staff in the Italian discipline at Flinders University rose to the challenge by providing classes in Italian on the Adelaide campus (from 1986). While the potential for earning additional student numbers was no doubt part of the attraction, it is fair to say that this initiative was predominantly motivated by altruistic factors, with staff keen to spread the good word to students who had expressed a desire to learn. The German staff at Adelaide had already begun to offer courses to students at Flinders as early as 1983.

At the administrative level, there was a similar level of goodwill and concern for the interests of students and staff. In a letter to his counterpart at Flinders University dated 17 June 1981, the Bursar of the University of Adelaide, David Beecher, noted: 'the T. E. C. [Tertiary Entrance Committee] encourages interaction between our two Universities, in order that students and staff may take advantage of opportunities to extend their experiences beyond the boundaries of a single university' ${ }^{51}$ It should be pointed out that Italian was not the only subject

\footnotetext{
${ }^{50}$ See E. C. Forsyth, The Relevance of Rabelais, p. 7.

${ }^{51}$ University of Adelaide Registry File no. 1980/2573.
} 
area involved in such 'interaction' between the two universities. Under what was known then as the 'Visiting Students Scheme', a good deal of cross-institutional co-operation had already been initiated by the two respective departments of Geography, and the University of Adelaide had arrangements in place that allowed students of other tertiary institutions to undertake particular courses of study that complemented those of their home institution. Units offered by Adelaide's Centre for Aboriginal Studies in Music, for example, were made available to Aboriginal Studies students at the South Australian College of Advanced Education. And students enrolled in Occupational Therapy and Physiotherapy at the South Australian Institute of Technology were actually required to study certain Anatomy subjects at the University of Adelaide. What was new in the case of Italian, however, was the fact that the member of staff, not the student, became the 'visitor', the Flinders teacher travelling to the Adelaide campus to offer a complete and discrete unit of language study.

This arrangement continued for some time, with other languages gradually being added to the mix. A decade further on, around 1990, the University Calendar lists an impressive array of languages available through this cooperative scheme Spanish and Modern Greek, for example, but also Latvian and Indonesian, along with Polish and Ukrainian (both of which were offered externally by Macquarie University, Sydney). Russian was made available through a complex triangular arrangement (it was offered by the University of Melbourne but hosted by Flinders and taught at Adelaide). Arabic was also on the books thanks to a collaborative arrangement between the Universities of Adelaide and Sydney. Various factors led to a formalisation of these cross-campus language teaching arrangements, which were now to become more fully reciprocal, with Adelaide offering Chinese to students on the Flinders campus (in addition to German, which had been taught there since the early 1980s). The more formal administrative arrangements were initiated by language staff at Flinders, who began a push to obtain formal recognition for the work they had been doing on the Adelaide campus. At around the same time, recommendations for greater institutional co-operation were coming from a number of quarters. In its influential report, The Language Challenge: Tertiary Language Planning. A Policy for South Australia (1990), the South Australian Institute of Languages, which would become defunct in the mid 1990s, flagged this 
kind of arrangement as a means of increasing student choice while rationalising the language offerings of the individual institutions. More generally, the Tertiary Entrance Committee had for several years been pushing for the rationalisation of all studies within the State. In any event, the collaborative arrangement regarding languages, which became known as the Outreach Programme, would be held up as a model for inter-institutional collaboration and hailed as a great success by language educators throughout the country.

\section{ChILl Winds}

Nothing is permanent, however, and while the success of the Outreach Programme was in many ways the culmination of a bright and productive period for languages, it also marked the beginning of difficult times to come. At the same time as creative solutions were being found to increase the range of languages available to students, chill winds were beginning to blow. French was the first to feel their effects. When John Davies retired at the beginning of 1988, the University rushed to leave the Chair vacant. A review of French was undertaken in 1990 and this was expanded in 1991 to include a review of the German Department - a sure sign, in those days, that questions were being asked. Without a Professor to champion its cause, the French Department indeed found itself under threat, with some in the Faculty going so far as to suggest it should be closed down. Fortunately, wiser heads prevailed, and the decision was made to begin a process of renewal in French, with the appointment in 1991 of two new staff — (Frances) Jean Fornasiero and John West-Sooby, both of whom were recruited from the University of New England (yet another example of the UNE connection). The department they joined at Adelaide, however, was not a happy one. Tensions had developed between various members of staff, including the casual teachers, and this resulted in the Dean, Robert Sellick, taking over the headship of the department in 1991 and 1992. It would take a little time before that situation could be resolved and the process of rebuilding could begin. Some hope did emerge for French around that time, with a decision made to advertise a Chair. The process was aborted, however, after the advertisement had been published, because the then Professor of Asian Studies managed to persuade the University that a second professorial appointment in his area should be made instead. 
The fate of German would also take a turn for the worse during the 1990s. When Brian Coghlan retired in 1991, German still had a Professor in Tony Stephens to defend the discipline. But he left shortly after, in the middle of 1994, to take up the Chair of German at the University of Melbourne, and the decision was made not to replace him. For a brief period after that, the German Department benefited from the support of an 'outsider', in the shape of John Milfull, the Professor of German at the University of New South Wales, who was brought to Adelaide to serve as Acting Dean from June to December 1994. When Milfull returned to UNSW, however, both French and German found themselves without a professorial figure to defend their interests - although Milfull had at least made some improvements in terms of the staffing in German. The Chair in French would remain unfilled until the promotion of Jean Fornasiero to Professor, at the end of 2010. The Chair in German is still vacant, and there is no sign that it will be filled any time soon. The resultant loss of status was consecrated by the fusion of the two departments, along with Classics and Linguistics, in 1997, through the creation of the Centre for European Studies (renamed the Centre for European Studies and General Linguistics in 2000). The loss of autonomy was a hard pill to swallow for all concerned, and it was no consolation that this kind of change was happening to languages right round the country. Some benefits in terms of collegiality and interdisciplinary activity did, however, result from this amalgamation.

Staffing levels fell to a low ebb in French and German during the 1990s, and remain a problem today, despite the extra support the Federal Government provides for languages in its funding formula for universities. The story of French and German during the last 20 years or so is, however, not all doom and gloom. Both departments in fact showed great resilience during that period and several important initiatives were taken. In terms of the curriculum, for example, new courses were introduced. A third year in the beginners' stream was introduced by German in 1991 (German IIIA), French would follow suit in 1998, with the creation of French IIIA (French IIA had been added in 1975, two years after the introduction of the first-year beginners' course). In 1995, French added an intermediate course in first-year (French IM) for students who were not beginners but who had not studied to Year 12 level. That initiative had to be abandoned at 
the end of 2002, however, due to a reduction in the staffing complement from five to four following the retirement of Blandine Stefanson.

Interdisciplinarity became the buzzword in the 1990s, and various members of staff from Classics, French and German worked individually or collaboratively to offer courses in European culture to students beyond their own disciplines under the 'European Studies' banner. Courses on comparative literature, cinema, the media and the history of ideas, many of them with colourful titles, proliferated in an attempt to boost student numbers and spread the word about European culture. Examples include: 'Songs for Heroes', 'The Outsider in 20th-Century European Fiction', 'History and Development of Mass Communication', 'The Death of God', 'Power, Love and Evil', 'Music and Politics', 'The Great Ideas of Western Civilisation', 'Opera as Idea and Ideal'.

New awards were also introduced during this period to promote the study of language and culture. In 1990, the Graduate Certificate in Language Education was introduced with the aim of offering language teachers the opportunity to upgrade their skills and refresh their cultural knowledge. German was the first cab off the rank at Adelaide, with Chinese, French and Japanese versions of the Graduate Certificate added in 1992, followed by Applied Linguistics. This remained on the books for another decade or so, but in reality enrolments dried up after only a few years, when the State Education Department ceased offering funding support for teachers to enrol in the programme. The introduction in 1998 of the Diploma in Languages proved to have a more lasting success. Following the model that was introduced at the University of Melbourne in 1994/1995, its main purpose was to allow students in other Faculties to add a language major to their Bachelor degree, but it also proved popular with BA students, many of whom found they did not have enough room in their degree for all the subjects they wanted to study. Enrolments in the Diploma in Languages grew rapidly and continue to be strong today. It has brought more students to languages, from a greater variety of backgrounds (including more male students). This has had a positive effect on classroom discussions and student interaction.

Around the same time, the Faculty introduced named degrees — variations on the BA that featured a particular strand of study. The BA (European Studies) included the requirement for students to complete a major in a European language, 
though this was eventually watered down. That degree was abandoned after about ten years, though students are still able to complete a major in European Studies within their BA. The argument for including a compulsory language requirement in the BA (International Studies), which has since morphed into the Bachelor of International Studies, was not won, however, despite the best efforts of languages staff. On the other hand, a new Bachelor degree focusing on language study was introduced in 2011 following the (very positive) review of languages conducted in 2010. The Bachelor of Languages, which is intended as a niche degree, is still in its first phase of operation, but it is hoped that it will have an enduring appeal for students. It is a further sign, in any case, of the enterprising spirit that continues to prevail in the languages, despite the many difficulties they encounter.

Last, but by no means least, a third European language discipline has been added to complement French and German. From 1987, Spanish had been taught on the North Terrace campus by staff from Flinders University and had proved to be popular with students. Indeed, for many years, the Outreach Programme had suffered from an imbalance in terms of enrolments - an imbalance that heavily favoured Flinders, given that many more Adelaide students enrolled in the languages offered by that University compared to the numbers of Flinders students who enrolled in Adelaide languages. As long as the scheme ran under a kind of 'gentlepersons' agreement', administrators at Adelaide were generally prepared to turn a blind eye to this, since the provision of a wider range of languages added to the overall attractiveness of the BA. During the 2000s, however, the Federal Government introduced changes to the administrative procedures governing cross-institutional enrolments, and this resulted in money having to change hands. With Spanish enjoying great popularity, the University of Adelaide decided that it would be better off financially if it started up its own programme - a decision that understandably caused some friction with Flinders.

A position of Senior Lecturer in Spanish was duly advertised, in 2008, and Jorge Paredes was appointed to found the discipline. He had been educated in Canada, where he had obtained a BA (Hons) at Guelph, then an MA at Queen's University, Kingston, and a PhD at the University of Alberta, in Edmonton. He came to Adelaide from the University of Otago, in New Zealand, but had previously taught at Monash University and was hence familiar with the Australian 
system. He was well placed to start building a major in Spanish. A second position was added in 2010 to assist him in this task. This lectureship was taken up by Sergio Holas, who was recruited from Flinders but who had previously taught at a number of other universities, including Queensland and Auckland. Despite some early frustrations, Spanish now offers a full major sequence, with courses in Spanish and Latin American culture to complement the language program. In recognition of this broader curriculum coverage, the discipline's name is now set to change from Spanish to Hispanic Studies. It continues to be a popular language among students, and enrolments are strong. Spanish has therefore been a valuable addition to the 'language ecology' at Adelaide.

It is appropriate to finish on this positive note, as one of the themes to emerge from the long history of modern European languages at the University of Adelaide is that of their resilience. Their fortunes have fluctuated over the journey, and their relative strengths have also waxed and waned. But they have for many years been important contributors to the liberal arts mission of the University, and of the Faculty more particularly. They survived their amalgamation into the Centre for European Studies in the mid-1990s and have if anything reclaimed a degree of autonomy and visibility with their incorporation as individual 'Disciplines' under the umbrella of the School of Humanities (since 2004). Their names are now different, with the old Departments of French and German Language and Literature giving way to the new nomenclature of French Studies and German Studies (1994), and the curriculum has become more varied. But they continue to provide students with a high level of training in language and culture, and have responded to the various challenges with great commitment and creativity. Further challenges no doubt await languages in the future, but history suggests that they will continue to cope admirably with them!

\section{REFERENGES}

Anon, 'EITEL, Ernest John died 10 November 1908', obituary published in The Advertiser, 11 November 1908. 
Barko, I. \& Martin, A., 'A Short History of the Teaching of French in Australian Universities', in P. Lane \& J. West-Sooby (eds), Traditions and Mutations in French Studies: The Australian Scene (Mount Nebo, Boombana Publications, 1997), pp. 19-92.

Denat, M., 'Don't you dare write me a dull Obituary! Mary Hope St Clair Crampton 18 May 1901-8 August 1996', The Adelaidean, 23 September 1996, p. 7.

Edgeloe, V. A., French and German in the University of Adelaide during the University's first hundred years of teaching, 1876-1975: a brief account (Adelaide, University of Adelaide, 1990).

Forsyth, E. C., The Relevance of Rabelais: some thoughts on the place of French Studies in an Australian University, Inaugural Lecture (Bundoora [Melbourne], La Trobe University, 1970).

Penny, H. H., 'Schulz, Adolf John (1883-1956)', Australian Dictionary of Biography, vol. 11 (Melbourne, Melbourne University Press, 1988), available online at: <http://adb.anu.edu.au/biography/schulz-adolf-john-8361/ text14671>.

Rowe, A. P., If the Gown Fits (Melbourne, Melbourne University Press, 1960). 


\section{Geography, Environment and Population at the University of Adelaide, 1904-2012 \\ Nick Harvey}

\section{INTRODUGTION}

In 1998, the former Departments of Geography and Environmental Studies were merged to create a Department of Geographical and Environmental Studies, which subsequently lost its departmental status in 2002 as part of a University of Adelaide restructuring process. In 2002, Schools became the main administrative units across the University, each comprising a number of 'Disciplines' rather than Departments. At the start of 2011 the Discipline of Geographical and Environmental Studies was renamed to 'Geography, Environment and Population' to better reflect its current teaching and research focus.

However, the origins of the Discipline go back to the start of the last century. A special volume of the South Australian Geographical Fournal ${ }^{1}$ documented

\footnotetext{
${ }^{1}$ N. Harvey \& F. Gale (eds), 'The centenary of academic geography in South Australia', South Australian Geographical Fournal, Special Issue, vol. 102 (Adelaide, Royal Geographical Society of South Australia Inc., 2004).
} 
a hundred years of geography teaching in South Australia and this chapter draws heavily on papers from that special volume ${ }^{2}$ together with publications relating to environmental studies which started much later as a discipline of study than geography but then became linked to geography in a number of Australian universities including Adelaide. ${ }^{3}$ In addition, university records and archives have been consulted in an attempt to provide a comprehensive history of the Discipline of Geography, Environment and Population at the University of Adelaide.

\section{GEOGRAPHY IN THE FIRST HALF CENTURY; PART-TIME STAFF AND EVENING LECTURES (1904-1950)}

In 1904 the first geography lectures at the University of Adelaide, titled 'Commercial Geography including elements of Technology', were given by the University Librarian, Mr John Clucas. ${ }^{4}$ Geography was taught as part of commerce and economics courses and preceded the formation of the Geography Department. This was a compulsory subject for the Advanced Commercial Certificate and subsequently the Diploma in Commerce. ${ }^{5}$ Initially, the course was given only to alternate years. There was one lecture a week given over three terms with a fee of 10 shillings and 6 pence per term. The general topics covered were environment, industry and commerce and the practical work dealt with the main principles of statistics, sketch maps and the distribution of materials of commerce and the practice of using technical and official publications. ${ }^{6}$

Clucas taught geography on a part-time basis in the evenings, in addition to his full-time position as the University Librarian. Clucas was interested in practical

\footnotetext{
${ }^{2}$ F. Gale, 'The Development of University Geography, 1904-1960', South Australian Geographical Fournal, 102 (2004), pp. 26-40; N. Harvey, 'The importance of Adelaide in the genesis of academic Geography in Australia', South Australian Geographical Fournal, 102 (2004), pp. 1-13; N. Harvey \& C. Forster, 'Geography in South Australian universities: future prospects', South Australian Geographical Fournal, 102 (2004), pp. 118-27; G. Hugo, 'Geography and environmental studies at the University of Adelaide since 1990', South Australian Geographical fournal, 102 (2004), pp. 82-97; and P. J. Smailes \& T. Griffin, 'Geography at the University of Adelaide, 1960-1991', South Australian Geographical Fournal, 102 (2004), pp. 62-81.

${ }^{3}$ N. Harvey, C. A. Forster, \& R. P. Bourman, 'Geography and Environmental Studies: Symbiosis for Survival in the 21st Century', Australian Geographical Studies, 40.1 (2002), pp. 21-32.

${ }^{4}$ M. Kirby, 'The University Departments, their History and Teaching: Geography', AUGU Monthly Newesletter and Gazette, July 1970, pp. 3-7.

${ }^{5}$ Ibid.

${ }^{6}$ Ibid., p. 3.
} 


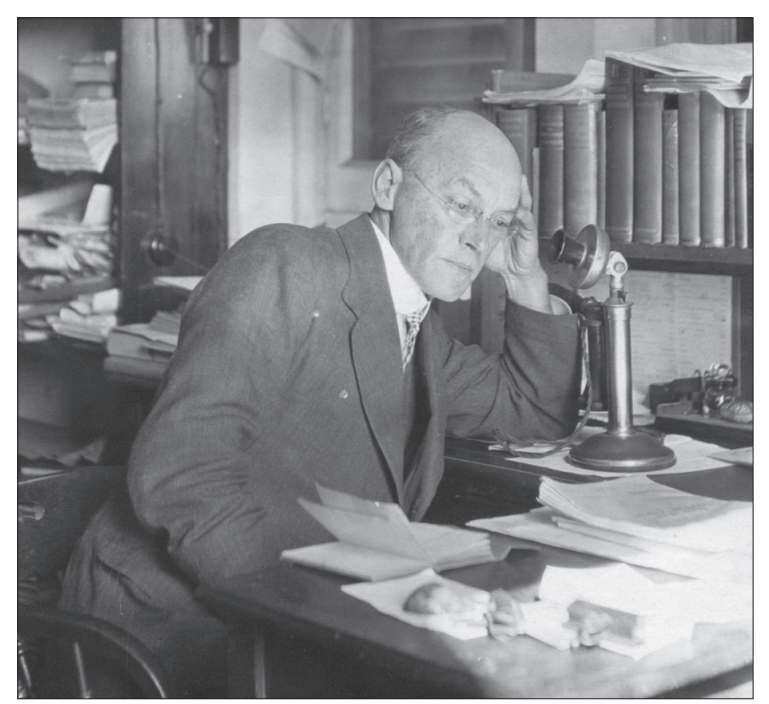

\section{John Clucas}

aspects of geography, believing in the importance of observation and spent some time surveying in the Adelaide Hills. ${ }^{7}$ Geography became increasingly popular as the University expanded in size. Women were well represented in the early years as shown in an early graduation photograph from 1914.

As noted by Gale, ${ }^{8}$ in 1908 the Diploma in Commerce replaced the Advanced Commercial Certificate and Technology was dropped from the title of the geography course, which then became titled Commercial Geography as a compulsory subject within the diploma. The content of the geography course changed to a more regional emphasis with a section on practical work added to the lectures. The calendar for 1908 described the practical segment as covering

the main principles of statistics, and the plotting out and explanation of statistical tables. Sketch-maps illustrating the geographical facts of the course, especially in connection with the distribution of materials of commerce. $^{9}$

\footnotetext{
${ }^{7}$ I. Raymond, Australian Dictionary of Biography, vol. 8, 1891-1939 (Melbourne, Melbourne University Press, 1981), pp. 31-2.

${ }^{8}$ F. Gale, 'The Development of University Geography, 1904-1960', South Australian Geographical Fournal, 102 (2004), pp. 26-40.

${ }^{9}$ The University of Adelaide, Calendar, 1904-1959, 1908.
} 


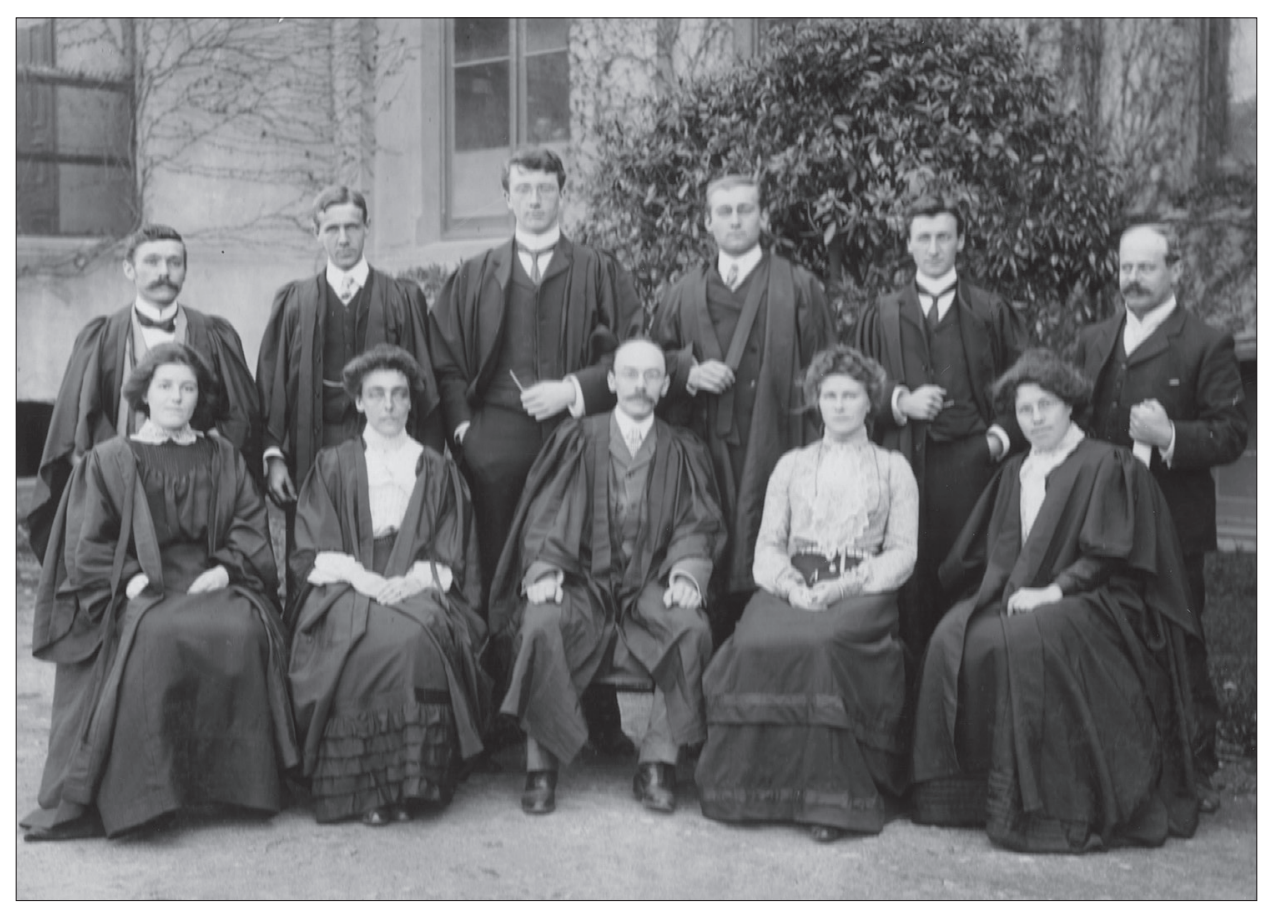

John Clucas with Economic Geography graduates of 1914

The course changed again in 1912 with the introduction of Griffith Taylor's book, Australia in its physiographic and economic aspects, as the primary text. According to Gale

the most significant change occurred in 1919 when Commercial Geography was elevated to a two year course and renamed Economic Geography Parts I and II. ${ }^{10}$

Both courses were taught by Clucas. As Gale notes, the growing role of regional geography became more obvious and

by 1921 the two subjects were simply labelled Economic Geography I and II and Geography looked set to find its rightful place within mainstream university teaching. ${ }^{11}$

However, regulations for the Diploma in Commerce were changed in 1928

\footnotetext{
${ }^{10}$ F. Gale, 'The Development of University Geography', p. 28.

${ }^{11}$ Ibid.
} 
and it was decided to scrap geography altogether. ${ }^{12}$ Geography and education are compared in the centenary history of the University as

Another Cinderella within the Faculty of Arts (also regarded as lacking 'rigour, coherence and substance') was Geography. Like Education, it led a shadowy half-life for many years before it was formally recognised and allowed to grow. ${ }^{13}$

The proposed scrapping of geography caused the Director of Education to threaten withdrawing an annual government grant of $£, 5,000$ which was provided for evening classes to enable teachers to further their education. ${ }^{14}$ This money paid for the lectures in geography along with other Arts subjects. According to Gale ${ }^{15}$ following the intervention of Sir Grenfell Price, who was a member of the University council for many years, the Vice-Chancellor, Sir William Mitchell, 'sent for the distinguished geographer Charles Fenner and put him in charge of a one-year scientific course'. ${ }^{16}$

When the continuation of geography as an academic discipline came under threat in the 1920s at the University of Adelaide, there was an established number of influential South Australians with connections to the Royal Geographical Society who supported its retention. The Royal Geographical Society of South Australia (formed in 1885) was not directly involved in the early development of academic geography but its influence was instrumental in ensuring its later survival and eventual success. ${ }^{17}$ It appears that when the Royal Geographical Society began extolling the virtues of academic geography, it was largely unaware that geography was already being taught along with commerce. In particular, the significant overlap between the membership of the Council of the Royal Geographical Society and the Council of The University of Adelaide strengthened the support for the subject. ${ }^{18}$ The Royal Geographical Society played an important role both

\footnotetext{
${ }^{12}$ F. Gale, 'The Development of University Geography'.

${ }^{13}$ W. G. K. Duncan \& R. A. Leonard, The University of Adelaide 1874-1974 (Adelaide, Rigby, 1973), p. 108.

${ }^{14}$ C. Kerr, Archie, The biography of Sir Archibald Grenfell Price (Melbourne, Macmillan, 1983), p. 196.

${ }^{15}$ F. Gale, 'The Development of University Geography'.

${ }^{16}$ C. Kerr, Archie, The biography of Sir Archibald Grenfell Price (Melbourne, Macmillan, 1983), p. 196.

${ }^{17}$ B. J. Ward, 'The role of the Royal Geographical Society of South Australia', South Australian Geographical Fournal, 102 (2004), pp. 14-25.

${ }^{18}$ Ibid.
} 
by giving geography some recognition within established society and at the same time providing an important ally from influential people who were office bearers within the Society.

It was not until 1930 when separately titled 'geography' courses were introduced into the Bachelor of Arts and Bachelor of Economics degrees ${ }^{19}$ with Dr Charles Fenner as lecturer. ${ }^{20}$ The appointment of Fenner as part-time lecturer in charge of geography was influential in the next phase of development for the academic discipline. Fenner espoused the value of geography to the community and stated that 'unless the subject is being taught authoritatively by the university it cannot be brought up to a proper standard in the schools'. ${ }^{21}$ In 1930 the introduction of Geography 1 into the syllabus of the Faculty of Arts was well-received with over one hundred enrolments. ${ }^{22}$ According to Gale, ${ }^{23}$ it was a very different course from the one given in the Diploma in Commerce with the addition of some human geography texts to complement Griffith Taylor's book on Australia as the major text and later in 1933 Fenner's own book, South Australia: A Geographical Study.

Fenner remained in charge of geography until late in 1951 but according to Gale ${ }^{24}$ for much of the time he relied heavily on Clarence Martin who was first appointed as acting lecturer in the third term of 1931 when Fenner was away. Martin assisted again for part of 1936, gave the full course in 1937 and then when Fenner became Director of Education in 1939, Martin was appointed as lecturer on a part-time basis although Fenner remained nominally in charge. Martin was a regional geographer who integrated the physical and human landscapes into a meaningful whole. According to Gale, ${ }^{25}$ when two years of geography could be offered from 1940 onwards, Martin taught Geography 2 but then filled in

\footnotetext{
${ }^{19}$ M. Kirby, 'The University Departments, their History and Teaching: Geography', AUGU Monthly Newesletter and Gazette, July 1970, pp. 3-7.

${ }^{20}$ F. Gale, 'The Development of University Geography'.

${ }^{21}$ C. Fenner, 'The Value of Geography to the Community', Proceedings of the Royal Geographical Society of Australasia, South Australian Branch, Session 1937-38, 34 (1939), pp. 61-8.

${ }^{22}$ A. A. Simpson, 'Annual Address of the President', Proceedings of the Royal Geographical Society of Australasia South Australian Branch, Session 1928-29, 31 (1930), pp. 12-19.

${ }^{23}$ F. Gale, 'The Development of University Geography'.

${ }^{24}$ Ibid.

${ }^{25}$ Ibid.
} 

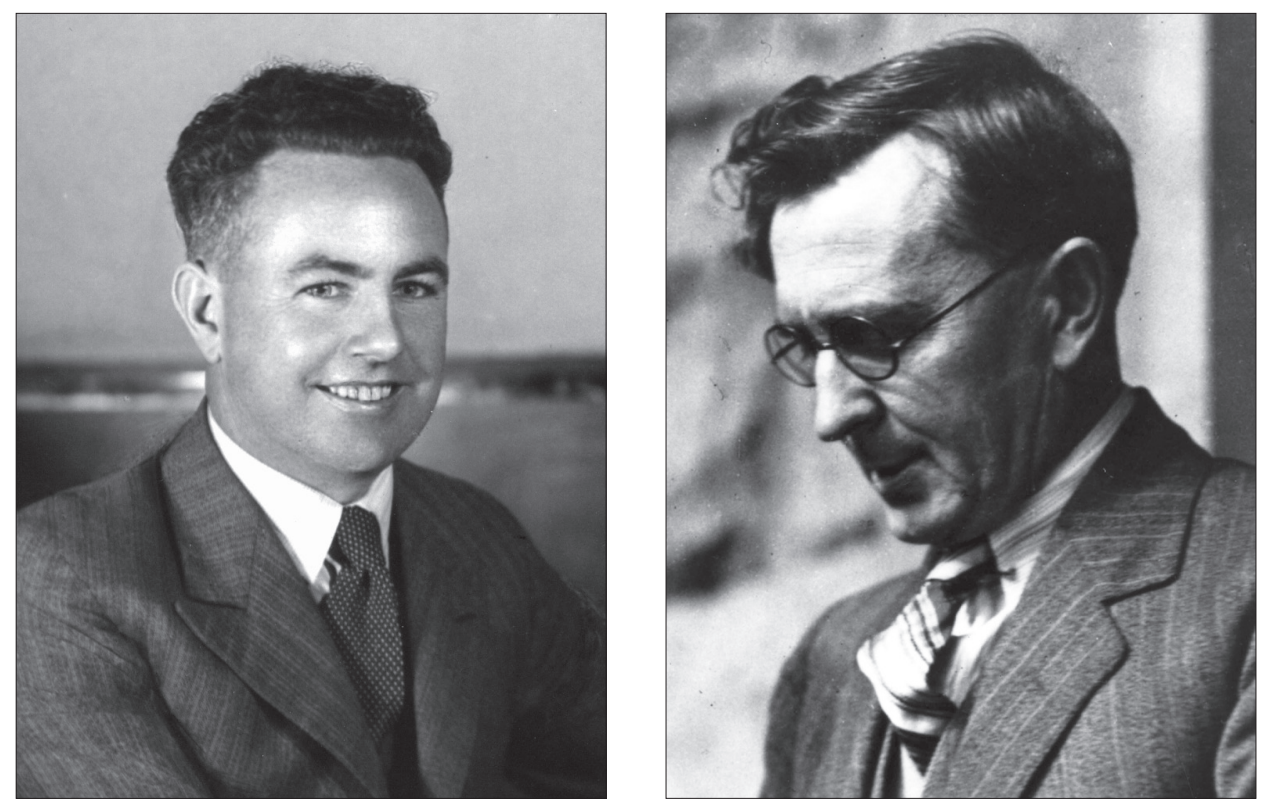

\section{Clarence Martin (left) and Charles Fenner (right)}

teaching Geography 1 for part of 1944 and then taught both Geography 1 and 2 in 1949/50. Martin remained a full-time geography teacher at Thebarton Boys Technical High School but he continued to lecture in geography at the University until the end of $1953 .{ }^{26}$

In 1939, academic geography was strengthened with the appointment of Ann Marshall as a part-time lecturer. According to Gale, ${ }^{27}$ Carl Sauer (an important American geographer) wrote to Grenfell Price and asked him to find Marshall a position in geography since she had been studying at Berkeley with Sauer. In the letter, Sauer said,

I think you are very fortunate to have her at work in your University. The pair of you are a rare combination which any academic institution should be proud to own. The woman is not only a talented teacher but she can rouse the latent spirit of inquiry to a rare degree. ${ }^{28}$

\footnotetext{
${ }^{26}$ Ibid.

${ }^{27}$ Ibid.

${ }^{28}$ F. Gale, 'Award: Griffith Taylor Medallist, Mrs Ann Marshall', Australian Geographical Studies, 27.2 (1989), pp. 247-9.
} 
At the end of the 1939, Fenner asked Marshall to work out an additional Geography 1 course. He also told her that all the human geography stuff she was teaching was interesting but the teachers had told him that her lectures would be more useful to them if she followed Fenner's textbook more closely. Marshall said, 'I politely resigned and he quickly said all right do it your way. So I saved Adelaide geography from being a part of geomorphology. ${ }^{29}$ In 1940 Marshall was appointed to a position as part-time lecturer, which allowed the offering of two years study of geography within the Faculty of Arts instead of one.

Marshall gave evening lectures twice a week but because petrol was rationed during the war years

Ann asked for petrol coupons so that she could manage to get to the

University after her baby sitter arrived. These were issued as 'Geography

Baby' coupons. ${ }^{30}$

Marshall also introduced a course on the history of human cultural development, which was a forerunner of cultural geography, a first in Australia. ${ }^{31}$ According to Gale, ${ }^{32}$ who was a student of Marshall and saw her as an important mentor, she collected numerous slides from personal field work and used these very effectively in the classroom. This was particularly important for the expanding first-year classes.

The year 1949 was important for the development of academic geography with the appointment of Archie Grenfell Price (later Sir Grenfell Price) as a parttime lecturer. This allowed for the introduction of a third-year in geography so that students had for the first time the opportunity to take a full major in geography. Grenfell Price, although a graduate in history rather than geography was well travelled which equipped him to teach a course on Geography of the Pacific. Like Marshall, Grenfell Price used many slides to illustrate his lectures and enthuse the students. According to Gale, ${ }^{33}$ Grenfell Price taught from his own travels or

\footnotetext{
${ }^{29}$ A. Marshall, 'Reply by Ann Marshall (Griffith Taylor Medallist)', Australian Geographical Studies, 27.2 (1989), pp. 249-50.

${ }^{30}$ F. Gale, 'The Development of University Geography', p. 33.

${ }^{31}$ F. Gale, 'Ann Marshall Pioneer woman geographer 27-12-1909-7-3-2001', The Age. Today Life and Times, 26 May 2001, p. 7.

${ }^{32}$ F. Gale, 'The Development of University Geography'.

${ }^{33}$ Ibid.
} 

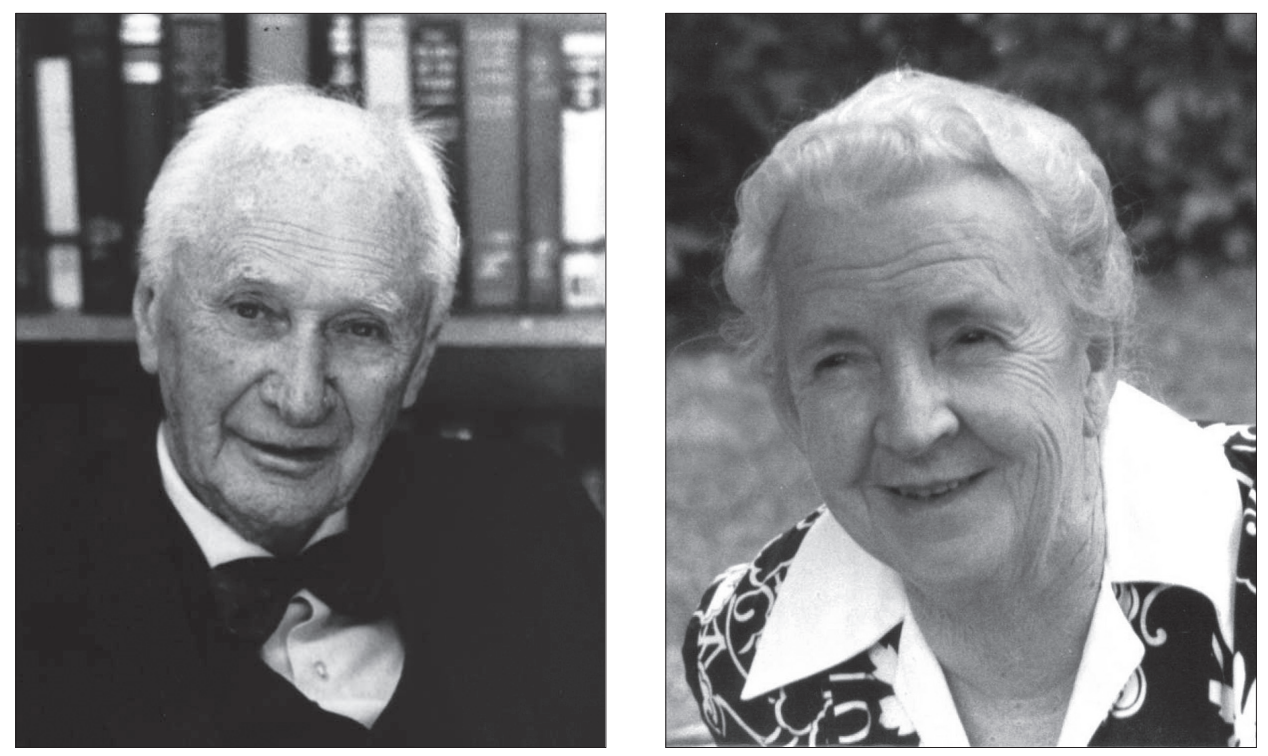

Archibald Grenfell Price (left) and Ann Marshall (right)

fieldwork stimulated ideas and encouraged discussion and questions. He was a great networker and students benefited from his first hand knowledge and detailed analysis of situations and places. There was a weekly one hour lecture at 5.15 and a two hour seminar at 7.15 and until the 1950s geography at all levels was taught only in the evenings to cater for school teachers.

Archie Price was a member of the University Council for 37 years (192562) and fought hard for geographical studies and became a great friend of Charles Fenner. ${ }^{34}$ In 1949 his efforts along with his friends to establish a proper Department of Geography at the University of Adelaide was successful. The University Council asked him to report on the possibility of changing the part-time Department into a Department with full Honours teaching, which happened in 1951.35

Thus by 1950, the earlier and sometimes chequered development of academic geography at the University of Adelaide was complete with the agreement to create a full-time position and establish a full major, providing for

\footnotetext{
34 Ibid.

${ }^{35}$ Ibid.
} 


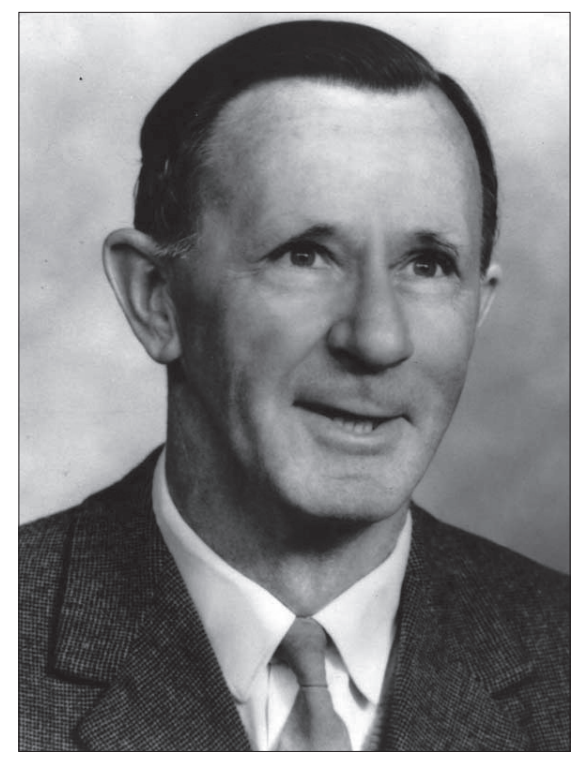

\section{Professor Graham Lawton}

departmental status. The next phase sees the development of the Department the creation of a Chair in Geography and a number of full-time appointments.

\section{GEOGRAPHY IN THE SECOND HALF GENTURY: DEVELOPMENT OF A STRONG DEPARTMENT (1951-1998)}

According to Gale, ${ }^{36}$ Price fought over many years for a rightful place for Geography and together with Marshall he enlisted the help of Griffith Taylor (considered the father of Australian geography) who was renowned for his advocacy of the subject. Finally, in 1950 the University agreed to a full-time position and Price went to Seattle to enlist a Melbourne graduate, Graham Lawton, who was teaching at the University of Washington. The appointment of Lawton as Reader in Geography in 1951 created a turning point for the discipline as it was the first full-time appointment and allowed the creation of an honours course followed by a graduate programme.

${ }^{36}$ Ibid. 
Geography rapidly became an important Department in the Faculty of Arts. In the 1950s there was a rapid expansion of staff with Bruce Mason appointed part-time in 1952 to teach climatology (and then a full-time senior lecturer in 1959); Keith Thomson in 1953 as a full-time lecturer; Ron Hefford in 1956 as a full-time tutor (subsequently promoted to lecturer in 1962); Ross Cochrane in 1957 as a full-time lecturer in biogeography; Ann Marshall was finally given a full-time lecturing position in 1958; and also in 1959 Roland Twidale as a fulltime lecturer. In 1959 Graham Lawton was promoted to be the first Professor of Geography at Adelaide. Thus within ten years the Department had moved from part-time staff to a consolidated position of 6 full-time staff including a professor, four lecturers and a tutor.

According to Gale, ${ }^{37}$ this provided a balance of three human geographers and three physical geographers which although geography was taught as a holistic discipline allowed a more detailed teaching of physical geography into biogeography, climatology and geomorphology and human geography following on the physical foundation with an economic, historical and political emphasis. Practical geography was always assumed to be essential with laboratory work and field camps in the second and third years of study.

The 1960s were important for the consolidation and expansion of the Geography Department. Trevor Griffin, Peter Smailes, Derek Smith and Fay Gale were appointed as lecturers in 1960, 1963, 1964 and 1966 respectively. In 1964 it moved from its initial home in the Mawson Laboratories, to a custom-built space on the eighth and ninth floors of the newly constructed Napier Building, including a map library, photography dark-room, biogeography laboratory with fume cupboard, and two teaching laboratories equipped with benches and light tables for mapping exercises, duplicating room, tutorial rooms and a seminar/ tearoom housing the departmental library. ${ }^{38}$

As in the earlier part of the century, geography was still an important subject in the school system, and many students were funded by the Education Department to become geography teachers. First-year geography lectures were repeated in the evenings to cater for practising teachers and some upper-level courses were offered

\footnotetext{
${ }^{37}$ Ibid.

${ }^{38}$ P. J. Smailes \& T. Griffin, 'Geography at the University of Adelaide'.
} 
in alternate years in the late afternoon to cater for part-time students. Apart from the common first-year courses, more specialised geography courses at upper levels were in place by the late 1960s. Research also became more important, with Rowl Twidale's publications in geomorphology; Nigel Wace's biogeographical work; Michael Williams on rural landscapes; and Fay Gale, in cultural geography. It was also in the 1960s that the first three Geography $\mathrm{PhDs}$ graduated.

Compulsory Level II field camps were held at the start of each year, creating an important sense of common purpose for geography students. A range of study options was provided with courses on South Asia, Economic Geography, Australia, Cartography and Social Geography. The Geography Department also ran two service courses for other Faculties. Economic Geography I was taught for the Economics Faculty first by Keith Thomson, and later by Ron Hefford. This was an important course with large numbers of students in the 60 s but enrolments later declined. Geography IIC (Climatology) was taught for the Science Faculty by Bruce Mason was less popular and according to Smailes and Griffin represented the beginning of discussions over whether Geography, particularly physical geography, should be recognised as options within the BSc degree. ${ }^{39}$

The 1970s saw some major staff changes with the resignation of Nigel Wace in 1971 and the retirements of Ann Marshall (1974) and Bruce Mason (1975) followed by the retirement of the foundation professor Graham Lawton in 1977. New staff were appointed in the 1970s: Blair Badcock in 1972, David Gilbertson and Sandra Taylor in 1975, and Peter Lamb and Dorothy Cloher in 1976. However, there was some instability once the professor had retired. In 1974 Fay Gale was elected as the first non-professorial Chair of the Department, and the first female Chairperson in the University. Three years later Griffin took over the Chair for two years at what was, according to Smailes and Griffin, a particularly difficult time. ${ }^{40}$ There was a university-wide freeze on all new appointments in 1977. In the same year, David Gilbertson resigned and his post was frozen for a year along with the professorial post, which was frozen for five months. At the same time there was a drop in undergraduate geography student numbers, which complicated matters. At the postgraduate level, only two more PhDs graduated

\footnotetext{
${ }^{39}$ Ibid.

${ }^{40}$ Ibid.
} 


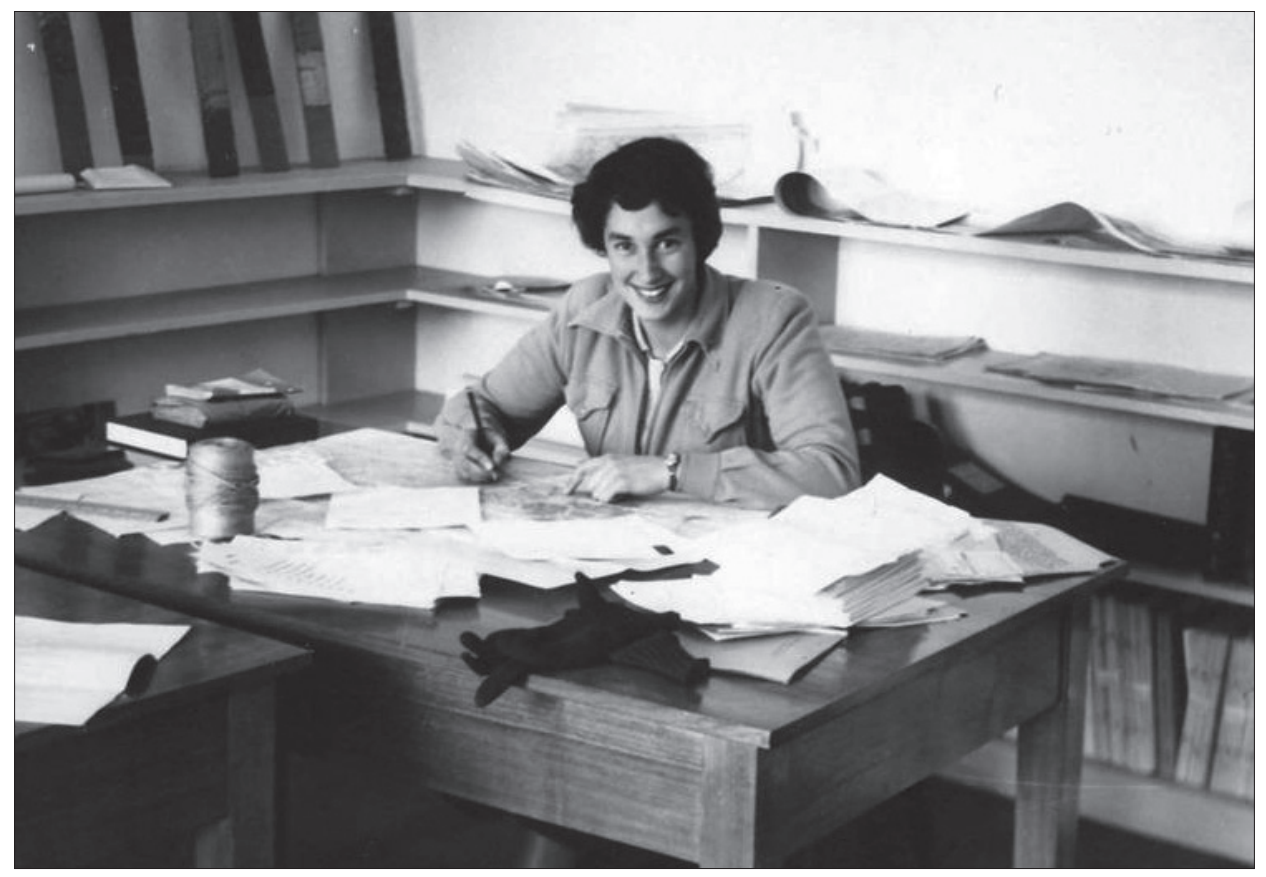

\section{Professor Fay Gale (photograph taken during her Honours year)}

during the 1970s. Michael Williams resigned in 1978 during the same year that Fay Gale was appointed as the Professor of Geography, the first female professor at the University of Adelaide. In 1979 Peter Lamb resigned, Peter Smailes returned to Australia and was reappointed as a lecturer in the Department, and Nick Harvey was appointed to a fixed-term lecturership. According to Smailes and Griffin, ${ }^{41}$ 1979 was 'an exhausting year' with half the staff on study-leave resulting in only five lecturing staff to teach a full set of courses.

The 1980s continued to be a challenge for the Department. Professor Gale was appointed as Chair and immediately began exploring various strategies for the survival of Geography in the face of a university-wide financial squeeze causing three posts in Geography to be frozen at the same time as the discipline had low student numbers. ${ }^{42}$ New staff were eventually appointed: Lesley Potter in 1981; Pauline Catt in 1983; Dawn Williamson in 1986; Bill Boyd to replace Pauline Catt

\footnotetext{
${ }^{41}$ Ibid.

${ }^{42}$ Ibid.
} 
after she resigned in 1986; Maureen Longmore in 1988; and Rob Lesslie in 1988. Remote Sensing (RS), taught in the 1970s as part of a techniques course, became more important with the appointment of Pauline Catt, a specialist in this area. At the postgraduate level, six PhDs completed in the 1980s and although this was more than the previous two decades it was still a low number, because Masters degrees were more popular.

In 1982 a Review of Earth Sciences recommended secondment of Rowl Twidale to the Department of Geology, noting that such a secondment would cause a serious imbalance between physical and human staffing in Geography. A more significant external review of the Department of Geography took place in 1987. According to Smailes and Griffin, ${ }^{43}$ the outcome of that review produced an agreed overall structure and set of aims and principles which recognised that the Department could no longer cover all the four major paradigms of teaching, research and scholarship recognised within the discipline of Geography. In response the Department decided to concentrate on just two of them:

- The spatial analysis theme: an understanding of the spatial ordering and distribution principles involved in both human and physical spatial phenomena

- The 'man/land' or human/environment interaction theme: an understanding of the relations between the natural environment and human activities.

In 1988 Fay Gale was appointed as Pro-Vice-Chancellor and Blair Badcock took over as Chair, with a new course structure in place. From 1989 onwards, the first-year course comprised one semester devoted to the principles of each of the two paradigms. Similarly, two of the second-year semester-length subjects followed up the two first-year lines with core skills and techniques, each leading to a wider range of options at third-year level. ${ }^{44}$ Geography students continued for several years to take second- and third-year Geomorphology courses taught from the Department of Geology and Geophysics.

Peter Smailes took over as Chair in 1989 at a time when a review of Environmental Studies was being conducted and there was concern of potential

\footnotetext{
${ }^{43}$ Ibid.

${ }^{44}$ Ibid.
} 
overlap of courses taught between Geography and Environmental Studies. The Review, however, recommended the appointment of a foundation professor in Environment Studies and supported the maintenance of separate departments. The University also gave approval to replace Fay Gale with the appointment of a new professor of Geography. Subsequently, Graeme Hugo was appointed as Professor of Geography but did not take up the post immediately.

At the start of the 1990s Trevor Griffin took over as Head of Geography awaiting the arrival of a new professor. Ted Davis was appointed in 1991 to look after first-year teaching and in the same year Sandra Taylor was seconded to Environmental Studies, which eventually became a permanent transfer. The arrival of Graeme Hugo, who took over as Head of Department, in early 1992 saw a number of changes, particularly as he brought with him staff from Flinders University - Dianne Rudd, Janet Matta (now Wall) and Margaret Young - to support his population research and teaching, along with 20 postgraduate students working in the population area. ${ }^{45}$ In order to strengthen teaching in physical geography, Ruth Lawrence and David Bass were appointed in 1992 to fixed-term positions.

Throughout the 1990s human and physical geography courses were taught separately underpinning the philosophical direction of the Department. In the late 1990s the Faculty moved to a two-tier system of first-year courses followed by 'advanced' courses, comprising a mix of the former second- and third-year courses. Although there were differences in the work required for these there was a loss of progression, particularly for physical geography. The development of geography in the 1990s had three different strands: human geography, physical geography, and the cross-cutting geographical information systems (GIS) and remote sensing. In all these areas, there was also a significant increase in research focus during the 1990s.

In Human Geography there were specialisations into different strands of economic, rural and social, urban and Southeast Asian geography. Economic Geography was taught by Derek Smith, but student numbers dropped when these courses were removed from the Economics degree. Peter Smailes taught

\footnotetext{
${ }^{45}$ G. Hugo, 'Geography and environmental studies at the University of Adelaide since 1990', South Australian Geographical fournal, 102 (2004), pp. 82-97.
} 
Rural and Social Geography and established a strong research profile in the rural studies literature with his work on the dynamics of rural communities. Blair Badcock taught Urban Geography where he had a strong research record on Australian cities and housing with contributions to policy development and to the development of the Australian Housing and Urban Research Institute. Lesley Potter taught Southeast Asian Studies, focusing on Indonesia where she also had a policy orientation research interest and linkages with international aid agencies.

A major change in Human Geography with the arrival of Graeme Hugo was the teaching and research in population studies and human resources, particularly the postgraduate program taught jointly with Flinders University and comprising mostly full fee-paying overseas students. Around half of the students doing the program came from Indonesia but others came from Sri Lanka, Bangladesh, Pakistan, Kenya, Ethiopia, the US and China. The program at Adelaide was mainly taught by Graeme Hugo, Dianne Rudd and Margaret Young. ${ }^{46}$ Dianne Rudd also taught a number of undergraduate population and methods courses and together with Graeme Hugo focused on the areas of ageing, migration, population studies and human resource development. Linked to this teaching was the growing research profile of the Geography Department in population geography and demography concentrating on Australian and Southeast Asian population issues. ${ }^{47}$ In the 1990s there were a number of ARC research grants along with significant funding from federal, state and local government. In particular, Martin Bell was appointed to a government funded five-year research position to conduct policy research on South Australia's population.

Physical geography in the 1990s was taught by Sandra Taylor then by Ruth Lawrence and David Bass, who was replaced by Peter Gell in 1995. Laboratory and fieldwork support was provided by a laboratory technician, Chris Grivell. Peter Gell developed a strong research team using diatoms for analysis of environmental history. In the late 1990s this led to the formation of a consulting company called 'Diatoma' which won competitive research grants plus government research contracts employed consultant researchers and also attracted a number of $\mathrm{PhD}$ students.

\footnotetext{
${ }^{46}$ Ibid.

${ }^{47}$ Ibid.
} 
Applied methodology courses such as remote sensing (RS) and geographical information systems (GIS) were largely cross-cutting across physical and human geography. RS courses developed in the 1980s by Pauline Catt were taught by Maureen Longmore in the 1990s jointly with colleagues from the Department of Geology for both Geology and Geography students but numbers dropped with diminished cross-faculty collaboration and Maureen resigned in 2000. GIS courses, however, were more successful particularly because of their practical applications and strong research linkages. The first GIS course was developed by Trevor Griffin in the 1990s with the help of Errol Bamford, the computing officer, at a time when not many GIS courses were being taught in other Australian geography departments. Trevor also took responsibility for two of the methods-based courses until his retirement in 1996.

Errol Bamford was a key driver behind the successful bid for a National Centre for Social Applications of GIS (also referred to as GISCA) funded as an ARC Key Centre, with Graeme Hugo as its Director. Errol then moved to GISCA and Margaret Young took over computing management in the Department for the rest of the decade. Her dedication, expertise and research support was appreciated by both staff and students. ${ }^{48}$ Undergraduate teaching of GIS was taken over by GISCA staff and a postgraduate program in Spatial Information Science was successfully taught with colleagues at the Waite Campus and at the University of South Australia. A key to GISCA's success was its research linkages and a focus on the application of GIS to social issues to improve equity and efficiency in the allocation of scarce resources in crucial areas like health, education, aged services, housing and a range of services. ${ }^{49}$ The development of ARIA (Accessibility and Remoteness Index of Australia) is now used as a standard in allocating millions of dollars of funding across Australia's regional areas for services like health and education. ${ }^{50}$

During the 1990s there was a strong Honours program with students such as Zoë Morrison who won a Rhodes Scholarship in 1998. Postgraduate coursework programs such as GIS (later Spatial Information Sciences), Population and Human

\footnotetext{
${ }^{48}$ Ibid.

${ }^{49}$ Ibid.

${ }^{50}$ Ibid.
} 
Resources (later Population and Migration) were strong in the 1990s. There was also a significant increase in the number of $\mathrm{PhD}$ theses with 21 completed in the 1990s, which was more than the total $\mathrm{PhDs}$ completed in the three previous decades. Harvey and Forster comment that of all the geography $\mathrm{PhD}$ theses completed between 1960 and 2004, over two-thirds of these were in the last 10 years. ${ }^{51}$ As noted by Hugo, the Department's research profile was recognised in the late 1990s as one of five Departments in the University, ranked highly according to a University of Adelaide benchmarking exercise against a number of other universities. $^{52}$

The cartographic unit and extensive map library in Geography had a major change in the 1990s with the retirement in 1993 of Max Foale, who had been in charge of the unit since 1964 with cartographers Christine Crothers, Debbie Hagger and Sue Murray. The unit had contributed significantly to the Department's research output but after Max's retirement this left only Christine Crothers and Sue Murray (who subsequently resigned) as the only two cartographers and with the advent of digital technology, usage of the map library continually declined during the 1990s. In the 1990s Margaret Bruce and Joanna Gagliardi continued to look after the administration of the Department. ${ }^{53}$ In 1996 Lesley Potter took over from Graeme Hugo as Head of Department.

\section{ENVIRONMENTAL STUDIES: FROM GROSS-FACULTY ORIGINS TO DEPARTMENTAL STATUS (1975-1998)}

Environmental Studies at the University of Adelaide had its origins in 1970 when Buddy Rodgers of the then Faculty of Agriculture Science led discussions on a committee into the need for a postgraduate award in Environmental Studies. ${ }^{54}$ At the time the focus was on science and technology but law, economic, social and political theory became incorporated when Rob Fowler, John Hatch and

\footnotetext{
${ }^{51}$ N. Harvey \& C. Forster, 'Geography in South Australian universities'.

${ }^{52}$ G. Hugo, 'Geography and environmental studies'.

${ }^{53}$ More detail on administrative staff appointments is contained in P. J. Smailes \& T. Griffin, 'Geography at the University of Adelaide'.

${ }^{54}$ K. Dyer, 'A brief history of the Mawson Graduate Centre for Environmental Studies', Appendix, in A Profile of the Maweson Graduate Centre for Environmental Studies, 21st Anniversary (1975-1996) (Adelaide, The University of Adelaide, 1996), pp. 22-5.
} 
Hugh Stretton joined the committee. Proposals for a Centre of Environmental Studies were narrowly endorsed by the Education Committee and subsequently the Centre had limited academic support from a range of disciplines because it was located outside the traditional faculty funding structure.

Harvey, Forster and Bourman note that

Environmental Studies units emerged in Australian universities in the 1970s, often at the graduate level, to fill a vacuum which emerged as Geography neglected society-environment relationships and applied studies to pursue more narrowly specialised research and teaching. ${ }^{55}$

They contend that public interest in environmental issues became important again after the Brundtland Report of 1987 and the Rio Earth Summit in 1992. Consequently, student interest in 'Environmental' degrees boomed in response to an increased societal awareness of the need for teaching and research in environmental issues. ${ }^{56}$

In 1975 John Hails, a geomorphologist, was appointed as Foundation Director to organise the first Master of Environmental Studies course with an intake of 20 students in 1976. The following year, 1977, Dr Ken Dyer, a social biologist, joined the Centre as a second member of staff. The course intake was restricted to 20 full-time Masters students per year and apart from the two academics within the Centre, staff from different faculties taught the other courses. Only three years after its creation, a review in 1978 caused further uncertainty. In 1981 Hails resigned and Dyer took over as Director for 7 years during which time Dr David Corbett, a geologist, joined the Centre staff in 1983. In 1984 the centre was attached to the Faculty of Arts, to give it a secure line of funding and in 1985 Pam Keeler was appointed as the Centre's part-time administrative officer (later becoming full-time). However, in the mid-1980s it was in trouble with low student numbers and only two permanent staff. At the same time, student numbers had dropped in Geography and there were discussions about a possible merger between Geography and Environmental Studies but this proposal was dropped when John Young was seconded, from the Department of History, as the new Director on the condition that that the Centre retained its independence.

\footnotetext{
${ }^{55}$ N. Harvey, C. A. Forster, \& R. P. Bourman, 'Geography and Environmental Studies'. ${ }^{56}$ Ibid.
} 
An independent external review of the Centre was then conducted in 1989 and concluded that it should remain independent. It recommended that the Centre should be strengthened and restructured, that a chair in environmental studies should be created and there should be an increase in staff. It also made a number of recommendations about course structure. In 1990, John Young retired while Ros Taplin and Phil Tighe took up part-time lectureships, although they had to leave the following year because of Phil's ill health. To provide backup support in 1991-92 Heather Aslin and Nick Harvey were seconded from the Department of Environment and Planning of the South Australian government for one year each. At the same time, David Bennett and Sandra Taylor were made interim directors for one year each and Tim Doyle was appointed to a tenurable position in 1991.

A turning point came in 1993 with creation of the Department of Environmental Studies, the potential to enrol $\mathrm{PhD}$ students for the first time, and the appointment of the Foundation Professor of Environmental Studies, Martin Williams, who was also made Head of Department for the first three years. Nick Harvey was also appointed to a tenurable position in 1993 bringing the number of full-time academic staff to five. The Centre was also given a dedicated Environmental Studies building on North Terrace after having had four previous locations in the previous 20 years. Martin Williams managed to negotiate a significant UNEP International Environmental Management program to be taught by the Centre with the appointment, in 1994, of Jan Carey as coordinator and the enrolment of 19 senior managers from 19 separate countries. This UNEP program created an immediate international dimension to the centre with valuable interactions with other postgraduate students. The program continued for a number of years before UNEP funding was withdrawn and it was taught offshore for a time in Singapore.

Martin Williams brought with him an international research reputation and together with Tim Doyle and Nick Harvey they were able to significantly increase the research outputs from the Centre. In 1996, Nick Harvey was appointed as Director at a time when the Centre had one of largest cohorts of postgraduates in the University with around 180 students. It also had a rapidly 
developing $\mathrm{PhD}$ program with 18 completions in the first 10 years. However, the strong postgraduate coursework culture was threatened in the late 1990s by the federal government's introduction of postgraduate coursework fees. This led to the creation of an undergraduate environmental studies degree (B Env Studies) to offset the predicted loss of postgraduate students.

\section{A merged Department of Geographical and Environmental Studies (1998-2002)}

In 1997, pressures for economic and administrative rationalisation within the Faculty led to renewed discussion for the merger of Geography and Environmental Studies. This was made easier given the fact that three of the Environmental Studies staff had their primary training in Geography. In mid 1998 the Mawson Centre for Environmental Studies merged with the Department of Geography and Nick Harvey took over as Head of the new Department. This paralleled similar mergers around Australia. ${ }^{57}$ Geography and Environmental Studies initially retained their separate disciplinary status and the Masters of Environmental Studies program substantially enhanced the numbers of coursework postgraduate students in the Department.

A strategic plan was developed in 1999 for the merged Department, which outlined four main goals:

- To provide an empowering and inspiring learning, teaching and research environment for a community of scholars drawn from Australia and overseas, particularly Asia and the Pacific

- To foster informed debate and critique the causes and consequences and solutions to global, regional and local environmental and social change

- To provide leadership and advice to the community, government and corporate organisations on environmental and social issues

- To address issues of social and environmental justice, particularly in relation to the spatial structures of society.

These underpinned separate objectives, strategies and performance indicators which were developed across six areas: 1) research, 2) consulting research, 3) 
undergraduate teaching, 4) postgraduate teaching, 5) international and industry links, and 6) service.

After just one year the merged Department was subject to an independent external review in 2000. The review endorsed the strong research record of the Department and recommended increased cooperation between the two disciplines across a range of specific recommendations on course offerings. The review committee supported the development of distinctive Environmental Studies and Geography disciplines but expressed some concern about Faculty restrictions on each discipline's offerings, problems of duplication of courses elsewhere in the University and the siloisation of the University, which constrained the recruitment of science and natural resource management students to the departmental courses. The committee recommended development of a greater coherence in the overall curriculum between the two disciplines on common pedagogical issues.

The staffing of the Department underwent a major shift with the retirement of many long serving and senior staff. Margaret Bruce retired in 1999 after a long service as the departmental secretary and administrator. Four senior and long-serving academics also retired: Ken Dyer and Blair Badcock in 2000, Peter Smailes in 2001, and Derek Smith in 2002. The administrative staff comprised Pam Keeler, as the senior administrator, Kris James, Sarah Hoggard, who was appointed in 1999, and Maria Fugaro, appointed in 2002.

During Nick Harvey's time as Head of Department he was seconded twice to administer the Faculty as Executive Dean, first for three months in 1999 and then again for seven months in 2001/2002. During the second longer period, Pam Keeler left the Department to take on the role of personal assistant to the Executive Dean and Peter Gell acted as Head of Department.

\section{The Discipline of Geographical and Environmental Studies, 2002- 2012 (renamed 'Geographr, EnVirondent and Population' in 2011)}

The function of Departments changed in mid-2002 with a university-wide administrative restructure creating schools rather than Departments as the administrative unit responsible for staffing and budgets. Most former Departments such as Geography and Environmental Studies became 'Disciplines' within a larger school, in this case the School of Social Sciences. The Head of Department, 
Nick Harvey, became the Head of Discipline maintaining responsibility for the curriculum but not for financial matters. This change created competition for funds between the four Disciplines in the school, which all had different cost structures for teaching and research.

Another senior academic Lesley Potter retired in 2003, making a total of three Associate Professors and two Senior Lecturers being lost to the Discipline over a four-year period. Subsequently, new staff were recruited, Louise Mendel in 2002, and Matthew Rofe and Marcus Lane in 2003, but all of these resigned within a relatively short time (2003, 2005 and 2007 respectively). In addition, the retirement of Martin Williams in 2007 (now Emeritus Professor) and the resignation of Peter Gell in 2008, left a gap in Physical Geography and Environmental Studies. However, a new staff profile for the Discipline was created with the appointments of Jennifer Bonham and Jungho Suh in 2006; John Tibby, Thomas Wanner and Douglas Bardsley in 2008; and Rachel Nanson, Melissa Nursey-Bray and Andrew Beer in 2010; although Nanson subsequently transferred to the Faculty of Science in 2011. Professor Andrew Beer strengthened the research capacity of the Discipline when he was appointed by bringing with him a number of research staff from Flinders University, Emma Baker, Debbie Faulkner and Selina Tually.

Nick Harvey remained as Head of Discipline until the end of 2004, when he relinquished his duties to take sabbatical leave in 2005/06. Between 2005 and 2007 the Head of Discipline position then changed hands six times. First, the Head of School, John Gray (an anthropologist) stood in as Head of Discipline in 2005; then Martin Williams for the first part 2006; John Gray again for the latter part of 2006; Marcus Lane for the first part of 2007; then Peter Gell from August to November 2007; and Dianne Rudd for last two months of 2007. However, between 2008 to 2012 there has been a period of relative stability, with Dianne Rudd taking over as Head of Discipline and also having responsibility for the important role of postgraduate coordinator.

In 2011 the Discipline changed its name to, 'Geography, Environment and Population' to reflect its current teaching and research focus and it is the last of the disciplinary units within the three South Australian universities to have the word 'Geography' in its title. The curriculum has maintained its underpinning theme of spatial analysis around which there are three main strands: 
1. Urban and regional and planning (including studies of cities, urban and regional planning and housing issues)

2. Environmental management and environmental change (including the biophysical and socio-economic dimensions of environmental policy and management, environmental economics, environmental sustainability, climate change and environmental change)

3. Population studies (including global population issues, social justice, and applied population studies related to migration, climate change, health and planning).

There is a teaching-research nexus with each of the above linked to a Universityapproved research centre. The first is linked to the Centre for Housing, Urban and Regional Planning; the second is linked to the Centre for Coastal Research; and the third linked to the Australian Population and Migration Studies Centre.

Geography, Environment and Population has recently suffered low undergraduate enrolments, which may be related to the demise of geography as a discipline within the secondary school system in South Australia. In terms of research performance, Adelaide did not rank very well for Human Geography compared with the rest of the country in the recent national ERA benchmarking exercise. However, Demography, which encompasses much of the Discipline's population studies at Adelaide, was rated as having a world standard and was ranked equal top with Demography at the Australian National University. These results in part reflect the nature of the ERA field of research codes, which do not account for some of the strong interdisciplinary research performance of the current staff. The Discipline continues to be a strong performer in terms of competitive research grants, it attracts a high number of postgraduate research students and it has a concentration of high performing researchers within its three research centres. The major challenge for the future of the Discipline appears to be at the undergraduate level, where there is a need to attract greater numbers of students to a revised curriculum that is appealing, comprehensive and relevant for the twenty-first century. 


\section{REFERENCES}

Adelaide University Magazine, 15 (1930), p. 1.

Australian Geographical Studies 'Australia's first University Geography Department, 1921-1996', Australian Geographical Studies, 34 (1996), pp. 281-3.

Badger, C., Three South Australian Librarians some personal recollections (Unpublished,

State Library of South Australia, nd.), Group:D 7172(T).

Badger, C. R., Who was Badger? Aspects of the life and work of Colin Robert Badger,

Director Adult Education, Victoria, 1974-1971 (Melbourne, Council of Adult Education, 1984).

Baker, J. N. N., The History of Geography (New York, Barnes \& Noble, 1963).

Bunbury, E. H., History of Ancient Geography (London, John Murray, 1983).

Cardew, R., 'Development of Environmental Studies Programs', in P. Coyte

(ed.), Directory of Postgraduate Study (Balgowlah [NSW], Australian Vice-

Chancellors' Committee, Graduate Careers Council of Australia and The

Graduate Connection, The Graduate connection, 1996), pp. 212-13.

Crofts, R., 'Geography Matters for the Environment of the Twenty-First

Century', Geography 84.4 (1999), pp. 345-53.

Duke, G. F., 'The development of Environmental Education', Australian Science Teachers Fournal, 20.2 (1974), pp. 17-30.

Duncan, W. G. K. \& Leonard, R. A., The University of Adelaide 1874-1974 (Adelaide, Rigby, 1973).

Dyer, K., 'A brief history of the Mawson Graduate Centre for Environmental Studies', Appendix, in A Profile of the Maweson Graduate Centre for Environmental Studies, 21st Anniversary (1975-1996) (Adelaide, The University of Adelaide, 1996), pp. 22-5.

Edgeloe, V. E., Humanities and Associated Studies in the University of Adelaide, 18761975 (Adelaide, The University of Adelaide, 1986).

Fenner, C., 'The Value of Geography to the Community', Proceedings of the Royal Geographical Society of Australasia, South Australian Branch, Session 1937-38, 34 (1939), pp. 61-8.

Freeman, T. W., A Hundred Years of Geography (Chicago, Aldine, 1961).

Gale, F., 'Award: Griffith Taylor Medallist, Mrs Ann Marshall', Australian 
Geographical Studies, 27.2 (1989), pp. 247-9.

Gale, F., 'Ann Marshall 1909-2001', Australian Geographical Studies, 39.3 (2001), pp. $365-7$.

Gale, F., 'Ann Marshall Pioneer woman geographer 27-12-1909-7-3-2001', The Age. Today Life and Times, 26 May 2001, p. 7.

Gale, F., 'The Development of University Geography, 1904-1960', South Australian Geographical Fournal, 102 (2004), pp. 26-40.

Gale, S. G., The Anniversary of University Geography in Australia (Sydney, Department of Geography, The University of Sydney, 1996).

Gale, S. G., 'The Beginnings of University Geography in Australia', Australian Geographical Studies, 35 (1997), pp. 349-51.

Gale, S. G., 'Edgeworth David and Australian Geography', Australian Geographical Studies, 37 (1999), pp. 73-7.

Harvey, N., 'The importance of Adelaide in the genesis of academic Geography in Australia', South Australian Geographical Fournal, 102 (2004), pp. 1-13.

Harvey, N. \& Forster, C., 'Geography in South Australian universities: future prospects', South Australian Geographical fournal, 102 (2004), pp. 118-27.

Harvey, N., Forster, C. A. \& Bourman, R. P., 'Geography and Environmental Studies: Symbiosis for Survival in the 21st Century', Australian Geographical Studies, 40.1 (2002), pp. 21-32.

Harvey, N. \& Gale, F. (eds), 'The centenary of academic geography in South Australia', South Australian Geographical Fournal, Special Issue, vol. 102. (Adelaide, Royal Geographical Society of South Australia Inc., 2004). Heathcote, L., 'Reply to Citation for Les Heathcote's Griffith Taylor Medal', Australian Geographical Studies, 35.2 (1997), pp. 229-34.

Holmes, J., 'Geography's emerging cross-disciplinary links: process, causes, outcomes and challenges', Australian Geographical Studies, 40.1 (2002), pp. $2-20$.

Hugo, G. J., 'Graham Lawton: a valued leader in Geography', The Adelaidean, 6.9 (June 1997), p. 6.

Hugo, G., 'Geography and environmental studies at the University of Adelaide since 1990', South Australian Geographical Fournal, 102 (2004), pp. 82-97.

James, P. E., All Possible Worlds (New York, Bobbs-Merrill, 1972). 
Jones, R., 'Geography in the Post-1987 Universities', Australian Geographical Studies, 40.1 (2002), pp. 48-57.

Kerr, C., Archie, The biography of Sir Archibald Grenfell Price (Melbourne, Macmillan, 1983).

Kirby, M., 'The University Departments, their History and Teaching:

Geography', AUGU Monthly Neresletter and Gazette, July 1970, pp. 3-7.

Lees, B., 'Australian Geography and Geographic Information Systems', Australian Geographical Studies, 40.1 (2002), pp. 33-47.

LeHeron, R., 'Keith Westhead Thomson CMG, MBE, 1924-1997', Australian Geographical Studies, 36.1 (1998), pp. 104-6.

Marginson, S. \& Considine, M., The Enterprise University: Power, Governance and Reinvention in Australia (Melbourne, Cambridge University Press, 2000). Marshall, A., 'Sir Grenfell Price: An Appreciation', in F. Gale \& G. H. Lawton (eds), Settlement and Encounter: Geographical Studies presented to Sir Grenfell Price (Melbourne, Oxford University Press, 1969).

Marshall, A., 'Reply by Ann Marshall (Griffith Taylor Medallist)', Australian Geographical Studies, 27.2 (1989), pp. 249-50.

Mason, N., 'Bruce Mason, 1914-2001', South Australian Geographical fournal, 100 (2001), pp. 79-81.

McLean, R., 'Citation for Les Heathcote's Griffith Taylor Medal', Australian Geographical Studies, 35.2 (1997), pp. 229-34.

Parker, F. L., 'Fiftieth Anniversary Jubilee Celebration', Proceedings of the Royal Geographical Society of Australasia, South Australian Branch, Session 1934-35, 36 (1936), pp. 52-6.

Peake-Jones, K., The Branch without a Tree: The Centenary History of the Royal Geographical Society of Australasia (South Australian Branch) Incorporated 1885-1985 (Adelaide, Royal Geographical Society of Australasia (South Australian Branch) Incorporated, 1985), p. 197.

Pemberton, D. A., 'Definitional problems for Environmental Education and Geographic Education', Fournal of Environmental Education, 21.1 (1989), pp. 5-14.

Powell, J. M., 'Revisiting Geography's Australian Foundations', Australian Geographical Studies, 37 (1999), pp. 70-2. 
Raymond, I., Australian Dictionary of Biography, vol. 8, 1891-1939 (Melbourne, Melbourne University Press, 1981), pp. 31-2.

Simpson, A. A., 'Annual Address of the President', Proceedings of the Royal Geographical Society of Australasia South Australian Branch, Session 1928-29, 31 (1930), pp. 12-19.

Smailes, P. J., 'Graham Henry Lawton, 1912-1997', Australian Geographical Studies, 35.3 (1997), pp. 345-8.

Smailes, P. J., 'Ann Marshall, 1909-2001', South Australian Geographical fournal, 100 (2001), pp. 75-80.

Smailes, P. J. \& Griffin, T., 'Geography at the University of Adelaide, 19601991', South Australian Geographical Fournal, 102 (2004), pp. 62-81.

Taylor, G., Geography in the Twentieth Century (New York, New York Philosophical Library, 1951).

The University of Adelaide, Calendar, 1904-1959, 1908.

Thomas, I., 'Australian Tertiary Environmental Courses: A status report', Australian Fournal of Environmental Education, 9 (1993), pp. 135-45.

Ward, B. J., 'The role of the Royal Geographical Society of South Australia', South Australian Geographical fournal, 102 (2004), pp. 14-25.

Watts, D. G., Environmental Studies (London, Routledge \& Kegan Paul, 2004). 


\section{8}

\section{Gender Studies and Social Analysis}

Margaret Allen and Susan Magarey

\section{Research Gentre for Women’s Studies 1982-2000}

Women's Studies arrived late at the University of Adelaide. In mid-1981, rumblings of concern about the position of women in the University finally gained a hearing. Four women - Amanda Cornwall, representing the Students' Association; Fay Gale, Professor of Geography and the only woman in a senior position on the teaching staff; Alison Mackinnon, a full-time Tutor in the University's Education Department; and Jill Thomas, Personal Assistant to the Vice-Chancellor presented a discussion paper on the subject to the University's Executive Committee. Executive Committee debated the paper. It began to appear that the women's concerns would disappear into a cloud of confusion. But then Professor Gale, dramatically, lost her temper: she thumped the table and raised her voice. ${ }^{1}$ The effect was dramatically instantaneous. Executive Committee established a working party to examine the position of women, and it invited submissions. ${ }^{2}$ By

\footnotetext{
${ }^{1}$ Personal communication from Professor Emerita Alison Mackinnon.

${ }^{2}$ Lumen, 10.4 (14 August 1981).
} 
the middle of 1982, the University Council had accepted most of its far-reaching recommendations - including an excellent case against Sexist Language, which deserves revisiting - and appointed an implementation committee. ${ }^{3}$

In this process, the Faculty of Arts secured one-off funding to establish a Research Centre for Women's Studies. Late in 1982, it advertised for a Director for this new body, the first of its kind in Australia. In 1983, Susan Magarey - a graduate of both the University of Adelaide and the Australian National University - accepted the position, and moved from Canberra where she had been teaching an undergraduate major in Women's Studies since 1978.

\section{What is Women's Studies?}

Women's Studies is a reflex of the social event upon the world of learning. As Magarey wrote, Women's Studies 'represent the continuing impact made upon the academy by the Women's Movement', by the resurgence of feminism in the second half of the twentieth century. ${ }^{4}$ In the long history of epistemology, an analogy can be drawn with the major shift in the fifteenth to seventeenth centuries in Europe in the direction of intellectual endeavour, from contemplation and exposition of the works of the deity to exploration and investigation of the 'natural' world and its inhabitants. As English poet Alexander Pope observed, 'The proper study of Mankind is Man' (1734). Just over two centuries later, French philosopher Simone de Beauvoir observed that his comment was all too literally true. Men, she remarked, have observed the world from their own point of view and then confused that with 'absolute truth' (1949).

Women's Studies marks a major shift in the direction of human intellectual inquiry, from an androcentric exploration of the world to a genuinely human inquiry, one which includes feminine as well as masculine points of orientation. It is a shift which acknowledges that androcentric research produces analyses which do not merely present women, or the feminine, as unimportant or invisible, but rather, analyses which are seriously inaccurate because they fail to ask the questions

\footnotetext{
${ }^{3}$ The University of Adelaide Bulletin, 8.9, July 1982.

${ }^{4}$ S. Magarey, 'Women's Studies in Australia - Towards Trans-Disciplinary Learning', fournal of Educational Thought (Calgary, Canada), 17.2 (August 1983).
} 
which, by compelling researchers to assemble information about both women and men, would produce accounts of a whole, rather than a half masquerading as a whole. In a shorter history of epistemology, it could be noted that Women's Studies was but one - a forerunner - in a series of challenges and changes in the intellectual disciplines summarised, in Australia, in the surveys of an array of new 'studies' published by the Academies of the Humanities and the Social Sciences at the end of the twentieth century. ${ }^{5}$

The University of Adelaide's understanding of Women's Studies was essentially compensatory, that is attending to the absence of women in the tertiary curriculum. Magarey's understanding of Women's Studies, however, was as a means to transform knowledge. As she said, 'You can't simply add the notion that the world is round to the notion that it is flat.' She argued for Women's Studies that were 'not only compensatory courses on women-and/in-this-or-that-specialism', but also courses, research and analyses which posed questions not answered adequately within the paradigms of a single discipline. Then it would be necessary to draw on several of the established intellectual disciplines, and find ways of synthesising their determinations into answers to such questions. This was work which could best be defined as 'trans-disciplinary'. ${ }^{6}$

Early in 1984, the Research Centre for Women's Studies issued a pamphlet which listed its six broad purposes. They were:

To initiate individual and group research projects by staff and students

To facilitate cross-disciplinary research

To supervise higher degrees on topics in the field of women's studies

To organise seminars, conferences and publications for the dissemination and critical discussion of research on women and of feminist theories

To attract outside grants and commissions from Government and other agencies for research on policy and other social issues concerning women

\footnotetext{
${ }^{5}$ Australian Academy of the Humanities \& Australian Research Council \& National Board of Employment, Education and Training (Australia), Knowing Ourselves and Others: The Humanities in Australia into the 21st Century, vol. 2 (Canberra, Dept. of Employment, Education, Training and Youth Affairs, 1998); K. K. Ruthven (ed.), Beyond the Disciplines: The Nerw Humanities, Papers from the Australian Academy of the Humanities Symposium 1991, Occasional Paper no. 13 (Canberra, Highland Press, 1992); Academy of the Social Sciences in Australia, Challenges for the Social Sciences and Australia, vol. 2 (Canberra, Australian Government Publishing Service, 1998).

${ }^{6}$ S. Magarey, 'Women's Studies in Australia'.
} 
To offer its collective and diverse expertise to Departments which wish to incorporate recent scholarship concerning women in their courses, and to assist students interested in undertaking honours or postgraduate research on women. ${ }^{?}$

It was not at all clear how a single appointment was to offer 'collective and diverse expertise'. But over the ensuing sixteen years Magarey did fulfil this brief, necessarily developing her transdisciplinary span to meet the invitations to speak arriving at the Research Centre from Departments as different as Plant Pathology and Psychology, Philosophy and Botany, to say nothing of the Department of Housing and the Working Women's Centre in the South Australian government. The University and the Faculty of Arts, though, remained firmly disciplinary, both intellectually and structurally.

The Research Centre's achievements can be summarised under the first three of those six goals.

\section{Individual and group research projects}

Many of the research projects initiated by the Research Centre for Women's Studies were designed to raise funds as much as to conduct research. Raising funds was imperative, Magarey learned, on her first visit to Adelaide after accepting the appointment, before she had taken up the post. The University's Office of Research - which in 1983 consisted of one person, the incomparable Geoff Hudson - suggested that she apply to the University Research Scheme, applications due in two days time. This gained the Research Centre a Research Assistant, Laurie Parkes, to compile a bibliography on the history of the family in Australia, a research tool of potential use to many. As an unofficial dimension of this post, while Magarey was back in Canberra completing her year's teaching there, Parkes also organised weekly gatherings of Women's Studies supporters, most from beyond the University of Adelaide, often with a cask of wine on the banks of the River Torrens.

Other research projects followed. By the time that Magarey took up her post, she had gained a grant of $\$ 42,694$ from the South Australian Department

\footnotetext{
${ }^{7}$ Papers of the Research Centre for Women's Studies, University of Adelaide Archives, Series 1474. Unless stated otherwise, all the following account is drawn from this collection.
} 


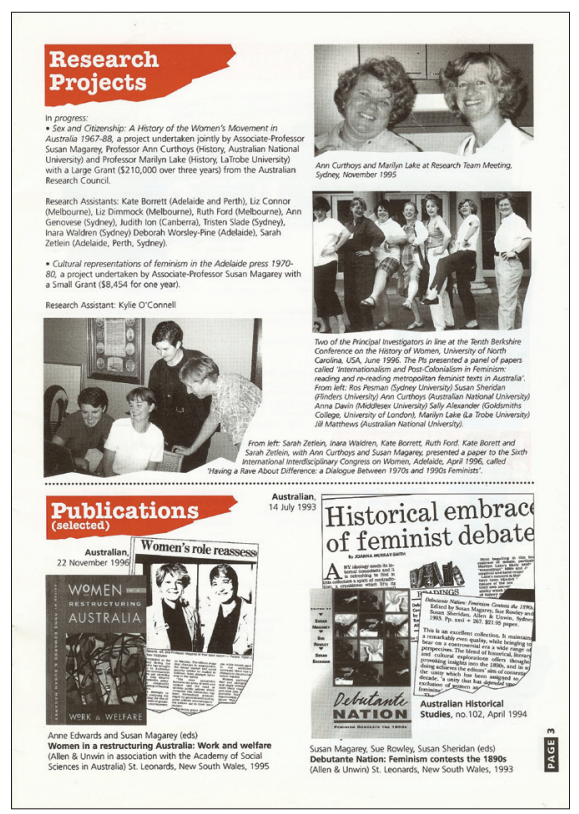

Research Projects: in process and published

of Labour, salaries for four full-time professional assistants and a full-time typist. By the end of the Research Centre's life, Magarey had earned over half a million dollars in research grants, mostly from the Australian Research Council. Her largest grant was for $\$ 210,000$ over three years for a History of the Women's Liberation Movement, a project that employed a total of nine research assistants at different times and produced several publications.

\section{Cross-disciplinary research}

\section{Public Lectures}

Dismayed by the general lack of understanding about what Women's Studies could be, Magarey applied to the University of Adelaide Foundation for funding for air-fares to bring to Adelaide a number of distinguished scholars to give public lectures under the general heading 'Changing Paradigms: The Impact of Feminist Theory on the World of Scholarship'. They filled the Napier Building's 
chief lecture theatre on five successive Wednesday evenings in 1984. ${ }^{8}$ The funding granted did not allow for accommodation, so Magarey provided this in her own home, then and often in the future.

\section{Seminars}

The Research Centre for Women's Studies offered a weekly seminar during the teaching sections of each year throughout its life. Presenters came from many parts of the University of Adelaide, as the University had determined that the Research Centre was to be concerned with research and scholarship in other faculties besides Arts. Presenters came from all over the city of Adelaide, from Flinders University and from the South Australian College of Advanced Education. Presenters came from all over the world; among many others, they included Professor Gayatri Chakravorty Spivak of the University of Pittsburgh; Angela Carter, English feminist novelist; Professor Elizabeth Wood from Sarah Lawrence College; Professor Leonore Davidoff from Essex University; Professor Jeanne F.I. Illo of the Ateneo de Manila University in The Philippines; Professor Sigrid Weigel of the University of Hamburg, Germany; Professor Toril Moi of Duke University; Ms Gertrude Mongella of the United Nations, New York; and Professor Carolyn Steedman of Warwick University.

\section{Conferences}

The Research Centre for Women's Studies organised and hosted many conferences. They ranged from an international gathering on Women and Tertiary Mathematics (1984), to a small national conference on Australian Feminist

\footnotetext{
${ }^{8}$ The lecturers were Professor Marilyn Strathern, Fellow of Girton College, Cambridge, co-editor of Nature, culture and gender (1980), Chancellor's Distinguished Professor at the University of California at Berkeley in 1984; Dr Kay Daniels, Senior Lecturer in History at the University of Tasmania, coeditor of Women in Australia: an annotated guide to records (1977), Chair of the Australian Government's Committee of Review of Australian Studies in Tertiary Education; Dame Roma Mitchell LLB, Inaugural Chair of the Human Rights Commission and Chancellor of the University of Adelaide; Dr Meredith Edwards, Research Fellow in the Social Justice Project, Australian National University, Senior Lecturer in Economics at the Canberra College of Advanced Education, author of The Income Unit in the Australian Tax and Social Security Systems (1983); and Associate-Professor Bettina Cass of Social Policy at the University of Sydney, formerly Senior Research Fellow at the Social Welfare Research Centre at the University of New South Wales, co-editor of Women, Social Welfare and the State in Australia (1983).
} 


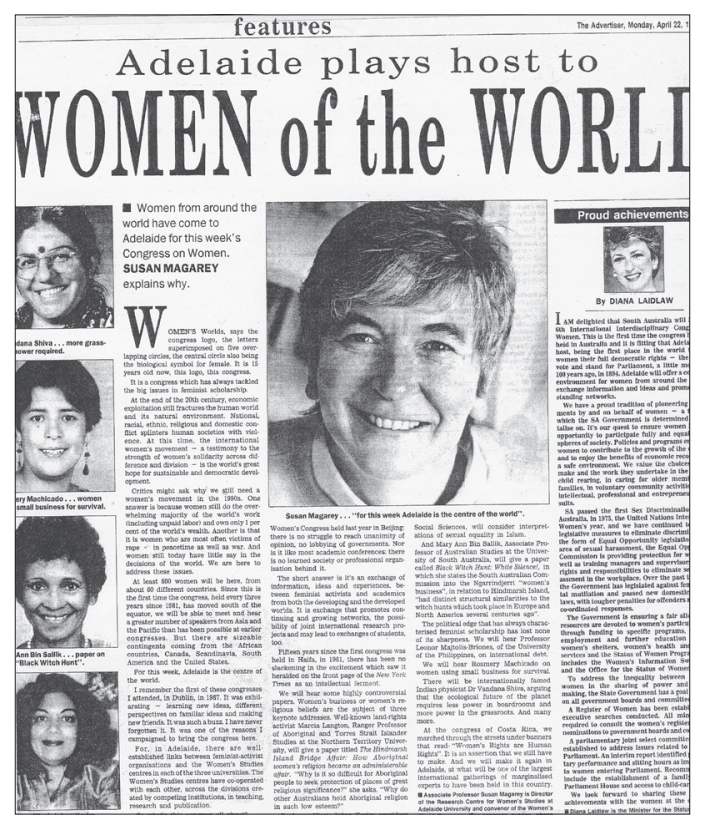

\section{Women of the World in The Advertiser, Monday 22 April 1996}

Biography and Autobiography (1989), to a UNESCO-funded Sub-Regional Workshop on Women's Studies in Asia \& the Pacific (1991), to a workshop funded by the Academy of the Social Sciences on Women and Restructuring: Work and Welfare held in Canberra (1992).

The most clearly interdisciplinary were two major international conferences. One was the third of the Humanities Research Centre's conferences on Feminism and the Humanities, in 1986. Titled 'Feminist Enquiry as a Transdisciplinary Enterprise', and held in Elder Hall, this event brought to University of Adelaide such distinguished speakers as Professor Rosi Braidotti, Columbia University Programs in Paris, Professor Anna Tröger, Institut für Soziologie, University of Hanover, and Professor Catharine R. Stimpson, Graduate School, Rutgers University. The University of Adelaide's Professor Fay Gale was also one of the speakers at this conference. The other was the Sixth International Interdisciplinary Congress on Women, sponsored jointly by the Universities of Adelaide, Flinders and South Australia and by AusAID in 1996. This brought to Adelaide 1,000 
participants, half from overseas, from fifty-seven different countries. Its speakers dominated the local press all week.

Susan Magarey also presented papers at international conferences across the world, ranging from Wellesley College, Massachusetts (1987), to the Universiti Sains Malaysia (1992), to Athens (1993) and Costa Rica (1993), to the University of Tromsö (1999) to the Fourth European Feminist Research Conference in Bologna, Italy (2000). In 1986, at the invitation of the United States government, she spent a month visiting Women's Studies Centres and Programs at various US universities, hosted by the United States Information Service.

\section{Publications}

Most of the Research Centre's research projects resulted in publications, as did some of the conferences; Magarey's curriculum vitae lists ten books, four of them monographs (one a prize-winner), six of them edited collections, and the Research Centre boasted a further five self-published reports. But the principal and longest lasting of the Research Centre's publications is the journal Australian Feminist Studies. Launched by Robyn Archer in the Staff Club in the summer of 1985, issue one carried the texts of the 'Changing Paradigms' public lectures from the previous year. Later issues pioneered publication of philosophical scholarship on Feminism and the Body (no. 5, 1987), on The Sex/Gender Distinction (no. 10, 1989), papers from the Third International Playwrights Conference (no. 21, 1995), on Feminist Science Studies (vol. 14, no. 29, 1999), and on "Gender in the "Contact Zone"" (vol. 16, no. 34, 2001). In her last editorial, Magarey noted that this issue captured 'exactly the combination and mutual implication of the local and the global, the scholarly and the political, that have been my primary aspirations for this journal'. ${ }^{9}$

Produced by the Research Centre, initially with the aid of a grant from the University Grants Committee, this bi-annual journal won ringing praise from such international scholars as Professor Joan Wallach Scott (The Institute of Advanced Study, Princeton) and Professor Martha Vicinus (University of Michigan). Catharine Stimpson, now Dean of Graduate Studies at New York University, declared it 'a gift to the whole world that cares about intellectual transformations'.

In 1996, it joined the stable of journals produced by the international

\footnotetext{
${ }_{9}^{9}$ S. Magarey, 'Editorial', Australian Feminist Studies, 20.47 (2005), p. 151.
} 
publishers Taylor \& Francis (now also Routledge). In June 2005, Susan Magarey, its Founding Editor, and Sue Sheridan (Women's Studies, Flinders University), its Founding Reviews Editor, passed this journal on to Macquarie University. The handover, which was also Magarey's festschrift, was marked by a conference 'Generations of Feminist Studies' with 37 papers and five keynote speakers: Desley Deacon from the Australian National University, Sneja Gunew from the University of British Columbia, Aileen Moreton-Robinson from the University of Queensland, Terry Threadgold from Cardiff University, and Martha Vicinus, Eliza M. Mosher Distinguished University Professor at the University of Michigan. The new Editor of Australian Feminist Studies is Professor Mary Spongberg. Its new Reviews Editor, Associate-Professor Nicole Moore, is now at the Australian Defence Force Academy.

\section{To supervise higher degrees in the field of Women's Studies}

Applicants for the position of Director of the Research Centre for Women's Studies were informed that the University of Adelaide did not offer any courses in Women's Studies and did not plan to do so. ${ }^{10}$ Nevertheless, the Management Committee of the Research Centre agreed with Magarey that without any undergraduate teaching in Women's Studies there were unlikely to be any graduates wanting to do research in Women's Studies. Accordingly, Magarey accepted invitations from the Anthropology, Education, English and History Departments to teach undergraduates: a special Honours option for them all, titled 'A History of Feminist Thought in the English-Speaking West 1780-1980'; for one year, a special Honours option for Anthropology on 'Sexualities', focussed on Michel Foucault's three-volume History of Sexualities; also for one year, a term in a second/third-year course offered in the History Department on 'Social and Political Ideas since the seventeenth century'. The reasons for these last two being for only one year appear below.

The Research Centre's major successes include Dr Anne Genovese, Honours in Law and History, now an Associate-Professor of Law at the University of Melbourne; Dr Judy Harrison/Lattas, Honours in English, now Senior Lecturer

\footnotetext{
${ }^{10}$ J. Blackburn, 'Research Centre for Women's Studies', University of Adelaide Archives, Box 1, Series 1474.
} 
in Women's Studies at Macquarie University; Dr Tamara Jacka, Honours in Asian Studies, now a Research Fellow at the Australian National University; Dr Elaine Jeffreys, Honours in Asian Studies, now a Lecturer at the University of Technology, Sydney; Professor Vera Mackie, Australian Research Council Future Fellow in the Centre for Asia-Pacific Social Transformation Studies at the University of Wollongong; and Dr Tonia Mezzini, Honours in History, now a distinguished medical practitioner.

\section{Trials, tribulations and triumphs}

Trials were concerned principally with gaining adequate funding, accommodation for the researchers employed on those funds, and coping with a surprising level of hostility and suspicion among university colleagues. Rather than dwelling on these difficulties, we will note here only that overcoming them owed a very great deal to the support of the Research Centre's Management/Advisory Committee, and in particular to Fay Gale, Peter Burns, Bob Bogner, Margaret King, Jean Blackburn and Carol Bacchi. All the work of the Research Centre was indebted to its founding half-time Secretary, the wonderful Maryan Beams, a university medallist in Sociology from Flinders University, and to her successor Mary Lyons.

We have already mentioned funding.

The Research Centre for Women's Studies was to move three times in the course of its seventeen-year life. From one room in the Napier Building, it moved to three rooms, with access to office space and a seminar room in the Wills Building, thence to Security House across North Terrace from the main campus. Subsequently, the University decided to build the Research Centre special offices in the undercroft of the Napier Building, a space that the twenty-first century has, at Susan Magarey's suggestion, translated into the Office of the Faculty of Humanities and Social Sciences (the successor to the Faculty of Arts).

Hostility and suspicion surfaced at moments when senior members of the University administration endeavoured to foil projects that Magarey was proposing. One administrator leant across the Dean of Arts to fondle her knee, presumably to distract her. Another refused to allow her to book lecture theatres for a conference because 'women wore high heels' and would disturb students in examinations nearby. Hostility was evident when a senior academic persisted in asking her if she 
was married so stridently that she would not have been able to deliver the paper she had been invited to present if his colleagues had not intervened.

Suspicion appeared when Magarey accepted invitations to teach for the Departments of Anthropology and History. In both cases, the Departments set up forms of exceptional supervision. The Anthropologists required that her Honours option be co-taught with two of their colleagues, who then refused to allow there to be any reading set, as that would, they maintained, 'pre-empt student choice'. (Ironically, when the Anthropology Department had to be disestablished for some years, the Research Centre provided home and succour for its two women members of staff.)

The History Department requested her to provide lectures on feminism for one term of a year-long course, but insisted that tutorials would be taken by a senior - non-feminist - member of staff. That Department also insisted that, as Magarey had a whole term to teach about feminism, one week should be sequestered for a lecture by an anti-feminist. (There was no recognition that the other two terms, being devoted to socialism and conservatism, could be considered to be, at least, non-feminist.) The Department then invited two prominent speakers who were touring the country in a campaign against the Commonwealth government's sex discrimination legislation, and released publicity for the lecture, publicity that appeared nationally, prompting questions from the Office of Women's Affairs in Canberra. The History Department did apologise to Magarey, afterwards, but then confessed that they did not really understand what for.

The first triumph was in securing the future for the Research Centre. ${ }^{11}$ The

\footnotetext{
${ }^{11}$ See S. Magarey, 'Setting up the first Research Centre for Women's Studies in Australia, 19831986', Australian Feminist Studies 13.27 (1998); Andrew Cook of Adelaide University Archives, Blog, 2011.The archives show that the campaign for the future of the Research Centre for Women's Studies included petitions from students at the University of Adelaide with no fewer than 329 signatures; 13 letters from prominent South Australian women; and 12 letters from prominent women across Australia, including the Hon. Susan Ryan, Minister for Education; Anne Summers, First Assistant Secretary in the Office for the Status for Women in the Department of the Prime Minister \& Cabinet; and Mary Draper, Coordinator of Women's Affairs in the Victorian Department of Premier \& Cabinet. Dr Hester Eisenstein, Assistant-Director of Equal Opportunity in Public Employment in the government of New South Wales, wrote that 'The Research Centre for Women's Studies is a welcome innovation that, under the skilful and intelligent leadership of Dr Susan Magarey, has already won a reputation for academic excellence'. Dr Sneja Gunew of the Women's Studies Course-Team at Deakin University wrote that 'We had already been looking to the Centre as a focus for the research interests generated by the courses we offer. The current Director, Dr Susan Magarey, has in a short time established the Centre as a unifying presence in Australian women's studies and
} 
second triumph was the unification of the Research Centre and the Women's Studies Course Team from the South Australian College of Advanced Education [SACAE], creating a new academic department, teaching a full range of undergraduate courses in Women's Studies as well as providing postgraduate supervision, eventually with a full professor of Women's Studies too. The need for the Research Centre had dwindled. It was closed in 2000, and Susan Magarey retired in 2003. Bewilderingly, the University of Adelaide made her a professor in 2004 and a professor emerita in 2012. She continued her work on Australian Feminist Studies until 2005.

\section{Department of Women's Studies to Gender Work and Social INQUIRY 1992-2012}

\section{Amalgamation and Transition}

Confounding all the earlier expectations of the Faculty of Arts at the University of Adelaide, the Department of Women's Studies established in 1992 was thoroughly interdisciplinary. The Department - the first in Australia - an effect of the merger of the city campus of SACAE and the University of Adelaide brought with it a dynamic team of scholars and a range of innovations in teaching, learning and research. The Women's Studies Course Team, initially made up of Margaret Allen, Ann Aungles, Jackie Cook, Kay Iseman (later Schaffer), Karobi Mukherjee and Myra Williams (later Betschild) had developed them at the Salisbury CAE in 1978 when team members taught Women's Studies subjects to undergraduate students within their different disciplines. Their most important joint activity was the Graduate Diploma in Women's Studies beginning from 1979, which was offered to both internal and external students. Later in the 1980s, feminist academics from other campuses in SACAE also taught in the program. The evening classes were generally taught at various central locations in the city, for the convenience of the students, who worked as teachers, nurses, lawyers, social workers and in the state bureaucracy. These, and the external students located across the country, often entered the Graduate Diploma/Master's program to improve their professions' service delivery to girls and women. They formed a different constituency from

it would be an irreplaceable loss if funding were to prevent its continuation'. 


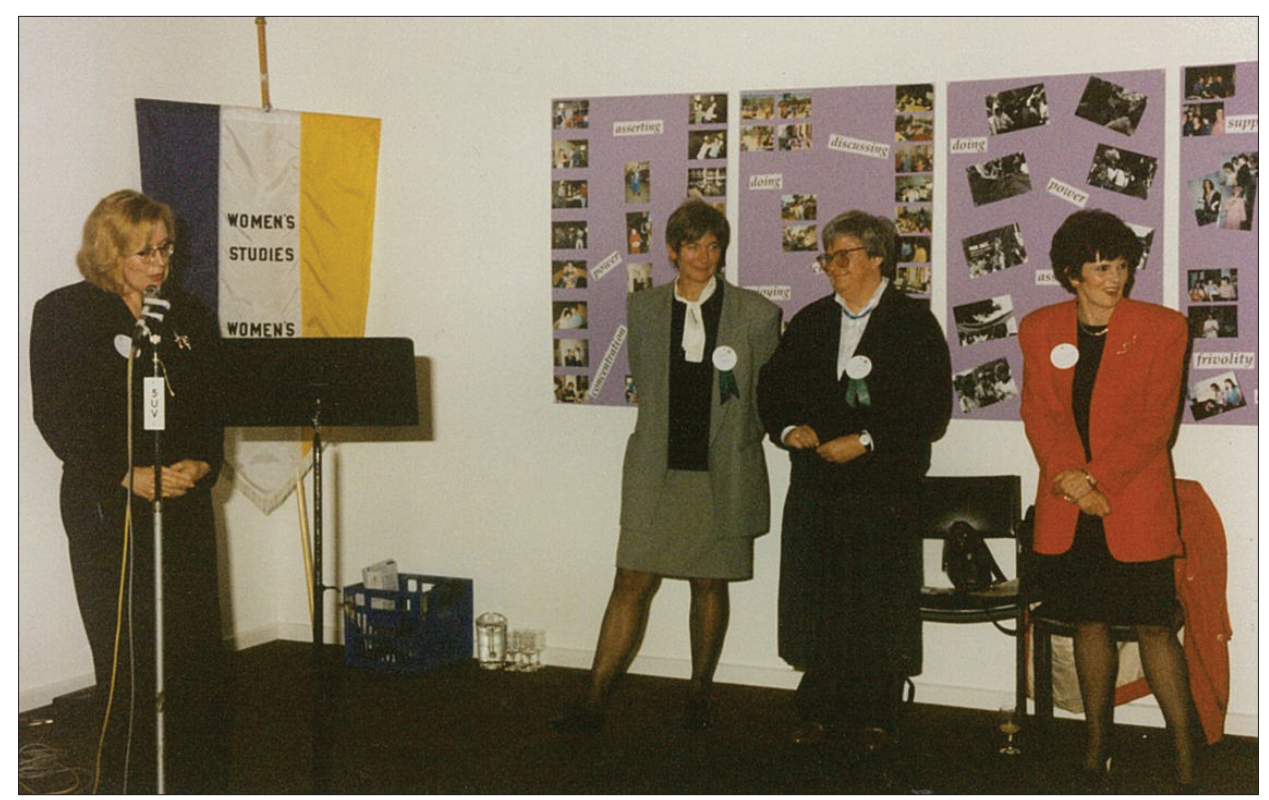

Launch of Women's Studies Department 1992. From left: Anne Summers AO, Susan Magarey, Margaret Allen, Susan Lenehan, Minister of Education. The posters on the wall show aspects of the work of the ex-SACAE Women's Studies Course Team (photograph courtesy of Margaret Allen)

most other university programs: mature-age, passionate activists, many of whom held or went on to hold positions of influence in public policy, education and academia.

In 1983, the team introduced the Associate Diploma in Women's Studies, an innovative equity-program for graduates from the Technical and Further Education (TAFE) Women's Studies certificate. This allowed mature-age women without matriculation who had completed the year-long TAFE course to bridge into CAE degree and diploma programs.

In 1989, these programs and staff moved to the city campus of SACAE on Kintore Avenue. From 1990, the staff developed a Masters program, in association with Women's Studies staff at Adelaide and Flinders University. With the creation of a single unified system of higher education in 1991, Women's Studies staff at SACAE city campus, Kay Schaffer, Myra Betschild, Margaret Allen and Chris Beasley, became members of the University of Adelaide. 
The transition into the University was not without its challenges. Not only did it involve the team coming to terms with new institutional structures, academic expectations, bureaucratic procedures and historical folkways - including coping with the faculty administration's repeated failure to amend departmental circulation lists to include them; it also required the transfer of a considerable library of feminist texts from SACAE to the Barr Smith Library. However, in 1992, the new Department of Women's Studies was established in the faculty, moving physically from the Schulz Building to shared premises with Susan Magarey and the Research Centre for Women's Studies in the Napier Undercroft. Susanne Schech and Margie Ripper joined the staff and Susan Magarey held a half-time position in the new Department. To ensure that the arrival was noticed, the new Department hosted a celebration in August 1992, attended by the ViceChancellor Gavin Brown, the Dean, Robert Sellick, and many members of the University community. Anne Summers AO, political adviser to the then Prime Minister Paul Keating, formally launched the Department. Susan Lenehan, the first graduate of the Graduate Diploma in Women's Studies program and then State Minister of Education, spoke about the importance of Women's Studies to her personal and professional life.

\section{Developing teaching}

The Department of Women's Studies offered a full, three-year undergraduate course of study, soon followed by a dedicated Women's Studies Honours program. While the merger involved some changes to the program, assessment measures and entry processes, closing off some of the study patterns and equity options which the old Women's Studies Course Team had pioneered, new opportunities, especially for research degrees and postgraduate scholarships, became available. The Associate Diploma program soon disappeared, as the University would not accept mature students who had not matriculated nor taken the Mature Age entry test. However, TAFE Women's Studies graduates entering the University by means of the Mature Entry test, still enrolled in Women's Studies for their university studies. The Non-Graded Pass system for the Graduate Diploma, an expression of the egalitarian feminist pedagogy inherent to the SACAE program, was replaced by graded assessment from 1992. The Department began awarding 
prizes, donated by women's organizations, to top students at every year level.

During the early 1990s, the Graduate Diploma and MA Women's Studies programs flourished. Extended requirements for individual research components in these programs allowed the Graduate Diploma to be accorded Honours equivalence. These students and those in the Masters coursework program, including those studying by external studies, became eligible for research higher degrees. In 1992, the Department graduated its first four MA students, all of whom subsequently completed doctoral studies at Adelaide or another Australian university. The Department began enrolling postgraduate students and in 1996, Jyanni Steffensen (ex MA program) and Barbara Pocock, then teaching in Labour Studies, were the first $\mathrm{PhD}$ graduates. Kay Whitehead (currently Professor in Education, Flinders University) graduated with a $\mathrm{PhD}$ jointly in Education and Women's Studies. Jyanni Steffensen subsequently held an ARC postdoctoral position in the Department, while Barbara Pocock subsequently was appointed as Professor at the University of South Australia where she heads the Centre for Work and Life. Despite the fact that the postgraduate students were not physically located in the Department until 1997, staff and students worked to create a supportive and an intellectually vibrant research community.

The Department and teaching was both multidisciplinary and interdisciplinary. The teaching staff included historians, sociologists, literary and cultural scholars and experts in women's health and recreation. From the 1970s, while active in a number of political, social and cultural campaigns around women's issues, they had participated in the creation of the interdisciplinary field of Women's Studies, making a place for it in the academy. They critiqued the male-centred assumptions of older established disciplines.

The subjects taught reflected both this multi-disciplinarity and also the personal reflexivity of the women's movement. Thus, one of the first-year undergraduate subjects, Women's Health Issues, taught in the early 1990s, involved critical analysis of the male dominated medical establishment along with an examination of specifically female health issues, including students' own health, and the encouragement of healthier lifestyles. In the Graduate Diploma, Personal and Professional Development allowed for examination of one's own career and position in one's profession along with development of a personal program for 
career enhancement. Autobiography and Creative Writing had long been part of the Graduate Diploma/MA program and a number of creative writers emerged from this course, including Adelaide poet Miriel Lenore, biographer Jill Golden, and writer Maria Palotta-Chiarolli. Interdisciplinary courses in Feminist Theory, Media and Cultural Studies were also taught both at undergraduate level and also in the Graduate Program. A wide range of subjects were taught in the Graduate Diploma program by both the full-time staff and also by visiting and temporary staff. These subjects evidenced the intellectual excitement of growing feminist perspectives on knowledge across a number of disciplines: Gender and Development, Women and the Environment, Women in History, the Division of Labour, Women and Social Policy, Women, Work and Economics, Perspectives on Sexualities, Popular Culture, Women and Representation and Women and Religion, among others. The intellectual projects, which spawned these courses saw similar contemporary developments at Sydney University and across the United States, notably at Harvard University.

Over the years and with the departure of key staff, such as Myra Betschild, who retired early in 1998, some of the emphases of the program changed. The more experiential parts diminished. This was also due in part to the ending of the Graduate Diploma and coursework MA programs, which had seen graduate women working mostly in the human services sector reflecting upon their personal and professional lives. Increasingly the student body was drawn from undergraduate students together with research higher degree students.

\section{Building a research record}

Within the binary system of higher education, the CAEs had not been funded for research. Nevertheless, staff quickly established a strong research output for the Department. In 1992, Margaret Allen was a Chief Investigator on an Australian Research Council Collaborative Grant (now ARC Linkage Grant) to investigate the position of women general and academic staff in Australian universities. The industry partner on this grant, which was one of the earliest such awards in the Social Sciences, was the National Tertiary Education Union. Staff members were successful in obtaining coveted ANU Humanities Research Centre Fellowships and $\mathrm{ARC}$ and National Health and Medical Research Council grants under many 
different schemes, including Discovery, Discovery Indigenous, LIEF, SPIRIT and Linkage with virtually every staff member and several postgraduates having held at least one such grant. Margie Ripper won grants for a series of projects around Domestic Violence, enlisting a number of postgraduates to work in this area, including Donna Chung, currently Winthrop Professor of Social Work at the University of Western Australia. All staff were active in organising and attending Women's Studies conferences, many held leadership positions in professional organizations including the Australian Women's Studies Association, the Cultural Studies Association of Australia and the Australian Critical Race and Whiteness Studies Association. To the surprise of many colleagues across the faculty, the comprehensive 1994 Faculty Review found that Women's Studies outperformed 8 of the 11 Departments in the faculty in terms of research grants, publications and $\mathrm{PhD}$ supervisions. ${ }^{12}$

\section{Interrogating 'Race', Whiteness and Ethnicity}

As a reflex of its socio-political event upon the world of higher learning, Women's Studies staff sought to encourage an auto-critique, focussed upon Indigenous issues, 'race', whiteness and ethnic diversity. For instance, during 1995-6, Barbara Baird, a part-time lecturer, ran a project 'Challenging Cultural Bias in the Women's Studies curriculum: Centring an Aboriginal perspective'. Staff learnt from Indigenous scholars and examined their own curriculum and teaching styles in order to make their curriculum more congruent with reconciliation. Three Indigenous students, Sonja Kurtzer (1999), Kathleen Mary Graham (2001) and Kathryn Stone (2009), completed Honours degrees in the Department. In 2004, Sonja Kurtzer won the first ARC Indigenous Discovery project held at the University of Adelaide.

A number of students in 'Australian Feminist History' and 'Life Stories: Australia 1850-1980' did oral histories of their immigrant families, leading to publications such as Tapestry (1999) by Maria Pallotta Chiarolli, currently Senior Lecturer at Deakin University. From 1999-2001, Toula Nicolacopoulos, now a Senior Lecturer at Monash University, held an ARC Postdoctoral Fellowship to investigate the post-war contribution of Greek migrants to the Australian labour

\footnotetext{
${ }^{12}$ Department of Women's Studies records, University of Adelaide archives, Series 1344.
} 
movement and the construction of political identities, publishing From Foreigner to Citizen: Greek Migrants and Social Change in White Australia, 1897-2000 (2004).

With academic interest turning to Whiteness Studies, postgraduate student Lara Palombo and visitor Dr Goldie Osuri (now at Macquarie University) with Margaret Allen ran the '(Inter)disciplining Whiteness Symposium' in September 2003, which led to the Department hosting the cross-university Whiteness Reading Group between 2004-8, in which new staff member Dr Anna Szorenyi and also Margaret Allen were long-term participants.

\section{Flushed with success to 1996: 'Annus Horribilis'}

The new Department quickly made a place for itself in the Faculty. Releasing funds for a Chair, Vice-Chancellor Brown declared in June 1995, 'the Department of Women's Studies has a critical intellectual role in the university and is of symbolic importance'. ${ }^{13}$ The future seemed bright, but in fact the Department was heading for its most difficult period. In August 1995, the dean froze the Chair position. Protesting to the Vice-Chancellor and the Academic Board, Kay Schaffer, as Head of Department, argued that the appointment of a Chair was necessary in order to acknowledge, recognise and strengthen the Department's outstanding research and scholarship record and provide necessary leadership within the Faculty, pointing out that the Arts Faculty had only one female professor and two associate professors, fewer than any tertiary institution in South Australia, and one of the worst records for senior female appointments in the country. The feminist community sent more than 250 letters and faxes protesting this delay, and early in 1996, the position was released and applications invited.

The year 1996 began so well. Kay Schaffer launched another book. ${ }^{14}$ In January Margaret Allen visited the Research Centre for Women's Studies at the SNDT Women's University in Mumbai as part of a three-way Association of Commonwealth Universities exchange with women's studies programs in Mumbai and at the University of the West Indies, ${ }^{15}$ thus beginning her research on

${ }^{13}$ Quoted in press release 6 August 1995, Department of Women's Studies records, University of Adelaide archives, Series 1344.

${ }^{14} \mathrm{~K}$. Schaffer, In the Wake of First Contact: The Eliza Fraser Stories (Melbourne, New York and Cambridge, Cambridge University Press, 1995/6).

${ }^{15}$ As part of this exchange, Dr Susanne Schech visited the University of West Indies late in 1995. 


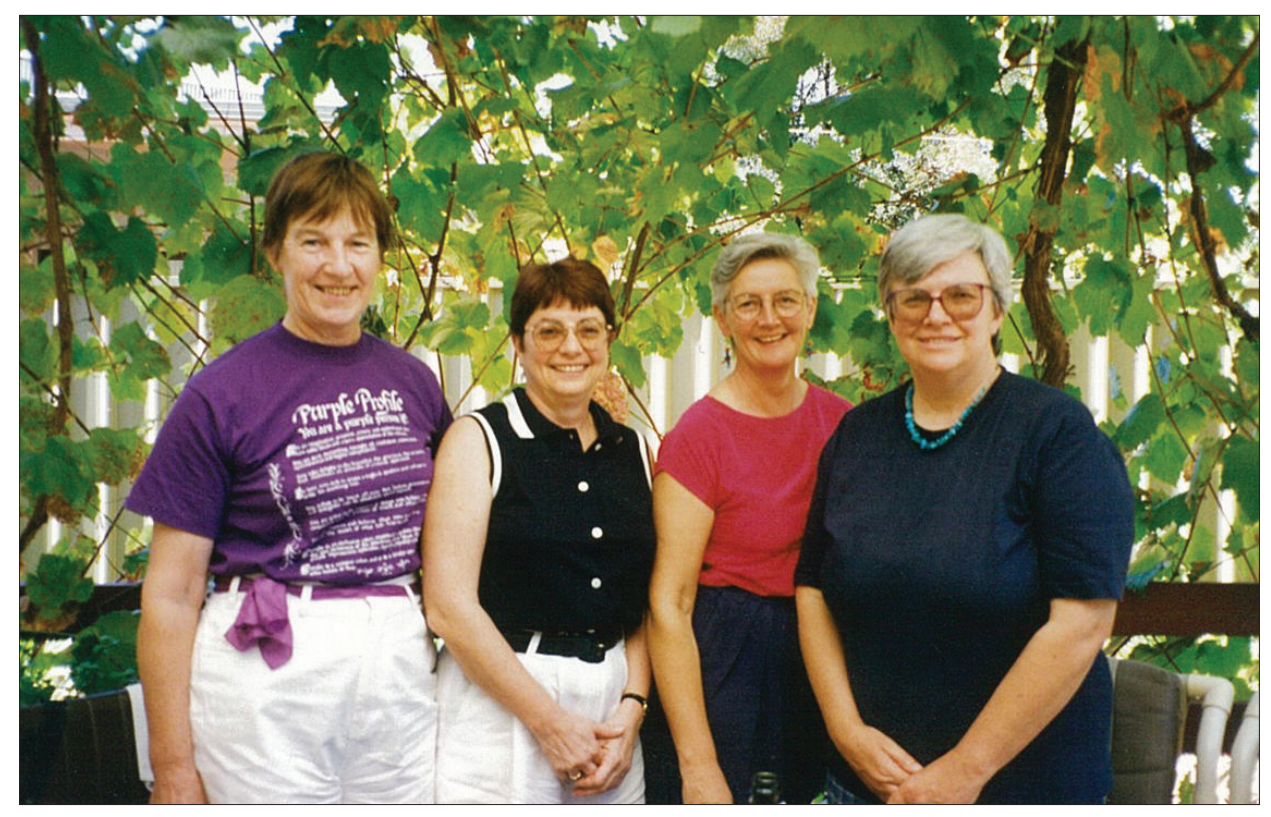

Women's Studies staff in 1996. From left: Myra Betschild, Kay Schaffer, Margie Ripper, Margaret Allen (photograph courtesy of Margaret Allen)

gendered transnational histories. The international exchange continued in April with the Sixth International Interdisciplinary Congress on Women, convened by Susan Magarey with a committee representing Women's Studies across the state and hosted by the Research Centre for Women's Studies, where 1000 delegates from 57 countries offered wonderful opportunities for forging new links and understandings. One result was that Margaret Allen subsequently undertook a feasibility study for a Women's Studies program at the National University of Laos.

The Howard Government's first Federal Budget in 1996, however, saw the imposition of prohibitive fees upon the graduate coursework programs. While existing students would be able to complete their programs on a HECS basis, the new measures heralded changes as the graduate coursework programs amounted to $25 \%$ of the Department's student load. The University's inept overreaction to the new budgetary environment affected the Department badly. With no warning

Early in 1996 she left the University for a new position at Flinders University. 
the Vice-Chancellor Mary O'Kane, Faculty Dean, Paul Nursey-Bray and Deputy Vice-Chancellor Doug McEachern marched (literally) into the Department to issue an edict, namely that henceforth the discipline name would be 'Gender Studies', it would be amalgamated with Anthropology, and that it must lose a third of the academic staff through redundancy and transfers to other Departments.

Such a radical, non-consultative and arbitrary management style, also practised on some other Departments (notably Labour Studies), led to protests across the University. It looked as if Women's Studies would lose its identity and autonomy by a merger with Anthropology. Women's Studies students via the Students' Association protested energetically to the Vice-Chancellor, the National Tertiary Education Union called an industrial dispute about the lack of consultation and the failure to call for a voluntary redundancy round and held a stop-work meeting. Departmental staff penned memos and took deputations to the Dean and Vice-Chancellor. Under continual attack, they wrote to the ViceChancellor:

This department has had to grapple with the amalgamation in 1991-2, the Review of 1994 and now another upheaval in 1996. We are feeling totally punch-drunk! When are we going to be left to get on with what we do so very well, i.e. teach, encourage women students, to develop our international links and to research and publish? ${ }^{16}$

\section{Regeneration}

Exploratory discussions about amalgamation were held with Anthropology. Neither group was very enthusiastic about the possibilities. In the event, the newly incoming Dean, Professor Penny Boumelha, brokered a more congenial amalgamation between Women's Studies and the Centre for Labour Studies. Labour Studies had also merged into the University from SACAE in 1991 and had pioneered accessible educational programs aimed at workers and trade unionists. Arguing for the appropriateness of this amalgamation, Penny Boumelha wrote:

Both of these current departments are interdisciplinary areas undertaking a crucial analysis of society from complementary perspectives involving a

${ }^{16}$ Memorandum, Department of Women's Studies to Mary O'Kane, Vice-Chancellor 28 October 1996, Department of Women's Studies records, University of Adelaide archives, Series 1344. 


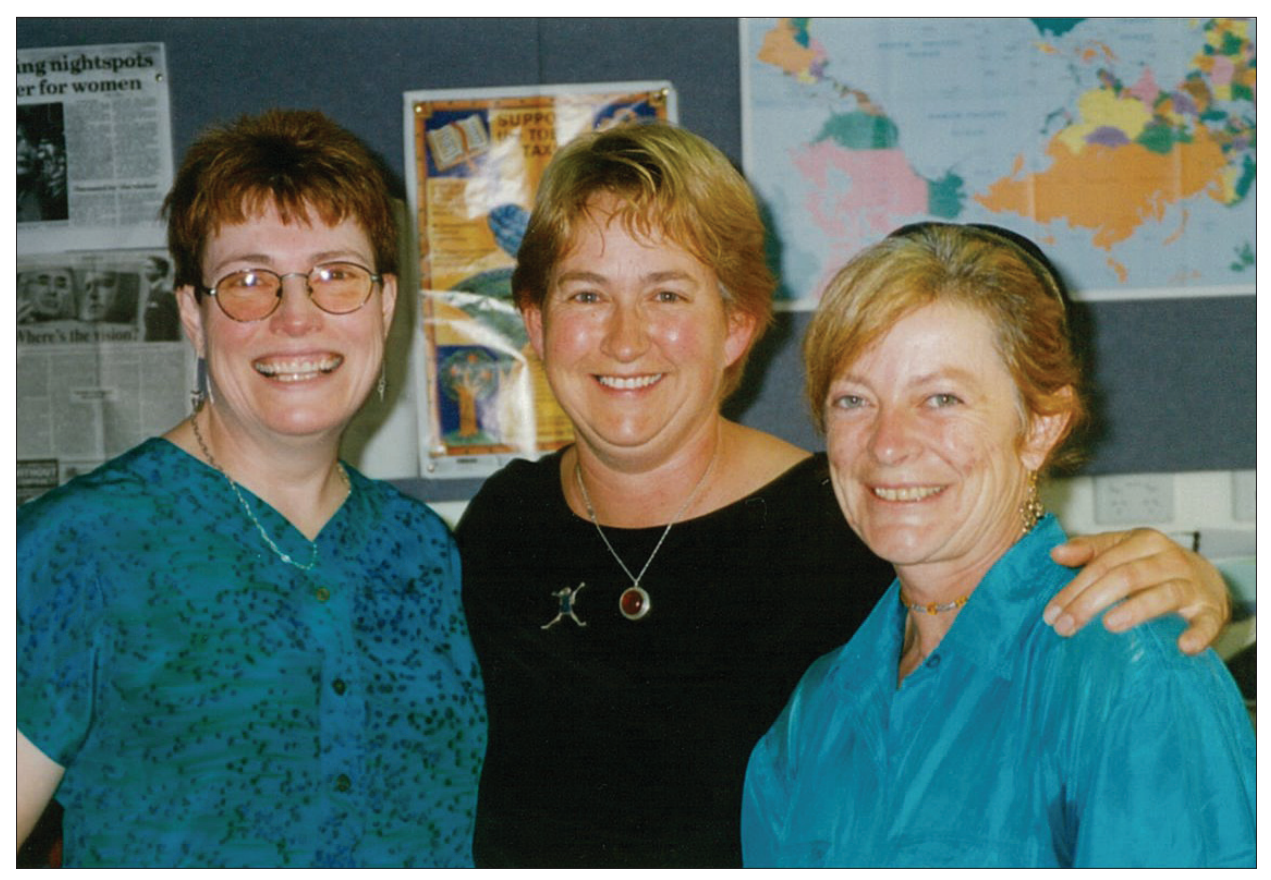

At a celebration in Social Inquiry, 2000. From left: Verna Blewett postgraduate student, Barbara Pocock and Chilla Bulbeck (photograph courtesy of Margaret Allen)

range of methodologies. They provide a parallel range of undergraduate, graduate and postgraduate programmes within the Faculty awards. Although both draw students from the mainstream entry, they share a clear focus on non-standard entry, particularly for mature-age entry, and particularly from community groups historically under-represented in higher education. Both are active in distance education and are committed to the development of multi-media resources for internal and external students as well as to innovative teaching and learning. The areas of research activity and interest of the two areas have several points of interaction and both have research programmes with an applied dimension and an orientation toward social justice. Their national and international research links are mutually reinforcing and their collaborative projects with other Universities in this state run in parallel. ${ }^{17}$

${ }_{17}$ P. Boumelha, Head of Division (sic), Memorandum 'Restructuring: A new Proposal' 9 December 1996, Department of Women's Studies records, University of Adelaide Archives, Series 1344. 
Indeed, this new Department of Social Inquiry ${ }^{18}$ marked a particularly fruitful period. This amalgamation brought feminist scholars Barbara Pocock and Kathie Muir into the Department.

The launch of the newly configured Department, in their new premises at 10 Pulteney Street, by Professor Lois Bryson was a great relief after the uncertainty of the previous year. At the launch, Professor Bryson spoke of her own research, which symbolised the 'points of interaction 'between Labour Studies and Gender Studies. The new team, with the addition of Labour Studies staff, including former Premier of South Australia, Don Dunstan AC, an Adjunct Professor of Labour Studies, amplified the 'orientation toward social justice'.

Finally, Chilla Bulbeck was appointed as the first Professor of Women's Studies in 1998: this being only the second Chair in Women's Studies in Australia. She was well placed to lead this new Department, having published on Australian feminism and on international feminism, as well as on labour history. Her textbook Social Sciences in Australia had just gone into a second edition. Postgraduate students were attracted to the Department to work with her and she won a number of ARC grants. She introduced the subject, 'Gender in a Post-Colonial World' drawing upon her new and widely cited book, Reorienting Western Feminisms. She proposed a social sciences orientation to extend the teaching of social justice issues, commencing with a first-year subject 'Social Sciences in Australia', popular with public health students as well as Faculty of Arts students. This was supplemented by the Social Research subject, taught by Margie Ripper. She and subsequently Susan Oakley developed the Social Sciences degree, through which current staff, Susan Oakley and Megan Warin, deliver critical research skills to students. This degree has become strongly identified with Gender Studies and Social Analysis.

The postgraduate research student body grew. With students and staff colocated on the same floor, a rich and supportive research environment was able to develop. The weekly seminar on Friday mornings during term time became a stimulating occasion. Usually two seminars were programmed, with a break for morning tea when staff, students and visitors could continue the seminar

${ }^{18}$ It was renamed 'Gender Studies/Labour Studies' in 2004-5, 'Gender, Work, and Social Inquiry' in 2006, and in 2012, 'Gender Studies and Social Analysis. 
discussions and initiate new interactions. Researchers at the Centre for Labour Research added to the rich mix. Visitors to the Department often commented favourably upon this lively, collegial atmosphere. These have included: Sidonie Smith, Professor and Chair of the University of Michigan English Department; Huang Lin, feminist scholar and editor of the journal Feminism in China; Sarah Ahmed, Professor of Race and Cultural Studies at Goldsmiths College; poet Diane Fahey as Australia Council Writer in Residence; Professor Deborah Bird Rose, now Professor of Social Inclusion, Macquarie University; and Professor Meera Kosambi and Professor Veena Poonacha, both from RCWS, SNDT Women's University Mumbai. ARC successes, particularly those of Barbara Pocock, brought new researchers and temporary staff into the Department. Research student graduations, always celebrated in style, have totalled around $35 \mathrm{PhDs}$ and 2 MAs. In addition, there have been 50 Honours theses and 21 students graduated with the coursework MA, which included a substantial thesis component.

\section{Reorganisation - yet again}

The heady days of the new Department with a large staff and new premises specifically designed for it fell victim shortly to more straitened university finances. Older staff took the opportunity offered by an early retirement redundancy round in 2002. Professor Kay Schaffer, Associate Professor Ray Broomhill and Patrick Wright (both from Labour Studies) took early retirement and Social Inquiry's strength in Labour Studies began to decline. ${ }^{19}$ However, the first-year subject, 'Gender, Work and Society' continues to attract students across the faculty and from business, economics and health studies. The remaining staff consolidated the programs. In place of separate Gender and Labour Studies majors, a Gender, Work and Social Inquiry major reflected both sides of the Department's genealogy. Subjects, cheekily titled, Youth, Work and Other Catastrophes, Fashion, Work and Identity, Gender, the Body and Health and Risk and Moral Panic in Australia

\footnotetext{
${ }^{19}$ Following her retirement, Kay Schaffer maintained her research, holding between 2002-6 an ARC Discovery on 'Indigenous Life Narratives and Racial Reconciliation in Australia and South Africa', visiting South Africa and co-teaching a course on reconciliation at the University of Cape Town with Professor Dorothy Driver, subsequently publishing Human Rights and Narrated Lives (2004) with Professor Sidonie Smith. Subsequently she has published with Dr Xianlin Song (Asian Studies) on Chinese women's recent writing.
} 
testified to innovative and dynamic curriculum development. In 2007, the move to the present location in the Ligertwood Building brought the discipline into closer contact with other parts of the faculty, and has seen the growth of links with Asian Studies' colleagues nearby in adjacent offices.

\section{Resilience}

Since 1991, the Department/Discipline has been transmogrified on a number of occasions. It has been forged in the difficult environments of amalgamation and of university retrenchment and constant reorganisation. Nevertheless, this organisational unit has been highly resilient, surviving and indeed flourishing. Now the focus is upon gender studies rather than women's studies and work on masculinities figures strongly in undergraduate teaching and in postgraduate and staff research. The recent retirements of senior staff Chilla Bulbeck (2008), Margie Ripper (2009) and Margaret Allen (2010) have seen another changing of the guard and the growth of new research and teaching strengths among current staff. ${ }^{20}$ The multidisciplinary program links GSSA with other disciplines, especially with Media, Public Health and Geography. Staff collaborate with, and contribute to, the recently established Fay Gale Centre for Research on Gender. A strong undergraduate program drawing students from across the faculty and from other faculties is buttressed by the Honours program and the postgraduate research program. Undergraduate student numbers have increased by 50\% since 2009. The importance placed upon good teaching is matched by continuing success in postgraduate supervision and in research, both in terms of publication and winning grants. In all its manifestations, Women's Studies and Labour Studies, Gender Studies, Social Inquiry and Gender, Work and Social Inquiry and Gender Studies and Social Analysis has come through with resilience and style.

\footnotetext{
${ }^{20}$ Retired staff remain active as postgraduate supervisors and as researchers. Margie Ripper's farewell gesture was organising the highly successful national Women and Gender Studies conference in 2010. Chilla Bulbeck's Sex, Love and Feminism in the Asia Pacific: A cross-cultural study of young people's attitudes appeared in 2009 and her Imagining the Future: Young Australians on sex, love and community appeared in 2012. Her festschrift was published in Australian Feminist Studies, 25.66 December 2010. A festschrift for Margaret Allen was published in Australian Feminist Studies, 27.73 September 2012.
} 


\section{Conclusion}

When the Research Centre for Women's Studies was established in 1982, the University was a very masculine institution. Since then these feminist academics have worked to educate the University - academic colleagues, administrators and students alike - about feminist and gender studies scholarship, and social equity. While the University has not yet been totally transformed, there has been slowly a degree of recognition of feminist and gender studies scholarship. Women's Studies and Gender Studies have placed the University of Adelaide on an international map, forging links with leading national and international scholars. Women's Studies and Gender Studies have offered a full program to undergraduates and to a wide range of postgraduate research students, carving out an interdisciplinary space in a predominantly disciplinary faculty. During the last three decades, Women's Studies and Gender Studies have made significant contributions to the success of the University in attracting grants, and conducting world-class research.

\section{REFERENCES}

\section{Primary Sources}

Department of Women's Studies records, University of Adelaide Archives, Series 1344.

Papers of the Research Centre for Women's Studies, University of Adelaide Archives, Series 1474.

\section{Reports}

Australian Academy of the Humanities \& Australian Research Council \& National Board of Employment, Education and Training (Australia), Knowing Ourselves and Others: The Humanities in Australia into the 21st Century, vol. 2 (Canberra, Dept. of Employment, Education, Training and Youth Affairs, 1998) 


\section{Secondary Sources}

Bulbeck, C., Sex, Love and Feminism in the Asia Pacific: A cross-cultural study of young people's attitudes (London, Routledge, 2009).

Cass, B.(co-ed.), Women, Social Welfare and the State in Australia (Sydney, George Allen \& Unwin, 1983).

Daniels, K. (co-ed.), Women in Australia: an annotated guide to records (Canberra, Australian Government Publishing Service, 1977).

Edwards, M., The Income Unit in the Australian Tax and Social Security Systems (Melbourne, Institute of Family Studies, 1983).

Lumen, 10.4 (14 August 1981).

Magarey, S., 'Women's Studies in Australia - Towards Trans-Disciplinary

Learning', Fournal of Educational Thought (Calgary, Canada), 17.2 (August 1983).

Magarey, S., 'Setting up the first Research Centre for Women's Studies in Australia 1983-1986', Australian Feminist Studies, 13.27 (1998).

Ruthven, K. K. (ed.), Beyond the Disciplines: The New Humanities, Papers from the Australian Academy of the Humanities Symposium 1991, occasional Paper no. 13 (Canberra, Highland Press, 1992).

Schaffer, K., In the Wake of First Contact: The Eliza Fraser Stories (Melbourne, New York \& Cambridge, Cambridge University Press, 1995/6).

Schaffer, K. \& Smith, S., Human Rights and Narrated Lives (New York, Palgrave/ MacMillan, 2004).

Strathern, M. (co-ed.), Nature, culture and gender (New York, Cambridge University Press, 1980).

University of Adelaide, Bulletin, 8.9 (July 1982). 


\section{9}

\section{History $^{1}$}

\section{Wilfrid Prest}

\section{INTRODUCTION}

This summary history of History at Adelaide is divided into three parts. The first surveys the faltering initial attempts to establish 'modern history' in the curriculum, and the subsequent half-century when the subject was effectively embodied by a single professor. In these early days, history was still a relative newcomer on the academic scene. Some post-classical history had been part of the upstart London University's BA degree from the 1830s, but modern (as distinct from Greek and Roman) history barely managed to squeeze into the formal undergraduate curriculum at Oxford and Cambridge before the 1850s. ${ }^{2}$ When

\footnotetext{
${ }^{1}$ So many people have helped in the preparation of this chapter that it is impossible to name them all . But exceptions must be made for Helen Bruce and Andrew Cook of the University of Adelaide Archives, Cheryl Hoskyn and Margaret Hosking of the Barr Smith Library and of the Somerville Room, State Library of South Australia. Lee Kersten, Peter Mayer and Felicity Prance provided photocopies and other assistance. Peter Burns, Robert Dare, Vesna Drapac, Bill Gammage, Ken Inglis, David Lemmings, Don Longo, Lotte Mulligan and Pat Stretton very kindly read and commented on drafts, thereby preventing numerous errors; I alone am responsible for those which remain.

${ }^{2}$ P. R. H. Slee, Learning and a Liberal Education: the Study of Modern History in the Universities of Oxford, Cambridge
} 
the University of Adelaide was founded a quarter-century later, the abolition of convict transportation to NSW and Victoria had combined with the legacy of the gold rushes to ensure that South Australia would remain significantly less populous and prosperous than those eastern colonies.

South Australia's first university did not establish a chair in modern history until 1900, ten years after Sydney and more than four decades on from the first classes in that subject at the University of Melbourne. Yet until the latter end of the twentieth century Adelaide's standing in the field bore favourable comparison with its better resourced and larger eastern counterparts. A series of outstanding professorial appointments culminated in that of Hugh Stretton, who built up what came to be one of Australia's liveliest and most innovative history departments. ${ }^{3}$ The second part of this chapter traces the changing fortunes of the Stretton era, from 1954 to 1989.

The final section brings us to the present day. Even before Stretton's retirement, his department was encountering serious difficulties, as economic rationalism encouraged market-driven approaches to education. Post-modernists within the academy joined triumphant cold warriors and technocrats in proclaiming history's sublime irrelevance to a brave new world of globalised consumerism. The replacement of history by 'Studies in Society and the Environment' as a stand-alone subject in the middle years of secondary schooling seriously weakened demand for history graduates as potential teachers. Meanwhile a new 'Relative Funding Model' significantly disadvantaged the humanities and social sciences in the allocation of Commonwealth higher education monies. Although the range of history offerings shrank as departing staff were not replaced, enrolments showed no commensurate decline: hence staff-student ratios deteriorated sharply. South Australia's lagging demographic growth and economic performance exacerbated the University's inability to overcome various deep-seated cultural and management problems.

and Manchester, 1800-1914 (Manchester, Manchester University Press, 1986), pp. 3-5.

${ }^{3}$ This chapter surveys teaching and research within the Department of History, its forebears and successors. It consequently neglects much historical work carried out elsewhere in the Faculty, and the wider University, including the Law School and Department of Economics, the Faculties of Mathematics, Medicine, Science, etc. 
Yet a new wave of serious history publishing for the general reader and the traumatic events of 11 September 2001 both clearly demonstrated in different ways that the end of history was not imminent. The next year, the Department of History became a discipline within the newly formed School of History and Politics. Despite initial concerns about the loss of autonomy consequent upon this mandatory merger, a range of new appointments and continuing robust student demand for both undergraduate and postgraduate offerings, together with some curricular and research initiatives, offer grounds for cautious optimism about the future of history at the University of Adelaide.

\section{Professor-Gods}

History was prominent among the list of subjects first proposed for a South Australian university. But by the time the University of Adelaide opened its (temporary) doors for classes in 1876, the decision to establish a chair in 'Modern History, Political Economy, Constitutional Law and English Literature' as one of four inaugural professorships had been overtaken by events. ${ }^{4}$ W. W. Hughes, the University's founding benefactor, reserved the right to name the subject areas of the two chairs associated with his deed of gift; he specified Classics for one and Philosophy (plus English) for the other. When a capital endowment of the same amount was secured from Thomas Elder, the new University's governing Council created two additional professorships in Mathematics and Natural Science (especially Geology and Mineralogy), each with an annual salary of $£ 1000$, a substantial premium over the $£ 600$ paid to the two Hughes professors. ${ }^{5}$

Instead of the history chair, a lectureship in History and Political Economy at a salary of $£ 250$ was envisaged. But this position remained unfilled, possibly because the available funds had been diverted to boost the salaries of the Elder professors to the same level as their Melbourne counterparts. ${ }^{6}$ A different outcome

\footnotetext{
${ }^{4}$ UAA, Minutes of University Association, 23 September, 26 November 1872.

${ }^{5}$ Ibid., 8 December 1872, 18 March, 27 May, 6 October 1873; Council Minutes [hence CM] I, 15 \& 22 January 1875.

${ }^{6}$ The salaries for the chairs of mathematics and science were originally proposed at $£ 700$ minimum (i.e. $£ 100$ more than the two Hughes professors); this was raised to $£ 1000$ at the end of the meeting, and after three lectureships (in history, botany and animal physiology, and engineering) had been agreed on: ibid., 15 January 1875.
} 
might have involved the brilliant young Charles Henry Pearson, a published medieval historian with an Oxford First, formerly professor at King's College London, now settled in South Australia for medical and other reasons. But although Pearsons's case for an Adelaide position was strongly urged by his fellowmembers of the University Association, backed by the Advertiser, and reinforced by his own 'very interesting and much appreciated' lectures on fourteenth-century England at the South Australian Institute, Pearson was lured away east, initially by a Melbourne University lectureship, then a lucrative headmastership. ${ }^{7}$ At the start of its second academic year, Chancellor Short lamented the narrowness of his new university's curriculum, limited 'to Ancient Classical or Modern English Literature, as well as science'. But the bishop's advocacy of additional lectures in 'History, Medieval or Modern, French, German, English', and attempts to bring back 'Professor Pearson of Melbourne' to deliver them, proved equally unavailing. ${ }^{8}$ Until the century ended, the only history taught at Adelaide was as part of a degree in classics or modern languages; in the 1890s the University's first honours graduates in the subject took their awards jointly in classics and ancient history. ${ }^{9}$

The Challis Bequest enabled Sydney University to establish a chair in Modern History in 1889; the Elder Bequest of 1897 permitted Adelaide to follow suit. But instead of combining ancient or classical history with all post-classical history in one academic teaching unit as at Melbourne and Sydney, Adelaide chose to keep Greek and Roman history as the classicists' preserve. The probable reason for what now seems an unfortunate decision was that, unlike his colleagues in the eastern states, Adelaide's new professor had to teach not only modern history but also English language and literature, the latter sloughed off from the formidable

\footnotetext{
${ }^{7}$ J. Tregenza, Professor of Democracy: The Life of Charles Henry Pearson, 1830-1894, Oxford Don and Australian Radical (Melbourne, Melbourne University Press, 1968), pp. 58-9, 62-5, 75. University Association Minutes, clipping on p. 92 (report of deputation meeting with Chief Secretary, 26 July 1873); The Advertiser, 10 October, 12 October, 7 November 1873. Neither the University Association nor the Council minutes corroborate the claim of the Melbourne The Argus, 21 November 1874, that Pearson had just then been offered an Adelaide history chair.

${ }^{8}$ CM I, 223-4, 'Memo ... Special Lectures and Examination', February 1877; ibid., 23 March, 27 April, 25 May.

${ }^{9}$ E. V. Boulger, Hughes Professor of English and Classics 1883-1894, was a short-listed applicant for the foundation Chair of History at the University of Sydney, to which G. A. Wood was appointed in 1890: B. Caine et al., History at Sydney 1891-1991: Centenary Reflections (Sydney, University of Sydney, 1992), pp. $4-5$.
} 


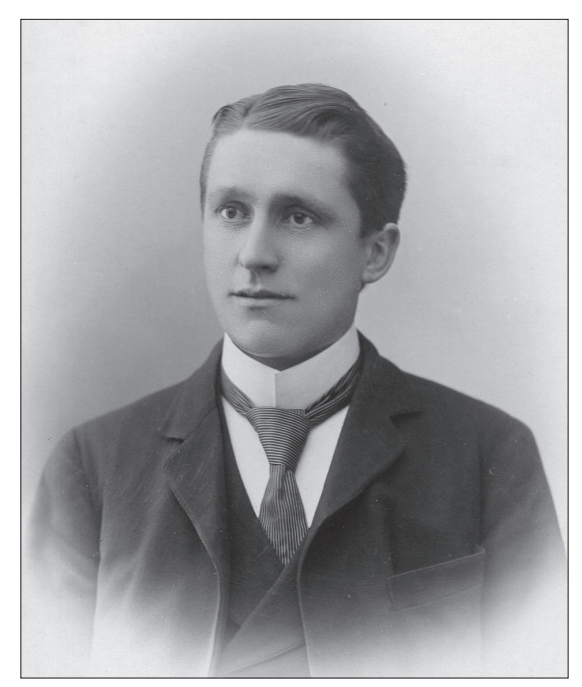

\section{Robert Langton Douglas}

William Mitchell's philosophy chair in a major reorganisation of the BA degree taking effect from 1900. ${ }^{10}$

After engaging the eminent scholars S. R. Gardiner and W. P. Ker to rank 16 London candidates (no serious attention seems to have been paid to the 9 local applicants), the University proceeded to overturn their recommendation of Joshua Jacobs, an erudite and productive but obviously Jewish critic, editor and historian. According to the Education Committee, 'while there is no doubt that Mr Jacobs is the most brilliant man', the second-ranked candidate 'would be better suited to the requirements of [a small: deleted] this University ...'. This report was accepted by Council without demur. ${ }^{11}$ Robert Langton Douglas, an Oxford graduate and former clergyman then in his mid-thirties, had been judged by the assessors to possess 'good qualities for a lecturer' and 'an independent interest in his subject', which they represented as Italian literature and history. Douglas indeed travelled to Adelaide from Italy, where he had been pursuing his passion for Renaissance art over the past decade; a monograph on Fra Angelico appeared in the year of his

\footnotetext{
${ }^{10}$ See V. Edgeloe, Annals of the University of Adelaide (Adelaide, Barr Smith Press, 2003), pp. 409-10, 423-4.

${ }^{11}$ CM, 15 December 1899; Agent-General's Reports, 2 \& 3/1900; Report of Education Committee, $1 / 1900$.
} 
appointment, and a history of Siena in 1902, while after his arrival he canvassed for and obtained the post of lecturer in Italian.

What the assessors and the University presumably did not know, but what gradually emerged, was that Douglas would leave behind him a deserted wife and family (not to mention at least one discarded mistress and several illegitimate offspring). In June 1901 Mrs Douglas sued in London for 'restitution of conjugal rights' (i.e. maintenance). Cabled reports of these proceedings in the local press occasioned a question in the House of Assembly, and doubtless some disapproving gossip. But it was the circumstantially detailed account of Douglas's serial philandering in the divorce petition she successfully initiated nine months later that proved his undoing. ${ }^{12} \mathrm{~A}$ special meeting of the Council 'to consider the position of Professor Douglas and the University', to which he made 'a lengthy statement', nevertheless concluded 'that it would be injurious to the interests of the University' for Douglas to continue in post. He duly resigned, doubtless encouraged by the inducement of an additional six months' salary. In response, twenty-five students vainly petitioned the Council against losing 'the services of so distinguished a scholar and so able a teacher, who in his lectures sets the noblest ideals before his students', while expressing the hope that if Douglas must go, his resignation might be postponed until the end of the year, so as not to prejudice their studies.

Yet even before Douglas left Adelaide for a colourful international career as art critic, dealer, gallery director and historian, the University had managed to fill the resultant vacancy with an outstanding candidate. ${ }^{13}$ George Cockburn Henderson was a native-born prodigy, the son of an immigrant Newcastle coalminer, whose outstanding academic record at Sydney's Fort Street School and then university had earned him a scholarship to Oxford. There he participated fully in university life, rowed for Balliol College, developed principled commitments to educational and social reform, won the Brackenbury Scholarship in History, but unexpectedly failed to gain a First. He subsequently conducted adult education

\footnotetext{
${ }^{12}$ The Times (London), 6 June 1901, p. 14; 22 March 1902, p. 6; CM VII, 8 April 1902; Dockets 1033, 1048, 1117/1900; 799/1901; 400, 470/1902.

${ }^{13}$ D. Sutton, Robert Langton Douglas: Connoisseur of Art and Life (London, Apollo Magazine, 1979); $<$ www.dictionaryofarthistorians.org/douglasr.htm>; C. Simpson, The Partnership (London, Bodley Head, 1987).
} 


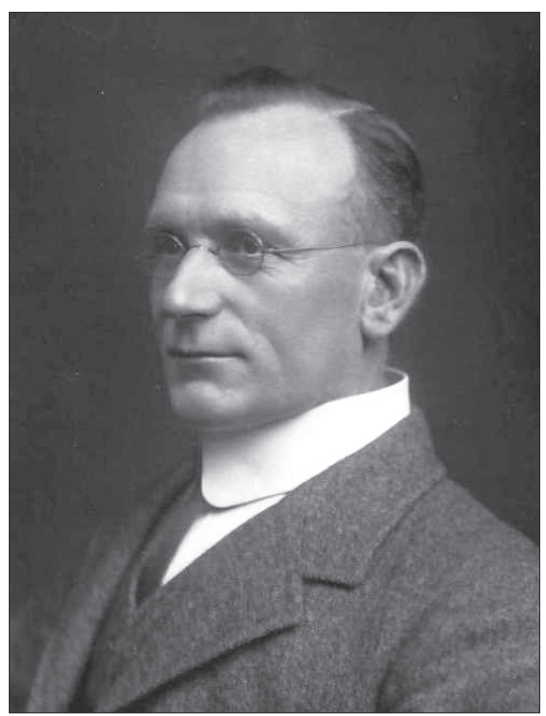

\section{George Cockburn Henderson, 1902}

classes for Oxford, and served as acting professor at Sydney on two occasions. By great good fortune the thirty-one-year-old Henderson was on his way back to Sydney for another term of extension lecturing when the Douglas scandal broke; persuaded to apply for the Adelaide post by his friend William Mitchell, Council interviewed him that same month and appointed him forthwith. ${ }^{14}$

Henderson quickly became prominent in the cultural, educational, social and sporting life of South Australia. His celebrated public lectures on historical and literary topics attracted capacity crowds (including governors and premiers) to the Adelaide Town Hall. They were equally in demand throughout rural South Australia and interstate: during his lecture tour to WA in 1907 the young May Gibbs prepared for the Western Mail a striking lithograph entitled 'Some Memory Impressions of Professor Henderson'. ${ }^{15}$ Notwithstanding his punishing undergraduate teaching load of eight lectures per week, four in history and four in English, Henderson published in 1907 a scholarly biography of the colonial

\footnotetext{
${ }^{14}$ CM VII, 30 April 1902; M. R. Casson, George Cockburn Henderson (Adelaide, Libraries Board of SA, 1964); G. L. Fischer, 'Henderson, George Cockburn (1870-1944)', Australian Dictionary of Biography; SLSA, PRG 6 (Henderson Papers).

${ }_{15}$ Western Mail, 14 June 2007.
} 


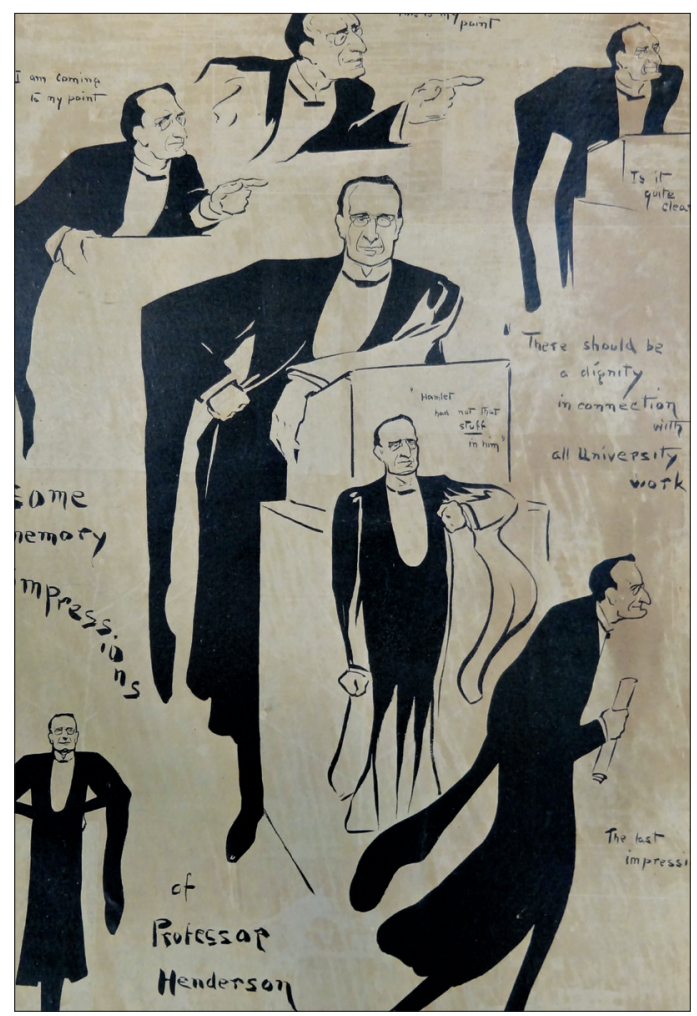

\section{May Gibbs, 'Some Memory Impressions of Professor Henderson'}

governor and statesman Sir George Grey. ${ }^{16}$ Commitment to the systematic study of Australian history and friendships with affluent fellow-members of the Adelaide Club and the board of the public library, museum and art gallery (on which he sat as university representative for nearly twenty years) underlay Henderson's efforts to establish a school of historical research in Adelaide. To this end he secured the endowment of the Tinline Scholarship for research on South Australian history, and persuaded British authorities to liberalise scholarly access to former government despatches exchanged between Adelaide and London. The establishment in 1920 of the Archives Department of the State Library, which became Australia's first public archives repository, was largely due to Henderson's tireless advocacy.

${ }^{16}$ G. C. Henderson, Sir George Grey: Pioneer of Empire in Southern Lands (London, Dent, 1907). 


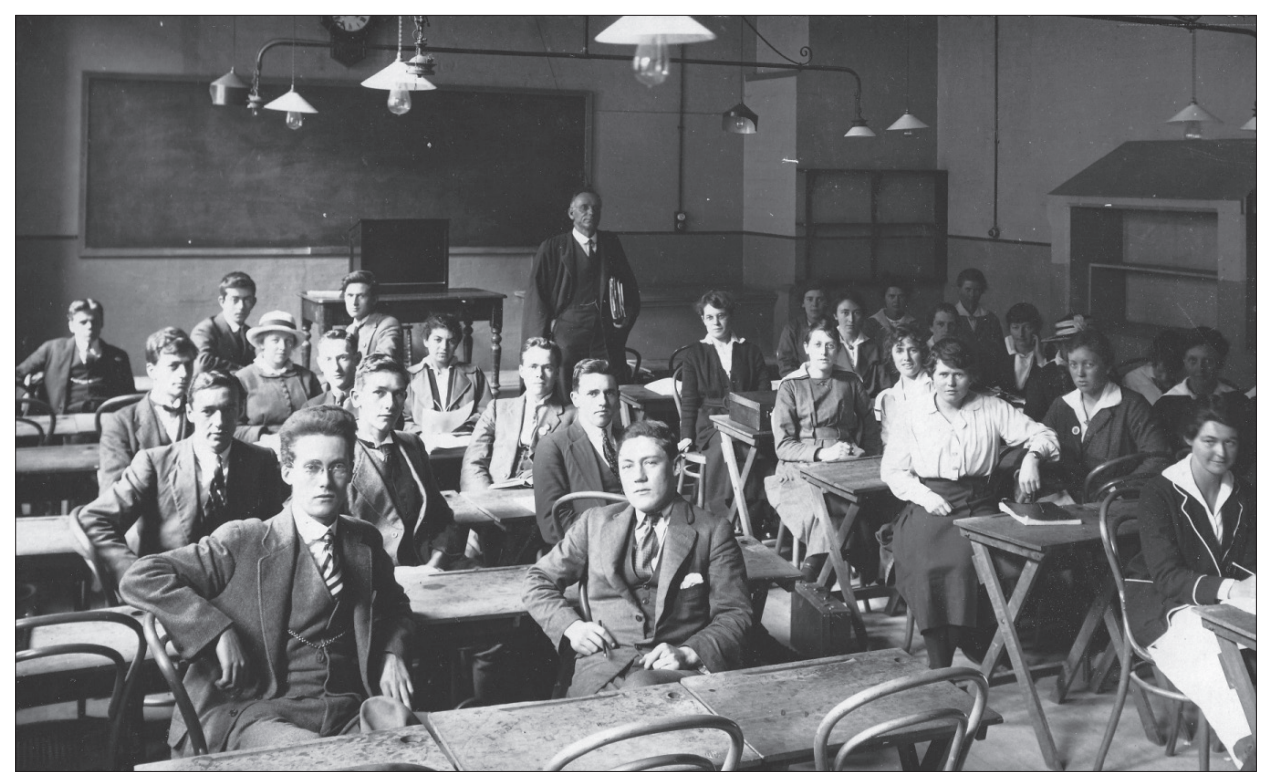

Professor Henderson and students in the History Room, 1918

An austere, intense and demanding teacher ('Students who split infinitives were severely treated'), Henderson took both himself and his subject very seriously: yet 'His own enthusiasm and interest aroused an equal enthusiasm in his students'. ${ }^{17}$ Like Douglas, he initially taught two year-long history courses, offered in alternate years: English history, political and constitutional (which included the history of Australia and 'other English colonies and dependencies') and European history from the Middle Ages to the twentieth century (the latter subsequently divided into separate medieval and later modern courses). Rather than surveying events, Henderson's lectures focused on significant personalities, most notably Francis of Assisi and Oliver Cromwell. No tutorials were provided, but besides end-of-term and annual written examinations students had to submit a single essay; from 1912 onwards these were read (and presumably assessed) by his former student Gwendoline Stevens, and after her marriage by the then still single Marjorie Casson (née Walker), employed on an annual honorarium of $£ 100$. While the numbers of students sitting examinations seem relatively modest (42 in

${ }^{17}$ Anon.,'Professor G. G. Henderson', Adelaide University Magazine, V.13 (15 October 1926), p. 15. 

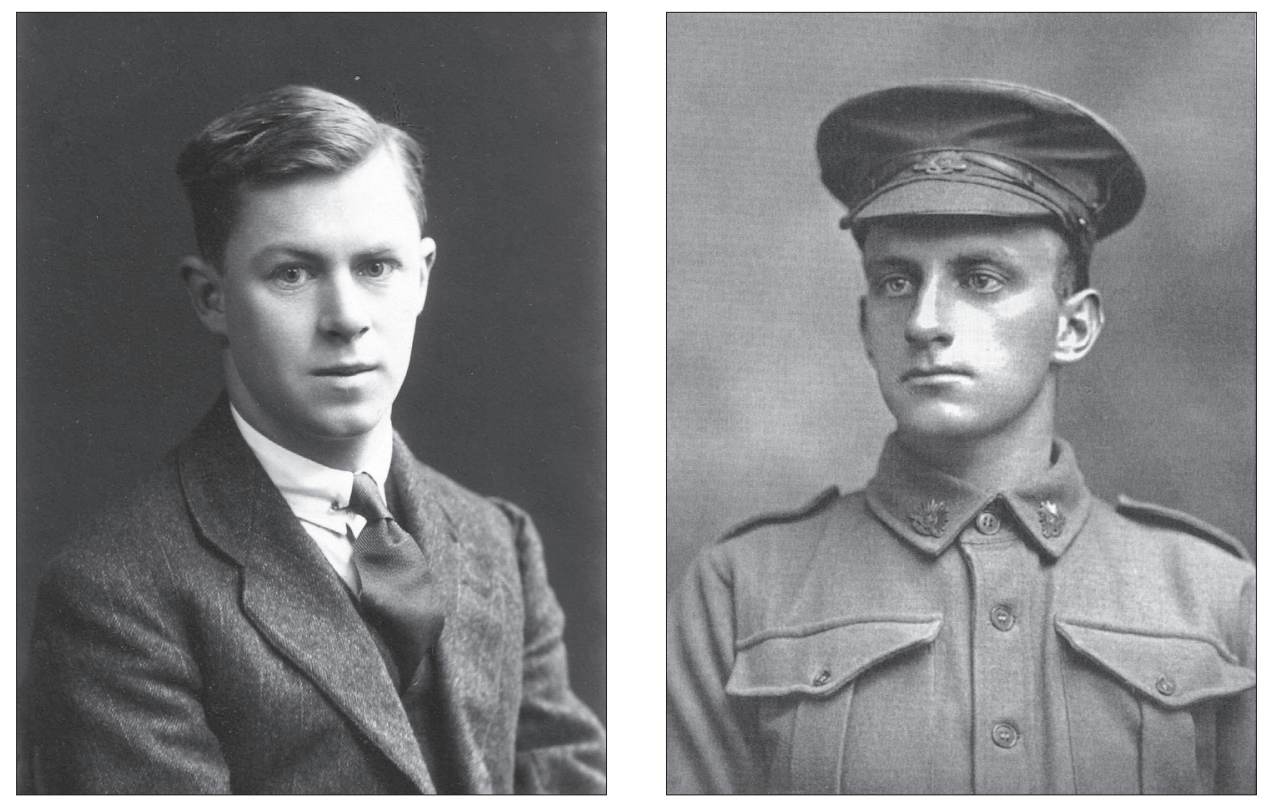

William Keith Hancock, 1926 (left) and Wilfrid Oldham, c. 1917 (right)

1910 for history and just half that for English), the University also enrolled a large cohort of non-graduating students, who attended lectures and submitted essays (270 in 1910, as against 393 undergraduates). And the numbers continued to grow.

By 1921, Henderson faced well over two hundred history and English examination scripts, although the latter were henceforth handled by another professor, following the endowment of the Jury Chair. ${ }^{18}$ He also now had a halftime assistant lecturer, Wilfrid Oldham, only the third student to complete an Adelaide History Honours degree specialising in 'British Imperial and Colonial History' with its required thesis on South Australian history 'based upon careful original research'. All three subsequently entered academic life: A. C. V. Melbourne at the University of Queensland, Linden A. Mander at Auckland and then the University of Washington, Seattle. Melbourne and Oldham were indeed the first Australian university history lecturers to hold earned doctorates, both written under the supervision of A. P. Newton at King's College, London University, with

${ }^{18}$ Calendar of the University of Adelaide 1911, pp. 386-7; Casson, George Cockburn Henderson, p. 35. The total 1921 enrolments as recorded in Henderson's book of class lists and results (UAA Series 350) were 84 in History I, 19 in History III, and 155 in English Language and Literature. 
funding from the Rockefeller Foundation. ${ }^{19}$ The originality of Oldham's thesis, 'the first full study, by any historian, of the transportation of British convicts to America and Australia' received some belated recognition when it was published posthumously more than half a century after submission. ${ }^{20}$

So in 1922 Henderson became Professor of Modern History alone. But the effects of long-term overwork and a disastrously ill-considered second marriage exacerbated his chronic depressive tendency to the point of collapse. Admitted to hospital in June 1923, Henderson's resignation was regretfully accepted in November. After returning to New South Wales, he resumed research and publication on Pacific history, also teaching classes at the University of Sydney. His invited successor was even younger than Henderson had been on his appointment. While W. K. Hancock did not actually take up his chair until 1926 (the intervening gap was filled by Wilfrid Oldham), journalists then still described him as 'the youngest professor in the British empire'. ${ }^{21}$ A Rhodes Scholar product of Melbourne University and (again) Balliol College Oxford, Hancock was the first Australian to win an All Souls College prize fellowship. Besides these impeccable academic credentials and an authoritative self-assurance, Hancock brought refreshing informality, even irreverence, to the complacent parochialism of $1920 \mathrm{~s}$ Adelaide, still Australia's third-largest city, even if 'a city I did not then learn to love'. ${ }^{22}$ He played hockey with the University team, drank in pubs with his students and invited them to the succession of homes he and his wife rented in Adelaide and the hills, although not to the various dining clubs which he convened, least of all 'The Society for Pissing against Banks' (this being the era of the Wall St Crash and Great Depression). Hancock was also a highly committed and effective teacher;

\footnotetext{
${ }^{19}$ W. Prest, 'Oldham, Wilfrid (1890-1959)' \& M. I. Thomis, 'Melbourne, Alexander Clifford Vernon (1888-1943)', Australian Dictionary of Biography; H. A. Bone, 'Linden A. Mander, 1897-1967', Political Research Quarterly, 20 (1967), p. 513. Calendar of the University of Adelaide 1926, p. 12.

${ }^{20}$ D. Bryne in W. Oldham in W. H. Oldman (ed.), Britain's Convicts to the Colonies (Sydney, Library of Australian History, 1990), p. 251.

${ }^{21}$ J. Davidson, A Three-Cornered Life: The Historian W K Hancock (Sydney, New South Press, 2010), ch. 3: 'Adelaide and Australia'; see also C. R. Badger, 'Sir Keith Hancock, a Tribute from a Grateful Pupil', Fournal of the Historical Society of South Australia, 18 (1990), pp. 18-27; W. K. Hancock, Country and Calling (London, Faber, 1954), p. 100 claims that in 1925 he accepted an invitation to the chair offered him by Sir William Mitchell, but he was actually appointed in 1924 following an interview in Adelaide: CM XII, 21 December 1923, 9 and 22 May, 7 June 1924; Docket 290/1924; Davidson, Three-Cornered Life, ch. 12 no. 8.
}

${ }^{22}$ W. K. Hancock, Country and Calling, p. 115. 
within two years of his arrival he had a class of five Honours students, including one woman (who graduated with a First) and two future Rhodes Scholars, while undergraduate history enrolments in 1930 stood at 64, more than double the number of a decade before. He extended and strengthened the undergraduate curriculum, emphasising British and modern European history and the history of political thought, rather than Australian history. Even so, Australia (1930), the main literary-historical product of his Adelaide years, was judged at Sir Keith Hancock's death in 1988 by a distinguished former Adelaide historian as still 'the most professional and profound single volume' on this continent. ${ }^{23}$

Adelaide was exceptionally fortunate to retain for more than seven years 'probably the most brilliant Professor of History that Australia has ever had'. ${ }^{24}$ But after two terms in Oxford (with Oldham as locum) in 1930, the restless Hancock again left this country at the end of 1933 to pursue his professional calling. Following a protracted search (in which Hancock was frequently consulted), another Australian Rhodes Scholar received an invitation to replace him in what the University had renamed, following Hancock's suggestion, the Chair of Political Science and History. ${ }^{25}$ At 51 years of age G. V. (Jerry) Portus was a known quantity, having successfully served as Henderson's replacement during the latter's leave of absence in 1914, then spending fifteen years as director of tutorial classes and lecturer in economic history at the University of Sydney. A respected scholar and prolific author, his rewritten Oxford B. Litt thesis remains a standard source on early eighteenth-century religious and philanthropic societies, while his later publications (more than twenty appear in the Barr Smith Library catalogue) included a widely-used Australian history textbook, a chapter in the Cambridge History of the British Empire, and a miscellany of writings on past and current economic, social and political issues. Portus was also a frequent ABC radio broadcaster and public speaker, as well as a very popular undergraduate teacher. ${ }^{26}$ Indeed the contrast between his lively lecturing and the wooden delivery

\footnotetext{
${ }^{23}$ K. S. Inglis, The Age, 15 August 1988.

${ }^{24}$ G. V. Portus in his inaugural lecture, reported in On Dit, 15 June 1934.

${ }^{25}$ CM, XIV, 30 June, 28 July 1933, 5 February 1934; Docket 147/1933.

${ }^{26}$ W. G. K. Duncan, 'Portus, Garney Vere (Jerry) (1883-1954)', Australian Dictionary of Biography; G. V. Portus, Happy Highways (Melbourne, Melbourne University Press, 1953); R. Thornton, "A Streak of Acting Ability": G. V. Portus, Educational Evangelist', Fournal of the Historical Society of South Australia, 16 (1988), pp. 104-13.
} 


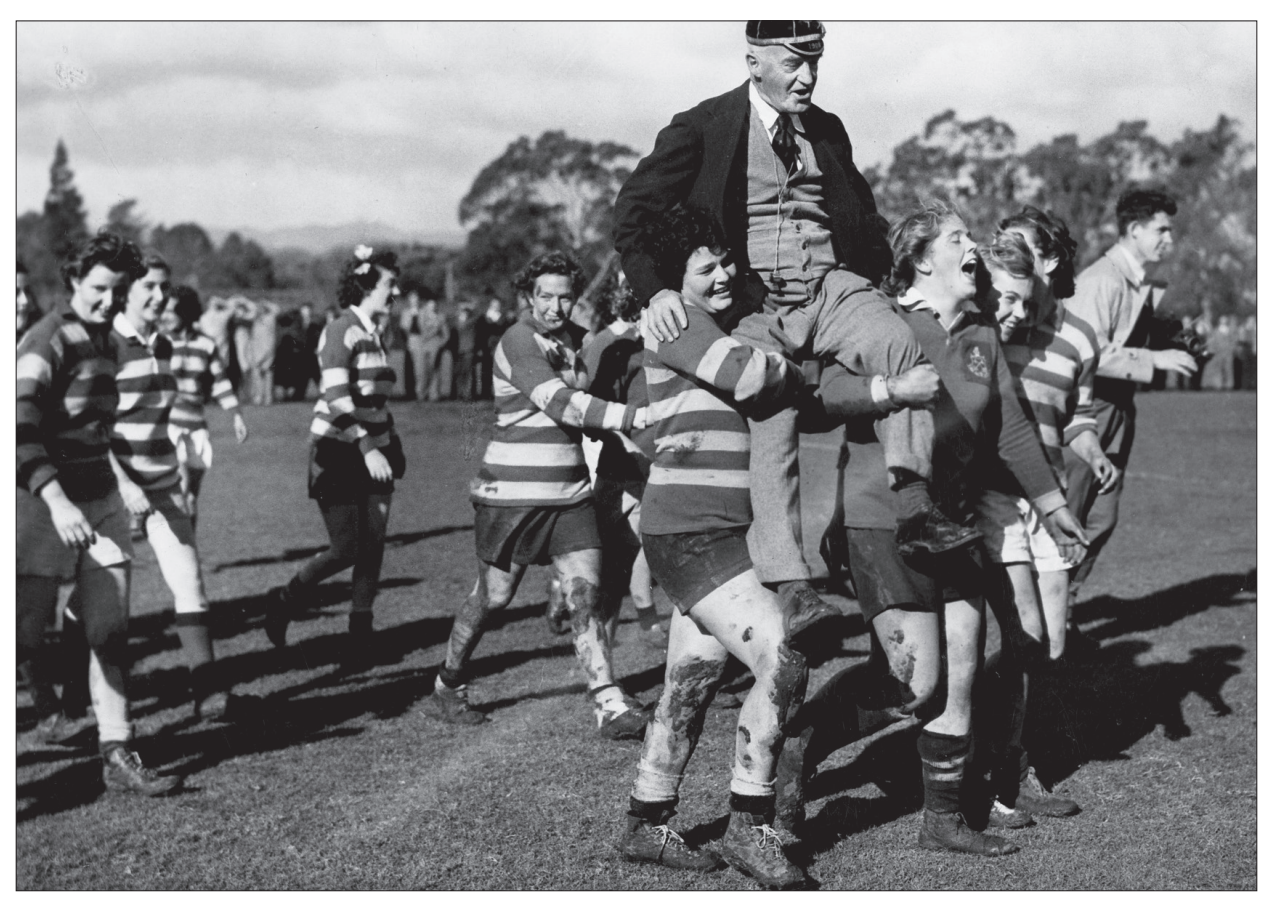

Professor Portus chaired from the rugby field, 1950 (photograph courtesy of the State Library of South Australia)

at dictation speed of other academics (possibly including Oldham) prompted a 1937 campaign for 'better brighter lectures' by the Adelaide branch of the national students' union. ${ }^{27}$ Like Henderson and Hancock, Portus (a former Rugby International) also took an active interest in student sport. The accompanying illustration depicts the finale of a 1950 men versus women university rugby game in aid of the World Student Relief Fund, refereed by Portus at the age of 67. As he recalled, 'I made some local rules for the match, the chief of which was that the men could handle the ball with one hand only ... a strict interpretation of this rule ... enabled me to blow the whistle when the girls were leading $3-0$. They were so delighted with their win that ... [t]wo of their heftier players grabbed me and swung my twelve stone on to their shoulders with ease. Then they carried me off the field, singing a song of victory as they went ${ }^{\prime} .^{28}$

\footnotetext{
${ }^{27}$ H. Wighton, 'The Lecture System', SLSA, PRG 204/16.

${ }^{28}$ G. V. Portus, Happy Highways, pp. 267-8.
} 
On his arrival Portus found Adelaide's history curriculum virtually identical to those of Melbourne, Sydney and Perth, where the professors, like Hancock, were all former pupils of Melbourne's Ernest Scott. Deprecating their focus on national histories, Portus, a committed internationalist, accepted the Adelaide chair on condition that he might introduce a first-year survey of world or universal history. With the sudden death of the economic historian Edward Shann in May 1935, Portus also took on that subject, as a third-year course alternating with Political Science, while in 1947 Political Institutions was added to his responsibilities. By 1948 (according to a graphic memorandum written as he faced imminent mandatory retirement after fifteen years service), there were 241 enrolments in History I, 105 in History II, 165 in Economic History and 21 in Political Institutions, with another 91 country or external students excused attendance at lectures. These 625 students were taught and assessed by the following staff: Portus himself, the faithful but ailing Dr Oldham and (since 1947) a new temporary assistant lecturer, Miss Kathleen Woodroofe, 'large and always beautifully dressed', whose 'stylish and polished' lectures in American and modern British history brought students 'flock[ing] to hear her' ${ }^{29}$ There were no tutorials, except for the handful of fourthyear Honours students. All pass students submitted two essays a year; a quarter were graded by staff, with the remainder 'farmed out to selected honours graduates of recent years'. Unlike 'Heads of the Scientific Departments', no clerical assistance was provided. All departmental correspondence had to be written in longhand, with important letters taken to the University's front office to be typed. Adelaide, 'the third largest University in the Commonwealth', was shockingly understaffed for teaching History and allied subjects, even by comparison with much smaller institutions: 'It is a disgrace to the University and a menace to its reputation', Portus wrote. ${ }^{30}$

\section{Halgyon Days: the Stretton Era}

This warning did not fall on entirely deaf ears. A. P. Rowe, newly appointed Vice-Chancellor, who began searching for Portus's successor with an enquiry

\footnotetext{
${ }^{29}$ J. Prest (née Wadham), 'The History and Politics Department at Adelaide University in my day', typescript, 2002. Another popular temporary lecturer, Keith Sainsbury, taught Political Institutions from 1951-4.

${ }^{30}$ SLSA, PRG 204/16, 'Report on the Department of Political Science and History'.
} 


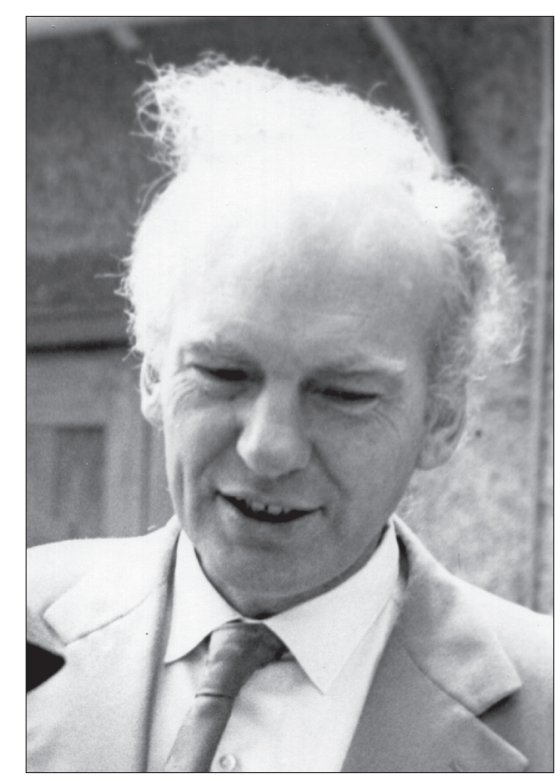

\section{Hugh Stretton, 19 February 1972}

to Hancock in mid-1948, soon came to accept the urgent need for additional permanent staff, especially after two offers of the chair had been turned down by potential candidates. By September 1949 Rowe had to admit that 'we have no idea at all where to turn for a Professor of History good enough to be a foundation stone in the rebuilding of our Arts Faculty' ${ }^{31}$ Eventually it was decided to offer a professorship (without advertisement) in what was now rebadged as 'History and Political Science', to W. G. K. Duncan, who had succeeded Portus as Director of Adult Education at Sydney, after a brilliant undergraduate career there and doctoral study at the LSE under Harold Laski. Understanding that the University intended to separate the two disciplines as soon as financially possible, Duncan eagerly looked forward to divesting himself of History. In 1950, when he took up his chair (Portus having delayed retirement by a year), Duncan was joined by Douglas Pike, a former Portus student who returned to Adelaide from a brief sojourn at the University of Western Australia as reader and de facto head of History. Close to finishing The Paradise of Dissent, his celebrated history of early

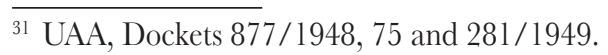


South Australia, Pike's 'room was a chaotic mess of papers and books, yet he found time for everyone'. ${ }^{32}$

The professorial hiatus ended in mid-1953, when Hugh Stretton, another Melbourne-trained Rhodes scholar, was appointed (again by invitation). ${ }^{33}$ Not yet turned thirty, Stretton had scarcely less illustrious academic credentials than Hancock, notably a Balliol tutorial fellowship in modern history, awarded even before his BA results were out. He would subsequently deny any claim to be a historian, as distinct from someone with broad interests in ideas and policies. Both his teaching and writing have certainly traversed a far wider range than most academic historians dare attempt. But Stretton's concerns with economic and social concepts and practice, especially in terms of equity, urban planning and welfare issues, show a marked sensitivity to historical context and the need for careful weighing of arguments and evidence in each particular case. Moreover, during his first fifteen years in Adelaide Stretton devoted himself to teaching history and building up the Department, which he headed until 1966. It was not until 1969, after relinquishing his chair and its associated administrative burden, that his remarkable flow of multidisciplinary publication began. ${ }^{34}$

From his arrival in October 1954, Stretton's department displayed a democratic, egalitarian spirit, sustained by regular participatory staff meetings and its professorial head's 'velvet guidance'. ${ }^{35}$ This anti-hierarchical, intellectually élitist ethos doubtless enhanced its attractions to the young academics Stretton proceeded to gather in from Australasia, the UK and the USA, starting in 1955 with the Cambridge-trained economic historian Heinz Kent. The Department's 1955 establishment of 6 had grown to 25 a decade later, while its national and international reputation simultaneously burgeoned. In an era of unprecedented university expansion and competition for academic staff, not all the stars Stretton

\footnotetext{
${ }^{32}$ J. Prest (née Wadham), 'The History and Politics Department at Adelaide University'. On Pike, later founding editor of the Austratian Dictionary of Biography, see J. Calvert, 'Douglas Pike (1908-1974) South Australian and Australian Historian', MA thesis, University of Adelaide, 2008.

${ }^{33}$ CM, XIX, 27 March, 31 July, 28 August 1953. However Stretton did not arrive in Adelaide until October 1954.

${ }^{34}$ L. Orchard \& R. Dare (eds), Markets, Morals and Public Policy (Annandale, Federation Press, 1989); R. Pascoe, The Manufacture of Australian History (Melbourne, Oxford University Press, 1979), pp. 133-9.

${ }^{35}$ I owe this apt phrase to Robert Dare, 'Power', paper delivered to History of History @ Adelaide symposium, 2 December 2011.
} 
brought to Adelaide stayed; sojourners of three years or less included a quartet of later acclaimed Australianists (Geoffrey Blainey, Frank Crowley, Alan Martin and Ian Turner), a remarkably talented Indian social and political historian, who died shortly after taking up a professorship at El Colegio de México (Prodyot C. Mukherjee) and an economic historian who returned to Ireland after stints at Adelaide and LaTrobe (John O'Brien).$^{36}$ Ken Inglis, who came to Adelaide in 1956 fresh from his Oxford doctorate, left for the ANU shortly after publishing a memorable dissection of contemporary South Australian politics and prejudice in The Stuart Case (1961). ${ }^{37}$ But a galaxy of talent stayed on. The star acquisition was George Rudé, the Marxist social historian 'from below' of eighteenth-century France and Britain (and subsequently convict Australia), who came in 1960 at the age of fifty to his first ever academic post (having been rebuffed for political reasons by another Australian university) and was rapidly promoted to a chair. ${ }^{38}$ Another outstanding if younger arrival from the UK that same year was the New Zealandborn Trevor Wilson, who would soon make his mark as a prize-winning student of twentieth-century British politics, before branching out with equal acclaim into social and military history. Succeeding in 1968 to the vacancy created by Rudé's resignation, Wilson would continue his exceptionally distinguished research and teaching career long after his mandatory retirement in $1993 .{ }^{39}$ Stretton's former mature-aged Oxford pupil W. A. (Peter) Phillips, who had fought in North Africa, escaped from Italian and German prison camps and survived Auschwitz, proved an outstanding undergraduate teacher, delivering set-piece lectures on twentiethcentury European history to capacity student audiences. ${ }^{40}$ His verbal clashes with the ebullient Melbourne-trained Russian historian Israel Getzler, a German-born refugee from Soviet Siberia, who left in 1966 for a chair at the newly-founded La Trobe University (where Adelaide history graduates and former staff would

\footnotetext{
${ }^{36}$ La Gaceta (Fondo de Cultura Económica), 33 (September 1973), p. 9; 'Obituary', Australian Studies, 13.2 (1998), pp. 1-2.

${ }^{37}$ Cf. K. S. Inglis, 'Hugh Stretton's University of Adelaide, 1954-56', Fournal of the Historical Society of South Australia, 18 (1990), pp. 9-12.

${ }^{38}$ J. Friguglietti, 'Rudé, George Frederick Elliot (1910-1993)', Oxford Dictionary of National Biography, <http://www.oxforddnb.com/view/article/53299>; Appointment in 1961 of a former Stern Gang member as lecturer in economic history was controversially blocked by Foreign Minister Alexander Downer's refusal of a visa on (unstated) security grounds: UAA 902, Brenner Case.

${ }^{39}$ War and Society, 23, Supplement 1 (2005), pp. iii-iv, et passim.

${ }^{40}$ P. Phillips, The Tragedy of Nazi Germany (London, Routledge, 1969), pp. 1-3, 162-3.
} 
form a distinctive cohort), enlivened the exchanges of History and Politics staff around the long refectory table (another Stretton artefact) in their joint fourthfloor Napier Building tearoom.

The tiny department Stretton inherited had consisted entirely of Adelaide history graduates. Thereafter imports predominated, more so than at Melbourne or Sydney (which had larger honours cohorts to draw on), especially following the 1956 retirement of Oldham and the resignations of Pike in 1960 and Woodroofe in 1966. Before jumbo jets and video conferencing, most non-Australian appointees had to be selected without interview, placing a high premium on their referees' testimony; Stretton was largely 'hiring on promise ... hiring people recommended by folk who knew them well ... and [he] had very good connections'. ${ }^{41}$ Despite the numbers involved there were surprisingly few mistakes and only one unmitigated disaster. ${ }^{42}$ From a present vantage point, Stretton's department lacked gender balance (a term not then in common use). When the early modernist Lotte Glow (later Mulligan) left for La Trobe in 1967, a year after Woodroofe's departure, the only remaining female academics were annually-appointed tutors, until the Australianist Decie Denholm was promoted to senior tutor in 1970. Denholm, Glow and Woodroofe all gained their higher degrees either under Stretton's supervision, or at very least with his encouragement. But the University of Adelaide had no senior women historian counterparts to Melbourne's Kathleen Fitzpatrick or Sydney's Marjorie Jacobs. Not that there was an over-abundance of female candidates on the Australian academic job market during the 1950s and early ‘60s; indeed Adelaide's first female professor (the geographer Fay Gale) was only appointed in 1978.

While the sequential structure of undergraduate teaching inherited by Stretton remained basically unaltered until the 1970s, additional staff permitted a notably wider range of subject offerings, not least in Asian history. The most significant pedagogical development was perhaps the introduction in 1967 of first-year tutorials taught by all members of staff, an altruistic decision taken

\footnotetext{
${ }^{41}$ Hugh Stretton, transcript of interview with Wilfrid Prest, 10 February 2005.

42 The individual in question proved unstable as well as incompetent and eventually committed suicide; another (local) appointee became an alcoholic. Between 1954 and 1969 there were some 35 appointments of lecturer and above, including (besides those listed in Edgeloe, Annals, 434-5) G. Blainey, G. Buxton, F. Crowley, D. Denholm, J. Frodsham, D. E. Kennedy, R. Leonard, A. Martin, J. O'Brien, P. Mukherjee, G. Sinzheimer and A. Sykes.
} 
notwithstanding Stretton's prudential counsel to the contrary. ${ }^{43}$ Student numbers had grown rapidly as post-war 'baby boomers' reached their late teens. Class lists for 1957 show a total of 407 undergraduate history enrolments and 10 fourthyear honours students; the equivalent figures for 1966 set an all-time record of 1383 undergraduates and 35 in honours. Postgraduates were also an increasing presence; whereas Portus had supervised a mere three MA students in 1948, by 1970 the department had 10 masters and 6 doctoral theses under way, half the latter being undertaken by members of staff. For most Adelaide historians research and publication were no less a priority than teaching. When Commonwealth funds became available on a competitive basis through the newly constituted Australian Research Grants Committee in 1966, four academics joined together in what would become the first of many successful ARGC/ARC applications from the History Department. And besides the usual domestic joys and distractions for scholars with young families (as most had), politics remained a major preoccupation throughout this era of Vietnam War and campus activism. Staff lent their weight to current causes: the Australianist John Tregenza and the Pacific historian John Young were prominent in the Campaign for Peace in Vietnam, George Rudé and others provided support for arrested student demonstrators, while the first-year tutor Jill Blewett and the South-East Asian specialist Roger Knight worked for abortion and homosexual law reform respectively.

In many respects the first half of the 1970s continued as before, with slightly less pressure of undergraduate numbers (despite History I enrolments rising from 314 in 1968 to 460 by 1974, and the University's largest fourth-year honours class). ${ }^{44}$ Stretton remained a vital influence. New appointments were still possible; indeed the department gained three additional lectureships and a parttime London-based research assistant from the Staff Development Comittee in 1974. One post went to the Russian historian Ric Zuckerman, ${ }^{45}$ who joined the Africanist Norman Etherington, the modern Japan specialist Steve Large and the early modern European historian Lynn Martin in bringing some US graduate

\footnotetext{
${ }^{43}$ H. Stretton, 'Inside the Degree Shop', Nation, 12 November 1966, pp. 11-13.

${ }^{44}$ Austin Gough to Registrar, 16 October 1974; Scholarships Committee, Survey of Classes of Honours 1972-1976.

${ }^{45}$ A. Rudszinski, 'Obituary', Flinders Fournal of History and Politics, 27 (2011), pp. 158-9; S. Mitchell, 'G'Bye California, G’Day Australia', Los Angeles Times Magazine, 25 June 1989.
} 


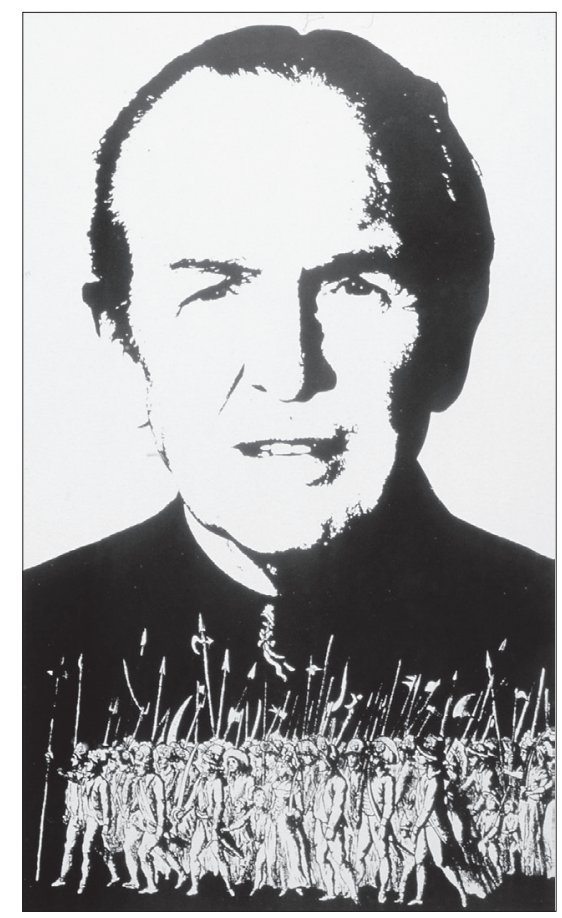

\section{George Rudé}

school (and other) values to Adelaide. Asian history remained a strength, with specialist courses covering India, Vietnam, Malaysia and Indonesia, as well as China and Japan; Yen Ching-hwang, a graduate of Singapore's Nanyang University and the ANU, would become a leading international authority on the history of overseas Chinese, as well as founder and president for several terms of the Chinese Association of South Australia.

Austin Gough, who succeeded to Stretton's chair in 1970, embodied different traditions. After editing country newspapers and working in the Commonwealth public service, a dazzling mature-aged student career at Melbourne University had seen him appointed lecturer in the year of his graduation, before going on to an Oxford DPhil in nineteenth-century French history, then Warwick and Monash universities. Erudite, urbane and witty, Gough's formidable reputation as scholar and teacher made him a welcome addition to Adelaide's strength in later modern 
European history, even as it became apparent that he was not entirely at ease with the department's form of participatory governance, now being adopted throughout the University, under the rubric of 'Departmental Government'. But in his fears for the integrity of academic decision-making the new professor of History was by no means the sole opponent of pressure to add elected undergraduate representatives to the departmental 'nucleus' of tenured and tenurable academic staff.

In 1975, Gough had been followed as elected departmental chairman (or head) by Norman Etherington, at that time still a senior lecturer, who had earlier persuaded the department to undertake a radical curricular restructuring. First-year still provided the main gateway to later studies in history, with an early modern Europe course (History IA) flanked by one or two other options. These latter gradually coalesced into the team-taught 'Old Societies and New States' (mainly colonial and post-colonial Asian and African history) and Australian History, which Bill Gammage quickly made his own after joining the department from Papua New Guinea in 1977. But second- and third-year students henceforth picked their courses from the same 'smorgasbord' of options, each supposedly demanding more advanced work of third- than second-year students. This less structured scheme suited academics keen to teach within their special fields of interest, and gave most students a wider choice, although making it difficult to provide them with a coherent course of study, let alone a common intellectual experience.

History's initiative was soon followed by other departments in the Faculty, just as the main features of departmental government in the broader University had been 'present and engrained in the [History] department long before ...'. This observation came from a comprehensive external review of the department conducted in 1980 by Professor Oliver MacDonagh of the Australian National University's Research School of Social Sciences. MacDonagh identified some potential problems with the workings of departmental government, as also the department's top-heavy demographic structure and uneven publications record. But his overall assessment was highly favourable, referring to its 'deservedly high reputation in the outside world of history' and 'phases of remarkable distinction ...': he judged History altogether 'an admirable department, devoted in teaching, 
marked by much fine scholarship, and justifiably high in both morale and mutual respect.'. ${ }^{4}$

There was every reason to welcome MacDonagh's tick of approval, for the environment in which the department existed became steadily more difficult over the succeeding decade. As early as 1976, federal budget cuts had prompted across-the-board reductions in University spending; thereafter financial austerity only intensified. ${ }^{47}$ Gammage's appointment vice John Tregenza (who joined the Art Gallery of South Australia as Curator of Historical Collections before becoming State Historian), was the last non-contract academic post to be filled in History for nearly twenty years. The teaching establishment accordingly shrank, from 29 full-time positions in 1975 to 22 by 1988, partly because undergraduate enrolments were either static or tending downwards. Between 1978 and 1988, History's share of Arts Faculty enrolments dropped from 15.4 to 12.6 per cent, although the total Faculty student load rose modestly over the same period. New departments and programmes (Anthropology, Asian Studies and Environmental Studies) now attracted students who might formerly have taken history subjects. Even as the department's own range of offerings contracted, other centres and programmes mounted subjects in Asian, economic, international and Australian political history. When Hugh Stretton retired in 1989, his popular course on political and social ideas was added to those already mothballed or abandoned, including African, economic, Japanese, medieval European and Pacific history, besides the popular modern European subjects taught by Leon Atkinson before his untimely death in $1985 .{ }^{48}$

In 1986 a departmental Teaching Sub-Committee report had concluded that 'we face a staffing problem in the near future and possibly a crisis in the long term if we seek to maintain our current practices and conventions'. Yet despite financial and administrative pressures, a threatened restructuring of the Arts Faculty and internal divisions on matters of principle as well as personality, the 1980s was not a decade of unrelieved decline and despondency. The South Australian sesquicentenary in 1986 and the Australian Bicentennial in 1988 both

\footnotetext{
${ }^{46}$ UAA, S. 484: O. MacDonagh, 'Review of Department of History 1980', pp. 7, 23.

${ }^{47}$ G. M. Badger, 'Memorandum ... The Financial Situation of the University in 1977', 24 November 1976.

${ }^{48}$ Barr Smith Library, Special Collections, MSS 0024.
} 
boosted interest in Australian history; Etherington had earlier been recruited as founding chair of the History Trust of South Australia, while Gammage edited one of the best-received volumes of the national Bicentennial History. ${ }^{49}$ Fruitful collaboration with fellow-historians at Flinders University continued, especially in the teaching of honours special subjects and the informal seminars of the Working Group in Social History. In 1987 Robert Dare became inaugural director of the interdisciplinary and inter-institutional Centre for British Studies, which strengthened pre-existing ties with the Art Gallery, where Wilfrid Prest chaired the board from 1978-85, while Peter Burns helped manage the ARC-funded Research Centre for Southeast Asian Ceramics constituted by the Gallery and University. Staff continued as before to win competitive grants and publish with leading international academic presses and journals, as also to involve themselves in local affairs, not least a protracted campaign to fund construction of the sailtraining vessel 'One and All', and a less successful struggle to preserve Adelaide's nineteenth-century townscape from indiscriminate development. ${ }^{50}$ History students played a significant role in campus journalism and politics, and won major awards, including a Rhodes Scholarship hat-trick. The History Club also seemed to go from strength to strength, organising talks, social events and publications. But towards the end of the decade, after student subscriptions, always volatile, fell off from their 1985 peak of 157, a 'telephone vote' ratified its change of name to 'History and Politics Club', in order 'to widen the appeal of the club and hopefully get new members. ${ }^{51}$

\section{Doing Somewhat More with A Good Deal Less}

When an external review of the Humanities and Social Sciences at the University of Adelaide was commissioned in 1994, the History Department's submission painted a bleak picture. It pointed out that when last reviewed in 1980, 'we had

\footnotetext{
${ }^{49}$ W. Gammage and P. Spearritt (eds), Australians 1938 (Sydney, Fairfax, Syme and Weldon Associates, 1987).

${ }^{50}$ [N. Etherington], Time Gentlemen Please! The Story of the Fight to Save the Aurora Hotel (Norwood, Aurora Heritage Action, 1984); S. Mosler, Heritage Politics in Adelaide (Adelaide, University of Adelaide Press, 2011).

${ }^{51}$ After Ralph Gibson (elected 1966), the next South Australian Rhodes scholars with Adelaide History honours degrees were Sam Wells (1979), Jenny Coles (1980) and Vesna Drapac (1981); AUA, 590, Box 1, 'AU History Club Minutes' (1979-1989).
} 
a complement of 27 full-time teaching staff (lecturer and above), responsible for 797 undergraduate, 34 honours and 25 postgraduate students ... the equivalent figures for the end of 1994 are 14 (possibly 13) staff, 674 undergraduates, 35 honours and 31 postgraduate students': thus the staff: student ratio had blown out from just over 1: 12 to 1: 20. Over the previous 12 months the department had lost, by retirement and voluntary redundancy, no less than one-third of its teaching staff, including one professor (Trevor Wilson), two readers and three senior lecturers: 'perhaps the greatest haemorrhage of talent in the Department's existence to date'. ${ }^{52}$ (At the end of that year Gammage also left to take up an ARC fellowship; nor did the losses stop there.) Following the University's part-merger with the South Australian College of Advanced Education in 1991, three lecturers in history from that institution joined the department. The best that could be said for this forced marriage was that it permitted the continued teaching of American history following Roger Hainsworth's retirement. A happier development in the subsequent year was the advent of three ARC research fellows. Although neither they nor their successors could do much to relieve the teaching burden, the holders of these prestigious awards generally enhanced the department's intellectual life and morale.

The 1994 reviewers made no explicit criticism of the History Department, a source of some relief in that era of intrusive managerialism, endemic financial crisis and rampant post-modernism, when the much-cited title of Francis Fukuyama's The End of History (1989) might well seem ominously prophetic. In South Australia the numbers of students presenting History as a Year 12 subject had dropped from 3782 in 1988 to 2876 five years later; by 1996 only just over 5 per cent of publiclyexamined Year 12 students were studying history. It was little consolation to know that, like the diminishing numbers of academic historians, this was all part of a national, even international trend. But serious efforts were made to strengthen relations with the History Teachers Association of South Australia and with schools teaching Year 12 History, partly by hosting exam preparation events attended by students and teachers. These measures, together with the Department's strong reputation for committed undergraduate teaching, sustained by multiple teaching

\footnotetext{
52 'Department of History, Submission to Review of Humanities and Social Sciences, August 1994', pp. 2,11 .
} 
prizes, helped keep undergraduate enrolments stable over the 1990s. Postgraduate research degree and honours enrolments did slightly better: by 1999, no fewer than 38 history $\mathrm{PhD}$ candidates were under supervision. Following directives from above to explore all possible sources of additional external revenue, the department also established a commercial arm to undertake commissioned historical research. This venture had limited success, and a new postgraduate coursework programme in public history, or Applied Historical Studies, also foundered after several years, the victim of inconsistent funding regimes and maladministration.

The Research Centre for the History of Food and Drink, which Lynn Martin persuaded the Department to adopt as its own in 1997, was a very different story. Besides establishing a thriving international network of scholars with interests in cultural rather than biological aspects of food and foodways, the Centre staged a series of extremely successful conferences, from which several volumes of published papers emerged. In conjunction with the Cordon Bleu organisation, Martin was also responsible for setting up the postgraduate coursework programme in Gastronomy/Food Studies, which admitted its first students in 2002 and is now directed by Barbara Santich. But the department's first successful postgraduate coursework awards were in Art History, taught jointly with the curatorial staff and collections of the neighbouring Art Gallery of South Australia, plus a cohort of subject specialists drawn from within and outside the University. After a rocky start in 2001, Art History is now established under the direction of Cathy Speck (recruited from the University of South Australia), recently assisted by Lisa Mansfield, who adds several undergraduate courses to her postgraduate responsibilities, thereby helping to bridge a narrowing if still palpable gap between these more recent additions to the discipline's offerings and its traditional pedagogical focus.

The Department of History was administratively transmuted into a discipline within the School of History and Politics at the beginning of 2002. Since then there has been wholesale change and renewal of personnel. Only three of the academic staff listed in the 1994 Faculty review are still teaching. Obliged to relinquish his chair on taking up an ARC Fellowship in 2002, the present writer subsequently moved to the Law School; now retired, he remains a visiting research fellow in history, like many former colleagues. David Lemmings, whose 
academic career took him from Sussex to Oxford to London, then to Adelaide and Newcastle, returned in 2008 as Head of School and Professor of History. In the latter position, besides pursuing research on law and society in early modern England, he directs the large Adelaide node of the ARC-funded Centre for the History of the Emotions, which currently supports several postdoctoral research fellows within the discipline.

All undergraduate courses have been reduced to semester length since the 1990s. But the traditional pattern of first-year survey (currently 'Europe, Empire and the World, 1492-1914' and 'The Twentieth Century: A World in Turmoil'), followed by more intensive second- and third-year offerings, is still in place. Professor Henderson would be heartened by the extent of honours and postgraduate research on South Australian topics, and delighted to learn that the new Cambridge history of South Australia is currently under contract to Robert Foster and Paul Sendziuk. Professor Portus would doubtless observe with gratification that world history is firmly back on the curriculum (not only in the subject 'Food and Drink in World History'), while intrigued by the diversity of other undergraduate offerings. These currently range from 'Indigenous Culture and History' to 'Reel History: film representations of World War II', from 'Migrants and the Making of Modern Australia' to 'Heresy and Witchcraft in Medieval Europe'. Most regrettably and alarmingly, however, Asian history has all but disappeared from the syllabus.

The fair-minded Portus would certainly be glad to discover that the longstanding gender imbalance among academic staff is not only righted, but now tilts slightly in favour of the women (with Vesna Drapac currently the first female head of History). Yet he might simultaneously ponder an apparent disproportionate shortage of male history students. Like his predecessors and successors, he would surely be concerned to note that the pedagogical burden of responsibility for some 1250 enrolled undergraduates and 24 honours students, plus nearly a hundred postgraduates pursuing degrees both by coursework and research, is borne by a mere 15 academics (five of them part-timers).

In his foreword to Marjorie Casson's 1964 memoir of G. C. Henderson, Hugh Stretton wondered how Henderson might have viewed the major changes experienced by Australian universities since the Second World War. Henderson, 
he thought, 'would certainly welcome the modern industry of historical research. But he would as certainly regret the cafeteria courses, the trivial and overloaded detail, and most of all the moral abdication, which are sometimes to be found in the modern industry of historical teaching, ${ }^{53} \mathrm{~A}$ half-century further on, as universities everywhere struggle to adapt to digital technology and mass higher education, Stretton's cautionary words have not lost their force. But Adelaide's History Discipline continues to serve the vital interests of a healthy democracy, primarily by encouraging citizens - among them future administrators, archivists, counsellors, curators, diplomats, entrepreneurs, journalists, politicians, public servants, social workers, teachers and writers - to enlarge their understanding of human life beyond the confines of the immediate here and now. Published scholarship from Adelaide builds on a local tradition of first-class historical writing. It likewise influences, sooner or later, the ways in which we and our children regard the past, and thus also the present and future, both in Australia and much of the world besides. How these responsibilities are discharged has changed considerably over the past century. But their essential nature and value remains.

\section{REFERENGES}

\section{Archives and Manuscripts}

Barr Smith Library, Special Collections:

MSS 0024, Papers of Leon Desmond Atkinson

University of Adelaide Archives (UAA):

Council Minutes (CM), vols. I, VII, XII, XIV, XIX (1877-1953)

Dockets (various dates and subjects)

History Club Minutes 1979-89

Reports (Education Committee and Agent-General, 1900)

Review of the Department of History, 1980

University Association Minutes

Privately held (Wilfrid Prest):

\footnotetext{
${ }^{53}$ M. R. Casson, George Cockburn Henderson, p. 3.
} 
Austin Gough to A E Shields (Registrar), 16 October 1974 (photocopy)

G. M. Badger 'Memorandum to Members of the University', 15

November 1976 (roneo)

Department of History, Submission to Review of Humanities and Social

Sciences, August 1994 (printout)

Hugh Stretton, transcript of interview, 10 February 2005 (printout)

Prest (nee Wadham), J, 'The History and Politics Department at Adelaide

University in my day', 2002 (printout)

Scholarships Committee Survey of Classes of Honours 1972-1976 (roneo) State Library of South Australia (SLSA):

PRG 6 (Henderson papers)

PRG 204 (Portus papers)

\section{Newspapers}

On Dit \& The Advertiser (Adelaide); The Age \& The Argus (Melbourne); Western Mail

(Perth); all but On Dit accessed via 'Trove' at the Australian National Library.

The Times (London).

\section{Other printed sources}

Anon.,'Professor G. G. Henderson', Adelaide University Magazine, V.13 (1926).

Australian Dictionary of Biography (Melbourne, Melbourne University Press, 1966...), accessible online at <http://adb.anu.edu.au/>.

Badger, C. R., 'Sir Keith Hancock, a Tribute from a Grateful Pupil', Fournal of the Historical Society of South Australia, 18 (1990), pp. 18-27.

Bone, H. A., 'Linden A. Mander, 1897-1967', Political Research Quarterly, 20 (1967).

Caine, B. et al., History at Sydney 1891-1991: Centenary Reflections (Sydney, University of Sydney, 1992).

Calendar of The University of Adelaide, 1877- ... .

Calvert, J., 'Douglas Pike (1908-1974) South Australian and Australian Historian', MA thesis, University of Adelaide, 2008. 
Casson, M. R., George Cockburn Henderson (Adelaide, Libraries Board of SA, 1964). Davidson, J., A Three-Cornered Life: The Historian W K Hancock (Sydney, New South Press, 2010).

Edgeloe, V. A., Annals of the University of Adelaide (Adelaide, Barr Smith Press, 2003).

[Etherington, N.], Time Gentlemen Please! The Story of the Fight to Save the Aurora Hotel (Norwood, Aurora Heritage Action, 1984).

Friguglietti, J., 'Rudé, George Frederick Elliot (1910-1993)', Oxford Dictionary of National Biography, <http://www.oxforddnb.com/view/article/53299>. Gammage, W. \& Spearritt, P. (eds), Australians 1938 (Sydney, Fairfax, Syme \& Weldon Associates, 1987).

Hancock, W. K., Country and Calling (London, Faber, 1954).

Henderson, G. C., Sir George Grey: Pioneer of Empire in Southern Lands (London, Dent, 1907).

Inglis, K. S., 'Hugh Stretton's University of Adelaide, 1954-56', Fournal of the Historical Society of South Australia, 18 (1990), pp. 9-12.

La Gaceta (Fondo de Cultura Económica), 33 (September 1973).

Mosler, S., Heritage Politics in Adelaide (Adelaide, University of Adelaide Press, 2011).

Mitchell, S., 'G'Bye California, G’Day Australia', Los Angeles Times Magazine, 25 June 1989.

'Obituary', Australian Studies, 13.2 (1998), pp. 1-2.

Oldham, W. in W. H. Oldham (ed.), Britain's Convicts to the Colonies (Sydney, Library of Australian History, 1990).

Orchard, L. \& Dare, R. (eds), Markets, Morals and Public Policy (Annandale, Federation Press, 1989).

Pascoe, R., The Manufacture of Australian History (Melbourne, Oxford University Press, 1979).

Phillips, P., The Tragedy of Nazi Germany (London, Routledge, 1969).

Portus, G. V., Happy Highways (Melbourne, Melbourne University Press, 1953).

Rudszinski, A., 'Obituary', Flinders 7 of History and Politics, 27 (2011), pp. 158-9.

Simpson, C., The Partnership (London, Bodley Head, 1987).

Slee, P. R. H., Learning and a Liberal Education: the Study of Modern History in the 
Universities of Oxford, Cambridge and Manchester, 1800-1914 (Manchester, Manchester University Press, 1986).

Stretton, H., 'Inside the Degree Shop', Nation, 12 November 1966, pp. 11-13. Sutton, D., Robert Langton Douglas: Connoisseur of Art and Life (London, Apollo Magazine, 1979); <www.dictionaryofarthistorians.org/douglasr.htm>. Thornton, R., "A Streak of Acting Ability”: G.V. Portus, Educational Evangelist', Fournal of the Historical Society of South Australia, 16 (1988), pp. 104-13.

Tregenza, J., Professor of Democracy: The Life of Charles Henry Pearson, 1830-1894, Oxford Don and Australian Radical (Melbourne, Melbourne University Press, 1968).

War and Society, 23, Supplement 1 (2005). 


\section{0}

\section{The History of Aboriginal Languages and Linguistics at the University of Adelaide}

Rob Amery

Whilst the Discipline of Linguistics at the University of Adelaide is relatively new, commencing in 1993 with the appointment of Professor Peter Mühlhäusler as the 'Foundation Professor of Linguistics', the University's work and engagement with Aboriginal languages dates back more than 65 years earlier, including the appointment of a 'Professor of Australian Linguistics' in 1970. Even though Linguistics is relatively small in Adelaide, both by national and international standards, a number of very important developments emerged first at the University of Adelaide within the field of Aboriginal languages and linguistics.

The beginnings of engagement through the University of Adelaide with Aboriginal languages research dates back to the establishment of the Board for Anthropological Research (BAR) at the University in 1926. ${ }^{1}$ Among other things,

\footnotetext{
${ }^{1}$ See P. Monoghan, 'Norman B. Tindale and the Pitjantjatjara Language', in W. B. McGregor (ed.), Encountering Aboriginal Languages. Studies in the history of Australian linguistics (Canberra, Pacific Linguistics, Research School of Pacific and Asian Studies, The Australian National University, 2008), pp. 25172, here pp. 255-9.
} 
the BAR encouraged the collection of vocabularies of Aboriginal languages. E. H. Davies, Professor and Dean of the Faculty of Music 1919-1947, was the 'first person in Australia to record, transcribe and write about aboriginal [sic] tribal and ceremonial songs and singing'2 in the period 1926-1930, when he accompanied BAR expeditions to Central Australia. The arrival of John Aloysius FitzHerbert, appointed as Professor of Classics at the University of Adelaide in 1928, gave the BAR a much stronger focus on Aboriginal languages. In 1930-31, FitzHerbert established a committee to devise a phonetic system suited to typewriters for the transcription of Aboriginal languages. ${ }^{3}$ This committee consisted of FitzHerbert together with Norman Tindale from the South Australian Museum and Charles Chewings.

In the early 1930s, FitzHerbert took on two outstanding students of Aboriginal languages: ${ }^{4}$ J. R. B. Love and T. G. H. (Ted) Strehlow. J. R. B. Love undertook a study of Worrora language spoken around Derby in the Kimberley region of Western Australia. ${ }^{5}$ Love's work on Worrora was presented as a Masters Thesis in 1933, recently published by Lincom Europa. ${ }^{6}$ A 12-page outline appeared earlier in Oceania Monographs. ${ }^{7}$ In recent years, Mark Clendon completed a $\mathrm{PhD}$ on Worrora through the University of Adelaide ${ }^{8}$ building on Love's pioneering work with further fieldwork with contemporary speakers. Ted Strehlow, son of missionary Carl Strehlow at Hermannsburg in Central Australia west of Alice

\footnotetext{
${ }^{2}$ See The University of Adelaide Library website, <www.adelaide.edu.au/library/special/mss/ davies>, accessed 28 Sept 2011.

${ }^{3}$ See J. Simpson et al., 'I Could Have Saved You Linguists a lot of Time and Trouble: 178 years of Research and Documentation of South Australia's Indigenous Languages, 1826-2004', in W. McGregor (ed.), Encountering Aboriginal Languages: Studies in the History of Australian Linguistics (Canberra, Pacific Linguistics, 2008), pp. 85-144, here p. 33; Monaghan, 'Norman B. Tindale and the Pitjantjatjara Language', 2008, pp. 257-8.

${ }^{4}$ FitzHerbert also supervised Lillian Mary Theakston Short's work from 1936 to 1938 on Hula, an Austronesian language spoken in southeast Papua. She was awarded an MA in 1939.

${ }^{5}$ Following his work on Worrora, Love went on to conduct further pioneering work in Pitjantjatjara, spoken in the northwest of South Australia.

${ }^{6}$ J. R. B. Love, 'The Grammatical Structure of the Worora Language of North-Western Australia' (MA thesis, University of Adelaide, 1932), republished by Lincom Europa, Munich, 2000 (edited by R. M. W. Dixon).

${ }^{7}$ J. R. B. Love, 'An Outline of Worora Grammar', in A. P. Elkin (ed.), Studies in Australian Linguistics, Oceania Monograph 3 (Sydney, University of Sydney, 1937-38), pp. 112-24.

${ }^{8}$ M. Clendon, A grammar of Worrorra (Halls Creek [WA], Kimberley Language Resource Centre, 2000).
} 
Springs, was one of the first white Australians to grow up speaking an Aboriginal language fluently. ${ }^{9}$ His Aranda Grammar was submitted as an MA thesis in 1938 and published in three parts in Oceania. ${ }^{10}$ Strehlow was appointed senior research fellow in Australian Linguistics at the University of Adelaide in 1946. He was later appointed Professor of Australian Linguistics from 1970-73 and Emeritus Professor in 1974. During this professorship, Strehlow pursued his own research and produced the classic Songs of Central Australia. ${ }^{11}$ However, he appears not to have supervised any postgraduate students or to have set anything in place for the continuation of linguistics at the University. Strehlow never really saw himself as a linguist, despite the title of the position he held. Rather, his main interest was in literature. In pursuing this interest, he made connections between Arrernte song texts and Icelandic, English and German literature. A current linguistics postgraduate student at the University of Adelaide, Clara Stockigt, is writing a historiography of the work of the Strehlows on Arrernte.

Anthropologists, namely Norman B. Tindale and Ronald Berndt, also received informal training in linguistics from FitzHerbert. Tindale is well-known for his often cited 1974 publication Aboriginal Tribes of Australia: their terrain, environmental controls, distribution, limits, and proper names ${ }^{12}$ and the accompanying map, and for his work on collecting vocabularies of Aboriginal languages and placenames research. ${ }^{13}$ Berndt is best known in South Australia for his Ngarrindjeri ethnography The World That Was, ${ }^{14}$ though he also carried out unpublished research on Ngadjuri with Barney Warrior and fieldwork at Ooldea. ${ }^{15}$ Berndt also collected song texts in Yolngu Matha in northeast Arnhemland. ${ }^{16}$

\footnotetext{
${ }^{9}$ For more information on Strehlow's early life, see Hill (2003) and McNally (1981).

${ }^{10}$ T. G. H. Strehlow, 'Aranda Grammar', Oceania, X111.1, pp. 71-103; XIII.2, pp. 177-200; XIII.4, pp. 310-61 (1942-43), MA thesis, University of Adelaide.

11 T. G. H. Strehlow, Songs of Central Australia (Sydney, Angas \& Robertson, 1971).

${ }^{12}$ An earlier version was published in the Transactions of the Royal Society of South Australia (Tindale, 1940).

${ }^{13}$ See P. Monaghan, 'Norman B. Tindale and the Pitjantjatjara Language', pp. 257-8.

${ }^{14}$ Berndt, R. \& Berndt, C., with Stanton, J., A world that was: The Yaraldi of the Murray River and the Lakes, South Australia (Carlton [Vic], Melbourne University Press at the Miegunyah Press, 1993).

${ }^{15}$ R. M. Berndt \& C. Berndt, 'A Preliminary Report of Fieldwork in the Ooldea Region, western South Australia', Oceania, XIII.3; XIV. 2/3 (1943-44).

${ }^{16}$ Berndt, R., Love Songs of Arnhem Land (West Melbourne, Thomas Nelson (Australia) Ltd., 1976).
} 


\section{The Teaching of Aboriginal Languages and Aboriginal Song}

Pitjantjatjara was the first Aboriginal language ever to be taught at a university, first taught at the University of Adelaide as a summer school course in 1966. This Pitjantjatjara language course was prepared with outside expertise. Jim Downing, a Uniting Church minister who was working to address communication needs in the various communities in the Pitjantjatjara/Yankunytjatjara Lands in the northwest of South Australia, ${ }^{17}$ together with Gordan Ingkatji, a Pitjantjatjara man from Ernabella, and exceptionally talented MIT linguist, Ken Hale, prepared course materials. ${ }^{18}$ Wilf Douglas, a United Aborigines Mission (UAM) linguist who had been working with the closely related Ngaanyatjarra dialect, also prepared a set of 30 lectures (Douglas, 1968) and Hank Siliakus prepared the accompanying audiotapes. Douglas visited the University for a day or two, but Nancy Sheppard, working together with Yankunytjatjara man Bobby Brown, taught the course. Mona Tur later had some input into the course. Sometime after 1979, the teaching of Pitjantjatjara relocated to Torrens Teachers College, which later became part of the South Australian College of Advanced Education, now the University of South Australia, where Pitjantjatjara is still taught to this day. Mona Tur taught the Pitjantjatjara courses for many years alongside Brian Kirke and Bill Edwards in these institutions, but had actually commenced her long career teaching Pitjantjatjara at the University of Adelaide, prior to relocation of the course. ${ }^{19}$

In 1975, Nancy Sheppard, together with Yanyi Baker, published an adaptation and Pitjantjatjara translation of Lewis Carroll's classic Alice in Wonderland. This was a landmark translation for the whole field of Australian Aboriginal languages. Prior to that, Bible translations had been undertaken in a number of languages, but this was a first in the field of secular literature. ${ }^{20}$

\footnotetext{
${ }^{17} \mathrm{Jim}$ Downing, subsequently set up the Institute for Aboriginal Development (IAD) in 1969, which established courses in interpreting and translation and in various Central Australian languages including Pitjantjatjara, Pintupi, Warlpiri and Arrernte. Yankunytjatjara man Yami Lester was recruited in 1970 and became Director of IAD in 1980. See Y. Lester, Yami. The Autobiography of Yami Lester (Alice Springs, IAD Press, 1993), pp. 114-27, 138-43, 200.

${ }^{18} \mathrm{~J}$. Downing, et al., [Pitjantjatjara language course materials for use at The University of Adelaide (1967)], ts.

${ }^{19}$ W. Edwards, 'Teaching an Aboriginal language at University level', Babel, 30.2, (1995), pp. 4-11 $\& 38$.

${ }^{20}$ See M. A. Gale, Dhangum Djorra'wuy Dhärou: a history of writing in Aboriginal languages (Adelaide, Aboriginal Research Institute, University of South Australia, 1997), pp. 109-10.
} 
Catherine Ellis, along with senior Pitjantjatjara songman Minyungu Baker and other members of the Iwantja community at Intalkanya (Indulkana) and members of the Aboriginal community in Adelaide, founded the Centre for Aboriginal Studies in Music (CASM) in 1975. Ellis had previously worked with T. G. H. Strehlow transcribing his song tapes from 1957 and completed a $\mathrm{PhD}$ at the University of Edinburgh in 1961. Upon returning to Adelaide, she lectured in ethnomusicology, holding positions of senior lecturer and reader within the Music Department at the University of Adelaide. Ellis took the ground-breaking step of employing Pitjantjatjara men Minyungu Baker, Billy Mangi and others as senior lecturers to teach Pitjantjatjara inma (music and song) within CASM. ${ }^{21}$

In 1997, Amery introduced a course titled Kaurna Language \& Language Ecology, in which he taught about the linguistics and sociolinguistics of the Kaurna language. This Kaurna course introduced the teaching of 'Revival Linguistics' within the tertiary sector. Revival Linguistics at the University of Adelaide has been further bolstered with the appointment of Professor Ghil'ad Zuckermann in 2011. When the Kaurna Language \& Language Ecology course was first introduced, Amery taught the Kaurna language itself in addition to teaching Kaurna linguistics. Teachers from Kaurna Plains School were attending this course at that time. Since the School of Languages Kaurna course was introduced in 2004 (also developed by Amery, but now taught by Kaurna man Jack Kanya Buckskin), the teaching of Kaurna language per se at the University of Adelaide has been abandoned, though a study of Kaurna linguistics continues, albeit now biannually.

Amery had previously assisted in the establishment of Kaurna language programs in schools (Kaurna Plains School in 1992, Elizabeth City High School and Elizabeth West Adult Campus in 1994), within the Cultural Tourism course at Tauondi College in 1995 and through TAFE at Warriparinga in 1996, concurrently with his $\mathrm{PhD}$ project. Prior to enrolling in his $\mathrm{PhD}$, Amery worked to develop the Australian Indigenous Languages Framework (AILF), which introduced the teaching of Aboriginal languages within accredited programs for the very first

\footnotetext{
${ }^{21}$ Newsome, J., 'Minyungu Baker', in W. Prest, K. Round \& C. Forte (eds), The Wakefield Companion to South Australian History (Kent Town, Wakefield Press, 2001b), p. 64.
} 
time in senior secondary studies. Professor Mühlhäusler served on the steering committee for this project and supervised Amery's $\mathrm{PhD}$ on the Kaurna language. ${ }^{22}$

\section{Establishing The DisciPline of LiNGUistics}

Linguistics, as we now know it today at the University of Adelaide, began with the appointment of Peter Mühlhäusler as Foundation Professor of General Linguistics in 1993. Mühlhäusler gained his early training (BA Honours) at Stellenbosch University in South Africa, gained a Master of Philosophy at Reading in 1972, an MA from Oxford in 1979 and completed his $\mathrm{PhD}$ at ANU in 1976 on pidgins and creoles, based on extensive fieldwork in Papua New Guinea. Mühlhäusler had previously taught at Oxford, Bond University and the Free University in Berlin. He had a strong interest in and concern for endangered languages and linguistic diversity, the topic of his inaugural public lecture.

In late 1990, the Faculty of Arts requested funding from the ViceChancellor's Development Fund. The Vice-Chancellor accordingly authorised funding for a period of five years and announced that negotiations were being conducted with the National Languages Institute of Australia (NLIA) for possible additional funding support. ${ }^{23}$ The impetus for the establishment of the Chair in Linguistics came from Professor Tony Stephens, inaugural Director of the Centre for Language Teaching and Research established within the Faculty of Arts in 1989 and the lobby for education in languages other than English. There is no mention in the Vice-Chancellor's memo of the University's pioneering work in Aboriginal languages and linguistics, though it does refer to German, French, Chinese and Japanese and the Centre for Intercultural Studies in Multicultural Education (CISME), which was established in 1989, and the South Australian Institute for Languages (SAIL). Clearly, the direction Linguistics took in endangered languages research and supporting Aboriginal languages came from the individual appointed and the students and colleagues he attracted, rather than the institution.

Initially, the Discipline of Linguistics was by itself administratively, but Mühlhäusler soon had to choose between being allied with Anthropology or

\footnotetext{
${ }^{22}$ R. Amery, Warrabarna Kaurna: Reclaiming an Australian Language (Lisse [The Netherlands], Swets \& Zeitlinger, 2000).

${ }^{23}$ University of Adelaide Council Minutes, 8 March 1991.
} 
European Studies. For a short period Linguistics was allied with Anthropology and a close collaboration developed with Dr Ade Peace. But Anthropology was problematic, as Mühlhäusler had several Iranian students who were not permitted by the Iranian regime to study anthropology. Mühlhäusler chose the latter, claiming to be the only professor who was in a position to profess all the disciplines subsumed by the Centre for European Studies, which then included Classics, German, French and European Studies, along with Linguistics. In 1998, following representations by Amery, Mühlhäusler and Schwarz regarding the problems of teaching Kaurna and supervising students undertaking research projects on languages totally unrelated to Europe, the name for the Centre was changed to the Centre for European Studies and General Linguistics. From the outset, a balance has been maintained between descriptive linguistics, endangered languages and applied linguistics.

For some years, Mühlhäusler was a one-man operation, though he had some secretarial assistance from Marie Reitano and Catherine Amis, and assistance with tutorials from Amery, then employed at the Senior Secondary Assessment Board of South Australia (SSABSA). Since 1993, the Discipline has grown from one to four teaching staff with additional part-time researchers. Following the completion of his PhD in 1998, Amery was offered a three-year 0.5 time contract, which was not renewed in 2001. Amery returned to the University in 2004 with 0.6 time employment in Linguistics, which was converted to full-time in 2006. Peter Mickan came to the University in 2000, also initially on a 0.5 time contract. Peter White joined the Discipline in 2005, half-time with Linguistics and half-time with Media. This was later converted to full-time employment in Linguistics. In 2008, White resigned and took up a position at the University of New South Wales. He was partly replaced by John Walsh, who took up a position shared with English on 1 July 2009. Through carefully crafted succession planning and lobbying by Mühlhäusler, Professor Ghil'ad Zuckermann, educated at the University of Tel Aviv and Oxford, joined Linguistics in February 2011, whereby Mühlhäusler's position was reduced to 0.5 time, principally focussed on his ARC-funded Norf'k project.

Teaching has been supplemented by a 0.2 Teaching Assistant position, held by Nayia Cominos from 2008 to 2011, and casual staff have been engaged 
to teach a number of courses. These include Des Moriarty and Ray Adams (Computer Assisted Language Learning), David Rose and John Polias (Functional Grammar \& Discourse), Dr Christina Eira (Language \& the Ethnography of Communication), Dr Mark Clendon (Phonology and Morphology \& Syntax), Dr Ian Green (Language \& the Ethnography of Communication \& Morphology \& Syntax), Hiromi Teramoto (Language Learning), Johanna Motteram (Language Teaching Methods), Andrea Rivett (Language Teaching Methods) and Candy Gray (Language Teaching in Specific Settings). Postgraduate students and others have also been employed as tutors, particularly in the larger first-year courses.

Course offerings have been gradually expanded with a mix of courses focussing on Indigenous languages, descriptive linguistics, language ecology, sociolinguistics and applied linguistics. Many courses mirror linguistics courses offered in other Australian universities, though a number of courses, such as Reclaiming Languages: a Kaurna Case Study and Environmental Linguistics are unique, being offered only at the University of Adelaide.

Mühlhäusler came to the University of Adelaide with research projects in progress, including the massive Atlas of Languages of Intercultural Communication in the Pacific, Asia and the Americas, which he was co-editing with researchers at ANU. ${ }^{24}$ The set of maps is accompanied by a second volume of 138 research papers. Research has also diversified and expanded, as discussed below, and the Discipline of Linguistics is also engaged intimately with various Aboriginal communities, through the Mobile Language Team (MLT), Kaurna Warra Pintyandi (KWP) and a range of research projects.

\section{The Teaching of Linguistics}

Prior to the establishment of the Discipline of Linguistics, some courses in Linguistics were taught since the 1970s by George Turner and Tim Mares as second- and third-year electives within the Department of English Language and Literature. Turner attempted to establish linguistics as a discipline at the University of Adelaide without success, so had resorted to 'guerrilla linguistics' ${ }^{25}$ as he called

\footnotetext{
${ }^{24} \mathrm{~S}$. Wurm et al. (eds), Atlas of languages of intercultural communication in the Pacific, Asia, and the Americas, Trends in Linguistics Documentation 13 (Berlin, Mouton de Gruyter, 1996).

${ }^{25}$ G. W. Turner, Linguistics in Australia since 1958 (Sydney, Sydney University Press for the Australian Academy of the Humanities, 1976), p. 10.
} 
it, where it is taught within another discipline, here within English. Linguistics II attracted 18 students in 1974 and 45 students in 1975, while 5 students were enrolled in Linguistics III in $1975 .{ }^{26}$ Turner taught a range of topics including phonology, historical linguistics and dialectology. Some linguistics was also taught within German and French.

Upon his arrival in 1993, Mühlhäusler commenced teaching Linguistics as a second/third-year level combined year-long Foundations of Linguistics course. In 2001, this course was converted from a year-long course to two semester-length first-year courses: Foundations of Linguistics and Language and the Ethnography of Communication. Courses offered in Linguistics slowly expanded. In 1994, Mühlhäusler introduced courses in Language Maintenance and Language Planning (later re-named Language Maintenance and Communication Planning) and Language, Cognition and Reality, followed by Language \& Environment'in 1996. In 1997, Amery introduced Kaurna Language \& Language Ecology, which was taught at the University of Adelaide until 2001 and reintroduced on Amery's return in 2004. Also in 1997, Des Moriarty was engaged to teach Computer Assisted Language Learning, whilst David Rose taught Functional Grammar and Discourse, also taught by John Polias after Rose's departure to the University of Technology (UTS) in Sydney. From 1997 until 2000 a Special Topic in Linguistics was offered in which Professor Roy Harris, from the University of Oxford, made three visits to the University of Adelaide to teach a course on Integrational Linguistics. Mühlhäusler also used this special topic to teach a course in pidgins and creoles. In 2001, CALL was dropped as an undergraduate subject and replaced by Language, Communication and Technology (LCT), which was offered until 2003. Language \& Meaning was introduced as an undergraduate subject in 2002 by Peter Mickan, followed by Language Learning in 2008. In 2005, Amery introduced Australian Indigenous Languages, which was later taught biannually, alternating with the Kaurna course. Course offerings were further expanded with the introduction of core linguistics subjects Phonology in 2007 and Morphology and Syntax in 2008 to further a deeper knowledge of these areas introduced in Foundations of Linguistics. Mass Communicative Discourses was taught by Peter White from 2006 to 2008, whilst John Walsh introduced Introduction to

${ }^{26}$ Ibid., p. 11. 
Discourse Analysis in 2011. Cross-cultural Communication was first taught in 2009, Language in a Global Society was to have been taught in 2010 and appears in the calendar. ${ }^{27}$ However, because of restrictions from above this course and the proposed capstone course Linguistic Data, Description and Analysis have not been offered. A new course proposed by Professor Ghil'ad Zuckermann, Languages in the 21st Century, was introduced in semester 1, 2012.

In 1998 the Masters in Applied Linguistics was established. At first, postgraduate versions of existing undergraduate courses were offered. A range of specialised postgraduate courses were developed in the tradition of systemic functional linguistics (SFL) beginning with English for Academic Purposes (1998), followed by Language Teaching for Specific Purposes (2001), Language and Meaning (2002), Language Teaching Methods (2003) and Language and Learning (2004). Computer Assisted Language Learning, having been introduced as an undergraduate course in 1997, has always been a part of the MA program from the outset. Students also have the opportunity to investigate special topics of interest through a dissertation and supervised projects. Almost one hundred MA Applied Linguistics dissertations have been completed since 2002.

Linguistics staff have also had input into a range of other programs. Amery taught a four-week Linguistics and Australian Languages module within the Foundations program at Wilto Yerlo from 1997 to 2001. This was carried on by Christina Eira following Amery's departure. Amery also gave guest lectures within Environmental Studies and History at the University of Adelaide and within the Australian Studies program at Flinders University.

\section{A Proposed Cross-Institutional Major in Indigenous Linguistics}

At the end of the twentieth century, there were several courses of relevance to Aboriginal languages taught in each of the three South Australian universities. Resourcing constraints meant that no institution was in a position to mount a major in Aboriginal languages and linguistics by themselves, so it was proposed to draw on the Australian Studies courses Australian Languages: Issues \& Debates I'and Australian Languages: Issues and Debates II, taught by Dr Christine Nichols

\footnotetext{
27 'Language in a Global Society' was offered by Zuckermann in semester 2, 2012.
} 
at Flinders University, the Pitjantjatjara language courses at the University of South Australia and the relevant Linguistics courses taught at the University of Adelaide. It was planned to supplement these existing course offerings with courses in Field Methods and Archival Research and Teaching Aboriginal Languages to form a cross-institutional major that would work in everyone's favour and begin to address the acute needs for training of teachers of Aboriginal languages. These needs had been raised persistently by the Steering Committee of the Australian Indigenous Languages Framework project and the DECS Aboriginal Languages Standing Committee.

\section{Postgraduate Research in Linguisticis}

With the establishment of the Discipline of Linguistics in 1993, many postgraduate projects have been undertaken on Aboriginal languages, languages of the region and a surprisingly wide range of other topics. Following the establishment of the Applied Linguistics program, an increased number of projects in systemic functional linguistics were undertaken. At least $27 \mathrm{PhDs}, 13$ Masters by research and 27 Honours projects have been successfully completed since 1993. Several students have gone on to study elsewhere (including the School of Oriental and African Studies (SOAS) at the University of London), and several have taken academic positions and occupy positions of influence within their respective countries. See Appendix A for a listing of PhD, Masters and Honours topics undertaken in Linguistics.

In addition, Mühlhäusler and Amery have provided supervisory support for a number of students enrolled in German or Austrian universities. These include a prize-winning MA by Andrea Moll with joint supervision from University of Freiburg and the University of Adelaide, a thesis on 'Language loss and revival: with special reference to Kaurna' by Heike Kiesling (2000) from Graz and Laura Zester from Düsseldorf on the Aversive suffix in Aboriginal languages in 2010.

\section{The Study and Support of the Kaurna Language}

Kaurna is the original language of Adelaide and the Adelaide Plains. All of the University of Adelaide's campuses and institutions are located on Kaurna land, 
thus the Kaurna language occupies a special place within the life of the University. ${ }^{28}$ Rob Amery, having previously worked to establish Kaurna language programs in schools, commenced a $\mathrm{PhD}$ in 1995 on the Kaurna language and its revival under the supervision of Peter Mühlhäusler. Prior to completion of the $\mathrm{PhD}$, Amery introduced the Kaurna Language and Language Ecology course in 1997 with the support of Mühlhäusler and the Department of Education and Children's Services (DECS), who contributed \$7,000 towards its establishment and teaching. Kaurna Language \& Language Ecology continued at the University of Adelaide until Amery's contract ran out in 2001 and was not renewed. The teaching of Kaurna was then relocated to the University of South Australia for three years, returning with Amery to the University of Adelaide in 2004. In 2009, the Kaurna course was rebadged as Reclaiming Languages: a Kaurna Case Study, thereby broadening the subject matter beyond Kaurna. In 2011, Ghil'ad Zuckermann had a significant input into this course with coverage of the emergence of Israeli. Numerous Kaurna research projects have been undertaken through the University of Adelaide, including placenames research and the development of resources to support the revival and teaching of Kaurna.

The University has hosted the Kaurna Warra Pintyandi (KWP) group since 2004 with Amery's return to the University. KWP, which grew out of workshops held in 2000, funded by a University of Adelaide small research grant, ${ }^{29}$ consists of Kaurna people working together with linguists, teachers of Kaurna and other specialists. It meets on a monthly basis to discuss requests for Kaurna names, translations and information about the Kaurna language, to provide advice on Kaurna language matters, and to host and work on a range of Kaurna language projects. At least 572 such requests have been addressed since the establishment of KWP, most in the last five years. ${ }^{30}$ Currently, between six and a dozen or more

\footnotetext{
${ }^{28}$ Roger Thomas approached Amery for a Kaurna translation of the Kaurna Acknowledgement that accompanies the University's Reconciliation Statement, which was signed on 8 July 2003. See $<$ http://www.adelaide.edu.au/reconciliation/>.

${ }^{29}$ R. Amery \& A. W. Rigney, 'Collaborative Language Revival - the work of Kaurna Warra Pintyandi' (Adelaide Plains, South Australia), Proceedings of FEL XI Working Together for Endangered Languages: Research Challenges and Social Impacts. The Eleventh Conference of the Foundation for Endangered Languages (Kuala Lumpur [Malaysia], Rumah University, University of Malaya, 26-28 October 2007, pp. 21-28.

${ }^{30}$ G. Rüdiger, Kaurna Warra Pintyandi (KWP), Preliminary Evaluation of Naming and Translation Requests 2002 to 2012, manuscript, 30 March 2012.
} 
requests are dealt with each month. In early 2011, KWP celebrated its 100th meeting. Whilst small, KWP is effective and has gained the respect, through the involvement of key Kaurna Elders, of the wider Kaurna community, government departments and the community at large. The University hosts the KWP web pages, ${ }^{31}$ manages KWP finances and makes available infrastructure for the day to day operations of the group. Through KWP, a strong and lasting relationship has been established with the local Kaurna community. ${ }^{32}$

KWP was successful in gaining funding through the Commonwealth Indigenous Languages Support (ILS) program for the next triennium (2012-2015) to establish a KWP Secretariat and to continue producing Kaurna radios shows and YouTube clips in Kaurna. Additional funds have been forthcoming from the South Australian Department of Education and Childhood Development (DECD) for the production of Kaurna language resources to support teaching programs in schools, including the updating of previously published materials, now with revised spelling.

\section{Linguistics Research AT THE UnIVERSITY OF AdELAIDE}

Research has always been a high priority in the Discipline. Soon after his arrival from Oxford University, Peter Mühlhäusler continued and completed work on the Atlas of languages of intercultural communication (see below). Mühlhäusler maintained and developed international collaborations in mission linguistics with Reinhard Wendt at the University of Hagen, in ecolinguistics with the University of Graz in 1997, the University of Luxemburg, where he was advisor for European language policy, German in the Pacific since 2005 with the Institut für Deutsche Sprache, Mannheim, an atlas of pidgin and creole studies with the Max Planck Institute in Leipzig, and metaphors with the Colloquium of Advanced Studies, Helsinki, in 2008. Zuckermann also brings with him numerous international links, especially in Israel, UK, Italy and China. Others also have their own international connections. A range of research assistants have been employed over the years, including

\footnotetext{
${ }^{31}$ See <www.adelaide.edu.au/kwp>.

${ }^{32}$ R. Amery, 'Reclaiming the Kaurna Language: a long and lasting collaboration in an urban setting' (forthcoming), to appear in J. Henderson (ed.), Language Documentation and Conservation, a collection of papers on the role of linguists in language centres and community language projects.
} 
Catherine Amis, Dr Michelle Cunningham, Dr Susan Lemar, Dr Heidi Kneebone, Cynthia Rathjen, Emma Coether, Melina Magdalena, Emma Murphy, Margareta Rebelos, Dr Christina Eira, Dr Mary-Anne Gale, Dr Paul Monaghan, Dr Petter Naessan, Dr Joshua Nash, Dr Nayia Cominos, Jasmin Morley, Chester Schultz, Kateryna Katsman and Katrina Lucas. Many Aboriginal people have also been employed casually, sharing their knowledge, recording sound files and working alongside researchers. They include Bobby Brown, Lucy Lester, Johnny Cullinan, the Crombie family, Mona Tur, Gladys Miller, Estelle Miller, Leonard Miller, Wanda Miller, Dr Lewis O’Brien, Dr Alitya Rigney, Georgina Williams, Dennis O’Brien, Emily O'Brien, Trent Wanganeen, Katrina Power, Jack Buckskin, Jamie Goldsmith, Taylor Power-Smith, Dorothy French, Veronica Brodie, Julia Yandell, Eileen McHughes, Neville Gollan, Totty Rankine, Rita Lindsay and many others. Gerhard Rüdiger, granted Adjunct status in 2010, has been busy translating some of Amery's and Christine Lockwood's publications into German and seeking out further documents relating to the Kaurna language and its documentation in Germany.

The Discipline of Linguistics has an impressive record of research output, given the size of the Discipline. In 1996, for instance, of the 43 publications attributed to the Centre for European Studies, 31 were produced by Linguistics. The previous year Linguistics published 9 out of 19 publications produced by the Centre. Peter Mühlhäusler has published prolifically since his arrival at the University in 1993 on pidgins and creoles, ecolinguistics, Norf'k and Aboriginal languages as well as papers on more general linguistic topics. Rob Amery has published mainly on Kaurna language and Kaurna linguistics. Peter Mickan, Peter White and John Walsh have published in applied linguistics in the tradition of systemic functional linguistics. Paul Monaghan, Petter Naessan and Mary-Anne Gale have published on west coast languages, Yankunytjatjara and Ngarrindjeri respectively, whilst postgraduate students have produced a smattering of additional papers over the years. Given his track record, Zuckermann promises to be a prolific writer in the future for Linguistics with 28 publications recorded in his research output since 2005. 
Several books have been written, notably Peter Mühlhäusler's Linguistic ecology: language change and linguistic imperialism in the Pacific region (1996), his Language of environment, environment of language: a course in ecolinguistics (2003) and Amery's Warrabarna Kaurna!: reclaiming an Australian language (2000). Another landmark publication is the Atlas of languages of intercultural communication in the Pacific, Asia, and the Americas, edited by Stephen Wurm, Peter Mühlhäusler and Darrell Tryon (1996). Mühlhäusler wrote or co-wrote a number of the chapters, some together with Amery. Whilst some research output is published in refereed journals, the majority appears in book chapters invited by the editors. Also, because many Aboriginal languages projects are oriented towards community needs, much of the research output from Linguistics appears in the form of resources produced to support language revival movements. Whilst this research output is not recognised by DEST, it is a very important part of community service (see below).

Since arriving at the University of Adelaide, Peter Mühlhäusler has been the recipient of several ARC Discovery grants, his latest to continue the study of the development of the Norf'k language. On his appointment to the Discipline in 2011, Ghil'ad Zuckermann (also previously at Oxford) brought with him an ARC grant to pursue a study of the genesis of Hebrew with lessons for no-longer spoken Australian languages including language hybridisation in the context of language revival.

Since the Commonwealth changed the eligibility rules for access to funding provided to support the maintenance and revival of Indigenous languages in 2001, the University of Adelaide has been successful in gaining funding for a range of projects undertaken in Yankunytjatjara/Antikirinya, Wirangu, Mirning, Kukada, Kaurna, Ngarrindjeri, Ngadjuri and Nyangumarta. These projects have ranged from resource guides, language documentation, oral histories and the development and production of dictionaries, wordlists, learner's guides, postcards, radio shows and song CDs to cost-benefit analyses, mentoring and training programs and how to manuals to support the revival and maintenance of Indigenous languages. No less than eight grant applications were submitted by researchers in Linguistics to the Indigenous Languages Support (ILS) program in February 2012 and most have been successful. 


\section{THE MAJOR AREAS OF LINGUISTICS RESEARCH ARE AS FOLLOWS:}

Environmental Linguistics/ Ecolinguistics

Colonial Linguistics/Missionary Linguistics

The Norf'k Language

Pidgins and Creoles

Revival Linguistics

Toponymy

Language Maintenance

Aboriginal languages research in the following languages:

Kaurna (Adelaide, SA)

Ngarrindjeri (Lower Murray River, SA)

Yankunytjatjara (far north west, SA)

Wirangu (west coast SA)

Kukada (west coast SA)

Mirning (Nullabor, SA)

Barngarla (Eyre Peninsula, SA)

Ngadjuri (mid north SA)

Dieri (Lake Eyre, SA

Nyangumarta (Pilbara, WA)

Worrora (Kimberley, WA)

Barossa Deutsch

New Arrivals Program

Systemic Functional Linguistics

Nor should we forget the linguistics research carried out by George Turner before the establishment of the Discipline and the work of Strehlow, Ellis, FitzHerbert and Davies discussed earlier. See Burton \& Burton (1988) for a bibliography of Turner's works. Notable amongst his numerous linguistics publications is a study of Australian and New Zealand English. ${ }^{33}$ Trevor Fennell of the French Department also produced a three-volume grammar of Latvian. ${ }^{34}$

\footnotetext{
${ }^{33}$ G. W. Turner, The English Language in Australia and New Zealand (London, Longman, 1966).

${ }^{34}$ T. Fennell, A Grammar of Modern Latvian (The Hague \& New York, Mouton, 1980).
} 


\section{The Mobile Language Team}

In 2001, a team of researchers undertook a language needs survey across the state of South Australia to gain an understanding of the Aboriginal languages situation and to make a series of recommendations to address these needs. The survey was led by Dr Patrick McConvell, then based at AIATSIS, but included Jonathan Nicholls based at the University of Adelaide at that time together with Lester Irabinna Rigney, Mary-Anne Gale and Rob Amery, all now based at the University of Adelaide, but then at Flinders University and the University of South Australia.

McConvell et al. (2001) recommended that two teams be established, one in Port Augusta to support the 'stronger' languages in the state, the other in Adelaide to support language revival programs in Adelaide and surrounding regions. These recommendations were partially taken up in 2009 with the establishment of just one Mobile Language Team (MLT) to serve the entire state of South Australia based at the University of Adelaide. The team initially consisted of Rob Amery (Manager), Karina Lester (Aboriginal Language Worker), Mary-Anne Gale (Linguist) and Paul Monaghan (Linguist). All members of the team had considerable experience working with Aboriginal communities in South Australia. Karina Lester is a fluent Yankunytjatjara-speaking member of her community with experience working for Natural Resource Management (NRM). The team looks much bigger than it actually is, as all staff are employed part-time within the MLT. An Aboriginal advisory committee was established to provide some guidance and advice to the team. This advisory committee was chaired by Prof Roger Thomas from Wilto Yerlo. In 2011, Ian Green took over management of the MLT and in April 2012, the role was assumed by Professor Jean Fornasiero, Head of the School of Humanities.

The MLT has assisted a number of Aboriginal groups to establish their own programs and to prepare their own grant applications (including a pioneering application to ILS from the Boandik (Bunganditj) community in Mt Gambier). Web pages have been established whereby individual languages can post their own materials on their own language pages. ${ }^{35}$ Since 2010 Karina Lester has produced a

\footnotetext{
${ }^{35}$ See <http://www.mobilelanguageteam.com.au/>.
} 
weekly radio program, Nganampa Wanka 'Our Language', where she has interviewed people from many different language communities about their language programs and language issues as well as linguists working with these programs. A regular newsletter reporting on MLT activities and profiling a particular language community is also produced. With capacity building as a central concern, Gale has established a Certificate III course Learning an Endangered Aboriginal Language and a Certificate IV course Teaching an Endangered Aboriginal Language through TAFE. The Certificate III course had its first graduates in 2011 with eight Ngarrindjeri and five Wirangu students taught by Gale and Monaghan respectively, whilst a Kaurna Certificate III course commenced in April 2012.

\section{Community Service}

Upon arrival in Adelaide, Mühlhäusler immediately became involved in local language groups including the South Australian Institute of Languages (SAIL), and, through contact with Amery, in the Australian Indigenous Languages Framework (AILF) project based at the Senior Secondary Assessment Board of South Australia (SSABSA), the DECS Aboriginal Languages Standing Committee and the partners and stakeholders group for Aboriginal language programs. Amery served as Chief Moderator for the Australian Indigenous Languages subject offered at senior secondary level in South Australia and the Northern Territory from 1999 until 2009 and serves as Specialist Vetter with the Victorian Board of Studies from 1995 to present. KWP (discussed earlier) performs an especially valuable community service in providing a forum whereby members of the public can meet with Kaurna people interested and knowledgeable in their language to address their Kaurna language requests. Mühlhäusler was instrumental in the Norf'k language gaining co-official status on Norfolk Island in 2004 and UNESCO recognition in 2007. Peter Mickan has been working with the Sudanese community and the New Arrivals Program to improve acquisition of English and integration into Australian society, whilst John Walsh is involved in an ARC project aimed at improving communication in medical contexts. 


\section{Shaping Language Policy}

The Discipline of Linguistics has always been responsive to opportunities to shape language policy. In 2002, Mühlhäusler developed a language plan for Norfolk Island. This gave rise to the Norfolk Island Language (Norf'k) Act 2004 and recognition by UNESCO following a submission from the Norfolk Island Government. Note also Mühlhäusler \& Damania's (2004) influential paper on a cost-benefit analysis of language revival. Amery has had input into the development of the new national curriculum in relation to Indigenous languages through ACARA. Most recently, Zuckermann, Lester, Amery (together with KWP members Alitya Rigney and Jack Buckskin) and Gale (together with MLT Advisory Committee member Verna Koolmatrie) all gave evidence to the House of Representatives Inquiry into the Teaching of Indigenous Languages on 2 April 2012.36

\section{Linguistias Events Hosted by the University of Adelaide}

The University of Adelaide has regularly hosted the annual Australian Linguistics Society (ALS) conference in 1976, 1986, 1993 and 2007 since the establishment of the Society in 1967. In conjunction with the 2007 ALS conference, the University hosted the annual Australex conference, a professional development day for South Australian community-based Aboriginal language programs and the Inaugural Indigenous Languages Conference (ILC), which attracted 300 delegates from across Australia. ${ }^{37}$ In 2012 the Discipline of Linguistics hosted the Society for the History of Linguistics in the Pacific conference and will host the Australex Conference in 2013.

In NAIDOC Week 2009, an exhibition Endangered Languages - Disappearing Diversity of materials and resources produced for Aboriginal languages was displayed in the Barr Smith Library and a symposium was convened on the same topic. This was followed up on 7 September 2011 with a Cultural Conversation interview and discussion with Professor Peter Mühlhäusler and Professor Ghil'ad Zuckermann.

\footnotetext{
${ }^{36}$ House of Representatives, Standing Committee on Aboriginal and Torres Strait Islander Affairs inquiry into Language Learning in Indigenous Communities. Public Hearing, Adelaide, Monday 2nd April 2012 (Hansard, Commonwealth of Australia, 2012).

${ }^{37}$ See R. Amery \& J. Nash, Warra Wiltaniappendi, Strengthening Languages. Proceedings of the Inaugural Indigenous Languages Conference (ILC), 24-27 September 2007 (Adelaide, University of Adelaide, 2008).
} 


\section{Reflecting on 85 years Engagement with Aboriginal Languages}

For the time, the University of Adelaide was a clear leader of the field in engagement with Aboriginal languages in the 1920s and 1930s prior to the appointment of Arthur Cappell in the Department of Anthropology at the University of Sydney. Even after Cappell's appointment, Adelaide served as a worthy rival. These early developments in linguistics within tertiary institutions have been often dismissed in previous histories of linguistics in Australia (Dixon, 1980) though the record was corrected by several contributions to the McGregor (2008) volume. Despite these promising beginnings in Adelaide, the retirement of FitzHerbert and Strehlow in 1974, with no succession plan and no postgraduate students of linguistics, left a gaping black hole only partly filled by some teaching in other disciplines. It may well have been Strehlow's attitude towards the University in the years prior to his retirement that caused the institution's apparent amnesia when it appointed Mühlhäusler as 'Foundation Professor'. In her biographical entry on T. G. H. Strehlow, Fort remarks:

his argumentative nature and threats to burn the collection rather than let the university look after it lost him the goodwill of important Aboriginal and academic supporters. Aboriginal leader Charles Perkins lamented that Strehlow's last ten years had 'turned all his life's work upside down'. ${ }^{38}$

At the same time that linguistics and Aboriginal languages were disappearing within the Faculty of Arts, interesting and important initiatives were taking place quite independently within the Elder Conservatorium of Music and the Department of Continuing Education.

Though it has a patchy record, the University of Adelaide has produced some remarkable and innovative developments within Aboriginal languages and linguistics: the first work in recording Aboriginal songs, the first comprehensive grammar of an Australian language (and produced by a bilingual ArrernteEnglish speaker at that), the employment of Pitjantjatjara songmen as senior lecturers, pioneering work in language reclamation, the development of innovative approaches to support Aboriginal languages and their speakers, pioneering work in language ecology and toponymy. The Discipline of Linguistics at the University

\footnotetext{
${ }^{38}$ C. Fort, 'Theodor George Henry Strehlow', in W. Prest, K. Round \& C. Fort (eds), The Wakefield Companion to South Australian History (Kent Town, Wakefield Press, 2001), p. 519.
} 
of Adelaide, despite its small size and restricted institutional environment brought about by financial constraints, has a proud record and worthy achievements that are noticed elsewhere in Australia and throughout the world.

\section{FUtURE DiReGtions For Linguistics}

Ghil'ad Zuckermann, appointed as Professor of the Linguistics of Endangered Languages in 2011, has clearly signalled his intention to make the University of Adelaide the world centre for revival linguistics, drawing both on his expertise in Israeli language revival and his international contacts together with local expertise in language revival work with local Aboriginal languages (notably Kaurna, Ngarrindjeri, and Wirangu) and the work of the Mobile Language Team, which has just been re-funded for the next triennium (2012-2015). Zuckermann is currently developing a relationship with the Barngarla community on Eyre Peninsula and has submitted an application for funding for preliminary work there. Future collaboration with Professor Lester Irabinna Rigney, who was appointed Dean of Wilto Yerlo in June 2011, will further strengthen Linguistics, given Rigney's longstanding interest in Kaurna and Narungga languages, Indigenous languages education and language rights.

\section{REFERENCES}

Amery, R., 'Reclaiming the Kaurna Language: a long and lasting collaboration in an urban setting' (forthcoming), to appear in J. Henderson (ed.), Language Documentation and Conservation, a collection of papers on the role of linguists in language centres and community language projects.

Amery, R. Warrabarna Kaurna: Reclaiming an Australian Language (Lisse [The Netherlands], Swets \& Zeitlinger, 2000).

Amery, R. \& Nash, J., Warra Wiltaniappendi, Strengthening Languages. Proceedings of the Inaugural Indigenous Languages Conference (ILC), 24-27 September 2007 (Adelaide, University of Adelaide, 2008).

Amery, R. \& Rigney, A. W, 'Collaborative Language Revival - the work of 
Kaurna Warra Pintyandi' (Adelaide Plains, South Australia), Proceedings of FEL XI Working Together for Endangered Languages: Research Challenges and Social Impacts. The Eleventh Conference of the Foundation for Endangered Languages (Kuala Lumpur [Malaysia], Rumah University, University of Malaya, 26-28 October 2007, pp. 21-28.

Berndt, R., Love Songs of Arnhem Land (West Melbourne, Thomas Nelson (Australia) Ltd., 1976).

Berndt, R. M. \& Berndt, C., 'A Preliminary Report of Fieldwork in the Ooldea Region, western South Australia', Oceania, XIII.3; XIV. 2/3 (1943-44). Berndt, R. \& Berndt, C., with Stanton, J., A world that was: The Yaraldi of the Murray River and the Lakes, South Australia (Carlton [Vic], Melbourne University Press at the Miegunyah Press, 1993).

Burton T. L. \& Burton, J. (eds), Lexicographical and Linguistic Studies: essays in honour of G.W. Turner (Cambridge, D. S. Brewer, 1988).

Clendon, M., A grammar of Worrorra (Halls Creek [WA], Kimberley Language Resource Centre, 2000).

Dixon, R. M. W., The languages of Australia (Cambridge, Cambridge University Press, 1980).

Downing, J., Hale, K. \& Ingkatji, G., [Pitjantjatjara language course materials for use at the University of Adelaide (1967)], ts.

Douglas, W. H. Pitjantjatjara course lecture notes (University of Adelaide, Adelaide, 1968a); outline of theory practice and comprehension methods, few notes on sounds, accents; 30 lectures for use with audiotapes prepared by H. J. Siliakus (BFC 721).

Edwards, W. 'Teaching an Aboriginal language at University level', Babel, 30.2, (1995), pp. 4-11\&38.

Fennell, T., A Grammar of Modern Latvian (The Hague \& New York, Mouton, 1980).

Forte, C., 'Theodor George Henry Strehlow', in W. Prest, K. Round \& C. Forte (eds), The Wakefield Companion to South Australian History (Kent Town, Wakefield Press, 2001), p. 519.

Gale, M. A., Dhangum Djorra'wuy Dhäwu: a history of writing in Aboriginal languages 
(Adelaide, Aboriginal Research Institute, University of South Australia, 1997).

Gale, M. A., 'Rekindling warm embers: teaching Aboriginal languages in the tertiary sector', Australian Review of Applied Linguistics 34.3 (2011), pp. 280-96, <http://www.nla.gov.au/openpublish/index.php/aral/article/ view/2278>.

Hill, B., Broken Song: TGH Strehlow and Aboriginal Possession (Milsons Point, Vintage, 2003).

House of Representatives, Standing Committee on Aboriginal and Torres Strait Islander Affairs inquiry into Language Learning in Indigenous Communities, Public Hearing, Adelaide, Monday 2 April 2012 (Hansard, Commonwealth of Australia, 2012).

Lester, Y., Yami. The Autobiography of Yami Lester (Alice Springs, IAD Press, 1993). Love, J. R. B., 'The Grammatical Structure of the Worora Language of NorthWestern Australia', MA thesis (University of Adelaide, 1932), republished by Lincom Europa, Munich, 2000 (edited by R. M. W. Dixon).

Love, J. R. B., 'An Outline of Worora Grammar', in A. P. Elkin (ed.), Studies in Australian Linguistics, Oceania Monograph 3 (Sydney, University of Sydney, 1937-38), pp. 112-24.

McConvell, P., Amery, R., Gale, M. A., Nicholls, C., Nicholls, J., Rigney, L. I. \& Tur, S. U., "“Keep that Language Going!” A Needs-Based Review of the Status of Indigenous Languages in South Australia', a consultancy carried out by the Australian Institute of Aboriginal and Torres Strait Islander Studies for the Aboriginal and Torres Strait Islander Commission, South Australia, 2002.

McGregor, W. (ed.), Encountering Aboriginal Languages: Studies in the History of Australian Linguistics (Canberra, Pacific Linguistics, ANU, 2008).

McNally, W., Aborigines, Artefacts and Anguish (Adelaide, Lutheran Publishing House, 1981).

Monoghan, P., 'Norman B. Tindale and the Pitjantjatjara Language', in W. B. McGregor (ed.), Encountering Aboriginal Languages. Studies in the history of Australian linguistics (Canberra, Pacific Linguistics, Research School of Pacific and Asian Studies, The Australian National University, 2008), pp. 
$251-72$.

Mühlhäusler, P., Linguistic ecology: language change and linguistic imperialism in the Pacific region (London \& New York, Routledge, 1996).

Mühlhäusler, P. \& Damania R., 'Economic Costs and Benefits of Australian Indigenous Languages: Discussion Paper', Aboriginal and Torres Strait Islander Services, 2004, <http://www.arts.gov.au/indigenous/MILR/ publications $>$.

Newsome, J., 'Catherine Joan Ellis', in W. Prest, K. Round \& C. Forte (eds), The Wakefield Companion to South Australian History (Kent Town, Wakefield Press, 2001a), p. 168.

Newsome, J., 'Minyungu Baker', in W. Prest, K. Round \& C. Forte (eds), The Wakefield Companion to South Australian History (Kent Town, Wakefield Press, 2001b), p. 64.

Rüdiger, G., 'Kaurna Warra Pintyandi (KWP), Preliminary Evaluation of Naming and Translation Requests 2002 to 2012', manuscript, 30 March 2012.

Sheppard, N. [with Yanyi], Alitïnya ngura Tjukurtjarangka (Alitji in the Dreamtime). Illustrations by Byron S. Sewell, adapted and translated from Lewis Carroll's story 'Alice in Wonderland' (Adelaide, Department of Adult Education, University of Adelaide, 1975).

Simpson, J., Gale, M. A. \& Amery, R., 'I Could Have Saved You Linguists a lot of Time and Trouble: 178 years of Research and Documentation of South Australia's Indigenous Languages, 1826-2004', in W. McGregor (ed.), Encountering Aboriginal Languages: Studies in the History of Australian Linguistics (Canberra, Pacific Linguistics, 2008), pp. 85-144.

Strehlow, T. G. H., 'An Aranda Grammar', MA thesis (University of Adelaide, 1938).

Strehlow, T. G. H., 'Aranda Grammar', Oceania, X111.1, pp. 71-103; XIII.2, pp. 177-200; XIII.4 (1942-43), pp. 310-61.

Strehlow, T. G. H., Songs of Central Australia (Sydney, Angas \& Robertson, 1971). Tindale, N. B., 'Results of the Harvard-Adelaide Universities Athropological Expedition, 1938-1939, Distribution of Australian Aboriginal tribes: A Field Survey', Transactions of the Royal Society of South Australia, 64.1 (1940), 
pp. 140-231.

Tindale, N. B., Aboriginal tribes of Australia: their terrain, environmental controls, distribution, limits and proper names (Berkeley, University of California Press, 1974).

Turner, G. W., The English Language in Australia and New Zealand (London, Longman, 1966).

Turner, G. W., Linguistics in Australia since 1958 (Sydney, Sydney University Press for the Australian Academy of the Humanities, 1976).

Wurm, S., Mühlhäusler, P. \& Tryon, D. (eds), Atlas of languages of intercultural communication in the Pacific, Asia, and the Americas, Trends in Linguistics Documentation, 13 (Berlin, Mouton de Gruyter, 1996). 


\section{Appendix A: A listing of PhDs, Masters by Research and Honours THESES}

\section{Table 1: PhD Theses}

\begin{tabular}{|c|c|c|c|}
\hline Author & Title & Supervisors & Date \\
\hline $\begin{array}{l}\text { Behin, } \\
\text { Bahram }\end{array}$ & $\begin{array}{l}\text { Aspects of the role of language in creating the } \\
\text { literary effect: implications for the reading of } \\
\text { Australian prose fiction. }\end{array}$ & $\begin{array}{l}\text { Peter Mühl- } \\
\text { häusler }\end{array}$ & 1997 \\
\hline $\begin{array}{l}\text { Mrowa, } \\
\text { Colette }\end{array}$ & $\begin{array}{l}\text { Communication, discourse, interaction in } \\
\text { language classes. }\end{array}$ & $\begin{array}{l}\text { Peter Mühl- } \\
\text { häusler }\end{array}$ & 1997 \\
\hline $\begin{array}{l}\text { Amery, } \\
\text { Rob }\end{array}$ & $\begin{array}{l}\text { Warrabarna Kaurna! Reclaiming Aboriginal } \\
\text { Languages from Written Historical Sources: a } \\
\text { Kaurna Case Study. }\end{array}$ & $\begin{array}{l}\text { Peter Mühl- } \\
\text { häusler } \\
\text { Jane Simpson }\end{array}$ & 1998 \\
\hline $\begin{array}{l}\text { Gale, } \\
\text { Mary-Anne }\end{array}$ & $\begin{array}{l}\text { Poor bugger whitefella got no dreaming: the } \\
\text { representation \& appropriation of published } \\
\text { Dreaming narratives with special reference to } \\
\text { David Unaipon's writings. }\end{array}$ & $\begin{array}{l}\text { Peter Mühl- } \\
\text { häusler } \\
\text { Sue Hosking }\end{array}$ & 2000 \\
\hline \begin{tabular}{|l|} 
Clendon, \\
Mark \\
\end{tabular} & Topics in Worora Grammar. & $\begin{array}{l}\text { Peter Mühl- } \\
\text { häusler }\end{array}$ & 2000 \\
\hline $\begin{array}{l}\text { Gibson, } \\
\text { Carol }\end{array}$ & $\begin{array}{l}\text { I've had a good life - I can't complain: a } \\
\text { description of cognitive, physiological and } \\
\text { environmental effects on discourse behaviour } \\
\text { with ageing and an analysis of discursive rep- } \\
\text { resentations of normal ageing. }\end{array}$ & $\begin{array}{l}\text { Peter Mühl- } \\
\text { häusler }\end{array}$ & 2001 \\
\hline $\begin{array}{l}\text { Nicholls, } \\
\text { Jonathan }\end{array}$ & $\begin{array}{l}\text { Language planning in the first ten years of } \\
\text { Ernabella mission. }\end{array}$ & $\begin{array}{l}\text { Peter Mühl- } \\
\text { häusler }\end{array}$ & $\mathrm{NG}$ \\
\hline $\begin{array}{l}\text { Monaghan, } \\
\text { Paul }\end{array}$ & $\begin{array}{l}\text { Laying down the country: Norman B. Tindale } \\
\text { and the linguistic construction of the North- } \\
\text { West of South Australia. }\end{array}$ & $\begin{array}{l}\text { Peter Mühl- } \\
\text { häusler }\end{array}$ & 2003 \\
\hline $\begin{array}{l}\text { Guan Eng, } \\
\text { Ho }\end{array}$ & $\begin{array}{l}\text { Exploring the socio-cultural structure of for- } \\
\text { mal ESL instruction in classroom talk: a case } \\
\text { study of a secondary school in Brunei. }\end{array}$ & Peter Mickan & 2003 \\
\hline
\end{tabular}




\begin{tabular}{|c|c|c|c|}
\hline \begin{tabular}{|l|} 
Sornchai, \\
Mungthai- \\
song
\end{tabular} & $\begin{array}{l}\text { Constructing EFL literacy practices: a qualita- } \\
\text { tive investigation in intertextual talk in Thai } \\
\text { university language classes. }\end{array}$ & Peter Mickan & 2003 \\
\hline $\begin{array}{l}\text { Ward, } \\
\text { Maurice }\end{array}$ & $\begin{array}{l}\text { Contracting participation out of union cul- } \\
\text { ture: patterns of modality and interactional } \\
\text { moves in a labour contract settlement. }\end{array}$ & Peter Mickan & 2004 \\
\hline $\begin{array}{l}\text { Boyes, } \\
\text { Maria (nee } \\
\text { Stephens) }\end{array}$ & $\begin{array}{l}\text { A decent writer: Professional environmental } \\
\text { communication among professional environ- } \\
\text { mental managers. }\end{array}$ & $\begin{array}{l}\text { Peter Mühl- } \\
\text { häusler }\end{array}$ & 2004 \\
\hline $\begin{array}{l}\text { Fazelim- } \\
\text { anie, } \\
\text { Ayatollah }\end{array}$ & $\begin{array}{l}\text { A linguistic analysis of some ESP texts used in } \\
\text { Iranian universities with special focus on cohe- } \\
\text { sion in texts of business and commerce. }\end{array}$ & $\begin{array}{l}\text { Peter Mühl- } \\
\text { häusler }\end{array}$ & 2004 \\
\hline $\begin{array}{l}\text { Bear- } \\
\text { Wingfield, } \\
\text { Rebecca }\end{array}$ & Kukada, West Coast South Australia. & $\begin{array}{l}\text { Peter Mühl- } \\
\text { häusler }\end{array}$ & $\mathrm{NG}$ \\
\hline $\begin{array}{l}\text { Kneebone, } \\
\text { Heidi }\end{array}$ & $\begin{array}{l}\text { The language of the chosen view: the first } \\
\text { phase of graphization of Dieri by Her- } \\
\text { mannsburg missionaries, Lake Killalpaninna } \\
\text { 1867-80. }\end{array}$ & $\begin{array}{l}\text { Peter Mühl- } \\
\text { häusler }\end{array}$ & 2005 \\
\hline $\begin{array}{l}\text { Abu Bakar, } \\
\text { Nadzrah }\end{array}$ & $\begin{array}{l}\text { Computers for teaching English as a second } \\
\text { language (secondary school) in Malaysia: a } \\
\text { case study. }\end{array}$ & $\begin{array}{l}\text { Peter Mühl- } \\
\text { häusler }\end{array}$ & 2005 \\
\hline $\begin{array}{l}\text { Yu, Shu- } \\
\text { Hui }\end{array}$ & $\begin{array}{l}\text { Listening and speaking skill development in a } \\
\text { Taiwanese tertiary EFL context: Manipulating } \\
\text { power-in-interaction for participation. }\end{array}$ & Peter Mickan & 2006 \\
\hline Lim, Mi-ok & $\begin{array}{l}\text { Exploring social practices in English classes: a } \\
\text { qualitative investigation of classroom talk in a } \\
\text { Korean secondary school. }\end{array}$ & Peter Mickan & 2007 \\
\hline $\begin{array}{l}\text { Tomita, } \\
\text { Akiko }\end{array}$ & $\begin{array}{l}\text { Bilingualism and biculturalism in Japanese } \\
\text { students in Australia. }\end{array}$ & $\begin{array}{l}\text { Peter Mühl- } \\
\text { häusler }\end{array}$ & $\mathrm{NG}$ \\
\hline
\end{tabular}




\begin{tabular}{|c|c|c|c|}
\hline $\begin{array}{l}\text { Oupra, } \\
\text { Simmee }\end{array}$ & $\begin{array}{l}\text { Language ecology and language planning in } \\
\text { Chiang Rai Province, Thailand. }\end{array}$ & $\begin{array}{l}\text { Peter Mühl- } \\
\text { häusler } \\
\text { Christina Eira }\end{array}$ & 2009 \\
\hline $\begin{array}{l}\text { Naessan, } \\
\text { Petter }\end{array}$ & $\begin{array}{l}\text { Yankunytjatjara continuity and change: a } \\
\text { linguistic ecology of the Yankunytjatjara } \\
\text { language, with particular emphasis on Coober } \\
\text { [Cooper] Pedy, South Australia. }\end{array}$ & $\begin{array}{l}\text { Peter Mühl- } \\
\text { häusler } \\
\text { Rob Amery }\end{array}$ & 2009 \\
\hline $\begin{array}{l}\text { Irving, } \\
\text { Catherine }\end{array}$ & $\begin{array}{l}\text { A study of language use in and in relation to } \\
\text { Antarctica and an analysis of its environmen- } \\
\text { tal impact. }\end{array}$ & $\begin{array}{l}\text { Peter Mühl- } \\
\text { häusler } \\
\text { Rob Amery }\end{array}$ & $\mathrm{NG}$ \\
\hline $\begin{array}{l}\text { Nguyen, } \\
\text { Phuong My }\end{array}$ & $\begin{array}{l}\text { Study on the role of Sino-Vietnamese ele- } \\
\text { ments in the standardisation of Vietnamese } \\
\text { computer technology. }\end{array}$ & Peter Mickan & $\mathrm{NG}$ \\
\hline $\begin{array}{l}\text { Moghad- } \\
\text { dam, Sharif }\end{array}$ & $\begin{array}{l}\text { Students' preparation for IELTS: development } \\
\text { of written and oral argumentative texts. }\end{array}$ & $\begin{array}{l}\text { Peter Mickan } \\
\text { Peter White }\end{array}$ & 2010 \\
\hline $\begin{array}{l}\text { Teramoto, } \\
\text { Hiromi }\end{array}$ & $\begin{array}{l}\text { New-arrival-ness as a social construct: a quali- } \\
\text { tative case study. }\end{array}$ & Peter Mickan & 2010 \\
\hline $\begin{array}{l}\text { Tunstill, } \\
\text { Guy }\end{array}$ & $\begin{array}{l}\text { A description of the Adnyamathanha lan- } \\
\text { guage (Flinders Ranges, SA) }\end{array}$ & $\begin{array}{l}\text { Peter Mühl- } \\
\text { häusler } \\
\text { Rob Amery }\end{array}$ & \\
\hline $\begin{array}{l}\text { Zoghi, } \\
\text { Aramesh }\end{array}$ & $\begin{array}{l}\text { Aims, expectations and caring in Australian } \\
\text { year } 12 \text { ESL: a case study of curriculum and } \\
\text { classroom practice. }\end{array}$ & $\begin{array}{l}\text { Peter Mickan } \\
\text { Peter Mühl- } \\
\text { häusler } \\
\text { Michelle } \\
\text { Pickard } \\
\text { Kate Cadman }\end{array}$ & 2011 \\
\hline Tariq, Elyas & $\begin{array}{l}\text { Diverging identities: a 'contextualised' explo- } \\
\text { ration of the interplay of competing discours- } \\
\text { es in two Saudi university classrooms. }\end{array}$ & $\begin{array}{l}\text { John Walsh } \\
\text { Michelle } \\
\text { Pickard }\end{array}$ & 2011 \\
\hline $\begin{array}{l}\text { Srinon, } \\
\text { Udom }\end{array}$ & $\begin{array}{l}\text { A longitudinal study of developments in the } \\
\text { academic writing of Thai university students } \\
\text { in the context of a genre based pedagogy. }\end{array}$ & $\begin{array}{l}\text { Peter White } \\
\text { Peter Mickan }\end{array}$ & 2011 \\
\hline
\end{tabular}




\begin{tabular}{|l|l|l|l|}
\hline $\begin{array}{l}\text { Nash, } \\
\text { Joshua }\end{array}$ & $\begin{array}{l}\text { Insular Toponymies: Place-naming on Norfolk } \\
\text { Island, South Pacific and Dudley Peninsula, } \\
\text { Kangaroo Island, South Australia. }\end{array}$ & $\begin{array}{l}\text { Peter Mühl- } \\
\text { häusler } \\
\text { Rob Amery }\end{array}$ & 2011 \\
\hline $\begin{array}{l}\text { Poh Yoke } \\
\text { Chu, Ce- } \\
\text { line }\end{array}$ & $\begin{array}{l}\text { Picture book reading in a new arrival context: } \\
\text { a multimodal perspective on teaching reading. }\end{array}$ & $\begin{array}{l}\text { Peter Mickan } \\
\text { John Walsh }\end{array}$ & 2011 \\
\hline $\begin{array}{l}\text { Cominos, } \\
\text { Nayia }\end{array}$ & $\begin{array}{l}\text { Managing the subjective: Exploring dialogistic } \\
\text { positioning in undergraduate essays. }\end{array}$ & $\begin{array}{l}\text { Peter White } \\
\text { Peter Mickan }\end{array}$ & 2011 \\
\hline $\begin{array}{l}\text { Vo, Duc } \\
\text { Vuy }\end{array}$ & $\begin{array}{l}\text { A discourse analysis of English-Vietnamese } \\
\text { news reports. }\end{array}$ & Peter White & 2012 \\
\hline
\end{tabular}

\section{Table 2: Research MA Theses}

\begin{tabular}{|c|c|c|c|}
\hline Author & Title & $\begin{array}{l}\text { Supervi- } \\
\text { sors }\end{array}$ & Date \\
\hline $\begin{array}{l}\text { Ariyanto, } \\
\text { Sugeng }\end{array}$ & $\begin{array}{l}\text { An applied linguistic analysis of EFL teacher } \\
\text { trainees' communicative competence in Jem- } \\
\text { ber, Indonesia. }\end{array}$ & $\begin{array}{l}\text { Peter Mühl- } \\
\text { häusler }\end{array}$ & 1996 \\
\hline Hartisari & $\begin{array}{l}\text { Aspects of language change in Gayo, a lan- } \\
\text { guage of Sumatra in Indonesia. }\end{array}$ & $\begin{array}{l}\text { Peter Mühl- } \\
\text { häusler }\end{array}$ & 1997 \\
\hline $\begin{array}{l}\text { Sapinski, } \\
\text { Tania }\end{array}$ & $\begin{array}{l}\text { Language use and language attitudes in a rural } \\
\text { South Australian community. }\end{array}$ & $\begin{array}{l}\text { Peter Mühl- } \\
\text { häusler }\end{array}$ & 1998 \\
\hline $\begin{array}{l}\text { Schwarz, } \\
\text { Silvia }\end{array}$ & $\begin{array}{l}\text { Aspects of form and function: with some refer- } \\
\text { ence to Warlpiri and Latin. }\end{array}$ & $\begin{array}{l}\text { Peter Mühl- } \\
\text { häusler }\end{array}$ & 1999 \\
\hline $\begin{array}{l}\text { Tomita, } \\
\text { Akiko }\end{array}$ & $\begin{array}{l}\text { Pronouns and expressions of politeness in the } \\
\text { teaching of Japanese as a foreign language in } \\
\text { Australia. }\end{array}$ & $\begin{array}{l}\text { Peter Mühl- } \\
\text { häusler } \\
\text { Rob Amery }\end{array}$ & 1999 \\
\hline $\begin{array}{l}\text { Liando, } \\
\text { Nihta }\end{array}$ & $\begin{array}{l}\text { Foreign language learning in primary schools } \\
\text { with special reference to Indonesia, Thailand } \\
\text { and Australia. }\end{array}$ & $\begin{array}{l}\text { Peter Mühl- } \\
\text { häusler } \\
\text { Peter Mickan }\end{array}$ & 1999 \\
\hline $\begin{array}{l}\text { Korompot, } \\
\text { Chairil } \\
\text { Anwar }\end{array}$ & $\begin{array}{l}\text { Teacher-student power relationships in lan- } \\
\text { guage classrooms: a comparative case study in } \\
\text { ESL and EFL contexts. }\end{array}$ & $\begin{array}{l}\text { Peter Mühl- } \\
\text { häusler } \\
\text { Peter Mickan }\end{array}$ & 1999 \\
\hline
\end{tabular}




\begin{tabular}{|c|c|c|c|}
\hline $\begin{array}{l}\text { Naessan, } \\
\text { Petter }\end{array}$ & $\begin{array}{l}\text { Manta tjamuku, manta kamiku - grandfather } \\
\text { country, grandmother country: a philologi- } \\
\text { cal and sociolinguistic study of the concept } \\
\text { 'Antikirinya'. }\end{array}$ & Rob Amery & 2000 \\
\hline Love, Susan & $\begin{array}{l}\text { French and Tây Bôi in Vietnam: a study of } \\
\text { language policy, practice and perceptions. }\end{array}$ & $\begin{array}{l}\text { Peter Mühl- } \\
\text { häusler } \\
\text { Blandine } \\
\text { Stefanson }\end{array}$ & 2000 \\
\hline $\begin{array}{l}\text { Fujiwara, } \\
\text { Yuhiko }\end{array}$ & $\begin{array}{l}\text { 'No'es and Japanese - a linguistic enquiry } \\
\text { into speech acts of negative response. }\end{array}$ & $\begin{array}{l}\text { Peter Mühl- } \\
\text { häusler } \\
\text { Peter Mickan }\end{array}$ & 2001 \\
\hline $\begin{array}{l}\text { Rumere, } \\
\text { Debbie }\end{array}$ & $\begin{array}{l}\text { Initial literacy in Papua New Guinea-indige- } \\
\text { nous languages, Tok Pisin or English? MEd } \\
\text { (commenced in Linguistics) }\end{array}$ & $\begin{array}{l}\text { Peter Mühl- } \\
\text { häusler }\end{array}$ & 2001 \\
\hline Mackey, Faye & $\begin{array}{l}\text { 'I never used to read.' Patterns of talk in regu- } \\
\text { lative and instructional discourse. A systemic } \\
\text { functional approach to analysing a literacy } \\
\text { difficulty. }\end{array}$ & Peter Mickan & 2006 \\
\hline $\begin{array}{l}\text { Wakizaka, } \\
\text { Miwako }\end{array}$ & $\begin{array}{l}\text { On the issues of language contact and lan- } \\
\text { guage shift in Tok Pisin - focusing on two } \\
\text { 'non-standard' varieties: highlands pidgin and } \\
\text { anglicised pidgin. }\end{array}$ & $\begin{array}{l}\text { Peter Mühl- } \\
\text { häusler } \\
\text { Rob Amery }\end{array}$ & 2008 \\
\hline $\begin{array}{l}\text { Mokoginta, } \\
\text { Karmila }\end{array}$ & $\begin{array}{l}\text { The intercultural analysis of Indonesian and } \\
\text { Australian students' nonverbal behaviour: an } \\
\text { effort to develop intercultural English learning } \\
\text { material. }\end{array}$ & $\begin{array}{l}\text { Rob Amery } \\
\text { Peter Mühl- } \\
\text { häusler }\end{array}$ & 2009 \\
\hline
\end{tabular}

\section{Table 3: BA (Hons) Completions}

\begin{tabular}{|l|l|l|l|}
\hline Author & Title & $\begin{array}{l}\text { Supervi- } \\
\text { sors }\end{array}$ & Date \\
\hline $\begin{array}{l}\text { Turner, } \\
\text { Carolyn }\end{array}$ & $\begin{array}{l}\text { Aspects of prepositional errors in German as a } \\
\text { second language. (Linguistics \& German) }\end{array}$ & $\begin{array}{l}\text { Peter Mühl- } \\
\text { häusler }\end{array}$ & 1993 \\
\hline
\end{tabular}




\begin{tabular}{|c|c|c|c|}
\hline $\begin{array}{l}\text { Sapinski, } \\
\text { Tania }\end{array}$ & The role of taboo in language change. & $\begin{array}{l}\text { Peter Mühl- } \\
\text { häusler }\end{array}$ & 1994 \\
\hline $\begin{array}{l}\text { Le Nevez, } \\
\text { Adam }\end{array}$ & $\begin{array}{l}\text { The myth of objectivity: communication and } \\
\text { the role that language plays. }\end{array}$ & $\begin{array}{l}\text { Peter Mühl- } \\
\text { häusler }\end{array}$ & 1995 \\
\hline Simic, Zorka & $\begin{array}{l}\text { A comparison of learning styles, attitudes and } \\
\text { motivation. }\end{array}$ & $\begin{array}{l}\text { Peter Mühl- } \\
\text { häusler }\end{array}$ & 1996 \\
\hline $\begin{array}{l}\text { Nicholls, } \\
\text { Jonathan }\end{array}$ & $\begin{array}{l}\text { By guess and by God: two short courses on } \\
\text { water. }\end{array}$ & $\begin{array}{l}\text { Peter Mühl- } \\
\text { häusler }\end{array}$ & 1997 \\
\hline $\begin{array}{l}\text { Martin, } \\
\text { Kylie }\end{array}$ & $\begin{array}{l}\text { Unity in diversity or diversity in unity? An } \\
\text { explorative study of the Javanese language } \\
\text { and cultural influence within the Indonesian } \\
\text { language, and its impact of the diversity on } \\
\text { Indigenous languages. }\end{array}$ & $\begin{array}{l}\text { Peter Mühl- } \\
\text { häusler }\end{array}$ & 1997 \\
\hline Love, Susan & $\begin{array}{l}\text { Moi te vouloir parler un peu. Pidgins, creoles } \\
\text { and non-standard French: a study of language } \\
\text { simplification and universals. (Linguistics \& } \\
\text { French) }\end{array}$ & $\begin{array}{l}\text { Peter Mühl- } \\
\text { häusler }\end{array}$ & 1997 \\
\hline $\begin{array}{l}\text { Disbray, } \\
\text { Samantha }\end{array}$ & Moravian Missionaries \& Language Contacts & $\begin{array}{l}\text { Peter Mühl- } \\
\text { häusler }\end{array}$ & 1997 \\
\hline $\begin{array}{l}\text { Monaghan, } \\
\text { Paul }\end{array}$ & $\begin{array}{l}\text { Him walkabout: aspects of the development } \\
\text { and diffusion of Pidgin English in South Aus- } \\
\text { tralia, } 1889 \text { to } 1939 .\end{array}$ & $\begin{array}{l}\text { Peter Mühl- } \\
\text { häusler }\end{array}$ & 1998 \\
\hline $\begin{array}{l}\text { Houston, } \\
\text { Stephen }\end{array}$ & $\begin{array}{l}\text { The writing that prepossessed George Taplin's } \\
\text { language: a thesis on his writing (which wasn't } \\
\text { altogether his). (Linguistics \& Politics) }\end{array}$ & $\begin{array}{l}\text { Rob Amery } \\
\text { Carol John- } \\
\text { son }\end{array}$ & 1999 \\
\hline O’Neill, Lisa & $\begin{array}{l}\text { 'Sorry' and Reconciliation: A Linguistic } \\
\text { Enquiry. }\end{array}$ & Rob Amery & 1999 \\
\hline $\begin{array}{l}\text { Ashmore, } \\
\text { Louise }\end{array}$ & (Linguistics \&Anthropology) & $\begin{array}{l}\text { Peter Mühl- } \\
\text { häusler } \\
\text { Ade Peace }\end{array}$ & \\
\hline $\begin{array}{l}\text { Magdelina, } \\
\text { Melina }\end{array}$ & $\begin{array}{l}\text { Environmental Advertising in German. (Lin- } \\
\text { guistics \& German) }\end{array}$ & $\begin{array}{l}\text { Peter Mühl- } \\
\text { häusler }\end{array}$ & \\
\hline
\end{tabular}




\begin{tabular}{|c|c|c|c|}
\hline $\begin{array}{l}\text { Barden, } \\
\text { Hannah }\end{array}$ & $\begin{array}{l}\text { The Translation Process: A Case Study Using } \\
\text { Verbal Protocols. }\end{array}$ & Peter Mickan & 2002 \\
\hline $\begin{array}{l}\text { Nguyen, } \\
\text { Phuong My }\end{array}$ & $\begin{array}{l}\text { The role of Sino-Vietnamese elements in the } \\
\text { formation of Vietnamese computer terminol- } \\
\text { ogy. }\end{array}$ & Peter Mickan & 2002 \\
\hline Watts, Emma & $\begin{array}{l}\text { Success in minority language revival pro- } \\
\text { grammes: a case study of Hawaiian, Irish and } \\
\text { Kaurna. }\end{array}$ & $\begin{array}{l}\text { Peter Mühl- } \\
\text { häusler }\end{array}$ & 2003 \\
\hline $\begin{array}{l}\text { Keng Wah } \\
\text { Sit, Maria }\end{array}$ & Singlish - threat and threatened. & $\begin{array}{l}\text { Peter Mühl- } \\
\text { häusler }\end{array}$ & 2003 \\
\hline $\begin{array}{l}\text { Hartigan, } \\
\text { Andrew } \\
\text { Francis }\end{array}$ & $\begin{array}{l}\text { Text in Context: Insights into the language use } \\
\text { of ESL classroom }\end{array}$ & Peter Mickan & 2003 \\
\hline $\begin{array}{l}\text { Lyall, Ellen } \\
\text { Louise }\end{array}$ & $\begin{array}{l}\text { Language and play: A study of the use of } \\
\text { sociodramatic play in Junior Primary German } \\
\text { program. }\end{array}$ & Peter Mickan & 2003 \\
\hline $\begin{array}{l}\text { Wood, } \\
\text { Sohpie } \\
\text { Yolande }\end{array}$ & Scaffolding and Interaction: ESL Case Studies & Peter Mickan & 2003 \\
\hline $\begin{array}{l}\text { Leong, Fang- } \\
\text { shao }\end{array}$ & $\begin{array}{l}\text { Japanese students in Adelaide: Problems en- } \\
\text { countered and teaching strategies }\end{array}$ & Peter Mickan & 2004 \\
\hline $\begin{array}{l}\text { Medvedev, } \\
\text { Alexei }\end{array}$ & $\begin{array}{l}\text { The Dialectic of Sound Symbolism in Human } \\
\text { Language. }\end{array}$ & $\begin{array}{l}\text { Peter Mühl- } \\
\text { häusler }\end{array}$ & 2005 \\
\hline $\begin{array}{l}\text { Chittlebor- } \\
\text { ough, James }\end{array}$ & Script Choice in Korean and Japanese. & Rob Amery & 2008 \\
\hline $\begin{array}{l}\text { Fahlberg, } \\
\text { Victoria }\end{array}$ & $\begin{array}{l}\text { Metaphors we buy by: The environment in } \\
\text { Australian and Japanese advertisements. }\end{array}$ & $\begin{array}{l}\text { Peter Mühl- } \\
\text { häusler }\end{array}$ & 2008 \\
\hline $\begin{array}{l}\text { Kemp-Attrill, } \\
\text { Gilbert }\end{array}$ & $\begin{array}{l}\text { Linguistic landscapes and language reclama- } \\
\text { tion in Adelaide. }\end{array}$ & Rob Amery & 2009 \\
\hline $\begin{array}{l}\text { Venning, } \\
\text { Christopher }\end{array}$ & $\begin{array}{l}\text { Navigating Bickerton: Similarity and Differ- } \\
\text { ence in Creole Tense-Modality-Aspect and the } \\
\text { Language Bioprogram Hypothesis. }\end{array}$ & $\begin{array}{l}\text { Peter Mühl- } \\
\text { häusler }\end{array}$ & 2011 \\
\hline
\end{tabular}




\begin{tabular}{|l|l|l|l|}
\hline $\begin{array}{l}\text { Stephenson, } \\
\text { Ammon }\end{array}$ & $\begin{array}{l}\text { Speaking the Unspoken: A Comparative } \\
\text { Analysis of Online Constructed Language Use } \\
\text { and Revival Linguistics }\end{array}$ & $\begin{array}{l}\text { Ghil'ad } \\
\text { Zuckermann }\end{array}$ & 2011 \\
\hline
\end{tabular}





\section{1}

\section{The Digital, Participatory and International Turn: Media at the University of Adelaide ${ }^{l}$ Mary Griffiths}

The Media discipline has a vibrant, entrepreneurial history, marked by creative innovation and problem-solving capacities. It emerged from cross-disciplinary teaching from the late 1970s to 2002 and then, as a sub-discipline of English, constructed the Bachelor of Media. It became a separate intellectual and administrative group in late 2006, growing rapidly and known today for innovative teaching and research, and lively engagement with its profession, community and industry. In a relatively short period, it has twice recalibrated the original degree, and established an Honours program, a growing postgraduate cohort, research agendas, valuable international connections, and a record of scholarship and publications, which includes the dynamic field of digital media.

Program and discipline differ markedly from the more modest proposals in 2001. The crucial turn in 2006 to a discipline-defining contemporary program in

\footnotetext{
${ }^{1}$ I am particularly grateful for the help received from Jean Fornasiero, Lee Kersten, Michael Griffiths, Michael Innes, Michael Neale, Ying Jiang and Steve Dye.
} 
digital and participatory media, with a distinctive, attractive niche among its South Australian competitors, was not easy to achieve. Media education's beginnings in technical tertiary institutions as 'craft' training explain certain strongly held misconceptions about the value of critical and creative media studies - which also produce technically adept graduates - to a prestigious research university. ${ }^{2}$ Those leading Media developments have encountered the common challenges originating from prevalent preconceptions, even prejudices, about contemporary media, which have in turn shaped judgements about tertiary media education; and a supposed contradiction in the discipline's 'theory plus praxis' approach has at times impeded the discipline's establishment. This theme recurs throughout the history and is linked to the issues being restaged in the current public debate about media, the future of journalism, the role of academics in media regulation, and media's impact on democracy more generally, both here ${ }^{3}$ and in the UK. ${ }^{4}$

The conundrum can be explained in part by how media education itself evolved. Some early Australian tertiary courses tended - like British and American counterparts - to focus on 'craft' skills and knowledge of industry. Others introduced students to ways of understanding media's socially constitutive power through theory and genre studies, and analysis of a growing body of cultural objects - texts of popular film, television, radio, print news, magazines, and music - and focused more on identity politics. Some did both. VHS, timeshifting devices for television viewing, the Internet, 'webification' and convergence platforms, and mobile devices later appeared as objects of study, and each flagged new kinds of media studies. Theorists refer to the differences as thinking in a Media 1.0 way, as opposed to the Internet-enabled Media 2.0 approach. ${ }^{5}$ Media 3.0, today developing apace, extends to aspects of the semantic web, cloud computing, visualisation, and data mining. As popularising and democratising

\footnotetext{
${ }^{2}$ For a detailed account of the establishment of, and challenges faced by, media and communications tertiary sector see a federally-funded research report: P. Putnis, B. Axford, L. Watson, W. Blood, 'Communication and media studies in Australian universities' (Canberra, Department of Communication and Education, University of Canberra, 2002).

${ }^{3}$ Independent Media Inquiry, <http://www.dbcde.gov.au/digital_economy>.

${ }^{4}$ The Leveson Inquiry, 2011, <http://www.leveoninquiry.org.uk>.

${ }^{5}$ D. Gauntlett, 'Ten things wrong with the media effects model', n. d., <http://www.theory.org.uk/ david/effects.htm>.
} 
agents for expert knowledge, these fields of representation and research are part of the norm in all forms of public communications and commercial media, in business and scientific research, and as objects of study.

The academic media field is thus fluid and protean in adapting to technologically-enabled social changes, yet Media shares all the fundamentals of traditional academic disciplines: a body of expert knowledge, including exemplary practices; a history of theoretical debates and controversies; outstanding historians; theorists and visionaries; a set of preferred disciplinary questions, and thus multiple international research communities which cross discipline boundaries easily, like the global technologies through which they network. Differences of opinion remain heated among academics: about media; its relation to communication and cultural studies; and the apparent loss of critical rigour in favour of the politics of engagement. ${ }^{6}$

Among those observing - including parents, career teachers, public intellectuals, and the professions most involved - pragmatic concerns also nuance thinking about what a media education should be. These are not selfinterested perspectives. Critical media programs aim to produce professionals for public and powerful positions in society. As communicators with future access to 'media megaphones' and distribution platforms with global reach, graduates with a respected media degree will eventually set agendas and influence important public debates. The chair of the globally-scrutinised UK media inquiry opened proceedings by stating:

The press provides an essential check on all aspects of public life. That is why any failure within the media affects all of us. At the heart of this Inquiry, therefore, may be one simple question: who guards the guardians??

Relevance in professional education is not a marketing consideration; it is primarily an ethical issue for educators, as their activities are publicly and now (with HECS impacting) privately funded. Disciplinary oversight keeps the process on course and democratic in spirit.

\footnotetext{
${ }^{6}$ M. Bérubé, 'What's the matter with cultural studies?' The Chronicle of Higher Education, 2009, <http://chronicle.com/article/Whats-the-Matter-With/48334/>, G. Turner, What's become of cultural studies? (London, Sage, 2012).
}

7 The Leveson Inquiry, 2011. 
The brevity of this history of media enables a close focus on the details of discipline establishment, and engagement with such questions, but necessarily lacks the detachment possible in the accounts of disciplines with longer histories.

\section{BEGINNINGS}

The faculty's media education began when Lee Kersten introduced a German film course in 1977. She advocated the teaching of media and film to the ViceChancellor, Kevin Marjoribanks, in the late 1980s: 'He asked for suggestions ...' Two subjects (levels 2 and 3) were offered for the first time in 1990: History of Mass Communications and Media Analysis. ${ }^{8}$ Peter Moss (Education), Alex Castles (Law), and Ron Newbold (Classics) contributed. Faculty staff then developed courses based on individual scholarship in film, print media and communication. When the B Media was proposed in 2001, the faculty already had fifty elective courses in the BA's media and communications major. According to staff involved in the proposal, the faculty needed to increase student numbers, and expected Media to achieve that goal.

In this institutional imperative lay the seeds of future tensions over the B Media's status, direction and resources. More crucially, a perceived divide between theory and praxis existed from its inception. A senior ex-colleague remembers: 'I always felt that there was opposition to the idea of media studies being less theoretical'. ${ }^{9}$ Heads of Media subsequently encountered this divide as they advanced creative solutions for maintaining praxis — such as freeware applications, partnerships, and industry-based production staff — and defended 'both-and' approaches to synthesising theoretical frameworks while educating students creatively and practically about what technologies can, and cannot, do. Periods of churn and change have since been directly linked to collisions between 'either-or' and 'both-and' approaches to media education, always exacerbated by scarcity of resources.

An Australian government-funded report on the emerging disciplinary field, published the year the B Media was introduced, might have given opponents

\footnotetext{
${ }^{8}$ L. Kersten, Personal correspondence, 2012.

${ }^{9}$ M. Innes, Personal correspondence, 2012.
} 
pause for thought. The University's entry, albeit late, into one of the most reliable areas of growth, was justified by national student growth statistics from 1989 -1999 quoted by the University of Canberra research team. ${ }^{10}$ By 2001, most research universities (Melbourne, Monash, NSW, Queensland, ANU and Sydney) offered media and communications programs and, like the University of Western Australia, the University of Adelaide was planning to do so the following year according to a September 2001 faculty newsletter. ${ }^{11}$

Faculty remained divided about the project, although there were strong advocates and the Prospective Students Office confirmed existing student interest in Adelaide. The new program was conceived of as 'filling a particular niche in the South Australia sector by virtue of its taking a highly analytical, reflexive approach, including a compulsory professional ethics component and allowing for a project and internship'. ${ }^{12}$ It was to be largely assembled from existing faculty electives, plus a few specialised media courses. Eventually, the '1 to 2' media academics were to form a discrete group within one of the newly-established schools. Media's home was to be the School of Social Sciences but last-minute changes, literally as the first academic arrived, placed the B Media administratively in the discipline of English in the School of Humanities. Media staff offices remained there, until relocated to Hughes Building (2006), then relocated to level 9, Napier (2011).

The distinction involved in shifting Media from 'social sciences' to 'humanities' is significant, not least because it refers to different levels of funding. The decision surprised some staff. It could have been an inauspicious start to a program and discipline in embryo: yet academics from English and Philosophy, along with Gender Studies, subsequently played a formative role in their eventual establishment. They helped recruit the next two Media staff and taught the survey Media courses: Media Engagements; Image, Text and Representation; Film Studies; and Professional Ethics. Several colleagues served on the B Media Award Committee until Media became a separate administrative centre, responsible for program governance and development.

\footnotetext{
10 P. Putnis et al., 'Communication and media studies in Australian universities' (Canberra, Department of Communication and Education, University of Canberra, 2002), p. 23.

${ }^{11}$ Ibid., p. 55.

${ }^{12}$ M. Gillies, 'Proposal for a B.Media', The University of Adelaide, 2001.
} 
The rapid institutional relocation suggests the administrative, resourcing and perception challenges presenting themselves immediately to the sole Media academic, Chika Anyanwu (with expertise in media and performing arts), until joined by a colleague in 2003 (Patrick Crogan, film theory), and later a part-time appointment shared with Linguistics (Peter White, discourse analysis). These constituted the sub-discipline until 2006.

Much was accomplished between 2002 and 2004. Anyanwu, colleagues in Architecture and the faculty business manager Gavin Smith established the first media production lab in the Schulz Building, and Peter Sansom, a technician and lab manager shared with the Electronic Music Unit of the Elder Conservatorium, later proved a creative co-developer of praxis elements until 2009. Media Policy, Media Law and the first production courses were developed and greatly valued by students as essential features of a new program facing local competition from a long-established journalism degree. The Adelaide University Media Association, AUMA, was established and hosted the first graduation ball at the Hilton Hotel.

In 2004, the program relied on a few Media courses and a large range of faculty electives, some media-related and others considered generally useful as liberalising, expansive elements in the education of future media professionals. The mix quickly proved insufficient to the task, as events soon demonstrated. The program also faced internal competition from the media and communications major, which led to questions of whether the B Media was sufficiently distinctive to earn its title. Program rules restricted entry to core courses to maintain status in relation to the BA. These, plus higher entry scores, were expected to attract an elite cohort of high-achievers. It proved to be the case at first, but later pressures on the faculty to increase numbers drove entry scores lower. Maintaining growth and creating a flagship program proved to be incompatible objectives given the resources. The faculty's enterprise, initiated optimistically if not entirely smoothly, began to falter.

Despite the good will and efforts of many staff, intense student criticism erupted - ironically as the first cohorts graduated and several quickly found employment in various parts of the sector. The Media students who complained were, from the start, outspoken about aspects of program content and organisation. The Executive Dean at the time notes: 
I well remember the meeting with the students very early on when we had to contend with the complaints by the students that what they were getting was not media as they had expected it. ${ }^{13}$

The head of Humanities, Gerard O'Brien, assumed control of program governance while faculty considered its options. After robust internal discussions, it was agreed that changes were needed. But, without a strong, specifically disciplinary base to give to its varied components rigour, coherence and direction, and staff a sense of identity and affirmation of their expertise, the B Media Award Committee encountered continuing difficulties in agreeing on future directions. Text-based disciplines - from which a strand of media studies had originated (and usually then separated itself at some point in different institutional and intellectual histories) - were represented in numbers on the program committee. The (then) developing roles of heads of discipline vis-à-vis heads of school contributed to difficulties. Lack of clarity about remit and authority have persisted in different guises, as Media staff were redeployed, recruited or left the University, and as fresh demands on the fledgling area emerged.

Adding to growing pressures on Media staff and, through them, school and faculty management, media was changing. Mobile and digital technologies were already stimulating exponential changes in the sector. Australian news organisations were beginning 'a troubled decade' of diminishing readerships. ${ }^{14}$ Graduate employment opportunities seemed scarcer as the sector, particularly print media, experienced the impact of the Internet on advertising revenues and business models.

The sum of the course offerings did not account for the visible effects of the 'digital revolutions,' and those teaching the program, particularly the electives, primarily had print, broadcast, discourse or film interests. Despite the program's close connections with Radio Adelaide and the six electives courses (in radio, multimedia and video production, four of them taught in what was then a firstrate 15-seat Mac lab), and despite the embryo internship course and the project,

\footnotetext{
${ }^{13}$ M. Innes, Personal correspondence, 2012.

${ }^{14}$ E. Beecher, 'Journalism's crisis is everyone's crisis', Horizon South Australia (Adelaide, Hawke Centre, 28 March 2012), <http://www.unisa.edu.au/hawkecentre/events/2012events/HorizonSAForum_ Beecher.mp3>.
} 
the program's graduate attributes needed to be brought closer to external and student expectations of a specialist media degree at a prestigious university.

It is axiomatic that consensus about, and adequate support for, media degrees are difficult to achieve, given the varieties of the genus, the number and kind of stakeholders involved in any one place, and the financial and human investment required. In Adelaide's case, the demand for more training in production skills, and more experience of media practice were basically demands for more 'craft' to be included in core studies. This has been reiterated, with varying levels of passion and force, throughout the discipline's history to date. In such a connected city, the issues were on public show.

\section{PRogram AND DISCIPLINE REGALIBRATION, 2006 ONWARDS}

By 2005 the inadvisability of beginning such a project without deploying the necessary resources was accepted. As further negative consequences became a near certainty, the faculty moved decisively, committing to further strategic investment. Michael Innes, Executive Dean, and Michael Neale, Director of Marketing and Strategic Communications, set up a Media Advisory Board (2005) following Mary Griffiths's recruitment as Associate Professor in Media, beginning six months later, in July 2006.

The new head arrived with a background of experience in the internationalisation of Monash University's flexible multi-campus communications programs, from an Associate Professor position in 'screen and media' at the University of Waikato. The reform agenda was supported by this international expertise, by a history of program development, an overview of the field gained in major Journalism and Communications reviews, and over ten years of scholarly editing on the impact of new media in refereed journals. Research on e-learning and e-democracy also provided an informed perspective on the digital media possibilities for Adelaide. A second active, purposeful and more adequately supported phase of discipline development began, and lasted until 2009, before familiar resourcing issues again engulfed the discipline and its head.

The leadership tasks assigned were: comprehensively to review program offerings in light of student feedback; decide if and how the degree could be reformulated; and be a catalyst for positive changes in morale and productivity. 
An honest, rigorous, 'radical and adventurous' rethinking of the faculty's options was requested. Time free of face-to-face teaching was allowed to write courses, mentor staff and establish industry connections.

The challenges were evident and manifold, as the following anecdote illustrates. The head was welcomed on a pre-employment visit to Adelaide with a Media Advisory Board lunch at The Historian, an iconic Adelaide meeting place. Before the pleasant event began — prefiguring many supportive, interesting meetings between experienced industry representatives and the head over the next five years - O'Brien handed over student Course Experience Questionnaire results to his new colleague. During the Board introductions, and fielding of lighthearted questions from executives about which local team she supported, the unacceptable figures could not be dismissed. Though based on a statistically small sample, they proved so disconcerting that black humour provided momentary relief in an unvoiced analogy drawn from the topic under discussion: it was tantamount to being told to take a tiebreaker penalty shot for a team facing possible relegation.

Precision was required to turn things around, and time was short. The position was worse than expected. Staff and student morale had become an issue, and the new head was immediately responsible for Media past, present and future. Non-stop phone calls and visits punctuated the early days of stewardship as staff, students, parents and members of community and industry insisted on having uncompromisingly-expressed views heard. By September 2006 students had settled down, as quality assurance measures were initiated and a suitably robust 'Informal Review' completed. ${ }^{15}$ Individual students and groups, and staff and industry colleagues, had been interviewed, all course content and confidential submissions considered, and many media organisations in the city visited and invited to become hosts for the placement course.

The snapshot provided illuminating insights into both the program's potential, and the issues needing immediate attention. Four options had been canvassed and put forward to O'Brien and Innes. With a more contemporary and differentiating focus on new technologies, a more clearly-articulated purpose and matching publicity, less repetitive content, with further quality assurance measures

\footnotetext{
${ }^{15}$ M. Griffiths, 'Informal review of the B.Media', Faculty of Humanities and Social Sciences, University of Adelaide, 30 September 2006.
} 
established, additional core media courses, an expanded set of staff competencies in new appointments, and further investment in technical facilities - it was worth faculty's support. The Internal Review predicted that by 2009 the University could have 'internationally competitive programs in media', and that proved to be the case.

An important decision concerned the proposed voluntary redeployment of up to three experienced staff to join the Media discipline. Critical, coherent mass defines a discipline, so this proved a controversial, unwelcome proposal in some quarters. However, John Gray, the head of Social Sciences, supported Michael Wilmore's move from Anthropology to Media (mid-2007). Production lab capacity relative to the expanding media cohort, and the niches filled by existing providers in the city, were also considered.

The proposal for a revivified degree program was quickly endorsed, with acceptance of thirty recommendations, covering program direction, content, governance, quality assurance, institutional location, and staffing. In a warmly worded personal email from the Executive Dean, assigning oversight to O'Brien, the Head of Media was assured of support for developments. ${ }^{16}$

Over the next three years, the Head of School and the Head of Discipline worked in concert - around the exigencies presented by their differing institutional remits, and testing the worth of development strategies - as the staff profile increased, and a revivified degree became reality. It was an exciting and positive time in discipline history. The program was designed to be rigorously theoretical, as well as creative and practical in approach from the first year onwards. It retained existing production courses. It was to be responsive to industry change and prepare its graduates for contemporary digital and participatory forms of media. The 'heritage' of media, the histories and practices of traditional print, analogue broadcast, and film studies, were maintained in the curriculum. A Media website was co-designed with Peter Sansom and staff from Marketing and Strategic Communications, where the head defined the future discipline and program niche as 'digital and participatory media', using the phase 'Today and Tomorrow's Media'. At Open Days from 2006 onwards, Media explained its niche difference and demonstrated innovative, representative ways of attracting prospective

${ }^{16}$ M. Innes, Personal correspondence, 2012. 

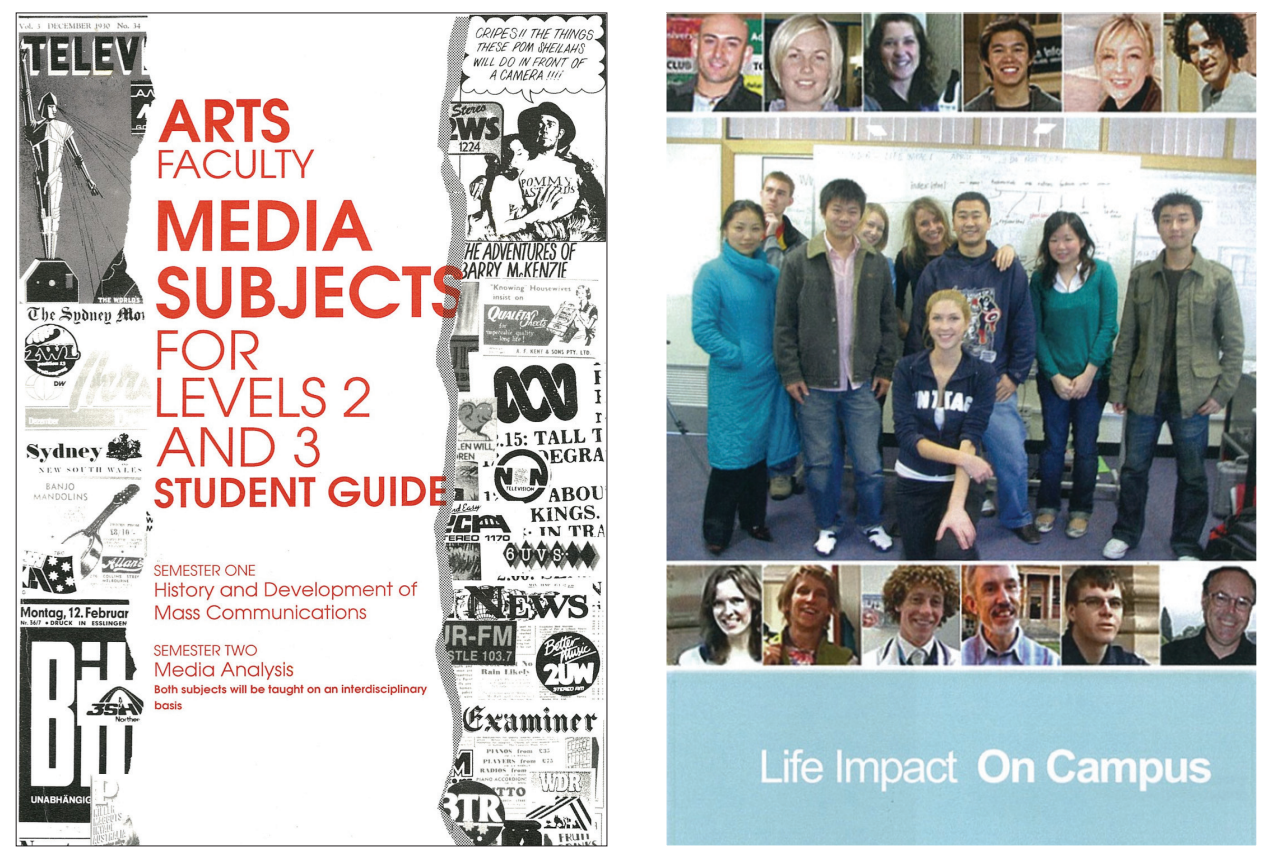

Life Impact On Campus

Advertising the first Media offerings, 1991 (left, source: Lee Kersten), and B Media production teams, Life Impact Campaign, 2006 (right)

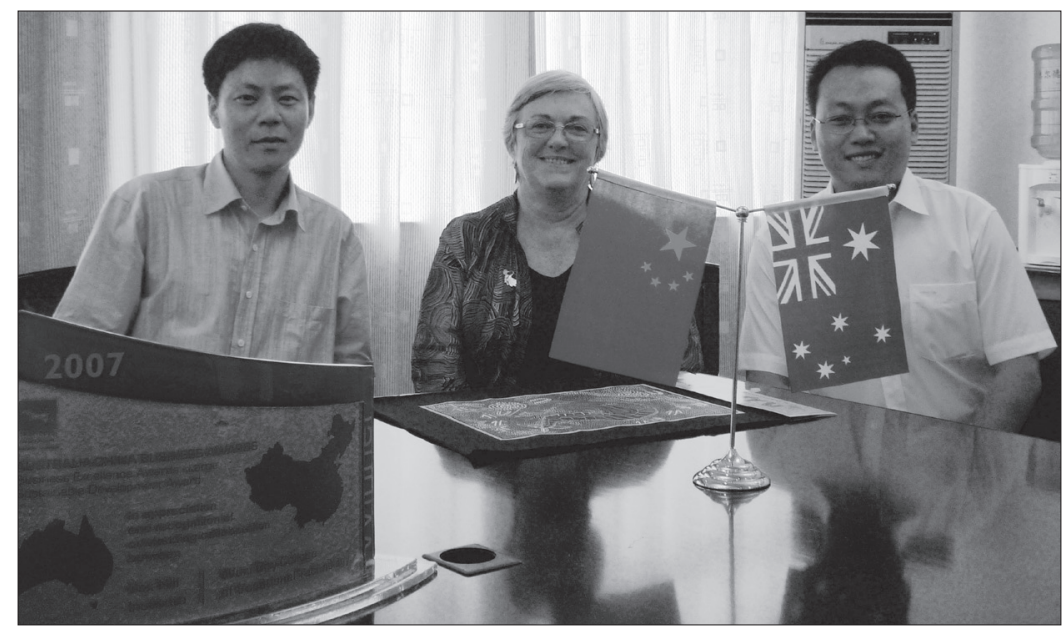

Media in China: a visit to academic partners of Wuxi Hollywood Digital Arts Research and Development Centre, Wuxi, to investigate a proposal for an articulated professional program, 2009 (photograph courtesy of Mary Griffiths) 


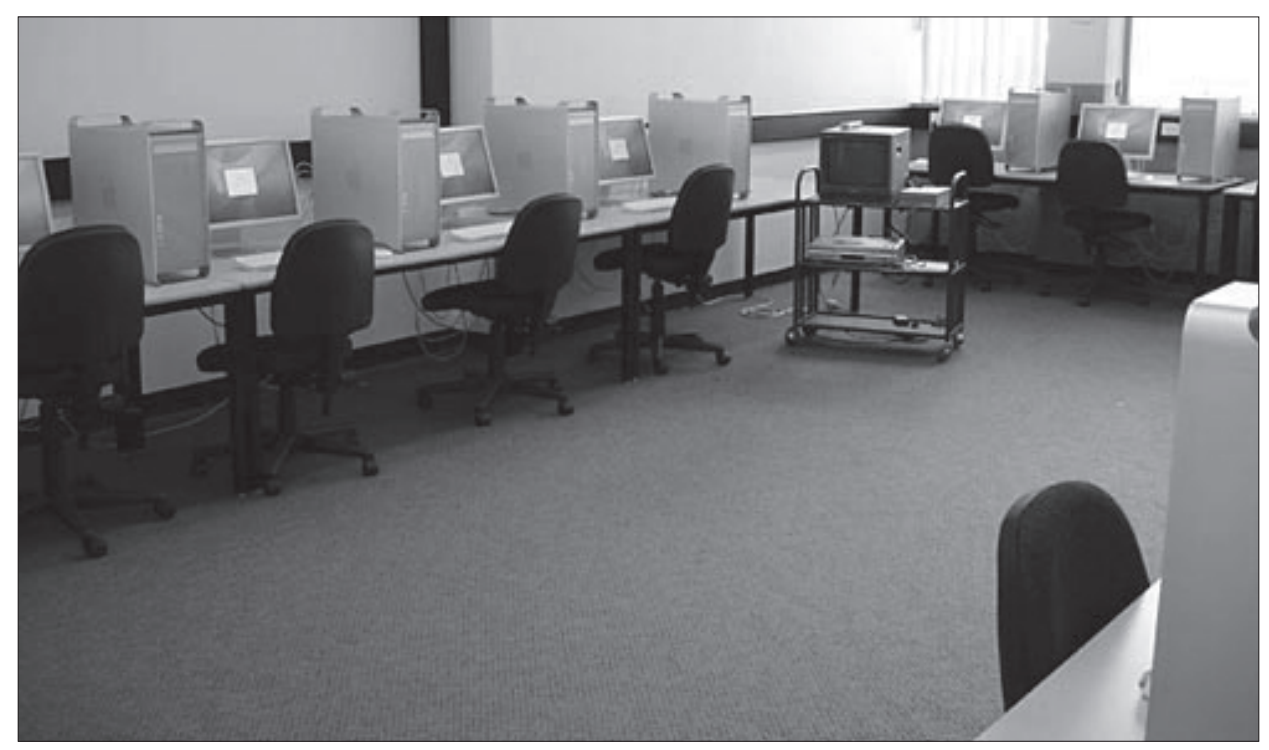

The first industry-standard G5 media production lab developed in Schulz 407 in 2002 (photograph courtesy of Peter Sansom)
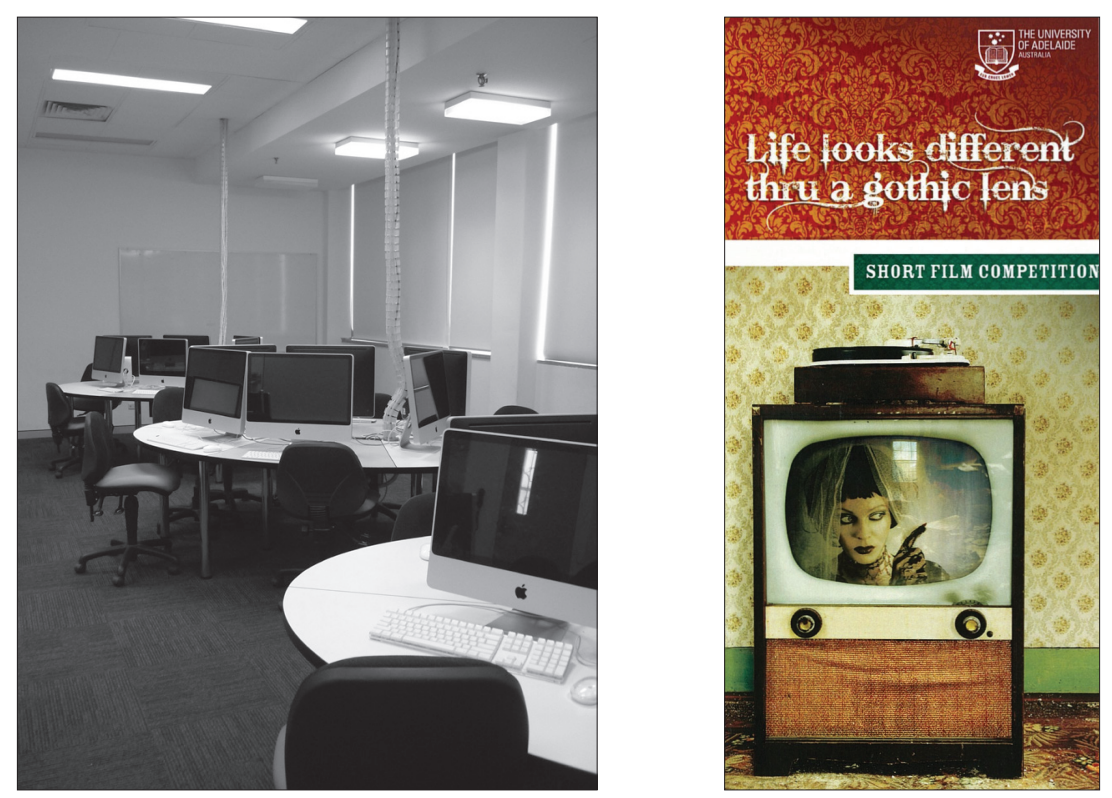

30 seat iMac Media Production Lab 2, Schulz 408, 2009 (left, photograph courtesy of Mary Griffiths), Open Day Film Festival Flyer, 2009 (right) 


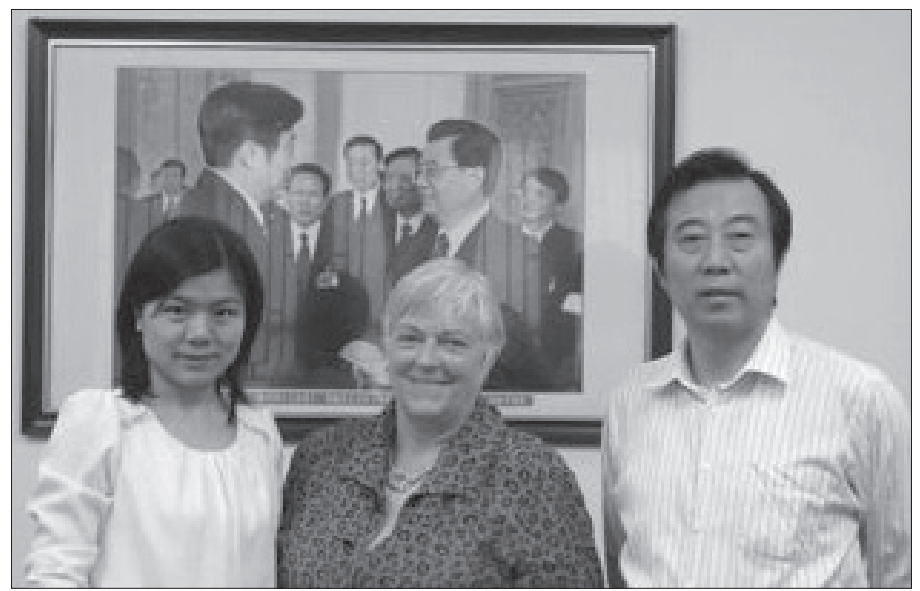

From left: Ying Jiang, Mary Griffiths and Jian Hua Jiang, Principal of Tai Zhou High School (the old high school of China's President Hu), Jiang Su Province, PRC, 2009. Investigating the possibility of their Year 12 students selecting our Bachelor of Media program in Adelaide (photograph courtesy of Mary Griffiths)

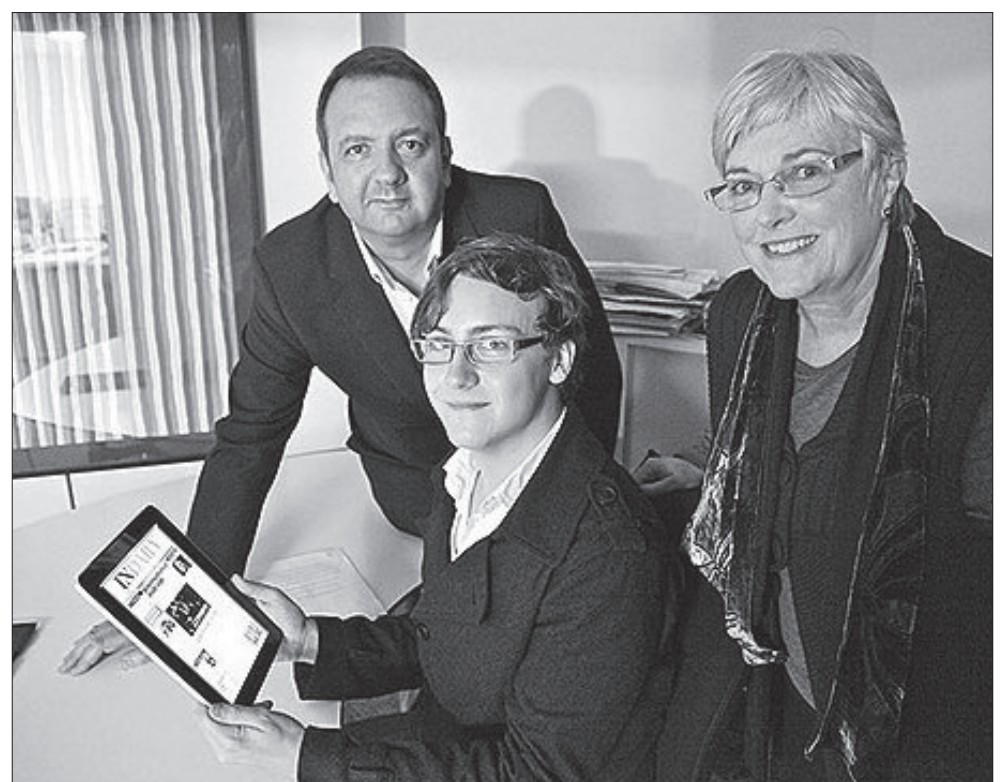

In 2010, Solstice, a local digital and print media organisation, awarded by open competition, the state's first Media scholarship of $\$ 7500$ to the B Media program. From left: Paul Hamra (Solstice), Will McRostie (prizewinner), and Mary Griffiths (source: $<$ http://www.adelaide.edu.au/news/print39666.html >) 


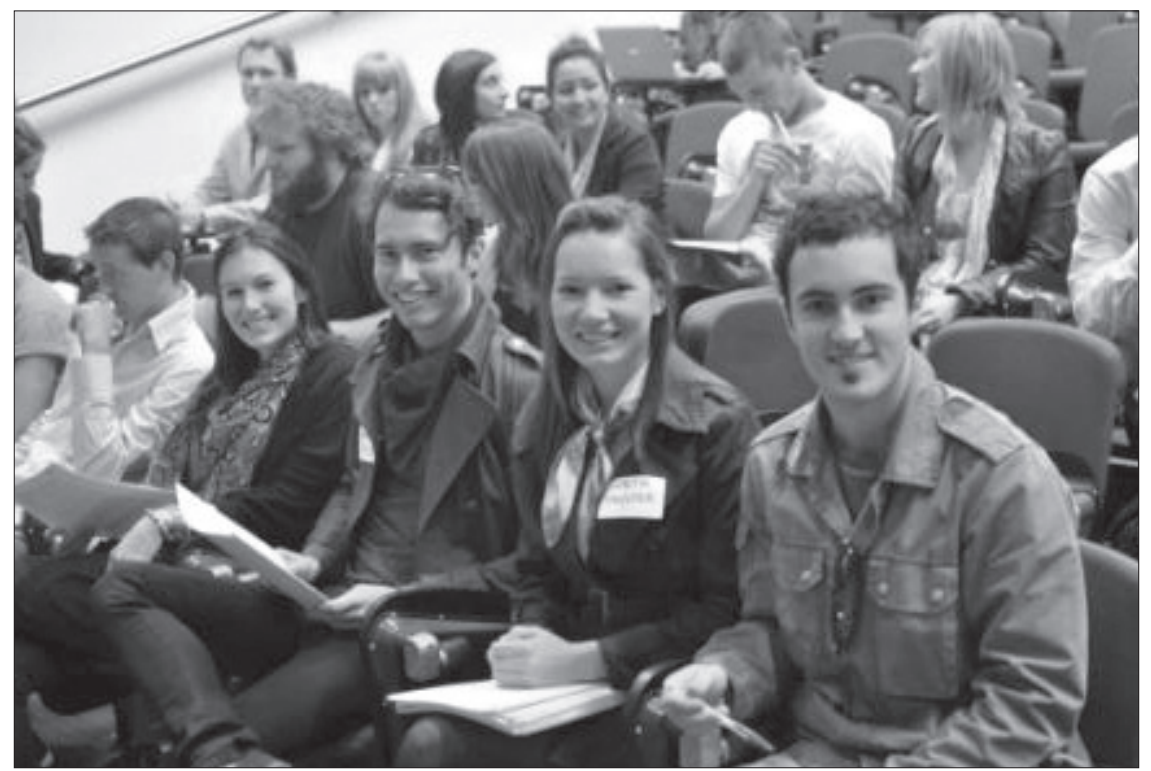

Media Democracies and e-Participation, 2010, final-year B Media students. The 'Government of Incognita' front-bench prepares to argue for its policy on mandatory Internet filtering in the offline section of the e-Sim co-created by teaching staff and students

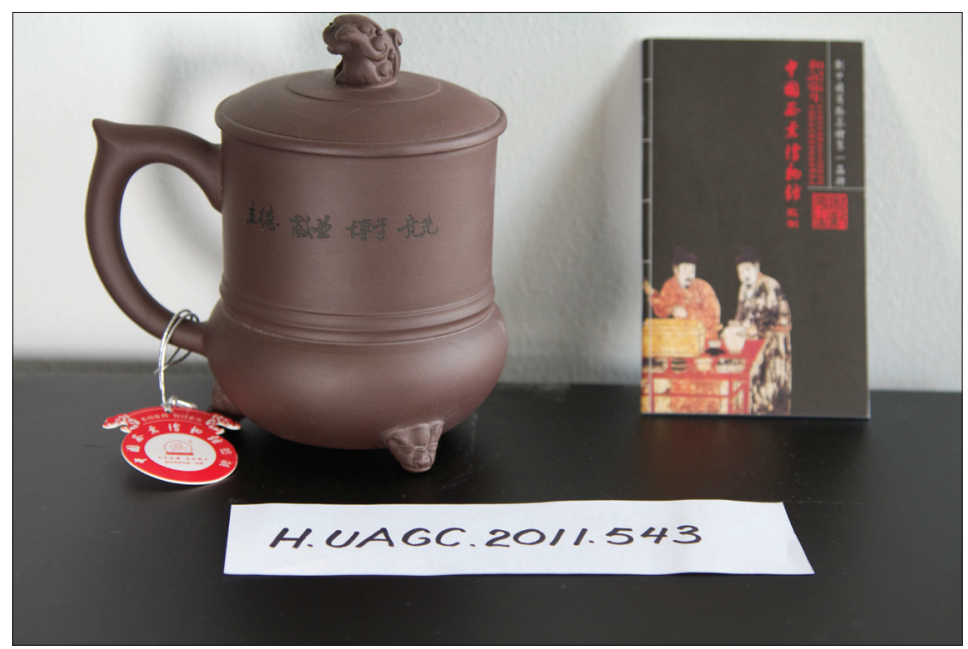

Contemporary Ghinese fine art: gift from Professor Fan, Greative and Cultural Industries Research Centre, Communications University of China. Accepted by Mary Griffiths on behalf of the Discipline of Media (photograph courtesy of Steven Dye) 


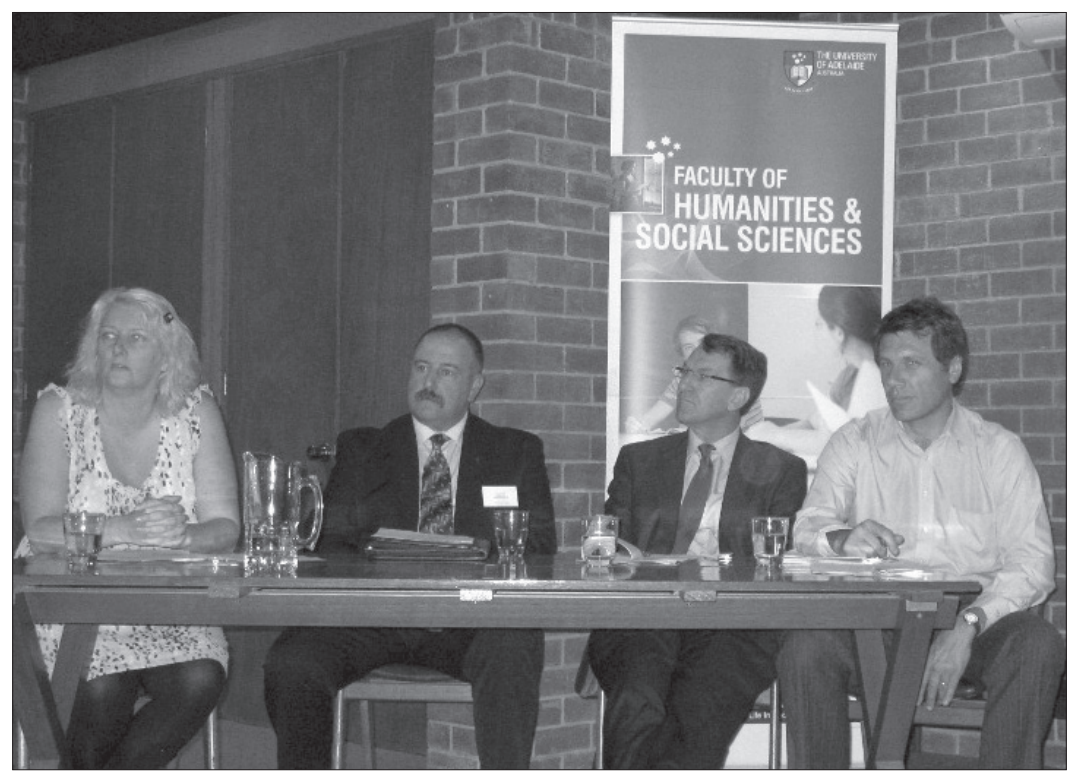

Freedoms, Citizens and the Politics of the Internet, a Public Symposium, jointly hosted by Media and Politics, November 2011. Freedom of the Press panel: From left: Tammy Franks (Greens Member for SA Legislative Council), Scott Ainslie (Australian Defence Force), Paul Chadwick (ABC) and Paul Starick (Head of News, Advertiser Newspapers Ltd)

students' attention (in partnership with industry and with Robert Ewers' faculty support). Memorably, in 2007, a live cross to UK scientists stationed at Halley Base in Antarctica ran from Napier G03 (with help from students as 'roving reporters'). Three annual short film competitions were organised with Marketing and Strategic Communications, a cross-disciplinary faculty group, film industry representatives and the Media Resource Centre. With faculty communications clearer about the program and its philosophy, an offensive began to restore the program's reputation assisted by faculty management, and an exciting journey began for the discipline.

The next annual discipline reports noted the milestones achieved (Griffiths, 2007a, 2007b, 2009a, 2009c, 2010a). Staff joined the discipline in 2007 (Rosslyn Prosser), 2008 (Rob Cover and Peter Pugsley), and 2009 (Sal Humphreys). Discipline responsibilities were assigned to staff in their first full-time positions, and this accelerated professional development. A second honours course was written, on mobile media; and the 0.6 technical officer was assigned an expanded, 
more creative role. B Media's nineteen course documents were approved. Media Industry Placement, Media Research Methods and Professional Practice had been substantially reoriented.

While so much effort was willingly being expended on teaching and on committees, Media staff continued to research, to publish, and were granted research leaves in the competitive faculty process, even as staff-student ratios hit highs of 41 to 1. In 2009 two ARC grant submissions were submitted (by Michael Wilmore and by Peter Pugsley), one of which was successful the next year; and Digital Literacies, a research project based on 2007-2008 first-year teaching activities, was funded by Faculty Research Committee and the Head of Discipline's consultancy funds. In 2008 the first discipline-based research retreat was held. A departmental seminar began. The first doctoral student graduated in 2009, Sukhmani Khorana, now holder of a prestigious postdoctoral fellowship at the University of Queensland. The second, Ying Jiang, received a $\mathrm{PhD}$ the following year. The decision was taken to put efforts into the recruitment of doctoral candidates rather than develop a coursework Masters. Other graduations followed. The contribution to governance outside the discipline continued. The head served on multiple working parties, and two staff served as Associate Deans (Prosser, Wilmore). The inaugural Arts Internship convenor came from Media (Cover) and two staff were promoted (Wilmore and, later, Cover).

Promising industry partnerships were developing meanwhile, most initiated by the head, others proposed by external partners. Two inaugural journalism internships were established at AdelaideNow (2007) at the invitation Rod Savage, the online editor (today News Ltd's national digital content manager). Regular contact was set up with the ABC, Clemenger and other organisations, which offered internships and other support. Channel 31, the community television station, (now Adelaide44) offered the potential use of its studio and invited the Head of Discipline to full board membership, as did Radio Adelaide. Media's contribution to the University's prize-winning marketing campaign 'Life Impact' (begun in 2005) still showcases Media students' production talents. Michael Neale, Gerard O'Brien and Teri Hoskin (the academic delivering the four production electives), had carried this innovative 2006 project between them, at the initiative 
of Neale. ${ }^{17}$ Student media support was supplied to international conferences, beginning the trends in volunteering and good corporate citizenship, a respected mark of the discipline.

Crucially, the annual reports demonstrated that critical program and discipline performance targets were being exceeded. They also recorded that opportunities were expanding for Media, as government working parties and state policy upgraded the status of media teaching. ${ }^{18}$ The Media documentation (business plans, overall performance development review reports, faculty committee reports, minutes of the Media Advisory Board, and end of year reports) shows commitment and progress.

Morale had radically improved from 2007 onwards, despite the heavy teaching and development loads. Program planning within the discipline was collegial and enthusiastically undertaken by most involved. The Head of Discipline, experienced in program innovations, established multiple collaborative drafting sessions, the first meetings occurring serendipitously during major structural award changes, which allowed Media more new courses. Teaching staff collaborated in the common project, consolidating their oversight of subject material by opening up their MyUni teaching sites to colleagues. The pedagogic concept of student-centric progressive learning became embedded in the program structure. For most, it was the first experience of concentrated and creative program design and maintenance. Sometimes collaborative expectations ran across the traditionally individualistic approach taken, for example, in BA programs, where individual research interest defines what is taught. Media, running a specialist program, could not afford that level of personal choice. The courses introduced from 2007 onwards fitted together: Introduction to Media: Digital Revolutions, Critical Histories of the Image, Story/Technology, and Broadcast Television and Radio established core understandings; and Screen, Directed Studies in Media, Global Media, Media Research Methods, Screen, and Media Democracies and E-Participation developed them.

\footnotetext{
${ }^{17}$ M. Neale, Personal correspondence, 2012.

${ }^{18}$ Memberships of SACE, HESS, MEGA and Creative Industries working parties, and research and participation in state education and industry policy, have contributed to the strategic positioning of the B Media.
} 
Introduction to Media: Digital Revolutions had been outlined in 2006 by the incoming head with future colleagues over email. It replaced the general survey course Media Engagements when she taught it as the lynchpin of the new degree in 2007 and 2008, before handing it over to a new colleague (Rob Cover) in 2009, who maintained its outline, content and approaches. It then passed to Sal Humphreys. This was a recurring pattern in this period: new courses, new course outlines, or reformatted courses were developed, before being co-taught or handed on to new staff, who subsequently developed new material as necessary. Caused by the delayed arrival of full-time staff, it was part of the 'border work' undertaken by the head, as program convenor. Internal coherence is an essential feature of professional awards, although this aspect of the work is sometimes misunderstood in more traditionally-organised disciplines for the reasons cited above.

By early 2009 the discipline's future looked secure. Disappointingly, considering the discipline's efforts and indications that positive change had occurred, the matriculation scores were dropped to tackle faculty recruitment shortfalls. The discipline's image was affected, as public perceptions about an award's prestige are based almost entirely on entry scores, supplemented by earlier students' experiences. The result of maintaining a long tail of about twenty enrolments annually led to the perception that Media was not the first choice of high achievers. It was not a correct assumption but, as the process was repeated for the next years, it helped nullify discipline efforts to show what had been achieved.

The recalibration work had been radical, intensive and collective, but also essentially 'backroom' and thus invisible to most faculty colleagues, although the head presented regular reports to Education Committee, Media Advisory Board, and School Executive. A disciplinary profile had been achieved, student numbers had grown (they were to peak in 2010), and discipline development accelerated alongside the gradual rollout of the new rigorously-researched, industry-focused curriculum. In chairing five selection panels over five years, the head had asked committee members to keep in mind the match between applicants' research interests and their potential capacity to contribute to the new program's digital and participatory orientation. Discipline creativity was on show as Prosser taught Critical Histories of the Image; Pugsley, Asian Screen; Cover, Digital Sexuality; 
Griffiths, Spark and Remix; and Humphreys, Digital Games. Wilmore revised Global Media, and Anyanwu wrote Creative Industries.

Three Media academics were recognised for aspects of teaching excellence (Prosser, Griffiths, and Cover). Two Media upper-level courses, Media Democracies and E-Participation (Griffiths) and Global Media (Wilmore) received extra course design support after being nominated for inclusion in the University's Enhanced E-Learning Project (eELTP, 2011). The first uses an E-Sim role-play, live tweeting and the CSIRO's free mobile voting platform Votapedia to replicate information flows in mediated political culture; the second experiments with online summative assessment.

In the postgraduate area, there were steady enrolments from 2008. In 2012, 22 research students are enrolled (several co-supervised with other Disciplines), completing theses on topics such as the impact of the Malaysian 'Internet election' on political culture, prison radio, uses of Facebook by Adelaide youth from Afghanistan, and documentary representations of migrant experience. International students are well represented among the postgraduates, providing fresh perspectives to their Australian supervisors and peers about media arrangements in other countries, including India, China, Indonesia, Malaysia and the Philippines.

Resources were needed to maintain praxis in the program from 2006. Professor Penny Boumelha suggested applying to the Vice-Chancellor's Discretionary Fund, and Nicholas Harvey and O'Brien supported the idea. The subsequent injection of an extra $\$ 160,000$ into the faculty budget financed a new 30-seat media production lab in the Schulz Building, shared with the Electronic Music Unit of the Elder Conservatorium.

Thus, a specialist Discipline of Media established itself through sustained and focused entrepreneurial activity. A small hub of three adjoining Hughes offices, once part of the PVC's International's suite, was turned, with the help of the business manager and a donation of three out-of-warranty Macs from Computer Sciences, into an open-access lab for students and visitors. Media launched the space with a late afternoon party for over 40 guests to thank everyone for their support. The 'Intermedia hub' was used for some years as an extra teaching and 
meeting area, and subsequently became the first of many postgraduate offices. This period, despite the workloads, increased university expectations and the frustrations occasioned by maintaining stability in the production area, was positive and productive.

\section{Mid-2009 TO 2011: OLDER CONTROVERSIES RE-EMERGE}

By 2009 there were seven members of staff. The four first-year classes each attracted over 180 students, and several upper-level core courses maintained enrolments of over 100. Media Industry Placement enrolments stood at 70. The Head regularly organised numbers of casual staff. The first 'professional' lab built now needed refurbishment. The hiring of appropriate casual staff for production, and rationalisations about the necessary costs of production were by now annual tasks for the head. Much was still required from staff in the way of extra-curricular activities. The Head had given approximately thirty presentations (some podcast), visited education fairs and given a public forum in Singapore, and had met education agents in Malaysia. In mid-2009 she and Ying Jiang visited Beijing for the first time to discuss research partnership arrangements with Professor Fan Zhou, and then met with representatives of industry and educational establishments in Wuxi City, a growing creative industry region north of Shanghai, to ascertain the opportunities for articulated media programs. Professor Fan subsequently spent six weeks as a guest of the discipline in 2010, visiting the ABC and government agencies, and giving a public talk on creative industries, co-sponsored by the Confucius Institute. ${ }^{19}$ The Memorandum of Agreement between Media and the Communications University of China ensures that the collaboration continues.

Inventive ideas were sometimes unsuccessful in gaining adequate support, but the Discipline produced more to replace them, and if inventive problemsolving is a true indicator of staff commitment, then the Discipline maintained it steadily. Despite the scale of productivity, indeed because of it, internal disagreements came to a head as workloads increased again at the start of 2009.

\footnotetext{
${ }^{19}$ Once established, overseas connections were regularly refreshed: for example, Mary Griffiths was an invited keynote presenter at Renmin University's Creative Industries conference in 2011; and Ying Jiang acts as interpreter when Chinese provincial leaders visit the University. They are coediting 'China', special issue 45.2 of Communication, Politics and Culture in 2012. Staff present regularly at international conferences and have held overseas visiting research fellowships.
} 
Signs of collective frustration were obvious. Rapid growth in so many directions at once had meant that major adjustments to the balance of research and teaching duties were necessary for those leading or committing to assist developments, and for others teaching the large first-year courses. Discipline members' divergent ambitions for the program were voiced, and then acted on, by individuals, outside regular Discipline discussions.

The following play of School and Faculty politics marked a period of great difficulty. The cost of production courses had become a recurring issue in discussions inside and outside the Discipline. A traditional dismissal of praxis because of the 'taint' of such courses as opposed to theory - was revived, and moved from the collegial exchange of deeply-held views to the political domain. Despite the nomenclature of the degree, the overwhelming evidence provided by the enthusiasm for the excellent Story/Tech and the Video Production courses taught by Prosser and Philip Elms respectively, and the annual student exit surveys demonstrating that students wanted more, not fewer, production choices, ${ }^{20}$ the Video and Multimedia streams had been discontinued by the time the Head of Discipline returned from research leave.

As in 2003-2006, student protests ensued, and continued throughout 2010. The Chair of the Media Advisory Board (which, through an oversight, had not been consulted or informed of changes) then received a confidential student email, critical of the new developments. The Board, following careful deliberation, asked for a faculty briefing to be provided. During that time, the Head of Discipline was sandwiched between mobilising student groups, staff who were not supportive of praxis if it meant even higher teaching loads, others who genuinely wanted a theory-only program, management representatives concerned to balance the budget, and, finally, industry representatives who were unable to understand the rationale or deliberative nature of academic decision-making. This uncomfortable position attracted the hostilities traditionally reserved for those bearing unwelcome messages.

C. P. Snow once noted about the play of academic politics: 'There is great dignity in being a spectator: and if you do it for long enough, you are dead inside'.

\footnotetext{
${ }^{20}$ M. Griffiths, 'B.Media, student consultation', May-June 2008; M. Griffiths, 'B.Media, student consultation' May-June 2009; M. Griffiths, 'B.Media, student consultation, May-June 2010.
} 
It could be said that few were 'dead inside' in the months of intense, contentious and determined negotiations, as the old ground of 'the theory wars' was traversed yet again, before it was accepted that the both/and approach to media education was essential if the media degree was to keep its current edge. By that time, the idea of production and the further embedding of praxis throughout the program (a democratising concept put forward in 2006) established itself more thoroughly. Concessions, or accommodations, had been made. In fact, by the date of the first formal review, further evidence of this logic had been provided by an independent survey. Robert Ewers, the faculty's manager of strategy, asked Marketing and Strategic Communications to work with the Head of Discipline, contacting alumni, current students and MIP hosts, to collect independent evidence on the perceived place of praxis. $^{21}$ The results endorsed the three years of student-only responses cited above. Both reports formed part of the Discipline response to the Five-Year Review.

\section{AfTER ENDORSEMENT, EQUILIBRIUM; AND A POSITIVE FUTURE}

Two extensive reviews of the program have bookended Media's development: the first to begin reform ${ }^{22}$ and the second as an independent university quality check, the delayed Five-Year Review. It was very positive. The external reviewers wrote:

Staff members of the Media discipline are commended for their strong team commitment to their work and for developing a well-structured and sequenced program, which maintains a central focus on Social Media and Digital Media. ${ }^{23}$

In this acknowledgement, and the faculty's later commendation of the leadership of the Discipline, the Review endorsed the completion of a significant set of initiatives and subsequent developments, begun in 2006, and taking some years to establish and bear fruit. Media's Implementation Plan ${ }^{24}$ noted that most recommendations had been completed by December 2010. Recognition that teaching methods match the program's focus on digital and participatory media

\footnotetext{
${ }^{21}$ HumSS - B Media Review, Strategic and Marketing Communications, 2010.

${ }^{22}$ M. Griffiths, 'Informal review of the B.Media', Faculty of Humanities and Social Sciences, University of Adelaide, 30 September 2006.

${ }^{23}$ Review of B.Media, 2010.

${ }^{24}$ M. Griffiths, 'B.Media implementation plan 2011-2013', 2011.
} 
was particularly welcomed, as the group's online and blended pedagogies are experimental, innovative and student-centric.

From the Review, the Discipline regained its lost equilibrium in fits and starts. Two staff had elected to move on, one leaving the University. Faculty agreed quickly to two replacement positions, and this had a very positive effect. One would be a senior appointment, where the practical expertise of a digital researcher could further develop the area of digital media praxis. The last duty of the Head of Discipline (who had been re-elected unopposed in March 2010) was to chair the appointment committee. Ming Cheung (digital design), and Ying Jiang (Chinese blogging) now contribute to the Discipline's dynamic teaching and research profile, and to its internationalism.

Media was finally co-located to the faculty home. Solstice Media sponsored the state's first Media Scholarship. The popularity of the remaining praxis courses has grown, not just in the Radio electives but in the newly-developed electives; and in Media Industry Placement, redeveloped and convened by the Head of Discipline over five years. It is the faculty's largest internship program, the closest to the concept of 'work-integrated learning'. In 2012 it opened with 100 enrolments, and over 40 local news, media and communications' organisations regularly hosting MIP students.

When the Head of Discipline stood down to reorient to research in June 2011, Michael Wilmore took on the role. He now leads the next set of Discipline developments. The B Media program again relies on fewer core courses and a renewed call on elective courses, although student numbers have decreased slightly. New majors have been proposed such as journalism, first suggested in 2010, and an articulation with TAFE has been agreed as another solution to the perennial issues of providing students with production options. With adequate resources, the revivified program served by a dedicated disciplinary staff can accommodate many new developments, as it could not have done in 2006.

The story of Media continues to change as other opportunities arise. It is a resourceful and energetic Discipline. There are many contributions and activities which have been omitted here: promising individual research agendas; the migration of ideas generated in Media across the faculty; industry partnerships; conferences hosted with successful outcomes; and the increasing number of alumni 
successfully pursuing different employment trajectories in Australia and overseas. The spirit of the early faculty plan has been rigorously served by Media academics, though their manner of adhering to its letter diverges in key points from what was imagined in the original. Differences of opinion and tensions, whilst seemingly destructive (and occasionally uncomfortable for those leading from the front), have in fact been productive. They are within the robust academic - and adversarial traditions deployed to test the worth of new ideas. Ultimately, they have resulted in a respected 'Media degree for the C21st' at one of the oldest universities in Australia, and the addition of an innovative contemporary Discipline with new research areas to the faculty.

\section{REFERENGES}

Beecher, E., 'Journalism's crisis is everyone's crisis', Horizon South Australia, (Adelaide, Hawke Centre, 28 March 2012), <http:/ /www.unisa.edu.au/ hawkecentre/events/2012events/HorizonSAForum_Beecher.mp3>.

Bérubé, M., 'What's the matter with cultural studies?', The Chronicle of Higher Education, 2009, <http://chronicle.com/article/Whats-the-Matter-With/ $48334 />$.

Gauntlett, D., 'Ten things wrong with the media effects model', n. d., <http:// www.theory.org.uk/david/effects.htm>.

Gillies, M., 'Proposal for a B.Media' (Adelaide, University of Adelaide, 2001).

Griffiths, M., 'Informal review of the B.Media' (Adelaide, Faculty of Humanities and Social Sciences, University of Adelaide, 30 September 2006).

Griffiths, M., Sansom, P., Zweck, V, \& White, K., <http://hss.adelaide.edu.au/ media_studies/ $>$.

Griffiths, M., 'Media business plan 2008-2010', 2007.

Griffiths, M., Application, Vice-Chancellor's Discretionary Fund, 2007.

Griffiths, M., 'B.Media, student consultation', May-June 2008.

Griffiths, M., Memo: 'Gerard O’Brien, Head of Humanities', 13 Jan 2009.

Griffiths, M., 'B.Media, student consultation’ May-June 2009. 
Griffiths, M., Memo: 'Nicholas Harvey and Gerard O’Brien'; 'China trip', 2009.

Griffiths, M., 'B.Media business plan 2010-2012', 2010.

Griffiths, M., 'B.Media, student consultation, May-June 2010.

Griffiths, M., 'Faculty response to the formal review', 2010.

Griffiths, M., 'Discipline response to the Review recommendations', 2010.

Griffiths, M., 'B.Media implementation plan 2011-2013', 2011.

HumSS - B Media Review 2010, Strategic and Marketing Communications.

Innes, M., Personal correspondence, 2012.

Kersten L., Personal correspondence, 2012.

Minutes, University of Adelaide, Media Advisory Board, 2006-2012.

Neale, M., Personal correspondence, 2012.

O’Brien, G., Personal correspondence, 2006-2011.

Putnis, P., Axford, B., Watson, L. \& Blood, W., 'Communication and media studies in Australian universities' (Canberra, Department of Communication and Education, University of Canberra, 2002).

Turner, G., What's become of cultural studies?' (Sage, London, 2012). 



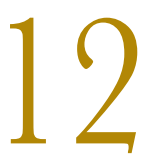

\section{Musical fusions}

Jenny Rosevear

The celebration of 125 years of the Faculty of Arts at the University of Adelaide is an ideal time to review the significant role of Music, whether as an area of practical and academic study throughout this time, as a faculty in its own right, or as a school within the Humanities and Social Sciences (HUMSS) Faculty, as has been the case since the mid-1990s. This chapter is organised in three sections. The first section covers the period 1885-1990, and makes reference to V. A. Edgeloe's The language of human feeling: A brief history of music in the University of Adelaide (1985), which documents the first one hundred years of Music within the University. The first section also includes the first major 'fusion' in the late 1890s between the newly formed Conservatorium and the Adelaide College of Music. The second section explores the development of Music since 1991, in particular the merger with the City Campus of the former South Australian College of Advanced Education in 1991, and the third section looks at the merger with the TAFE Flinders Street School of Music in 2002. 
The context for the study of music is very firmly grounded within the Elder Conservatorium, which came out of Sir Thomas Elder's generous bequest to the University in 1897, with the foundation stone of the Conservatorium being laid in 1898. The first Bachelor of Music (MusBac) course, however, commenced earlier, when Australia's first chair in Music was established in 1884, which had largely been enabled by support from the Governor, Sir William Robinson, who had secured donations to support the appointment for a five-year period. ${ }^{1}$ The study of Music as part of the Bachelor of Arts has seen a relatively small but steady stream of students over the years, with a focus on academic, not practical, studies in Music. The general mechanism for Music in the Bachelor of Arts has been students undertaking theoretical, historical and socio-historical subjects taught by Elder Conservatorium staff. It is only since 2007 that Bachelor of Arts students have been able to count any practical Music subjects towards their Arts degree, with Conservatorium ensemble subjects (such as Elder Conservatorium Symphony Orchestra, Elder Conservatorium Chorale, Elder Conservatorium Wind Orchestra) now being formally allowed in their Arts degree.

\section{Music Within the University of Adelaide: 1885-1990}

The Act of the Provincial Legislature of 1874 provided the necessary authority for the University to confer degrees in Arts, Science, Law, Medicine and Music. ${ }^{2}$ While Music was established as part of this initial brief, it was some years before music study became a reality. The first professor of Music, Joshua Ives, a graduate of the University of Cambridge, began teaching the first-year of the Bachelor of Music degree in April 1885. ${ }^{3}$ Ives based the degree on the University of Cambridge model, in which harmony and counterpoint featured prominently along with a substantial original composition exercise at third-year level. Somewhat surprisingly, the degree did not include any study of music history. The balancing of tension between the theoretical and practical aspects of Music has fluctuated throughout the University's history. The first degree was theoretically

\footnotetext{
${ }^{1}$ W. G. K. Duncan \& R. A. Leonard, The University of Adelaide 1874-1974 (Adelaide, Rigby, 1973).

${ }^{2} \mathrm{~V}$. A. Edgeloe, The language of human feeling: A brief history of music in the University of Adelaide (Adelaide, The University of Adelaide, 1985).

${ }^{3}$ Ibid.
} 
oriented, and performance was eventually accepted as an alternative to the third-year level composition requirement. Edgeloe describes how amending the University regulations was perceived to be a 'radical step ... to allow executancy, at an appropriately high level'. ${ }^{4}$ The formal inclusion of performance in the degree came about in 1907 at the instigation of Ives' successor, John Ennis.

Sir Thomas Elder's generous bequest to the University in 1897 of $£ 65,000$ included $£ 20,000$ for a school of music. This enabled some security of funding for the chair of music position, which had become increasingly reliant on income from public music examinations. The bequest also enabled the provision of performance training. At the same time as Music was being established at the University, the Adelaide College of Music in Wakefield Street, established by Immanuel Gotthold Reimann in 1883, taught practical music, quite separately from the University's music offerings. It is of interest to note that Cecil Sharp (1859-1924), renowned for his later work in collecting English folk songs, had spent some time in Adelaide as assistant organist at St Peter's Cathedral, and working as associate to Chief Justice Sir Samuel James Way from 1882 to 1889, before going into partnership with Reimann as joint director of the Adelaide College of Music, prior to Sharp's return to England in 1892. With the advent of Elder's bequest in 1897, negotiations were held between the University and Reimann to incorporate the Adelaide College of Music (including Reimann and some of his staff) as the core of the newly established Conservatorium, resulting in the first of the significant musical fusions that are part of the Conservatorium's history. Thus the provision of both theoretical and practical studies of music became a reality at the University, although initially this was through the diploma course entitled 'Associate in Music', which was introduced in 1900. Ives had the title of Elder Professor of Music as well as the Director of the Elder Conservatorium, although his position was not renewed in 1901 in somewhat contentious circumstances and following many years of disagreements and disaffection between Ives and the University, and Ives and community music teachers.

Aside from the degree, Ives was extensively involved in public examinations in music, which were also based on British models and were developed in order

\footnotetext{
${ }^{4}$ Ibid., p. 13.
} 
to obtain an additional source of income'. ${ }^{5}$ The University Council had initially created a 'Board of Musical Studies', the function of which was to report on matters relating to the degree and to public music examinations, although the latter apparently consumed far more attention. However a 'Faculty of Music' took effect from 1905 and dealt with degree matters (including the doctorate which had been introduced in 1898) until 1914, when the Board and the Faculty were combined, thus having one body responsible for both academic and practical music programs as well as public examinations in music. ${ }^{6}$ The Faculty, being concerned with theoretical and academic aspects of music, assumed a more prestigious position, while the Board was looked down upon as being inferior because it was mainly concerned with practical aspects of music and was therefore 'in some respects of sub-graduate standard and status' ${ }^{7}$

John Matthew Ennis was the second Elder Professor of Music, presiding from 1902 to 1918. During his tenure, there was continuation of the arrangements, begun by Ives, of combined examinations with the University of Melbourne Conservatorium. These examinations evolved to cover both theoretical and practical elements and were in direct competition with the examinations conducted in Australia by the Associated Board of the Royal College of Music and the Royal Academy of Music from London. The Australian-grown arrangement expanded to include the University of Tasmania (1911), the University of Queensland (1913), the University of Western Australia (1914) and the New South Wales Conservatorium (1918), thus leading to the formation of the Australian Music Examinations Board (AMEB) in 1918. Aside from introducing performance to the degree as an alternative to composition, Ennis also introduced music history into the curriculum. Ennis instituted some prizes for achievements in musical performance, and he exerted a positive influence which saw an increase in the provision of good quality recitals in Elder Hall. Ennis resigned in 1918 due to failing health. He was replaced by E. Harold Davies, who was the Elder Professor of Music from 1919 to 1947.

\footnotetext{
${ }^{5}$ D. Bridges, 'Some historical backgrounds to Australian music education', Australian Fournal of Music Education, 10 (1972), pp. 13-16, here p. 13.

${ }^{6}$ V. A. Edgeloe, The language of human feeling.

${ }^{7}$ Ibid., p. 15.
} 
Davies was born into a musical family in 1867 in Shropshire, England, and travelled to Gawler, South Australia, in 1887 to join his brother Charles who had shifted to Australia in pursuit of a warmer climate for his health. Charles was organist and choirmaster at the Congregational Church in Gawler. ${ }^{8}$ Harold Davies' younger brother, Walford, stayed in England and also had a successful career in music, being knighted in 1922 and becoming Master of the King's Musick in 1934. Harold Davies became organist and choirmaster at St Peter's, Glenelg, and also taught pupils, one of whom he later married in 1893. Under Ives' tutelage, Davies undertook the Bachelor of Music, and later qualified for the Doctor of Music in 1902. He was the first person to achieve this qualification. Davies was very active as a teacher, musician and scholar during the years while Ennis was the Elder Professor, and Ennis invited Davies to become a member of the newly created Faculty of Music. Davies was well respected by the music teaching fraternity, and when Ennis retired due to ill health at the end of 1918, the appointment of Davies to the Chair in Music was warmly welcomed.

During the following twenty-nine years in this position, Davies consolidated and developed Music at the University, as well as being committed to developing music in the wider community. The curriculum for the Bachelor of Music and the Associate Diploma continued largely unchanged under Davies, although he introduced musical perception as a subject in 1925 and generally improved entry standards and outcomes. In 1937, Davies had proposed that Music be an optional subject in an Arts degree, believing there were parallels between music and literature and that both had a role in cultural education, but this did not come to fruition in his time. Davies was a prolific writer and frequently contributed articles to the newspaper as well as making use of the latest technology - the wireless — in order to broadcast concerts from the Elder Conservatorium. ${ }^{9}$ Davies made extensive use of broadcasting, both as a vehicle for music appreciation and as a platform for his views on various topics. Davies was an innovator, being the first Australian to undertake extensive field trips between 1927 and 1930 into outback Australia, recording and conducting research into tribal Aboriginal songs. ${ }^{10}$ Davies

\footnotetext{
${ }^{8}$ D. Bridges, More than a musician. A life of E. Harold Davies (Melbourne, Australian Scholarly Publishing, 2006).

${ }^{9}$ C. Symons, Fohn Bishop, a life for music (Melbourne, Hyland House, 1989).

${ }^{10}$ D. Bridges, More than a musician.
} 
received international recognition in 1931 when, along with Bernard Heinze of Melbourne and William Orchard of Sydney, he was elected as a Fellow of the Royal College of Music. These were the first Australians to receive this esteemed honour. $^{11}$

Davies died suddenly on 1 July 1947 whilst still holding the position of Elder Professor of Music. His successor was Adelaide-born John Bishop (1903-1964), who was a distinguished graduate of the Elder Conservatorium and a recipient of the Elder Overseas scholarship, which enabled him to study piano and conducting at the Royal College of Music in London. After a stint as an orchestral and choral conductor in Wellington, New Zealand, and later Director of Music at Scotch College in Melbourne and conductor of the Melbourne University Conservatorium Orchestra, Bishop was appointed as Elder Professor and Director of the Conservatorium in 1948. Bishop extended Davies' cause and proposed a three-year sequence of Music study, with a major in either theoretical or practical study, as part of the Bachelor of Arts. According to Symons, Bishop sought to 'change the emphasis from the more scholarly, withdrawn approach of Dr Davies to something more practical, creative and lively'. ${ }^{12}$ Bishop also introduced an additional Honours year of study to the Bachelor of Music, which now included musicology and electronic music as areas of study. Bishop recognised that the days of the Diploma were numbered, given that questions were being raised by the Australian Universities Commission about the lower academic standard of diplomas in many universities. Bishop introduced an annual visiting composer scheme, which saw an impressive range of composers each visiting for at least a six month period, beginning with Henk Badings in 1962. Aside from his influence in developing music in the University, Professor John Bishop OBE was instrumental in establishing the Adelaide Festival of Arts (with the first Festival being held in 1960). In conjunction with Ruth Alexander, he convened the first National Music Camp in 1948, which led to the creation of the renowned Australian Youth Orchestra, an organisation which is recognised internationally and which continues to play a significant role in Australia's musical culture. To this day, Bishop's legacy continues to resound strongly through these organisations, which have continued to flourish.

\footnotetext{
${ }^{11}$ V. A. Edgeloe, The language of human feeling.

12 C. Symons, Fohn Bishop, p. 190.
} 
Following Bishop's sudden and untimely death in 1964, David Galliver was appointed as the next Elder Professor and Director of the Elder Conservatorium in 1966. Galliver was an invited performer for Britten's Requiem at the 1964 Adelaide Festival of Arts, and Bishop had seized the opportunity and appointed Galliver as a singing teacher and lecturer in the history of music in 1964. Born in Bristol in 1925, Galliver went on to achieve an Honours degree in modern languages in New College Oxford along with studies in organ and singing at the Royal College of Music, eventually becoming highly regarded as a concert tenor. ${ }^{13}$ By the time Galliver took up his role as Professor and Director, staffing arrangements for the practical and theoretical elements saw that there was a far greater number of practical staff. Galliver continued in his dual role until 1976, and thereafter was solely Elder Professor from 1976 to 1983. This may have been brought about by the large increase in student numbers creating an unmanageable workload for a combined Professor and Director position. The Associate Diploma was phased out in 1972, and this saw more practical content introduced to the Bachelor of Music. Galliver was keen to ensure that musicians were trained as scholars in both practical and theoretical areas. A three-year sequence of music subjects continued to be offered in the Bachelor of Arts although these were more theoretical, not practical, subjects, with areas such as history, musicology, ethnomusicology, electronic music, and music in education being offered. ${ }^{14}$ During Galliver's time, ethnomusicology was introduced to the Conservatorium with the appointment of Dr Catherine Ellis, who established the Centre for Aboriginal Studies in Music in 1976, which continues to this day to be an unparalleled innovation in Indigenous education. Galliver retired in 1983 and was Emeritus Professor from 1986. He was succeeded by Professor Heribert Esser, an eminent conductor from Germany, who was the Elder Professor from 1987 until his departure in 1994.

During the late 1970s, when the economic recession was having an impact on education, the Conservatorium was experiencing some image difficulties and bad press as reflected in an article in The Advertiser on 14 July 1979 entitled 'The Con at Death's Door?'. There was also growing competition from other tertiary

\footnotetext{
${ }^{13} \mathrm{H}$. Lauer, 'The role of the first five Elder professors in the development of music in the Elder Conservatorium 1885-1985', Masters diss., The University of Adelaide (1998).

${ }^{14}$ V. A. Edgeloe, The language of human feeling.
} 
institutions in offering performance courses, which led to some questioning about the place of performance training and whether the title 'Elder Conservatorium of Music' should be replaced by a 'Department of Music'. ${ }^{15}$ However, it was resolved to retain the original name and along with strategic changes to increase performance staffing levels which had declined, the outlook improved significantly when the Conservatorium offerings changed in 1982 with the creation of two separate degrees, namely 'Bachelor of Music' and 'Bachelor of Music (Performance)'. ${ }^{16}$ It should also be mentioned that another post-secondary music institution was growing, with the opening in 1970 of the School of Music of the Adelaide College of Technical and Further Education (TAFE), generally known by its location, namely the Flinders Street School of Music. While there were various options for music study at various TAFE campuses, according to Fox, 'the initial motivation for the establishment of the [Flinders Street] School of Music was related more specifically to the phasing out of the AUA Diploma at the Conservatorium, and the reduction of single study teaching.' ${ }^{17}$

\section{1: THE MERGER WITH THE Gity GAMPus OF THE FORMER SOUTH Australian Gollege of Advanced Education}

The next major structural change to the Conservatorium came about in 1991, when the City Campus of the former South Australian College of Advanced Education merged with the University of Adelaide. In order to explain this merger, it is necessary to explore some aspects of tertiary education in Australia. In the late 1960s, Teachers' Colleges, which had been state-run entities, became federally funded Colleges of Advanced Education (CAEs), which resulted in an increase in the number of these organisations. In Adelaide in the 1970s, Music could be studied at all five CAE campuses: Adelaide College of the Arts \& Education (formerly Adelaide Teachers College), Sturt CAE (formerly Bedford Park Teachers College), Hartley CAE (Torrens Campus), Salisbury CAE, and Murray Park CAE (Magill). Trainee teachers for junior primary and primary levels undertook

\footnotetext{
${ }^{15}$ M. Fox, 'Music education in South Australia 1836-1984', in A. McCredie (ed.), From Colonel Light into the footlights (Norwood, SA, Pagel Books, 1988), pp. 383-410, here p. 405.

${ }^{16}$ Ibid., p. 404.

${ }^{17}$ Ibid., p. 408.
} 
compulsory curriculum studies in Music, and it was possible to take a Music major as part of a Diploma in Teaching. The Adelaide and Torrens CAEs expanded their offerings beyond teacher training to develop various degrees including music performance and the Torrens CAE was among the first in Australia to offer study in the field of jazz. The CAE Music offerings were in direct competition to the Elder Conservatorium, which no longer had a monopoly on tertiary music study.

The five separate CAEs were amalgamated in 1982 into the South Australian College of Advanced Education (SACAE), which was a single organisation operating with five separate campuses. The provision of performance training on different campuses was not financially sustainable and the music departments of the City, Magill, Salisbury and Torrens (Underdale) campuses were combined and became located at the City Campus of SACAE, in Kintore Avenue, site of the former Adelaide Teachers College and Adelaide College of the Arts and Education, and literally a stone's throw from the Elder Conservatorium. The SACAE Music staff were mostly shifted to the City Campus, although staff who were involved with the provision of compulsory music for primary and junior primary teacher training courses tended to remain at their original campus.

The Head of the School of Music of the City Campus of SACAE was Brian Chatterton, whose vision saw innovation and curriculum development generate substantial competition to the Elder Conservatorium. By the mid-1980s, the City Campus of SACAE had developed a 4-year Bachelor of Music degree, which seemed to offer a more comprehensive package than the Elder Conservatorium's 3-year degree. SACAE also offered the 4-year Bachelor of Education (Secondary Music), as well as a degree in Jazz Performance, which had its origins under the guidance of $\mathrm{Hal} \mathrm{Hall} \mathrm{at} \mathrm{the} \mathrm{former} \mathrm{Torrens} \mathrm{CAE.} \mathrm{Another} \mathrm{innovation} \mathrm{was} \mathrm{the}$ establishment in 1985 of the Australian String Quartet as the Quartet in Residence, with founding members William Hennessy, Douglas Weiland, Keith Crellin and Janis Laurs. The Quartet developed into one of Australia's finest chamber groups, whilst also contributing to the performance teaching program at the City Campus of the SACAE.

In the meantime, John Dawkins, the federal Labor Education Minister from 1987 to 1992, brought in a series of sweeping changes to tertiary education, which led to CAEs converting to, or amalgamating with, universities, thereby reducing 
the overall number of tertiary institutions in Australia. The Dawkins reforms led to the disbanding of the SACAE, with the reconfigured model taking effect from the beginning of 1991. The restructuring was very complex, with an agreement occurring in June, 1989, for a consolidated institution to be formed from a merger between SACAE, Roseworthy Agricultural College and the University. However, the University withdrew from the agreement in August 1989, following concerns from many parts of the University about possible lowering of academic standards. A new agreement was drawn up which involved just the City Campus of SACAE rather than all of the SACAE campuses. The SACAE City Campus, which had included Music, Dance, Drama, Education, Labour Studies, Women's Studies and Languages, combined with the relevant departments at the University of Adelaide. The Magill, Salisbury and Underdale campuses of SACAE along with the South Australian Institute of Technology amalgamated to form the new University of South Australia, while the Sturt campus of SACAE became part of Flinders University. From 1991, Music degrees were now only being offered by one institution again, the Elder Conservatorium of the University of Adelaide, but now, to consternation in some quarters, there was jazz at the Con! This amalgamation came during the reign of Professor Heribert Esser, the Elder Professor from 1986 to 1993.

It should also be noted that, aside from the impetus for change from the federal level, the South Australian government had conducted its own enquiry into performing arts training, commencing in March of 1990, with the final Report being presented in December of 1990. The Committee of Enquiry into Performing Arts Training was chaired by Mary Beasley (see Appendix A for membership of the Committee and Terms of Reference). The Report noted the various offerings available in music performance via degrees at the Conservatorium and the City Campus of SACAE, and the Diploma in Music at TAFE Flinders Street School of Music. The Report described the relationship between these three institutions to be 'one of mutual respect and cooperation', ${ }^{18}$ but noted the overlap and duplication particularly between SACAE and the Elder Conservatorium. The recommendations of the Beasley Report, with regard to the combining of

\footnotetext{
${ }^{18}$ M. Beasley, 'Report of the Committee of Enquiry into tertiary performing arts training in South Australia' (Government of South Australia, 1990), p. 8.
} 
courses, mirrored the changes about to be implemented as a result of the Dawkins reforms. However, the Beasley Report saw a different solution and recommended the creation of an Academy of Performing Arts, to be known as the Helpmann Academy, to be located on the University of Adelaide North Terrace campus and to comprise revised music performance courses, a new dance performance course, a revised drama performance course, a technical theatre course and a new postgraduate professional writing and music composition course. ${ }^{19}$ The vision for the new Academy in music was purely performance related and did not embrace the broad context of academic areas of music necessary to provide a well-rounded tertiary education in music.

Whilst the ambitious range of courses being suggested did not become a reality in a new Academy of Performing Arts, nevertheless, the entity of the Helpmann Academy came into being in 1994. However, the Helpmann Academy did not offer courses of study, but developed as 'a unique partnership of the major tertiary arts training establishments in South Australia, unifying the skills and resources of the state's universities and TafeSA', ${ }^{20}$ with its main aim being to assist arts students make a successful transition from study to becoming practicing artists in the profession. The Academy is named in honour of South Australia's famous dancer and actor, Sir Robert Helpmann (1909-1986). Throughout its existence, the Helpmann Academy has undertaken extensive fund-raising, which has led to financial support for collaborative projects between its partner institutions and which has provided grants and funding for various activities such as awards, exhibitions, professional mentorships, visiting artists, publicity services and international exchange programs for students. While the Helpmann Academy never eventuated as envisaged in the Beasley Report, it has nevertheless played a significant role, and has assisted more than 5000 emerging artists support their own work, enter their professions with confidence and go on to make strong contributions to South Australia's community, economy and identity'. ${ }^{21}$

Returning now to the amalgamation between the School of Music of the City Campus of SACAE and the Elder Conservatorium of Music, the University's 


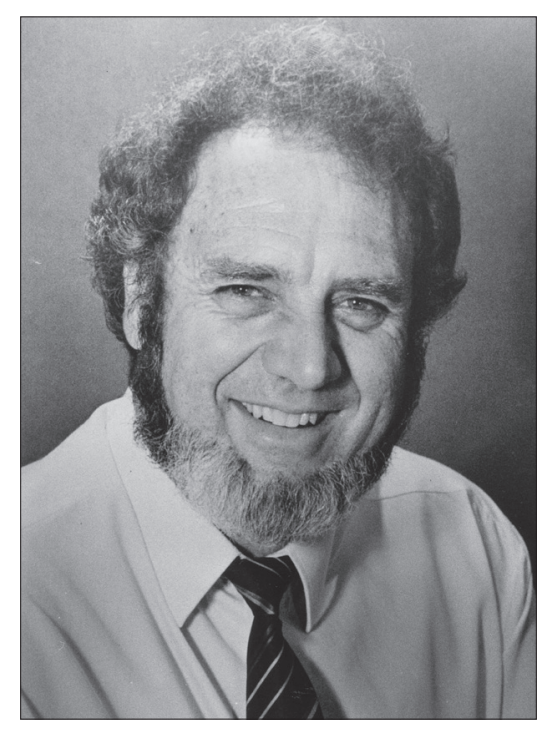

Brian Chatterton c. 1995 (photograph courtesy of the State Library of South Australia)

newly formed Faculty of Performing Arts came into being at the beginning of 1991. The Faculty of Performing Arts comprised of four departments, namely, the Elder Conservatorium (i.e. performance), Music Studies, Dance and Drama. The first Dean of the Faculty of Performing Arts was Dr David Swale in 1991, followed by Brian Chatterton from 1992-1993, then Dr Anita Donaldson from 1 June 1993. Initially, the existing music programs offered by both institutions continued, whilst a single 3-year degree was being developed by staff from both former institutions. Students who had commenced as SACAE 4-year degree students had the option of continuing with a 4-year degree, or they could be transitioned into a 3-year degree, and in any event could choose to have their degree badged with the University of Adelaide. The new degree that was developed, not surprisingly called the Bachelor of Music (New), contained specialisations in jazz or classical performance, music education, ethnomusicology, musicology, or composition. The University's music facilities had comprised Elder Hall and its inbuilt teaching rooms and studios, two levels of the Hughes Building and the Music section in the Barr Smith Library. Now, thanks to the amalgamation, the existing University resources were expanded to include the former CAE facilities, namely, several 
floors of the Schulz Building, the Madley Dance Space and lower Madley teaching rooms and practice rooms, Scott Theatre, and the Hartley Building, thus greatly increasing rehearsal and teaching spaces, and library facilities.

In addition to the increase in available facilities, the amalgamation also saw an expansion in the availability, size and quality of large ensembles. In particular, the SACAE Concert Band, which, under the direction of Hal Hall and Robert Hower had won many national titles, achieved even higher accolades as a symphonic wind ensemble, known today as the Elder Conservatorium Wind Orchestra and conducted by Robert Hower, a graduate of the Eastman School of Music (Rochester, NY), from where this ensemble style originated. Likewise, the Elder Conservatorium Symphony Orchestra flourished with more players competing for places in the ensemble.

The existence of two Departments of music, namely Music Studies and the Elder Conservatorium, within the Faculty of Performing Arts, was not conducive to a unified entity. Added to this subject split was the geographical divide - Music Studies staff were initially located in the Hughes Building and the Schulz Building, while performance staff were spread further, with Jazz staff in the Madley basement, and classical performance staff located mainly in Elder Hall but also in parts of the Schulz and Hartley buildings. Even more than twenty years later, the geographical spread still exists. At the time, staff could opt to which Department they wished to be assigned and in the early years the two Departments tended to operate independently.

By the mid-1990s, financial pressures in the tertiary sector saw a number of voluntary separation packages (VSPs) being offered to staff across the University, as a way of limiting expenditure on staffing in the longer term. A number of staff left the institution at this time, including Professor Esser and Brian Chatterton. The University was undergoing some re-structuring of its Faculties, combining Faculties into Divisions. The Faculty of Performing Arts became the Elder Conservatorium School of Performing Arts (ECSPA) within the Division of Performing Arts, Law, Architecture, Commerce and Economics (PALACE), with the Executive Dean of the Division being Professor Judith Brine. The Dean of ECSPA, after the departure of Brian Chatterton, was Dr Anita Donaldson, who had been the Head of Dance. 


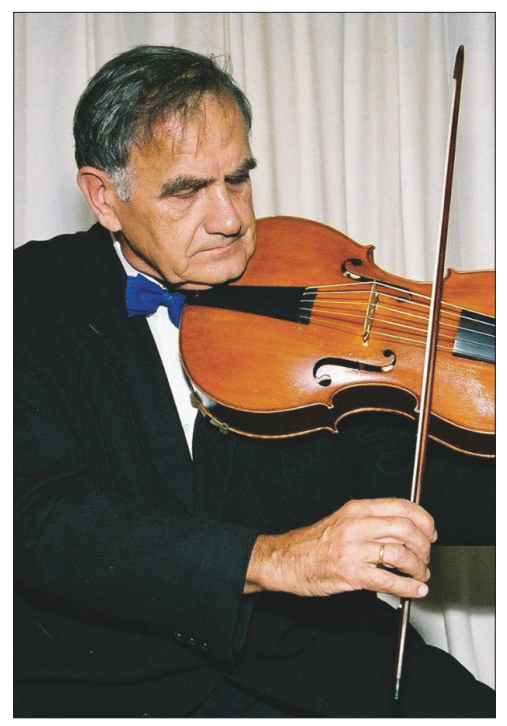

Richard Hornung (photograph courtesy of Eva Hornung)

In 1996, the federal Liberal Education Minister, Senator Amanda Vanstone, announced a five per cent Federal Government Budget cut to tertiary funding, with institutions to determine how the cuts would be implemented within their own context. It was at this time that the University, under new Vice-Chancellor Mary O'Kane, discontinued studies in Drama and Dance, with Dance to become articulated with a degree course through DETAFE. ${ }^{22}$ Nevertheless, ECSPA retained its name, even though it was in the process of phasing out Dance and Drama.

During the 1980s and 1990s, the TAFE Flinders Street School of Music (FSSM) continued to grow and develop under the leadership of Richard Hornung. There were some links between ECSPA and FSSM, largely through staff who were teaching in both institutions, and, as had been the case for many years, FSSM studies could be taken into consideration if students later applied to study a Music degree at the University. By the middle of the 1990s, in addition to the large number of Certificates and Diplomas that were offered by FSSM, plans were

\footnotetext{
${ }^{22} \mathrm{~J}$. Edge (ed.), 'Minimal course change following restructure', Adelaidean - Newes from the University of Adelaide, 4 November 1996.
} 
implemented by the FSSM to offer music degrees in line with the requirements of the Australian Qualifications Framework (AQF). Once again, the Conservatorium was no longer the sole provider of degrees in music in Adelaide.

During the mid-1990s, various discussions, involving both institutions, were periodically held with the topic being 'co-location' at either North Terrace or at Light Square, which was seen as a way of better utilisation of the resources of each, but maintaining the different programs offered at each institution. However, no firm decisions resulted from the numerous co-location discussions. Nevertheless, a working party, to carry out a feasibility study into the creation of a National Institute of Music in Adelaide, was instigated by the Helpmann Academy in June 1998. The proposal for such an institute involved the University of Adelaide, TAFE and the Adelaide Symphony Orchestra with purpose built facilities at the Torrens Parade Ground being considered. Whilst the proposal for a National Institute of Music in Adelaide did not get off the ground, the ViceChancellor, Professor Mary O'Kane, and the Chief Executive of the Department of Education, Training and Employment, Geoff Spring, agreed, in 1998, to consider the combination of the two institutions, with the aim being to create 'a centre of excellence for the provision of tertiary music education and training. ${ }^{23}$ A Steering Group to oversee the review process was chaired by the then Deputy Vice-Chancellor (Academic), Professor Penny Boumelha, with representatives from the University and the Government. A Review Committee was set up in 1999, with submissions for the Review being called in late September 1999 to be considered by the Committee in late October 1999, with the Report being completed before the end of the year. The Terms of Reference and membership of the Review Committee are contained in Appendix B.

The Review made a total of eleven recommendations, most of which were relatively straightforward and generally welcomed. However, the first recommendation created a great deal of controversy. It stated: 'That the Flinders Street School of Music and the Elder Conservatorium be amalgamated into a new entity, to be located at a site yet to be identified, but excluding premises presently occupied by either institution' ${ }^{24}$ There were many newspaper articles

\footnotetext{
${ }^{23}$ Review of Tertiary Music Education \& Training in South Australia (1999), p. 2.

${ }^{24}$ Ibid., p. 6.
} 
about this recommendation, including an article featuring University Council member Justice John Perry's attack of the plan on the basis that 'any attempt to move "the Con" from North Tce constitutes a moral and legal breach of founding benefactor Sir Thomas Elder's Trust'. ${ }^{25}$ The University Council considered the Review at its meeting on 20 March 2000, which was attended by a large number of music staff and students from both institutions who were concerned about the prospect of a new off-campus entity. The Vice-Chancellor spoke to her paper, outlining the principles from the Review, and moved that the Council endorse these principles. The motion was seconded by Justice Perry, who indicated that the paper addressed his previous concerns. ${ }^{26}$ The University Council unanimously endorsed the principles, which included the merger of the two institutions, with the new Elder School of Music to be part of the University of Adelaide and to be located within the North Terrace campus or immediately adjacent to it. The Council also agreed to implement Recommendation 4, namely, 'that recruitment processes be initiated as soon as possible to fill the concurrently held positions of Director and Elder Professor, ${ }^{27}$ in order that the new leadership would be in place to oversee the amalgamation process. The Council minutes also included the following:

Three Bachelor of Music students were given leave by the Acting Chancellor to sing the My Fair Lady song, 'Wouldn't it be loverly' which begins with the words 'All I want is a room somewhere ... With one enormous Chair ...'The performance was met by applause from Council members and observers. Most observers then left the Council room. ${ }^{28}$

The position for the new Director and Elder Professor was advertised with applicants giving a public address as part of the selection process in late 2000. By April 2001, the announcement was made that Professor Charles Bodman Rae was taking up the dual positions (initially on the basis of a 5-year term), and would be starting in semester 2, 2001. Professor Bodman Rae had previously been Dean of the Royal Northern College of Music in Manchester, England, and also Head of School at Leeds College of Music, and in addition to his fine reputation as a

\footnotetext{
${ }_{25}$ The Advertiser, 10 February 2000, p. 5.

${ }^{26}$ University of Adelaide Council Minutes, 20 March 2000, p. 3.

${ }^{27}$ Review of Tertiary Music Education \& Training in South Australia (1999), p. 6.

${ }^{28}$ University of Adelaide Council Minutes, 20 March 2000, p. 3.
} 
composer, pianist and scholar, he had prior experience with institutional mergers in England. Professor Bodman Rae quickly adjusted to his new surroundings and relished the challenges and complexities put forward in the merger process. He had to negotiate staffing issues which were very contentious, especially for FSSM staff who had been under a different award for their pay and conditions.

Once the University Council had decided to endorse the merger of the Elder Conservatorium and the Flinders Street School of Music back in March 2000, it paved the way for staff from both institutions to form various joint working committees based on discipline areas such as performance, composition, music technology, music education, musicology and music theory, in order to develop the new curriculum. There was a great deal of activity with regard to planning and preparing the academic programs to be offered, with both degree and predegree programs being included. The University became a Registered Training Organisation (RTO) which enabled it to be a provider of Vocational Education and Training (VET) programs. This led to continuation and expansion of this area, which had been a significant part of the FSSM offerings. The necessary proposals were developed and put forward to the University's Program Approval Committee early in 2001 which led to the new programs being available for students from 2002. Three separate degrees in Music were offered by the new Elder School of Music (ESM): the 3-year Bachelor of Music (catering for Classical and Jazz Performance majors), the 3-year Bachelor of Music Studies (with majors in either Composition, Music Technology or Integrated Studies), and the 4-year Bachelor of Music Education (with a practical area required in classical or jazz performance, composition or music technology). The VET area was developed with the support of the state government, and the initial offerings included a Certificate III in Music, a Certificate IV in Music (Classical or Jazz), and a Certificate IV in Music Technology. These were later expanded to include the Diploma in Music (Classical or Jazz), and a Diploma in Music (Sound Engineering).

In the meantime, Professor Malcolm Gillies, who had been a member of the Music Review Committee, was appointed Executive Dean of the Faculty of the Humantities and Social Sciences in October 1999, and during the following year also took on the role of Executive Dean of the Faculty of PALACE following Professor Judith Brine's announcement that she was stepping down. Professor 
Mary O'Kane resigned as Vice-Chancellor in August 2001 and was replaced in the short term by Professor Cliff Blake before the appointment of Professor James McWha in August 2002. By mid-2002, the Elder School of Music, previously part of the Faculty of PALACE, became one of the schools within the Faculty of Humanities and Social Sciences, with 'LACE' being joined by Education to form the Faculty of the Professions. Professor Gillies left the University in 2002 and Professor Mike Innes was appointed to the role of Executive Dean of the Faculty of Humanities and Social Sciences. In addition to the practical aspects of removing duplication of programs and consolidating resources of the FSSM and the Elder Conservatorium, the merger was seen as a viable way of moving forward with economic certainty, given that both institutions had been subject to negative financial pressures. Positioning the new ESM within the Faculty of Humanities and Social Sciences was seen as a viable structure to minimise the financial impact of funding music courses, which are expensive to run.

\section{2: Merger with the TAFE Flinders Street School of Music}

The Elder School of Music formally came into operation on 1 January 2002, with FSSM staff and equipment being shifted to the North Terrace campus. In these early days, as well as the new programs being offered, it was necessary to see out the old programs of each of the former institutions. Professor Bodman Rae set up a structural hierarchy according to the conservatoire paradigm with the designation of relevant staff as Heads of Programs and Heads of Studies in order to help manage the complexities of the new ESM. Since the merger, there has been significant growth and consolidation in all areas of operation.

Although Professor Bodman Rae's five and a half year term as Director finished at the end of 2006, he had not only managed the merger process but had facilitated numerous initiatives, including the introduction of Masters and $\mathrm{PhD}$ programs in Performance under the Research Training Scheme (RTS), and the introduction of a Diploma in Instrumental Music (similar in concept to the Diploma in Languages). The Music facilities were extensively redeveloped during 2003-2004 with funding provided by the Federal Government (\$4 million), the State Government ( $\$ 2$ million) and the University of Adelaide (\$2 million). The refurbished facilities provided a much-needed increase in the number of rehearsal 


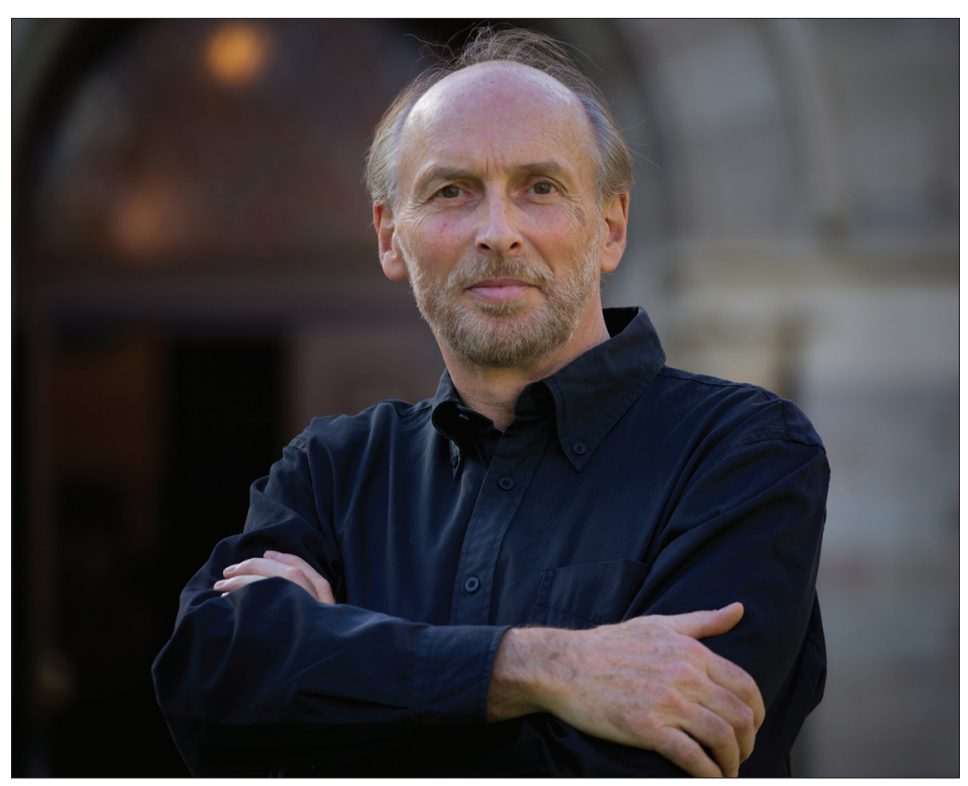

\section{Professor Charles Bodman Rae}

spaces, along with significant improvements to teaching spaces and surrounding areas in the Hartley Building, the Music Library in the Hartley Building, the Madley studios, the Schulz Building, and various teaching studios in the Elder Hall building. In July 2005, following due process and with the agreement of staff, the name was changed from the Elder School of Music to the Elder Conservatorium of Music. Professor Bodman Rae re-established links with organisations such as the Adelaide Festival of Arts and the Adelaide Symphony Orchestra, which have resulted in many successful artistic collaborations, including a performance in November 2005 in the Adelaide Town Hall of Mahler's Ninth Symphony by the combined Elder Conservatorium Symphony Orchestra and the Adelaide Symphony Orchestra, conducted by Arvo Volmer, Chief Conductor of the ASO. Professor Bodman Rae rekindled links with the National Music Camp organisation, which has seen the Camp being held in Adelaide in 2007, 2009 and 2011.

Professor David Lockett, a former Associate Dean and Head of Keyboard at the Elder Conservatorium, became the new Director of the Conservatorium at the beginning of 2007, with Professor Bodman Rae continuing as the Elder 
Professor of Music. Professor Lockett further consolidated the activities of the Conservatorium. He also brought the Access Centre into operation, an idea that had originally arisen from Professor Bodman Rae's plans for a Junior Strings program. The Access Centre administers the Young Conservatorium, which offers a program for beginner string, classical guitar and piano players aged between 6 and 9 years and is held on Saturday mornings. Professor Lockett relinquished the Director's position at the end of 2009, and has since been awarded the title of Emeritus Professor, continuing to perform, teach piano part-time and supervise Higher Degree students.

Associate Professor Carl Crossin was appointed to the Director's position at the beginning of 2010, and Professor Bodman Rae continued as the Elder Professor of Music. Associate Professor Crossin had been a member of the FSSM staff, and in the ESM initially undertook the role of Head of Choral Music, being Conductor of the newly formed Elder Conservatorium Chorale, Bella Voce (female choir) and Adelaide Voices (a chamber choir). Associate Professor Crossin was awarded an OAM for his services to music in 2007, having conducted the widely renowned Adelaide Chamber Singers, one of Australia's leading chamber choirs, for more than 20 years. The undergraduate Music programs were reviewed by the University in 2009, and Associate Professor Crossin has implemented the review findings which have led to restructuring of the degree offerings for 2012. This has led to a single 3-year Bachelor of Music degree being offered, within which there are eight different specialisations, namely: Classical Performance, Jazz Performance, Composition, Musicology, Music Education, Performance and Pedagogy, Sonic Arts (formerly Music Technology), and a new area, Popular Music and Creative Technologies.

Since the Dawkins reforms of the late 1980s, expectations for academic staff to be involved in both teaching and research have continued to grow. The aspect of recognition of what constitutes research has been especially contentious for the creative and performance aspects of Music. The Federal Government has instituted the Excellence in Research for Australia (ERA) process, which assesses 'the research quality at universities across Australia, using a combination of measures on researchers, research outputs, research income, reputation and 
other measures'. ${ }^{29}$ The ERA process of 2009 and 2010 for the overall discipline of Studies In Creative Arts and Writing at the University has seen the top rating being awarded. This includes the Elder Conservatorium of Music, which is the only music academy in Australia to achieve this rating. It is also the only institution in Australia to have doctoral research programs in all disciplines of Music, and since 2004 it has had the highest concentration of Music research students in Australia.

In contemplating the multidisciplinary nature of Music within the Conservatorium and the Faculty of Arts and later the Faculty of Humanities and Social Sciences over the last 125 years, one is struck by the way in which Music has grown and developed throughout that time, even when financial circumstances have been limited. Each of the fusions that have occurred has increased the breadth of opportunities for the study of Music. In addition to the many thousands of students who have completed Music degrees, and in addition to the relatively modest number who have undertaken Music study as part of a Bachelor of Arts degree, Music has continued to be a vibrant part of the University, with the Evening series and Lunch Hour series of concerts displaying the best of staff and students and linking with the community and bringing people onto the campus in Elder Hall. The legacy provided by Sir Thomas Elder's endowment of 1883 and bequest of 1898 continues to resound as strongly as ever today.

\section{REFERENCES}

Bridges, D., 'Some historical backgrounds to Australian music education', Australian Fournal of Music Education, 10 (1972), pp. 13-16.

Bridges, D., More than a musician. A life of E. Harold Davies (Melbourne, Australian Scholarly Publishing, 2006).

Beasley, M., 'Report of the Committee of Enquiry into tertiary performing arts training in South Australia' (Government of South Australia, 1990).

Duncan, W. G. K. \& Leonard, R. A., The University of Adelaide 1874-1974

${ }^{29}$ University of Adelaide, 'Excellence in Research for Australia (ERA)', in Research Branch, <http:// www.adelaide.edu.au/research/about/ERA/2000/>, accessed 1 February 2012. 
(Adelaide, Rigby, 1973).

Edge, J. (ed.), 'Minimal course change following restructure', Adelaidean - Newes from the University of Adelaide, 4 November 1996.

Edgeloe, V. A., The language of human feeling: A brief history of music in the University of Adelaide (Adelaide, The University of Adelaide, 1985).

Fox, M., 'Music education in South Australia 1836-1984', in A. McCredie (ed.), From Colonel Light into the footlights (Norwood [SA], Pagel Books, 1988), pp. 383-410.

'Helpmann Academy', <http://www.helpmannacademy.com.au/>, accessed 13 January 2012.

Lauer, H., 'The role of the first five Elder professors in the development of music in the Elder Conservatorium 1885-1985', Masters diss., The University of Adelaide, 1998.

Review of Tertiary Music Education \& Training in South Australia, 1999.

Symons, C., Fohn Bishop, a life for music (Melbourne, Hyland House, 1989).

The Advertiser, 14 July 1979.

The Advertiser, 10 February 2000.

University of Adelaide Council Minutes, 20 March 2000.

University of Adelaide, 'Excellence in Research for Australia (ERA)', in Research Branch, <http://www.adelaide.edu.au/research/about/ERA/2000/>, accessed 1 February 2012. 


\section{APPENDIX A}

Committee of Enquiry into Performing Arts Training in South Australia appointed in 1990 by Minister for the Arts, The Hon. Ann Levy, MP, and the Minister for Employment and Further Education The Hon. Mike Rann, MP (1990)

Terms of Reference:

1. To examine and evaluate professional training in the performing arts offered by the South Australian tertiary sector taking into account:

- The nature and extent of current and likely future needs of the performing arts industry;

- State and Commonwealth Government policies in relation to the tertiary education sector particularly those relating to access and equity and to course articulation and credit transfer;

- The resources presently available to the tertiary education sector and likely to be available in the future; and

- Expected trends in the funding of tertiary education institutions

2. To advise the Minister for the Arts and the Minister of Employment and Further Education on a future strategy for meeting any deficiencies in existing education and training programs and for effecting any other changes seen to be desirable. This strategy will embrace:

- The needs of the performing arts industry;

- The needs of performing arts training providers; and

- Government policy on education and the arts.

Membership:

Ms Mary Beasley, Chairperson, SA Health Industry Development Council Chairperson

Mr Len Amadio, Director, Department for the Arts

Mr Robert Fletcher, Executive Officer (Resources and Planning), Office of Tertiary 
Education (from May 1990 vice Dr Fred Ebbeck, Chief Executive Officer, Office of Tertiary Education)

Ms Patricia Lange, freelance arts consultant/manager whose major client is the Adelaide Chamber Orchestra

Professor Ren Potts, Professor of Applied Mathematics, The University of Adelaide

Mr Peter Kirby, Chief Executive Officer, Department of Employment and Technical and Further Education

Ms Dale Durie, Training Development Executive, SA Arts Industry Training Council

\section{APPENDIX B}

Review of Tertiary Music Education \& Training in South Australia, 1999 Terms of Reference:

The major providers of tertiary music education and training in South Australia are the Elder Conservatorium of the University of Adelaide and the Flinders Street School of Music of the Adelaide Institute of TAFE.

The Vice-Chancellor of the University of Adelaide and the Chief Executive of the Department of Education, Training and Employment have agreed to consider the eventual combination of the two music institutions with the aim of creating a centre of excellence for the provision of tertiary music education and training.

The Review Panel is asked to consider the most appropriate means for the future provision of tertiary music education and training. In particular, advise on:

- How awards and programs at degree and sub-degree level currently offerec across the participating institutions can be consolidated into a single suite of courses both in performance and other areas of music study;

- The appropriate academic and general staffing levels necessary 
to offere the suite of courses identified on a co-located site;

- Appropriate models for instrumental teaching including investigation of funding models and mechanisms;

- The place of Music Studies, the Performing Arts Technology Unit and research in Music;

- The most suitable arrangements for the provision of orchestral and ensemble teaching, drawing where possible upon members of the Adelaide Symphony Orchestra; and

- What opportunities exist for the further development of feepaying and commercially-based activities.

Members of the Review Committee:

Convenor: Professor Richard Johnstone, University of Sydney

Professor Malcolm Gillies, previously in Music at the University of Queensland, became Executive Dean of Humanities and Social Sciences at the University of Adelaide in October, 1999.

Mr Mark Walton, Sydney Conservatorium of Music.

Associate Professor Mel Waters, Director of the Melba Memorial Conservatorium of Music. 



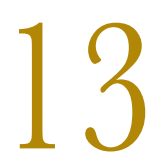

\section{Philosophy at the University of Adelaide}

\section{Chris Mortensen, Graham Nerlich, Garrett Cullity and Gerard O'Brien}

The University of Adelaide was established in 1874. It is the third oldest Australian university. An inaugural grant of $£ 20,000$ was provided by Walter Watson Hughes for two foundation professorships: in English Language and Literature and Mental and Moral Philosophy, and in Classics and Comparative Philology and Literature.

The first occupant of the philosophy chair was the Rev. John Davidson. He was not a university graduate, but his ministry of the Church of Scotland entailed a considerable education. He seems to have taught mostly logic, presumably Aristotelian logic. His successor was Edward Vaughn Boulger, philosopher, literary theorist and classicist, who had a strong academic background from Trinity College, Dublin before coming to Adelaide. Boulger is notable for having conflicted with the University over tenure of appointment, which the University did not award at the time. He was forced to resign in 1894 due to intoxication.

\footnotetext{
${ }^{1}$ An earlier version was published as Chris Mortensen and Graham Nerlich, 'Philosophy at the University of Adelaide', in G. Oppy and N. N. Trakakis (eds), A Companion to Philosophy in Australia and New Zealand (Melbourne, Monash University Publishing, 2010).
} 
The first real philosopher to be appointed was William Mitchell, who arrived from Scotland in early 1895. He had already published several papers in Mind, including one as an undergraduate. His main work was Structure and Growth of the Mind (1907). On the strength of this, he was invited to give two series of Gifford Lectures at the University of Aberdeen (1924 and 1926), which were published as The Place of Minds in the World (1933). Mitchell gave up the chair in 1923. However, he was (unpaid) Vice-Chancellor 1916-1942, where he was the principal driving force for a major expansion of courses and buildings, and the Teachers Training College. He was knighted in 1927, and died in 1962 at the age of 101. Jack Smart recalls visiting him on his 101st birthday and asking him his advice on how to make 101; his reply was: 'Young man, get to 100 first.'

Mitchell is not studied these days. One reason for this is his forbidding philosophical style. Structure and Growth is almost entirely innocent of logical signposting. This must be held responsible for the misapprehension among historians of Australian philosophy that Mitchell was an idealist. But in a recent book-length analysis of Structure and Growth, Marty Davies effectively demolishes this myth. Mitchell is much more plausibly read as an early realist-empiricist with a particular interest in the nature of the mind and its development, that is, its causal history over the individual's lifetime, such as a philosophical psychologist might have. If anything, he seems to have been a materialist about the mind, though with something of the flavour of the 'new mysterians' such as McGinn. ${ }^{2}$ The mind-centredness of his approach might well have contributed to the idealist confusion; but it is a fair assessment that he anticipated some of the doctrines for which Adelaide, and Australia for that matter, later became famous.

Mitchell's successor was John McKellar Stewart. He was an Australian, a graduate of Melbourne and Edinburgh. He took the Adelaide chair in 1924. His studies in Europe meant that his philosophy had a continental orientation. He wrote particularly on Bergson (1913), and also Nietzsche. His philosophy is even less noticed today than Mitchell's. He became Vice-Chancellor in 1945, and retired as Vice-Chancellor and professor of philosophy in 1950. The University had for many years a policy of appointing young promising professors; and on his

\footnotetext{
${ }^{2}$ See W. M. Davies, The Thought of Sir William Mitchell 1861-1962, A Mind's Own Place, Studies in the History of Philosophy, Vol. 73 (Lewiston [USA], The Edward Mellen Press, 2003).
} 
retirement, McKellar Stewart generously suggested that his department should take a quite new direction, alien to the concerns of his own studies. Accordingly, his successor was a youthful Scot, J. J. C. (Jack) Smart, who arrived in Adelaide in 1950 to fill the Hughes Chair.

It was a most fortunate appointment. The old philosophy-psychology link was to be cut and separate departments established. Smart appointed U. T. Place to begin and head the newly forming discipline of psychology. He also appointed C. B. Martin, who remained in the Department for many years. In these years, Martin's work in metaphysics, especially in philosophy of mind, was unique in style and widely influential in the Australian context. He later published freely.

Smart's influence on the University community was immediate and widespread. This was made easier by the comparatively small size of the University. The department ran a small, informal, interdisciplinary group that met to discuss the new, post-war turn in philosophy. One focus of discussion was Wittgenstein's Philosophical Investigations (1953). Visitors and participants from Economics, English Literature, Mathematics and Physics took a vigorous part with Smart, Place and Martin in densely argued sessions. Place published his theory of the identity of sensations with brain processes (an output of these discussions, especially with Smart and Martin). The theory was taken up by Smart in philosophical vein and published in a philosophical journal. The identity theory flourished in philosophy and rapidly became a major and contentious influence on the philosophy of mind internationally. In one variant or another, it has dominated the subject ever since. It was ironically but affectionately referred to as 'the Australian Heresy'.

Smart's and Martin's decades in Adelaide were halcyon days for the Department. This was particularly so for more advanced students who enjoyed a degree of access to and friendship with their teachers that was much missed in graduate studies overseas. For so small a University a surprising number of its undergraduates became prominent philosophers. Brian Ellis, Graham Nerlich, Brian Medlin, and Max Deutscher went on to fill Chairs in various universities, as did Chris Mortensen who was a graduate student. Michael Bradley and Ian Hinckfuss have also been stimulating presences in Australian philosophy, far beyond what their list of publications and academic rank would suggest. 
Smart's range of interests was very wide, including metaphysics, philosophy of mind, philosophy of religion and ethics. He was and remains a materialist, a scientific realist, an atheist and an act utilitarian. His style is limpid, direct, incisive and terse and always reads so simply that it is easy to overlook its depth and novelty. His early work on the metaphysics of time was important in undermining what is known as the A-theory of time. The flow of time is a myth since there is no good answer to the question how fast it flows. Few searching arguments in metaphysics can be put so briefly and clearly.

A committed Christian on his arrival in Adelaide, Smart was charged with holding views on other philosophical issues which were inconsistent with religious beliefs. Smart breezily admitted the charge and announced himself an atheist henceforth, a declaration to which he firmly stuck. This kind of frankness and commitment to where the argument leads explains the definition of 'to outsmart' in the Philosophical Lexicon - to outsmart an opponent is to dismay him by admitting his objection forthwith or embracing the paradox presented.

In many publications Smart defended scientific realism by arguing that the difficulties raised by relativists, conventionalists or subjectivists were merely that realism is novel and surprising rather than objectionable. That was perhaps a fine example of outsmarting. Smart's scientific realism was also connected with the increased influence by and on US philosophy, which became the centre of gravity of the discipline from the beginning of the 1960s onwards. Smart had been trained in Oxbridge philosophy, but scientific realism was a substantial break from that way of doing linguistic philosophy.

In the 1960s, the expansion of universities led to a larger membership of staff in the department and a considerable increase in student numbers due to service courses which Faculty regulations made necessary. As was the case everywhere else, this was a mixed blessing. Demands on staff time came at a cost to informal and fruitful discussion and staff perforce became more remote from students.

Smart also played a significant part in negotiating the bequest for the Gavin David Young Lectures, which has brought many highly distinguished philosophers to Australia and continues to do so. The list of Gavin David Young lecturers reads 
like a who's who of late twentieth-century philosophy: Ryle, Quine, Flew, Feigl, Davidson, Lewis, Hempel, Dennett, Smart, Putnam, Blackburn, and, in 2012, Jackson.

Smart resigned from the University in 1972, distressed by the changes to the amiable relations with colleagues and students that meant so much to him. It was his affection for the place rather than any estrangement from it that caused his regretful departure.

His successor in the Hughes Chair in 1974 was a former student, Graham Nerlich. Nerlich came to Adelaide from turbulent times in his tenure as Professor of Philosophy at the University of Sydney. A significant part of these quite prominent, indeed notorious, difficulties was played by the requirement that professors must be administrative Heads of their Departments. However, 1974 saw the beginning of significant changes in administrative style at Adelaide: these played some part in Nerlich's decision to return. Headship of the Department was no longer tied to occupancy of the Chair. It became an elected position independent of academic rank. Nerlich was elected immediately and quickly moved to allow student representation at staff meetings, among other democratic measures. These changes have persisted, and were instituted not only in Philosophy but also in the University generally.

Nerlich's research and publication in his two decades in the Hughes Chair was divided mainly between studies in the ontology of space, time and space-time, and ethics. In the former and larger output he defended realism toward space-time and especially a unique role for it in ontology as providing geometrical, non-causal explanation in General Relativity. Geometric non-causal explanation was also argued to figure in the explanation of incongruent counterparts and the failure of similarity geometry in non-Euclidean space. Nerlich's interest in the philosophy of physics had been stimulated early by Smart, and both have enjoyed good relations with the physics department, relations that continue to the present day in the form of a philosophy of physics seminar attended by several noted physicists. In ethics, Nerlich pursued a form of naturalism that sees the development of ethical and broadly cultural practices arising, analogously to the universal yet diverse flourishing of languages, in the natural life of human populations. In addition to 
Nerlich, strengths in the Department in the 1970s and 1980s were logic (Bradley, Hughes, Mortensen), ethics (Chandler) and the philosophy of religion (Gill).

For many decades, too, the Department has enjoyed the presence of a vigorous, student-run Philosophy Club. This is a valuable adjunct to formal teaching, since it makes clear to students and those members of the public who attend that philosophy is a way of life, and a great deal of fun. The Adelaide Philosophy Club can be traced back at least to 1929, and is still active today.

In 1994, the Faculty of Arts faced a major revision of financial and administrative practices, which created a crisis. Nerlich resigned for that reason, in what would have been his year of compulsory retirement under former rules. The headship of the Department fell to Mortensen.

Mortensen's book Inconsistent Mathematics was published in 1995. The thesis was that there is room for expansion of our conception of mathematics, by recognising the rich structure available within inconsistent theories. These are not especially theories of foundational concepts such as set theory or semantics or category theory (though these are well known to generate paradox). Rather, mathematical theories of any kind generate contradictions out of standard mathematical tools such as collapse under congruence relations, homomorphisms, cut-and-paste and many other techniques. The philosophical thesis here is that, far from paraconsistent (inconsistency-tolerant) reasoning being revisionist (as intuitionist mathematics is), it represents an extension of what has hitherto been thought possible for mathematics. Work in this area is ongoing, with impossible images (such as those of M. C. Escher) throwing up interesting and novel challenges for mathematical treatment. Mortensen was promoted to the Hughes chair in 1998.

U. T. Place died in England on 2 January 2000. He bequeathed his brain to the Adelaide philosophy department, to be displayed with the caption: 'Did This Brain Contain the Consciousness of U T Place?'. Reminiscent of Bentham's gift to the University of London, this was an instructive piece of philosophy and a fine piece of dark humour: a worthy afterthought on his importance to Adelaide and Australian philosophy. It resides in the anatomy museum, and can be seen on the Department's website. 
Later in 2000, an agreement was reached with the University that four senior staff not far from retirement would go in return for their being replaced by four young, tenured staff. The appointments of Jenny McMahon, Jon Opie, Philip Gerrans and Garrett Cullity were the result of this process.

In 2003, Philosophy became a Discipline within the new School of Humanities, containing also the Disciplines of Media, English, Classics, Linguistics, French and German. Mortensen retired in 2005. Two new appointments were made in consequence. Jennie Louise was the discipline's logic specialist, teaching and writing also in ethics, before transferring to the discipline of Public Health in 2011. Jordi Fernandez joined the discipline in 2006 as a specialist in epistemology and the philosophy of mind. Garrett Cullity had published his book The Moral Demands of Affuence (2004) two years before. The book sets up 'the Extreme Demand' on the (relatively) affluent, roughly that one should give everything away to the poor and suffering until the sacrifice outweighs the good it does. While acknowledging the strength of the case for the Extreme Demand (and the weakness of extant arguments against it), Cullity nonetheless argues that it ultimately undermines itself. The book won a Eureka Prize in 2008. Cullity was promoted to Hughes professor in 2006. Gerard O'Brien was also made professor in 2007, and head of school 2005-2011. His work developing an analog approach to the nature of mental representation extends the Adelaide tradition of empirically informed philosophy of mind, bringing it to the forefront of contemporary work in cognitive science. The current (2012) strengths of the rejuvenated department are cognitive science and the philosophy of mind (O'Brien, Gerrans, Opie, Fernandez), ethics (Cullity, Gamble), and aesthetics (McMahon). Adelaide has been strong on the philosophy of mind ever since Smart (if not Mitchell), and the major presence of cognitive science can be regarded as the triumph of the physicalist program started by Smart and Place so many years before. The strength in ethics also represents the continuation of an Adelaide tradition in which Smart and Nerlich made good contributions. 


\section{REFERENCES}

Cullity, G., The Moral Demands of Affluence (Oxford, The Clarendon Press, 2004).

Davies, W. M., The Thought of Sir William Mitchell 1861-1962, A Mind's Own

Place, Studies in the History of Philosophy, Vol. 73 (Lewiston [USA], The Edward Mellen Press, 2003).

Edgeloe, V. A., Servants of Distinction, Leadership in a Young University 1874-1925

(Adelaide, The University of Adelaide Foundation, 1993).

Hinckfuss, I., The Existence of Space and Time (Oxford, The Clarendon Press, 1975).

McKellar Stewart, J., A Critical Exposition of Bergson's Philosophy (London, Macmillan, 1913).

Mitchell, W., Structure and Growth of the Mind (London \& New York, Macmillan, 1907).

Mortensen, C., Inconsistent Mathematics (Dordrecht, Kluwer Mathamatics and Its Applications Series, 1995).

Nerlich, G., The Shape of Space, 2nd edn (Cambridge, Cambridge University Press, 1994).

Nerlich, Graham, Values and Valuing: Speculations on the Ethical Life of Persons (Oxford, The Clarendon Press, 1989).

Smart, J.J. C., An Outline of a System of Utilitarian Ethics (Melbourne, Melbourne University Press, 1960).

Smart, J. J. G., Philosophy and Scientific Realism (London, Routledge \& Kegan Paul, 1963).

Smart, J.J. C., Between Science and Philosophy (New York, Random House, 1968). 


\title{
14
}

\section{Politics at the University of Adelaide ${ }^{l}$}

\author{
Peter Mayer
}

Politics was taught at Adelaide long before there was a Politics Department. And, metonymically appropriately, high politics was intimately connected with the prolonged labour which eventually brought the Department into being.

In 1934 Professor G. V. 'Jerry' Portus was appointed to the Chair of History and Politics. ${ }^{2}$ In his Report on the Department of Political Science and History, ${ }^{3}$ Portus noted that in 1935 he added a third-year course in Political Science and an Honours course that covered 'the constitutional development of the British Commonwealth' and the 'evolution of political ideas'. In 1937, following the death of Professor Shann, Portus also undertook to teach Political Science and Economic History in alternate years. In 1947, the course in Political Institutions previously taught in Commercial Studies was transferred to History.

\footnotetext{
${ }^{1}$ I am grateful to Rebekkah Bernheim, Felicity Prance and Helen Bruce for assisting my research for this chapter.

${ }^{2}$ See Chapter 9 this volume.

${ }^{3}$ G. V. Portus, Report on the Department of Political Science and History (n. d. c 1949. PRG 204/16).

${ }^{4}$ Ibid., p. 1.
} 
Portus reported that in 1948 there were only 25 students taking Political Institutions out of a total of 625 undergraduates enrolled in the Department.

\section{W. G. K. Duncan}

Portus retired in 1950. His position was filled by W. G. K. Duncan in the following year. A working class student of exceptional ability, Duncan received his BA from Sydney University in 1924 and his MA in 1926. He won a scholarship which allowed him to complete his $\mathrm{PhD}$ under the supervision of Harold Lasky at the London School of Economics in 1930. ${ }^{5}$ After a distinguished career in workers' education in Sydney he was appointed by invitation to take up the Chair in Adelaide. ${ }^{6}$

Duncan reported that in 1950 'only four students were enrolled in Political Science, a course given only in alternate years'. In 1951, the Department of History and Political Science consisted of a professor, a reader, a senior lecturer and two lecturers.

\footnotetext{
${ }^{5}$ An account of travelling to London on the same ship as Duncan, as well as their postgraduate friendship in London can be found in T. Beaglehole, A Life of 7.C. Beaglehole: New Zealand Scholar (Wellington, Victoria University Press, 2006), Ch. 4: 'London 1926-27'. Stephen Holt rightly notes that although Duncan was 'a pioneering Australian social scientist' who 'deserves to be remembered', he is most famous now as having 'served as the basis for an unpleasant character in a novel [For Love Alone] by the writer Christina Stead. He had the misfortune to find himself portrayed by an immensely hostile and persuasive story teller'; S. Holt, 'A Steadfast Revenge: Dr Duncan and Mr Crow', National Library of Australia News (August 2003), pp. 7-10, here p. 7. For Duncan's reaction to the portrayal, see H. Rowley, 'Christina Stead', in P. Craven (ed.), The Best Australian Essays 2002 (Melbourne, Black Ink, n.d. circa 2003), p. 162; H. Stretton, 'Duncan, Walter George Keith (1903-1987)', Australian Dictionary of Biography, National Centre of Biography, Australian National University, <http://adb.anu.edu.au/biography/duncan-walter-george-keith-12443/text 22375>, accessed 15 February 2012.

${ }^{6}$ Duncan was the founding director of the Australian Institute of Political Science in 1932. He was the founding editor of the Current Affairs Bulletin serving between 1942 and 1950. Duncan was invited to give the ABC's Boyer Lectures for 1962, which were later published under the title In Defence of the Common Man. Stretton reports that Derek Whitelock "introduced it as "the Magna Carta of Australian adult education", and asserted that it was "the most substantial, comprehensive and thoughtful document on adult education in this country"; H. Stretton, 'Duncan, Walter George Keith (1903-1987)'.
}

${ }^{7}$ W. G. K. Duncan \& R. A. Leonard, The University of Adelaide 1874-1974 (Adelaide, Rigby, 1973), p. 106. 


\section{Politics of Politics in the 1950s}

In 1953 the University Council decided that the time had come to create separate departments of History and of Politics. Newly appointed Professor Hugh Stretton would be Professor of History, and Duncan would become Professor of Politics.

Professor Duncan, in a note to the Council, stated that the proposed change of name from Political Science to Politics was 'not only more convenient' but was 'more in line with current usage' and was thus 'the most appropriate general term for a whole Department'. ${ }^{8}$ Political Science was often used in the past in distinction from Political Philosophy but, he observed, the term 'has dropped out of use, just as has "political economy". Not one of the books referred to in our courses uses the term whereas there are a dozen or more which [use the word Politics in their titles]'.

In a new Department, teaching about both institutions and the history of political ideas, 'a general inclusive term (emphasising neither theory nor institutions) is called for, and the most appropriate, as well as the most convenient, title seems to be simply "Politics".

Duncan added, presciently;

The only objection to the term seems to be that the outside public might be misled into thinking that the University is 'teaching politics', or is 'Mixed up in politics'. This is to use the word in a derogatory sense, and it would be a pity if this were accepted as 'common usage' or the 'prevailing attitude' here in Australia. It certainly isn't in England, where the academic use of the word is neither feared nor misunderstood.

If, however, the Council feels that the term 'politics' has fallen into disrepute in Australia, and that it would be unwise to ignore this fact, I suggest that the Chair be entitled 'Political Theory' (or, as in Oxford) 'Political and Social Theory', but that the Department be known as a Department of Politics, offering courses known as Politics I, Politics II, etc., with sub-titles indicating whether they deal mainly with theory, institutions or the history of political ideas.

\footnotetext{
$\overline{{ }^{8} 9 \text { September } 1953 .}$
} 
The possibility raised by Duncan that 'the outside public might be misled into thinking that the University is "teaching politics" proved to be very near the mark, save that it was the Premier of South Australia himself, Sir Thomas Playford, who raised the objection in January of 1954. The state government informed the University that it would not consent to proposed amendments to University statutes in which the word 'Politics' was used in the title of the new Chair,

as in its view the word was associated with the hurly-burly of the hustings. It suggested that the Chair be known as the Chair of Political Science, or Political Economy. The University protested, and correspondence with the Government went on during 1954; the Government however would not change its views. ${ }^{9}$

With neither University nor Government willing to accede to the position of the other, in the interim the new Department was - confusingly - called the Department of History and Political Science and existed alongside of the newly formed Department of History. Duncan held the title of Professor of History and Political Science.

\section{DeGision to Greate the Department}

In November 1965, twelve years after the original decision to create a Politics Department, the University again approved the change of name to Department of Politics, and, this time without opposition from the government of South Australia. This followed a change of government and, perhaps not coincidentally, a year in which Duncan served as Dean of the Faculty of Arts.

\section{THE 'OLD DUNK' YEARS 1966-1968}

The rechristened Department had eight members of staff, many of whom subsequently went on to distinguished careers. W. G. K. Duncan (remembered subsequently as 'old Dunk') was Professor; Dr Peter Loveday was Reader; Robert

\footnotetext{
${ }_{9}^{9}$ H. E. Wesley-Smith, 'Politics' Office of the Academic Registrar 3 October, 1978, 903/53. 'Information given, by trunk-line telephone, to Professor Colin Tatz, University of New England, 26.9.78' Docket No 903/1953, Minister of Education: Allowance of Statutes \& Regulations December 1953. The information was subsequently included in C. Tatz \& G. Starr, 'Australia', in W. G. Andrews (ed.), International Handbook of Political Science (Westport, Greenwood Press, 1978).
} 


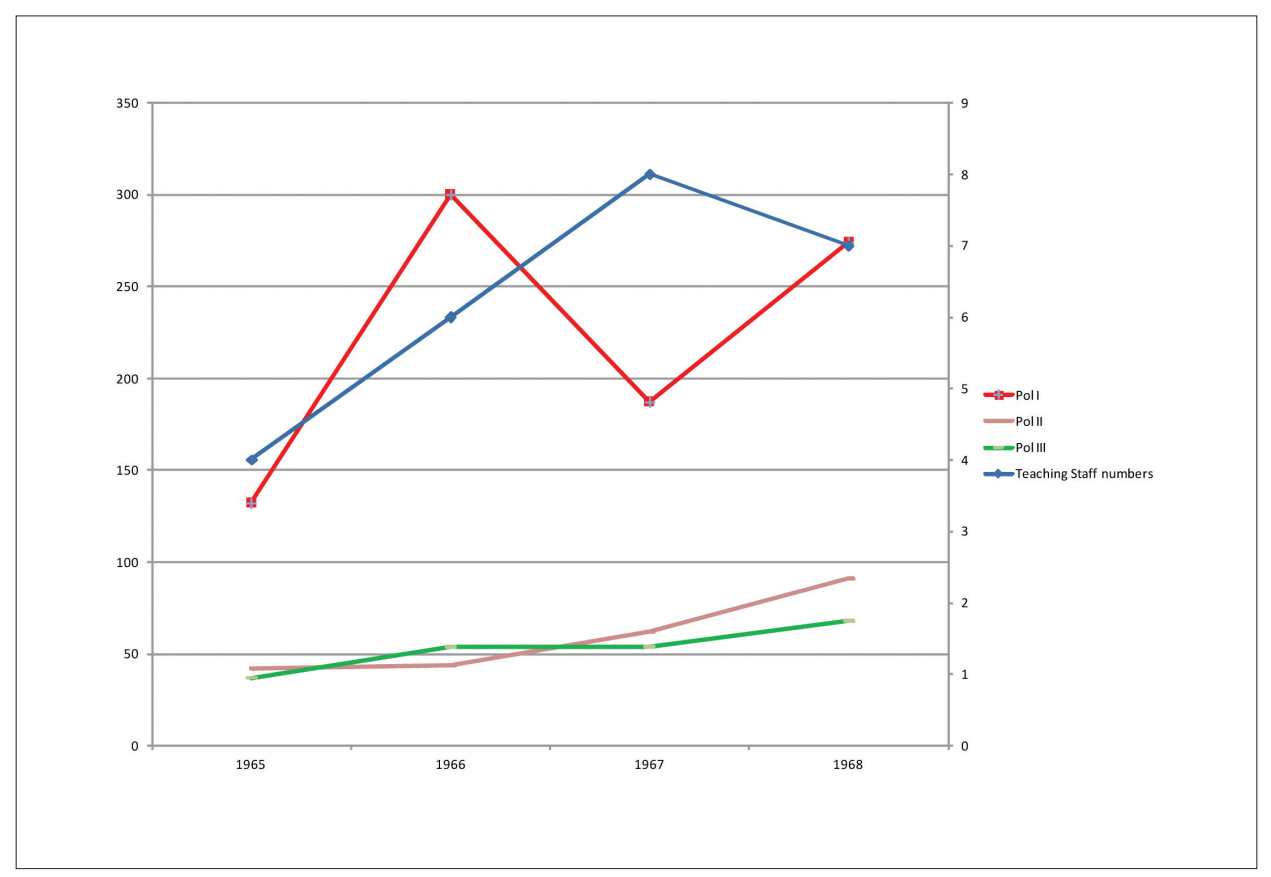

Figure 1: Student Enrollments and Teaching Staff Numbers, 1965-1968

'Bob' Reid was Senior Lecturer; Alan Ward and Dr Neil Blewett were Lecturers; Robert Hetherington was Senior Tutor; and Jeannette Hollinsworth and Marilyn Marshall were Tutors. Loveday and Blewett had both been Rhodes Scholars. Loveday soon moved to the Australian National University where he later served as Field Director of the ANU's North Australia Research Unit in Darwin. Ward later served as Professor at the College of William and Mary in Virginia. Blewett was a founding Reader and subsequently Professor at the new Flinders University and was later a Labor member of the Federal House of Representatives, serving as an effective Minister for Health during the early years of the HIV crisis. Blewett subsequently served in other ministerial portfolios as well and was later appointed as Australian High Commissioner to the UK. Hetherington moved to the University of Western Australia, later serving as a Labor Member of the Legislative Council in Western Australia from 1977-1989 during which time he introduced an ultimately unsuccessful bill to legalise homosexuality. Reid served a term as Dean of Arts at the University of Adelaide before his untimely death. 
Enrolments in the new Department grew rapidly, as can be seen in Figure 1. Within two years, numbers in all three years of study had doubled. No doubt the existence of a separate Department played a part in the growth of student numbers, as did the excitement of the Dunstan years, the growth of public concern over Australia's involvement in the Viet Nam war, the Soviet invasion of Czechoslovakia, the Paris student movement of 1968 as well as the influence of the Civil Rights Movement in the United States.

In the closing years of W. G. K's long tenure some highly significant appointments were made. Mr Jeffrey 'Jeff' Scott, a specialist in Australian politics, was appointed in 1967. In the following year Dr Robert 'Bob' Catley, an international relations specialist from the ANU, was appointed. Catley had two periods of service in the Department, broken by a term in the House of Representatives in Canberra as the Labor Member for Adelaide. After leaving Adelaide, Catley subsequently held chairs in Darwin and the University of Newcastle.

Several who were undergraduates at the time recall that teaching was largely focussed on political institutions and that increasingly, 'old Dunk' himself seemed to be a person out of his times who was intolerant of the more radical opinions of some of his students. This was especially manifest in his condemnation of students' demands for university reforms and their involvement in anti-war protests. In a radio interview with Noel Adams of the $\mathrm{ABC}$ the year after he retired, Duncan said,

Listening to what the students are demanding, I think I'm going to be labelled pretty soon as a reactionary, because I don't think they've thought through at all clearly what they want... Now I think students have legitimate grievances, but that's made them, I think, quite immune to sober rational argument. ${ }^{10}$

Some of the undergraduates of this period seem in retrospect to be true 'wuderkinder' who went on to distinguished careers in academia and elsewhere. Amongst them were Doug McEachern, Anna Yeatman, Anne Summers, Phil McMichael, Dean Jaensch and John Lonie.

\footnotetext{
${ }^{10}$ N. Adams, 'Interview with Professor W G K Duncan', Transcript of Interview 15 June 1969, now in Retirement ABC radio project, Mortlock Library of South Australiana, J. D. Somerville Oral History Collection, OH26/3.
} 


\section{The years With Graeme Duncan 1969-1975}

W. G. K. Duncan was followed in the Chair of Politics by another Duncan - no relation - Dr Graeme Duncan. A Victorian, Graeme Duncan came to Adelaide from Monash University. His specialty was Political Theory and he had made his mark with a well-reviewed book on Marx and Mill. ${ }^{11}$ Duncan, a clever and witty individual with a tendency to occasionally take academic banter to the very edge of wisdom, summarised the situation he found upon arrival in a suitably deft essay 'On Coming to a Chair':

Moving from Monash to Adelaide University was like shifting to a new culture - from a new and rapidly expanding institution with a large Politics Department and a radical mystique to an old, slowly moving university with a mere handful of Politics teachers. The change was complicated by my rise in the world. Moving from relative impotence at Monash to at least the trappings of power here encouraged, for a moment, the illusions of the revolutionary leader - that the millennium was now at hand, that the good had the means of rapid innovation in their hands and could create bright and beautiful courses and human relationships. Of course, the dream was untrue, and disillusionment quickly set in. The habits and preferences of established members of the department, the suspicions of outsiders and the shortage of cash - all normal and predictable things - were serious constraints. Everything could not be done at once, if ever. ${ }^{12}$

\section{Expansion}

Despite his perception of constraints, Duncan's arrival in the Department coincided with a period of unparalleled growth in the university sector, the result of implementation of the Murray Report and major changes to university funding made by the Whitlam government.

Duncan's appointment fostered a major change in tone and direction in the direction of teaching in the Department. Burning public concerns surrounding the unpopular Viet Nam War and conscription were unquestionably important in generating student interest in the study of both domestic and international

\footnotetext{
${ }^{11}$ Conal Condren in his review of the work of Australia's political theorists notes a contrary view of Duncan's book (1985), p. 58.

${ }^{12}$ G. Duncan, 'On Going to a Chair', Politics 5.1 (May 1970), pp. 78-80, here p. 78.
} 


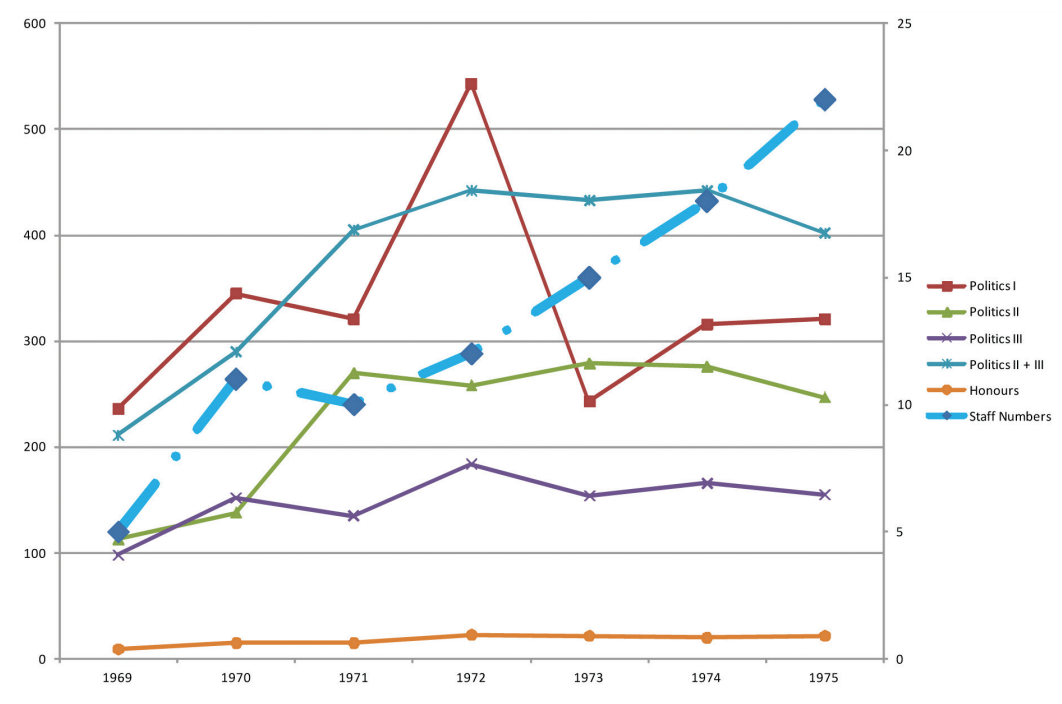

Figure 2: Politics Department, 1969-1975

politics. As can be seen in Figure 2, student numbers grew with unprecedented rapidity. By 1972, numbers in Politics I had risen to over 540; because there was no lecture theatre large enough to accommodate so many students, lectures were held that year in the Bonython Hall. Radical social and political ideas were studied, debated and developed. Feminism emerged in these years as a new, powerful and profoundly transforming subject of both activism and scholarly debate and study.

\section{Anne Summers' recollections}

In her autobiography Ducks on the Pond, Anne Summers - a pioneer feminist, who went on to a distinguished career in journalism, was author of the seminal feminist study of Australian history Damned Whores and God's Police, and also served a period in Canberra as Head of the Office for the Status of Women - recollected the changes which began taking place in 1969:

I found some consolation in the fact that the Politics syllabus had at last begun to reflect the real world. We had two new teachers who each breathed 
life, and a degree of radicalism, into what we were studying. Brian Abbey, a jovial, bearded political sociologist, had arrived from that Maoist hotbed, Monash University, full of often surprising information... .

Our international [r] elations teacher, the engaging Dr Robert Catley, had visited the Soviet Union on his way from England to take up his post in Adelaide, and impressed us with his knowledge of this Communist empire. Brian and Bob were part of the new wave of younger teachers who had been encouraged to join the Politics Department since 1968 when the founding professor, W. G. K. Duncan, had retired and had been replaced by Graeme Duncan, who was less of a traditionalist and believed students of politics should immerse themselves in contemporary political issues as much as the study of political theory, which was his speciality.

I was relieved at the changing of the guard because I had not fared well under the old regime. In second year, old Professor Duncan had personally marked down my essay that had supported the proposition that there was a Sino-Soviet split, on the grounds that I was being ideological. Now not only were we being encouraged to read more broadly, but the violent upheavals that were taking place around the world had become subjects we could examine and debate. ${ }^{13}$

\section{Appointments}

In 1970 three new Lecturers and a Senior Tutor were appointed: Dr John Robbins, Brian Abbey, Dr Peter Mayer and Dr Dean Jaensch. Robbins arrived from the UK to teach Sociology; Abbey was the first of several recruits from Duncan's former department at Monash; and Mayer came from the US to teach Asian Politics. In 1973 Bruce McFarlane, a distinguished scholar of Political Economy, was appointed as Reader; Dr John Playford came from Monash to teach Australian Politics; and Paul Nursey-Bray arrived from Belfast (having taught earlier in Rhodesia/Zimbabwe and Uganda) to lecture on Marxism and Third World Ideologies especially African political thought. In 1974 there were further appointments: Dr Neale Hunter was appointed to teach Chinese Politics; Dr Paul Corcoran arrived from the US to teach Classical Political Theory; and Patrick Flanagan was appointed to teach Contemporary Political Theory. In 1975

\footnotetext{
${ }^{13}$ A. Summers, Ducks on the Pond: an autobiography 1945-1976, foreword by Ruth Park (Ringwood
} [Vic], Viking, 1999), pp. 231-2. 
Dr James 'Jim' Kemeny arrived from the UK to teach in the Political Sociology stream. In that year there were 22 members of staff, counting both lecturers and tutors, a number the Department appears never to have reached again in later years.

In 1974 the rapid growth in student and staff numbers facilitated the Department's claim that it should have a second professor. After failing to find a suitable external appointment, the University offered the second chair to its Reader, Bruce McFarlane, in $1976 .{ }^{14}$ Ironically, at the end of 1975 Graeme Duncan resigned his Chair to take up a position of Chair at the University of East Anglia in the UK. McFarlane, a man of powerful and perceptive intellect, extraordinary memory, as well as upon occasion an erratic and explosive temper, was at that time best known for his positive appraisal of China's Great Leap Forward in The Chinese Road to Socialism, co-authored with Ted Wheelwright (New York, Monthly Review Press, 1970).

Between 1970 and 1975 a succession of exceptionally able Tutors were appointed: Anna Yeatman, John Lonie, Alan Patience, Doug McEachern, Greg O'Leary, Adrienne Moore, George Anthony, Adrian Vickery, Marion Rumball, Brian Trainor, Laurie Rivers, Jack Barbalet, Karen Throssell, Rosemary Pringle, Derek Verrell, and Geoff Stokes. Most of these promising young scholars subsequently went on to distinguished academic careers.

Dr Marian Sawer was appointed as the Department's first Postdoctoral Fellow in 1975. While in the Department, Marian completed work on her book Marxism and the Question of the Asiatic Mode of Production (The Hague, Nijhoff, 1977).

\section{Publications}

During the Graeme Duncan years a more active research culture of the Department began to emerge. On the eve of his arrival in Adelaide, John Playford (with Douglas Kirsner) published Australian Capitalism: towards a socialist critique

\footnotetext{
${ }^{14}$ Notes of the deliberations of the Appointments Committee are held in the Barr Smith Library Special Collections, Mayer, Peter Baldwin Archives.
} 
(Ringwood [Vic], Penguin, 1972). ${ }^{15}$ In 1974 Bob Catley and Bruce McFarlane published From Tweedledum to Tweedledee: the new Labour government in Australia, a critique of its social model (Sydney, ANZ Books, 1974). The titles of both works succinctly convey the critical focus which characterised much research undertaken in this period of the Department's history. In particular, many of those referred to by Irving as contributors to the 'technocratic labour thesis' worked in the Adelaide Politics Department: 'The most influential if not coherent expression of the thesis was in From Tweedledum to Tweedledee by Catley and McFarlane'. ${ }^{16}$ In 1974 Melanie Beresford and Pat Vort-Ronald each published pioneering feminist analyses of class and society from the perspective of political economy.

\section{Subjects taught}

Until 1971 a relatively restricted curriculum was taught: Politics I - Democratic Politics, Politics II - Comparative Politics, Politics III - Industrial Society \& Theories of Community. From 1971 the shape of a more contemporary curriculum began to emerge. By 1974, following a common Politics I, a growing range of options was available to second-year students: Political Sociology; Political Theory and American Politics; European Politics; Marxism and Third World Ideologies; Contemporary Social Theory; Asian Politics; International Politics. The clumsy and artificial division of courses into Politics IIA and IIB, did not entirely disappear until a decade later. From thence until an overall reform of curriculum in the University in 2009, subjects were offered by title and those open to second and third-year students were in most instances open to both years.

\section{YEARS OF CONSOLIDATION, 1976-1988}

Predictably, in retrospect, the ending of the Viet Nam War led to a retreat in student and staff numbers from the exceptional peak experienced in the early

\footnotetext{
${ }^{15}$ In his survey of 'Radical Political Science in Australia' Irving discusses at some length the importance of Playford's (pre-Adelaide) critiques of Australian capitalism: T. H. Irving, 'Radical Political Science in Australia' in Don Aitkin (ed.), Surveys of Australian Political Science (Sydney, George Allen \& Unwin, 1985).

${ }^{16}$ T. H. Irving, 'Radical Political Science in Australia', p. 333; others were John Lonie, Doug McEachern and Melanie Beresford.
} 


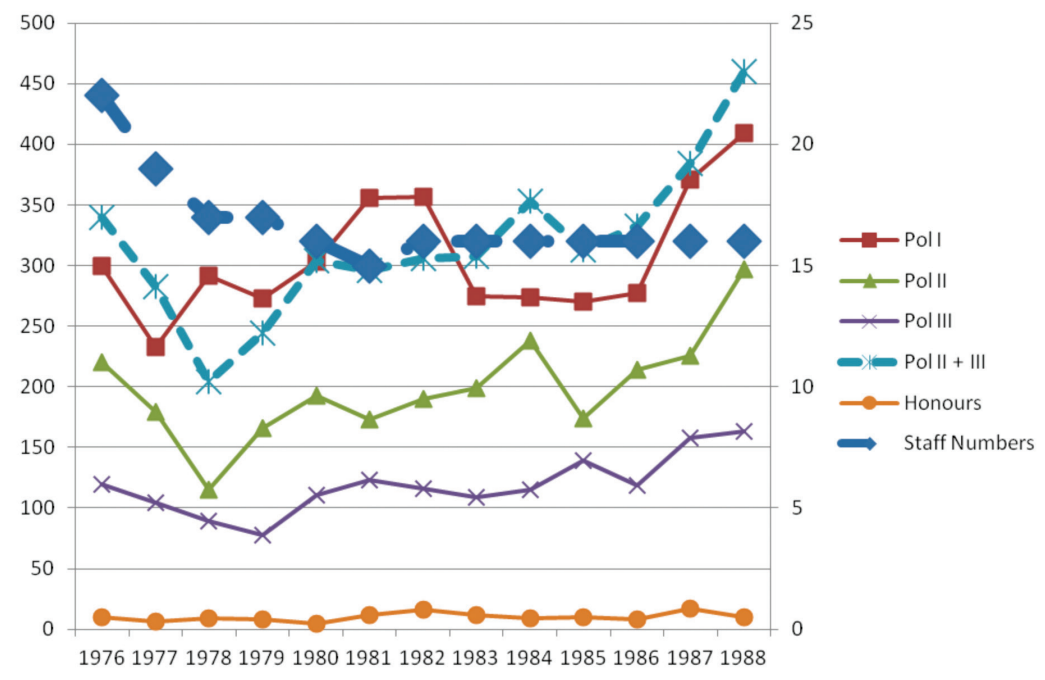

Figure 3: Politics Department, 1976-1988

1970s. As can be seen in Figure 3, student numbers, while still substantial, were noticeably lower in this period. Staff numbers declined from the peak of 1975 and remained unchanged throughout most of the 1980s. What was significant, though, was the emerging change in the gender composition of the Department. In 1979, the Department appointed its first female lecturer, Dr Carol Bacchi. Bacchi, who had been a tutor in the History Department, brought not only her experience as an historian and a teacher, but introduced the first courses on feminism into the Politics syllabus. ${ }^{17}$ Through this time publications by members of the Department reflected their research interests in political theory, Australian political economy and in comparative politics.

\footnotetext{
${ }^{17}$ Over the years, Bacchi would establish an international reputation for her work on feminist theory and public policy. Bacchi was elected as a Fellow of the Academy of Social Sciences in Australia in 2000. She retired as Emerita Professor in 2009.
} 


\section{9-1999: MILLENIUM'S END}

The early 1990s witnessed a brief upsurge of student interest in Politics, a response to momentous world events, including the fall of the Berlin Wall, the collapse of the Soviet Union and the end of the Cold War, the crushing of protests in Tienanmin Square and the First Gulf War following the invasion of Kuwait. As can be seen in Figure 4, this modest spike in interest was relatively transient and student numbers remained relatively stable during the decade.

The composition of staff continued to change in the 1990s. In 1992, Dr Lenore Coltheart was appointed to teach in political thought, feminist theory, Australian politics and Aboriginal politics. Dr Vicki Spencer, a Rhodes Scholar, was appointed in 1994 to lecture in political theory, especially in the large first-year subject, Justice, Law and the State. In 1996, Dr Robert 'Bob' Catley returned to the Department after a term in Federal Parliament as the Member for Adelaide, and a subsequent period of lecturing at the University of South Australia. In 1998 student numbers in International Politics had risen to the point that there were real strains on existing staff. In that year Dr Felix Patrikeeff, an Oxford graduate specialising in East Asia, was appointed.

The changing composition of the lecturing staff was also reflected in the focal concerns of their teaching. In place of an earlier emphasis on readings from the Marxist tradition, in the 1990s readings in feminism, the environment, aspects of public policy, globalisation and human rights became more frequent. In 1990 Carol Johnson taught a full-year course on Australian Politics, while John Playford taught a companion course on Australian Political History. John Robbins offered half-year subjects: An Introduction to Political Sociology and the Sociology of Power. Paul Corcoran offered a semester-length Introduction to Political Thought. Greg McCarthy taught the two-semester course, Public Policy in Australia. Carol Bacchi offered A Survey of Feminist Thinkers in one semester and Women and Policy in the following semester. Doug McEachern taught a semester course on Comparative Politics that looked at responses to recession in Britain, France, Germany, Japan, the US and Australia. Paul Nursey-Bray offered a semester course on Anarchism and in other semesters Marx and his Successors - which 
included Lenin, Trotsky, Luxemburg, Gramsci, Sartre, Foucault and Habermas. Peter Mayer taught Third World Political Economy over the full year.

When Lenore Coltheart was appointed, she offered The Landscape of Australian Politics, a new departure which would 'explore the relations between land and politics in Australia, with an emphasis on Aboriginal and European concepts of property in land'. Sources used in the course included 'paintings, explorer's journals, Aboriginal histories and heritage studies'. She also offered Women in Australian Political Development, which examined the 'historical background of colonial, federal, and state political processes'.

In the early 1990s the use of personal computers gradually became widespread. Because they were expensive, they had to be shared, and those on limited-term appointments recollect that their access was distinctly inferior to that of tenured members of staff.

During this decade a number of significant appointments were made in a context of changing industrial relations in the university sector. A number of those appointed as tutors (soon to be redesignated as Lecturers A) would successfully convert once limited-term appointments into tenurable positions and outstanding academic careers. In 1991 Dr Pal Ahluwalia was appointed as a Tutor. In later years Dr Ahluwalia proved to be a prodigiously active researcher especially in the field of the politics of post-colonial studies, a field in which he was a pioneer. In 2006 he secured promotion to Professor. ${ }^{18}$ In the same year, Dr Clement 'Clem' Macintyre, a specialist in British and European politics and parliaments, was appointed. ${ }^{19}$ In 1991 Dr Christine 'Chris' Beasley joined the Department, initially to replace Dr Bacchi who was seconded to the Australian National University. A specialist in feminist thought, sexual and body politics and cultural studies, Beasley became a permanent member of the Department in $1998 .{ }^{20}$

The 1990s was a period of high scholarly productivity in the Department. Pal Ahluwalia and Paul Nursey-Bray collaborated on numerous works on African politics. Their books, Post-colonialism: Culture and Identity in Africa (New York, Nova

\footnotetext{
${ }^{18}$ Ahluwalia resigned in 2006 to take up a succession of overseas positions, first at Goldsmiths College, and then at the University of California; in 2012 he was Pro-Vice Chancellor (Division of Education, Arts and Social Sciences) at the University of South Australia.

${ }^{19}$ In 2010, Macintyre was Professor and Head of School of History and Politics.

${ }^{20}$ She became Joint Director of the Fay Gale Centre for Research on Gender in 2010.
} 
Science Publishers, 1997) and The Post-colonial Condition: Contemporary Politics in Africa (Commack [NY], Nova Science Publishers, c1997), were significant in bringing the insights of the post-colonial approach to the study of contemporary Africa. This was also a highly productive period for Bob Catley, who, amongst other works, published Globalising Australian Capitalism (Cambridge, Cambridge University Press) in 1996. Greg O'Leary edited Adjusting to Capitalism: Chinese workers and their state (New York, ME Sharpe, 1998).

Carol Bacchi published two significant feminist contributions to the study of politics: Same Difference: Feminism and Sexual Difference (Sydney, Allen \& Unwin, 1990) and The Politics of Affirmative Action: 'Women', Equality and Category Politics (London, Sage, 1996). In 1999, Bacchi published her path-breaking study of the policy process, Women, Policy and Politics: the construction of policy problems (London, Sage, 1999). Chris Beasley also published two major feminist studies in this period: Sexual Economyths: Conceiving a Feminist Economics (St Leonards, Allen \& Unwin, 1994) and What is Feminism anyway?: understanding Contemporary Feminist Thought (St Leonards, Allen \& Unwin, 1998).

Doug McEachern published significant works on the state and the connection between business and politics: The Expanding State: Class and Economy in Western Europe Since 1945 (London, Wheatsheaf-Harvester Press, 1990; New York, St Martin's Press, 1990) and Business Mates: The Power and Politics of the Hawke Era (Sydney, Prentice Hall, 1991). McEachern and Tim Doyle published the first edition of their widely-used text-book Environment and Politics (London \& New York, Routledge) in 1998; revised editions were published in 2001 and 2008, and the book has been translated into Korean, Turkish and Hindi. Carol Johnson published her major analysis of the Labor Party in power, The Labor Legacy: Curtin, Chifley, Whitlam, Hawke (St Leonards, Allen and Unwin) in 1989.

In the area of political theory, Paul Corcoran published the suitably-titledfor-the-end-of-the-millenium Awaiting Apocalypse (London, Macmillan; New York, St Martin's Press, 2000). Wayne Cristaudo published Metaphysics of Science and Freedom: From Descartes to Kant to Hegel (Aldershot, Gower, 1991) as well as several articles on Heidegger. Vicki Spencer published a number of articles on aspects of Herder and nationalism. Paul Nursey-Bray published his comprehensive Anarchist Thinkers and Thought: An Annotated Bibliography (Westport [CN], Greenwood Press) in 


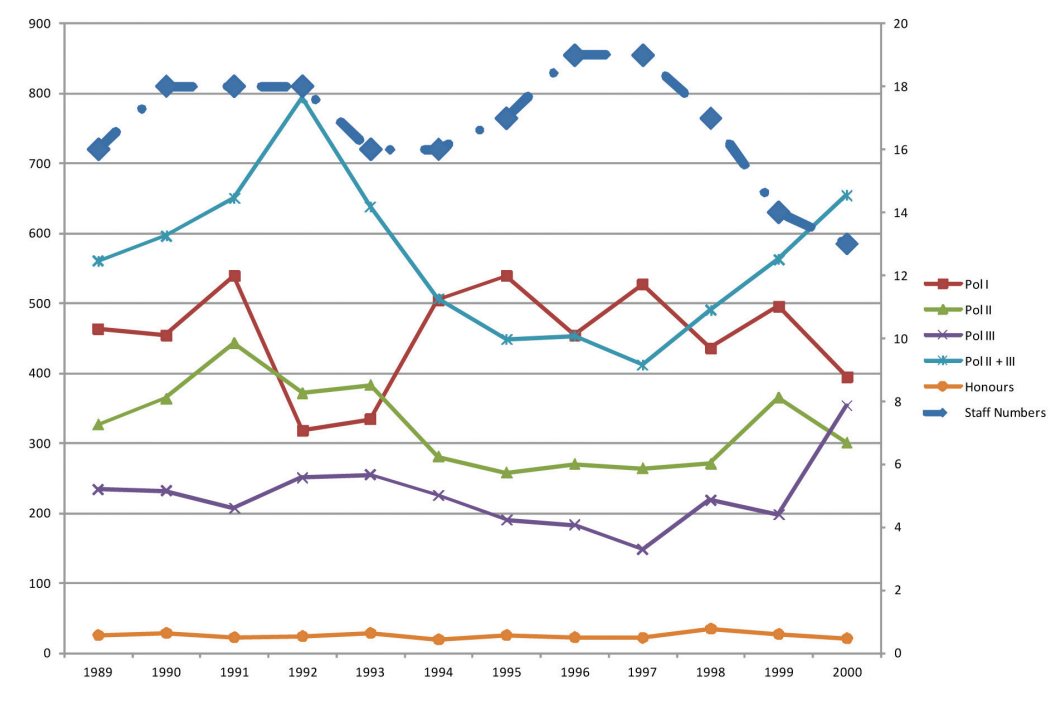

Figure 4: Politics Department, 1989-2000

1992. Nursey-Bray also published a number of articles on the anarchist thinkers William Godwin and Errico Malatesta.

As can be seen from Figure 4, funding cuts to universities under the Howard government after 1996 are evident in the decline in staff numbers resulting from the inability to replace staff after they left the Department. In 1996 the student to staff ratio was 19:1; in 1997 it rose to 26:1 and was 25:1 in1998.

\section{The Noughties: 2000-2011}

Although student interest in aspects of international politics and comparative politics had always been high, it rose to sustained heights in the new millennium. The destruction by al Qaeda of The World Trade Center in New York City on 11 September 2001, the subsequent declaration by the United States of a 'War on Terrorism', followed by military conflicts in Afghanistan and Iraq all had their predictable impacts on student interest in Politics, above all in aspects of 


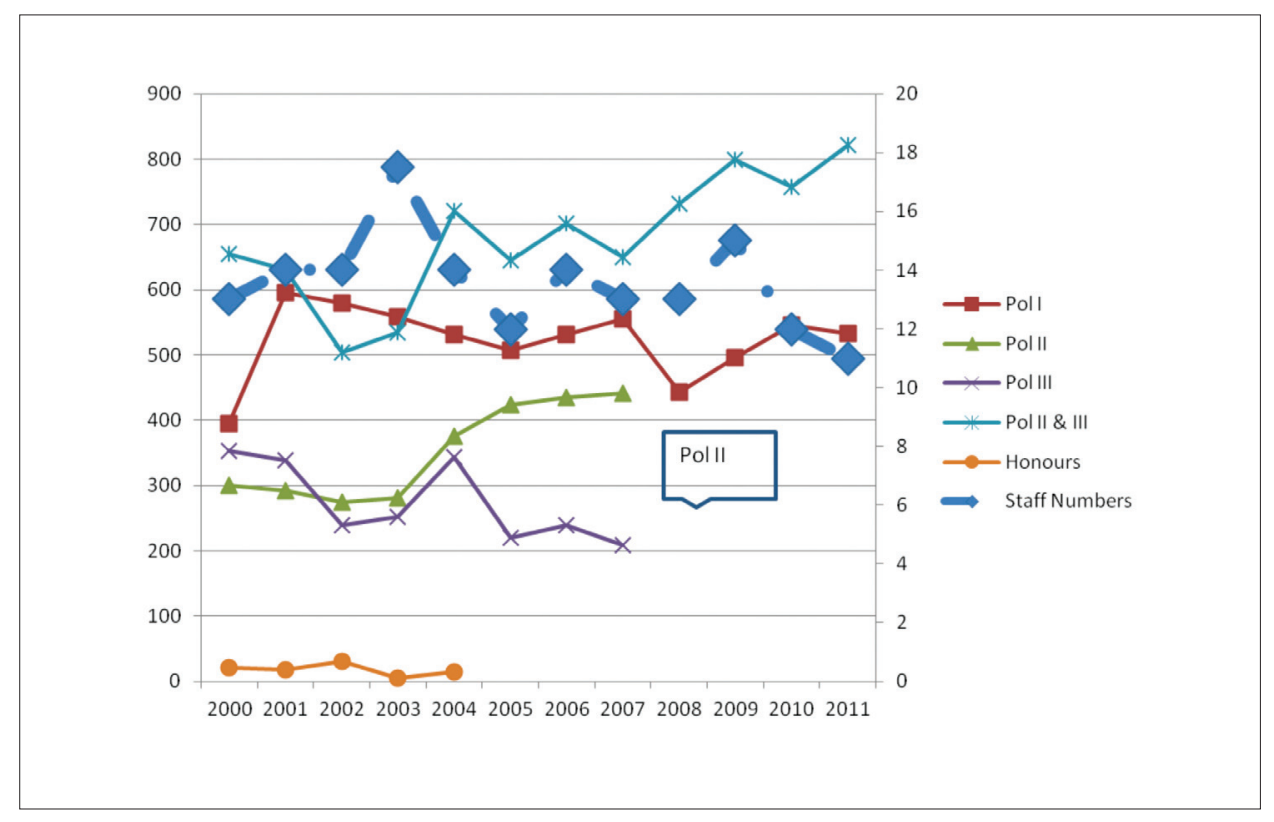

Figure 5: Politics Department, 2001-2011

international politics. In 2001 numbers in first-year rose to over 600 and for most of the decade they remained at or over 500. As Figure 5 illustrates, the combined numbers of students studying Politics in second- and third-year maintained a relatively steady increase. ${ }^{21}$

The increasing interest in the international and comparative politics streams placed a growing load on those members of staff teaching in these areas. And because the demand for qualified specialists in these fields was being felt in universities around the world, competition for staff also grew. The result was that many very promising scholars in these fields were appointed, though too many of them moved on to other appointments after only a few years.

One of the initiatives which flowed from the appointment of Kanishka Jayasuriya in 2010 was the establishment of the Indo-Pacific Governance Research Centre. The focus of the Centre is on 'new forms of aid governance and participation, migration and inequalities, and environmental and human security'.

\footnotetext{
${ }^{21}$ After 2008 the older distinction between second- and third-year courses was extinguished so that only the combined figure for upper level students remains comparable with earlier years.
} 


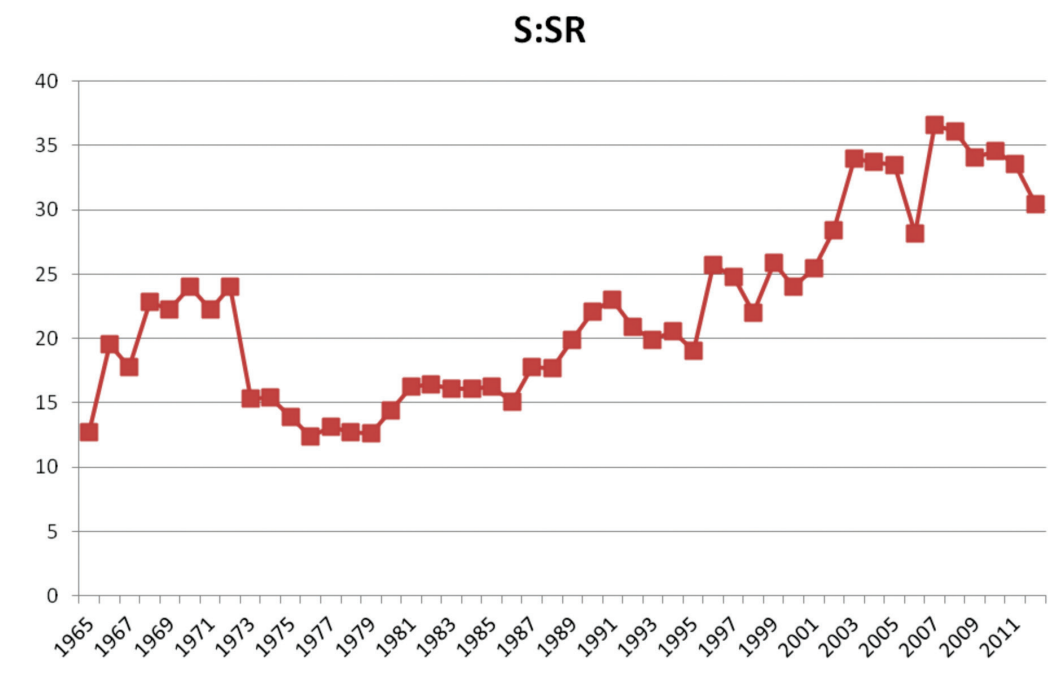

Figure 6: Student to Staff Ratio, 1965-2011

The Noughties were another decade in which staff members made significant publications. In 2001 Paul Nursey-Bray and Carol Bacchi produced Left Directions (Nedlands, University of Western Australia Press), which contained wide-ranging essays, to which a number of other members of staff contributed, on the future of the Left in politics. Other notable publications during this period were in the fields of Australian politics, political theory (especially feminist theory) and, reflecting broader shifts in the discipline, in international and environmental politics.

Tim Doyle's research on environmental politics reached national notice in 2005 when it was learned that an Australian Research Council grant to him to study 'the way non-government organisations influenced the environmental agendas of foreign countries ${ }^{222}$ had been vetoed by then Minister for Education Dr Brendan Nelson.

${ }_{22}$ H. Alexander, 'How Nelson gagged researchers', Sydney Morning Herald, 29 October 2007, <http://www.smh.com.au/news/federal-election-2007-news/how-nelson-gagged-researche rs/2007/10/28/1193555533349.html>, accessed 29 May 2012. 


\section{Student to Staff Ratios}

When one reviews the 45-plus years of the existence of the Politics Department/ Discipline, it is striking that it has always taught very large numbers of undergraduates with very modest numbers of tenured and tenurable staff. What has made that situation manageable has been the rising numbers of casual tutors, mostly recruited from amongst the Politics postgraduate students, for whom parttime tutoring offered an important opportunity to develop skills in university teaching. The ratio of students to tenured or tenurable staff has risen more or less regularly since around $1966 .{ }^{23}$ In that year it stood at 12:1. By 1991 it had risen to 23:1. In 1999 it reached 26:1 and in 2007 reached 37:1, the highest in the nearly half century life of the Department. A linear regression on the years between 1967 and 2012 indicates that the student load increased on average by $7 \%$ each year. ${ }^{24}$

\section{Exaellence IN TEAGHING}

The Politics Department has a proud tradition of excellence in teaching. In 1994 Chris Beasley was awarded the Stephen Cole the Elder prize for the excellence of her teaching.

In a submission to a Faculty Review in 1994 it noted:

The Department has continued to engage in regular reviews of teaching programs at all levels. The Honours program was reviewed in 1979, 1986-7, and 1991. The postgraduate program was reviewed in 1980, and in 1986 and is about to be reviewed this year. There was another major review of the undergraduate program in 1986 and a reconsideration of subject offerings and teaching strategies in 1993, which is continuing.

In that year, a compilation of student assessments of teaching for 20 lecturers was assembled. A similar set of questions was administered for all students and all teaching staff (lecturers and casual tutors) in 2010. Table 1 (see p. 380) indicates that even hard-to-please first-year students were overwhelmingly positive about the effectiveness of their teachers in 1994; approval levels were even higher for those in second- and third-year in 1994. No doubt as a result of the far broader

\footnotetext{
${ }^{23}$ In the absence of official reports on student:staff ratios for the years after 1997, I have estimated the figures from numbers for Effective Full-Time Students and Full-Time staff.

${ }^{24}$ At that rate of increase, by 2020 there will be 40 students for each tenured or tenurable member of staff.
} 


\begin{tabular}{|l|l|l|l|}
\hline Course Year & $\begin{array}{l}\text { Percent in "Broad } \\
\text { Agreement" = Agree } \\
\text { somewhat, Agree, } \\
\text { Strongly Agree }\end{array}$ & $\begin{array}{l}\text { Number } \\
\text { of Staff }\end{array}$ & $\begin{array}{l}\text { Number } \\
\text { of } \\
\text { Students }\end{array}$ \\
\hline Politics I 1994 & $94 \%$ & 10 & 311 \\
\hline Politics II- III 1994 & $97 \%$ & 10 & 198 \\
\hline Politics All Student levels 2010 & $87 \%$ & 50 & 3051 \\
\hline
\end{tabular}

Table 1: 'All things considered, how would you rate the effectiveness of this person as a university teacher?'

\begin{tabular}{|l|l|l|l|}
\hline Course Year & $\begin{array}{l}\text { Percent in "Broad } \\
\text { Agreement" = Agree } \\
\text { somewhat, Agree, } \\
\text { Strongly Agree }\end{array}$ & $\begin{array}{l}\text { Number } \\
\text { of Staff }\end{array}$ & $\begin{array}{l}\text { Number } \\
\text { of } \\
\text { Students }\end{array}$ \\
\hline Politics I 1994 & $94 \%$ & 10 & 311 \\
\hline Politics II- III 1994 & $98 \%$ & 10 & 198 \\
\hline Politics All Student levels 2010 & $88 \%$ & 50 & 3051 \\
\hline
\end{tabular}

Table 2: 'This person shows enthusiasm for encouraging student learning'

\begin{tabular}{|l|l|l|l|}
\hline Course Year & $\begin{array}{l}\text { Percent in "Broad } \\
\text { Agreement" = Agree } \\
\text { somewhat, Agree, } \\
\text { Strongly Agree }\end{array}$ & $\begin{array}{l}\text { Number } \\
\text { of Staff }\end{array}$ & $\begin{array}{l}\text { Number } \\
\text { of } \\
\text { Students }\end{array}$ \\
\hline Politics I 1994 & $87 \%$ & 10 & 311 \\
\hline Politics II- III 1994 & $92 \%$ & 10 & 198 \\
\hline Politics All Student levels 2010 & $81 \%$ & 50 & 3051 \\
\hline
\end{tabular}

Table 3: 'This person stimulates my interest in learning in this course' 
range of teachers surveyed in 2010, the levels of approval were lower in that year. Table 2 presents evidence of very similar high levels of positive assessments of the enthusiasm of teachers by second- and third-year students. Table 3 presents the results for the two years to a question about the stimulation experienced by students.

\section{SERVICE TO THE UNIVERSITY}

In its submission to the Faculty in 1994, shortly after the end of the era of collegial governance in the University, the Department noted that it

has been a major contributor to the governance of the university under the 'Corbett' system of 1981-1992. It provided 2 Deans (Dr. Robbins 1980-81, Mr. Nursey-Bray 1985-1986), 2 Executive members (Dr. Mayer [Staffing] 1983-85, Mr. Abbey [Academic Matters] 1987-89) and Convenor [Mr. Abbey 1990-92]. There has also been a substantial contribution to the range of other University Committees and procedures.

It has also had a substantial role in the Staff Association, providing 3 Presidents (Mr. Abbey 1984-5, Dr. Robbins 1986-88, 1990-1992, Dr. Catley 1989) and several Committee members.

\section{Service to the Community}

Members of the Department have always played an active role in sharing their knowledge and expertise with the community. Professor Portus, for example, was described in Radio Call magazine as 'one of the most popular A.B.C. speakers who has been "messing about in front of microphones", as he describes it, for the last ten years'. ${ }^{25}$ W. G. K. Duncan was also a frequent contributor to public discussion, especially in the area of adult education. He appeared regularly on the $\mathrm{ABC}$ and in the press. ${ }^{26}$ In the 1970 s McFarlane and Catley contributed regular commentaries on economic affairs to a number of national newspapers and many members of staff contributed to radio commentaries. This engagement with the media has continued throughout the years and staff members are regularly sought to provide expert commentary on national and international issues and events.

\footnotetext{
${ }^{25}$ Radio Call magazine, 18 May 1939.

${ }^{26}$ See for example, 'S.A. Professor Calls for Thought Freedom', Mail, 4 February 1955; 'UK Depresses SA Professor: "Incurably Feudal in Outlook", Newes, 15 April 1957.
} 


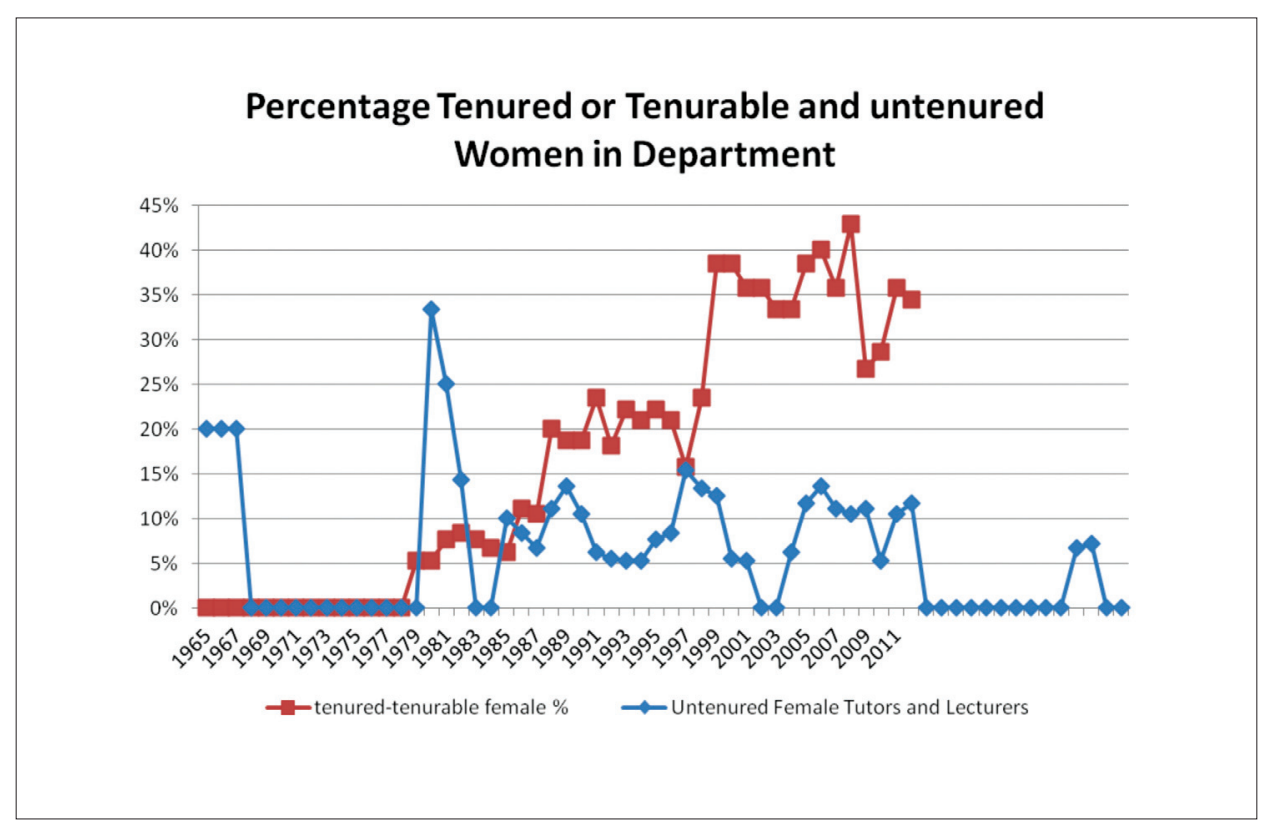

Figure 7: Percentage of Tenured or Tenurable and Untenured Women in the Politics Department, 1965-2011

In its submission to the Arts Faculty in 1994, the Department observed that it

Has a distinguished record of community service... Members of the Department have links with a diverse list of organisations which include the former SA Women's Advisor's Unit, Women's Health centres, the Save the Children Fund, the State Theatre Company, Amnesty International, the S.A. Energy Forum (a member is chair of this forum), SA Campaign Against Racial Exploitation, FILEF (an Italian community organisation), SA Council of Social Services, Parents for Affordable Childcare (S.A.), Parents of Children in Childcare (national), the S.A. Historical Society, Community Aid Abroad and other overseas aid agencies, Blackwood/Belair and District Community Association, Religious Society of Friends (Quakers), South Australian Council of Churches,[University Radio Station] 5UV, Ministerial Housing Advisory Panel and the Unites Nations Youth Group. Five members of the Department have been involved in activities for the 
SSABSA [Senior Secondary Assessment Board of South Australia] Years 11 and 12 Politics Courses.

\section{Changing GENDER RATio}

Women have taught in the Politics Department from its formation. However, in the first decade, all of them were untenured Tutors. The first tenurable woman to be appointed to the Department was Dr Carol Bacchi, appointed in 1979 (as noted earlier). Since that year there are two discernable patterns to the gender of appointees to the Department/Discipline. As can be seen in Figure 7, on average appointments of women to Tutorships and temporary Lectureships have accounted for about $10 \%$ of academic staff. Because of the small numbers involved and the exigencies of appointments, in quite a few years there were no women in such positions.

On the other hand, the percentage of women appointed to tenured and tenurable positions have tended to form a growing percentage of total staff, rising from 5\% in 1979 to $43 \%$ in 2008. Due to the impact of retirements and the unpredictable outcome of appointments, the percentage of women in the Discipline appeared to have reached a plateau towards the end of the 2000s. It is evident that this did not constitute a 'glass ceiling', since three of four Professors in the Discipline in 2008 were women, while 1 of 5 Associate Professors was a woman. Nevertheless, despite its record of achievement, it is clear that the goal of achieving full gender equality in the Discipline of Politics is still to be achieved.

It is essential, when considering the role that women have played in the life of the Department/Discipline, to acknowledge the remarkable administrative officers who have served over the years as the first port of call for students and others seeking to contact Politics, provided essential support to all aspects of the work of teaching and research by academic staff and been an integral contributors to the achievements made over the decades. Susan 'Sue' Campbell was the foundation secretary; she served between 1966 and 1973. Gloria Sumner came to the Department in 1973 having previously served as secretary to the Registrar; Gloria left the Department 1979. Christine 'Chris' McElhinney joined the University in 1975 and came to the Politics Department in 1980. Chris worked 
in the Department until it was merged into the School of History and Politics in 2002. She continued to work in the School office until her retirement in 2012 - a record of continuity of administrative service to Politics without equal.

\section{Conclusion}

Over the years the Politics Department/Discipline has taught over 52,000 students in lectures and tutorials. Some - John Hill, Amanda Vanstone, Pat Conlon, Natasha Stott Despoya and Penny Wong to name a few - have gone on to distinguished careers in politics. Others, such as Anne Summers, Annabel Crabbe, Misha Schubert, Samantha Maiden, Suzie O'Brien, Sarah Martin and Tom Richardson have distinguished themselves in journalism. Some have risen to the top ranks in diplomacy - Merry Wickes as Ambassador to Jordan, Joel Kaapandaa as Namibia's High Commissioner to India. Many others have been civil servants, trade unionists, teachers, academics and above all, engaged citizens.

There are discernible demographic cycles in the lives of Departments. In certain periods, opportunities for expansion and fresh appointments bring in cohorts of younger lecturers with new approaches and abundant energies. Over the years, as their individual careers mature, their records of publications and university service grow and in time, those who remain rise up in the promotional ranks. Where once the promotional profile was characterised by a concentration of lecturers, in middle-age of the cycle there is a predominance of senior lecturers and in maturity, of associate professors and professors. And then, following retirements, the cycle begins again.

The Discipline of Politics at the University of Adelaide is arguably in the mature phase of such a cycle. More than half of its staff in 2012 are at or above the rank of Associate Professor. And the next phase of a new cycle is already visible. The remaining members of staff who were appointed in the first fifteen years of the Department's existence have now retired. ${ }^{27}$ Their replacements are already in position, charting the directions of their careers and with them the future trajectory of the Discipline.

The areas in which fresh appointments have been made reflect in large measure the changing patterns of student interest. The steady growth of

${ }^{27}$ Carol Bacchi retired in 2009, Paul Corcoran retired in 2010 and Peter Mayer retired in 2011. 
undergraduate interest in international aspects of politics has required the Discipline's teaching and appointments to accommodate this trend. A recent decision the rename the Discipline as Politics and International Studies (POLIS) is a figurative waymark of the distance the Discipline has moved from the days of its foundation when it offered only year-long subjects focused on Democratic Politics, Comparative Politics and Industrial Society.

There are also less easily categorised cultures of intellectual focus which often persist in departments. In the first two decades of the life of the Department, the intellectual centre of gravity of research and publication was very clearly on the critical and radical Left of the discipline. In contemporary surveys of Political Science such as that edited by Don Aitkin, publications by many members of the Department appear, not in the conventional mainstream, but rather in the critical fringe. Whether it was in writings on aspects of political theory, critical assessments of United States foreign policy, the economic policies of Labor under Whitlam or the emerging field of feminism, the topics, tone and focus of publications were rarely in the comfortable orthodox centre of the discipline.

As the direct engagement with Marxist political economy waned during the 1980s, exploration of other critical approaches to the study of politics took its place. In the following decades scholars in the Department published on an impressively broad range of topics: the impact of globalisation on Australia, the Asian economic crisis, affirmative action, the construction of public policy issues, the politics of the environment, gender and sexuality, identity politics, critical approaches to international relations and post-colonialism - to select but some from the full range. ${ }^{28}$

What is consistent throughout the changes in the focus of interest over the years is that, as public intellectuals, members of Politics have been consistently engaged in important contemporary debates on issues facing Australian society. If one can make any prediction about the Discipline of Politics and International Relations in the future, it is that this will remain an enduring aspect of its intellectual culture.

${ }^{28}$ See Carol Johnson's 'Radical Approaches' in R. A. W. Rhodes (ed.), The Australian Study of Politics (Houndmills, Palgrave Macmillan and Australian Political Studies Association, 2009). 


\section{REFERENGES}

Adams, N., 'Interview with Professor W G K Duncan' Transcript of Interview 15 June 1969, 'Now in Retirement' ABC radio project, Mortlock Library of South Australiana, J. D. Somerville Oral History Collection, OH26/3. Alexander, H., 'How Nelson gagged researchers', Sydney Morning Herald, 29 October 2007, <http://www.smh.com.au/news/federal-election-2007news/how-nelson-gagged-researchers/2007/10/28/1193555533349. html>, accessed 29 May 2012.

Beaglehole, T., A Life of 7.C. Beaglehole: New Zealand Scholar (Wellington, Victoria

University Press, 2006), <http://www.nzetc.org/tm/scholarly/tei-

BeaLife-tl-body-dl-d4.html>, accessed 15 February, 2012.

Condren, C., 'Political Theory' in Don Aitkin (ed.), Surveys of Australian Political

Science (Sydney, George Allen \& Unwin, 1985).

Duncan, G., 'On Going to a Chair' Politics, 5.1 (May 1970), pp. 78-80.

Duncan, W. G. K., In Defence of the Common Man (Sydney, Australian Broadcasting Commission, 1962).

Duncan, W. G. K. \& Leonard, R. A., The University of Adelaide 1874-1974 (Adelaide, Rigby, 1973).

Holt, S., 'A Steadfast Revenge: Dr Duncan and Mr Crow', National Library of Australia Newes, August 2003, pp. 7-10.

Irving, T. H., 'Radical Political Science in Australia' in D. Aitkin (ed.), Surveys of Australian Political Science (Sydney, George Allen \& Unwin, 1985).

Johnson, C., 'Radical Approaches' in R. A. W. Rhodes (ed.), The Australian

Study of Politics (Houndmills, Palgrave Macmillan and Australian Political Studies Association, 2009).

Portus, G. V., Report on the Department of Political Science and History (n.d. c 1949. PRG 204/16).

Rowley, H., 'Christina Stead', in P. Craven (ed.), The Best Australian Essays 2002 (Melbourne, Black Ink, n.d. circa 2003).

Stretton, H., 'Duncan, Walter George Keith (1903-1987)', Australian Dictionary of Biography, National Centre of Biography, Australian National University, $<$ http://adb.anu.edu.au/biography/duncan-walter-george-keith-12443/ 
text22375), accessed 15 February 2012.

Summers, A., Ducks on the Pond: an autobiography 1945-1976; foreword by R. Park (Ringwood [Vic], Viking, 1999).

Wesley-Smith, H. E., 'Politics', Office of the Academic Registrar 3 October 1978, 903/53, 'Information given, by trunk-line telephone, to Professor Colin Tatz, University of New England, 26.9.78’ Docket No 903/1953, Minister of Education: Allowance of Statutes \& Regulations - December 1953 [The information was subsequently included in C. Tatz \& G. Starr 'Australia', in W. G. Andrews (ed.), International Handbook of Political Science (Westport, Greenwood Press, 1978)]. 



\section{Appendix I \\ Deans of the Faculty of Arts at the University of Adelaide 1887-2012}

$\begin{array}{llll}1887 & \text { W. H. Bragg } & 1911 & \text { G. C. Henderson } \\ 1880 & \text { W. H. Bragg } & 1912 & \text { G. C. Henderson } \\ 1889 & \text { E. V. Boulger } & 1913 & \text { W. Mitchell } \\ 1890 & \text { D. F. Kelly } & 1914 & \text { W. Mitchell } \\ 1891 & \text { W. H. Bragg } & 1915 & \text { H. D. Naylor } \\ 1892 & \text { R. W. Chapman } & 1916 & \text { H. D. Naylor } \\ 1893 & \text { E. V. Boulger } & 1917 & \text { G. C. Henderson } \\ 1894 & \text { E. V. Boulger } & 1918 & \text { G. C. Henderson } \\ 1895 & \text { W. H. Bragg } & 1919 & \text { H. D. Naylor } \\ 1896 & \text { W. Mitchell } & 1920 & \text { H. D. Naylor } \\ 1897 & \text { E. v. B. Bensley } & 1921 & \text { J. R. Wilton } \\ 1898 & \text { R. W. Chapman } & 1922 & \text { J. R. Wilton } \\ 1899 & \text { W. Bragg } & 1923 & \text { A. T. Strong } \\ 1900 & \text { W. Mitchell } & 1924 & \text { A. T. Strong } \\ 1901 & \text { R. L. Douglas } & 1925 & \text { J. M. Stewart } \\ 1902 & \text { E. v. B. Bensley } & 1926 & \text { J. M. Stewart } \\ 1903 & \text { E. v. B. Bensley } & 1927 & \text { W. K. Hancock } \\ 1904 & \text { E. v. B. Bensley } & 1928 & \text { W. K. Hancock } \\ 1905 & \text { W. Mitchell } & 1929 & \text { J. R. Wilton } \\ 1906 & \text { G. C. Henderson } & 1930 & \text { J. R. Wilton } \\ 1907 & \text { W. Mitchell } & 1931 & \text { J. A. Fitzherbert } \\ 1908 & \text { W. Mitchell } & 1932 & \text { J. A. Fitzherbert } \\ 1909 & \text { H. D. Naylor } & 1933 & \text { J. M. Stewart } \\ 1910 & \text { H. D. Naylor } & 1934 & \text { J. M. Stewart }\end{array}$




$\begin{array}{llll}1935 & \text { G. V. Portus } & 1968 & \text { B. L. D. Coghlan } \\ 1936 & \text { G. V. Portus } & 1969 & \text { G. J. Horne } \\ 1937 & \text { J. I. M. Stewart } & 1970 & \text { C. J. Horne } \\ 1938 & \text { J. I. M. Stewart } & 1971 & \text { W. F. Hambly } \\ 1939 & \text { A.J. Schulz } & 1972 & \text { R. L. Reid } \\ 1940 & \text { A.J. Schulz } & 1973 & \text { W. R. Prest } \\ 1941 & \text { J. R. Wilton } & 1974 & \text { A. H. Winefield } \\ 1942 & \text { J. R. Wilton } & 1975 & \text { A. H. Winefield } \\ 1943 & \text { J. G. Cornell } & 1976 & \text { A. R. Stephens } \\ 1944 & \text { J. G. Cornell } & 1977 & \text { N. Etherington } \\ 1945 & \text { H. W. Sanders } & 1978 & \text { F. H. Mares } \\ 1946 & \text { H. W. Sanders } & 1979 & \text { F. H. Mares } \\ 1947 & \text { J. A. Fitzherbert } & 1980 & \text { J. R. Robbins } \\ 1948 & \text { J. A. Fitzherbert } & 1981 & \text { J. R. Robbins } \\ 1949 & \text { J. A. Fitzherbert } & 1982 & \text { I. D. Brice } \\ 1950 & \text { J. G. Cornell } & 1983 & \text { I. D. Brice } \\ 1951 & \text { A. G. Price } & 1984 & \text { P. F. Nursey-Bray } \\ 1952 & \text { A. G. Price } & 1985 & \text { P. F. Nursey-Bray } \\ 1953 & \text { W. G. Duncan } & 1986 & \text { J. M. Brebner } \\ 1954 & \text { W. G. Duncan } & 1987 & \text { J. M. Brebner } \\ 1955 & \text { A. N. Jeffares } & 1988 & \text { R. G. Dare } \\ 1956 & \text { J.J. C. Smart } & 1989 & \text { R. G. Dare } \\ 1957 & \text { H. Stretton } & 1990 & \text { R. Sellick } \\ 1958 & \text { H. Stretton } & 1991 & \text { R. Sellick } \\ 1959 & \text { J. R. Trevaskis } & 1992 & \text { R. Sellick } \\ 1960 & \text { J. R. Trevaskis } & 1993 & \text { R. Sellick } \\ 1961 & \text { G. H. Lawton } & 1994 & \text { R. Sellick/J. Milfull } \\ 1962 & \text { G. H. Lawton } & 1995 & \text { P. F. Nursey-Bray } \\ 1963 & \text { M. A. Jeeves } & 1996 & \text { P. F. Nursey-Bray } \\ 1964 & \text { M. A. Jeeves } & 1997 & \text { P. A. Boumelha } \\ 1965 & \text { W. K. Duncan } & 1998 & \text { P. A. Boumelha } \\ 1966 & \text { L. F. Neal } & 1999 & \text { A. J. Watson/N. Harvey/ } \\ 1967 & \text { L. F. Neal } & & \text { M. G. Gilles } \\ & & & \\ 195 & & & \\ 1958 & & & \end{array}$




$\begin{array}{ll}2000 & \text { M. G. Gilles } \\ 2001 & \text { M. G. Gilles/N. Harvey } \\ 2002 & \text { N. Harvey/ J. M. Innes } \\ 2003 & \text { J. M. Innes } \\ 2004 & \text { J. M. Innes } \\ 2005 & \text { J. M. Innes } \\ 2006 & \text { J. M. Innes }\end{array}$

2000 M. G. Gilles

2007 J. M. Innes/N. Harvey

2008 N. Harvey

2009 N. Harvey

$2010 \quad$ N. Harvey

2011 N. Harvey

2012 N. Harvey 


\section{Appendix II \\ The University of Adelaide Fulbright Scholars \\ 1950-2011}

Name

(*Denotes current or

previous staff member)

Edward Radoslovich

Robert Reid

Phillip Mayfield

Ivars Alksnis

Stanley Kennedy

Anthony Haydon

Jens Radok

Peter Dennis

Kenneth Pearson

Donald Griffin
Class of

1954

1954

1959

1962

1962

1964

1965

1966

1967

1968
University of Adelaide

Degrees

BSc, BSc (Hons), MSc,

DSc, BA

BA (Hons), MA

BA (Hons)

MA

$\mathrm{PhD}$ admitted Council Mtg 1957 ad eundem gradum

PhD (Belfast). Lecturer in

Physical and Inorganic

Chemistry

BA (Hons)

$\mathrm{PhD}$ (science) admitted ad

eundem gradum Council

Mtg 1963 MA (Melb), DrIng

(TU Munich)

BA (Hons)

BA (Hons), PhD

BE (Hons), PhD, BA 
David Kelly

Andrew Parkin

Margaret Bakker

Keith King*

Borivoje Taskovic

Julie Abraham

Wilfrid Prest*

Angela Coaldrake*

Susan Dwyer

Robin Graham*

Stella Rozanski

Alan Johnson* (Fulbright

Postdoctoral Research

Scholarship 1985-86)

Nicholas Shaw

Padma Newsome

Simon Blewett

Charles Hurst

Joanne Lawry

Joy McEntee*
1970

1974

1976

1976

1976

1979

1979

1981

1986

1990

1993

1995

1996

1997

2002

2003

2003

2003
LLB (Hons), BA

BA (Hons), MA

BMus (Hons), PhD (Perf

Arts), Grad Dip Com \&

Corp, LLM (Corp \& Com)

BSc (Hons) Uni NSW, PhD

(Physical Chemistry)

BA (Hons), PhD, Grad Dip

Bus Admin

BA (Hons)

BA (Hons) (Melb Uni)

BA (Syd), MA (Hawaii), PhD

(Music) (Michigan)

BA (Hons)

BSc (Qld), MSc, PhD

(California), DAgrSc (Qld)

BA, LLB (Hons)

BAppSc (SA Inst Tech), PhD

(Parasite Immunology)

(Flinders), MA (Hons)

(Wollongong), MEdMgmt

(Flinders), DSc (Wollongong)

BA (Jur), LLB (Hons), LLM

(Comm)

BMus (Hons), MMus

BA, LLB (Hons)

BA (Hons) (Melb Uni), BSc

(Melb Uni), PhD (Quantum

Field Theory) (Cambridge)

BMus (Hons)

Grad Cert Ed (Higher Ed)

awarded 2006 
392 A History of the Faculty of Arts

Amy Ellks

2007

BMus (Perf) (Class

Woodwind), BMus (Perf)

(Hons)

Matthew Lee

2010

BA, BA (Hons), LLB, LLB

(Hons) 


\section{Appendix III \\ Australia Day and Queen's Birthday Honours, Faculty of Arts staff and alumni 2003-2012}

Companion of the Order of Australia (AG)

The Hon Robert Hill AC (LLB 1968, BA 1983)

Queen's Birthday 2012

Officer of the Order of Australia (AO)

Dr Lynn M. F. Arnold AO (BA 1979, BEd 1990, PhD 2003)

Queen's Birthday 2004

The Honourable Dr John C. Bannon AO (LLB 1967, BA 1968)

Australia Day 2007

Dr Judith Cashmore AO (BA (Hons) 1972, DipEd 1973)

Queen's Birthday 2010

The Honourable Caroline Hogg AO (BA 1963)

Australia Day 2012

Professor Graeme Hugo AO (BA (Hons) 1968, University staff)

Queen's Birthday 2012

Dr Dean Harold Jaensch AO (BA 1967, MA 1969, PhD 1974)

Queen's Birthday 2003

The Honourable Justice Kemeri A. Murray AO (LLB 1953, BA 1954)

Queen's Birthday 2004

Emeritus Professor Jillian I. Roe AO (BA (Hons) 1963)

Queen's Birthday 2007

Mr Scoresby A. Shepherd AO (LLB 1958, BA 1959, MEnvSt 1980)

Queen's Birthday 2006 
Mr Peter Ronald Vallee AO (BA no date)

Queen's Birthday 2003

Ms Imogen de Mortimer Zethoven AO (MEnvSt 1992)

Australia Day 2006

\section{Member of the Order of Australia (AM)}

Emeritus Professor Hedley Beare AM (BA 1954, DipSecEd 1956) Australia Day 2009

Mr Ian Ross Bidmeade AM (LLB 1969, BA 1986)

Queen's Birthday 2008

Dr Denis Binnion AM (BA (Hons) 1970, DipEd 1977)

Queen's Birthday 2012

Dr Margaret J. E. King Boyes AM (BA 1969)

Australia Day 2004

Mr Robert Brookman AM (BA 1974)

Queen's Birthday 2010

Dr Aileen Connon AM (MD 1965, Grad Dip Anthrop 1995)

Australia Day 2005

Mr Garry Coombes AM (BA 1980)

Australia Day 2009

Mr Dilip G. Chirmuley AM (Grad Dip Env St 1989)

Australia Day 2006

Ms Natasha Stott Despoja AM (BA 1991)

Queen's Birthday 2011

Mrs Janice Maxine Davis AM (BA(Jur)) 1992)

Queen's Birthday 2008

Dr David Dolan AM (deceased) (MA 1976)

Queen's Birthday 2011

Ms Anne Dunn AM (DipSocSt 1968, BA 1974)

Australia Day 2010

Ms Carol Frances Gaston AM (DipEnvSt 1982)

Queen's Birthday 2008 
Mr John Halbert AM (DipPhysEd 1958, BA 1971, MA 1977)

Australia Day 2009

Ms Lyndall M. Hendrickson AM (BA (Drama St) year unknown)

Queen's Birthday 2004

Ms Diana Hill AM (BA 1969)

Australia Day 2012

Dr Adam Jamrozik AM (DipSocSc 1966, BA (Hons) 1969)

Australia Day 2008

Ms Pamela Linke AM (DipSocSt 1963)

Australia Day 2006

Emeritus Professor David Lockett AM (BMus 1971, BMus (Hons) 1972, MMus

1981, DMus 2004)

Queen's Birthday 2010

Professor Susan M. Magarey AM (BA 1965, DipEd 1966 and University Staff)

Queen's Birthday 2006

Dr Joseph Magliaro AM (BA 1986, BA (Hons) 1987)

Queen's Birthday 2011

Ms Mary L. Morris AM (MEnvSt 1991)

Queen's Birthday 2005

Mr David W. Moyle AM (BA 1967)

Australia Day 2006

Mr Nicholas Newland AM (RDA 1968, MEnvSt 1993)

Australia Day 2010

Mrs Penelope Ann Paton AM (BA 1974, BA(Hons) 1975)

Queen's Birthday 2008

Professor Barbara Pocock AM (BEc 1978, BEc (Hons) 1979, PhD (Arts) 1997)

Queen's Birthday 2010

Mr Ian Purcell AM (BA 1968)

Australia Day 2005

Dr Helen M. J. Reid AM (MEdSt 1993, PhD (Arts) 1996)

Queen's Birthday 2004

Mr Raymond J. Stanley OBE AM (DipArts \& Ed 1952, BSc 1961)

Queen's Birthday 2004 
Dr Adrian Walter AM (BMus (Perf) 1984, BMus (Perf) (Hons) 1985, Grad Dip

Ed (Sec) 1985)

Australia Day 2009

\section{Medal of the Order of Australia (OAM)}

Mr Noel Ancell OAM (BA 1970, BMus1970, BMus (Hons) 1975)

Australia Day 2009

Mr Colin H. Brideson OAM (DipPrimEd 1959, BA 1966)

Australia Day 2007

Mr John E. Butler OAM (BA 1969, BA (Hons) 1972)

Australia Day 2006

Mr Robert N. Childs \& Mrs Jane M. P. Childs OAM (BA 1971)

Queen's Birthday 2004

Sister Catherine Ellen Clark OAM (BA 1979)

Australia Day 2003

Mr Keith Andrew Conlon OAM (BA 1968, LLB 1968)

Queen's Birthday 2003

Mr Barry Neil Couzner OAM (BA 1970, DipPhysEd 1970, DipEd 1973)

Queen's Birthday 2008

Mr Keith Thomas Crellin OAM (University Staff)

Queen's Birthday 2008

Mr Carl Crossin OAM (BMus 1979, BMus (Hons) 1980, University Staff) Australia Day 2007

Mr Roger Cundell OAM (BMus1994, BMus (Hons) 1995, Grad Dip Ed 1996) Australia Day 2009

Mr Dace Darzins OAM (BA 1959, DipSecEd 1963)

Australia Day 2004

Dr Anita Donaldson OAM (Diploma of Associate 1969, BA 1970)

Queen's Birthday 2003

Mr Thomas Dyster OAM (DipArts \& Ed 1949, BA 1953, DipPrimEd 1956) Australia Day 2011

Ms Margaret L. Flint OAM (BA 1972)

Queen's Birthday 2007 
Mr Alessandro Gardini OAM (BSc 1962, BA 1966, DipEd 1973, AdvDipEd 1975, MEd 1982)

Queen's Birthday 2003

Mrs Dawn Geyer OAM (BA 1982, Grad Dip Ed (In Service) 1985) Australia Day 2010

Mr Keith R. Giddings OAM (DipArts \& Ed 1958, BA 1962, DipSecEd 1963) Queen's Birthday 2006

Ms Jennifer Anne Gore OAM (BA 1974)

Queen's Birthday 2003

Dr Ian Arnold Harmstorf OAM (BA 1961, MA 1972)

Queen's Birthday 2003

Mrs Ina Harbison OAM (MEnvSt 1981)

Australia Day 2012

Mrs Diana Jean Harris OAM (DipMus 1960, BMus(Hons) 1974)

Queen's Birthday 2008

Mr Donald Hawking OAM (BA 2002)

Australia Day 2009

Ms Anne Hazell OAM (BA 1972)

Queen's Birthday 2003

Mr John Herendi OAM (BA 1966)

Australia Day 2006

Mr Robert Hetherington OAM (BA (Hons) 1951)

Queen's Birthday 2004

Mr Ernst Heyne OAM (DipArts \& Ed 1960)

Queen's Birthday 2010

Ms Elizabeth Ho OAM (BA 1972, BA (Hons) 1973)

Australia Day 2012

Mr Douglas Knuckey OAM (BA 1975, BA (Hons) 1976)

Australia Day 2011

Ms Elizabeth J. Koch OAM (BMus 1972, BMus (Hons) 1973, MMus 1983 and University Staff)

Queen's Birthday 2006 
Ms Sandra M. Lashchuk OAM (MMus 1985, BMus 1966, BMus (Hons) 1967, Grad Dip Ed (year unknown))

Queen's Birthday 2004

Mr Ambrose Linke OAM (BA 1960)

Queen's Birthday 2010

Mrs Vera K. Matthews OAM (DipArts \& Ed 1953)

Australia Day 2007

Ms Pamela Mamouney OAM (DipArts \& Ed 1956)

Australia Day 2010

Mr David McSkimming OAM (BMus 1970, BMus (Hons) 1971, MMus 1975) Australia Day 2012

Ms Elizabeth Raupach OAM (BA 1975, Dip Ed 1978)

Australia Day 2008

Mr John Rendle Stock OAM (BA 1971)

Queen's Birthday 2003

Mr Bruce N. Robson OAM (BA 1979)

Queen's Birthday 2004

Mrs Jean Russel Yule OAM (BA 1939)

Queen's Birthday 2004

Dr Pamela Ryan OAM (BA 1979, DipAppPsych 1985)

Queen's Birthday 2011

Mr Ashleigh H. Tobin OAM (BMus 1964, MMus 1972)

Australia Day 2006

Mr Trevor Wiseman OAM (DipPhysEd 1971, BA 1975)

Queen's Birthday 2009

Ms Judith Worrall OAM (BSc 1961, DipSecEd 1963, BSc (Hons) 1977,

DipCompSc 1982, MA(StArtHist) 2004)

Australia Day 2011

Pastor Wayne Zweck OAM (BA (Hons) 1965)

Queen's Birthday 2012 


\section{Appendix IV \\ The University of Adelaide Rhodes Scholars}

1904-2011

Name

Mr Roy Lister Robinson

Dr Henry Herman Leopold

A. Brose

Mr Alan W. Morey

Mr Francis Edgar Williams

Mr Howard Luscombe Rayner

Mr Stanford Howard

Mr Thomas Ashurst

(should be Ashhurst)

Mr John Heywood Reynolds

Mr Brian William Hone

Mr Lewis Charles Wilcher
Class of

1905

1913

1914

1915

1916

1922

1919

1929

1930

1930
University of Adelaide

Degrees

$\mathrm{BSc}$

BSc

Studied Medical Science

(and was in third year) but died in the Great War

BA (Hons), MA

Studying MBBS at Adelaide

and went to Oxford to

pursue medical course -

newspaper item

Studied 1st year Science and

continued at Oxford and

became leading surgeon -

newspaper item

Studying Science withdrew

in 1922 and continued at

Oxford

BA (Hons)

BA

BA (Hons) 
Mr Eric William Gray 1932

Mr Theodor Siegfried Dorsch 1933

Mr Ronald William Trafford 1936

Cowan

Mr Leslie Finlay Crisp

Mr Duncan Campbell Menzies

Sir Richard Arthur Blackburn

Mr John Lewis Gough

Professor Herbert Walter Piper

Emeritus Professor Roger

Gilbert Opie

Mr Charles Robin Ashwin

Emeritus Professor R John

Lawrence

Mr Edward Robert Pocock

Dr Shaun Disney

Dr Edmund Ralph Boyce

Gibson

Mr Simon Best

Mr Robert Nicholas Jose

(not Adelaide)

Mr Richard Samuel Wells

Ms Jennifer Anne Coles

Ms Vesna Maria Drapac

Ms Ursula Anne Goggs

Ms Vicki Ann Spencer

Ms Kathryn Jane Brown

Ms Susan Jane Coles

1988

1989
1938

1939

1940

1946

1946

1951

1952

1953

1956

1965

1966

1973

1974

1979

1980

1981

1981

1986
BA (Hons)

BA

BA (Hons)

BA (Hons), MA

BA

BA

BA (Hons)

BA (Hons), DLitt

MA

BA (Hons)

BA (Hons), DipSocSc

BA (Hons), MA

BA, BSc (Hons)

BA

BA (Hons)

ANU

BA

BA (Hons)

BA (Hons)

BA (Hons), MA

BA (Hons) (Flinders)

Lecturer (not Adelaide)

at Adelaide University in

1994. Enrolled at Adelaide

for BA in 1979 but withdrew

- no exam

BA (Hons), MA 
Ms Danielle Clode

Ms Sarah Marie Kelly

Dr Elizabeth Mary Leane

Dr Rachel Buxton

Ms Zoë Morrison

Ms Tamson Pietsch

Mr Phillip Killicoat

Ms Rachel Swift

Mr Jonathan Webb

Dr Nicole Krzys

Mr Sam Stranks

Ms Rebecca Richards
1990

1992

1995

1998

1999

2003

2004

2004

2006

2007

2008

2011
BA (Hons)

BA (Jur), LLB (Hons)

BA (Hons), BSc

BA (Hons)

BA (Hons)

BA (Hons)

BA, BEc (Hons)

BA, BSc (Hons)

$\mathrm{BA}, \mathrm{BSc}(\mathrm{MolBiol}), \mathrm{BSc}$ (Hons)

MBBS, BA (Hons)

BA, BSc (Hons)

BA 
This book is available as a fully-searchable pdf from www.adelaide.edu.au/press 